\title{
From Bonded Laborers to Educated Citizens? Immigration, Labor Markets, and Human Capital in São Paulo, Brazil (1820-2010)
}

Dissertation in order to acquire the doctoral degree from the Faculty of Economic Sciences at the Georg-August-Universität Göttingen

Submitted by

Bruno Gabriel Witzel de Souza

Born in Rio Claro (SP), Brazil

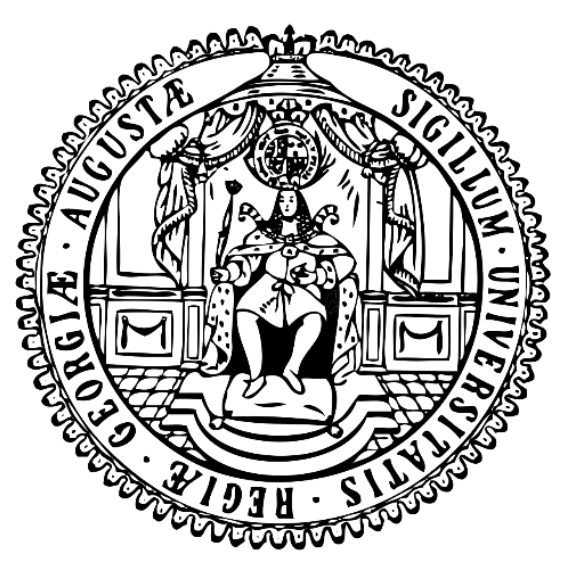

Göttingen, 2019 

First Examiner: Prof. Dr. h. c. Stephan Klasen, Ph.D. Chair of Development Economics Georg-August-Universität Göttingen

Second Examiner: Prof. Dr. Jan Luiten van Zanden

Chair of Global Economic History

Utrecht University

\section{Third Examiner: Prof. Dr. Holger Strulik}

Chair of Macroeconomics and Development

Georg-August-Universität Göttingen 

"Vão-se as datas e as letras eruditas na pedra e na alma, sob etéreos ventos, em lúcidas venturas e desditas" (Cecília Meireles. Romanceiro da Inconfidência) 



\section{Acknowledgements}

To write these lines as the last endeavor of the thesis is not an easy task. In fear of having forgotten a name, I express my sincere gratitude for the paths trailed together in the last years.

To conduct research at the Chair of Stephan Klasen has been a unique opportunity. I thank him for the academic advice and broad intellectual interest, which have inspired so many students all around the world. Jan Luiten van Zanden provided me with very attentive advice. Visiting his Chair at the University of Utrecht was an outstanding experience. Finally, Holger Strulik was a critical commentator of the ideas developed in this thesis since their first proposal. Two other people contributed majorly for this work as well. Renato Colistete not only critically discussed the drafts, but also became a friend and an intellectual reference. Thank you, Professor. Philip Keefer guided me academically for a long period; many improvements in this final version are due to his careful readings.

A number of people helped me to develop the concepts discussed herein. I would like to mention the nicely addressed comments by Aldo Musacchio, Alexandre Saes, Andrew Seltzer, Blanca Sánchez-Alonso, Guilherme Grandi, Hakan Mihci, Hillel Rapoport, Inmaculada Martínez-Zarzoso, Maria Lamounier, Sabino Porto Junior and Samuel Garrido. Moreover, I thank Maria Bassanezi, Marília Marx Jordan, and the friends Sylvester (in memoriam) and Ursula Davatz for providing me with fundamental primary sources.

I was also lucky to get in contact with young scholars highly motivated to bridge History and Development. I benefited a lot from the views of André Lanza, Bram van Besouw, Giacomo Gabutti, Jakob Molinder, Matthias Blum, Piet Groot, Sebastian Schöttler, Simon Lange and Thomas Kang. The friendship and collaboration with Gabriele Cappelli have been particularly fruitful. Finally, I had the happy opportunity of becoming friends with Leonardo Gardenal. Our joint projects presented me to one of the most caring and admirable researchers I know.

A group of friends almost made me believe that indeed Extra Gottingam non est vita. I thank you for all discussions and the fun, especially to Atika Pasha, Franziska Dorn, Hendrik Kruse, Jana Lenze, Lennart Kaplan, Marcello Pérez-Alvarez - for the old friendship and eternal late dinners -, Nathalie Scholl, Pooja Balasubramanian and Slava Yakubenko. It is also time to return some words to Manuel Santos Silva. We shared not only an office, but also a professional passion. May time not weed out the "colorful" language of our debates!

All the thinking that "there is no life out of Göttingen" probably came to me while sitting on a train far away from that city. On weekly paths, Lea Strub reminded me of some fundamental goals, not least of those for studying Development Economics. Her support and love kept me going and her ideals inspire my admiration more and more.

To conclude, I express my gratitude and love to my parents. My father's passion for books and my mother's reverence for knowledge have been my main guides in life. Thank you so much. Finally, my grandparents were the sources of all my curiosity. I have no doubt that my questions on why things are as they are nowadays have their origins in listening to Biléu's reflections on life and death, to Cida's songs of the 1930s, to Dalva's stories about Avenida 12, and to Tijolo's narratives on the old roadways of São Paulo. This thesis is yours. 



\section{Table of Content}

Introduction

Immigration policies, nationalities and occupational sorting: new evidence from the Age of Mass Migration in São Paulo, Brazil (1820-1920).

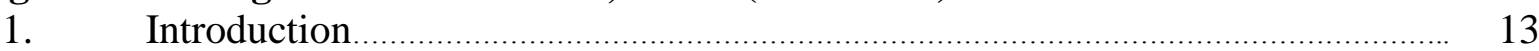

2. Immigration, selectivity and occupational sorting: a literature review ................. 18

3. Immigration policies in São Paulo: from settlers to bonded laborers to settlers.... 22

3.1. First experiments with settlement colonies (1820s-30s) .................................. 24

3.2. Complementary policies: public works and settlement in public lands................. 28

3.3. The reemergence of official settlement colonies (1870s-1920s) ...................... 30

3.4. Official and private colonies in the western agricultural frontier $(1900 \mathrm{~s}-20 \mathrm{~s}) \ldots . . .38$

4. Policy, selectivity and sorting in São Paulo: assumptions and hypotheses ........... 40

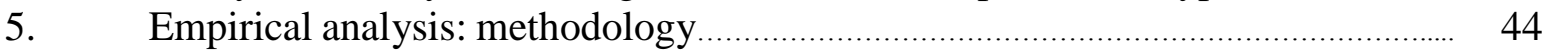

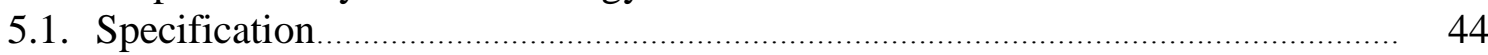

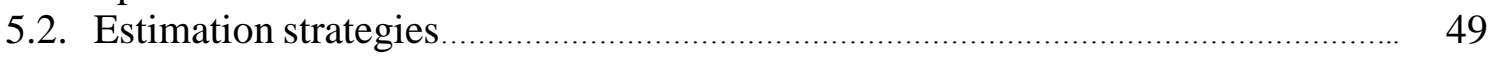

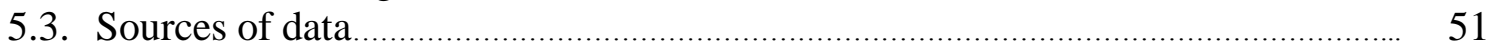

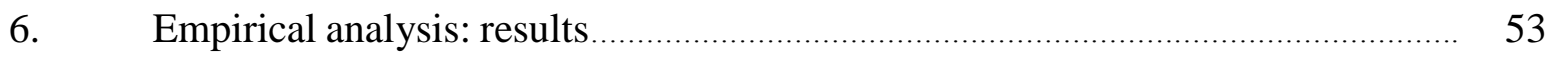

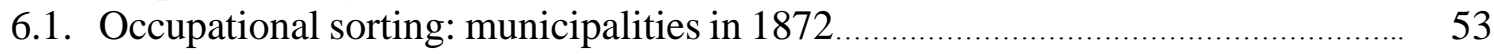

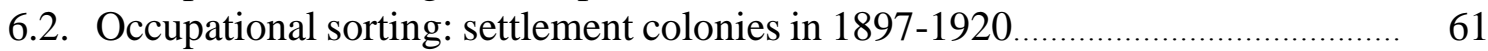

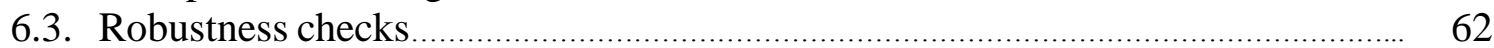

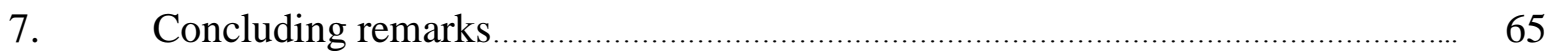

8. Appendix: Complementary tables and maps ............................................................. 69

The rationale of sharecropping: immigrant bonded laborers and the transition from

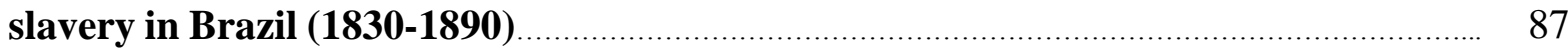

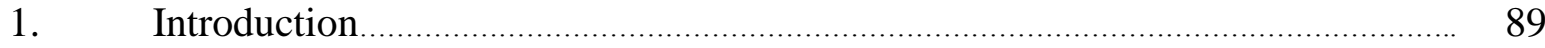

2. Bonded labor and the abolition of slavery in Brazilian coffee plantations............. 94

3. The rise of European bonded labor under sharecropping (1835-60) .................. 98

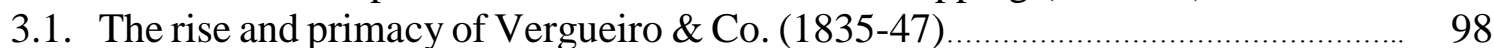

3.2. The expansion of bonded labor under sharecropping contracts $(1847-60) \ldots \ldots \ldots \ldots . .103$

4. The decline of sharecropping (1860-90) ............................................................ 108

4.1. Labor riots and movements of social unrest ....................................................... 108

4.2. Endogenous market responses: migratory costs and immigrants' networks......... 110

4.3. New labor arrangements and subsidized mass immigration (1860-90) ................ 113

5. The rationale of sharecropping and bonded labor: a theoretical analysis............. 117

5.1. The adoption of sharecropping: theoretical and historical explanations................ 118

5.2. The bonding of labor and the pervasiveness of the credit dimension...................... 126

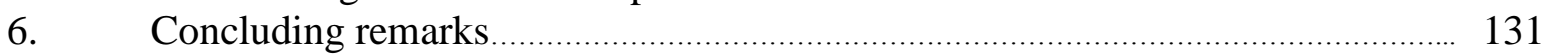

7. Appendix: Per Worker Costs of sharecropping, fixed rents and wage systems..... 133

Immigration and the path dependence of education: the case of German-speakers

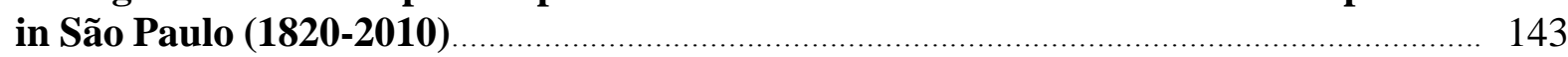

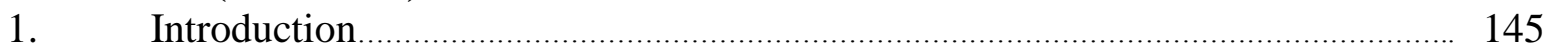

2. German-speakers and human capital: historical overview and hypotheses........ 148

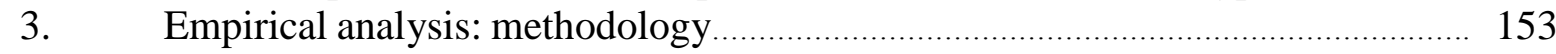

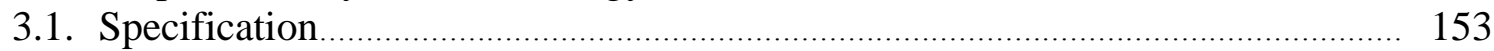

3.2. Estimation strategies and historical identification .............................................. 155

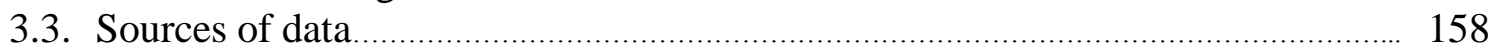




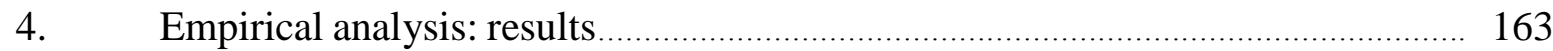

4.1. The effect of German-speakers on educational performance $-1872 \ldots \ldots \ldots \ldots \ldots \ldots \ldots . . . . .163$

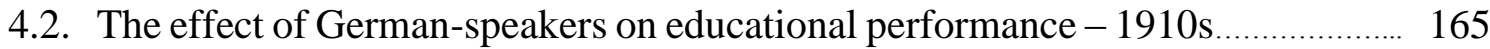

4.3. The path dependence of education - current estimates ......................................... 174

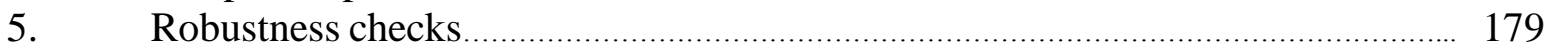

5.1. Sensitivity to MCAs: Western Frontier, Old-West and Holloway's Regions........ 179

5.2. Number of observations and bootstrapping techniques: a discussion................... 180

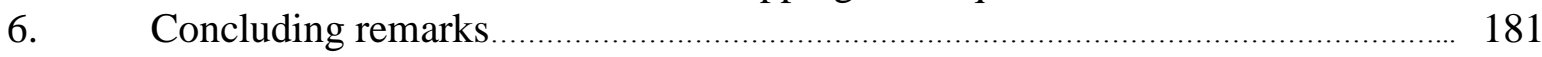

7. Appendix: Complementary tables \& robustness checks for settlement colonies 185

\section{Appendices}

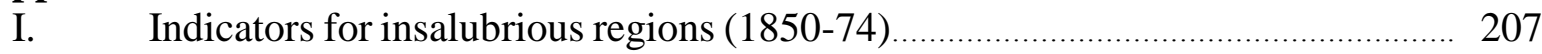

II. Labor riots and movements of social unrest among immigrants .......................... 211

III. Brazilian Digital Newspaper's Repository....................................................... 219

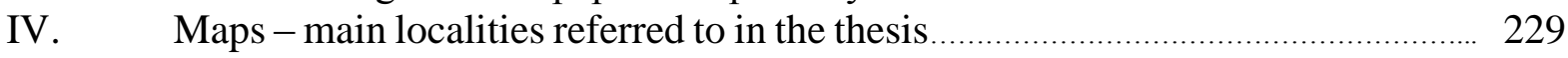

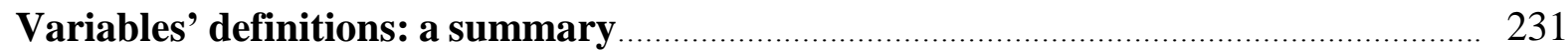

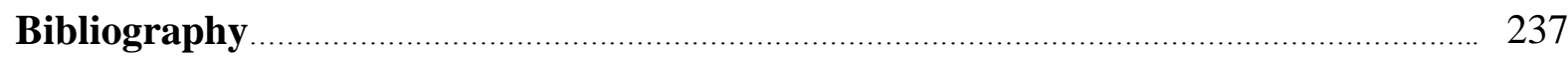




\section{List of Tables}

\section{Chapter 1}

1.1 Descriptive statistics (selected variables) ..................................................................... 34

1.2 Percentage of foreigners: municipalities (1872) and settlement colonies (1897-1920).... 36

1.3 Number of foreigners: municipalities (1872) and settlement colonies (1897-1920) _....... 37

1.4 Partial effects: occupations and immigration policies - municip. (1872) ........................ 54

1.5 Partial effects: occupations and immigration policies - minorities municip. (1872)....... 59

1.6 Partial effects: occupations and immigration policies - settl. colonies (1897-1920)........ 63

A1.1 Other determinants of immigration - municipalities (1872) .......................................... 69

A1.2 Other determinants of immigration - settlement colonies (1897-1920) ........................ 72

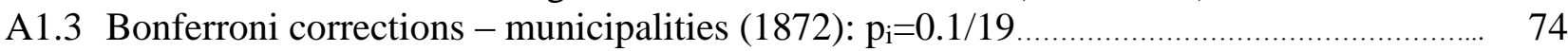

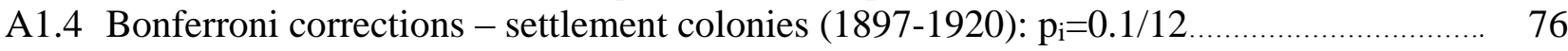

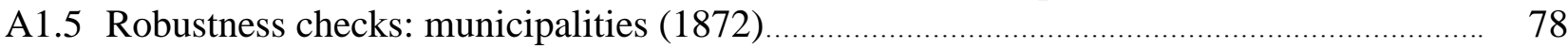

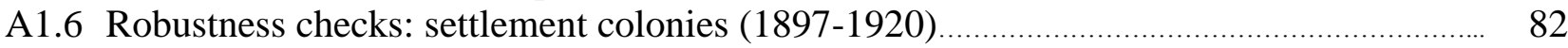

\section{Chapter 3}

3.1 Difference-in-means tests (by share of German-speakers and their schools) ................... 152

3.2 Descriptive statistics (selected variables) ...................................................................... 162

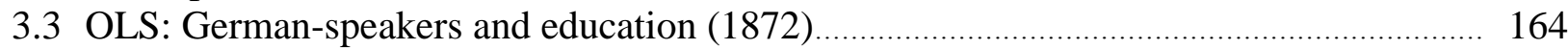

3.4 IV: German-speakers and education (1910s) - total enrolment ..................................... 167

3.5 IV: German-speakers and education (1910s) - enrolment state schools .......................... 168

3.6 IV: German-speakers and education (1910s) - enrolment private schools........................ 169

3.7 IV: German-speakers and education (1910s) - enrolment municipal schools................... 170

3.8 IV: German-speakers and education (1910s) - completion state schools........................ 171

3.9 OLS: Path dependence and flows of human capital (2000s) ............................................. 175

3.10 OLS: Path dependence and stocks of human capital (2000s) - with historical enrolment in state schools

A3.1 OLS: Path dependence and stocks of human capital (2000s) - avg. years education......... 185

A3.2 OLS: Path dependence and stocks of human capital (2000s) - illiteracy rate .................. 186

A3.3 OLS: Path dependence and stocks of human capital (2000s) - education MHDI............ 187

A3.4 OLS: Summary of subsample analyses (1872) ....................................................... 189

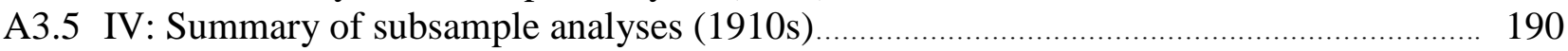

A3.6 OLS: Summary of subsample analyses: flows (2000s) ............................................... 192

A3.7 OLS: Summary of subsample analyses: stocks (2000s) …............................................ 195

A3.8 German-speakers in the MCAs of the Old-West ........................................................... 196

A3.9 OLS: German-speakers and education (1872) - bootstrapped: zero-imputed data.......... 197

A3.10 IV: German-speakers and education (1910s) - bootstrapped: zero-imputed data.............. 198

A3.11 OLS: Path dependence and flows of human capital (2000s) - bootstrapped: zeroimputed data.

A3.12 OLS: Path dependence and stocks of human capital (2000s) - bootstrapped: zeroimputed data with historical enrolment in state schools ............................................... 201

A3.13 Correlation matrix: German schools and settlement colonies........................................ 202

A3.14 IV: Partial effects of German Schools and settlement colonies (1910s)......................... 205

\section{Appendices}

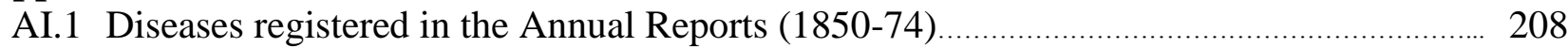

AIII.1 Newspapers researched in the Brazilian Digital Newspapers' Repository ....................... 220

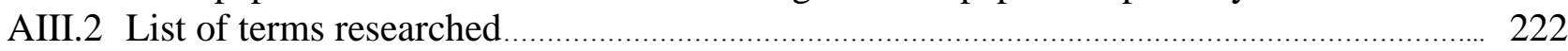

AIII.3 Descriptive statistics: Index of themes by specific regions ............................................. 225 



\section{List of Figures}

\section{Chapter 1}

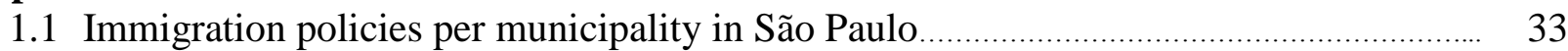

1.2 Geographic distribution of the main variables of interest (1872) .................................. 83

1.3 Geographic distribution of the main immigrant nationalities (1872) .............................. 84

\section{Appendices}

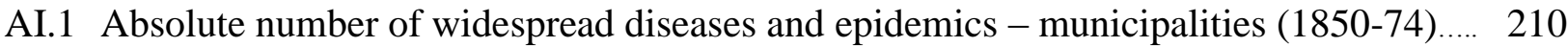

AI.2 Insalubrious regions according to geographic location (1850-74) …........................... 210

AIII.1 Number of pages of newspapers by region of publication ........................................... 223

AIII.2 Index of themes distributed by region of publication.................................................... 224

AIII.3 Index of themes distributed by year of publication.......................................................... 226

AIII.4 Trend in news (index): German-speaking countries..................................................... 226

AIII.5 Trend in news (index): Vergueiro \& Cia .................................................................. 227

AIII.6 Trend in news (index): Immigration policies............................................................. 227

AIV.1 Selected Brazilian provinces (1872) - Map................................................................... 229

AIV.2 Selected municipalities in São Paulo (1872) - Map........................................................ 230 



\section{Introduction}

The claim that history matters for our understanding of economic development stepped down from its pedestal of an alleged eternal truth in the nineteenth century to become a humble hypothesis at the beginning of the twenty-first century ${ }^{1}$. Relatedly, in the last two decades, Development Economics revived the debate about the interconnections between Economics and History ${ }^{2}$. To the economist interested in the diverging paths of material and human wellbeing across and within nations, historical analyses currently offer two main research branches. The first is the theoretical and empirical inquiry into the deep determinants of physical capital accumulation, human capital formation and technological progress ${ }^{3}$. The second is the methodological quest for historical data that provide increasingly more refined identification strategies and for historical events that allow for quasi-experimental designs ${ }^{4}$.

In this thesis, I aim at contributing to these two branches of the literature and fostering yet another one, acknowledged more frequently by economic historians than by development economists, namely the study of historically specific events that have parallels to current developmental challenges. Although the disciplinary boundaries between Development Economics and Economic History became more blurred in recent times, this thesis builds upon the stronger assumption that historical discoveries provide a too important building block to the understanding of development to be taken only as data by the economist ${ }^{5}$.

The thesis studies the consequences of the Age of Mass Migration (1820-1920) for the socioeconomic development of the province/state of São Paulo, Brazil, in the short and long run. The determinants of immigration and the economic integration of foreigners in the short run is the object of the empirical analysis in Chapter 1. This analysis focuses on how immigrants sorted across different localities in São Paulo. The underlying question, derived from the literature on the determinants of immigration, is on how policies interact with local labor market conditions to explain the geographic and occupational allocation of immigrants. While this first approach considers institutions related to labor markets as exogenous, Chapter

\footnotetext{
${ }^{1}$ Classical views on the relationship between Economics and History include Gras (1920, 1927), Sombart (1929), Schumpeter (1947, 1949), Spiethoff (1952), Dorfman (1955), Solow (1985) and Hodgson (2001).

${ }^{2}$ Nunn (2009) and Woolcock, Szreter and Rao (2011). The metaphor of the latter, seeing history as a river whose paths are less obvious than currently assessed by economists, has remarkable parallels to Nef (1944, p. 11).

${ }^{3}$ A summary of this immense literature is in Acemoglu (2009, Chapter 4).

${ }^{4}$ See Farnam's (1912) and McIver's (1943) critics. Currently, see Diamond and Robinson's (2010) compendium.

${ }^{5}$ See Ashley (1895, p. 118), Loos (1918, p. 549) and Schumpeter (1949, pp. 350-1) on the benefits and risks of specialization within subfields of Economics.
} 
2 takes a step back and explores the history of contract labor in Brazilian coffee plantations. The chapter proposes a theoretical model and collects new archival evidence to explain the immigration of agricultural bonded laborers. These were hired to work mainly under sharecropping contracts in the plantations, during the Brazilian transition from slavery. This analysis revisits the literature on the rationale of sharecropping and bonded labor, contributing with a historically specific case study. Chapter 3, in turn, broadens the time horizon of the empirical exercise to assess the impacts that a group of immigrants - namely, German-speakers - had on the accumulation of human capital in the long run. The chapter is a contribution to the literature on how immigration can change the developmental path of certain regions. Empirical results show, however, that this impact was less direct than usually assumed and that educational path dependence varied substantially between private and public schools.

\section{Why São Paulo?}

For most of Brazil's colonial history (1500-1822), the region corresponding to the current state of São Paulo was of marginal economic importance to the Portuguese Empire. Its geographic position, limited natural endowments for the mercantilist trade and relatively low demographic density made São Paulo less attractive than northeastern Brazil ${ }^{7}$. This relative economic irrelevance started to change by the mid-nineteenth century. The expansion of coffee plantations in that province of newly independent Brazil triggered a process of sustained economic growth that translated into a booming industrial economy in the twentieth century. As a result, the state underwent its own reversal of fortune ${ }^{8}$ : this once neglected colonial economy is now responsible for about a third of the Brazilian GDP.

However, various indices of human development reveal that São Paulo remains caught in a middle-income trap. Average life expectancy at birth (75.7 years) is comparable to those of Argentina and Oman'; and expected years of schooling (10.33) are between those of Yemen and Laos ${ }^{10}$. Income inequality remains infamously high, even above the Brazilian average (with Gini coefficients of 0.56 and 0.53 , respectively) and comparable to those of Bolivia and

\footnotetext{
${ }^{6}$ Appendix IV maps the main regions referred to in this thesis.

7 Almeida Prado (2007, p. 119), Buarque de Holanda (2007, pp. 107-9) and Naritomi, Soares and Assunção (2012).

${ }^{8}$ Summerhill (2010, p. 13).

${ }^{9} \mathrm{https}$ ://data.worldbank.org/indicator/SP.DYN.LE00.IN, accessed on November 28 2018. Data from 2010.

${ }^{10} \mathrm{http}$ ://hdr.undp.org/en/content/expected-years-schooling-males-years, idem. Data from 2010.
} 
the Central African Republic ${ }^{11}$. Furthermore, $4.7 \%$ of the state's population still lived under the Brazilian poverty line and $16.1 \%$ were vulnerable to poverty in $2010^{12}$. Finally, an average black in São Paulo has an overall HDI of 0.73, comparatively to 0.81 of an average white; and the incidence of poverty is twice as high for the blacks as for the whites ${ }^{13}$.

In short, although São Paulo performs well relatively to the Brazilian average, human development is still constrained and its fruits remain unequally distributed. These features fit a path of development typical of some Latin American regions. On the one hand, the rural exportled economy of the nineteenth century allowed for the accumulation of capital in plantations and initiated an intense path of modernization. This process coincided with the expansion of infrastructure - mainly in transport and in some public goods -, the consolidation of financial capital markets and an intense sectoral diversification in the twentieth century. On the other hand, these deep modifications did not alter some ingrained extractive institutions. To cite two prominent examples, the facts that Brazil was the last country in the Americas to abolish slavery in 1888 and that the plantation system survived probably tell us something about the blackwhite divide and the concentration of riches mentioned above.

Fundamental to this thesis is the observation that the deep economic changes in the nineteenth century were frequently simultaneous to the transformation of those Latin American regions into major destinations to immigrants during the Age of Mass Migration. São Paulo is an archetypical example of this phenomenon. Related to the transition from slavery in Brazil and the expansion of the coffee economy deep into the new agricultural frontiers, the province/state received $c a$. 1.74 million immigrants between 1872 and 1919. These cumulative migratory flows led to a share of foreign-born population at about $21 \%$ in $1900^{14}$.

Based on similar observations, a plethora of studies has defended the importance of those immigrants for the modernization process of São Paulo. This thesis builds on some hypotheses of this classical Brazilian historiography, which are then re-evaluated along the three chapters with some new empirical and theoretical tools ${ }^{15}$.

\footnotetext{
${ }^{11}$ https://data.worldbank.org/indicator/SI.POV.GINI?locations=BR and http://hdr.undp.org/en/content/incomegini-coefficient, idem. Data from 2013.

${ }^{12}$ The poverty line for 2010 was set at BRL 4.7/day (equivalent to U $\$ 2.65 /$ day in nominal exchange rates averaged monthly for 2010). The vulnerability line was set at BRL 8.5/day (U\$4.83/day).

${ }^{13}$ Atlas de Desenvolvimento Humano, a program by UNDP, IPEA and Fundação João Pinheiro to calculate HDI for Brazilian municipalities (http://www.atlasbrasil.org.br, idem). Unless otherwise indicated, data from 2010.

${ }^{14}$ Levy (1974, Appendix Tables 3 and 8).

${ }^{15}$ Throughout the thesis, the term "Brazilian historiography" refers to all historiographical production focused on Brazil, independently of the nationality of the researcher.
} 
Moreover, such discussions aim at contributing to a renewed branch of research on the global effects of international migration and its relationship to economic development. For this, it is fortunate to notice that the international literature has now steadily started to re-explore different Latin American experiences, as the region provides some unique contexts that combine institutional persistence from the colonial past with deep modifications brought about by the Age of Mass Migration.

\section{Structure and content}

The chapters of the thesis are distributed thematically. The first provides an overview of different immigration waves to study economic integration in the short run. The second zooms into the hiring of bonded laborers to discuss persistence in immigration policies. The third analyzes the impact of German-speaking immigrants on human capital accumulation to understand its development in the long run.

The first question addressed refers to the relationship between immigration policies and the occupational integration of foreigners. Chapter 1 stresses the importance of incorporating policies into the empirical evaluations of the determinants of immigration during the Age of Mass Migration. The first discussion focuses on the differences between the two main immigration policies that prevailed in São Paulo from the 1820s to the 1920s, namely the hiring of foreign agricultural laborers to plantations and of settlers to rural colonies. Based on this, the empirical approach identifies the main channels of economic integration available to foreigners. The econometric analysis evaluates the impacts of immigration policies and of the distribution of occupations on the number of immigrants settled across regions. This procedure is repeated for all nationalities available in a cross-section of municipalities in 1872 and in a(n) (unbalanced) panel of rural colonies for the period 1897-1920. Results show that economic integration in the urban economy in the 1870s varied with immigrants' origins. Moreover, important nuances appear if the occupational composition of municipalities is interacted with prevailing immigration policies - a result that is particularly strong for manufacturing-related occupations. For the rural economy, immigrants did not integrate as agricultural laborers, despite the efforts of plantation owners in accomplishing this goal. Furthermore, to the vast majority of immigrants, landownership remained what it had been in their countries of origin: a far distant dream. Except for some minorities and nationalities related to specific immigration policies, the average foreigner in the 1870s did not become a rural proprietor. Finally, the 
sample of colonies in 1897-1920 shows that settlers in those rural areas did not divert to nonagricultural occupations, a result expected by the definition of an immigration policy that aimed at transforming foreigners into rural proprietors. Nevertheless, under the light of results of the previous period, the chapter casts doubt on whether these settlers were able to remain as landowners in the longer-run.

Chapter 2 studies the immigration of bonded agricultural laborers. Concentrated mainly in the period 1835-1890, these migratory waves were related to the transition from slavery in Brazil. Besides reviving a classical theme of the Brazilian historiography with new theoretical tools and factual evidence, this chapter contributes to the long-standing inquiry into the rationale of bonded labor and sharecropping. More specifically, the chapter discusses the history of contracts proposed to bonded immigrants. A credit interlinkage in the contracts supplied by landowners provided immigrants with the necessary funds to cover migration-related costs. This led poor and otherwise credit-constrained foreigners to bond the labor of their entire households to the repayment of the outstanding debts thus incurred. Moreover, sharecropping prevailed as the first successful labor-rental arrangement in these contracts. The chapter thus assesses the economic and political interests of plantation owners in bonding the labor of immigrants and in adopting sharecropping contracts. A theoretical framework is proposed that allows for the interlinkage of credit to three types of labor-rental dimensions: sharecropping, fixed rents and wage systems. The theoretical and historical analyses lead to two propositions. First, the credit-labor interlinkage provided landowners with a stable and secure supply of labor in substitution to the constrained inflow of slaves. Historical evidence confirms that this mechanism became a constituent part of the immigration policy in São Paulo. By facilitating the immigration of people with fewer alternatives, the credit-labor interlinkage transformed Brazil into an important destination to immigrants without the promotion of institutional reforms. The chapter argues that albeit potentially increasing the inflow of non-bonded foreigners, such reforms remained very costly in political terms for the Brazilian elites. Second, the adoption of sharecropping as the labor-rental dimension of the contracts resulted more from the emulation of other historical and international experiences than from a purely economic decision of landowners.

Finally, Chapter 3 takes the path of long-term analyses. It is a contribution to the thriving literature on whether immigrants change the path dependence of certain developmental outcomes. This empirical exercise analyzes the determinants of human capital accumulation in the long run. The chapter asks whether German-speaking immigrants influenced the 
educational attainment of the municipalities where they settled. A first novelty of this chapter is to disentangle the human capital brought by immigrants into three dimensions, namely the immigrant's on-the-job skills, the schools they founded and their share in the population ceteris paribus interpreted as their cultural contribution. The focus on German-speakers is justified by the fact that this ethno-linguistic group founded the largest number of foreign schools in Brazil and presented one of the highest literacy rates of all immigrants, ranking especially high above Brazilian standards in educational attainment. Results show that the main positive influence of German-speaking immigrants on the educational attainment of receiving societies was due to the schools they founded. This conclusion supports the institutionalist view over the cultural approach to the impact of immigrants: while the share of foreigners had no effect on educational attainment either in the nineteenth, or in the twentieth century, German schools positively influenced the process of human capital accumulation. However, educational path dependence is far from straightforward, as this positive effect of the German schools required time to mature and dissipated afterwards. Nevertheless, these foreign educational institutions substantially influenced enrolment in private and state schools at the beginning of the twentieth century. Another contribution of this chapter is to show that current flows of human capital are strongly associated with their historical levels. At the same time, path dependence is conditional on specific features of the educational system: while the chapter finds a positive persistence for enrolment in private schools throughout the twentieth century, a negative relation is found between current and historical enrolment levels in state schools.

\section{Contributions to the literature}

The research questions of this thesis always address a historically specific case study that has a parallel to current developmental challenges. Therefore, each chapter aims at contributing to an intersecting branch of the literature on Development Economics and Economic History.

The question on whether and how immigration is related to socioeconomic development is far from being a new preoccupation. On the contrary, such question has long occupied academicians and policymakers alike. For the view that historical experiences contain useful information to teach us about current challenges and opportunities posed by immigration, it is reassuring to read how a leading Brazilian politician in the nineteenth century anticipated by 150 years some of the arguments I defend in the current thesis. Even if the analyses are now supported by more solid theoretical frameworks and better-assessed scientific inference, the 
understanding of migration-related phenomena owes much to a long-standing hypothesis, thus posited in 1871: "For those who currently [in 1871] look for the causes of the progress of the province, this fact must not be forgotten [...]. In the lives of the peoples, circumstances that sometimes seemed insignificant later appear to the inquiring spirit as a happening of utmost importance for their consequences. Such was the immigration essay practiced [with contract laborers]"16.

In this spirit, the first chapter is a contribution to literature on the determinants of immigration, whose historical studies are famously looking for a set of "fundamentals" that drive the move of people, past and now ${ }^{17}$. The statistical analysis of this chapter demonstrates the importance of taking immigration policies explicitly into account for assessing the determinants of immigration. The chapter argues that the literature needs to consider more cautiously policies that promoted immigration in the past, rather than focusing only on those that deterred the inflows of people ${ }^{18}$. Empirical results show that some hypotheses of the literature are not always confirmed if we take into account the interactions between economic conditions and specific immigration policies ${ }^{19}$. Moreover, the chapter considers the economic integration not only of the main groups of immigrants, but also of minorities. While this approach introduces some noise into the statistical inference, results show some patterns not previously hypothesized about the economic integration of minorities with distinct migratory histories.

The second chapter revisits the puzzle on why sharecropping and bonded labor are such pervasive arrangements in the history of agricultural production. Historically, sharecropping has been not only a mechanism of labor allocation and risk sharing - as assessed by a more classical literature -, but also of crop formation, of organizing production under seasonality and of setting property rights between tenants and landlords - as assessed by a more recent, usually institutional approach ${ }^{20}$. The case of São Paulo adds yet another economic and political motivation to this list, namely the employment of sharecropping as the labor dimension of a contract that interlinked labor to credit. The contribution of this chapter is to discuss the economic and political rationale of the credit-labor interlinkage jointly. The chapter concludes

\footnotetext{
${ }^{16}$ Francisco Rangel Pestana in Correio Paulistano (18/10/1871, pp. 1-2), originally published in Almanak de Campinas. The author referred more specifically to the economic development fostered by German-speaking bonded laborers hired by Senator Nicolau Vergueiro - the object of Chapter 2.

${ }^{17}$ See the literature review by Abramitzky and Boustan (2017).

${ }^{18}$ See theoretical and empirical proposals of Haas $(2010,2011,2014)$.

${ }^{19}$ For a succinct review of hypotheses of the emigration life cycle, see Hatton and Williamson (2002).

${ }^{20}$ See the renewed approaches and reviews by Carmona and Simpson (1999, 2012) and Garrido (2017).
} 
that the credit dimension outlived sharecropping and became a cornerstone of the Brazilian immigration policy, aiming primarily at bonding the labor force of immigrants. While in the past bonding labor was seen as a politically desirable goal, the fight against the economic and institutional underpinnings that support bonded labor survives as a current global challenge in agricultural labor markets of low-income countries nowadays ${ }^{21}$. Even if for different reasons, the credit-labor interlinkage and the relationship between bonded labor and sharecropping remain as vivid a challenge today as it had been in a far-distant corner of Brazil by the midnineteenth century.

Finally, the third chapter assesses the influences of immigrants on the developmental paths of regions where they settle ${ }^{22}$. This analysis is a contribution to the thriving debate on whether the inflows of people per se are able to change outcomes of receiving societies that had been previously hampered by extractive institutions ${ }^{23}$. Although the chapter answers this question positively, it also shows that historical determinants are not fate: the institutional contributions of immigrants required time to mature and vanished over the course of a century. These conclusions were reached by refining two dimensions of the empirical literature with the collection of new data. First, the chapter considers variations in the path dependence of different types of schools, roughly understood as private or public. Second, it disentangles the human capital brought by immigrants in three components, namely the institutional contribution of schools founded by foreigners, immigrants' on-the-job skills and their cultural impact, defined as the ceteris paribus effect of the share of immigrants in the population.

\section{Main conclusions and implications}

Similar to troubled economists of the turbulent first decades of the twentieth century, current development economists inclined to historical analyses feel the urges of a world changing in fast pace $^{24}$. In face of overwhelming global challenges and humanitarian crises, one feels the need of a justification to keep slowly scratching the dust of the past in geographically specific studies. Pure curiosity and freedom of inquiry per se are necessary features of a society that I

\footnotetext{
${ }^{21}$ Premchander, Prameela and Chidambaranathan (ILO, 2014).

${ }^{22}$ See the classical views by Sokoloff and Engerman (2000) and Acemoglu, Johnson and Robinson (2001, 2002).

${ }^{23}$ See the ongoing debate between Glaeser, La Porta, Lopez-de-Silanes and Shleifer (2004), as well as Gennaioli, La Porta, Lopez-de-Silanes and Shleifer (2013), on the one hand, and Acemoglu, Gallego and Robinson (2014), on the other.

${ }^{24}$ See Gras (1927), Nef (1944) and the academic discourses by Johnson (1937), Mills (1941) and Nef (1941).
} 
consider desirable ${ }^{25}$. Notwithstanding, the public question remains: are these historical analyses of any use to understand and solve some current problems $?^{26}$

What this thesis does is to provide historical, empirical and theoretical evidence on the relationship between immigration and institutions in the receiving societies. Its main conclusions point to positive and enduring influences of immigrants on the socioeconomic development of destination regions. Chapter 3 demonstrates how the local society benefited directly from the organization of German schools at the beginning of the twentieth century and indirectly nowadays. The empirical analysis shows a positive influence of German schools on the enrolment of students not only in private organizations, but also in schools established by the government of São Paulo. This result is interpreted as a contagion effect on the overall demand for education and as a spillover on the supply of educational services. The intense interaction between Brazilians and foreigners was fundamental for the former to benefit from the arrival of the latter. If the development triggered by immigration in the past can be used as a guide for the challenges and potentialities of current migratory waves, this conclusion provides strong evidence on the importance of tightening, from the start, the laces between immigrants and natives in immigrant-based societies ${ }^{27}$.

The findings of the other chapters point to similar conclusions, but for the opposite reason, i.e. by showing how some ingrained extractive institutions perpetuated in spite of the arrival of immigrants. Chapter 1 demonstrates that only specific groups of immigrants sorted positively as rural proprietors, even when the immigration policy was allegedly tailored to settle foreigners in rural areas. By the third quarter of the nineteenth century, immigrants were not able to change the distribution of land prevailing in a typical Latin American plantation economy. A classical literature on this theme has established the deleterious effects that similar degrees of land concentration have for the distribution of political power and investments in public goods. This result is not surprising under the conclusions of Chapter 2, which argues that plantation owners had economic incentives to bond the labor force of foreigners and that political elites benefited by obtaining immigrants without promoting institutional reforms against their own direct interests.

\footnotetext{
25 Telling whether a blurred data-point in a nineteenth century source refers to a pig or to a sheep might be absolutely irrelevant for statistical inference; but it was not so for the life of the girl who fed it.

${ }^{26}$ On this, see the initiative History and Policy Partnership (http://www.historyandpolicy.org/policy-papers).

${ }^{27}$ The literature on the determinants of immigration is extremely cautious in stressing historical specificities. See in particular Hatton and Williamson (2004, pp. 14-6), Freeman (2006, pp. 159-60) and Hatton (2011, p. 207).
} 
These conclusions indicate that ruling elites have enough instruments to block the influences of foreigners. Nevertheless, the same chapters show that immigrants find their way around. This indicates how modelling agency adequately remains an important task in migration studies. Chapter 1 shows how different nationalities adapted to the immigration policies in sorting in urban occupations. Perfectly mirrored patterns were found for some nationalities in their processes of economic integration, demonstrating that some groups benefited from specific immigration policies and local economic conditions, while others had to adapt their integration channels in spite of those policies. Chapter 2, in turn, surveys the reactions of bonded laborers to control mechanisms imposed by plantation owners; they strengthened their own networks, rioted and gained some prominence in international debates about immigration. 


\title{
1. Immigration policies, nationalities and occupational sorting: new evidence from the Age of Mass Migration in São Paulo, Brazil (1820-1920)
}

\begin{abstract}
Summary
This chapter studies the occupational sorting of immigrants in São Paulo. It shows the importance of incorporating immigration policies into empirical analyses of the determinants of immigration during the Age of Mass Migration (1820-1920). The chapter first discusses the historical differences between the two main immigration policies that prevailed in São Paulo at the time, namely the hiring of foreign bonded laborers for plantations and settlers to rural colonies. Based on this, the empirical approach identifies the channels for the economic integration of foreigners. I evaluate the impacts of prevailing immigration policies and the distribution of professions on the number of immigrants of each nationality settled across different regions. This analysis is conducted for a cross-section of municipalities in 1872 and a panel of settlement colonies in 1897-1920. Results show that sorting in the urban economy in the 1870s varied with immigrants' origins and immigration policies, not always as hypothesized. In the rural economy, immigrants did not integrate as agricultural laborers, despite the efforts of plantation owners. Furthermore, to the vast majority of immigrants, landownership remained what it had been in their countries of origin: a far distant dream. Finally, the sample of settlement colonies in 18971920 shows the prevalence of farming-related activities, as expected from this policy. Nevertheless, in light of the results of the previous period, this study questions the longer-term sustainability of landownership thereby obtained.
\end{abstract}





\section{Introduction}

The transatlantic flows of people during the Age of Mass Migration not only reshaped the demographic and ethnic composition of entire regions in the course of a single generation, but also had long-standing consequences for the economic development of the western world $^{1}$. From 1820 to 1918 , about 3.48 million people immigrated to Brazil, introducing the country, most especially its central-southern regions, into the global circulation of labor ${ }^{2}$. The motives that led people to emigrate, their expectations about receiving regions and the actual possibilities of achieving their imagined goals influenced the composition of the flows, the interplay with the expectations of various interest groups in receiving societies and the processes of socioeconomic assimilation ${ }^{3}$. Many of the consequences of the Age of Mass Migration in the short and long run were a collateral effect of the interaction between these forces.

In the Americas, the province/state of São Paulo became a major destination in this period ${ }^{4}$. The history of immigration in this region has two features of interest to the literature on the determinants of migration and economic integration ${ }^{5}$. First, the government of São Paulo experimented with an ample array of policies to attract immigrants. These included the hiring of European bonded laborers to plantations; projects to indenture Asian immigrants; the foundation of rural colonies for the settlement of foreigners; and the hiring of laborers for public works. Second, although southern Europeans - mainly from Portugal, Italy and Spain - constituted the highest share of immigrants by the end of the 1920s, São Paulo also received the inflow of minorities whose countries of origin had very distinct migratory histories.

\footnotetext{
${ }^{1}$ The periodization 1820-1920 for the Age of Mass Migration follows approximately Ferrie and Hatton's (2015) "rise and mass migration from Europe" (1820-1914). The period 1820-1920 encompasses all migratory cases discussed in this thesis, being thus preferred to defining the Age of Mass Migration between 1850 and 1920 (Abramitzky, Boustan and Eriksson, 2012; Abramitzky and Boustan, 2017). Other classifications include Borja's (1994) "First Great Migration" (1881-1924); Hatton and Williamson's (2002) and Kosack and Ward's (2014) "European mass emigration" (1860-1914); and Freeman's (2006) "earlier period of mass migration" (1870-1940).

${ }^{2}$ Levy (1974, Appendix Table 2).

${ }^{3}$ Cohn (1995, p. 398), Wegge (2002, p. 365), Abramitzky et al. (2012, p. 1833), Kosack and Ward (2014, p. 1016), Covarrubias, Lafortune and Tessada (2015, p. 115).

${ }^{4}$ South America received $21 \%$ of the 55 million European emigrants in the period 1820-1914 (Ferrie and Hatton, 2015). Balderas and Greenwood (2010, pp. 1302-3) present slightly dissonant numbers, referring to 1870-1910.

${ }^{5}$ Compared to the U.S. and Argentina, the Brazilian labor force was the least augmented by foreigners (Williamson, 2015, p. 9); however, this conclusion has to be qualified by region within Brazil (Sánchez-Alonso, 2007).
} 
These features are explored in the current chapter to study the determinants of immigration across regions of São Paulo. In particular, I ask how local economic opportunities influenced the sorting of foreigners and how such opportunities related to prevailing immigration policies. For this purpose, I study the sorting of 19 nationalities identified across municipalities in 1872 and of 12 nationalities recorded among settlers in rural colonies in the period $1897-1920^{6}$.

Four questions related to the occupational sorting of foreigners are addressed. First, in the booming rural economy of São Paulo, was the average immigrant, irrespective of his/her origin, attracted by agricultural employment in a farm or plantation? Second, in a society built upon the institutions of slavery and the plantation system, did the average immigrant become a landowner, or were rural elites able to block this channel of economic integration? Finally, did the average immigrant abandon the rural economy in search of better occupational opportunities in the urban economy? Related to the last question, were some nationalities more attracted to specific sectors, namely to manufacturing, services, or traderelated occupations?

These questions are explored within a broader inquiry about the importance of immigration policies. In particular, I ask how the main policies to attract immigrants to São Paulo interacted with the distribution of occupations in local labor markets to determine the sorting of foreigners. This leads me to consider the relationship between two well-developed branches of the literature that grew more or less independently of each other; namely, the determinants of immigration and selectivity, on the one hand, and the political economy of migratory policies, on the other.

Overall, the literature on the determinants of current international migration is confident in arguing that it provides "clear answers to why people immigrate"7. A similar view prevails in the analyses of the Age of Mass Migration ${ }^{8}$. Indeed, a major motivation to study historical migration has been to identify the so-called "fundamentals" that have led people to move across borders, then and now ${ }^{9}$. The most prevalent models to study historical and current

\footnotetext{
${ }^{6}$ I follow Martins (1989), Ferrie (1997a), Walker (2000) and Abramitzky et al. (2014) in hypothesizing that nationality influenced selectivity. In contrast, Eltis (1983, footnote 255), Galenson (1991, p. 590-2) and Grubb (1994, pp. 795, 803) emphasize differences less by origin and more by skills.

${ }^{7}$ Freeman (2006, p. 152). Massey, Arango, Hugo, Kouaouci, Pellegrino and Taylor (1993) and Haas (2010) qualify these conclusions in light of alternative economic and sociological theories of migration.

${ }^{8}$ See the literature review in Abramitzky and Boustan (2017). Haas (2010, pp. 3-6; 2011, pp. 8-9) and Hatton (2011, pp. 188-91) discuss the transition from ad hoc push-pull analyses to more solid theoretical frameworks.

${ }^{9}$ Hatton and Williamson (2002, 2009), Freeman (2006, pp. 160-2) and Ferrie and Hatton (2015, pp. 69-70).
} 
determinants consider migration a rational response to economic incentives, especially to lifelong income gaps across countries for a given level of skill ${ }^{10}$. Under usual assumptions of rational choice, potential migrants make a cost-benefit analysis and decide to move when facing an expected positive differential ${ }^{11}$. In the long run and under stable conditions, factor prices converge and international migration declines as a global equilibrium is reached ${ }^{12}$.

A related concern of these models has been to determine who goes abroad. This academic preoccupation reflects a persistent societal question. Perhaps nothing illustrates best its recurrence and the negative light in which it tends to be framed than the sad similarity between the Brazilian press in the nineteenth century and a U.S. president in the twenty-first century respectively claiming that groups of immigrants are the "scum of Europe" and "[Mexican] rapists"13. Theory predicts that immigrants self-select according to the transferability of their skills and the relative inequality on the returns to such skills in different countries ${ }^{14}$. Historical studies have qualified these propositions by showing that the skill composition of immigrants, the distribution of earnings and the costs of migration changed substantially over time. Considering these various effects, immigrants were, in general, positively self-selected during the Age of Mass Migration. However, the trend declined throughout the nineteenth century and results differ according the considered countries of origin ${ }^{15}$.

The literature on immigration policies, in turn, has mostly used models of political economy to explain the emergence of restrictive immigration policies in the Americas from the beginning of the twentieth century ${ }^{16}$. To some extent, the literature on the determinants has used the absence of official constraints to immigration in the nineteenth century as an identification strategy. Influential studies claimed that policies that deter immigration are most likely endogenous to other determinants; therefore, the nonexistence of such policies in the nineteenth century has been used to the empirical advantage of these studies ${ }^{17}$. A problem

\footnotetext{
${ }^{10}$ See a review of the literature in Borjas (1994) and Hatton (2014).

${ }^{11}$ Roy (1951), Borjas (1989), Freeman (2006), Docquier, Peri and Ruyssen (2014) and Hatton (2014).

12 Sjaastad (1962, p. 80), Borjas (1989, pp. 458-9), Grogger and Hanson (2011, p. 51) and McKenzie, Stillman and Gibson (2010, p. 914).

${ }^{13}$ A Phenix - 1839 (02/01, p. 4); The Washington Post (16/06/2015). Abramitzky and Boustan (2017, p. 1311) discuss how immigration has remained a polemical political topic since the nineteenth century.

${ }^{14}$ Borjas (1989, pp. 465-72; 1994, pp. 1687-92). For a historical comparison between Argentina, Brazil and the U.S., see Balderas and Greenwood (2010, p. 1306).

${ }^{15}$ Hatton and Williamson (1994, pp. 535-6; 2004, pp. 13-6, 21), Sánchez-Alonso (2007, p. 401), Ferrie and Hatton (2015, p. 60), Williamson (2015, p. 91) and Abramitzky and Boustan (2017, pp. 1311-2, 1321-4).

${ }^{16}$ Hatton and Williamson (2004, p. 25) and Ferrie and Hatton (2015, pp. 64-6).

${ }^{17}$ Hatton (2011, p. 207), Abramitzky et al. (2012, 1832-3) and Covarrubias et al. (2015, pp. 116).
} 
with this approach is that it considers only policies that restricted the inflow of people ${ }^{18}$. However, the nineteenth century was pervaded by a myriad of policies to promote immigration, rather than to deter it. Deliberate attempts to attract foreigners can be found especially in São Paulo ${ }^{19}$.

Policies that stimulated immigration influenced selectivity and the economic integration of foreigners. To understand the role of such policies in the occupational sorting of immigrants is the main task of this chapter. In this, I attempt to contribute to a research gap pointed out by Hatton and Williamson (2009) and Haas (2010, 2011). Contrary to the former, however, my analysis focuses on proactive policies to promote immigration rather than to block it. Contrary to the latter, the policies studied here are only those directly related to immigration; they do not include ampler, social-wide, policies that might influence the decision to migrate, such as modifications in the welfare state or in the initiatives to promote the cultural integration of foreigners.

Immigration policies carried out in São Paulo between 1820 and 1920 can be classified into two main categories. One policy referred to the foundation of rural colonies for the settlement of immigrants in smallholdings. Problems with the setting and enforcement of property rights, precarious infrastructure and opposition from plantation owners led to the decline of this policy from the early 1830 s to the late 1870 s, before it rebounded in the 1890 s. The other policy aimed at creating a stable supply of immigrant labor to the plantations. Mainly from the 1850 s to the 1870 s, this policy fostered the hiring of poor and credit-constrained Europeans, who bonded their labor to loans advanced by landowners in order to cover migration-related costs. From the 1880s, the government of São Paulo took over the financial risk of these loans and started to subsidize the immigration costs of households who accepted employment in the plantations ${ }^{20}$.

I differentiate between these policies in the empirical analysis with two strategies. The first is to repeat the same estimations of occupational sorting for two samples, namely for a crosssection of municipalities in 1872 and for a panel of settlement colonies in the period 1897 1920. While the sample of colonies in 1897-1920 is composed of rural settlers, the crosssection of municipalities in 1872 comprises all types of immigrants, including cohorts of

\footnotetext{
${ }^{18}$ Balderas and Greenwood (2010) is an important exception.

${ }^{19}$ Sánchez-Alonso (2007), Balderas and Greenwood (2010, pp. 1314-5) and Hatton (2011, p. 190).

${ }^{20}$ In contrast to Klein (1995), I consider the subsidization a continuance of the bonded labor policy. Both aimed at creating a stable supply of poor laborers (Martins, 1989; Sánchez-Alonso, 2007, p. 406). See also Chapter 2.
} 
settlers in rural colonies founded since the 1820 s and of laborers who had arrived to work in the plantations since the $1840 \mathrm{~s}^{21}$. To differentiate between these policies, I assign to each municipality in 1872 binary identifiers on whether that municipality ever had a settlement colony or a farm that employed bonded labor. These binary variables are then interacted with the occupational composition of the labor force. To be sure, estimates thus obtained do not allow us to infer anything about the socioeconomic mobility of any particular immigrant. Such assessment would require microdata linking different immigration flows ${ }^{22}$. Notwithstanding, results do show the average effect of certain immigration policies and of the sector composition of local labor markets on the sorting of foreigners. This advances our understanding of the patterns of allocation of immigrants and adds the nuances of a geographically disaggregated analysis that compares different nationalities and policies in a Latin American setting ${ }^{23}$.

The empirical results show the importance of considering the heterogeneous effects of immigration policies and occupational sorting on different nationalities. For the urban economy, no single general pattern for the geographic allocation of foreigners could be found with respect to occupational sorting. The economic structure of different municipalities influenced the allocation of foreigners in different ways according to their countries of origin. In the municipalities in 1872, trade-related occupations were the most common channel for the economic sorting of Portuguese immigrants and some minority groups. The sorting into manufacturing and services, in turn, depended on the countries of origin and prevailing immigration policies. By contrast, some more homogenous patterns were found in the rural economy, in which institutional constraints on landownership and agricultural labor seem to have played an important role. There is compelling evidence that the average immigrant of any nationality did not sort positively as agricultural laborer and that only a restricted group of minorities did so as landowners. Finally, the sample of colonies in 1897-1920 shows that most nationalities that ended up as settlers indeed became farmers in the rural colonies. However, the evidence of previous decades pointing to the low attainment of landownership among immigrants casts doubts on the sustainability of this result in the long run.

\footnotetext{
${ }^{21}$ The cohort confoundedness criticized by Borjas (1989, 1994) and Abramitzky et al. (2014).

${ }^{22}$ Galenson (1991), Cohn (1995), Herscovici (1998), Wegge (1999, 2002), Walker (2000), Stewart (2006), Abramitzky et al. (2012), Kosack and Ward (2014), Salisbury (2014) and Pérez (2017) provide refined microdata on historical selectivity and assimilation. To the best of my knowledge, Monasterio and Lopes (2018) is the only study focused on Brazil that has identified individuals by surnames, in an approach that could extend to census linkages.

${ }^{23}$ Hatton $(2011$, pp. 193, 200) presents a claim for disaggregated studies; Sánchez-Alonso (2007, pp. 397-8) and Balderas and Greenwood (2010, p. 1302) defend studies on the determinants of immigration beyond the U.S.
} 
The chapter is organized as follows. Section 2 reviews the literature on the determinants of immigration, selectivity and sorting. Section 3 provides the historical background by focusing on the history of settlement colonies and comparing this policy to the hiring of laborers to the plantations. To this end, I explore new information from the Brazilian Digital Newspaper's Repository and a quantitative dataset on rural colonies from the Statistical Yearbooks of the State of São Paulo ${ }^{24}$. Section 4 sets the hypotheses on how immigration policies impacted selectivity and sorting. Section 5 presents the methodology for the empirical analysis; its results are shown in Section 6. Section 7 concludes.

\section{Immigration, selectivity and occupational sorting: a literature review}

The most influential theoretical framework on the determinants of international migration models the decision of an agent $i$ (individual or household) to emigrate from a country of origin $o$ to a foreign destination $f$ as a cost-benefit analysis represented by ${ }^{25}$ :

$$
d_{i, o f}=f\left(\Delta w_{i, o f}, z_{i, f}, c_{i, f}, v_{i, o f}\right)
$$

The agent emigrates conditional on a positive evaluation of costs and benefits, i.e. $d_{i, o f}>0$. This decision is determined by four sets of variables. First, the agent takes into account the earning gaps between origin and destination; the difference $\Delta w_{i, o f}$ is the present value of the lifelong income expected by the agent in both countries. Second, the home bias with respect to destination, $z_{i, f}$, reflects the agent's preferences towards a certain country ${ }^{26}$. This includes non-economic factors that might drive the decision to migrate, keeping constant expected economic gains. Loosely speaking, this set captures the cultural and institutional distance between origin and destination, as perceived by the potential migrant. Third, the costs of immigrating to destination $f$ are captured by $c_{i, f}$. These include disbursements on transport and settlement ${ }^{27}$; foregone income while on the move; the opportunity cost of not going to

\footnotetext{
${ }^{24}$ For an assessment of the Repository research in this thesis, see Appendix III.

${ }^{25}$ Borjas (1989, 1994) based on Roy (1951). The parametrization I present adapts Hatton and Williamson (2002).

${ }^{26}$ Nothing impedes this value to be negative, i.e. a bias towards foreign countries (Wegge, 2002, p. 372).

${ }^{27}$ See the cost categories in Carrington, Detragiache and Vishwanath (1996, pp. 914-5).
} 
alternative destinations; and the psychological burden of the move ${ }^{28}$. Fourth, $v_{i, o f}$ can reflect a set of immigration policies at origin and destination ${ }^{29}$.

Historical analyses have improved the literature on the determinants of immigration in three directions. First, the set of variables taken into account in the cost-benefit analysis was much refined since the original proposition that migrants responded to purely economic gains. Second, a growing branch of the literature has focused on the persecution of minorities and on humanitarian crises as explanatory reasons for the flows of people ${ }^{30}$. Besides its lessons for the current challenge of having 25.9 million refugees and asylum seekers globally, this strand of the literature has questioned the hegemony of theories based on economic determinants $^{31}$. Third, analyses of migration flows over time have added a dynamic component to otherwise static models. In particular, the emigration life cycle hypothesis posited how demographic and economic changes determine which regions supply emigrants and how the skill composition is distributed across different migratory waves. The hypothesis is that countries undergo an inverted-U emigration pattern. Early stages of demographic transition create population pressure, while sustained economic growth allows for the overcoming of poverty constraints that hinder initial emigration. As gaps in income close and the demographic transition maturates, emigration declines. This hypothesis explains why northwestern Europeans prevailed in the flows of the early nineteenth century and southern and eastern Europeans during the last quarter of that century ${ }^{32}$.

The literature on selectivity builds on a related framework ${ }^{33}$. Immigrants can self-select based on idiosyncratic and/or observable dimensions. The former includes agents' behavior and ethical codes. The latter encompasses agents' education, health, occupation and skills ${ }^{34}$. The literature has advanced by considering whether (and how) these dimensions influence the costs and benefits of migration. Whether selectivity depends more on economic opportunities or on costs has important consequences for the motives that lead people to move and how

\footnotetext{
${ }^{28}$ Sjaastad (1962, pp. 84-5), Wegge (2002, p. 372), Balderas and Greenwood (2010, p. 1305), Borger (2010, p. 3), Grogger and Hanson (2011, p. 54) and McKenzie and Rapoport (2010, p. 811).

${ }^{29}$ This differs from Hatton and Williamson (2002, p. 8), who consider fixed costs, $c$ (independent of individual), and interpret $v_{i}$ (independent of country) as a catchall variable for idiosyncratic characteristics of immigrants.

${ }^{30}$ Hatton (2011, pp. 193-4) and Abramitzky and Boustan (2017, pp. 1322-3, 1333). Hatton and Williamson (2002, p. 10) defend the primacy of economic determinants, a view held theoretically also by Borjas (1989, p. 472).

${ }^{31}$ International Migration Report (2017). See Chiswick (1999, pp. 181, 184-5), Ferrie (1997a, pp. 309, 313-5), Kosack and Ward (2014, pp. 1019-21) and Abramitzky and Boustan (2017, p. 1322).

${ }^{32}$ Hatton and Williamson (1992, p. 3; 2009, p. 20) and Ferrie and Hatton (2015, p. 56).

${ }^{33}$ Sjaastad (1962), Borjas (1987) and Chiswick (1999). For selectivity, see Orrenius and Zavodny (2005).

${ }^{34}$ Borjas (1989, pp. 465-72) and Abramitzky et al. (2012, p. 1834).
} 
they integrate in the receiving societies. The historiography of the Age of Mass Migration has swung between these two explanations: for the case of immigration to the U.S., a recurrent question is whether immigrants were primarily opportunity seekers at destination or poverty expellees from countries of origin ${ }^{35}$.

Originally, selectivity was seen as a function of the income distribution for the range of skills at origin and destination. Ceteris paribus, if inequality is higher at origin than at destination, low-skilled immigrants can expect a greater leap forward from the move ${ }^{36}$. Moreover, the higher the migration costs, the higher the bars to be surpassed. Relatedly, networks change relative costs, as the stock of foreigners abroad provides information, remittances and even pre-paid tickets to prospective immigrants, thus loosening poverty constraints that initially limited mass migration ${ }^{37}$. Combined with the fact that mobility costs substantially decreased in the nineteenth century, this model predicts a decline in selectivity and suggests that the skill composition of the flows became increasingly more dependent on immigrants' countries of origin $^{38}$.

More recently, immigration costs started to be viewed not as an exogenous parameter, but as a function of agents' observable and unobservable skills ${ }^{39}$. Borger (2010) and Covarrubias et al. (2015) synthesized this perspective by modeling the so-called "liquidity constraint restrictions". In these models, domestic economic growth narrows the income gaps with destination, leading to positive selectivity; however, growth also lowers liquidity constraints for all potential emigrants, leading to negative selectivity. The net effect becomes an empirical question ${ }^{40}$. A problem for the empirical identification of selectivity in this case is that agents differ in an almost infinite array of characteristics. Unobservable characteristics include behavioral and ethical codes, entrepreneurship and attitudes towards risk. In nonexperimental designs, these components can be measured only indirectly, e.g. with the residual of earnings' differentials after controlling for observables ${ }^{41}$. The difficulties of these assessments are larger in historical analyses, for which even indirect measures are scarce. The opposite problem occurs for selectivity in observables, for which the challenge is to identify

\footnotetext{
${ }^{35}$ Cohn (1995, pp. 393-404).

${ }^{36}$ Borjas $(1987,1989,1994)$.

${ }^{37}$ Hatton and Williamson (1992, p. 10; 1994, pp. 534-5; 2002, p. 9; 2004, p. 21), Wegge (2002, pp. 369-70), Ferrie and Hatton (2015, p. 57) and Abramitzky and Boustan (2017, p. 1325). See also Section 4 of Chapter 2.

${ }^{38}$ Borjas (1994, pp. 1685-7), Hatton and Williamson (2004, pp. 4-5, 13-6) and Ferrie and Hatton (2015, p. 60).

${ }^{39}$ Carrington et al. (1996) were the first to model endogenous costs to networks. See also Chiswick (1999, pp. 182-3), McKenzie and Rapoport (2010, pp. 811-2) and Abramitzky et al. (2012, p. 1836).

${ }^{40}$ Same conclusion as in Orrenius and Zavodny (2005, p. 220).

${ }^{41}$ Salisbury (2014, pp. 50-2). See McKenzie et al. (2010, p. 925) for an experimental design.
} 
dimensions that are relevant for the context considered ${ }^{42}$. The most common candidates include immigrants' wealth $^{43}$; education ${ }^{44}$; health (proxied by anthropometry) ${ }^{45}$; and occupation $^{46}$.

Finally, the literature on immigrants' occupational and geographic sorting mirrors the questions posited above ${ }^{47}$. If we accept that immigrants respond to a cost-benefit calculation, then it makes little difference, in economic terms, whether the reallocation of labor occurs across or within borders ${ }^{48}$. Any initial mismatch between the supply of immigrants' skills and demands in local labor markets will be corrected by further reallocations of labor. Local demands for skills vary according to the relative scarcity of factors in the receiving societies and their sectoral composition. Under these considerations, historical analyses have shown the array of economic opportunities available to immigrants in the Americas. In particular, considering the open agricultural frontier in the U.S. in the nineteenth century, this literature has mainly dealt with the settling of frontier regions and with the access to landownership in them ${ }^{49}$. More recently, the sorting of immigrants in urban occupations has gained attention ${ }^{50}$. Finally, in an innovative panel data setting, Abramitzky et al. (2014) show how occupational assimilation in the U.S. in the early twentieth century was strongly associated with immigrants' origins; those from countries that had a higher real wage than the European mean had an advantage in high-paying occupations over and above American-born workers. With a similar methodology, Pérez (2017) shows that European immigrants in Argentina were more frequently able to upgrade their occupational status even when compared to the U.S.

In this study, I assess the occupational sorting of immigrants across municipalities and settlement colonies. The problem is that occupational sorting is not independent of selectivity, as we have just seen. For this reason, the next section explores historical evidence on selectivity according to immigration policies, with a focus on settlement colonies. In

\footnotetext{
${ }^{42}$ See a parallel to the categories in Roy (1951, p. 135).

${ }^{43}$ Wegge $(1999,2002)$ and Abramitzky et al. (2012).

44 Orrenius and Zavodny (2005), Borger (2010), McKenzie and Rapoport (2010) and Grogger and Hanson (2011).

${ }^{45}$ Humphries and Leunig (2009, pp. 122-3) summarize this literature. See also Kosack and Ward (2014).

${ }^{46}$ Borjas, Bronar and Trejo (1992), Wegge (2002) and Salisbury (2014).

47 Grogger and Hanson (2011, pp. 43-6). Stewart (2006), Sánchez-Alonso (2007), Kosack and Ward (2014), Salisbury (2014) and Abramitzky et al. (2014) adopt a similar approach in historical terms.

${ }^{48}$ Sjaastad (1962, p. 80), Hatton and Williamson (1992, pp. 13-4), Carrington et al. (1996, p. 926) and Freeman (2006, p. 148). Salisbury (2014, p. 46) qualifies the differences between internal and international migration.

${ }^{49}$ See in particular the reviews of literature in Ferrie (1997a; 1997b), Stewart (2006) and Salisbury (2014).

${ }^{50}$ Galenson (1991), Herscovici (1998) and Walker (2000).
} 
particular, I discuss the complaints of Brazilian authorities about alleged skill inadequacies of immigrants. Occupational sorting depends also on institutions prevailing at local labor markets. I therefore discuss the difficulties in setting and enforcing property rights over public lands; these problems pervaded the Brazilian immigration policy from the first settlement colonies and help to explain the empirical finding that foreigners usually did not sort as landowners in the 1870s.

\section{Immigration policies in São Paulo: from settlers to bonded laborers to settlers $^{51}$}

From 1820 to 1920 , the predominant immigration policy in São Paulo swung between two main projects: the foundation of colonies for the rural settlement of immigrants or the hiring of bonded laborers, mainly to work in coffee plantations.

The central Brazilian government tended to favor immigration to rural settlements administered by public authorities ${ }^{52}$. These colonies had some economic motivations, such as the expansion of local markets and the diffusion of technologies brought by immigrants. However, their main goals were political, such as increasing demographic density ${ }^{53}$; whitening the population with European immigrants; and consolidating frontier regions with foreigners who would gradually identify themselves as Brazilians ${ }^{54}$. This policy prevailed in São Paulo in the 1820s, where tentative experiments were carried out mainly with Germanspeakers. These colonies lost importance due to problems in setting and enforcing property rights over public lands, in supplying infrastructure and due to the opposing interests of plantation owners. Settlement colonies started regaining ground in the 1870 s, once their goals became more aligned with the interests of plantation owners ${ }^{55}$. New rural colonies were

\footnotetext{
51 The title of this section parodies the title of Engerman (1983).

52 Viotti da Costa (1998, pp. 109-13; 2004, p. 190). Buarque de Holanda (1941, p. 5) and Oberacker Jr. (2004, pp. 260-4) show how the central government had emphasized rural settlements since the colonial times.

${ }^{53}$ In the 1820s-30s, Brazil and São Paulo had demographic densities of 1.2 and 0.7 inhabitants per sq. kilometer, respectively. São Paulo had about 284,000 inhabitants in 40 municipalities in 1836. The territory of the current state of Paraná, at the time part of São Paulo, had about 36,000 inhabitants in six municipalities (Bassanezi, 1998 , pp. 28, 165). For the country as a whole, the density estimates are based on the averaged population of 1819 and 1830 (Annuario Estatístico do Brasil, p. 1293) and area from ww2.ibge.gov.br/home/geociencias/areaterritorial (Área Territorial Brasileira, accessed on December 112017 ). The oldest area estimate I found was from 1889.

${ }^{54}$ Oberacker Jr. (2004, pp. 260-4), Buarque de Holanda (1941, pp. 6-7) and Dean (1977, p. 95).

55 Or at least not in competition with them, as stated for 1908 in Colistete and Lamounier (2014, p. 5).
} 
expected to reduce real wages by increasing the supply of foodstuff. Moreover, some settlements resulted from the financial bailout of plantation owners who went bankrupt and had their estates sold in installments for settlers.

The elite of plantation owners, in turn, aimed at securing a stable supply of agricultural labor. This policy gained ground around 1850, when the Brazilian government officially abolished the transatlantic slave trade. This was also a period of expanding coffee plantations, which increased the demand for labor. Therefore, from the 1850s to the $1870 \mathrm{~s}$, this immigration policy aimed primarily at finding new sources of secure, stable and cheap labor to substitute slaves. The most successful alternative in the 1850s-60s was the hiring of bonded laborers, especially Portuguese and German-speakers. Immigrants were mostly poor and creditconstrained households who bonded their labor to the repayment of loans offered by Brazilian landowners to cover immigration costs. In the $1850 \mathrm{~s}-60 \mathrm{~s}$, this policy provided public credit to landowners who conducted the hiring in Europe. From the 1880s to the 1920s, the official policy aimed at fully subsidizing immigrants' fares. Immigration costs were covered directly with public funds, placing the burden and risk of debt onto the state. Linked with the position of Italian provinces in their emigration life cycle, this policy led to the mass immigration of Italians to São Paulo.

There were two other important categories of immigrants. The first refers to expatriates with high levels of physical and/or human capital ${ }^{56}$. Despite having interesting aspects, studying this category involves biographical accounts that do not constitute an object of this thesis. The second were laborers hired by the provincial government for public works, especially for the construction and maintenance of roadways. This category of immigrant tended to be related to the other policies. In the early nineteenth century, laborers in public works signed contracts that also allowed for settlement in public lands. From the 1850s, the main Brazilian hirer of bonded laborers to the plantations became the hirer of laborers to public works as well ${ }^{57}$.

These four categories of immigrants are not mutually exclusive. The collective imaginary of the countryside of São Paulo is filled with stories of ancestors who "made America" by arriving in Brazil as rural laborers and becoming small landowners afterwards ${ }^{58}$. While the

\footnotetext{
${ }^{56}$ Klein (1995, pp. 208-9).

${ }^{57}$ Lamounier (2000, p. 47) shows how such proposals survived in later periods for the construction of railways.

${ }^{58}$ Dean (1976, pp. 493-4). For the prevalence of the same ideology in Argentina, see Pérez (2017, p. 975).
} 
empirical analysis of this chapter shows that this description is not accurate for the experience of the average immigrant - at least not until the 1870 s -, these accounts point to the importance of considering socioeconomic mobility as part of occupational sorting. On a related note, nothing impeded a bonded laborer first hired to work in a plantation from later settling in a colony, or vice-versa. Given that municipalities in the 1870 s and settlement colonies in the 1890s-1910s constitute the units of analysis of this chapter, I cannot determine whether an individual in the sample of settlement colonies was not also a bonded laborer in the first sample. Therefore, when discussing the results, I will be talking about the impact that the characteristics of municipalities and settlement colonies had on the average sorting of immigrants. This has no implication for the history of any single immigrant and his/her socioeconomic mobility ${ }^{59}$.

\section{1. $\quad$ First experiments with settlement colonies (1820s-30s)}

The most successful Brazilian rural colonies in the 1820s were located in the southernmost province of Rio Grande do Sul. Nevertheless, São Paulo witnessed some important experiments with this immigration policy as well. The first attempt to found a settlement with foreigners in the province was that of Baron von Langsdorf ${ }^{60}$. However, barriers imposed by political disputes constrained this initiative and the Baron settled the immigrants in his own farm, in Rio de Janeiro ${ }^{61}$. The other attempts were related to a commission established by the Brazilian Empire to attract settlers from the German States ${ }^{62}$. Most immigrants thus hired went to the southern provinces, but the central government ordered the settlement of a parcel in São Paulo ${ }^{63}$. In response, the Baron of Antonina founded colony Rio Negro in $1828^{64}$. The other German-speakers were directed to São Paulo and would settle in Santo Amaro and Itapecerica $^{65}$. Finally, official documents referred also to a so-called German colony of Entrada da Matta in $1832^{66}$.

\footnotetext{
${ }^{59}$ Dean (1977, pp. 119, 178), Oberacker Jr. (2004, pp. 264-79) and Petrone (2004, pp. 342-7).

${ }^{60}$ Langsdorf was a German-born scientist and Russian Consul in Brazil (Benigsen, 1954; Schnaiderman, 1966).

${ }^{61}$ Karastojanov (1998, note 78).

62 See the opinion published in O Farol Paulistano (26/03/1828, pp. 2-4).

${ }^{63}$ Oberacker Jr. (2004, p. 263-4, 269).

${ }^{64}$ Scheler (1905, p. 171) and Sommer (1953, IV). This municipality is in the current state of Paraná. Baron of Antonina is co-signer of the 1835 consortium of Luiz Vergueiro \& Co., discussed in Chapter 2.

${ }^{65}$ Correio Paulistano (20/02/1855, p. 1). Viotti da Costa (1998, pp. 110-1) describes this episode in detail.

${ }^{66}$ O Novo Farol Paulistano - 1832, p. 1 (11/02; 19/05).
} 
The emphasis on German-speaking immigrants is a classic example of how non-economic motives influenced immigration policy for an entire century ${ }^{67}$. The Brazilian focus on the German States was associated with the objective of whitening the population and, most likely, with the origin of the first Empress of independent Brazil - the Archduchess of Austria $^{68}$. Combined with the ascending position of the German States in their emigration life cycle, these political forces created an important path for future immigration waves. The hiring of bonded laborers in the 1850s, for instance, took place mainly in the German States paired with the hiring in Portugal ${ }^{69}$. Moreover, most likely because of immigrant networks and selectivity, the share of German-speakers in settlement colonies in São Paulo in the 1890s-1910s was significantly above the shares of Austrian, German and Swiss immigrants to the state as a whole.

Among these colonies, those in Santo Amaro and Itapecerica became the most successful ${ }^{70}$. In November 1827, the provincial government was informed about the arrival of the Germanspeakers ${ }^{71}$. By the end of that year, 926 German-speakers from Rhineland, Silesia and East Prussia, divided into 142 households and 72 single individuals, arrived at the capital of the province or remained at the seaport municipality of Santos ${ }^{72}$.

One year later, Nicolau Pereira de Campos Vergueiro, member of the Council of the Provincial Government, future senator and one of the most prominent figures in the history of immigration to Brazil, voiced his opposition to the policy of founding settlement colonies ${ }^{73}$. His arguments reflected the interests of plantation owners and started a central debate about Brazilian immigration policy. While the provincial government struggled to determine where and how to settle the German-speakers, the foreigners kept receiving a daily subsistence subsidy from the provincial treasury. Vergueiro intervened for the termination of these subsidies $^{74}$. Arguing that "the entirety of Brazil has been settled with European immigrants

\footnotetext{
${ }^{67}$ Grubb (1994,pp. 798, 815) argues that the emergence of Brazil, Poland and Russia as alternative destinations was one of the causes for the drop in the number of German-speakers immigrating to the U.S. in the 1820s.

${ }^{68}$ Levy (1974, p. 51) and Oberacker Jr. (2004, pp. 260-3).

69 The most important Brazilian firm hiring immigrants, Vergueiro \& Co., had connections with Germanspeaking regions, as some of its senior personnel had studied or worked in northern German States. See Chapter 2.

${ }^{70}$ Siriani (2003) provides a detailed monograph about this immigration wave.

${ }^{71}$ O Farol Paulistano (15/11/1828, pp. 1-2); Correio Paulistano (20/02/1855, p. 1).

72 Of these, 326 settled in the village of Itapecerica and most of the others in Santo Amaro; another 36 were allocated to the village of Itanhaém and 37 to Cubatão (Correio Paulistano, 20/02/1855, p. 1).

${ }^{73}$ See Buarque de Holanda (1941, p. 12), Dean (1977, p. 96) and Viotti da Costa (1998, p. 110).

${ }^{74}$ For discussions about the benefits and subsidies, see O Farol Paulistano (26/03/1828, p. 2-4; 04/03/1829, pp. $1-2 ; 10 / 11 / 1829$, p. $1 ; 20 / 06 / 1829$, pp. $1-2)$.
} 
without the aid of the government and I was one of them", the future senator proposed three alternatives to the Germans-speakers ${ }^{75}$. First, they could look for private employment in urban occupations. Second, the government could offer them plots of land in unsettled regions. Third, and most preferably to Vergueiro, they should be distributed as laborers to plantations in the countryside. Counselor Antonio da Veiga supported this view, claiming that immigrants would diffuse labor-saving technologies brought from Europe, an expected innovation that was particularly welcomed in the context of potential shortages in the supply of slave labor ${ }^{76}$.

Vergueiro further pointed to the existence of a number bottlenecks of promoting settlement colonies. A prominent problem was the lack of basic infrastructure. No preparation had been taken even to lodge the foreigners upon arrival in 1827; two years later, the ranches that the government decided to construct in Santo Amaro were still not ready. Furthermore, there was a lack of proper institutions to set and enforce property rights over public lands ${ }^{77}$. In hindsight, this can be viewed as the result of a limited state capacity - only slowly surpassed with increasing provincial revenues in the nineteenth century - and of the economic and political interests of landowners in limiting access to land ${ }^{78}$.

The debates on where to found the colony subsumes these problems and Vergueiro stressed the opposing interests of Brazilians and foreigners on this matter ${ }^{79}$. On the one hand, the provincial government favored settlements in isolated areas with low population density. On the other, the Inspector of Colonization, Dr. Mello Franco, argued that the villages of Itapecerica, M'boy and Carapicuíba had better infrastructure and transport facilities ${ }^{80}$. Some deputies, including Vergueiro, also favored locations closer to urban areas because of expected economic spillovers and easier integration of foreigners. The decisive argument to found the colony in the neighborhood of the villages, however, had to do with property rights.

\footnotetext{
${ }^{75} \operatorname{Idem}(15 / 11 / 1828$, pp. 1-2).

${ }^{76}$ Idem (20/08/1828, pp. 1-3). Technological diffusion rarely occurred (Correio do Sertão, 05/12/1903, p. 1). Buarque de Holanda (1941, pp. 6-7), Goldman (2004, pp. 321-2), Viotti da Costa (1998, p. 111) and Siriani (2003, pp. 45-56) argue that Brazilian conditions impeded an immediate technological transfer from Europe and the U.S.

${ }^{77}$ Besides the political debate reported in O Farol Paulistano (15/11/1828, pp. 1-2), see also the lack of planning and coordination between the central and the state governments reported in idem (08/04/1829, p. 2).

78 A regulatory law on landownership was enacted only in 1850 and affected smallholdings only in southern Brazil (Dean, 1971, pp. 621-3; Engerman and Sokoloff, 2011, pp. 19, 32-3). See also Sánchez-Alonso (2007, p. 401) and Engerman and Margo (2010, pp. 302-5).

79 O Farol Paulistano (15/11/1828, pp. 1-2).

${ }^{80}$ Dr. Mello Franco studied medicine at the University of Göttingen. His daughter became the Baroness of Rio Claro and Countess of Araraquara (Sommer, 1953 - IV; Begliomini, n.d.; Karastojanov, 1998, p. 118, note 388).
} 
Field-Marshal Rendon noticed that the three villages were old Jesuit aldeamentos confiscated by the provincial government and with plots already registered. Counselor Veiga opposed the expropriation of indigenous and squatters in the region. Moreover, according to him, the provincial government had not incorporated the Jesuit estates at the time. While the matter was not resolved, the government allowed some German-speakers to rent plots in the region ${ }^{81}$. After a lengthy debate, the colony was finally founded in the village of Santo Amaro. Problems persisted, however. The gathering of immigrants was troublesome, as some refused to follow the schedule of transfers to the colony, and infrastructure remained precarious. Moreover, establishing property rights required the demarcation and registration of plots. Led by the first director of the colony, Teófilo Schmidt, some discontent immigrants rioted and refused to accept the plots, considering them of low quality. Dr. Mello Franco assumed the responsibility of setting legal rights, but faced enormous difficulties ${ }^{82}$.

This first migratory wave to settlement colonies in São Paulo illustrates a recurrent feature of this immigration policy, namely, the disequilibrium between the government's proclaimed intention to set property rights and its ability to enforce them. This problem persisted for a long time in this region and elsewhere ${ }^{83}$. Foreign settlements received renewed public attention in the 1860 s due to projects to settle American and English immigrants ${ }^{84}$. Despite laudatory views about the economic prosperity fostered by the German-speakers settled in the 1820 s, public authorities noticed that problems with the enforcement of property rights over public lands still persisted, about thirty years $\operatorname{later}^{85}$. It is also illustrative that uncertainties regarding land titles constituted a major restriction to the settlement of Americans in the municipality of Xiririca in the 1860s. On this occasion, a private colony was dissolved after Brazilian landowners reclaimed the lands that had been demarcated for the settlement ${ }^{86}$.

\footnotetext{
${ }^{81}$ For the political debates, see O Farol Paulistano - 1828 (30/07, p. 1; 20/08, pp. 1-3; 03/09, pp. 2-3).

${ }^{82}$ Idem - 1829 (08/04, pp. 2-3; 06/06, p. 2; 20/06, pp. 1-2; 10/11, p. 1).

${ }^{83}$ Idem - 1830 (19/01, p. 2; 27/05, p. 1). Dr. Mello Franco announced the end of his works in the colony in idem (03/07, p. 4).

${ }^{84}$ Goldman (1957; 2004, pp. 308-314). The demonym American will be used throughout the thesis to refer to a citizen of the U.S. unless otherwise explicitly indicated.

85 Diário de S. Paulo (18/10/1865, p. 2). This differs from the opinion expressed in Correio Paulistano (26/03/1866, p. 2), which considered the German-speaking colony a waste of public funds, leading only to the spread of pauperism from Europe.

${ }^{86}$ Goldman (1957, p. 18).
} 


\subsection{Complementary policies: public works and settlement in public lands}

The hiring of laborers for public works, mainly to construct roadways, gained importance in the $1850 \mathrm{~s}$, but the first proposals to hire this specific type of immigrant date back to the 1820s. This modality of immigration was strongly associated with German-speakers, who allegedly had comparative advantages in the required skills. In the 1850s, the firm Vergueiro \& Co. - founded by Senator Vergueiro and sons - was the main hirer of immigrants for public works, a business it developed together with the hiring of laborers to plantations. In the 1820s-30s, however, the main immigration policies were still focused on settlement colonies. Therefore, immigration for public works remained linked to settlement upon the completion of contracts.

In 1829 , the provincial government had already proposed the transformation of the subsidies conceded to the German-speakers into salaries for those who accepted employment in the construction of roadways ${ }^{87}$. In 1835 , the theme returned to the political forefront with a proposal presented by a consortium formed by Platt \& Reid, in Rio de Janeiro, and Widow Aguiar \& Sons, in Santos. The consortium aimed at establishing a land- and river-shipping company between the municipalities of Santos and Cuiabá, with a stopover in Porto Feliz; the project further included the construction of a railway between Santos and the villages/municipalities of São Paulo, Constituição, Itú and Porto Feliz. Coupled with the infrastructure projects was the aim to foster immigration and settlements. The consortium demanded the rights to settle unoccupied land around the planned rail line and amended a project for a milder naturalization law if settlers were foreigners ${ }^{88}$.

This project was subjected to intense debates in the Provincial Assembly, once again counting with an active participation of Nicolau Vergueiro ${ }^{89}$. The Assembly accepted the concession of land, but debated for long how to regulate it. In particular, provincial representatives questioned the optimal number of immigrants and the area to be conceded ${ }^{90}$.

In hindsight, the project was clearly unfeasible, as the municipalities to be connected by the consortium are more than 1,300 kilometers distant from each other. Nevertheless, the

\footnotetext{
${ }^{87}$ O Farol Paulistano (01/07/1829, p. 2).

${ }^{88}$ O Paulista Official (05/09/1835, pp. 3-4; 10/02/1836, pp. 3-4).

${ }^{89}$ Notice that this is the same year in which Luiz Vergueiro \& Co. proposed the consortium to hire European laborers. It is reasonable to argue that these projects did not coexist by chance. See Chapter 2.

${ }^{90}$ O Paulista Official - 1836 (10/02, pp. 3-4; 12/02, p. 3; 15/02, pp. 2-3; 18/02, p. 1; 01/03, p. 3).
} 
objective of hiring immigrants for public works and of promoting settlements along road- and railways became a new constant in the political debates on how to promote immigration ${ }^{91}$.

Another immigration wave took place under a commission established in 1838 to hire specialized laborers for the public industry Royal Ironworks of St. John, Ipanema, in the municipality of Sorocaba, and, once again, for the construction of roadways ${ }^{92}$. Despite being numerically limited, this immigration wave had an explicit focus on skilled craftsmen. This hiring was again strongly related to the Vergueiro family. Francisco de Souza Queiroz, brother-in-law of Nicolau Vergueiro, captained the approval of the project of the roadway, then coordinated by Vergueiro himself ${ }^{93}$. This experience enhanced Vergueiro's political authority and management capacity to hire immigrants. It is reasonable to conclude that his hiring of contract laborers in the 1850s built on the expertise accumulated in the $1820 \mathrm{~s}-30 \mathrm{~s}^{94}$.

Major Johann Bloem, director of the Royal Ironworks and responsible for the hiring, commissioned the Brazilian consul in Bremen to contract the laborers. By the end of 1838, 218 adult men and 59 women and children, mostly Prussians, arrived in São Paulo; 56 had been hired to work in the Royal Ironworks, but 18 refused the position upon arrival ${ }^{95}$.

Reports in the press soon considered these immigrants a costly and useless experiment ${ }^{96}$. This perception worsened in 1839, as the defection of some laborers, dissatisfied with the working conditions in the roadways, triggered strong xenophobic reactions ${ }^{97}$. Contemporaneous analyses stressed the alleged skill inadequacies of immigrants to the occupations they were expected to undertake - a theme that became recurrent in future discussions about foreign laborers. Major Bloem was accused of hiring individuals with no experience or skills for roadway construction, leading to a pool of immigrants allegedly constituted by many petty

\footnotetext{
${ }^{91}$ Lamounier (2000, pp. 47-8).

${ }^{92}$ A Phenix - 1839 (06/02, p. 3; 23/03, p. 4; 21/08, pp. 1-2). See also Viotti da Costa (1998, p. 111) and Kupfer, Kutschat, Rothfuss and Fouquet (2016).

${ }^{93}$ O Paulista Official (27/10/1838, pp. 1-2; 02/01/1839, pp. 1-4).

${ }^{94}$ Sommer (1950) argues that José Vergueiro - son of Nicolau - coordinated a police force that suppressed a riot of German-speakers in 1839. This most likely influencing the manner by which he dealt with an important riot in the farm of his father in 1856, the so-called Sharecropper's Riot. See Chapter 2 on this matter.

95 These figures are based on the report of the president of the province published in Correio Paulistano (20/02/1855, p. 1). An exhaustive and critical account of this hiring process is in A Phenix (02/01/1839, pp. 14).

96 Remunerations included a fixed daily payment ( 0.5 mil-réis), a varying parcel (0.16 mil-réis), when specialized crafts were demanded, and a food ration of 0.135-0.16 mil-réis. Major Bloem agreed upon the varying parcel, but did not have governmental consent for it (A Phenix - 1839: 02/01, pp. 1-4; 21/08, pp. 1-2; 27/04, pp. 2-3).

${ }^{97}$ See a parallel with later construction of railroads, as described in Lamounier (2000, p. 74).
} 
service providers ${ }^{98}$. Even the supervisor of the works, the engineer Karl Bresser, presented similar complaints, arguing that a retailer and a tavern-keeper administered important sections of the roadway ${ }^{99}$.

\subsection{The reemergence of official settlement colonies (1870s-1920s)}

Settlement colonies regained ground as an immigration policy in the 1870s. At the beginning of that decade, José Vergueiro advocated that the policy of hiring bonded laborers to the plantations, fostered by his father for thirty years, had reached a saturation point and that even the deceased senator had considered the immigration of bonded laborers only a step towards the inflow of non-bonded Europeans. José Vergueiro justified this view by mentioning cases of upward mobility among German-speakers who had worked in the plantations but later became landowners ${ }^{100}$. He even claimed that farm Angélica, proprietary to Vergueiro \& Co., had been bought for allotment or lease to immigrants ${ }^{101}$. It is impossible to determine whether these words reflect true intentions, but historical evidence shows that this was never the strategy actually adopted by those landowners. Farm Angélica had been cultivated, since its foundation, by slaves and foreign bonded laborers. In the 1870s, the impawning of that farm probably made its allotment economically more attractive to Vergueiro \& Co. than its foreclosure ${ }^{102}$.

In 1871, the central Brazilian government dispatched instructions to diplomatic outposts with the aim of fostering rural colonies in the provinces of Espírito Santo, Minas Gerais, Santa Catarina and São Paulo ${ }^{103}$. None of the colonies founded by the central government in the 1820 s was active by the $1870 \mathrm{~s}^{104}$. The consulates in Antwerp, Bremen and Hamburg were informed that the Brazilian government intended to cover the transportation costs of settlers. Moreover, to make landownership feasible to immigrants, the government proposed a package that included not only plots of land, but also seeds, tools and areas ready for

\footnotetext{
${ }^{98}$ A Phenix - 1839 (02/01, pp. 1-4; 23/03, p. 4; 27/04, pp. 2-3).

${ }^{99} \operatorname{Idem}(31 / 03 / 1841$, pp. 3-4).

${ }^{100}$ Gazeta de Campinas (24/04/1870, pp. 1-2).

${ }^{101} \operatorname{Idem}(10 / 04 / 1870$, pp. 1-2).

${ }^{102}$ It is noteworthy to read José Vergueiro defending the thesis that "large agricultural estates are advantageous only $[\ldots]$ to their few and happy proprietors; $[\ldots]$ The division of land is as necessary to the progress and development of a nation as the division of labor; and it is only via immigration that our country will be able to reach this fortunate result" (Gazeta de Campinas, 10/04/1870, p. 2). Dean (1977, p. 122) cites the same excerpt. ${ }^{103}$ Diário de S. Paulo (10/12/1871, p. 3).

${ }^{104}$ For the list of colonies in the 1820s, see Siriani (2005, p. 92).
} 
cultivation (i.e. cleared from forestry). The payment schedule for the package involved five installments, starting in the second year upon arrival, and a subsidy of 20 mil-réis per child between five and ten years old ${ }^{105}$. Resounding old complaints about immigrants' skill inadequacies, the government highlighted its willingness to hire "individuals used to rural works, excluding those, who living in manufacturing cities, are unable to adapt easily to agriculture" 106 .

Other proposals sprouted up between the 1870s and the 1920s, when 28 settlement colonies were founded by the government of the province/state ${ }^{107}$. The foundation and evolution of these colonies indicate a long but imperfect process of institutional learning. Similar to landowners who still attempted to hire bonded laborers in the $1870 \mathrm{~s}$, the government became increasingly worried about the provision of public goods to attract foreigners. Better facilities included educational services, enhanced infrastructure in transports and communications and the improved enforcement of property rights.

The history of specific settlement colonies is of increasing interest, but it goes beyond the scope of this chapter ${ }^{108}$. Nevertheless, I collected data for a sample of settlement colonies from the Statistical Yearbooks of the State of São Paulo ${ }^{109}$.

Table 1.1 presents descriptive statistics for this dataset and compares their overall means to the cross-section of municipalities in 1872. Comparisons between these samples are only tentative, as one refers to settlement colonies, mainly during the first decades of the twentieth century, and the other, to entire municipalities before the mass immigration to São Paulo. Nevertheless, comparisons are still informative about different immigration policies. To refine them, I categorized the sample of municipalities in 1872 into three groups according to immigration policies prevailing in them. The first category determines whether a municipality had a settlement colony before 1872 , corresponding to the indicator (ID settlement $=1$ ). The second category determines whether at least one farm in a municipality employed

${ }^{105}$ Correio Paulistano $(21 / 09 / 1878$, p. 3). Prices ranged from two to eight réis per approximately four sq.meters; plots ranged from 131 to 605 sq.-km, including opened pathways.

${ }^{106}$ Diário de S. Paulo (10/12/1871, p. 3).

${ }^{107}$ Rocha, Ferraz and Soares (2017, p. 113).

${ }^{108}$ See Dean (1977, pp. 175-7) and Viotti da Costa (1998, pp. 181-2) for a historical account of the settlements of Canoas, Cascalho and Jorge Tibiriçá (only the latter included in my sample).

${ }^{109}$ Colonies Bandeirantes (municipality of São José do Barreiro), Bom Sucesso (Campo Largo de Sorocaba), Campos Salles (Campinas), Conde de Parnaíba (Campinas), Gavião Peixoto and section Nova Paulicéia (Araraquara), Jorge Tibiriçá (Rio Claro), Martinho Prado Junior (Mogi Guaçú), Monção (Avaré), Nova Europa (Ibitinga), Nova Odessa (Campinas), Nova Veneza (Campinas), Pariquerá Assú (Iguape), Piaguhy (Guaratinguetá), Sabaúna (Mogi das Cruzes), São Bernardo (capital) and Visconde de Indaiatuba (Mogi Mirim). 
bonded laborers in the 1850s-60s, corresponding to the indicator (ID bonded $=1$ ). The third category refers to municipalities where none of the previous policies prevailed. Figures 1 and 2, below, map these localities in 1872 and the municipalities that had a colony in the period 1897-1920.

The descriptive statistics are in line with the now well-established empirical findings by Rocha, Ferraz, and Soares (2017), which show that settlement colonies performed outstandingly in terms of human capital. The overall literacy rate for colonies in the period 1897-1920 was $40.91 \%$. This pooled mean hides, however, large heterogeneities between and within colonies. With an overall standard deviation of $18.07 \%$, literacy in settlement colonies varied from a minimum of $9.57 \%$ in colony Nova Veneza in 1913, to a maximum of $83.09 \%$ in Jorge Tibiriçá in 1914. These numbers compare to very low literacy rates in the municipalities in 1872, whose average among the free population was only at $19.11 \%$. If subcategorized by regions where different migratory policies prevailed, the data indicate a small, but positive correlation between literacy and immigration: literacy rates among the free population reached $18.73 \%$ in municipalities where settlement colonies had prevailed; $22.20 \%$ where bonded immigrants were prevalent; and $17.92 \%$ in municipalities where none of the immigration policies dominated.

Immigrants also brought important cultural traits, particularly in religious matters. About $16 \%$ of the settlers in 1897-1920 were non-Catholics; this figure, however, varied largely with the ethno-linguistic composition of the colonies. To cite the most prominent cases, colonies Bom Sucesso and Nova Veneza had only Catholic inhabitants. The former was exclusively constituted of Brazilian settlers, while the latter was composed majorly by Italian and Spanish immigrants. Non-Catholics, in turn, were a majority in some settlements in specific years, including colonies Bandeirantes, Campos Salles, Gavião Peixoto and Nova Odessa. In most cases, the predominance of non-Catholics peaked around 1911 - a year associated with a rebound in the immigration of German-speakers and with the inflow of Russians. For municipalities in 1872, non-Catholics remained a very small minority. In municipalities where settlement colonies had prevailed, non-Catholics reached $1.01 \%$, most likely related to German and English immigrants. Where bonded laborers had prevailed, the share of non-Catholics was only $0.59 \%$. This probably reflects the fact that a significant number of Portuguese had been hired as bonded laborers and that an important share of the German-speakers were also Catholics. Finally, where no specific immigration policy had prevailed, non-Catholics constituted only $0.16 \%$ of the total population. 
Figure 1.1 - Immigration policies per municipality in São Paulo ${ }^{1}$
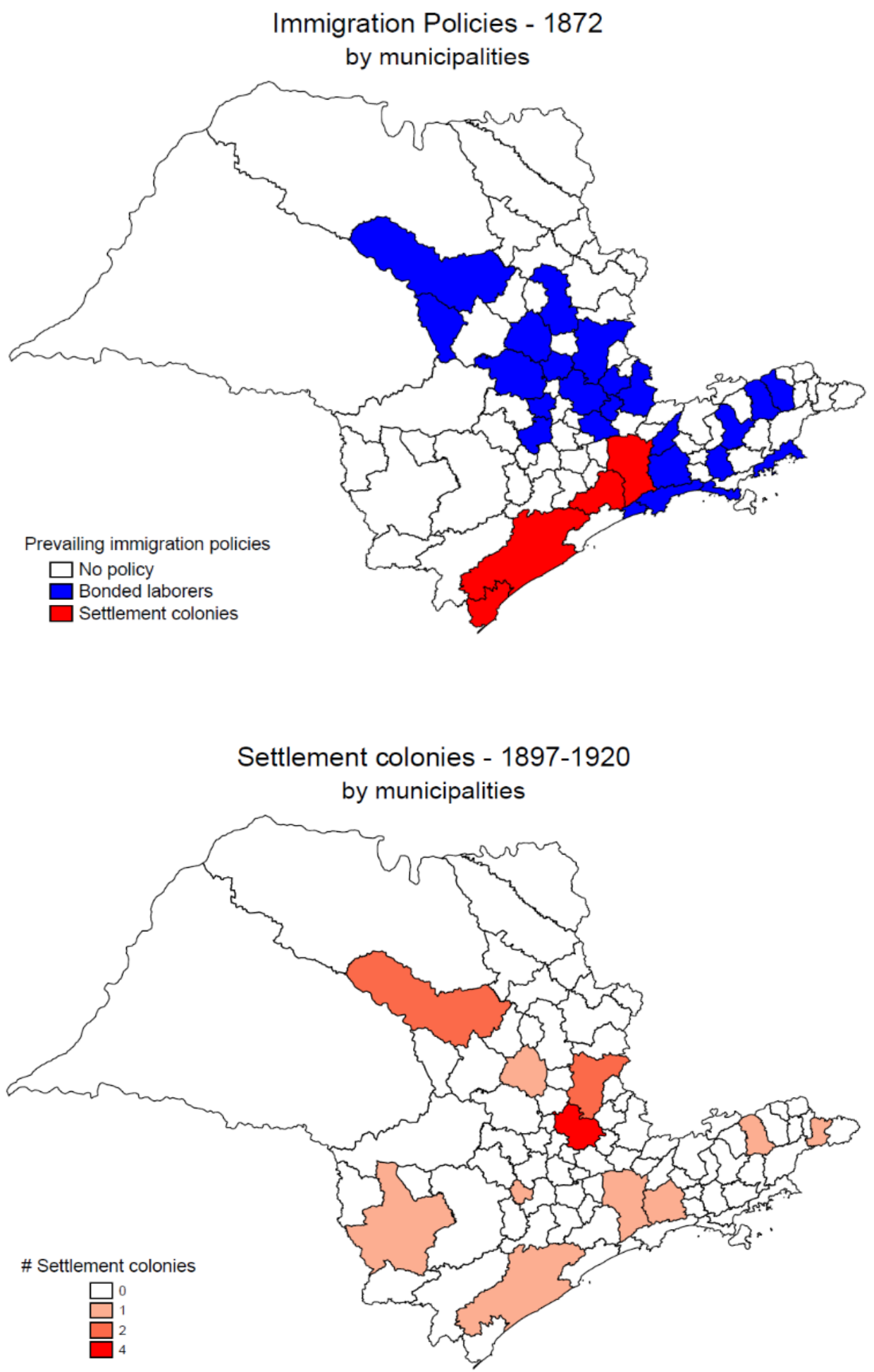

Note: (1) Both maps use political borders of 1872, i.e. settlement colonies in 1897-1920 are plotted against borders that prevailed in 1872. 
Table 1.1 - Descriptive statistics (selected variables)

\begin{tabular}{|c|c|c|c|c|c|c|c|c|c|c|c|c|c|c|c|c|c|}
\hline & \multicolumn{12}{|c|}{ Sample 1 - Cross-section of Municipalities in 1872} & \multirow{2}{*}{\multicolumn{5}{|c|}{$\begin{array}{c}\text { Sample } 2 \text { - Pooled Panel of Settlement Colonies } \\
\text { in 1897-1920 (Overall) }\end{array}$}} \\
\hline & \multicolumn{4}{|c|}{$\begin{array}{l}\text { Municipalities with at least one } \\
\text { settlement colony }{ }^{1} \\
\mathrm{~N}=4\end{array}$} & \multicolumn{4}{|c|}{$\begin{array}{l}\text { Municipalities with at least one farm } \\
\text { employing bonded labor }{ }^{2} \\
\mathrm{~N}=24\end{array}$} & \multicolumn{4}{|c|}{$\begin{array}{l}\text { None of the previous categories } \\
\qquad \mathrm{N}=61\end{array}$} & & & & & \\
\hline & Mean & S.D. & Min. & Max. & Mean & S.D. & Min. & Max. & Mean & S.D. & Min. & Max. & $\mathrm{N}$ & Mean & S.D. & Min. & Max \\
\hline \multicolumn{18}{|c|}{$\underline{\text { Demography }}$} \\
\hline Population & 15425 & 11725 & 3945 & 31385 & 12130 & 6935 & 1593 & 31397 & 7943 & 4474 & 1566 & 21426 & 104 & 1465 & 868.5 & 134 & 3740 \\
\hline$\%$ Infants $(\%)^{3}$ & 13.08 & 4.95 & 6.77 & 18.86 & 12.51 & 4.19 & 5.37 & 21.96 & 13.99 & 3.72 & 5.93 & 21.42 & 83 & 22.45 & 5.34 & 6.99 & 31.91 \\
\hline$\%$ Children $^{4}$ & 23.14 & 3.29 & 18.32 & 25.73 & 23.17 & 6.08 & 10.65 & 40.36 & 23.30 & 6.12 & 8.66 & 37.00 & 83 & 19.56 & 4.21 & 7.66 & 29.75 \\
\hline$\%$ Young adults 5 & 9.95 & 1.07 & 9.30 & 11.56 & 10.37 & 1.96 & 8.46 & 15.96 & 9.98 & 1.71 & 5.68 & 14.00 & 83 & 18.72 & 6.81 & 8.75 & 49.45 \\
\hline$\%$ Singles & 67.52 & 5.08 & 61.42 & 73.48 & 66.98 & 8.11 & 48.71 & 78.65 & 66.97 & 6.48 & 52.42 & 80.36 & 100 & 55.99 & 14.02 & 17.13 & 83.66 \\
\hline$\%$ Widows & 3.61 & 1.18 & 2.22 & 4.61 & 4.63 & 3.60 & 1.21 & 15.58 & 4.43 & 2.99 & 0.93 & 14.88 & 100 & 2.34 & 1.23 & 0.21 & 6.74 \\
\hline \multicolumn{18}{|c|}{ Education and culture } \\
\hline Literacy rate & 18.73 & 7.56 & 12.21 & 28.05 & 22.20 & 12.58 & 5.74 & 49.90 & 17.92 & 9.59 & 5.77 & 44.33 & 84 & 40.91 & 18.07 & 9.57 & 83.09 \\
\hline Enrolment rate & 4.41 & 2.34 & 1.57 & 6.80 & 3.42 & 1.94 & 0.86 & 8.97 & 3.44 & 1.90 & 0.59 & 8.61 & - & - & - & - & - \\
\hline \# Schools & - & - & - & - & - & - & - & - & - & - & - & - & 84 & 2.63 & 1.55 & 1 & 6 \\
\hline$\%$ Non-Catholics & 1.01 & 1.03 & 0 & 2.36 & 0.59 & 1.03 & 0 & 3.86 & 0.16 & 0.56 & 0 & 3.20 & 96 & 16.08 & 18.17 & 0.43 & 71.12 \\
\hline \# Religious buildings & - & - & - & - & - & - & - & - & - & - & - & - & 32 & 1.25 & 0.44 & 1 & 2 \\
\hline \multicolumn{18}{|c|}{ Economic determinants and networks } \\
\hline \# Slaves & 1600 & 1571 & 492 & 3828 & 2702 & 2725 & 198 & 13685 & 1399 & 1277 & 63 & 8281 & - & - & - & - & - \\
\hline Stock immigrants 1854 & 537.75 & 586.43 & 2 & 1264 & 115.71 & 245.23 & 0 & 994 & 29.90 & 74.77 & 0 & 486 & - & - & - & - & - \\
\hline Municipal budget ${ }^{6,7}$ & 19668 & 28496 & 1995 & 52542 & 12917 & 13797 & 179 & 49650 & 4395. & 3972 & 530.11 & 16577 & - & - & - & - & - \\
\hline \# Free non-whites & 4471 & 3732 & 1076 & 8723 & 3484 & 2454 & 545 & 9682 & 2390 & 1558 & 305 & 8314 & - & - & - & - & - \\
\hline L-productivity (nominal) ${ }^{6,8}$ & - & - & - & - & - & - & - & - & - & - & - & - & 81 & 203.3 & 137.1 & 23.12 & 566.9 \\
\hline$\%$ Cultivated area & - & - & - & - & - & - & - & - & - & - & - & - & 93 & 31.18 & 21.74 & 1.96 & 90.81 \\
\hline \multicolumn{18}{|c|}{ Sector composition (excluding rural economy) } \\
\hline$\%$ Manuf. & 19.38 & 14.58 & 0 & 34.59 & 14.43 & 9.51 & 0 & 30.64 & 19.85 & 11.5 & 0 & 60.42 & 100 & 2.50 & 3.56 & 0 & 18.68 \\
\hline$\%$ Serv. & 6.6 & 6.98 & 0 & 13.71 & 9.83 & 12.04 & 1.68 & 61.54 & 8.25 & 11.05 & 0 & 60 & - & - & - & - & - \\
\hline$\%$ Trade & 26 & 5.53 & 20 & 33.42 & 22.84 & 9.13 & 7.37 & 36.78 & 21.15 & 14.2 & 0 & 75.41 & 100 & 0.92 & 0.89 & 0 & 4.46 \\
\hline$\%$ Public Adm. & 27.82 & 15.63 & 17.64 & 51.11 & 14.39 & 13.34 & 1.59 & 67.74 & 18.62 & 10.66 & 2.13 & 50.59 & 100 & 0.54 & 0.81 & 0 & 5.26 \\
\hline$\%$ Other professions & - & - & - & - & - & - & - & - & - & - & - & - & 100 & 3.52 & 10.18 & 0 & 64.25 \\
\hline \multicolumn{18}{|c|}{ Agricultural labor and landownership } \\
\hline \# Farms ${ }^{9}$ & 21 & 12.25 & 10 & 37 & 107.7 & 76.49 & 16 & 337 & 61.7 & 44.56 & 4 & 184 & - & - & - & - & - \\
\hline \# Foreign landowners ${ }^{9}$ & 1.5 & 1 & 0 & 2 & 2.7 & 4.12 & 0 & 17 & 1.95 & 6.77 & 0 & 44 & - & - & - & - & - \\
\hline \# Free agric. laborers & 3974.25 & 1740.89 & 1904 & 6121 & 3156 & 2276.73 & 366 & 9778 & 2326.43 & 1834.24 & 247 & 10718 & - & - & - & - & - \\
\hline \# Foreign agric. laborers & 96 & 114.63 & 26 & 267 & 105.37 & 159.93 & 0 & 750 & 30.85 & 63.21 & 0 & 485 & - & - & - & - & - \\
\hline
\end{tabular}




\subsubsection{Nationalities, policies and the emigration life cycle}

The ethno-linguistic composition of settlement colonies in 1897-1920 is worth discussing at this point, especially vis-à-vis the origins of foreigners in municipalities in 1872 and other migratory flows at the beginning of the twentieth century. Tables 1.2 and 1.3 present the shares of each nationality in the total population and the number of immigrants from each nationality, respectively.

The most outstanding characteristic of settlement colonies in 1897-1920 is the high share of foreigners among its inhabitants, with an overall mean of $45.31 \%$. This is far above the share of immigrants in municipalities in 1872 , where the highest mean was $4.2 \%$ in regions that had employed bonded laborers, compared to $3.67 \%$ where settlement colonies had prevailed and $2.22 \%$ where no immigration policy had dominated. This disparity in shares is to be expected because of the design of that policy and the nature of the samples. The average population of municipalities in 1872 was much larger than the number of inhabitants in a rural colony in the 1890s-1920s. If the absolute number of immigrants is considered, we notice that settlement colonies in 1897-1920 did not differ so substantially from municipalities in 1872. Naturally, the total number of immigrants in Brazil, in general, had skyrocketed since the mass immigration of Italians in the late 1880s; but the numbers of those going to settlement colonies were comparable to previous immigration waves to municipalities in 1872 .

The composition of nationalities changed between 1872 and 1897-1920, reflecting the maturation of sending countries in their emigration life cycles and changes in Brazilian immigration policies. Some nationalities that had settled in the municipalities in 1872 were not present in the colonies in 1897-1920, including Latin Americans and Americans. Moreover, attempts to hire Chinese coolies - likely related to the presence of those immigrants in 1872 - had been substituted by the more successful immigration of the Japanese $^{110}$. As a consequence of the mass immigration of Italians, this nationality was the most numerous in the colonies in 1897-1920. Also in line with general migratory flows to Brazil, Spanish immigrants became numerically prominent in the colonies, in contrast to their position as a minority in 1872 .

${ }^{110}$ Conrad (1975) and Yang (1977). 
Table 1.2 - Percentage of foreigners: municipalities (1872) and settlement colonies (1897-1920)

\begin{tabular}{|c|c|c|c|c|c|c|c|c|c|c|c|c|c|c|c|c|}
\hline & \multicolumn{12}{|c|}{ Sample 1 - Cross-section of Municipalities in 1872} & \multirow{2}{*}{\multicolumn{4}{|c|}{$\begin{array}{l}\text { Sample } 2 \text { - Pooled Panel of Settlement } \\
\text { Colonies in 1897-1920 (Overall) })^{2}\end{array}$}} \\
\hline & \multicolumn{4}{|c|}{$\begin{array}{c}\text { Municipalities with at least one } \\
\text { settlement colony } \\
\mathrm{N}=4\end{array}$} & \multicolumn{4}{|c|}{$\begin{array}{l}\text { Municipalities with at least one farm } \\
\text { employing bonded labor } \\
\mathrm{N}=24\end{array}$} & \multicolumn{4}{|c|}{$\begin{array}{l}\text { None of the previous categories } \\
\qquad N=61\end{array}$} & & & & \\
\hline & Mean $^{1}$ & S.D. & Min. & Max. & Mean & S.D. & Min. & Max. & Mean & S.D. & Min. & Max. & Mean & S.D. & Min. & Max. \\
\hline Foreigners & 3.67 & 3.23 & 0.91 & 7.83 & 4.20 & 3.38 & 0.55 & 11.00 & 2.22 & 2.58 & 0 & 14.48 & 45.31 & 24.47 & 0 & 96.19 \\
\hline Germans & 0.51 & 0.57 & 0.08 & 1.34 & 0.78 & 1.16 & 0 & 3.74 & 0.17 & 0.48 & 0 & 3.40 & 6.92 & 9.52 & 0 & 45.51 \\
\hline Swiss & 0.17 & 0.20 & 0 & 0.46 & 0.10 & 0.21 & 0 & 0.80 & 0.02 & 0.13 & 0 & 0.98 & 0.80 & 4.98 & 0 & 44.93 \\
\hline Portuguese & 1.00 & 1.45 & 0.25 & 3.18 & 0.88 & 0.66 & 0.15 & 2.45 & 0.48 & 0.67 & 0 & 4.38 & 2.98 & 3.78 & 0 & 16.09 \\
\hline Austrians & 0.02 & 0.02 & 0 & 0.05 & 0.02 & 0.10 & 0 & 0.50 & 0.01 & 0.05 & 0 & 0.41 & 3.52 & 4.87 & 0 & 17.49 \\
\hline French & 0.17 & 0.18 & 0.03 & 0.42 & 0.07 & 0.08 & 0 & 0.30 & 0.03 & 0.05 & 0 & 0.21 & 0.15 & 0.56 & 0 & 4.49 \\
\hline Danish & 0.00 & 0.01 & 0 & 0.02 & 0.00 & 0.00 & 0 & 0.01 & 0.00 & 0.00 & 0 & 0.03 & - & - & - & - \\
\hline Spanish & 0.04 & 0.07 & 0 & 0.14 & 0.01 & 0.02 & 0 & 0.05 & 0.02 & 0.06 & 0 & 0.34 & 6.08 & 6.42 & 0 & 30.78 \\
\hline Dutch & 0.00 & 0.01 & 0 & 0.01 & 0.00 & 0.01 & 0 & 0.04 & 0.00 & 0.01 & 0 & 0.07 & - & - & - & - \\
\hline Belgians & 0.01 & 0.01 & 0 & 0.03 & 0.01 & 0.02 & 0 & 0.10 & 0.00 & 0.02 & 0 & 0.17 & 0.09 & 0.28 & 0 & 1.51 \\
\hline English & 0.84 & 1.66 & 0 & 3.32 & 0.03 & 0.08 & 0 & 0.33 & 0.03 & 0.14 & 0 & 1.06 & 0.01 & 0.04 & 0 & 0.40 \\
\hline Americans & 0.03 & 0.04 & 0 & 0.09 & 0.05 & 0.19 & 0 & 0.91 & 0.04 & 0.23 & 0 & 1.72 & - & - & - & - \\
\hline Italians & 0.18 & 0.22 & 0.05 & 0.51 & 0.14 & 0.12 & 0 & 0.52 & 0.12 & 0.13 & 0 & 0.77 & 14.12 & 14.61 & 0 & 64.29 \\
\hline Swedes & 0.00 & 0.01 & 0 & 0.02 & 0.00 & 0.01 & 0 & 0.04 & 0.01 & 0.04 & 0 & 0.33 & 0.24 & 1.03 & 0 & 9.29 \\
\hline Russians & 0.01 & 0.03 & 0 & 0.06 & 0.00 & 0.01 & 0 & 0.07 & 0.00 & 0.01 & 0 & 0.07 & 5.32 & 10.25 & 0 & 68.34 \\
\hline Hungarians & 0.01 & 0.01 & 0 & 0.03 & 0.00 & 0.00 & 0 & 0.00 & 0.00 & 0.00 & 0 & 0.00 & 0.12 & 1.19 & 0 & 12.14 \\
\hline Orientals & 0.00 & 0.01 & 0 & 0.02 & 0.00 & 0.00 & 0 & 0.02 & 0.00 & 0.00 & 0 & 0.02 & - & - & - & - \\
\hline Chinese & 0.00 & 0.00 & 0 & 0.00 & 0.00 & 0.01 & 0 & 0.02 & 0.00 & 0.01 & 0 & 0.05 & - & - & - & - \\
\hline Argentinians & 0.00 & 0.01 & 0 & 0.02 & 0.00 & 0.00 & 0 & 0.01 & 0.00 & 0.00 & 0 & 0.02 & - & - & - & - \\
\hline Bolivians & 0.00 & 0.00 & 0 & 0.00 & 0.00 & 0.02 & 0 & 0.09 & 0.00 & 0.00 & 0 & 0.00 & - & - & - & - \\
\hline Paraguayans & 0.01 & 0.01 & 0 & 0.03 & 0.01 & 0.01 & 0 & 0.03 & 0.01 & 0.03 & 0 & 0.25 & - & - & - & - \\
\hline Polish & - & - & - & - & - & - & - & - & - & - & - & - & 1.18 & 5.49 & 0 & 34.91 \\
\hline Syrians & - & - & - & - & - & - & - & - & - & - & - & - & 0.21 & 0.50 & 0 & 2.61 \\
\hline Japanese & - & - & - & - & - & - & - & - & - & - & - & - & 0.86 & 3.43 & 0 & 18.88 \\
\hline
\end{tabular}

Notes: (1) Cells register the percentage of each nationality, e.g. 0.84 for the English in municipalities with at least one settlement colony refers to $0.84 \%$; (2) Overall $\mathrm{N}=104$. 
Table 1.3 - Number of foreigners: municipalities (1872) and settlement colonies (1897-1920)

\begin{tabular}{|c|c|c|c|c|c|c|c|c|c|c|c|c|c|c|c|c|}
\hline & \multicolumn{12}{|c|}{ Sample 1 - Cross-section of Municipalities in 1872} & \multirow{2}{*}{\multicolumn{4}{|c|}{$\begin{array}{l}\text { Sample } 2 \text { - Pooled Panel of Settlement } \\
\quad \text { Colonies in 1897-1920 (Overall) }{ }^{2}\end{array}$}} \\
\hline & \multicolumn{4}{|c|}{$\begin{array}{c}\text { Municipalities with at least one } \\
\text { settlement colony } \\
\mathrm{N}=4\end{array}$} & \multicolumn{4}{|c|}{$\begin{array}{l}\text { Municipalities with at least one farm } \\
\text { employing bonded labor } \\
\mathrm{N}=24\end{array}$} & \multicolumn{4}{|c|}{$\begin{array}{l}\text { None of the previous categories } \\
\qquad N=61\end{array}$} & & & & \\
\hline & Mean $^{1}$ & S.D. & Min. & Max. & Mean & S.D. & Min. & Max. & Mean & S.D. & Min. & Max. & Mean & S.D. & Min. & Max. \\
\hline Foreigners & 573 & 898 & 100 & 1918 & 305 & 426 & 18 & 1844 & 79 & 118 & 0 & 801 & 317 & 406 & 0 & 1733 \\
\hline Germans & 121 & 200 & 7 & 420 & 109 & 172 & 0 & 534 & 12 & 27 & 0 & 187 & 51 & 95 & 0 & 455 \\
\hline Swiss & 21 & 26 & 0 & 58 & 17 & 38 & 0 & 129 & 1 & 7 & 0 & 54 & 2 & 10 & 0 & 93 \\
\hline Portuguese & 272 & 485 & 10 & 999 & 127 & 167 & 14 & 770 & 45 & 92 & 0 & 683 & 24 & 46 & 0 & 233 \\
\hline Austrians & 4 & 4 & 0 & 9 & 2 & 7 & 0 & 36 & 0 & 3 & 0 & 21 & 34 & 87 & 0 & 433 \\
\hline French & 41 & 62 & 1 & 133 & 9 & 19 & 0 & 93 & 3 & 5 & 0 & 25 & 1 & 5 & 0 & 43 \\
\hline Danish & 1 & 3 & 0 & 5 & 0 & 0 & 0 & 1 & 0 & 0 & 0 & 2 & - & - & - & - \\
\hline Spanish & 11 & 22 & 0 & 44 & 2 & 4 & 0 & 17 & 2 & 6 & 0 & 37 & 50 & 102 & 0 & 589 \\
\hline Dutch & 1 & 2 & 0 & 4 & 1 & 2 & 0 & 10 & 0 & 1 & 0 & 5 & - & - & - & - \\
\hline Belgians & 1 & 2 & 0 & 4 & 2 & 7 & 0 & 32 & 0 & 1 & 0 & 9 & 0 & 2 & 0 & 12 \\
\hline English & 34 & 65 & 0 & 131 & 7 & 22 & 0 & 104 & 2 & 9 & 0 & 68 & 0 & 1 & 0 & 7 \\
\hline Americans & 8 & 14 & 0 & 29 & 8 & 27 & 0 & 130 & 3 & 13 & 0 & 100 & - & - & - & - \\
\hline Italians & 46 & 77 & 2 & 161 & 19 & 26 & 0 & 118 & 9 & 11 & 0 & 60 & 93 & 134 & 0 & 674 \\
\hline Swedes & 2 & 3 & 0 & 6 & 1 & 3 & 0 & 13 & 0 & 3 & 0 & 17 & 1 & 6 & 0 & 58 \\
\hline Russians & 5 & 9 & 0 & 18 & 0 & 1 & 0 & 5 & 0 & 1 & 0 & 4 & - & - & - & - \\
\hline Hungarians & 2 & 4 & 0 & 8 & 0 & 0 & 0 & 0 & 0 & 0 & 0 & 0 & 0 & 3 & 0 & 38 \\
\hline Orientals & 1 & 3 & 0 & 5 & 0 & 0 & 0 & 1 & 0 & 0 & 0 & 1 & - & - & - & - \\
\hline Chinese & 0 & 1 & 0 & 1 & 0 & 0 & 0 & 2 & 0 & 1 & 0 & 8 & - & - & - & - \\
\hline Argentinians & 1 & 3 & 0 & 5 & 0 & 0 & 0 & 1 & 0 & 0 & 0 & 1 & - & - & - & - \\
\hline Bolivians & 0 & 0 & 0 & 0 & 1 & 6 & 0 & 27 & 0 & 0 & 0 & 0 & - & - & - & - \\
\hline Paraguayans & 3 & 4 & 0 & 9 & 1 & 1 & 0 & 2 & 0 & 2 & 0 & 13 & - & - & - & - \\
\hline Polish & - & - & - & - & - & - & - & - & - & - & - & - & 7 & 44 & 0 & 408 \\
\hline Syrians & - & - & - & - & - & - & - & - & - & - & - & - & 2 & 7 & 0 & 53 \\
\hline Japanese & - & - & - & - & - & - & - & - & - & - & - & - & 10 & 61 & 0 & 516 \\
\hline
\end{tabular}

Notes: (1) Values are rounded up to the first natural number; (2) Overall $\mathrm{N}=192$; the difference with respect to Table 1.2 is explained by missing data on total population to calculate the shares. 
By contrast, some features demonstrate the persistence of migratory flows between 1872 and 1897-1920. German-speakers retained their relative importance in settlement colonies in 1897-1920. These figures are at odds with the composition of the main immigration flows to Brazil in this period. The gross-inflow of immigrants to São Paulo between 1895 and 1919 was about 1.23 million people, $40.65 \%$ from Italy, $21.84 \%$ from Spain and $17.7 \%$ from Portugal $^{111}$. Notwithstanding, Germans still constituted the second largest foreign group in the settlement colonies in 1897-1920 and the overall share of Austrians was above that of the Portuguese. These disparities indicate a certain selectivity against the Portuguese in the settlement colonies. They also reflect the importance of path dependence in the immigration of Germans and Austrians to settlement colonies.

In absolute terms, only the Germans and Portuguese had a mean higher than 100 immigrants in at least one category of municipality. Americans, English, French, Italians and Swiss, in turn, were concentrated in some more specific localities and at least one municipality had more than 100 immigrants of those nationalities (maxima in Table 1.3). The French-speaking Swiss and the French constituted a minority hired as bonded laborers ${ }^{112}$. Americans were mainly a special group of expatriates from the U.S. South, who emigrated in the aftermath of the Civil War and settled majorly in the central plateau of São Paulo ${ }^{113}$. The English, in turn, tended to prevail on the southern coast of São Paulo, prominently in the settlement of Cananéia ${ }^{114}$.

\subsection{Official and private colonies in the western agricultural frontier (1900s-20s)}

Since 1889, a federalist Republican regime had substituted the centralism of the old Brazilian Empire, giving a very advantageous economic position to the state of São Paulo ${ }^{115}$. The government of the state had solid public revenues from the export of coffee and used the capital accumulated in that booming rural economy to subsidize immigration and to conduct

\footnotetext{
${ }^{111}$ Levy (1974, Appendix Table 8).

112 See Bassanezi (1998, pp. 406-8) and references therein.

113 This statement is valid on average only. Goldman (1957) discusses the heterogeneities among American immigrants in São Paulo.

${ }^{114}$ Kuhlman (1905, p. 90). Goldman (2004, pp. 309, 311-2) argues that these nationalities tended to confounded contemporaneously. Interestingly, the results of the empirical exercise show that Americans and English behaved very differently in terms of occupational sorting.

115 See Engerman and Sokoloff (2011) for the relation between decentralization, immigration and landownership.
} 
a domestic policy that kept the prices of coffee artificially high, further stimulating the expansion of the plantations ${ }^{116}$. This led to the advancement of the agricultural frontier and of the transport infrastructure to the south- and north-western parcels of the state in the first decades of the twentieth century ${ }^{117}$. A number of settlement colonies, founded by the government and private incorporators, followed thereafter.

In the period 1900-1920, the inflow of about 814,000 immigrants implied an increase in the pool of rural laborers and in the contingent of people moving in the direction of the agricultural frontier ${ }^{118}$. Land allotment became a more prevalent strategy for rural settlement $^{119}$.

Settlement via private land selling was not a novelty per se, as it had been a successful strategy in settling the southern provinces ${ }^{120}$. Moreover, three migratory waves were associated with this strategy in São Paulo. First, in 1850 the private colony Superaguy was established by Charles Perret-Gentil, a Swiss ex-consul and businessman who had kinship ties with the Vergueiro family ${ }^{121}$. Second, in the aftermath of the American Civil War, some Confederate entrepreneurs attempted to found private colonies on the southern coast of the province. These experiments soon failed and most of the Americans who did not return to the U.S. settled in the economically booming central plateau of São Paulo. Finally, similar experiments in the same region had been conducted with English settlers ${ }^{122}$.

The novelties in the early twentieth century were the expanding agricultural frontiers and the role that private incorporators, trustees and, in some cases, speculators played in the selling of land to foreigners. Nevertheless, two features remained from previous immigration waves. First, the propaganda efforts of some land-sellers bore a remarkable resemblance to the old pro-emigration propaganda of the 1850 s, especially in creating exaggerated expectations among immigrants. Second, some cases of land-selling included explicit deception by the offer of plots over which property rights had not yet been set ${ }^{123}$. Although improved since the first colonies in Santo Amaro and Itapecerica, founded a century before, legal institutions

\footnotetext{
${ }^{116}$ Dean (1971, pp. 624-5), Holloway (1978, p. 192) and Monasterio and Reis (2008, p. 10).

117 James (1932, 1940), Platt (1935) and Waibel (1950) provide interesting case studies.

${ }^{118}$ Holloway (1978, pp. 202-3).

${ }^{119}$ Martins (1989, p. 24), Klein (1995, pp. 211-2) and Colistete and Lamounier (2014, pp. 7-8).

${ }^{120}$ Oberacker Jr. (2004).

${ }^{121}$ Located in the current state of Paraná; Oberacker Jr. (2004, pp. 279) and Heflinger Jr. (2009, p. 40).

122 Goldman (2004, pp. 311-2).

123 Silva (2010, pp. 54-8); See further potential examples in the Archives of Instituto Martius-Staden: Documents GIVh, n. 72/2 and 198; Deutsche Zeitung São Paulo (28/10/1924; 08/10/1925).
} 
safeguarding landownership among immigrants remained notably impaired at the beginning of the twentieth century.

\section{Policy, selectivity and sorting in São Paulo: assumptions and hypotheses}

In the empirical exercise, I test for the interplay of the main factors that determine the occupational sorting of immigrants. The first refers to the goals of policymakers with each immigration policy. The second is related to the pool of available immigrants. Combined, these factors determine different patterns of selectivity. The final sorting then depends on the interaction between selectivity and economic opportunities prevailing at local labor markets.

In the cross-section of municipalities in 1872 , I interact variables that identify the immigration policy prevalent in a region with the number of individuals working in different sectors in that locality. The former captures the selectivity of immigrants implied by the policy. I use here the same identifiers applied to the descriptive statistics, namely municipalities that had a settlement colony $(I D$ settlement $=1)$ and those with farms that employed bonded laborers (ID bonded $=1$ ). The second set of variables reflects the economic opportunities available to immigrants. In the current section, I propose five hypotheses about these interactions.

Policymakers expected both settlers in rural colonies and laborers in the plantations to have some experience in agricultural occupations ${ }^{124}$. However, the emphasis on immigrants' professions depended on their adaptability to tasks to be performed in Brazil. Settlers were expected to have a more solid rural background than agricultural laborers, as the latter performed ordinary tasks in the plantations - e.g. harvesting and pruning coffee trees -, which did not require specialized agricultural skills. The adaptation costs and risks of employing an urban immigrant as an unskilled agricultural laborer were likely smaller than having him/her as a proprietor in a rural colony. Although self-interested, this was the argument made by Senator Vergueiro to defend the employment of foreigners in the plantations $^{125}$. This leads to:

\footnotetext{
${ }^{124}$ See Hatton and Williamson (2004, p. 16) for a parallel with the U.S. at the beginning of the nineteenth century.

${ }^{125}$ See Buarque de Holanda (1941, p. 13). Menard (1973) and Wegge (2002, pp. 380-3) present similar arguments for indentures and immigrants in the U.S. in the seventeenth and nineteenth centuries, respectively.
} 
Assumption 1: Policymakers expected settlers in rural colonies and bonded laborers in plantations to have an agricultural background, but the emphasis was stronger for the former.

Conversely, the policies aimed at selecting different immigrants by wealth and income. Settlers were expected to pay for the first installments of land acquisition, while bonded laborers had even their immigration costs covered by loans advanced by the farmers. This leads to:

Assumption 2: Bonded laborers were more likely to be poorer than rural settlers by the very definition of these immigration policies.

If occupational selectivity depended on wealth or income, these policies would have led to different skill compositions of the migratory flows. By the mid-nineteenth century, the demographic transition in western-Europe, the pauperism associated with it and the expectation of upward mobility in the Americas induced the emigration of people with very diverse occupational backgrounds. At the same time, the industrial revolution created profound economic difficulties for proto-industrial manufacturers, cottage artisans and skilled craftsmen, particularly in England, the German States, as well as parts of Switzerland, France and the Benelux ${ }^{126}$. Moreover, those skills had fewer competitors in Brazilian labor markets. Although we still do not have good micro-based evidence on the occupational composition of immigrants' flows to Brazil in general, regional studies have shown that immigration by the mid-nineteenth century was, to a large extent, a flee from poverty and from proletarianization in Europe ${ }^{127}$. This leads to:

Assumption 3: The advancement of the industrial revolution in northwestern Europe led to the pauperization of traditional craftsmanship. Therefore, the poorest group of immigrants most likely the bonded laborers - should have been more than proportionally selected among craftsmen.

Naturally, not all expectations of policymakers were fulfilled in the actual hiring of immigrants ${ }^{128}$. Section 3 has shown how plantation owners, administrators of public works and directors of settlement colonies alike complained about the skill inadequacies of

\footnotetext{
${ }^{126}$ Hatton and Williamson $(2004$, p. 20; 2009, pp. 17-9). Hatton (2011, p. 192) further suggests that "[...] on balance, agricultural populations were less mobile than urban/industrial populations".

${ }^{127}$ Argollo Ferrão (1999) and Bezerra (2001, p. 17).

${ }^{128}$ Information asymmetry about skills can even be a cause of international migration (Chiswick, 1999, p. 183).
} 
immigrants ${ }^{129}$. Moreover, some rural settlers and laborers in public works were no better off than bonded laborers in their countries of origin ${ }^{130}$. Nevertheless, these assumptions are still in line with the average effects captured by the empirical analysis.

Finally, economic opportunities and institutional constraints at destination conditioned the occupational sorting of settlers and bonded laborers. Three main channels of occupational sorting were open to foreigners in São Paulo. In the rural sector, immigrants could either be employed as agricultural laborers in a farm, or strive towards landownership. Alternatively, they could opt out of the rural sector in favor of urban labor markets ${ }^{131}$.

To become an unskilled laborer in a plantation involved relatively low adaptation costs in terms of skills and potentially high remunerations in an expanding rural economy with an expectedly high land per labor ratio. However, labor productivity was impaired by prevailing technologies and plantation laborers had a low social status in a slave-based country. To become a landowner, in turn, was a leitmotiv for migration in the nineteenth century ${ }^{132}$. However, the cost of land was high and Brazilian rural elites had no interest in expanding access to landownership, as this could cause a lower supply of agricultural laborers and potential economic and political competition. This leads to:

Assumption 4: Starting-off as settlers in rural colonies facilitated access to land in an environment that tended to constrain landownership otherwise.

Old bonded laborers and rural settlers who opted out of the rural sector could have sorted into manufactures, services, or trade-related activities. This strategy could be pursued by all immigrants who identified an occupational niche, usually in municipalities around their first residence or via a network of immigrants ${ }^{133}$. Immigrants with non-agricultural backgrounds were probably more numerous in urban occupations, as the costs to acquire such skills could have been substantial ${ }^{134}$. This leads to:

\footnotetext{
${ }^{129}$ For a parallel with Mexicans in the U.S. in the 1910s-20s, see Kosack and Ward (2014, pp. 1021-2).

130 See specific cases in Oberacker Jr. (2004, pp. 262-4), as well as those reported in Farol Paulistano (26/03/1828, pp. 2-4) and Correio Paulistano (20/02/1855, p. 1).

${ }^{131}$ See categories in Ferrie (1997a; 1997b).

${ }^{132}$ Dean (1976, p. 487), Martins (1989, p. 9), Hatton and Williamson (1992, pp. 12-3; 1994, p. 538; 2004, p. 16) and Hatton (2011, p. 193). Eltis (1983, p. 257), Massey et al. (1993, p. 452), Wey (2005, pp. 145-9), Stewart (2006, p. 558) and Salisbury (2014, p. 53) stress the extra-income benefits of landownership in the past and now.

${ }^{133}$ Salisbury (2014, p. 57) describes this strategy for the U.S. and Pérez (2017, pp. 1002-3), for Argentina.

${ }^{134}$ Roy (1951, p. 145), Sjaastad (1962, pp. 87-90), Stewart (2006, p. 566) and Salisbury (2014, pp. 47-8).
} 
Assumption 5: Immigrants with a non-rural background had lower adaptation costs in reverting back to urban professions after working for a period in the rural economy.

Moreover, the distribution of immigrants per sector most likely varied by nationality ${ }^{135}$. On the one hand, cultural and linguistic proximity to Brazilians implied a comparative advantage in services and trade-related occupations ${ }^{136}$. On the other, a background in craftsmanship implied a comparative advantage in manufacturing.

From these assumptions, I propose the following hypotheses to be tested empirically:

Hypothesis 1: On average, rural settlers had a higher likelihood of being landowners, as this policy targeted more strongly such occupational background (Assumption 1) and lowered institutional constraints towards landownership (Assumption 4). Therefore, I expect a positive interaction of variables related to landownership and the indicator (ID settlement).

Hypothesis 2: On average, bonded laborers had a lower likelihood of being landowners, for the opposite reasons detailed in Hypothesis 1 and because they were relatively poorer upon arrival in Brazil (Assumption 2). The hypothesis is reinforced if we also assume that bonded laborers exercised mainly urban occupations at origin (Assumption 3). Therefore, I expect a negative or nonexistent relationship between foreign landownership and the indicator (ID bonded).

Hypothesis 3: The sorting of bonded immigrants as agricultural laborers is ambiguous. On the one hand, they started off in this occupation and could have faced a theoretically high return to labor. On the other, social stigma against physical labor and institutional/technological constraints counteracted the willingness of ex-bonded laborers to remain in the plantations. If Assumptions 3 and 5 are adequate, they also had a comparative advantage in urban occupations.

Hypothesis 4: On average, rural settlers sorted out of urban occupations for the same reasons as stated in Hypothesis 1. Therefore, I expect negative interactions between urban occupations and (ID settlement).

Hypothesis 5a: On average, bonded laborers prevailed in urban occupations because of policy expectations (Assumption 1), immigrants' economic prospects (Assumption 2) and constraints

\footnotetext{
${ }^{135}$ Balderas and Greenwood (2010, p. 1306).

${ }^{136}$ See Sánchez-Alonso (2007, pp. 412-3, 422) and hypotheses on Portuguese assimilation in Brazil in Pasckes (1991, p. 82). In the same direction, for the importance of colonial past, see Abramitzky et al. (2014, pp. 476-9).
} 
on rural alternatives (Assumption 4). This is reinforced if bonded laborers had a comparative advantage in non-rural occupations (Assumptions 3 and 5). Therefore, I expect significant interactions between urban occupations and (ID bonded).

Hypothesis 5b: The signs of these interactions would vary by sector and nationality. Immigrants from countries that were culturally and linguistically closer to Brazil had a comparative advantage in services and trade-related activities - especially the Portuguese. Immigrants from countries undergoing more advanced phases of the industrial revolution had a comparative advantage in manufacturing-related activities.

\section{Empirical analysis: methodology}

\subsection{Specification}

The previous hypotheses are now tested empirically with a cross-section of municipalities in 1872 and an unbalanced panel of up to 16 settlement colonies located in 13 municipalities for the period 1897-1900 and 1911-1920, except for 1917.

The following baseline aims at assessing whether (and how) the allocation of immigrants across municipalities and settlement colonies correlates with occupational sorting per sector and the prevailing immigration policies:

$$
\begin{aligned}
& \text { Immig }_{\text {ont }}=\alpha+\left(\text { Sector } \operatorname{comp}_{n t}\right)^{\prime} \beta \\
&+\left(\text { Sector } \operatorname{comp}_{n t}\right) *(\text { ID settlement } \\
&1872)^{\prime} \gamma \\
&+\left(\text { Sector } \operatorname{comp}_{n t}\right) *\left(\text { ID bonded }_{1872}\right)^{\prime} \delta \\
&+\left(W_{n t}\right)^{\prime} \theta+\left(Z_{n t}\right)^{\prime} \vartheta+\left(R_{n t}\right)^{\prime} \kappa+\alpha_{t}+\alpha_{n}+\varepsilon_{n t}{ }^{137}
\end{aligned}
$$

The number of immigrants of origin $o$ in region $n$ (municipalities or colonies) and period $t$ (cross-section in 1872 or panel in 1897-1920) is explained by the distribution of occupations across sectors - the variables in the set $\left(\right.$ Sector comp $\left.p_{n t}\right)$ - interacted with indicators for immigration policies and conditional on further controls ${ }^{138}$.

\footnotetext{
${ }^{137}$ Of course, the time component reflected in the subscript $t$ varies only in the panel.

${ }^{138}$ The interactions are valid only for the cross-section of municipalities, as for the panel of settlement colonies in 1897-1920, $\left(I D\right.$ settlement $\left._{1872}=0\right)$ and $\left(I D\right.$ bonded $\left._{1872}=0\right)$, by construction.
} 
The dependent variable is defined as the number of individuals of a certain nationality living in a municipality or in a settlement colony. There are two reasons for defining the dependent variable as the absolute number of foreigners instead of their shares in the population or densities in a certain area. The first is to harmonize the units of observation of the dependent variable and the main covariates of interest, i.e. the number of people working in each sector. Alternatively, the share of foreigners could have been regressed on the sectoral shares. However, this approach would be feasible only for the urban economy with the current data, as I do not have an adequate denominator to determine the share of people who were agricultural laborers or landowners, as explained in Section 5.3. In any case, all regressions control for total population and area of a municipality or settlement colony ${ }^{139}$. Second, the total number of immigrants allows for better comparisons between the samples, as the shares and densities of foreigners varied substantially between municipalities in 1872 and settlement colonies in 1897-1920, as shown in Section 3.3.1.

The interactions between the set of variables in (Sector comp $\left.p_{n t}\right)$ and the two policy indicators provide the main estimates of interest, as they allow us to test for the interplay between occupational sorting and immigration policies ${ }^{140}$.

To recapitulate, the identifiers for immigration policies are the binary variables (ID bonded) and (ID settlement). The former determines whether a municipality had at least one farm with bonded laborers in the 1850s-60s (ID bonded $=1$ ). The latter determines whether a municipality had a settlement colony founded up to $1872(\text { ID settlement }=1)^{141}$.

$\left(\right.$ Sector $\left.\operatorname{comp}_{n t}\right)$ includes the total number of individuals working in different sectors ${ }^{142}$. For the urban economy, the 1872 sample includes manufacturing $\left(M a n u f_{n t}\right)$, services $\left(\operatorname{Ser} v_{n t}\right)$ and trade-related occupations $\left(\operatorname{Trade}_{n t}\right)^{143}$. This sample was constructed by counting individuals in nominal lists that recorded different professions per municipality, which I

\footnotetext{
139 I checked for baselines with shares and densities as the dependent variables. General conclusions about sectoral allocation was not qualitatively altered. However, results do change in significance for some nationalities and specific sectors.

140 This strategy has been increasingly used to assess selectivity (McKenzie and Rapoport, 2010, p. 815; Orrenius and Zavodny, 2005, p. 227). In historical analyses, see Walker (2000, pp. 266-8) and Stewart (2006, pp. 564-7).

${ }^{141}$ Please notice that no triple interaction was included because there is no municipality in 1872 simultaneously with $(I D$ settlement $=1)$ and $(I D$ bonded $=1)$.

142 All regressions control for the total number of professions registered in the almanacs to accommodate concerns with the scale of labor markets.

${ }^{143}$ Another control refers to public administrators (Public Adm $m_{n t}$ ).
} 
aggregated into these sectors ${ }^{144}$. For $1897-1920$, the set was constructed using the number of individuals per sector, as recorded in the original sources ${ }^{145}$. For this sample, we do not have the variable $\left(\operatorname{Ser} v_{n t}\right)$; instead, a catchall category of other professions (Other $\left.{ }_{n t}\right)$ was included. The latter is not defined explicitly in the source, but most likely referred to a category of workers providing services in the colonies and to households still awaiting their allocation to a plot of land. Finally, for the rural economy, I control for the total number of landowners (Landowners ${ }_{n t}$ ) and of foreign landowners (Foreign land Ft $_{\text {) }}$ per municipality in 1872. Moreover, the total number of free agricultural workers $\left(\operatorname{Agr} L_{n t}\right)$ is added. The latter is ceteris paribus interpreted as the number of non-proprietors working in agriculture in $1872^{146}$. For the sample of settlement colonies in 1897-1920, the professional category of "farmers" is the omitted group, against which I compare the sorting of immigrants into other, non-agricultural, occupations.

The other controls aim at eliminating confounders that could bias the coefficients on the immigration policies or the sectoral distribution of occupations.

For foreigners who were already at destination, i.e. whose immigration costs had already been covered, the literature reviewed in Section 2 suggests the need to control for economic characteristics related to returns to skill, $w_{i, f}$, and cultural-institutional determinants, $z_{i, f}$. Aggregating $i$ agents at destination $n$, we obtain the measures of economic performance and cultural-institutional proximity of the baseline, i.e. the sets $\left(W_{n t}\right)$ and $\left(Z_{n t}\right)^{147}$. I complement these with a set of controls for regional characteristics that may vary over time $\left(R_{n t}\right)$ or not $\left(\alpha_{n}\right)$. Finally, the panel estimates include a time trend $\left(\alpha_{t}\right)$. The error term, $\varepsilon_{n t}$, is corrected for heteroscedasticity and/or serial correlation (in the panel); for the latter, the error term is always clustered at the level of settlement colonies.

Ideally, $\left(W_{n t}\right)$ should control for measures of remuneration to skill. Currently, however, there is no possibility of conducting such analysis. To the best of my knowledge, there is no complete dataset on return to skills in Latin America disaggregated even at the level of

\footnotetext{
${ }^{144}$ See Chapter 3 for details about the compilation of this source.

145 With the exception of the categories Manufacturers and Industrialists, which appear separately in the sources.

${ }^{146}$ See Section 5.3. for the precise interpretation of this effect.

${ }^{147}$ Docquier et al. (2014, p. S41).
} 
provinces for this period ${ }^{148}$. Furthermore, rural employment at the time was subjected to labor arrangements that confounded returns to skill and contractual design ${ }^{149}$. To circumvent these limitations, I add demographic controls and proxies for productivity to the baseline. In both samples, demographic controls include the total population, the shares of singles and widows (with married people as the omitted group) and the share of people in age categories harmonized across samples ${ }^{150}$. In 1872, the best proxy I have for cross-municipal differences in productivity is the number of slaves. Although far from perfect, this proxy has been used to identify booming regions in slave-based economies ${ }^{151}$. Considering the high price of slaves, especially after the abolition of the transatlantic traffic, captives were allocated to regions where their marginal productivity was highest ${ }^{152}$; moreover, the amount of capital invested in slaves represented a substantial part of the operational capital of plantation owners ${ }^{153}$. For the settlement colonies in 1897-1920, I have a more direct measure of labor productivity, as the sources registered the nominal value of each settlement's annual production. Combining this information with demographic data, I use the value of production per person older than seven years as a control for labor productivity.

The controls for cultural-institutional proximity in $\left(Z_{n t}\right)$ include, for both samples, education-related variables; the share of non-Catholics - capturing cultural distances and the existence of minority clusters; and the number of all other nationalities in a region reflecting the degree of complementarity or substitutability between immigrants of origin $o$ and all other foreigners living in that locality.

Potentially time-varying regional characteristics are included in the set $\left(R_{n t}\right)$. For municipalities in 1872, I control for the number of non-white free individuals; this variable reflects the likelihood of manumissions and the attractiveness of regions to non-whites,

\footnotetext{
${ }^{148}$ See also Pérez (2017, pp. 981, 989-90) for Argentina. Hatton and Williamson's (1994, pp. 544-6) wage index refer to unskilled urban occupations (see also Freeman, 2006). Sánchez-Alonso (2007, p. 404) is critical about the quality of historical cross-country real wages, arguing that Williamson's dataset is particularly fragile for Brazil.

${ }^{149}$ For the non-monetary returns implied by the design of Brazilian agricultural contracts, see Dean (1976, p. 488), Martins (1989, pp. 9, 20-2) and Sánchez-Alonso (2007, p. 406).

${ }^{150}$ The dataset for the settlement colonies has four age categories: younger than 7 years, 7-14, 14-21 and older than 21. To homogenize the data, I followed a similar categorization for municipalities in 1872, with the following age categories: younger than 6 years, 6-15, 16-20 and older than 20. See Section 6.3 for details.

${ }^{151}$ Summerhill (2010). See Dean (1977, p. 184) and Viotti da Costa $(1998$, p. 196) for a methodological reflection.

${ }^{152}$ Beiguelman (1967, p. 150), Engerman and Sokoloff (2011, pp. 20-1) and Naritomi, Soares and Assunção (2012, pp. 398-9). For a conditioning of this claim on the availability of different technologies of production, see Engerman and Margo (2010, p. 307).

${ }^{153}$ See Viotti da Costa (1998, pp. 53-4) and references therein.
} 
characteristics that influenced total labor supply. Moreover, I control for the share of public administrators with a non-Iberian surname (Foreign Public $A d m_{n t}$ ) to capture the openness of local governments to the political and civic participation of foreigners. For the colonies in 1897-1920, in turn, this set includes the share of cultivated area in the settlements in order to control for their expansion potentialities.

Another crucial time-varying determinant for the allocation of immigrants is the likelihood of survival of foreigners. Considering the lack of data on mortality per municipality in the 1870 s, I constructed indicators to capture the insalubrity of municipalities based on government reports ${ }^{154}$. For the baseline, I coded two binary variables based on this qualitative source. The first indicates whether a region was generally considered insalubrious because of its geography, e.g. by being close to rivers that caused frequently outbreaks of epidemics. The second indicates whether a municipality had a widespread disease worth reporting in the provincial records for the period 1850-74 ${ }^{155}$. For the settlement colonies in 1897-1920, the sources registered total mortality and mortality among foreigners, which I use as controls in the baseline and in the robustness checks, respectively.

Regional characteristics that are time-invariant, $\left(\alpha_{n}\right)$, are dropped in the estimations for settlement colonies in 1897-1920 because of the fixed effects ${ }^{156}$. For municipalities in 1872, controls include latitude, area, altitude and a categorical variable for different regions in the province $^{157}$. Finally, considering the importance of networks in altering patterns of selectivity, I add a control for the stock of immigrants in 1854 at the level of municipalities. This measure for network includes the total number of foreigners in a municipality in 1854 , as data are not disaggregated by nationality ${ }^{158}$.

\footnotetext{
154 Alternatively, I could have used mortality rates in 1854, as these data exist at the level of municipalities. However, individuals would probably have adapted their locational choice based on these levels of mortality.

${ }^{155}$ For the construction and definition of these indicators, see Appendix I.

156 To compare specifications across estimation strategies, I do not include them in the POLS estimates either.

${ }^{157}$ Based on Holloway's classification, as in Carvalho Filho and Colistete (2010).

${ }^{158}$ To control for the quality of the data, I also add a binary indicator for municipalities whose information on networks had a statistical remark in the original source or in the compilation by Bassanezi (1998).
} 


\subsection{Estimation strategies}

Considering the data compiled for this chapter, specifications for municipalities in 1872 are estimated via ordinary least squares (OLS). This methodological approach is insufficient for a causal assessment for reasons discussed below. Therefore, the estimates thus obtained should be interpreted as conditional correlations, which are nonetheless informative about immigrants' occupational sorting.

The main limitation of OLS estimates is that they synthesize an average effect for cohorts that might have self-selected differently over time. Moreover, they ignore self-selection of return migrants who are in the sample for a single cross-sectional collection of data ${ }^{159}$. Abramitzky et al. (2014) and Pérez (2017) are, to the best of my knowledge, the only studies on historical assimilation that were able to address properly this limitation by constructing a panel with individuals linked across censuses. In the current analysis, I mitigate this bias with the indicators for immigration policy; the identifier for bonded laborers attempts to capture the policy effects for cohorts arriving in the 1850s and 1860s; the identifier for settlers, in turn, is constructed with colonies that had been founded since the 1820s. Certainly, estimates are still average effects of different cohorts, but the partial effects are separated by regions where each policy prevailed.

The second limitation is the potential endogeneity of occupational sorting. Because immigrants screen economic opportunities, their occupational choices might be associated with businesses they start themselves, creating a direct simultaneity between the number of immigrants in a region and its sectoral composition ${ }^{160}$. A solution is to instrument the endogenous variables ${ }^{161}$. Adequate instruments even provide the least biased estimators when compared to experimental designs that assess selectivity in non-observable characteristics ${ }^{162}$.

Following this methodology, I attempted to instrument the variables in (Sector $\operatorname{comp}_{n \text { 1872 }}$ ) with the distribution of occupations in 1835; i.e. the number of manufacturers in 1872 was instrumented by the number of manufacturers in 1835 and analogously so for services, trade and public administration. Instruments were constructed with a primary source that recorded

\footnotetext{
${ }^{159}$ Borjas (1989, 1994), Freeman (2006, pp. 152-3) and Docquier et al. (2014, p. S58). In historical analyses, see Ferrie (1997a, p. 309), Hatton (2011, pp. 195-6) and Abramitzky et al. (2012, p. 1833).

${ }^{160}$ Borjas et al. (1992, p. 166). Ferrie (1997a, pp. 308, 317) links this argument to the problem of cohort effects.

${ }^{161}$ Ferrie (1997a, p. 317).

162 McKenzie et al. (2010, pp. 915, 940-2).
} 
the number of individuals per profession in the municipalities in $1835^{163}$. In terms of exclusion restriction, the occupational distribution in 1835 preceded the arrival of most cohorts of immigrants, except for the first rural settlers of Santo Amaro and Itapecerica - who I expect to have majorly remained in or around those colonies by 1835 . Conditional on further controls, the validity of the instruments builds on the argument that immigrants who arrived after 1835 would not have previously self-selected according to the distribution of occupations in that specific year.

Unfortunately, this approach failed statistically, with weak instruments that rarely presented an F-statistic larger than one. Considering that inadequate instruments are particularly harmful for inference in non-experimental designs, I abandoned this estimator ${ }^{164}$. Nevertheless, this statistical failure is informative. If instruments were weak because of measurement error from sources that had limitations in accuracy and comparability, then more refined data harmonization should solve the problem ${ }^{165}$. However, it could also be that instruments were non-orthogonal and that better controls for returns to skill are required. If that is the case, the estimates for the sectoral composition in 1872 could indeed be biased. Monasterio and Reis (2008, pp. 26-8) provide some hints to evaluate these possibilities with Brazilian data. On the one hand, they find that the share of labor in manufacturing in 1872 had no significant impact on the sectoral distribution of labor in 1920. This result is similar to my weak first-stage, in which the sectoral composition in 1872 was regressed on its correspondent in 1835. On the other hand, the authors do find a significant correlation between the percentage of foreigners in manufacturing in 1872 and the geographic distribution of manufactures in that year, hinting towards the problem of simultaneity.

For the settlement colonies in 1897-1920, I explore the panel structure of the sample to obtain either pooled OLS (POLS) or fixed effects (FE) estimators. The choice between these estimators depended on the rejection of the null-hypothesis that the idiosyncratic terms are zero. I made no use of random effects (RE) estimates due to the structure of the data. The panel is unbalanced and has a cross-sectional dimension of similar size as the time dimension, reaching a maximum of $\mathrm{N}=16$ colonies and a time dimension up to $\mathrm{T}=12$ years. This structure leads to estimations with 11 groups and 49 observations. Furthermore, due to

\footnotetext{
${ }^{163}$ Mueller ([1838] 1978). I thank André Lanza for kindly providing me with this source. ${ }^{164}$ McKenzie et al. (2010, p. 942).

${ }^{165}$ Mueller ([1838] 1978, p. XIII) pondered: "The lack of clarity and uniformity in some of the tables [...] are reasons that oblige us to declare that it is not advisable to trust fully the statistical data that embed the present essay and [the data] should be seen [more] as some approximation to the truth [...]".
} 
negative serial correlation, the estimated variance of the idiosyncratic terms are automatically set to zero. For those two reasons, estimates obtained with RE were identical to those of POLS, therefore justifying the final choice only between POLS and FE estimates. It should be remarked that the unbalanced nature of the panel is caused by the compilation of the data for a varying number of settlement colonies and for some different variables over time elements that do not imply any specifically obvious selection-bias. Furthermore, the error term in the final estimations is always clustered at the level of the settlement colonies ${ }^{166}$.

\subsection{Sources of data}

For the sample of municipalities, the main source of data is the 1872 Brazilian Census, which provides information on immigrants, demography, education and religion (separated between Catholics and non-Catholics). The dataset was complemented with geographic information from Fundação Sistema Estadual de Análise de Dados (SEADE). The identifiers for immigration policies are based on the literature: (ID settlement) was coded with data from Rocha, Ferraz and Soares (2017); (ID bonded) is based on Witzel de Souza (2011), complemented by Bassanezi (1998) - the latter being also the source for the stock of immigrants in $1854^{167}$. Finally, the variables for the insalubrity of municipalities were constructed with the Annual Reports of the Presidency of São Paulo.

For the sample of settlement colonies, all required data was compiled from the Statistical Yearbooks of the State of São Paulo (1897-1920).

The sources for the variables in the set (Sector comp $n t$ ) varied for the urban and rural sectors in the municipalities in 1872. To construct the distribution of urban occupations, I used information from the almanac of Luné and Fonseca (1873). To construct the distribution of rural occupations, I used information both from Luné and Fonseca (1873) and the 1872 Census.

\footnotetext{
${ }^{166}$ Naturally, to test $H_{0}: u_{i}=0$ for deciding between the POLS and the FE estimators, I had to use the estimates with non-clustered standard errors.

${ }^{167}$ I thank Maria Bassanezi for kindly providing me with the corresponding compiled dataset.
} 
From Luné and Fonseca (1873), I obtained the number of landowners (Landowners (Lt $_{\text {) }}$ and of foreigners among them (Foreign landown $\left.{ }_{n t}\right)^{168}$. The 1872 Census provided a measure of total agricultural employment that summed up all free workers in agriculture, i.e. excluding slaves $^{169}$. This is the variable $\left(\operatorname{Agr} L_{n t}\right)$. The problem is that the historiography does not know exactly the composition of this professional category in the census ${ }^{170}$. It certainly included agricultural laborers, but it is likely that proprietors were counted as well ${ }^{171}$.

However, this chapter aims fundamentally at disentangling the different effects that employment as agricultural labor and landownership had on the sorting of immigrants. To accomplish this, the baseline simultaneously controls for: (i) the number of proprietors $\left(\right.$ Landowner $\left._{n t}\right)$; (ii) the number of foreigners among them (Foreign landown $\left.n_{n t}\right)$; and (iii) the number of agricultural laborers $\left(\operatorname{Agr} L_{n t}\right)$. Once the total number of proprietors is controlled for, the ceteris paribus interpretation of $\left(\operatorname{Agr} L_{n t}\right)$ gives us the number of agricultural laborers only:

- Assuming that Agr $L_{1872 \text { Census }}=$ Landowners + Agricultural laborers .

- If we control for Landowners $=$ Landowners $_{\text {Luné and Fonseca 1873, }}$

- Then, ceteris paribus, Agr $L_{1872 \text { Census }}=$ Agricultural laborers $+\epsilon$, where $\epsilon$ refers to measurement errors stemming from definitional differences between the 1872 Census and Luné and Fonseca (1873).

For the settlement colonies in 1897-1920, the variables in the set (Sector comp $p_{n t}$ ) were constructed directly from the Statistical Yearbooks and refer to professions that settlers exercised in the colonies. Descriptive statistics in Table 1.1 show that an overall mean of $92.52 \%$ of settlers worked as farmers in the colonies in 1897-1920, as expected from this immigration policy. However, a certain number of individuals in this sample still exercised non-agricultural tasks, a variation that will be explored in the empirical analysis.

\footnotetext{
168 The coding of the variable (Foreign landown $n_{n t}$ ) was conducted manually by identifying non-Iberian surnames.

169 The 1872 Census has also the category Servants and Journeymen (Paiva et al., 2012, p. 82). While the latter could include a homonymous category of agricultural workers, the former refers to domestic occupations.

${ }^{170}$ This seems to be a general limitation with census data, as it has been observed in historical analyses for the U.S. (Ferrie, 1997a, pp. 301-3; Stewart, 2006, p. 549) and Argentina (Pérez, 2017, p. 989); as well as for current analyses in Mexico (Wey, 2005, p. 156). Dean (1976, p. 491) and Colistete and Lamounier (2014, p. 16) notice a similar problem even for the specialized agricultural census conducted in 1905 in São Paulo.

${ }^{171}$ Senra (2006) and Monasterio and Reis (2008). Paiva, Godoy, Rodarte and Santos (2012) present census microdata in which proprietors and laborers cannot be differentiated. I thank André Lanza for this information.
} 


\section{Empirical analysis: results}

Section 3.3.1. showed that only the Americans, English, French, Germans, Italians, Portuguese and Swiss had more than 100 immigrants in at least one municipality of São Paulo in 1872. The other 13 nationalities were minorities, in some cases even with a single or no individual in certain municipalities categorized by prevailing immigration policies. Although numerically limited, these minorities presented enough variation within the categories of immigration policies and between municipalities to permit adequate estimations, adding analytical nuances to the study of occupational sorting of foreigners ${ }^{172}$. For ease of exposition, I present the results for minorities in the municipalities in 1872 in different tables. By contrast, because estimates for settlement colonies in 1897-1920 are limited to 12 nationalities, they are presented all together.

\subsection{Occupational sorting: municipalities in 1872}

The baseline results (Table 1.4, below) lead to two main conclusions. First, the significance and signs of different occupations varied substantially by immigration policy and nationality. This makes us confident about the proposal to consider the simultaneous effect of origin and policy on the sorting of foreigners in receiving societies. Second, such variations were less prominent in the rural sector than in the urban. With some exceptions, becoming a landowner in São Paulo remained to the average immigrant what it had been in their countries of origin: a far distant dream. On a related note, there is no evidence of a systematic and positive sorting of foreigners as agricultural laborers, suggesting that Brazilian landowners failed to keep foreign workers employed in their farms even in regions where policies to bond labor had prevailed.

Results for the rural economy show that constraints prevailing in the Brazilian agrarian society were binding in limiting foreigners' access to land. Different immigration waves and policies did not change this situation substantially, at least not until 1872. To start with, it is safe to reject Hypothesis 1, which posited a positive relationship between landownership and the immigration policy based on settlement colonies. With the exception of the English, the ${ }^{172}$ Given the degrees of freedom, the baseline could not be estimated for the Hungarians in the municipalities in
1872 , nor for the English, Hungarians and Swiss in the colonies in 1897-1920. 
interactions between those two variables were either non-significant or negatively so for all nationalities. Neither do we observe a positive significant sorting of foreign landowners in regions where bonded labor had prevailed, a result in line with Hypothesis 2, which argued that the interaction between bonded labor and landownership would be nonexistent or negative.

Table 1.4 - Partial effects: occupations and immigration policies - municipalities (1872)

\begin{tabular}{|c|c|c|c|c|c|c|c|}
\hline & Germans & Swiss & Portug. & French & English & Amer. & Italians \\
\hline \multirow[t]{2}{*}{ Foreign land } & $-4.094 * *$ & -0.320 & 1.270 & 0.0999 & -0.394 & $2.395 * * *$ & -0.228 \\
\hline & $(1.812)$ & $(0.598)$ & $(1.577)$ & $(0.163)$ & $(0.452)$ & $(0.221)$ & $(0.297)$ \\
\hline \multirow[t]{2}{*}{ Foreign land*(ID bonded) } & 9.979 & 6.682 & 8.625 & 0.999 & 0.487 & $-3.51 * * *$ & 3.063 \\
\hline & $(9.524)$ & $(4.112)$ & (7.627) & $(0.837)$ & $(1.325)$ & $(0.792)$ & $(1.807)$ \\
\hline \multirow[t]{2}{*}{ Foreign land*(ID settl) } & $-201.1 * * *$ & 31.54 & $-135.7 * * *$ & $-12.43 * *$ & $84.3 * * *$ & $-56.62 * * *$ & -4.136 \\
\hline & $(53.62)$ & $(18.54)$ & $(44.76)$ & $(5.546)$ & $(10.77)$ & $(5.962)$ & $(12.43)$ \\
\hline \multirow[t]{2}{*}{ Agr L } & 0.00392 & 0.00325 & 0.00403 & 0.00297 & 0.00274 & -0.00192 & -0.0014 \\
\hline & $(0.0098)$ & $(0.004)$ & $(0.0108)$ & $(0.0018)$ & $(0.0031)$ & $(0.0016)$ & $(0.003)$ \\
\hline \multirow[t]{2}{*}{ Agr L*(ID bonded) } & -0.00893 & -0.0011 & $0.0162 *$ & $-0.004 * *$ & $-0.005 * *$ & -0.00114 & 0.00397 \\
\hline & $(0.0093)$ & $(0.0036)$ & $(0.0082)$ & $(0.0015)$ & $(0.0021)$ & $(0.00112)$ & $(0.0035)$ \\
\hline \multirow[t]{2}{*}{ Manuf } & 0.189 & 0.200 & -0.692 & 0.0932 & 0.225 & 0.0313 & -0.124 \\
\hline & $(0.609)$ & $(0.172)$ & $(0.587)$ & $(0.0832)$ & $(0.204)$ & $(0.0786)$ & $(0.152)$ \\
\hline \multirow[t]{2}{*}{ Manuf*(ID bonded) } & -1.222 & -0.209 & 0.907 & -0.0525 & -0.221 & 0.00624 & -0.184 \\
\hline & $(0.737)$ & $(0.233)$ & $(0.696)$ & $(0.0765)$ & $(0.220)$ & $(0.0978)$ & $(0.184)$ \\
\hline \multirow[t]{2}{*}{ Manuf*(ID settl) } & $22.76 * * *$ & -1.704 & 3.128 & 0.484 & $-11.4 * * *$ & 1.081 & 0.409 \\
\hline & $(5.855)$ & $(2.175)$ & (5.639) & $(0.670)$ & $(1.593)$ & $(0.659)$ & $(1.353)$ \\
\hline \multirow[t]{2}{*}{ Serv } & -0.0425 & 0.0634 & -0.378 & 0.0294 & 0.0717 & 0.00571 & -0.0769 \\
\hline & $(0.305)$ & $(0.104)$ & $(0.328)$ & $(0.0588)$ & $(0.117)$ & $(0.0569)$ & $(0.165)$ \\
\hline \multirow[t]{2}{*}{ Serv*(ID bonded) } & 0.403 & -0.0777 & -0.234 & 0.0633 & $0.232 *$ & $0.129 *$ & -0.212 \\
\hline & $(0.527)$ & $(0.214)$ & $(0.519)$ & $(0.0661)$ & $(0.114)$ & $(0.0645)$ & $(0.158)$ \\
\hline \multirow[t]{2}{*}{ Serv*(ID settl) } & $17.38^{*}$ & -0.0086 & -7.196 & -0.0597 & $-13.1 * * *$ & $-4.28 * * *$ & 1.143 \\
\hline & $(9.807)$ & $(2.813)$ & (7.700) & $(0.803)$ & $(1.986)$ & $(0.841)$ & (1.939) \\
\hline \multirow[t]{2}{*}{ Trade } & -1.108 & -0.182 & $1.666 * *$ & $-0.187 *$ & -0.0712 & -0.0129 & 0.157 \\
\hline & $(0.771)$ & $(0.207)$ & $(0.646)$ & $(0.0929)$ & $(0.134)$ & $(0.102)$ & $(0.167)$ \\
\hline \multirow[t]{2}{*}{ Trade*(ID bonded) } & $1.808^{*}$ & 0.221 & $-1.906^{* *}$ & $0.26 * * *$ & $0.386^{* *}$ & $0.165^{*}$ & -0.101 \\
\hline & (1.036) & $(0.285)$ & $(0.849)$ & $(0.0837)$ & $(0.166)$ & $(0.0961)$ & $(0.158)$ \\
\hline \multirow[t]{2}{*}{ Trade*(ID settl) } & $-21.5 * * *$ & 1.180 & 1.712 & 0.0853 & $12.5^{* * *}$ & 0.848 & -0.491 \\
\hline & (7.135) & $(2.329)$ & $(6.325)$ & $(0.714)$ & $(1.804)$ & $(0.729)$ & $(1.475)$ \\
\hline Full set of covariates ${ }^{1}$ & Yes & Yes & Yes & Yes & Yes & Yes & Yes \\
\hline Adj. $R^{2}$ & 0.836 & 0.571 & 0.940 & 0.931 & 0.741 & 0.915 & 0.804 \\
\hline Obs. & 64 & 64 & 64 & 64 & 64 & 64 & 64 \\
\hline
\end{tabular}

Notes: (1) Further determinants of immigration are presented in Table A1.1 (in the appendix to this chapter); (2) The interaction (ID settl)*Agr L is omitted due to collinearity. Robust standard errors in parenthesis if the hypothesis of homoscedasticity was rejected at the 10 percent level. *,** and $* * *$ indicate $\mathrm{p}<0.10, \mathrm{p}<0.05$ and $\mathrm{p}<0.01$, respectively.

Despite generally pointing to the same conclusions, three regimes of occupational sorting in landownership can be discerned in Table 1.4. First, the objective of founding rural colonies to settle immigrants as landowners was fulfilled only for the English. For those repelled by this immigration policy and mechanism of occupational sorting - i.e. with a significant and negative interaction between landownership and (ID settlement) -, an alternative was to 
acquire land in regions where other immigration policies had prevailed. A second pattern was observed for the Germans. This nationality negatively sorted as landowners also in regions where no immigration policy had prevailed and did not sort as agricultural laborers either, therefore ending up in urban occupations where settlement colonies had prevailed ${ }^{173}$. It is noticeable that this pattern is exactly the opposite of what occurred to the English. Finally, Americans were repelled as landowners in regions where bonded labor and settlement colonies had prevailed. However, they sorted positively as landowners in regions where no immigration policy had prevailed, indicating a distinctive group of immigrants. There is abundt historical evidence that Americans developed a strong immigrant community in the current municipality of Santa Bárbara, where $(I D$ settlement $=0)$ and $(I D$ bonded $=$ $0)^{174}$.

These conclusions fundamentally agree with a pessimistic strand of the literature on access to land in plantation-based economies ${ }^{175}$. The cost of land tended to be prohibitively high to the average immigrant; legal uncertainties recurrently limited landownership - as shown in the historical section; and Brazilian rural elites had no economic or political incentives to change institutions that supported this status quo ${ }^{176}$. Considering land distribution in the municipality of Rio Claro - one of the central regions for the policy based on bonded laborers -, Dean (1977, pp. 180-1) calculates that the costs of repatriation of an immigrant family were only about five percent of the costs of buying land for the same household. Whether later immigration waves faced better opportunities to buy land is a question that cannot be answered with the evidence compiled for the current chapter. Klein (1995), for instance, is optimistic about the number of landowners among immigrants in São Paulo, especially after the $1880 \mathrm{~s}^{177}$. In contrast, Petrone (2004, pp. 343-5), dealing with the mass immigration of Italians, highlights the complex relationship between immigrants' aspirations for landownership and the objective of Brazilian farmers to obtain labor force, even if some among the latter recognized the importance of easing access to land to increase the inflow of foreigners. This author, however, remarks the importance of the urban economy - especially

\footnotetext{
${ }^{173}$ Differently from Italians in Argentina, German-speakers in São Paulo were not able - at least until this period - to increase access to land because of a longer integration period (Sánchez-Alonso, 2007, pp. 412-3).

174 Goldman (1957; 2004). In 1872, 100 Americans lived in Santa Bárbara, second only in number to the other 130 living in the municipality of Limeira; $50.4 \%$ of the Americans in the sample lived in municipalities for which $(I D$ bonded $=1)$; and $7.96 \%$ for which $(I D$ settlement $=1)$.

${ }^{175}$ See the literature review in Engerman and Sokoloff (2011). For Brazil, see Dean (1976) and Martins (1989).

${ }^{176}$ See the arguments presented in Chapter 2.

${ }^{177}$ Ferrie and Hatton (2015, p. 59) cite Klein (1995) to argue that agricultural laborers who arrived in Brazil in the 1880 s succeeded in becoming landowners.
} 
in terms of craftsmanship and industry - in settling Italian immigrants who left the rural economy (Ibid., pp. 346-7). Considering the scale of later immigration waves, it is not surprising to notice an increased number of foreign landowners. However, it is hard to conceive that persistent institutional constraints that determined land inequality in the 1870s would have been modified in the course of a single generation ${ }^{178}$. In this, the implications of my results are in line with the inequality analysis on landownership by Colistete and Lamounier (2014). For the northwestern region of São Paulo in 1905, they find that foreigners were the majority among landowners, but total area and proxies for rural capital remained concentrated in the hands of a small group of larger landowners.

Similar conclusions are reached for the sorting of foreigners as agricultural laborers. The idea of immigrants eagerly looking for agricultural employment was more propaganda of plantation owners than a reality in the labor markets being formed in that slave-based economy. The only significant and positive case of sorting as agricultural laborers occurred with the Portuguese, whose significance at the $10 \%$ level in the baseline is sensitive to the robustness checks. For all other nationalities - including the minorities -, agricultural labor had either a non-significant or a negative impact on the sorting of immigrants. The prevalence of bonded labor in the 1850s-60s did not root the labor force of foreigners to the regions where those farms were located. Although highly praised by plantation owners, cases of immigrants spontaneously signing new contracts upon the completion of their obligations as bonded laborers were rather exceptional, or at least not the average channel of occupational sorting. While Hypothesis 3 posited an ambiguous direction for the effect of bonded labor on the sorting as agricultural laborers, the empirical analysis points to an unambiguous non-positive effect.

More nuanced results appear according to immigrants' origins and immigration policies in the urban economy. Hypothesis 4 describes well the relationship between immigration based on settlement colonies and the sorting into urban occupations, but for opposite reasons depending on the nationality considered. That hypothesis posited that rural settlers sorted less significantly into urban occupations because they would have stayed in their rural properties. Table 1.4 shows the validity of this hypothesis for the English. Because they were the exception in attaining landownership in regions where settlement colonies had prevailed, the

\footnotetext{
178 For Rio Claro, Dean (1976, p. 491) argues that foreign landowners were usually members of a small bourgeoisie from the urban center or from the capital of the state, who had never worked as rural laborers.
} 
English negatively sorted into manufacturing and services in those regions. Inversely, Germans sorted positively into services and manufacturing at the same time as they were negatively sorted as landowners in those same regions.

There is some evidence supporting Hypothesis $5 a$, namely that foreigners sorted into urban occupations where bonded labor had prevailed. This is in line with results that showed that this immigration policy interacted with agricultural labors and with foreign landownership did not increase the number of foreigners in the municipalities. Accordingly, we notice a positive sorting of Americans and English into services in those regions. For trade-related activities, a certain specialization seems to have occurred across regions by immigration policy and nationalities. On the one hand, Americans, English, French and Germans sorted positively into trade-related occupations in regions where bonded labor had prevailed ${ }^{179}$. On the other, Portuguese were negatively sorted into trade-related activities in those municipalities, but were positively so in regions where no immigration policy had prevailed.

Finally, results are only partially in line with Hypothesis $5 b$, which associated northwestern Europeans with skilled crafts and gave southern Europeans a comparative advantage in occupations that benefited from cultural and linguistic proximity to Brazilians. As already seen, the Portuguese did sort into trade-related activities, but the sign of the effect depended on the interaction with the immigration policy. However, the sorting of Italians did not depend on any variable related to immigration policies or occupations. By contrast, various minorities, including non-Latin language speakers, positively sorted into trade-related activities. This sector probably offered a simpler or cheaper mechanism of economic integration. Contrary to expectations, the English sorted negatively into services and manufacturing in regions where settlement colonies had prevailed, but positively so in traderelated occupations. Germans behaved exactly in the opposite direction. The fact that English became landowners in those regions while Germans did not indicates how each nationality adopted different strategies of economic integration. Although Hypothesis $5 b$ predicted a similar occupational sorting for the English and Germans, the results highlighted more the importance of conditioning such predictions on prevailing immigration policies.

Similarly, none of the main nationalities sorted positively into manufacturing or services where no immigration policy had prevailed. A word of caution is due here, especially in face of the historiographical perception that Germans and Swiss frequently worked as skilled

${ }^{179}$ The significance for the Americans and Germans is relatively weak in the robustness checks. 
craftsmen and service providers in the $1870 \mathrm{~s}^{180}$. As Chapter 3 demonstrates, Germanspeakers indeed attained a monopoly in some specialized crafts in certain municipalities. What the current results show is that, conditional on other factors, the distribution of occupations did not determine the overall sorting of German-speakers - a conclusion that does not contradict the descriptive observation that German-speakers did monopolize some occupations in certain regions.

\subsubsection{Occupational sorting: municipalities in 1872 - minorities}

Results for the occupational sorting of minorities (Table 1.5, below) confirm the previous conclusions. First, rural labor markets imposed on the minorities similar constraints as those faced by larger groups of immigrants. Second, results for the urban economy remained dependent on immigration policies and nationalities. Interestingly, some patterns emerged for the sorting of specific minorities, which were in line with larger groups of immigrants.

Similar to the Germans, the Austrians and Russians were repelled from landownership in regions where settlement colonies prevailed ${ }^{181}$. Since they did not sort as agricultural laborers either, their alternative was to look for employment in the urban economy. Consequently, these two minorities also sorted into manufacturing-related activities and services precisely where settlement colonies had prevailed. Similar to the English and French, the Belgians, Bolivians, Danish and Swedes were negatively associated with agricultural labor in regions where bonded labor had prevailed, but were positively sorted into trade-related activities in those regions.

Finally, municipalities that had an official settlement colony seem also to have failed in rooting the average minority groups to the property of land. However, some minorities were the lucky ones who positively sorted as foreign landowners in regions where bonded labor had prevailed. In these exceptional cases, Belgians, Bolivians and Dutch were positively sorted as landowners. These are the exceptions that prove the rule, as these three nationalities altogether totaled only 120 individuals, equivalent to $0.83 \%$ of foreigners living in São Paulo in 1872 .

\footnotetext{
${ }^{180}$ Buarque de Holanda (1941, pp. 23-4) and Oberacker Jr. (1967, pp. 469-75). For a revision of hypotheses on entrepreneurship and immigration to São Paulo, see Campos Araújo, Cruz Paiva and Rodrigues (2006). Argollo Ferrão (1999) provides a case study of occupational assimilation of old German-speaking bonded laborers. ${ }^{181}$ These two nationalities sorted negatively as landowners also in regions with no specific immigration policy.
} 
Table 1.5 - Partial effects: occupations and immigration policies - minorities in the municipalities (1872)

\begin{tabular}{|c|c|c|c|c|c|c|c|c|c|c|c|c|}
\hline & Austr. & Danish & Spanish & Dutch & Belgians & Swedes & Russians & Orient. & Chinese & Argent. & Boliv. & Parag. \\
\hline Foreign land & $\begin{array}{c}-0.476 * * * \\
(0.0549)\end{array}$ & $\begin{array}{c}0.00234 \\
(0.00750)\end{array}$ & $\begin{array}{c}-0.00815 \\
(0.159)\end{array}$ & $\begin{array}{l}0.00338 \\
(0.0251)\end{array}$ & $\begin{array}{l}0.00172 \\
(0.0397)\end{array}$ & $\begin{array}{c}0.0251 \\
(0.0429)\end{array}$ & $\begin{array}{c}-0.086 * * * \\
(0.0260)\end{array}$ & $\begin{array}{c}-0.00152 \\
(0.00938)\end{array}$ & $\begin{array}{c}0.0328 \\
(0.0264)\end{array}$ & $\begin{array}{l}-0.00230 \\
(0.00537)\end{array}$ & $\begin{array}{c}0.0100 \\
(0.0316)\end{array}$ & $\begin{array}{c}0.0171 \\
(0.0197)\end{array}$ \\
\hline Foreign land*(ID bonded) & $\begin{array}{l}-0.271 \\
(0.272)\end{array}$ & $\begin{array}{l}-0.0137 \\
(0.0300)\end{array}$ & $\begin{array}{l}-0.957 \\
(0.645)\end{array}$ & $\begin{array}{c}0.417 * * \\
(0.183)\end{array}$ & $\begin{array}{c}0.962 * * * \\
(0.183)\end{array}$ & $\begin{array}{l}-0.230 \\
(0.320)\end{array}$ & $\begin{array}{l}-0.0262 \\
(0.0754)\end{array}$ & $\begin{array}{c}0.0508 \\
(0.0430)\end{array}$ & $\begin{array}{l}-0.181 * \\
(0.0982)\end{array}$ & $\begin{array}{l}-0.00791 \\
(0.0249)\end{array}$ & $\begin{array}{l}0.302 * \\
(0.166)\end{array}$ & $\begin{array}{l}-0.0843 \\
(0.109)\end{array}$ \\
\hline Foreign land*(ID settl) & $\begin{array}{c}-5.977 * * * \\
(1.910)\end{array}$ & $\begin{array}{l}-1.035 \\
(0.701)\end{array}$ & $\begin{array}{l}-0.550 \\
(4.162)\end{array}$ & $\begin{array}{c}0.681 \\
(0.926)\end{array}$ & $\begin{array}{c}1.196 \\
(1.546)\end{array}$ & $\begin{array}{c}1.208 \\
(1.926)\end{array}$ & $\begin{array}{c}-2.174 * * * \\
(0.651)\end{array}$ & $\begin{array}{c}-0.644^{*} \\
(0.328)\end{array}$ & $\begin{array}{l}-0.0884 \\
(0.839)\end{array}$ & $\begin{array}{c}-0.758 * * * \\
(0.233)\end{array}$ & $\begin{array}{c}0.898 \\
(1.248)\end{array}$ & $\begin{array}{l}-1.090 \\
(0.657)\end{array}$ \\
\hline Agr L & $\begin{array}{c}-0.000561 \\
(0.00045)\end{array}$ & $\begin{array}{c}3.07 \mathrm{e}-05 \\
(6.18 \mathrm{e}-05)\end{array}$ & $\begin{array}{l}0.000321 \\
(0.00117)\end{array}$ & $\begin{array}{l}4.12 \mathrm{e}-05 \\
(0.00025)\end{array}$ & $\begin{array}{l}0.000428 \\
(0.00047)\end{array}$ & $\begin{array}{c}-0.000294 \\
(0.00049)\end{array}$ & $\begin{array}{c}-0.000113 \\
(0.00015)\end{array}$ & $\begin{array}{c}4.79 \mathrm{e}-06 \\
(9.41 \mathrm{e}-05)\end{array}$ & $\begin{array}{c}-2.65 e-05 \\
(0.002)\end{array}$ & $\begin{array}{l}-5.00 e-05 \\
(6.68 \mathrm{e}-05)\end{array}$ & $\begin{array}{l}0.000311 \\
(0.00038)\end{array}$ & $\begin{array}{l}-0.000217 \\
(0.00028)\end{array}$ \\
\hline Agr L*(ID bonded $)$ & $\begin{array}{l}0.000539 \\
(0.00033)\end{array}$ & $\begin{array}{l}-0.00016^{*} \\
(8.69 \mathrm{e}-05)\end{array}$ & $\begin{array}{l}-7.17 e-05 \\
(0.00081)\end{array}$ & $\begin{array}{r}-0.000187 \\
(0.00018)\end{array}$ & $\begin{array}{l}-0.001 * * * \\
(0.00034)\end{array}$ & $\begin{array}{l}-0.0008 * * \\
(0.00032)\end{array}$ & $\begin{array}{c}8.78 \mathrm{e}-05 \\
(0.00012)\end{array}$ & $\begin{array}{c}2.75 e-05 \\
(8.63 e-05)\end{array}$ & $\begin{array}{c}7.19 \mathrm{e}-05 \\
(0.00014)\end{array}$ & $\begin{array}{c}5.18 \mathrm{e}-05 \\
(4.27 \mathrm{e}-05)\end{array}$ & $\begin{array}{c}-0.001 * * * \\
(0.0003)\end{array}$ & $\begin{array}{c}0.000174 \\
(0.00017)\end{array}$ \\
\hline Manuf & $\begin{array}{l}-0.0230 \\
(0.0194)\end{array}$ & $\begin{array}{c}0.00519 \\
(0.00487)\end{array}$ & $\begin{array}{c}0.0291 \\
(0.0691)\end{array}$ & $\begin{array}{c}0.0226 \\
(0.0169)\end{array}$ & $\begin{array}{l}0.00828 \\
(0.0164)\end{array}$ & $\begin{array}{c}0.0491 \\
(0.0399)\end{array}$ & $\begin{array}{c}-0.00553 \\
(0.00676)\end{array}$ & $\begin{array}{l}0.000590 \\
(0.00385)\end{array}$ & $\begin{array}{c}-0.0195^{*} \\
(0.0108)\end{array}$ & $\begin{array}{c}-0.000939 \\
(0.00214)\end{array}$ & $\begin{array}{l}0.00123 \\
(0.0138)\end{array}$ & $\begin{array}{c}0.00430 \\
(0.00962)\end{array}$ \\
\hline Manuf*(ID bonded) & $\begin{array}{c}0.0450 \\
(0.0263)\end{array}$ & $\begin{array}{l}-0.00219 \\
(0.00332)\end{array}$ & $\begin{array}{c}0.0865 \\
(0.0845)\end{array}$ & $\begin{array}{l}-0.0148 \\
(0.0120)\end{array}$ & $\begin{array}{l}-0.0193 \\
(0.0209)\end{array}$ & $\begin{array}{l}-0.0183 \\
(0.0212)\end{array}$ & $\begin{array}{l}-0.00385 \\
(0.0136)\end{array}$ & $\begin{array}{l}-0.00139 \\
(0.00500)\end{array}$ & $\begin{array}{c}0.0370 * * \\
(0.0147)\end{array}$ & $\begin{array}{l}-0.00316 \\
(0.00322)\end{array}$ & $\begin{array}{l}0.00571 \\
(0.0152)\end{array}$ & $\begin{array}{l}-0.00509 \\
(0.00763)\end{array}$ \\
\hline Manuf*(ID settl) & $\begin{array}{c}1.912 * * * \\
(0.244)\end{array}$ & $\begin{array}{c}0.0689 \\
(0.0578)\end{array}$ & $\begin{array}{c}0.179 \\
(0.582)\end{array}$ & $\begin{array}{l}-0.0311 \\
(0.112)\end{array}$ & $\begin{array}{l}0.0312 \\
(0.194)\end{array}$ & $\begin{array}{l}-0.129 \\
(0.196)\end{array}$ & $\begin{array}{c}0.310 * * * \\
(0.0644)\end{array}$ & $\begin{array}{c}0.0124 \\
(0.0334)\end{array}$ & $\begin{array}{l}-0.0952 \\
(0.109)\end{array}$ & $\begin{array}{c}0.0449 \\
(0.0315)\end{array}$ & $\begin{array}{l}0.0732 \\
(0.159)\end{array}$ & $\begin{array}{c}0.0671 \\
(0.0913)\end{array}$ \\
\hline Serv & $\begin{array}{l}-0.0145 \\
(0.0128)\end{array}$ & $\begin{array}{l}0.000913 \\
(0.00294)\end{array}$ & $\begin{array}{c}0.0993 * * \\
(0.0415)\end{array}$ & $\begin{array}{c}0.00964 \\
(0.00965)\end{array}$ & $\begin{array}{l}-0.00625 \\
(0.00997)\end{array}$ & $\begin{array}{c}0.0165 \\
(0.0225)\end{array}$ & $\begin{array}{l}-0.00197 \\
(0.00424)\end{array}$ & $\begin{array}{c}-0.00077 \\
(0.00284)\end{array}$ & $\begin{array}{l}0.000524 \\
(0.00564)\end{array}$ & $\begin{array}{l}0.000213 \\
(0.00178)\end{array}$ & $\begin{array}{l}-0.00979 \\
(0.00986)\end{array}$ & $\begin{array}{r}-0.000519 \\
(0.00652)\end{array}$ \\
\hline Serv*(ID bonded) & $\begin{array}{l}-0.0157 \\
(0.0216)\end{array}$ & $\begin{array}{c}0.00494 \\
(0.00324)\end{array}$ & $\begin{array}{l}-0.0681 \\
(0.0531)\end{array}$ & $\begin{array}{c}-0.000833 \\
(0.0120)\end{array}$ & $\begin{array}{l}0.0378^{*} \\
(0.0206)\end{array}$ & $\begin{array}{c}0.0262 \\
(0.0206)\end{array}$ & $\begin{array}{l}-0.00725 \\
(0.00760)\end{array}$ & $\begin{array}{l}-0.00077 \\
(0.00408)\end{array}$ & $\begin{array}{c}-0.0104 \\
(0.00977)\end{array}$ & $\begin{array}{l}-0.00214 \\
(0.00307)\end{array}$ & $\begin{array}{c}0.0561 * * * \\
(0.0172)\end{array}$ & $\begin{array}{l}0.000757 \\
(0.00981)\end{array}$ \\
\hline Serv*(ID settl) & $\begin{array}{c}3.010^{* * * *} \\
(0.351)\end{array}$ & $\begin{array}{c}0.0626 \\
(0.0496)\end{array}$ & $\begin{array}{l}0.0723 \\
(0.877)\end{array}$ & $\begin{array}{l}0.0488 \\
(0.122)\end{array}$ & $\begin{array}{c}0.244 \\
(0.232)\end{array}$ & $\begin{array}{l}0.0308 \\
(0.209)\end{array}$ & $\begin{array}{c}0.438 * * * \\
(0.0875)\end{array}$ & $\begin{array}{l}-0.0138 \\
(0.0505)\end{array}$ & $\begin{array}{l}-0.252^{*} \\
(0.136)\end{array}$ & $\begin{array}{l}0.00724 \\
(0.0457)\end{array}$ & $\begin{array}{c}0.313 \\
(0.203)\end{array}$ & $\begin{array}{c}0.119 \\
(0.123)\end{array}$ \\
\hline Trade & $\begin{array}{l}0.0476 * \\
(0.0242)\end{array}$ & $\begin{array}{l}-0.00290 \\
(0.00280)\end{array}$ & $\begin{array}{c}0.0882 \\
(0.0592)\end{array}$ & $\begin{array}{l}-0.0279 \\
(0.0227)\end{array}$ & $\begin{array}{c}-0.0307 \\
(0.0261)\end{array}$ & $\begin{array}{l}-0.0788 \\
(0.0521)\end{array}$ & $\begin{array}{c}-0.00603 \\
(0.0127)\end{array}$ & $\begin{array}{c}0.00708 \\
(0.00520)\end{array}$ & $\begin{array}{c}0.0187 \\
(0.0120)\end{array}$ & $\begin{array}{l}-0.00025 \\
(0.00255)\end{array}$ & $\begin{array}{l}-0.0206 \\
(0.0202)\end{array}$ & $\begin{array}{l}0.00828 \\
(0.0120)\end{array}$ \\
\hline Trade*(ID bonded) & $\begin{array}{c}-0.0673 * * \\
(0.0290)\end{array}$ & $\begin{array}{l}0.00746^{*} \\
(0.00385)\end{array}$ & $\begin{array}{c}-0.101 \\
(0.0795)\end{array}$ & $\begin{array}{c}0.0194 \\
(0.0180)\end{array}$ & $\begin{array}{c}0.0619 * * \\
(0.0241)\end{array}$ & $\begin{array}{l}0.0700 * \\
(0.0384)\end{array}$ & $\begin{array}{l}-0.00257 \\
(0.0104)\end{array}$ & $\begin{array}{l}-0.00450 \\
(0.00495)\end{array}$ & $\begin{array}{c}-0.0423 * * \\
(0.0156)\end{array}$ & $\begin{array}{c}0.00412 \\
(0.00264)\end{array}$ & $\begin{array}{c}0.0569 * * * \\
(0.0186)\end{array}$ & $\begin{array}{l}0.00479 \\
(0.0104)\end{array}$ \\
\hline Trade*(ID settl) & $\begin{array}{c}-2.371 * * * \\
(0.279)\end{array}$ & $\begin{array}{l}-0.0549 \\
(0.0548)\end{array}$ & $\begin{array}{l}-0.132 \\
(0.689)\end{array}$ & $\begin{array}{l}0.0237 \\
(0.117)\end{array}$ & $\begin{array}{l}-0.0809 \\
(0.204)\end{array}$ & $\begin{array}{c}0.127 \\
(0.206)\end{array}$ & $\begin{array}{c}-0.320 * * * \\
(0.0713)\end{array}$ & $\begin{array}{l}0.00886 \\
(0.0381)\end{array}$ & $\begin{array}{c}0.151 \\
(0.117)\end{array}$ & $\begin{array}{l}-0.0164 \\
(0.0358)\end{array}$ & $\begin{array}{l}-0.150 \\
(0.172)\end{array}$ & $\begin{array}{l}-0.0604 \\
(0.104)\end{array}$ \\
\hline Full set of covariates & Yes & Yes & Yes & Yes & Yes & Yes & Yes & Yes & Yes & Yes & Yes & Yes \\
\hline Adj. $R^{2}$ & 0.873 & 0.806 & 0.688 & 0.692 & 0.890 & 0.444 & 0.922 & 0.713 & 0.455 & 0.905 & 0.882 & 0.670 \\
\hline Obs. & 64 & 64 & 64 & 64 & 64 & 64 & 64 & 64 & 64 & 64 & 64 & 64 \\
\hline
\end{tabular}




\subsubsection{Determinants of immigration: some remarks}

Although this chapter is primarily concerned with occupational sorting, the coefficients of other determinants are also of interest to the history of immigration. The other covariates of the baselines are presented in Tables A1.1-A1.2 (in the appendix to this chapter).

Overall, results confirm the predictions of the literature on the determinants of immigration. In particular, immigrant networks and the religious indicator for cultural proximity were the most frequently significant determinants. American, French, German and Portuguese immigrants were positively influenced by the total stock of foreigners living in the municipalities in 1854 . Not by chance, these were the main nationalities hired to work as bonded laborers or under special immigration regimes. By contrast, Austrians, Belgians, Bolivians, Dutch and Russians were negatively associated with the stock of immigrants in 1854, indicating their independent arrival as part of new or exceptional immigration waves. It is likely that some of them immigrated to specific localities as expatriates with high levels of physical or human capital. The cultural clustering of immigrants played an independent role as well (besides the network effects), as the share of non-Catholics largely and positively influenced the number of Austrians, Germans and Russians, but negatively so for the Portuguese.

Contrary to the expectation, only specific minorities sorted positively on the number of slaves per municipality, which is the proxy for economic productivity in the regressions. Moreover, no nationality was influenced by the presence of non-white free individuals, but the number of other expatriates did determine the allocation of some nationalities. This probably indicates a higher degree of competition or complementarity among foreigners than between immigrants and non-white, free Brazilians.

It is also noteworthy that only the Portuguese sorted against regions that registered widespread diseases or epidemics in the period 1850-74. This result deserves further analysis, as it indicates that the Portuguese indeed had an informational advantage in their choices of where to settle, probably stemming from the Brazilian colonial past.

Finally, the allocation of immigrants across municipalities in 1872 was rarely determined by demographic and educational conditions. With the exception of the Portuguese, who sorted into municipalities with higher literacy but lower enrolment rates, no other nationality was influenced by local levels of human capital. By 1872, immigrants did not look for the 
"brightest" cities in terms of human capital, a reassuring result for the analysis of Chapter 3 , in which I look at the impact that German-speakers had on the educational system of municipalities.

\subsection{Occupational sorting: settlement colonies in 1897-1920}

The empirical analysis for settlement colonies in 1897-1920 confirms what one would expect by looking at the low share of non-agricultural professions in Table 1.1. On average, households that ended up in this sample - irrespective of their previous professions - did not divert to non-agricultural occupations once living in a rural colony. In the settlement colonies in 1897-1920, the hypotheses that this immigration policy was associated with rural labor could not be rejected.

In particular, Germans, Italians, Portuguese and Spanish - who constituted the main nationalities in the colonies - did not sort out of farming in favor of any other profession. The significant coefficients (Table 1.6, below) show that Syrians were the only minority to sort positively into non-agricultural activities in the settlement colonies ${ }^{182}$. All other cases presented a negative sign when significant, indicating that immigrants sorted against those occupations in favor of the omitted group, i.e. farming. This occurred for Austrians, French, Russians and Swedes. The significance of some estimates are sensitive to changes proposed in the robustness checks. Nonetheless, modifications of significance always favor the conclusion that immigrants sorted in favor of rural occupations ${ }^{183}$.

These results thus differ from those obtained for the municipalities in 1872. At the beginning of the twentieth century, foreigners who made it into a settlement colony seem to have put some significant effort in not diverting to non-agricultural occupations. For this sample, results reject the hypothesis of large variations in the occupational sorting by nationality. It is therefore safe to conclude that settlement colonies played an important role in assuring that foreigners did not divert into non-agricultural occupations.

\footnotetext{
182 The positive sorting into manufacturing is not confirmed in the robustness checks. On the other hand, the sorting into trade-related occupations is very robust (see Table A1.6, in the appendix to this chapter).

${ }^{183}$ With the exception of the French, whose signs depend on the estimator (POLS vs. FE).
} 
A final word of caution is due, however. The fact that an individual was reported as a farmer does not exclude the possibility that he/she exercised other occupations as well. That is precisely what was reported for colony São Bernardo in 1900: of 327 Brazilian farmers, three were administrators of the colony; of 644 foreign farmers, nine were also traders and 10 were industrialists. The same most likely happened in other settlement colonies and periods. Therefore, the point is not that settlers were perfectly specialized in agricultural production, but that they did not divert their main occupation to non-agricultural tasks.

\subsection{Robustness checks}

The coefficients of the immigration policies and occupations estimated in the robustness checks are reported in the appendix to this chapter. Given that most were already discussed in the footnotes to the main results, this section aims primarily at explaining the procedures adopted and commenting on more general changes.

The main concern with the results refers to multiple hypothesis testing, as statistical inference for each covariate is repeated 19 times in the sample of municipalities in 1872 and 12 times in the sample of settlement colonies in 1897-1920. Consequently, the first robustness check applies the Bonferroni correction to the baseline. This correction leads to a stricter confidence level based on the number of trials being tested. This implies that the rejection of the nullhypothesis becomes conditional on $p_{i} \leq \alpha / m$, where $p_{i}$ refers to the $\mathrm{p}$-value of the estimate, $\alpha$ is the significance level (considered throughout the thesis at the 10\%-level) and $m$ equals the number of trials (19 and 12, respectively).

Tables A1.3-A1.4 report the corrections and highlight in colors the differences with respect to the baseline. For the settlement colonies, the correction was excessively strict and no variable remained significant. By contrast, some more interesting patterns could be observed for the municipalities in 1872. Although most effects indeed vanish, the remaining results confirm the low access of foreigners to landownership and the exceptionalism of the English and Americans in this regard ${ }^{184}$.

${ }^{184}$ Except for English and Belgians in specific regions, as in the baseline. 
Table 1.6 - Partial effects: occupations and immigration policies - settlement colonies (1897-1920)

\begin{tabular}{|c|c|c|c|c|c|c|c|c|c|c|c|c|}
\hline & Germans & Portug. & French & Italians & Austr. & Spanish & Belgians & Swedes & Russians & Polish & Syrians & Japanese \\
\hline Manuf. & $\begin{array}{l}0.0531 \\
(0.107)\end{array}$ & $\begin{array}{l}-0.0240 \\
(0.120)\end{array}$ & $\begin{array}{c}0.0199 \\
(0.0227)\end{array}$ & $\begin{array}{l}-0.192 \\
(0.428)\end{array}$ & $\begin{array}{c}-0.422 * * \\
(0.137)\end{array}$ & $\begin{array}{c}-0.00839 \\
(0.216)\end{array}$ & $\begin{array}{l}0.000588 \\
(0.00238)\end{array}$ & $\begin{array}{l}-0.00308 \\
(0.00363)\end{array}$ & $\begin{array}{l}-0.248 \\
(0.190)\end{array}$ & $\begin{array}{l}-0.0160 \\
(0.0291)\end{array}$ & $\begin{array}{l}0.0720 * \\
(0.0375)\end{array}$ & $\begin{array}{l}-0.220 \\
(0.152)\end{array}$ \\
\hline Trade & $\begin{array}{c}0.525 \\
(0.474)\end{array}$ & $\begin{array}{l}-0.519 \\
(0.579)\end{array}$ & $\begin{array}{l}-0.232 * \\
(0.124)\end{array}$ & $\begin{array}{l}-0.148 \\
(0.286)\end{array}$ & $\begin{array}{l}-0.346 \\
(0.541)\end{array}$ & $\begin{array}{c}0.938 \\
(1.111)\end{array}$ & $\begin{array}{c}0.00621 \\
(0.00808)\end{array}$ & $\begin{array}{c}9.67 \mathrm{e}-05 \\
(0.0107)\end{array}$ & $\begin{array}{c}-1.126^{* *} \\
(0.439)\end{array}$ & $\begin{array}{c}0.129 \\
(0.0866)\end{array}$ & $\begin{array}{c}0.482 * * * \\
(0.134)\end{array}$ & $\begin{array}{c}0.942 \\
(0.718)\end{array}$ \\
\hline Other professions & $\begin{array}{c}0.0215 \\
(0.0249)\end{array}$ & $\begin{array}{l}-0.0346 \\
(0.0357)\end{array}$ & $\begin{array}{l}-0.00070 \\
(0.00846)\end{array}$ & $\begin{array}{c}-0.00172 \\
(0.0590)\end{array}$ & $\begin{array}{c}-0.044 * * \\
(0.0152)\end{array}$ & $\begin{array}{c}0.0303 \\
(0.0387)\end{array}$ & $\begin{array}{l}-5.25 \mathrm{e}-05 \\
(0.00016)\end{array}$ & $\begin{array}{l}-0.0012 * \\
(0.00063)\end{array}$ & $\begin{array}{c}-0.0684 \\
(0.0694)\end{array}$ & $\begin{array}{l}-0.00102 \\
(0.00255)\end{array}$ & $\begin{array}{c}0.0128 \\
(0.0115)\end{array}$ & $\begin{array}{l}-0.0235 \\
(0.0388)\end{array}$ \\
\hline Full set of covariates ${ }^{1}$ & Yes & Yes & Yes & Yes & Yes & Yes & Yes & Yes & Yes & Yes & Yes & Yes \\
\hline Obs. & 49 & 49 & 49 & 49 & 49 & 49 & 49 & 49 & 49 & 49 & 49 & 49 \\
\hline Groups & 11 & 11 & 11 & 11 & 11 & 11 & - & 11 & 11 & 11 & - & 11 \\
\hline Estimator & $\mathrm{FE}$ & FE & FE & $\mathrm{FE}$ & FE & FE & POLS & FE & FE & FE & POLS & FE \\
\hline
\end{tabular}


Results for agricultural labor were more affected, as this variable and its interactions became non-significant in all cases. For the urban economy, the similitude in the sorting of Germans, Austrians and Russians survived the correction. By contrast, trade-related activities became statistically non-significant for all nationalities, except for the French and Bolivians where bonded labor had prevailed.

The other checks test for the sensitivity of results to the inclusion of different controls.

For the sample of municipalities in 1872, the baseline constrained the data on the age structure of the population to harmonize the 1872 Census with the age categories listed in the dataset for the settlement colonies in 1897-1920. In the first check, I refine these age structures and include the shares of people in the age ranges 21-30, 31-60 and older than 60 . In the second, I consider the share of singles and widows in the total population rather than only among free individuals. As a third check, I change the indicators that capture the degree of insalubrity of a municipality. I first substitute the binary indicator on whether a municipality had recorded a widespread disease in the period 1850-74 by the number of such cases. In the sequence, instead of having a binary indicator on whether a region was considered insalubrious because of its location, I use a categorical variable to classify specific geographic areas considered insalubrious. Finally, I add the municipal budget as a further indicator of the economic prosperity of a municipality. The objective is to assess the economic performance in the urban economy, rather than having only the number of slaves as a proxy for rural productivity.

Overall, results were robust to modifications in the demographic variables and in the indicators for the insalubrity of a region. However, results change, sometimes substantially in terms of significance, when the municipal budget is added as a control. However, comparisons to the baseline are problematic in this case, as the final sample is reduced by 23 observations.

For the sample of settlement colonies in 1897-1920, I first change the mortality indicator to consider casualties only among foreigners, under the assumption that this information spread more easily among immigrants - although I do not differentiate by nationality in this case ${ }^{185}$.

\footnotetext{
185 Lamounier (2000) stresses the mortality differences between foreigners and Brazilians in railway
} construction. 
Second, I add the total number of buildings existing in a colony to reflect the infrastructure and capital accumulated in a rural settlement. Results are robust to these modifications. Finally, in a previous approach, I included measures for the net inflow of the total population and of immigrants to or from a colony. These variables proxied for the attractiveness of a rural settlement in the short run. Results were sensitive to this modification. However, I did not pursue these robustness checks further because an identifier group (referring to colony Conde de Parnaíba) was dropped, impairing comparisons to the baseline.

\section{Concluding remarks}

This chapter studied the occupational sorting of immigrants across municipalities of São Paulo in 1872 and settlement colonies in 1897-1920. Its main contribution to the literature on the determinants of immigration was to consider explicitly how different immigration policies influenced the allocation of foreigners. The empirical analyses showed some unexpected results regarding the occupational sorting of different nationalities once these policies were taken into account, adding nuances on how certain nationalities benefited from the design of different immigration policies, while others had to find their own channels of economic integration. Furthermore, the chapter provided a sub-national case study for Latin America during the Age of Mass Migration. In this context, São Paulo is an example of a region that widely experimented with different policy instruments and received immigrants from a vast array of nationalities.

The migratory waves to São Paulo in the period 1820-1920 were classified into two main categories according to the prevailing immigration policies, namely the hiring of foreign bonded laborers to the plantations and the settlement of immigrants in rural colonies. The historical analysis emphasized how Brazilian policies swung between these alternatives throughout the nineteenth and early twentieth centuries. These policies attracted immigrants of different nationalities, partly following the European emigration life cycle, but not limited to it. The empirical analysis, in turn, showed how local economic opportunities and institutional constraints molded the sorting of immigrants, leading to three main conclusions. First, immigrants sorted against rural employment, even in regions where bonded labor had been the prevalent immigration policy. Second, foreign landownership had a rather limited impact on the sorting of immigrants, even where the immigration policies were based on the 
foundation of settlement colonies. Third, the sorting into urban occupations was influenced both by immigrants' nationality and the prevailing immigration policy in the regions where they settled.

The analysis was conclusive in showing either a nonexistent or a negative association between the presence of foreigners and agricultural labor. This conclusion is aligned with sociological and historical accounts that show how physical and manual labor were negatively perceived in a society that was based on slavery until 1888. Even in regions where bonded labor had prevailed, immigrants avoided agricultural employment, contrary to the aims of plantation owners. These results are also in line with the literature that argues that labor remuneration was hampered by technological and institutional constraints, even in an economy with a potentially high land per labor ratio. Relatedly, only specific groups of immigrants were positively correlated with landownership. Only the sorting of Americans was positively correlated with foreign landownership in regions where no immigration policy had prevailed. With the exception of the English, rural settlement colonies failed to make foreigners sort positively as rural proprietors. Moreover, regions where bonded labor had prevailed only experimented the positive sorting of a tiny minority in foreign landownership. Other contributions of immigrants aside, they were on average unable to change deeply rooted institutions that made Latin America infamous for its degree of land concentration.

Complementing these results, estimates for the settlement colonies in 1897-1920 showed that immigrants sorted majorly as farmers in those rural settlements. On average, foreigners who were in a settlement colony at the beginning of the twentieth century put significant effort in remaining in agricultural occupations. Whether this result translated into a higher share of foreign landowners in later periods cannot be answered with the evidence compiled for this study. Nevertheless, the negative effect of the interaction between foreign landownership and settlement colonies on the number of Germans in 1872 is an important reminder that there was no automatic link between initial settlement in a rural colony - as accomplished by an important German migratory wave in the $1820 \mathrm{~s}$ - and the attainment of longer-term landownership.

For the urban economy, important nuances appeared once occupational sorting was interacted with the immigration policies. Contrary to the hypothesis that northwestern Europeans had sorted into manufactures and specialized services, results showed that the English and Germans behaved almost in perfectly opposite directions, with each adapting to opportunities 
available locally. While the English sorted positively in foreign landownership in regions where settlement colonies had prevailed, Germans did not and instead sorted into manufacturing-related occupations. Relatedly, the prediction that southern Europeans had sorted into services and trade-related occupations was not fully confirmed. Trade-related professions provided a potentially cheaper channel of occupational sorting for a wide array of nationalities.

While studying the determinants of immigration for more than twenty nationalities introduced some statistical noise into the results, the emergence of some patterns shows the fruitfulness of this approach. The exceptionalism of the English and American immigrants in Brazil was clearly shown with data for the first time. Similarities in the sorting of some minorities against agricultural employment and in favor of trade-related occupations was a new finding; and so was the unexpected differences between the English and Germans in their occupational sorting. By contrast, the widespread distribution of Portuguese across regions could have been hypothesized due to the Brazilian colonial past. Nevertheless, the chapter was positive in showing that this was the only nationality to avoid regions with more registered epidemics and that the Portuguese were underrepresented in the settlement colonies in $1897-1920$.

Notwithstanding, further empirical and historical research is still required in this thriving literature. First, the elaboration of indices on returns to skill disaggregated at sub-national levels is urgently required to better assess the determinants of immigration to Latin America. A challenge is to consider how contractual designs blurred the relationship between labor remuneration and marginal productivity. Moreover, the results of this chapter are conditional correlations. Causal assessments require adequately instrumenting the occupational distribution in municipalities or matching individuals across censuses. The second approach has been the direction mostly pursued by the literature, but it might be less successful for the case at hand, for which the next available census is from 1890. First, it is likely that a large parcel of the pioneering settlers and bonded laborers - who arrived in 1828 and 1840 - were already dead by then. Second, the census occurred immediately after the mass inflow of Italians, likely confounding the effects for other nationalities. Finally, the current analysis provides average results. Only by advancing the history of specific immigration waves will we be able to accommodate individual cases into this general framework. Studies on the local history of settlement colonies, of plantations employing bonded laborers and of public works 
making use of immigrant labor are promising in the global context of the Age of Mass Migration. 


\section{Appendix: Complementary tables and maps}

Table A1.1 - Other determinants of immigration - municipalities (1872)

\begin{tabular}{|c|c|c|c|c|c|c|c|}
\hline & Germans & Swiss & Portug. & French & English & Amer. & Italians \\
\hline \multirow[t]{2}{*}{ ID insalubrious region } & 3.187 & -1.057 & -25.60 & 3.510 & -6.464 & -0.438 & 4.276 \\
\hline & $(18.30)$ & $(6.552)$ & (18.69) & $(2.476)$ & (7.284) & (3.559) & $(6.210)$ \\
\hline \multirow[t]{2}{*}{ ID diseases } & 12.42 & 0.335 & $-43.80 * *$ & 2.085 & 2.091 & -0.473 & -5.435 \\
\hline & (22.24) & $(7.485)$ & $(19.76)$ & $(2.612)$ & $(4.000)$ & (2.509) & $(5.474)$ \\
\hline \multirow[t]{2}{*}{ Population } & -0.000947 & -0.00112 & -0.00424 & $-3.02 \mathrm{e}-06$ & -0.00207 & $0.00198 *$ & 0.00275 \\
\hline & $(0.00685)$ & $(0.00278)$ & $(0.00609)$ & $(0.0009)$ & $(0.00226)$ & $(0.00109)$ & $(0.00210)$ \\
\hline \multirow[t]{2}{*}{ \# Free non-whites } & -0.00295 & 0.000212 & -0.00164 & -0.00148 & 0.000956 & -0.00234 & -0.00672 \\
\hline & $(0.0168)$ & $(0.00557)$ & $(0.0126)$ & $(0.00198)$ & $(0.00362)$ & $(0.00207)$ & $(0.00432)$ \\
\hline \multirow[t]{2}{*}{ \# Slaves } & -0.00789 & -0.00331 & 0.0186 & 0.00204 & 0.00200 & $-0.00270 *$ & 0.00132 \\
\hline & $(0.0136)$ & $(0.00572)$ & $(0.0132)$ & $(0.00153)$ & $(0.00277)$ & $(0.00134)$ & $(0.00465)$ \\
\hline \multirow[t]{2}{*}{$<6$ years old (share) } & -92.62 & -17.83 & -153.7 & 42.31 & 81.31 & 34.11 & -20.47 \\
\hline & $(292.1)$ & $(83.00)$ & (194.2) & $(25.82)$ & $(64.47)$ & (33.37) & $(68.86)$ \\
\hline \multirow[t]{2}{*}{ 6-15 years old (share) } & 58.66 & -42.47 & -50.23 & -29.93 & 19.11 & -24.30 & 15.81 \\
\hline & $(160.9)$ & $(63.25)$ & $(145.7)$ & (19.65) & $(32.32)$ & $(22.17)$ & $(42.26)$ \\
\hline \multirow[t]{2}{*}{ 16-20 years old (share) } & 92.89 & 40.16 & 644.8 & 82.47 & -30.74 & 92.62 & 30.11 \\
\hline & $(552.2)$ & $(200.5)$ & $(589.0)$ & $(59.76)$ & $(85.29)$ & $(64.73)$ & $(148.1)$ \\
\hline \multirow[t]{2}{*}{ Singles (share) } & 337.0 & 53.54 & -294.4 & 12.00 & 25.32 & $-50.10 *$ & 18.94 \\
\hline & $(234.0)$ & (71.16) & (180.9) & (24.58) & $(55.22)$ & $(28.30)$ & $(45.92)$ \\
\hline \multirow[t]{2}{*}{ Widows (share) } & 1,147 & 134.2 & $-947.5 *$ & -11.52 & 5.243 & 55.41 & 90.52 \\
\hline & $(841.9)$ & $(206.1)$ & $(467.1)$ & (59.04) & $(100.1)$ & $(57.51)$ & $(122.6)$ \\
\hline \multirow[t]{2}{*}{ Literacy rate } & -98.43 & -18.66 & $294.2 * *$ & -13.51 & -15.85 & -23.61 & 40.59 \\
\hline & $(154.2)$ & (47.99) & $(140.5)$ & (18.87) & (28.03) & (21.58) & $(52.06)$ \\
\hline \multirow[t]{2}{*}{ Enrol. Rate } & 349.1 & -30.30 & $-1,070 *$ & -4.015 & -66.54 & 53.60 & -155.3 \\
\hline & (661.0) & (198.0) & $(602.1)$ & (79.66) & (114.1) & (77.87) & (140.9) \\
\hline \multirow[t]{2}{*}{ Non-Catholics (share) } & $9,317 * * *$ & 565.7 & $-4,138^{*}$ & -73.99 & 613.0 & -66.15 & -278.4 \\
\hline & $(2,717)$ & (884.4) & $(2,080)$ & (168.4) & (609.4) & (252.9) & $(327.0)$ \\
\hline \multirow{2}{*}{$\begin{array}{l}\text { Foreign Public Adm } \\
\text { (share) }\end{array}$} & 83.66 & 31.24 & $1,364 * * *$ & -29.81 & 115.5 & -63.72 & 208.6 \\
\hline & $(480.5)$ & $(148.0)$ & (489.3) & (71.64) & $(124.2)$ & $(52.11)$ & (178.4) \\
\hline \multirow[t]{2}{*}{ Stock Immigrants 1854} & $0.188 *$ & -0.0348 & $0.215^{* * *}$ & $0.0144 * *$ & 0.00375 & $0.124 * * *$ & -0.0102 \\
\hline & $(0.0977)$ & $(0.0281)$ & $(0.0748)$ & $(0.00643)$ & $(0.0124)$ & $(0.00983)$ & $(0.0161)$ \\
\hline Geographic controls ${ }^{1}$ & Yes & Yes & Yes & Yes & Yes & Yes & Yes \\
\hline Occupational distr. $^{2}$ & Yes & Yes & Yes & Yes & Yes & Yes & Yes \\
\hline Observations & 64 & 64 & 64 & 64 & 64 & 64 & 64 \\
\hline Adj. $R^{2}$ & 0.836 & 0.571 & 0.940 & 0.931 & 0.741 & 0.915 & 0.804 \\
\hline
\end{tabular}


Table A1.1 (Ctd.)

\begin{tabular}{|c|c|c|c|c|c|c|}
\hline & Austr. & Danish & Spanish & Dutch & Belgians & Swede \\
\hline \multirow[t]{2}{*}{ ID insalubrious region } & 0.311 & 0.0442 & -2.858 & -0.132 & -0.444 & 0.400 \\
\hline & $(0.784)$ & $(0.115)$ & $(2.395)$ & $(0.431)$ & $(0.662)$ & $(0.622)$ \\
\hline \multirow[t]{2}{*}{ ID diseases } & -0.499 & -0.0153 & -0.688 & -0.117 & -0.238 & 0.344 \\
\hline & $(0.683)$ & $(0.117)$ & (1.609) & $(0.428)$ & $(0.654)$ & $(0.740)$ \\
\hline \multirow[t]{2}{*}{ Population } & 0.000194 & $-6.73 e-05$ & -0.00104 & $-2.89 \mathrm{e}-05$ & -0.000201 & 0.000168 \\
\hline & $(0.000292)$ & $(7.32 \mathrm{e}-05)$ & $(0.000780)$ & $(0.000146)$ & $(0.000213)$ & $(0.000259)$ \\
\hline \multirow[t]{2}{*}{ \# Free non-whites } & -0.000375 & 0.000210 & 0.00164 & $-3.24 \mathrm{e}-06$ & $-7.78 \mathrm{e}-05$ & -0.000208 \\
\hline & $(0.000653)$ & $(0.000205)$ & $(0.00172)$ & $(0.000266)$ & $(0.000454)$ & $(0.000468)$ \\
\hline \multirow[t]{2}{*}{ \# Slaves } & $0.00125 * *$ & $1.92 \mathrm{e}-05$ & 0.000607 & 0.000176 & $0.00102 * *$ & 0.000281 \\
\hline & $(0.000510)$ & $(7.17 e-05)$ & $(0.00135)$ & $(0.000226)$ & $(0.000433)$ & $(0.000338)$ \\
\hline \multirow[t]{2}{*}{$<6$ years old (share) } & -8.955 & 0.757 & 22.06 & $7.962 *$ & $11.47 *$ & 10.85 \\
\hline & (7.615) & (1.464) & (24.08) & $(4.660)$ & $(6.526)$ & (10.07) \\
\hline \multirow{2}{*}{ 6-15 years old (share) } & 8.563 & -0.187 & -5.448 & -2.450 & 4.546 & -0.990 \\
\hline & $(6.639)$ & (1.013) & (13.64) & $(4.023)$ & $(6.804)$ & $(4.602)$ \\
\hline \multirow[t]{2}{*}{$16-20$ years old (share) } & -12.25 & 0.718 & -6.706 & 0.958 & -6.894 & -7.558 \\
\hline & (19.29) & (3.609) & $(45.71)$ & (8.922) & $(15.00)$ & (12.96) \\
\hline \multirow[t]{2}{*}{ Singles (share) } & -3.845 & -1.478 & -5.577 & 0.160 & -3.352 & -2.290 \\
\hline & $(5.782)$ & (1.695) & $(19.82)$ & (3.328) & (5.914) & $(6.832)$ \\
\hline \multirow[t]{2}{*}{ Widows (share) } & -29.81 & -5.455 & -34.34 & -4.041 & -18.89 & -0.878 \\
\hline & $(20.70)$ & $(6.772)$ & (41.09) & $(8.243)$ & (14.76) & (18.68) \\
\hline \multirow[t]{2}{*}{ Literacy rate } & 3.567 & -0.994 & 7.254 & 0.468 & -4.014 & -2.144 \\
\hline & $(4.788)$ & $(0.787)$ & (11.12) & $(2.736)$ & $(4.658)$ & $(5.467)$ \\
\hline \multirow[t]{2}{*}{ Enrol. Rate } & -18.62 & -1.021 & 13.85 & -5.248 & -20.44 & 15.95 \\
\hline & (18.98) & $(3.883)$ & $(51.91)$ & $(11.87)$ & (23.76) & $(23.52)$ \\
\hline \multirow[t]{2}{*}{ Non-Catholics (share) } & $832.8 * * *$ & 0.523 & 8.513 & 4.580 & 21.38 & -20.24 \\
\hline & $(82.37)$ & $(9.565)$ & $(228.8)$ & $(31.69)$ & $(48.27)$ & $(45.65)$ \\
\hline \multirow[t]{2}{*}{ Foreign Public Adm (share) } & $37.18 * * *$ & -3.783 & 4.899 & -2.729 & 14.69 & -12.37 \\
\hline & $(13.01)$ & $(4.015)$ & $(45.69)$ & $(9.345)$ & $(15.04)$ & (20.69) \\
\hline \multirow[t]{2}{*}{ Stock Immigrants 1854} & $-0.021 * * *$ & -0.000342 & -0.00361 & $-0.00198 *$ & $-0.0045 * *$ & -0.00431 \\
\hline & $(0.00261)$ & $(0.000391)$ & $(0.00598)$ & $(0.00113)$ & $(0.00180)$ & $(0.00279)$ \\
\hline Geographic controls ${ }^{1}$ & Yes & Yes & Yes & Yes & Yes & Yes \\
\hline Occupational distribution $^{2}$ & Yes & Yes & Yes & Yes & Yes & Yes \\
\hline Observations & 64 & 64 & 64 & 64 & 64 & 64 \\
\hline Adj. $R^{2}$ & 0.873 & 0.806 & 0.688 & 0.692 & 0.890 & 0.444 \\
\hline
\end{tabular}


Table A1.1 (Ctd.)

\begin{tabular}{|c|c|c|c|c|c|c|}
\hline & Russians & Orientals & Chinese & Argent. & Boliv. & Parag. \\
\hline \multirow[t]{2}{*}{ ID insalubrious region } & 0.0561 & 0.00458 & -0.103 & -0.0266 & -0.0896 & -0.190 \\
\hline & $(0.223)$ & $(0.198)$ & $(0.341)$ & $(0.0964)$ & $(0.641)$ & $(0.404)$ \\
\hline \multirow[t]{2}{*}{ ID diseases } & -0.416 & 0.156 & -0.162 & 0.0436 & -0.133 & 0.207 \\
\hline & $(0.409)$ & $(0.179)$ & $(0.339)$ & $(0.0806)$ & $(0.507)$ & $(0.386)$ \\
\hline \multirow[t]{2}{*}{ Population } & $-1.24 \mathrm{e}-05$ & $-3.36 e-05$ & -0.000127 & $-2.05 e-05$ & $-5.34 \mathrm{e}-05$ & 0.000109 \\
\hline & $(8.78 \mathrm{e}-05)$ & $(7.14 \mathrm{e}-05)$ & $(0.000135)$ & $(3.08 \mathrm{e}-05)$ & $(0.000189)$ & $(0.000143)$ \\
\hline \multirow[t]{2}{*}{ \# Free non-whites } & $4.18 \mathrm{e}-05$ & 0.000104 & 0.000374 & $7.64 \mathrm{e}-05$ & -0.000339 & -0.000208 \\
\hline & $(0.000171)$ & $(0.000157)$ & $(0.000273)$ & $(9.26 \mathrm{e}-05)$ & $(0.000390)$ & $(0.000265)$ \\
\hline \multirow[t]{2}{*}{ \# Slaves } & $4.74 \mathrm{e}-05$ & $5.65 \mathrm{e}-06$ & 0.000200 & $0.000141 *$ & $0.000766^{*}$ & $7.29 \mathrm{e}-05$ \\
\hline & $(0.000198)$ & $(8.16 \mathrm{e}-05)$ & $(0.000214)$ & $(7.27 \mathrm{e}-05)$ & $(0.000384)$ & $(0.000194)$ \\
\hline \multirow[t]{2}{*}{ < 6 years old (share) } & 4.251 & -1.556 & -0.551 & 0.862 & 5.738 & 0.114 \\
\hline & $(5.139)$ & $(2.195)$ & $(3.525)$ & $(0.976)$ & $(4.456)$ & $(3.461)$ \\
\hline \multirow[t]{2}{*}{ 6-15 years old (share) } & 0.880 & 0.778 & -3.563 & $1.552^{*}$ & 2.605 & 2.281 \\
\hline & $(2.242)$ & $(1.708)$ & $(2.503)$ & $(0.830)$ & (5.198) & $(2.915)$ \\
\hline \multirow[t]{2}{*}{$16-20$ years old (share) } & -1.858 & -3.134 & 6.306 & $-5.367 *$ & -2.387 & 7.856 \\
\hline & $(5.334)$ & (4.185) & $(9.387)$ & $(2.884)$ & (12.54) & $(7.813)$ \\
\hline \multirow[t]{2}{*}{ Singles (share) } & 1.643 & -0.302 & -2.537 & -0.497 & -4.475 & -1.367 \\
\hline & (2.954) & $(1.472)$ & $(3.560)$ & $(0.915)$ & (5.058) & $(3.542)$ \\
\hline \multirow[t]{2}{*}{ Widows (share) } & -1.815 & -5.226 & -9.398 & -1.154 & -9.513 & -0.212 \\
\hline & $(5.017)$ & $(4.468)$ & $(8.069)$ & $(2.143)$ & (11.16) & $(6.465)$ \\
\hline \multirow[t]{2}{*}{ Literacy rate } & 2.362 & 0.741 & 2.650 & $-1.555 * *$ & -3.561 & -1.236 \\
\hline & $(2.234)$ & $(1.538)$ & $(2.780)$ & $(0.754)$ & $(4.237)$ & $(3.185)$ \\
\hline \multirow{2}{*}{ Enrol. Rate } & -5.228 & -0.775 & 9.464 & 5.156 & -14.70 & -2.130 \\
\hline & (6.593) & $(5.047)$ & (11.39) & $(3.442)$ & $(21.12)$ & $(11.70)$ \\
\hline \multirow[t]{2}{*}{ Non-Catholics (share) } & $127.7 * * *$ & -3.234 & -49.31 & 6.564 & 2.356 & -14.44 \\
\hline & $(23.41)$ & (12.78) & $(37.00)$ & $(8.410)$ & $(38.49)$ & $(24.27)$ \\
\hline \multirow[t]{2}{*}{ Foreign Public Adm (share) } & 3.723 & 0.320 & -6.357 & 0.881 & 17.07 & 4.448 \\
\hline & $(4.959)$ & $(4.141)$ & (7.918) & (2.189) & (13.98) & $(8.317)$ \\
\hline \multirow[t]{2}{*}{ Stock Immigrants 1854} & $-0.0032 * * *$ & 0.000143 & 0.00189 & 0.000126 & $-0.0042 * *$ & -0.000343 \\
\hline & $(0.000675)$ & $(0.000488)$ & $(0.00123)$ & $(0.000258)$ & $(0.00165)$ & $(0.00120)$ \\
\hline Geographic controls ${ }^{1}$ & Yes & Yes & Yes & Yes & Yes & Yes \\
\hline Occupational distribution $^{2}$ & Yes & Yes & Yes & Yes & Yes & Yes \\
\hline Observations & 64 & 64 & 64 & 64 & 64 & 64 \\
\hline Adj. $R^{2}$ & 0.922 & 0.713 & 0.455 & 0.904 & 0.882 & 0.670 \\
\hline
\end{tabular}

Note: (1) Geographic controls include: Holloway's geographic categories for municipalities of São Paulo (as in Carvalho Filho and Colistete, 2010), altitude, latitude and area; (2) Occupational distribution: categories presented in the main text; (3) Besides reported variables, all regressions include a constant, the total number of farmers, of workers in public administration, the total number of professions registered in a municipality, an indicator for the quality of data on the stock of immigrants in 1854 and the number of other expatriates in a municipality; (4) Robust standard errors in parenthesis if the hypothesis of homoscedasticity was rejected at the 10 percent level. *, ** and $* * *$ indicate $\mathrm{p}<0.10, \mathrm{p}<0.05$ and $\mathrm{p}<0.01$, respectively. 
Table A1.2 - Other determinants of immigration - settlement colonies (1897-1920)

\begin{tabular}{|c|c|c|c|c|c|c|}
\hline & Germans & Portug. & French & Italians & Austr. & Spanish \\
\hline Year & $\begin{array}{c}-14.33 * * * \\
(3.526)\end{array}$ & $\begin{array}{l}-4.305 \\
(6.026)\end{array}$ & $\begin{array}{c}-1.776^{* *} \\
(0.793)\end{array}$ & $\begin{array}{c}-20.20 * \\
(9.685)\end{array}$ & $\begin{array}{c}-27.87 * * * \\
(6.886)\end{array}$ & $\begin{array}{l}-4.071 \\
(8.170)\end{array}$ \\
\hline Population & $\begin{array}{l}0.105 * * \\
(0.0436)\end{array}$ & $\begin{array}{l}0.0521 * \\
(0.0258)\end{array}$ & $\begin{array}{c}0.00817 \\
(0.00457)\end{array}$ & $\begin{array}{l}0.191 * * \\
(0.0693)\end{array}$ & $\begin{array}{l}0.165 * * \\
(0.0575)\end{array}$ & $\begin{array}{c}0.0687 \\
(0.0619)\end{array}$ \\
\hline Total mortality & $\begin{array}{l}0.0560 \\
(0.306)\end{array}$ & $\begin{array}{c}-0.700 * \\
(0.336)\end{array}$ & $\begin{array}{c}0.180 * \\
(0.0962)\end{array}$ & $\begin{array}{c}-0.0278 \\
(1.028)\end{array}$ & $\begin{array}{l}-0.627 * \\
(0.326)\end{array}$ & $\begin{array}{r}-0.0537 \\
(0.959)\end{array}$ \\
\hline$<7$ years old (share) & $\begin{array}{l}302.6^{*} \\
(139.3)\end{array}$ & $\begin{array}{c}92.63 \\
(198.8)\end{array}$ & $\begin{array}{c}68.75 \\
(51.17)\end{array}$ & $\begin{array}{c}509.1 \\
(306.1)\end{array}$ & $\begin{array}{c}279.5 \\
(204.9)\end{array}$ & $\begin{array}{c}567.2 * * \\
(247.4)\end{array}$ \\
\hline $7-14$ years old (share) & $\begin{array}{c}12.02 \\
(72.87)\end{array}$ & $\begin{array}{l}-148.3 \\
(109.5)\end{array}$ & $\begin{array}{c}4.353 \\
(32.58)\end{array}$ & $\begin{array}{c}185.6 \\
(187.4)\end{array}$ & $\begin{array}{l}-180.6 \\
(135.3)\end{array}$ & $\begin{array}{c}47.97 \\
(150.1)\end{array}$ \\
\hline 14-21 years old (share) & $\begin{array}{l}226.6^{*} \\
(115.8)\end{array}$ & $\begin{array}{l}-43.59 \\
(88.69)\end{array}$ & $\begin{array}{l}69.30^{*} \\
(33.17)\end{array}$ & $\begin{array}{l}520.4^{*} \\
(236.1)\end{array}$ & $\begin{array}{c}154.6 \\
(174.7)\end{array}$ & $\begin{array}{c}245.4 \\
(203.2)\end{array}$ \\
\hline Singles (share) & $\begin{array}{l}141.7 \\
(93.45)\end{array}$ & $\begin{array}{c}-80.61^{*} \\
(36.51)\end{array}$ & $\begin{array}{c}7.899 \\
(7.020)\end{array}$ & $\begin{array}{c}133.5 \\
(123.7)\end{array}$ & $\begin{array}{c}25.03 \\
(77.87)\end{array}$ & $\begin{array}{l}-123.6 \\
(124.5)\end{array}$ \\
\hline Widows (share) & $\begin{array}{l}1,116^{*} \\
(586.0)\end{array}$ & $\begin{array}{c}-804.4 * * \\
(357.8)\end{array}$ & $\begin{array}{l}228.0 * * \\
(98.24)\end{array}$ & $\begin{array}{c}847.1 \\
(764.0)\end{array}$ & $\begin{array}{c}203.6 \\
(800.0)\end{array}$ & $\begin{array}{l}-1,536 \\
(881.7)\end{array}$ \\
\hline Literacy rate & $\begin{array}{l}-84.74 \\
(65.04)\end{array}$ & $\begin{array}{l}94.45^{*} \\
(46.19)\end{array}$ & $\begin{array}{l}-14.70 \\
(13.23)\end{array}$ & $\begin{array}{l}-196.2 \\
(125.7)\end{array}$ & $\begin{array}{l}-94.33 \\
(109.2)\end{array}$ & $\begin{array}{c}60.11 \\
(190.8)\end{array}$ \\
\hline \# Schools & $\begin{array}{c}6.658 \\
(5.271)\end{array}$ & $\begin{array}{c}0.154 \\
(3.224)\end{array}$ & $\begin{array}{l}-2.388^{*} \\
(1.298)\end{array}$ & $\begin{array}{c}5.996 \\
(9.212)\end{array}$ & $\begin{array}{l}-3.166 \\
(11.06)\end{array}$ & $\begin{array}{c}3.007 \\
(7.866)\end{array}$ \\
\hline Non-Catholics (share) & $\begin{array}{c}463.7 * * * \\
(79.83)\end{array}$ & $\begin{array}{l}-129.4 \\
(88.69)\end{array}$ & $\begin{array}{c}14.04 \\
(10.76)\end{array}$ & $\begin{array}{c}205.1 \\
(168.6)\end{array}$ & $\begin{array}{l}-119.1 \\
(88.62)\end{array}$ & $\begin{array}{l}-245.8 \\
(148.6)\end{array}$ \\
\hline Cultivated area (share) & $\begin{array}{l}-35.69 \\
(35.43)\end{array}$ & $\begin{array}{l}-14.45 \\
(46.16)\end{array}$ & $\begin{array}{c}2.832 \\
(6.766)\end{array}$ & $\begin{array}{c}43.24 \\
(90.23)\end{array}$ & $\begin{array}{l}102.3^{*} \\
(54.21)\end{array}$ & $\begin{array}{c}22.61 \\
(35.58)\end{array}$ \\
\hline Labor productivity (nominal) & $\begin{array}{l}0.112 * * \\
(0.0446)\end{array}$ & $\begin{array}{c}0.0367 \\
(0.0883)\end{array}$ & $\begin{array}{c}0.0127 \\
(0.00709)\end{array}$ & $\begin{array}{l}0.301 * \\
(0.136)\end{array}$ & $\begin{array}{c}0.146^{*} \\
(0.0740)\end{array}$ & $\begin{array}{c}0.161 \\
(0.133)\end{array}$ \\
\hline Occupational distribution ${ }^{1}$ & Yes & Yes & Yes & Yes & Yes & Yes \\
\hline Estimator & FE & FE & $\mathrm{FE}$ & $\mathrm{FE}$ & FE & FE \\
\hline Observations & 49 & 49 & 49 & 49 & 49 & 49 \\
\hline Within $\mathrm{R}^{2}$ & 0.902 & 0.505 & 0.802 & 0.789 & 0.872 & 0.832 \\
\hline Groups by colony & 11 & 11 & 11 & 11 & 11 & 11 \\
\hline
\end{tabular}


Table A1.2 (Ctd.)

\begin{tabular}{|c|c|c|c|c|c|c|}
\hline & Belgians & Swedes & Russians & Polish & Syrians & Japanese \\
\hline \multirow[t]{2}{*}{ Year } & -0.0431 & $-0.499 * * *$ & $-31.29 * *$ & $1.461 * *$ & -0.565 & 1.313 \\
\hline & $(0.0601)$ & $(0.118)$ & $(10.11)$ & $(0.620)$ & $(0.966)$ & (7.178) \\
\hline \multirow{2}{*}{ Population } & 0.000175 & 0.00110 & $0.153 * *$ & $-0.0185^{*}$ & 0.0173 & 0.101 \\
\hline & $(0.000239)$ & $(0.000758)$ & $(0.0487)$ & $(0.00838)$ & $(0.0130)$ & $(0.0943)$ \\
\hline \multirow[t]{2}{*}{ Total mortality } & -0.00456 & -0.0118 & -0.568 & -0.158 & -0.00375 & -0.997 \\
\hline & $(0.00469)$ & $(0.00929)$ & $(0.724)$ & $(0.101)$ & $(0.0938)$ & $(0.730)$ \\
\hline \multirow[t]{2}{*}{ < 7 years old (share) } & -4.036 & -7.248 & 519.7 & -3.612 & -34.14 & -83.51 \\
\hline & $(5.669)$ & (7.072) & $(497.3)$ & $(25.27)$ & $(48.97)$ & $(167.7)$ \\
\hline \multirow[t]{2}{*}{ 7-14 years old (share) } & 1.001 & 3.095 & -217.1 & -15.93 & -21.32 & -317.0 \\
\hline & $(2.092)$ & (3.188) & $(255.9)$ & $(28.57)$ & $(29.41)$ & $(264.7)$ \\
\hline \multirow[t]{2}{*}{ 14-21 years old (share) } & -3.529 & -5.377 & 268.6 & 52.68 & -41.35 & -262.1 \\
\hline & $(4.592)$ & (3.282) & $(171.0)$ & $(30.54)$ & $(37.98)$ & $(160.9)$ \\
\hline \multirow[t]{2}{*}{ Singles (share) } & 0.654 & -0.943 & -13.93 & -5.299 & -2.637 & -158.6 \\
\hline & $(0.725)$ & $(0.946)$ & $(76.76)$ & (10.73) & $(13.98)$ & (139.3) \\
\hline \multirow[t]{2}{*}{ Widows (share) } & 2.807 & -1.532 & -452.0 & -48.07 & -270.8 & $-1,728$ \\
\hline & (7.207) & $(14.88)$ & $(902.5)$ & (90.76) & $(216.9)$ & $(960.3)$ \\
\hline \multirow[t]{2}{*}{ Literacy rate } & 0.471 & 1.655 & -23.39 & 6.757 & 12.79 & 179.1 \\
\hline & $(1.520)$ & (2.066) & $(54.47)$ & $(13.32)$ & $(21.27)$ & $(188.2)$ \\
\hline \multirow[t]{2}{*}{ \# Schools } & -0.173 & -0.0304 & -16.34 & $2.470^{*}$ & -3.039 & 6.075 \\
\hline & $(0.228)$ & $(0.221)$ & $(11.27)$ & $(1.217)$ & $(1.998)$ & $(5.485)$ \\
\hline \multirow[t]{2}{*}{ Non-Catholics (share) } & $3.003 * *$ & 1.137 & 115.1 & 10.86 & 13.47 & 104.9 \\
\hline & $(1.130)$ & $(2.277)$ & $(157.4)$ & (14.29) & $(15.92)$ & (188.3) \\
\hline \multirow[t]{2}{*}{ Cultivated area (share) } & 0.533 & -0.0359 & 104.2 & $-20.14 * *$ & $20.39 *$ & 19.25 \\
\hline & $(0.421)$ & $(1.265)$ & $(117.3)$ & $(8.556)$ & $(10.82)$ & $(41.32)$ \\
\hline \multirow[t]{2}{*}{ Labor productivity (nominal) } & 0.000846 & 0.00197 & 0.127 & 0.00761 & 0.0321 & -0.000161 \\
\hline & $(0.00142)$ & $(0.00143)$ & $(0.0788)$ & $(0.0134)$ & $(0.0278)$ & $(0.103)$ \\
\hline \multirow[t]{2}{*}{ Occupational distributon ${ }^{1}$} & Yes & Yes & Yes & Yes & Yes & Yes \\
\hline & POLS & $\mathrm{FE}$ & $\mathrm{FE}$ & FE & POLS & FE \\
\hline Observations & 49 & 49 & 49 & 49 & 49 & 49 \\
\hline Within/Adj. $\mathrm{R}^{2}$ & 0.303 & 0.679 & 0.728 & 0.825 & 0.564 & 0.565 \\
\hline Groups by colony & - & 11 & 11 & 11 & - & 11 \\
\hline
\end{tabular}

Notes: (1) Occupational distribution: categories presented in the main text; (2) Besides reported variables, all regressions include a constant, the number of workers in the administration of the colonies, the total number of professions registered in a colony and the number of other expatriates in the settlement colonies; (3) Clustered standard errors at the level of settlement colonies; (4) POLS estimates include the variable ID colony, a categorical control for each settlement colony in the sample, corresponding to the FE of the other estimations; please notice that this variable is not the same as the policy indicator (ID settl.) reported in the main table for the municipalities in 1872 . *, $* *$ and $* * *$ indicate $\mathrm{p}<0.10, \mathrm{p}<0.05$ and $\mathrm{p}<0.01$, respectively. 
Table A1.3 - Bonferroni corrections - municipalities (1872): $\mathrm{p}_{\mathrm{i}}=0.1 / 19^{1}$

\begin{tabular}{lccccccc}
\hline & Germans & Swiss & Portug. & French & English & Amer. & Italians \\
\hline Foreign land & -4.094 & -0.320 & 1.270 & 0.0999 & -0.394 & $2.395 \#$ & -0.228 \\
& {$[0.0275]$} & {$[0.5917]$} & {$[0.4227]$} & {$[0.5407]$} & {$[0.3857]$} & {$[-0.0053]$} & {$[0.4447]$} \\
Foreign land*(ID bonded) & 9.979 & 6.682 & 8.625 & 0.999 & 0.487 & $-3.505 \#$ & 3.063 \\
& {$[0.2997]$} & {$[0.1117]$} & {$[0.2637]$} & {$[0.2387]$} & {$[0.7107]$} & {$[-0.0051]$} & {$[0.0967]$} \\
Foreign land*(ID settl) & $-201.1 \#$ & 31.54 & -135.7 & -12.43 & $84.35 \#$ & $-56.62 \#$ & -4.136 \\
& {$[-0.0043]$} & {$[0.0957]$} & {$[0.0003]$} & {$[0.0289]$} & {$[-0.0053]$} & {$[-0.0053]$} & {$[0.7367]$} \\
Agr L & 0.00392 & 0.00325 & 0.00403 & 0.00297 & 0.00274 & -0.00192 & -0.00138 \\
& {$[0.6867]$} & {$[0.3617]$} & {$[0.7057]$} & {$[0.1077]$} & {$[0.3797]$} & {$[0.2297]$} & {$[0.6707]$} \\
Agr L*(ID bonded) & -0.00893 & -0.00109 & 0.0162 & -0.00396 & -0.00545 & -0.00114 & 0.00397 \\
& {$[0.3417]$} & {$[0.7637]$} & {$[0.0525]$} & {$[0.0079]$} & {$[0.0090]$} & {$[0.3107]$} & {$[0.2607]$} \\
Manuf & 0.189 & 0.200 & -0.692 & 0.0932 & 0.225 & 0.0313 & -0.124 \\
& {$[0.7537]$} & {$[0.2497]$} & {$[0.2447]$} & {$[0.2677]$} & {$[0.2767]$} & {$[0.6887]$} & {$[0.4167]$} \\
Manuf*(ID bonded) & -1.222 & -0.209 & 0.907 & -0.0525 & -0.221 & 0.00624 & -0.184 \\
& {$[0.1047]$} & {$[0.3727]$} & {$[0.1997]$} & {$[0.4937]$} & {$[0.3177]$} & {$[0.9447]$} & {$[0.3217]$} \\
Manuf*(ID settl) & $22.76 \#$ & -1.704 & 3.128 & 0.484 & $-11.4 \#$ & 1.081 & 0.409 \\
& {$[-0.0046]$} & {$[0.4357]$} & {$[0.5787]$} & {$[0.4717]$} & {$[-0.0053]$} & {$[0.1077]$} & {$[0.7597]$} \\
Serv & -0.0425 & 0.0634 & -0.378 & 0.0294 & 0.0717 & 0.00571 & -0.0769 \\
& {$[0.8847]$} & {$[0.5407]$} & {$[0.2537]$} & {$[0.6167]$} & {$[0.5387]$} & {$[0.9157]$} & {$[0.6407]$} \\
Serv*(ID bonded) & 0.403 & -0.0777 & -0.234 & 0.0633 & 0.232 & 0.129 & -0.212 \\
& {$[0.4467]$} & {$[0.7137]$} & {$[0.6507]$} & {$[0.3417]$} & {$[0.0465]$} & {$[0.0507]$} & {$[0.1857]$} \\
Serv*(ID settl) & 17.38 & -0.00856 & -7.196 & -0.0597 & $-13.13 \#$ & $-4.278 \#$ & 1.143 \\
& {$[0.0832]$} & {$[0.9927]$} & {$[0.3537]$} & {$[0.9357]$} & {$[-0.0053]$} & {$[-0.0052]$} & {$[0.5557]$} \\
Trade & -1.108 & -0.182 & 1.666 & -0.187 & -0.0712 & -0.0129 & 0.157 \\
& {$[0.1577]$} & {$[0.3807]$} & {$[0.0109]$} & {$[0.0500]$} & {$[0.5947]$} & {$[0.8947]$} & {$[0.3527]$} \\
Trade*(ID bonded) & 1.808 & 0.221 & -1.906 & $0.262 \#$ & 0.386 & 0.165 & -0.101 \\
Trade*(ID settl) & {$[0.0878]$} & {$[0.4387]$} & {$[0.0286]$} & {$[-0.0008]$} & {$[0.0234]$} & {$[0.0938]$} & {$[0.5217]$} \\
& -21.46 & 1.180 & 1.712 & 0.0853 & $12.53 \#$ & 0.848 & -0.491 \\
& {$[0.0007]$} & {$[0.6117]$} & {$[0.7837]$} & {$[0.9007]$} & {$[-0.0053]$} & {$[0.2507]$} & {$[0.7367]$} \\
\hline
\end{tabular}


Table A1.3 (Ctd.)

\begin{tabular}{|c|c|c|c|c|c|c|c|c|c|c|c|c|}
\hline & Austr. & Danish & Spanish & Dutch & Belgians & Swedes & Russians & Orient. & Chinese & Argent. & Boliv. & Parag. \\
\hline \multirow[t]{2}{*}{ Foreign land } & $-0.476 \#$ & 0.00234 & -0.00815 & 0.00338 & 0.00172 & 0.0251 & $-0.0856 \#$ & -0.00152 & 0.0328 & -0.00230 & 0.0100 & 0.0171 \\
\hline & {$[-0.0053]$} & {$[0.7527]$} & {$[0.9547]$} & {$[0.8887]$} & {$[0.9607]$} & {$[0.5587]$} & {$[-0.0024]$} & {$[0.8677]$} & {$[0.2207]$} & {$[0.6667]$} & {$[0.7487]$} & {$[0.3897]$} \\
\hline \multirow{2}{*}{ Foreign land*(ID bonded) } & -0.271 & -0.0137 & -0.957 & 0.417 & $0.962 \#$ & -0.230 & -0.0262 & 0.0508 & -0.181 & -0.00791 & 0.302 & -0.0843 \\
\hline & {$[0.3227]$} & {$[0.6467]$} & {$[0.1447]$} & {$[0.0262]$} & {$[-0.0052]$} & {$[0.4737]$} & {$[0.7267]$} & {$[0.2437]$} & {$[0.0722]$} & {$[0.7477]$} & {$[0.0760]$} & {$[0.4397]$} \\
\hline \multirow[t]{2}{*}{ Foreign land*(ID settl) } & $-5.977 \#$ & -1.035 & -0.550 & 0.681 & 1.196 & 1.208 & $-2.174 \#$ & -0.644 & -0.0884 & $-0.758 \#$ & 0.898 & -1.090 \\
\hline & {$[-0.0009]$} & [0.1467] & {$[0.8907]$} & [0.4637] & {$[0.4417]$} & {$[0.5307]$} & {$[-0.0026]$} & {$[0.0555]$} & {$[0.9117]$} & {$[-0.0020]$} & {$[0.4727]$} & [0.1037] \\
\hline \multirow[t]{2}{*}{ Agr L } & -0.000561 & $3.07 \mathrm{e}-05$ & 0.000321 & $4.12 \mathrm{e}-05$ & 0.000428 & -0.000294 & -0.000113 & $4.79 \mathrm{e}-06$ & $-2.65 e-05$ & $-5.00 e-05$ & 0.000311 & -0.000217 \\
\hline & [0.2147] & {$[0.6187]$} & [0.7807] & {$[0.8627]$} & [0.3637] & {$[0.5477]$} & [0.4597] & {$[0.9547]$} & {$[0.8877]$} & [0.4567] & {$[0.4127]$} & [0.4387] \\
\hline \multirow[t]{2}{*}{ Agr L*(ID bonded) } & 0.000539 & -0.000161 & $-7.17 \mathrm{e}-05$ & -0.000187 & -0.00100 & -0.000772 & $8.78 \mathrm{e}-05$ & $2.75 \mathrm{e}-05$ & $7.19 \mathrm{e}-05$ & $5.18 \mathrm{e}-05$ & $-0.00119 \#$ & 0.000174 \\
\hline & [0.1047] & {$[0.0697]$} & [0.9247] & [0.2967] & {$[0.0013]$} & {$[0.0191]$} & {$[0.4477]$} & {$[0.7477]$} & {$[0.6147]$} & [0.2317] & {$[-0.0047]$} & [0.3187] \\
\hline \multirow[t]{2}{*}{ Manuf } & -0.0230 & 0.00519 & 0.0291 & 0.0226 & 0.00828 & 0.0491 & -0.00553 & 0.000590 & -0.0195 & -0.000939 & 0.00123 & 0.00430 \\
\hline & {$[0.2417]$} & {$[0.2907]$} & {$[0.6717]$} & {$[0.1887]$} & {$[0.6117]$} & [0.2247] & {$[0.4157]$} & {$[0.8737]$} & {$[0.0773]$} & [0.6587] & {$[0.9247]$} & [0.6537] \\
\hline \multirow[t]{2}{*}{ Manuf*(ID bonded) } & 0.0450 & -0.00219 & 0.0865 & -0.0148 & -0.0193 & -0.0183 & -0.00385 & -0.00139 & 0.0370 & -0.00316 & 0.00571 & -0.00509 \\
\hline & {$[0.0947]$} & [0.5097] & [0.3107] & [0.2237] & [0.3597] & [0.3917] & {$[0.7747]$} & [0.7777] & [0.0132] & [0.3307] & {$[0.7057]$} & {$[0.5057]$} \\
\hline \multirow[t]{2}{*}{ Manuf*(ID settl) } & 1.912\# & 0.0689 & 0.179 & -0.0311 & 0.0312 & -0.129 & $0.31 \#$ & 0.0124 & -0.0952 & 0.0449 & 0.0732 & 0.0671 \\
\hline & {$[-0.0053]$} & {$[0.2387]$} & {$[0.7557]$} & [0.7777] & {$[0.8677]$} & [0.5107] & {$[-0.0052]$} & {$[0.7077]$} & {$[0.3867]$} & [0.1607] & {$[0.6437]$} & [0.4637] \\
\hline \multirow[t]{2}{*}{ Serv } & -0.0145 & 0.000913 & 0.0993 & 0.00964 & -0.00625 & 0.0165 & -0.00197 & -0.000770 & 0.000524 & 0.000213 & -0.00979 & -0.000519 \\
\hline & {$[0.2627]$} & {$[0.7537]$} & [0.0191] & {$[0.3217]$} & {$[0.5307]$} & {$[0.4647]$} & [0.6407] & [0.7837] & {$[0.9217]$} & [0.9007] & {$[0.3247]$} & [0.9317] \\
\hline \multirow[t]{2}{*}{ Serv*(ID bonded) } & -0.0157 & 0.00494 & -0.0681 & -0.000833 & 0.0378 & 0.0262 & -0.00725 & -0.000774 & -0.0104 & -0.00214 & $0.0561 \#$ & 0.000757 \\
\hline & {$[0.4677]$} & [0.1347] & {$[0.2067]$} & [0.9397] & {$[0.0725]$} & [0.2097] & [0.3447] & [0.8457] & {$[0.2917]$} & [0.4887] & {$[-0.0020]$} & [0.9337] \\
\hline \multirow[t]{2}{*}{ Serv*(ID settl) } & 3.010\# & 0.0626 & 0.0723 & 0.0488 & 0.244 & 0.0308 & $0.438 \#$ & -0.0138 & -0.252 & 0.00724 & 0.313 & 0.119 \\
\hline & {$[-0.0053]$} & {$[0.2137]$} & [0.9297] & [0.6877] & [0.2967] & [0.8787] & {$[-0.0052]$} & {$[0.7817]$} & {$[0.0715]$} & [0.8697] & {$[0.1307]$} & [0.3387] \\
\hline \multirow[t]{2}{*}{ Trade } & 0.0476 & -0.00290 & 0.0882 & -0.0279 & -0.0307 & -0.0788 & -0.00603 & 0.00708 & 0.0187 & -0.000253 & -0.0206 & 0.00828 \\
\hline & [0.0545] & [0.3037] & {$[0.1437]$} & {$[0.2247]$} & {$[0.2447]$} & [0.1377] & [0.6337] & {$[0.1797]$} & {$[0.1267]$} & [0.9167] & {$[0.3127]$} & [0.4907] \\
\hline \multirow[t]{2}{*}{ Trade*(ID bonded) } & -0.0673 & 0.00746 & -0.101 & 0.0194 & 0.0619 & 0.0700 & -0.00257 & -0.00450 & -0.0423 & 0.00412 & $0.0569 \#$ & 0.00479 \\
\hline & [0.0237] & {$[0.0587]$} & [0.2097] & {$[0.2867]$} & {$[0.0112]$} & {$[0.0748]$} & {$[0.8027]$} & {$[0.3667]$} & {$[0.0066]$} & [0.1247] & {$[-0.0001]$} & [0.6437] \\
\hline \multirow[t]{2}{*}{ Trade*(ID settl) } & $-2.371 \#$ & -0.0549 & -0.132 & 0.0237 & -0.0809 & 0.127 & $-0.320 \#$ & 0.00886 & 0.151 & -0.0164 & -0.150 & -0.0604 \\
\hline & {$[-0.0053]$} & [0.3217] & {$[0.8447]$} & [0.8367] & {$[0.6897]$} & [0.5387] & {$[-0.0051]$} & {$[0.8127]$} & {$[0.2017]$} & {$[0.6467]$} & {$[0.3867]$} & [0.5597] \\
\hline
\end{tabular}

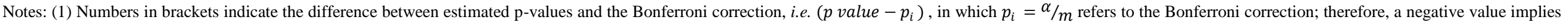

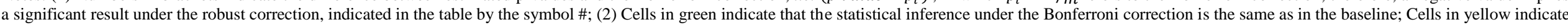
that a significant coefficient in the baseline turned out to be non-significant with the Bonferroni correction. 
Table A1.4 - Bonferroni corrections - settlement colonies (1897-1920): $\mathrm{p}_{\mathrm{i}}=0.1 / 12$

\begin{tabular}{|c|c|c|c|c|c|c|c|c|c|c|c|c|}
\hline & Germans & Portug. & Austr. & French & Spanish & Belgians & Italians & Swedes & Russians & Polish & Syrians & Japanese \\
\hline Manuf. & $\begin{array}{c}0.0531 \\
{[0.6207]}\end{array}$ & $\begin{array}{c}-0.0240 \\
{[0.8377]}\end{array}$ & $\begin{array}{c}-0.422 \\
{[0.0033]}\end{array}$ & $\begin{array}{c}0.0199 \\
{[0.3907]}\end{array}$ & $\begin{array}{c}-0.00839 \\
{[0.9617]}\end{array}$ & $\begin{array}{l}0.00555 \\
{[0.4327]}\end{array}$ & $\begin{array}{c}-0.192 \\
{[0.6547]}\end{array}$ & $\begin{array}{c}-0.00308 \\
{[0.4067]}\end{array}$ & $\begin{array}{c}-0.248 \\
{[0.2117]}\end{array}$ & $\begin{array}{c}-0.0160 \\
{[0.5867]}\end{array}$ & $\begin{array}{c}-0.0314 \\
{[0.5837]}\end{array}$ & $\begin{array}{c}-0.220 \\
{[0.1707]}\end{array}$ \\
\hline Trade & $\begin{array}{c}0.525 \\
{[0.2857]}\end{array}$ & $\begin{array}{c}-0.519 \\
{[0.3827]}\end{array}$ & $\begin{array}{c}-0.346 \\
{[0.5287]}\end{array}$ & $\begin{array}{c}-0.232 \\
{[0.0816]}\end{array}$ & $\begin{array}{c}0.938 \\
{[0.4097]}\end{array}$ & $\begin{array}{l}0.000788 \\
{[0.8867]}\end{array}$ & $\begin{array}{c}-0.148 \\
{[0.6077]}\end{array}$ & $\begin{array}{l}9.67 \mathrm{e}-05 \\
{[0.9847]}\end{array}$ & $\begin{array}{c}-1.126 \\
{[0.0198]}\end{array}$ & $\begin{array}{c}0.129 \\
{[0.1587]}\end{array}$ & $\begin{array}{c}0.282 \\
{[0.1617]}\end{array}$ & $\begin{array}{c}0.942 \\
{[0.2107]}\end{array}$ \\
\hline Other professions & $\begin{array}{c}0.0215 \\
{[0.3997]}\end{array}$ & $\begin{array}{c}-0.0346 \\
{[0.3467]}\end{array}$ & $\begin{array}{c}-0.0443 \\
{[0.0074]}\end{array}$ & $\begin{array}{c}-0.0007 \\
{[0.9277]}\end{array}$ & $\begin{array}{c}0.0303 \\
{[0.4437]}\end{array}$ & $\begin{array}{c}0.000536 \\
{[0.4567]}\end{array}$ & $\begin{array}{r}-0.00172 \\
{[0.9687]}\end{array}$ & $\begin{array}{r}-0.00116 \\
{[0.0865]}\end{array}$ & $\begin{array}{c}-0.0684 \\
{[0.3397]}\end{array}$ & $\begin{array}{r}-0.00102 \\
{[0.6877]}\end{array}$ & $\begin{array}{c}-0.001 \\
{[0.0072]}\end{array}$ & $\begin{array}{r}-0.0235 \\
{[0.5507]}\end{array}$ \\
\hline
\end{tabular}




\section{Tables A1.5 and A1.6 - Explanatory notes}

Table A1.5 reports the partial effects for the interactions between immigration policies and the sector composition of municipalities in 1872. Each numbered row corresponds to a robustness check, as summarized below and explained in the main text:

1. Changes in the demographic data by adding further age categories.

2. Changes in the demographic data by considering marriages with respect to total population.

3. Use of a categorical variable to indicate regions considered insalubrious.

4. Use of a counting variable for the number of widespread diseases in the period 1850-74.

5. Simultaneous incorporation of (3) and (4).

6. Inclusion of the control Municipal budget.

Table A1.6 reports the partial effects of occupational distribution in settlement colonies in 1897 1920. It follows the same structure as Table A1.5.

1. Changes in the mortality indicator by considering casualties only among foreigners.

2. Inclusion of a control for the total number of buildings in a settlement colony.

For details on the robustness checks, see Section 6.3. 
Table A1.5 - Robustness checks: municipalities (1872)

\begin{tabular}{|c|c|c|c|c|c|c|c|c|c|c|c|c|c|c|c|}
\hline & & Manuf. & $\begin{array}{c}\text { Manuf } \\
* \\
\text { (ID bond) }\end{array}$ & $\begin{array}{c}\text { Manuf } \\
* \\
\text { (ID settl) }\end{array}$ & Serv. & $\begin{array}{c}\text { Serv. } \\
* \\
\text { (ID bond) }\end{array}$ & $\begin{array}{c}\text { Serv. } \\
* \\
\text { (ID settl) }\end{array}$ & Trade & $\begin{array}{c}\text { Trade } \\
* \\
\text { (ID bond) }\end{array}$ & $\begin{array}{c}\text { Trade } \\
* \\
\text { (ID settl) }\end{array}$ & Agr.-L & $\begin{array}{c}\text { Agr L } \\
* \\
\text { (ID bond) }\end{array}$ & $\begin{array}{l}\text { Foreign } \\
\text { Farmer }\end{array}$ & $\begin{array}{l}\text { Foreign } \\
\text { land } \\
* \\
\text { (ID bond) }\end{array}$ & $\begin{array}{c}\text { Foreign } \\
\text { land } \\
* \\
\text { (ID settl) }\end{array}$ \\
\hline 1 & & 0.237 & -1.281 & $23.29 * * *$ & 0.0374 & 0.399 & 18.38 & -1.239 & 1.955 & $-22.08 * *$ & 0.00324 & -0.0107 & $-4.356^{*}$ & 9.969 & $-197.4 * * *$ \\
\hline 2 & & 0.231 & -1.120 & $23.37 * * *$ & 0.00396 & 0.505 & 16.28 & -1.055 & 1.859 & $-21.49 * *$ & 0.00682 & -0.0121 & $-3.925^{*}$ & 8.711 & $-208.9 * * *$ \\
\hline 3 & 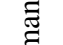 & 0.188 & -1.236 & $22.84 * * *$ & -0.0362 & 0.395 & $17.53^{*}$ & -1.103 & $1.816^{*}$ & $-21.58 * * *$ & 0.00379 & -0.00889 & $-4.135 * *$ & 10.11 & $-200.3 * * *$ \\
\hline 4 & Ẽ & 0.273 & -1.220 & $16.85^{*}$ & 0.118 & 0.189 & 11.09 & -0.940 & 1.787 & -15.11 & 0.00353 & -0.00660 & $-4.028 * *$ & 10.93 & $-166.4 * *$ \\
\hline 5 & & 0.273 & -1.239 & $17.00 *$ & 0.130 & 0.180 & 11.34 & -0.927 & 1.800 & -15.33 & 0.00336 & -0.00662 & $-4.085 * *$ & 11.18 & $-165.7 * *$ \\
\hline 6 & & -0.642 & -1.498 & $144.9^{*}$ & -1.289 & 0.0764 & 30.84 & -2.215 & 1.905 & $-115.1 *$ & -0.0132 & -0.000250 & $-16.87 * *$ & -4.553 & \\
\hline 1 & & 0.185 & -0.171 & -1.352 & 0.0761 & -0.0430 & 0.737 & -0.179 & 0.194 & 0.697 & 0.00304 & -0.00175 & -0.368 & 6.219 & 33.46 \\
\hline 2 & & 0.226 & -0.202 & -1.752 & 0.0780 & -0.0490 & -0.304 & -0.178 & 0.239 & 1.320 & 0.00348 & -0.00174 & -0.259 & 6.547 & 30.81 \\
\hline 3 & $\tilde{n}$ & 0.197 & -0.205 & -1.663 & 0.0486 & -0.0730 & 0.000313 & -0.202 & 0.215 & 1.173 & 0.00328 & -0.000975 & -0.301 & 6.487 & 30.73 \\
\hline 4 & $\stackrel{3}{n}$ & 0.238 & -0.181 & $-6.613^{*}$ & 0.179 & -0.201 & -4.750 & -0.0447 & 0.189 & 6.298 & 0.00340 & $2.81 \mathrm{e}-05$ & -0.266 & $6.940^{*}$ & $64.96 * *$ \\
\hline 5 & & 0.235 & -0.180 & $-6.567^{*}$ & 0.169 & -0.199 & -4.714 & -0.0584 & 0.186 & $6.268^{*}$ & 0.00340 & 0.000127 & -0.260 & $6.821^{*}$ & $64.50 * *$ \\
\hline 6 & & -0.195 & -0.970 & $57.12 *$ & -0.332 & $-0.989 *$ & 11.00 & -0.427 & 0.312 & $-44.84 * *$ & 0.00228 & 0.0108 & $-6.804 * *$ & 4.863 & \\
\hline 1 & & -0.747 & 0.944 & 3.183 & -0.239 & -0.417 & -10.01 & $1.816^{*}$ & -1.940 & 2.522 & 0.00557 & 0.0170 & 1.101 & 10.05 & $-145.3 * * *$ \\
\hline 2 & & -0.657 & 0.766 & 2.621 & -0.385 & -0.293 & -6.449 & $1.602 * *$ & $-1.896 * *$ & 1.772 & 0.00115 & $0.0182 * *$ & 1.140 & 9.912 & $-130.9 * * *$ \\
\hline 3 & $\stackrel{\dot{00}}{E}$ & -0.664 & 1.018 & 2.083 & -0.331 & -0.193 & -8.854 & $1.768 * *$ & $-1.941 * *$ & 2.968 & 0.00513 & $0.0150^{*}$ & 1.549 & 8.788 & $-138.7 * * *$ \\
\hline 4 & o & -0.889 & 0.919 & 7.923 & -0.543 & 0.0661 & -0.804 & $1.540 * *$ & $-1.863^{*}$ & -3.786 & 0.00597 & 0.0123 & 0.984 & 6.655 & $-151.8 * *$ \\
\hline 5 & & -0.867 & 1.030 & 6.582 & -0.502 & 0.101 & -2.707 & $1.635 * *$ & $-1.906 *$ & -2.208 & 0.00708 & 0.0112 & 1.261 & 6.654 & $-152.3^{*}$ \\
\hline 6 & & -0.194 & 5.645 & -295.1 & 0.889 & 1.120 & -87.22 & 3.095 & -4.288 & 244.8 & 0.0539 & 0.000133 & 30.30 & 23.36 & \\
\hline 1 & & -0.0196 & 0.0394 & $1.944 * * *$ & -0.00648 & -0.0165 & $3.056 * * *$ & 0.0405 & -0.0561 & $-2.404 * * *$ & -0.000619 & 0.000392 & $-0.495 * * *$ & -0.255 & $-5.758 * *$ \\
\hline 2 & & -0.0224 & 0.0417 & $1.909 * * *$ & -0.0145 & -0.0153 & $3.030 * * *$ & $0.0462 *$ & $-0.0652 * *$ & $-2.374 * * *$ & -0.000603 & 0.000554 & $-0.476 * * *$ & -0.234 & $-6.009 * * *$ \\
\hline 3 & $\dot{\dot{H}}$ & -0.0224 & 0.0437 & $1.905 * * *$ & -0.0112 & -0.0169 & $3.012 * * *$ & $0.0520 * *$ & $-0.0657 * *$ & $-2.373 * * *$ & -0.000573 & 0.000516 & $-0.481 * * *$ & -0.227 & $-5.787 * * *$ \\
\hline 4 & $\bar{Z}$ & -0.0252 & 0.0452 & $2.012 * * *$ & -0.0175 & -0.0106 & $3.126 * * *$ & $0.0445 *$ & $-0.0665 * *$ & $-2.481 * * *$ & -0.000540 & 0.000474 & $-0.479 * * *$ & -0.299 & $-6.466 * *$ \\
\hline 5 & & -0.0248 & 0.0440 & $2.011 * * *$ & -0.0144 & -0.0115 & $3.135 * * *$ & $0.0485 *$ & $-0.0650 * *$ & $-2.489 * * *$ & -0.000550 & 0.000450 & $-0.483 * * *$ & -0.258 & $-6.317 * *$ \\
\hline 6 & & 0.00345 & -0.0168 & 0.259 & -0.00686 & -0.00377 & -0.109 & 0.0353 & -0.0245 & -0.157 & $-5.25 e-05$ & $0.000347 *$ & -0.0291 & 0.112 & \\
\hline 1 & & 0.118 & -0.102 & 0.130 & -0.00275 & 0.0923 & -0.116 & $-0.201 *$ & $0.289 * *$ & 0.351 & 0.00263 & $-0.00387 * *$ & 0.195 & 1.104 & $-12.03 * *$ \\
\hline 2 & & 0.0977 & -0.0469 & 0.300 & 0.0281 & 0.0742 & -0.196 & $-0.184 *$ & $0.262 * * *$ & 0.270 & 0.00266 & $-0.00392 * *$ & 0.151 & 0.973 & $-11.60 *$ \\
\hline 3 & 氖 & 0.0891 & -0.0674 & 0.625 & 0.0233 & 0.0573 & 0.161 & $-0.199 *$ & $0.266 * * *$ & -0.0837 & 0.00282 & $-0.00378 * *$ & 0.0618 & 0.989 & $-12.06 * *$ \\
\hline 4 & 矛 & 0.0963 & -0.0593 & 1.038 & 0.0188 & 0.0668 & 0.395 & $-0.202^{*}$ & $0.265 * * *$ & -0.470 & 0.00285 & $-0.00392 * *$ & 0.102 & 1.075 & $-16.94 * *$ \\
\hline 5 & & 0.0923 & -0.0739 & 1.234 & 0.0113 & 0.0622 & 0.661 & $-0.216^{* *}$ & $0.270 * * *$ & -0.693 & 0.00270 & $-0.00375 * *$ & 0.0661 & 1.062 & $-17.05 * *$ \\
\hline 6 & & 0.0168 & -0.229 & -4.461 & -0.215 & 0.118 & -3.234 & -0.572 & 0.432 & 4.718 & 0.00477 & -0.00435 & 0.758 & 1.141 & \\
\hline
\end{tabular}


Table A1.5 (Ctd.)

\begin{tabular}{|c|c|c|c|c|c|c|c|c|c|c|c|c|c|c|c|}
\hline & & Manuf. & $\begin{array}{c}\text { Manuf } \\
* \\
\text { (ID bond) }\end{array}$ & $\begin{array}{c}\text { Manuf } \\
* \\
\text { (ID settl) }\end{array}$ & Serv. & $\begin{array}{c}\text { Serv. } \\
* \\
\text { (ID bond) }\end{array}$ & $\begin{array}{c}\text { Serv. } \\
* \\
\text { (ID settl) }\end{array}$ & Trade & $\begin{array}{c}\text { Trade } \\
* \\
\text { (ID bond) }\end{array}$ & $\begin{array}{c}\text { Trade } \\
* \\
\text { (ID settl) }\end{array}$ & Agr.-L & $\begin{array}{c}\text { Agr L } \\
* \\
\text { (ID bond) }\end{array}$ & $\begin{array}{c}\text { Foreign } \\
\text { Farmer }\end{array}$ & $\begin{array}{c}\text { Foreign } \\
\text { land } \\
* \\
\text { (ID bond) }\end{array}$ & $\begin{array}{c}\text { Foreign } \\
\text { land } \\
* \\
\text { (ID settl) }\end{array}$ \\
\hline 1 & & 0.00595 & -0.00321 & 0.0620 & 0.000240 & 0.00433 & 0.0572 & -0.00438 & 0.00875 & -0.0477 & $3.22 \mathrm{e}-05$ & $-0.000148 *$ & 0.00293 & -0.00772 & -1.028 \\
\hline 2 & & 0.00517 & -0.00313 & 0.0754 & 0.000964 & 0.00449 & 0.0723 & -0.00332 & $0.00781 *$ & -0.0628 & $3.33 \mathrm{e}-05$ & $-0.000158 *$ & $-1.80 \mathrm{e}-05$ & -0.00501 & -1.069 \\
\hline 3 & . & 0.00512 & -0.00238 & 0.0711 & 0.000764 & 0.00487 & 0.0658 & -0.00316 & $0.00749^{*}$ & -0.0572 & $2.88 \mathrm{e}-05$ & $-0.000159^{*}$ & 0.00189 & -0.0147 & -1.033 \\
\hline 4 & อี & 0.00535 & -0.00196 & 0.0346 & 0.00170 & 0.00413 & 0.0300 & -0.00189 & $0.00721^{*}$ & -0.0192 & $3.23 \mathrm{e}-05$ & $-0.000154 *$ & 0.00264 & -0.0130 & -0.797 \\
\hline 5 & & 0.00529 & -0.00219 & 0.0378 & 0.00156 & 0.00407 & 0.0342 & -0.00214 & $0.00726^{*}$ & -0.0227 & $3.00 \mathrm{e}-05$ & $-0.000152 *$ & 0.00209 & -0.0135 & -0.800 \\
\hline 6 & & -0.00260 & 0.00247 & 0.202 & -0.00326 & 0.00439 & 0.140 & -0.00539 & 0.00453 & -0.180 & $-3.77 \mathrm{e}-05$ & $-8.01 \mathrm{e}-05$ & -0.0288 & -0.0576 & \\
\hline 1 & & -0.0177 & $0.179 * *$ & 0.341 & $0.0724 * *$ & -0.0908 & -0.0669 & 0.140 & $-0.204 *$ & -0.227 & 0.00105 & 0.000848 & 0.0244 & -1.247 & -1.950 \\
\hline 2 & & 0.0225 & 0.0832 & 0.281 & $0.0977 * *$ & -0.0728 & 0.184 & 0.0861 & -0.0993 & -0.239 & 0.000476 & $-5.90 \mathrm{e}-05$ & -0.0331 & -0.911 & -1.059 \\
\hline 3 & $\overline{\underline{n}}$ & 0.0319 & 0.0986 & 0.0729 & $0.102 * *$ & -0.0630 & -0.0989 & 0.0958 & -0.105 & -0.000613 & 0.000441 & -0.000196 & 0.0235 & -0.969 & -0.924 \\
\hline 4 & है & 0.0237 & 0.0845 & 0.698 & $0.0862 * *$ & -0.0511 & 0.603 & 0.0725 & -0.0971 & -0.682 & 0.000341 & -0.000256 & -0.0163 & $-1.011^{*}$ & -3.797 \\
\hline 5 & & 0.0265 & 0.0974 & 0.541 & $0.0899 *$ & -0.0467 & 0.383 & 0.0809 & -0.102 & -0.497 & 0.000469 & -0.000371 & 0.0167 & $-1.032 *$ & -3.832 \\
\hline 6 & & 0.147 & 0.655 & -20.55 & $0.309^{*}$ & 0.236 & 1.097 & 0.227 & -0.289 & $14.50 *$ & -0.000496 & -0.00392 & $1.811^{*}$ & -2.024 & \\
\hline 1 & & 0.0180 & -0.00868 & -0.0652 & 0.00266 & -0.000506 & -0.0273 & -0.0169 & 0.00623 & 0.0659 & 0.000108 & $-3.67 e-05$ & 0.0243 & $0.412 * *$ & 0.331 \\
\hline 2 & & 0.0229 & -0.0144 & -0.0558 & 0.00926 & $-4.34 \mathrm{e}-05$ & 0.0359 & -0.0277 & 0.0189 & 0.0462 & $-9.13 e-06$ & -0.000167 & 0.00879 & $0.417 * *$ & 0.815 \\
\hline 3 & $\overline{0}$ & 0.0225 & -0.0143 & -0.0308 & 0.00873 & -0.000415 & 0.0457 & -0.0290 & 0.0189 & 0.0261 & $4.62 \mathrm{e}-05$ & -0.000183 & 0.00529 & $0.404 * *$ & 0.620 \\
\hline 4 & $\overline{\bar{\Xi}}$ & 0.0231 & -0.0138 & -0.172 & 0.0128 & -0.00385 & -0.0829 & -0.0237 & 0.0184 & 0.169 & $5.05 e-05$ & -0.000162 & 0.00439 & $0.417 * *$ & 1.676 \\
\hline 5 & & 0.0230 & -0.0134 & -0.173 & 0.0120 & -0.00357 & -0.0867 & -0.0247 & 0.0179 & 0.173 & $5.42 \mathrm{e}-05$ & -0.000157 & 0.00591 & $0.406^{* *}$ & 1.637 \\
\hline 6 & & 0.0154 & -0.0446 & 2.422 & 0.000548 & -0.0531 & 0.143 & -0.0382 & 0.0228 & -1.764 & -0.000189 & 0.000537 & -0.195 & 0.263 & \\
\hline 1 & & 0.00330 & -0.0153 & -0.0704 & $-0.0159 *$ & 0.0283 & -0.0340 & -0.0142 & $0.0470^{*}$ & 0.0699 & $0.000595^{*}$ & $-0.000652 * *$ & 0.0346 & $1.055 * * *$ & 0.237 \\
\hline 2 & & 0.00932 & -0.0210 & 0.00123 & -0.00655 & $0.0383 *$ & 0.241 & -0.0314 & $0.0621 * *$ & -0.0580 & 0.000342 & $-0.000963 * * *$ & 0.00593 & $0.983 * * *$ & 1.355 \\
\hline 3 & 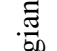 & 0.00889 & -0.0174 & 0.0113 & -0.00508 & $0.0385^{*}$ & 0.214 & -0.0286 & $0.0615^{* *}$ & -0.0581 & 0.000447 & $-0.00103 * * *$ & 0.00636 & $0.968 * * *$ & 1.167 \\
\hline 4 & $\frac{b 0}{D}$ & 0.00876 & -0.0177 & -0.172 & -0.00179 & $0.0339 *$ & 0.0571 & -0.0248 & $0.0604 * *$ & 0.128 & 0.000445 & $-0.000971 * * *$ & 0.00290 & $0.959 * * *$ & 2.657 \\
\hline 5 & & 0.00936 & -0.0159 & -0.198 & -0.000311 & $0.0343 *$ & 0.0230 & -0.0223 & $0.0601 * *$ & 0.157 & 0.000463 & $-0.000997 * * *$ & 0.00692 & $0.968 * * *$ & 2.697 \\
\hline 6 & & -0.0481 & 0.121 & -1.850 & -0.0196 & 0.0429 & 2.056 & -0.0241 & -0.0211 & 0.681 & $4.03 e-05$ & -0.000795 & -0.122 & 0.617 & \\
\hline 1 & & 0.0697 & 0.0584 & $-11.11 * * *$ & -0.0162 & 0.195 & $-13.90 * * *$ & 0.156 & 0.0324 & $12.46^{* * *}$ & 0.00485 & -0.00269 & -0.196 & -0.349 & $78.72 * * *$ \\
\hline 2 & & 0.215 & -0.210 & $-11.35 * * *$ & 0.0685 & $0.239 * *$ & $-13.11 * * *$ & -0.0677 & $0.389 * *$ & $12.51 * * *$ & 0.00293 & $-0.00555 * *$ & -0.379 & 0.434 & $83.89 * * *$ \\
\hline 3 & : & 0.232 & -0.194 & $-11.67 * * *$ & 0.0825 & $0.243 * *$ & $-13.54 * * *$ & -0.0491 & $0.379 * *$ & $12.85^{* * * *}$ & 0.00301 & $-0.00577 * *$ & -0.325 & 0.503 & $83.72 * * *$ \\
\hline 4 & ธ్ & 0.227 & -0.228 & $-10.72 * * *$ & 0.0587 & $0.238 * *$ & $-12.55^{* * *}$ & -0.0900 & $0.390 * *$ & $11.84 * * *$ & 0.00261 & $-0.00543 * *$ & -0.392 & 0.560 & $78.95 * * *$ \\
\hline 5 & & 0.234 & -0.200 & $-11.11 * * *$ & 0.0718 & $0.247 * *$ & $-13.07 * * *$ & -0.0647 & $0.382 * *$ & $12.29 * * *$ & 0.00291 & $-0.00574 * *$ & -0.320 & 0.566 & $79.17 * * *$ \\
\hline 6 & & 0.429 & $3.309 *$ & $-123.9 *$ & 0.484 & $2.371^{*}$ & 30.52 & 0.593 & -1.119 & $79.58 *$ & -0.0148 & $-0.0204^{*}$ & $5.350 *$ & -11.16 & \\
\hline
\end{tabular}


Table A1.5 (Ctd.)

\begin{tabular}{|c|c|c|c|c|c|c|c|c|c|c|c|c|c|c|c|}
\hline & & Manuf. & $\begin{array}{c}\text { Manuf } \\
\quad * \\
\text { (ID bond) }\end{array}$ & $\begin{array}{c}\text { Manuf } \\
* \\
\text { (ID settl) }\end{array}$ & Serv. & $\begin{array}{c}\text { Serv. } \\
* \\
\text { (ID bond) }\end{array}$ & $\begin{array}{c}\text { Serv. } \\
* \\
\text { (ID settl) }\end{array}$ & Trade & $\begin{array}{c}\text { Trade } \\
* \\
\text { (ID bond) }\end{array}$ & $\begin{array}{c}\text { Trade } \\
* \\
\text { (ID settl) }\end{array}$ & Agr.-L & $\begin{array}{c}\text { Agr L } \\
* * \\
\text { (ID bond) }\end{array}$ & $\begin{array}{l}\text { Foreign } \\
\text { Farmer }\end{array}$ & $\begin{array}{c}\text { Foreign } \\
\text { land } \\
* \\
\text { (ID bond) }\end{array}$ & $\begin{array}{c}\text { Foreign } \\
\text { land } \\
* \\
\text { (ID settl) }\end{array}$ \\
\hline 1 & & 0.00784 & 0.0312 & 0.921 & -0.0220 & $0.149 *$ & $-4.569 * * *$ & 0.0558 & 0.0969 & 1.018 & -0.00177 & -0.000694 & $2.504 * * *$ & $-3.562 * * *$ & $-58.15 * * *$ \\
\hline 2 & & 0.0211 & 0.00595 & 1.040 & -0.00200 & 0.0973 & $-4.197 * * *$ & -0.0124 & 0.135 & 0.816 & -0.00218 & -0.000573 & $2.342 * * *$ & $-3.537 * * *$ & $-55.10 * * *$ \\
\hline 3 & $\dot{\vec{\Xi}}$ & 0.0302 & 0.00808 & $1.096^{*}$ & $-6.80 e-05$ & $0.131^{*}$ & $-4.275 * * *$ & -0.0205 & 0.162 & 0.846 & -0.00190 & -0.00110 & $2.401 * * *$ & $-3.579 * * *$ & $-56.92 * * *$ \\
\hline 4 & 完 & 0.0257 & 0.00299 & 1.767 & -0.0109 & $0.149 * *$ & $-3.586^{* *}$ & -0.0335 & $0.169^{*}$ & 0.122 & -0.00191 & -0.00135 & $2.382 * * *$ & $-3.552 * * *$ & $-61.00 * * *$ \\
\hline 5 & & 0.0246 & 0.00541 & 1.770 & -0.0171 & $0.151 * *$ & $-3.598 * *$ & -0.0416 & $0.166^{*}$ & 0.135 & -0.00189 & -0.00130 & $2.391 * * *$ & $-3.634 * * *$ & $-61.28 * * *$ \\
\hline 6 & & $0.285^{*}$ & 0.454 & -6.127 & 0.0450 & $0.633^{*}$ & -3.705 & -0.234 & 0.140 & 5.446 & -0.00754 & $-0.00640 *$ & $3.226 * *$ & $-6.060 * *$ & \\
\hline 1 & & -0.105 & -0.219 & 0.558 & -0.0537 & -0.132 & 2.072 & 0.141 & -0.0647 & -0.882 & -0.00233 & 0.00247 & -0.250 & 2.719 & -0.950 \\
\hline 2 & & -0.112 & -0.170 & 0.0846 & -0.0762 & -0.199 & 0.829 & 0.164 & -0.110 & -0.160 & -0.00188 & 0.00403 & -0.149 & $2.919^{*}$ & -2.415 \\
\hline 3 & .ేี & -0.130 & -0.202 & 0.601 & -0.0884 & -0.219 & 1.430 & 0.136 & -0.0976 & -0.711 & -0.00156 & 0.00422 & -0.272 & $3.000 *$ & -3.855 \\
\hline 4 & 䔍 & -0.137 & -0.169 & -0.563 & -0.0609 & -0.210 & 0.421 & 0.185 & -0.109 & 0.460 & -0.00110 & 0.00379 & -0.241 & 2.853 & 4.480 \\
\hline 5 & & -0.331 & -0.509 & -12.04 & $-0.756^{*}$ & -0.312 & -1.945 & -0.758 & 0.197 & 9.766 & 0.00368 & 0.00850 & 0.802 & 3.388 & \\
\hline 6 & & -0.142 & -0.189 & -0.280 & -0.0742 & -0.216 & 0.797 & 0.161 & -0.104 & 0.144 & -0.00130 & 0.00404 & -0.288 & 2.797 & 4.194 \\
\hline 1 & & 0.0488 & -0.0216 & -0.222 & 0.00790 & 0.0255 & -0.121 & -0.0699 & 0.0641 & 0.235 & -0.000250 & $-0.000588^{*}$ & 0.0547 & -0.171 & 0.726 \\
\hline 2 & & 0.0475 & -0.0165 & -0.169 & 0.0148 & 0.0249 & 0.0193 & -0.0780 & $0.0665^{*}$ & 0.158 & -0.000382 & $-0.000691 * *$ & 0.0301 & -0.238 & 1.536 \\
\hline 3 & $\frac{8}{8}$ & 0.0483 & -0.0200 & -0.106 & 0.0144 & 0.0258 & 0.0624 & -0.0821 & $0.0700^{*}$ & 0.102 & -0.000311 & $-0.000738 * *$ & 0.0214 & -0.248 & 1.192 \\
\hline 4 & $\sum_{0}^{\infty}$ & 0.0495 & -0.0195 & -0.0242 & 0.0145 & 0.0271 & 0.119 & -0.0818 & $0.0707^{*}$ & 0.0211 & -0.000313 & $-0.000770 * *$ & 0.0254 & -0.218 & 0.370 \\
\hline 5 & & 0.0488 & -0.0211 & 0.00476 & 0.0122 & 0.0268 & 0.154 & -0.0853 & $0.0707 *$ & -0.00850 & -0.000330 & $-0.000737 * *$ & 0.0220 & -0.236 & 0.295 \\
\hline 6 & & 0.0603 & -0.0193 & 1.204 & 0.0162 & 0.0145 & 0.223 & -0.0859 & 0.0646 & -0.882 & -0.00138 & -0.000197 & 0.0692 & -0.744 & \\
\hline 1 & & -0.00639 & -0.000773 & $0.293 * * *$ & -0.00628 & -0.0121 & $0.392 * * *$ & -0.00706 & -0.00560 & $-0.294 * * *$ & $-4.47 \mathrm{e}-05$ & 0.000217 & $-0.0809 * * *$ & -0.0174 & $-2.309 * * *$ \\
\hline 2 & है & -0.00387 & -0.00402 & $0.292 * * *$ & -0.00142 & -0.00536 & $0.421 * * *$ & -0.00601 & -0.00154 & $-0.301 * * *$ & -0.000141 & $7.07 e-05$ & $-0.0799 * * *$ & -0.0253 & $-2.139 * * *$ \\
\hline 3 & $\cdot \frac{\pi}{5}$ & -0.00519 & -0.00408 & $0.304 * * *$ & -0.000414 & -0.00762 & $0.434 * * *$ & -0.00392 & -0.00199 & $-0.317 * * *$ & -0.000115 & $7.43 e-05$ & $-0.0870 * * *$ & -0.00715 & $-2.101 * * *$ \\
\hline 4 & $\underline{2}$ & -0.00680 & -0.00307 & $0.299 * *$ & -0.00221 & -0.00540 & $0.444 * * *$ & -0.00581 & -0.00264 & $-0.313 * *$ & $-9.29 e-05$ & $5.68 \mathrm{e}-05$ & $-0.0872 * * *$ & -0.0458 & $-1.944 *$ \\
\hline 5 & & -0.00652 & -0.00334 & $0.294 * * *$ & -0.000749 & -0.00572 & $0.443 * * *$ & -0.00383 & -0.00205 & $-0.312 * * *$ & $-9.46 e-05$ & $4.33 \mathrm{e}-05$ & $-0.0886^{* * * *}$ & -0.0277 & $-1.877 *$ \\
\hline 1 & & 0.00386 & -0.00741 & $3.59 \mathrm{e}-05$ & 0.000992 & -0.000908 & -0.0168 & 0.00274 & 0.00284 & 0.0206 & $-3.01 \mathrm{e}-05$ & $-1.50 \mathrm{e}-05$ & -0.00479 & 0.0770 & -0.575 \\
\hline 2 & & 0.000748 & -0.00191 & 0.0122 & -0.000728 & -0.000505 & -0.0110 & 0.00684 & -0.00399 & 0.00862 & $-4.56 \mathrm{e}-07$ & $2.65 \mathrm{e}-05$ & -0.00130 & 0.0570 & $-0.658 *$ \\
\hline 3 & $\dot{\tilde{0}}$ & 0.000719 & -0.00141 & 0.00988 & -0.000228 & -0.000876 & -0.0160 & 0.00783 & -0.00433 & 0.0106 & $4.86 \mathrm{e}-06$ & $2.23 \mathrm{e}-05$ & -0.00180 & 0.0572 & $-0.621 *$ \\
\hline 4 & $\tilde{O}$ & 0.000537 & -0.00220 & 0.104 & -0.00272 & 0.000781 & 0.0686 & 0.00440 & -0.00382 & -0.0848 & $-5.14 \mathrm{e}-06$ & $1.76 \mathrm{e}-05$ & -0.00185 & 0.0545 & $-1.320 * *$ \\
\hline 5 & & 0.000659 & -0.00212 & 0.101 & -0.00224 & 0.000742 & 0.0653 & 0.00510 & -0.00371 & -0.0822 & $-4.05 e-06$ & $1.21 \mathrm{e}-05$ & -0.00186 & 0.0597 & $-1.300 * *$ \\
\hline 6 & & 0.0118 & 0.00486 & 0.139 & -0.00172 & 0.0140 & 0.220 & 0.00521 & -0.00917 & -0.178 & -0.000186 & $-3.97 e-05$ & -0.00456 & -0.0104 & \\
\hline
\end{tabular}


Table A1.5 (Ctd.)

\begin{tabular}{|c|c|c|c|c|c|c|c|c|c|c|c|c|c|c|c|}
\hline & & Manuf. & $\begin{array}{c}\text { Manuf } \\
* \\
\text { (ID bond) }\end{array}$ & $\begin{array}{c}\text { Manuf } \\
* \\
\text { (ID settl) }\end{array}$ & Serv. & $\begin{array}{c}\text { Serv. } \\
* \\
\text { (ID bond) }\end{array}$ & $\begin{array}{c}\text { Serv. } \\
* \\
\text { (ID settl) }\end{array}$ & Trade & $\begin{array}{c}\text { Trade } \\
* \\
\text { (ID bond) }\end{array}$ & $\begin{array}{c}\text { Trade } \\
* \\
\text { (ID settl) }\end{array}$ & Agr.-L & $\begin{array}{c}\text { Agr L } \\
* * \\
\text { (ID bond) }\end{array}$ & $\begin{array}{l}\text { Foreign } \\
\text { Farmer }\end{array}$ & $\begin{array}{c}\text { Foreign } \\
\text { land } \\
* \\
\text { (ID bond) }\end{array}$ & $\begin{array}{c}\text { Foreign } \\
\text { land } \\
* \\
\text { (ID settl) }\end{array}$ \\
\hline 1 & & -0.0183 & $0.0354 *$ & -0.105 & 0.000907 & -0.0147 & $-0.292 *$ & 0.0160 & $-0.0392 * *$ & 0.172 & $-8.24 \mathrm{e}-07$ & 0.000112 & 0.0300 & -0.151 & -0.167 \\
\hline 2 & & $-0.0198 *$ & $0.0351 * *$ & -0.0720 & 0.000725 & -0.0115 & -0.227 & 0.0179 & $-0.0413 * *$ & 0.127 & $1.68 \mathrm{e}-06$ & $6.80 \mathrm{e}-05$ & 0.0264 & -0.164 & -0.216 \\
\hline 3 & 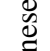 & $-0.0194^{*}$ & $0.0374 * *$ & -0.0981 & 0.000450 & -0.0102 & $-0.257^{*}$ & 0.0187 & $-0.0425^{* *}$ & 0.156 & $-2.23 e-05$ & $6.93 \mathrm{e}-05$ & 0.0341 & $-0.183^{*}$ & -0.109 \\
\hline 4 & : & $-0.0198 *$ & $0.0374 * *$ & -0.119 & 0.000894 & -0.0102 & -0.269 & 0.0194 & $-0.0425 * *$ & 0.175 & $-1.80 \mathrm{e}-05$ & $6.47 \mathrm{e}-05$ & 0.0325 & $-0.188^{*}$ & 0.135 \\
\hline 5 & & $-0.0198^{*}$ & $0.0378 * *$ & -0.124 & 0.000856 & -0.0100 & -0.275 & 0.0194 & $-0.0427 * *$ & 0.180 & $-1.40 \mathrm{e}-05$ & $6.26 \mathrm{e}-05$ & 0.0336 & $-0.190^{*}$ & 0.128 \\
\hline 6 & & -0.0277 & 0.0139 & -0.981 & 0.0154 & -0.0315 & -1.496 & 0.0216 & -0.0237 & 1.227 & 0.000646 & $-9.13 e-05$ & 0.183 & 0.188 & \\
\hline 1 & & -0.00164 & -0.00123 & 0.0504 & -0.000776 & -0.00208 & 0.0193 & -0.000308 & 0.00236 & -0.0242 & $-4.00 \mathrm{e}-05$ & $6.62 \mathrm{e}-05$ & -0.00189 & -0.0211 & $-0.733^{* *}$ \\
\hline 2 & & -0.000671 & -0.00337 & 0.0405 & 0.000236 & -0.00212 & 0.00545 & -0.000317 & 0.00406 & -0.0129 & $-6.14 \mathrm{e}-05$ & $5.62 \mathrm{e}-05$ & -0.00180 & -0.00624 & $-0.732 * * *$ \\
\hline 3 & 远 & -0.000895 & -0.00305 & 0.0436 & 0.000314 & -0.00210 & 0.00532 & $-8.38 \mathrm{e}-05$ & 0.00411 & -0.0149 & $-4.88 \mathrm{e}-05$ & $4.99 \mathrm{e}-05$ & -0.00204 & -0.00720 & $-0.758 * * *$ \\
\hline 4 & $\underset{z}{+\infty}$ & -0.000674 & -0.00311 & 0.0241 & 0.000752 & -0.00289 & -0.0147 & 0.000376 & 0.00397 & 0.00585 & $-5.15 e-05$ & $6.04 \mathrm{e}-05$ & -0.00191 & -0.00494 & $-0.634 * *$ \\
\hline 5 & & -0.000627 & -0.00301 & 0.0224 & 0.000887 & -0.00287 & -0.0168 & 0.000589 & 0.00396 & 0.00766 & $-5.04 \mathrm{e}-05$ & $5.84 \mathrm{e}-05$ & -0.00170 & -0.00391 & $-0.629 * *$ \\
\hline 6 & & -0.00357 & -0.0320 & 0.868 & 0.000632 & -0.0142 & -0.390 & -0.00255 & 0.0197 & -0.478 & $-5.69 \mathrm{e}-05$ & $7.62 \mathrm{e}-05$ & -0.0435 & 0.0882 & \\
\hline 1 & & $-8.93 e-05$ & 0.00517 & -0.000231 & -0.0145 & $0.0464 * *$ & 0.103 & -0.0135 & $0.0523^{* *}$ & -0.0362 & 0.000426 & $-0.000957 * * *$ & 0.0266 & $0.394 * *$ & 0.244 \\
\hline 2 & & 0.00247 & 0.00423 & 0.0443 & -0.00997 & $0.0555^{* * *}$ & 0.306 & -0.0211 & $0.0560 * * *$ & -0.129 & 0.000228 & $-0.00115^{* * *}$ & 0.0121 & $0.316^{*}$ & 1.094 \\
\hline 3 & $\gtreqless$ & 0.00154 & 0.00609 & 0.0653 & -0.00880 & $0.0561 * * *$ & 0.303 & -0.0191 & $0.0571 * * *$ & -0.143 & 0.000315 & $-0.00120 * * *$ & 0.0106 & $0.312 *$ & 0.923 \\
\hline 4 & D̊ & 0.00127 & 0.00640 & -0.00448 & -0.00814 & $0.0548 * * *$ & 0.243 & -0.0183 & $0.0564 * * *$ & -0.0707 & 0.000319 & $-0.00118 * * *$ & 0.0103 & $0.299 *$ & 1.473 \\
\hline 5 & & 0.00156 & 0.00672 & -0.0132 & -0.00707 & $0.0548 * * *$ & 0.233 & -0.0167 & $0.0566^{* * *}$ & -0.0629 & 0.000323 & $-0.00120 * * *$ & 0.0107 & $0.310^{*}$ & 1.515 \\
\hline 6 & & $-0.0484 * * *$ & $0.165 * * *$ & $-4.067 * * *$ & $-0.0357 * * *$ & $0.107 * * *$ & $1.987 * * *$ & $-0.0428 * *$ & -0.0140 & $2.297 * * *$ & $1.83 \mathrm{e}-05$ & $-0.00146^{* * *}$ & $0.111 * *$ & -0.0748 & \\
\hline 1 & & 0.00471 & -0.00624 & 0.0631 & -0.000442 & 0.00190 & 0.122 & 0.00855 & 0.00540 & -0.0586 & -0.000231 & 0.000159 & 0.0183 & -0.0831 & -1.077 \\
\hline 2 & & 0.00473 & -0.00527 & 0.0551 & -0.000602 & 0.000458 & 0.113 & 0.00827 & 0.00413 & -0.0509 & -0.000246 & 0.000191 & 0.0181 & -0.0836 & -1.003 \\
\hline 3 & iె & 0.00474 & -0.00428 & 0.0551 & 0.000686 & 0.000929 & 0.103 & 0.0102 & 0.00483 & -0.0482 & -0.000208 & 0.000156 & 0.0188 & -0.0736 & $-1.074^{*}$ \\
\hline 4 & है & 0.00423 & -0.00616 & 0.188 & -0.00310 & 0.00281 & 0.228 & 0.00474 & 0.00568 & -0.184 & -0.000230 & 0.000161 & 0.0167 & -0.0793 & $-1.985^{*}$ \\
\hline 5 & & 0.00465 & -0.00519 & 0.172 & -0.00190 & 0.00301 & 0.207 & 0.00665 & 0.00562 & -0.167 & -0.000220 & 0.000143 & 0.0187 & -0.0704 & $-1.947 * *$ \\
\hline 6 & & 0.0129 & -0.0179 & 0.642 & 0.0162 & -0.0266 & -0.223 & 0.0463 & -0.00337 & -0.377 & 0.000212 & 0.000287 & -0.0494 & 0.126 & \\
\hline
\end{tabular}
Notes: (1) Estimates for the Hungarians cou
please refer to the explanatory note in p. 76. 
Table A1.6 - Robustness checks: settlement colonies (1897-1920)

\begin{tabular}{|c|c|c|c|c|c|}
\hline Checks & & Manuf. & Trade & Other prof. & Estimator \\
\hline 1 & \multirow{2}{*}{ Germans } & 0.0999 & 0.531 & 0.0132 & $\mathrm{FE}$ \\
\hline 2 & & 0.0575 & 0.477 & 0.0217 & $\mathrm{FE}$ \\
\hline 1 & \multirow{2}{*}{ Portug. } & 0.214 & -0.966 & -0.0411 & $\mathrm{FE}$ \\
\hline 2 & & -0.0231 & -0.530 & -0.0345 & $\mathrm{FE}$ \\
\hline 1 & \multirow{2}{*}{ Austr. } & $-0.687 * * *$ & -0.167 & -0.0352 & FE \\
\hline 2 & & $-0.418 * *$ & -0.395 & $-0.0442 * *$ & $\mathrm{FE}$ \\
\hline 1 & \multirow{2}{*}{ French } & $0.100 * *$ & -0.177 & -0.00224 & POLS \\
\hline 2 & & 0.0118 & -0.132 & -0.000860 & $\mathrm{FE}$ \\
\hline 1 & \multirow{2}{*}{ Spanish } & 0.293 & 1.074 & 0.0716 & FE \\
\hline 2 & & 0.0455 & 0.506 & 0.0336 & FE \\
\hline 1 & \multirow{2}{*}{ Belg. } & 0.000969 & 0.00304 & $-2.92 \mathrm{e}-06$ & POLS \\
\hline 2 & & 0.000477 & 0.00691 & $-7.66 \mathrm{e}-05$ & POLS \\
\hline 1 & \multirow{2}{*}{ Italians } & $-0.980 * *$ & 0.673 & 0.0432 & $\mathrm{FE}$ \\
\hline 2 & & -0.210 & 0.0766 & -0.00190 & $\mathrm{FE}$ \\
\hline 1 & \multirow{2}{*}{ Swedes } & -0.00124 & -0.0242 & $-0.00208 *$ & POLS \\
\hline 2 & & -0.00376 & 0.00799 & -0.00117 & $\mathrm{FE}$ \\
\hline 1 & \multirow{2}{*}{ Russians } & $-0.599 * *$ & $-1.253 * *$ & -0.0983 & $\mathrm{FE}$ \\
\hline 2 & & -0.294 & -0.546 & -0.0733 & $\mathrm{FE}$ \\
\hline 1 & \multirow{2}{*}{ Polish } & -0.0442 & 0.147 & 0.00117 & $\mathrm{FE}$ \\
\hline 2 & & -0.0185 & $0.158 *$ & -0.00108 & $\mathrm{FE}$ \\
\hline 1 & \multirow{2}{*}{ Syrians } & -0.0717 & $0.584 * * *$ & 0.0156 & POLS \\
\hline 2 & & 0.0594 & $0.558 * *$ & 0.0101 & POLS \\
\hline 1 & \multirow{2}{*}{ Japan. } & $-0.409 *$ & 0.807 & -0.00831 & $\mathrm{FE}$ \\
\hline 2 & & -0.125 & 0.175 & -0.0212 & $\mathrm{FE}$ \\
\hline
\end{tabular}

Note: For a precise definition of each robustness check $(1 \& 2)$, please refer to the explanatory note in p. 76. 
Figure 1.2 - Geographic distribution of the main variables of interest (1872)
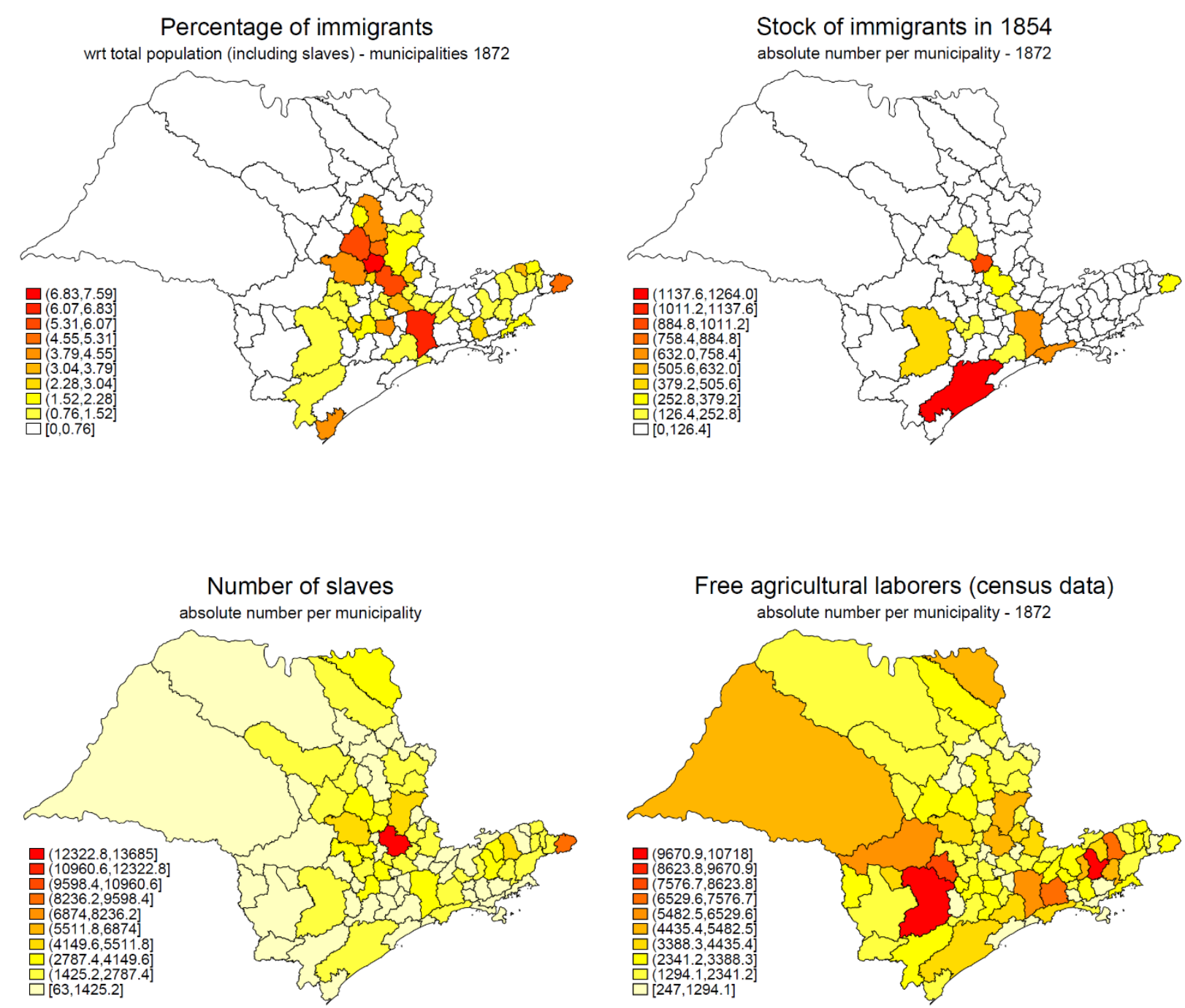

Free agricultural laborers (census data)

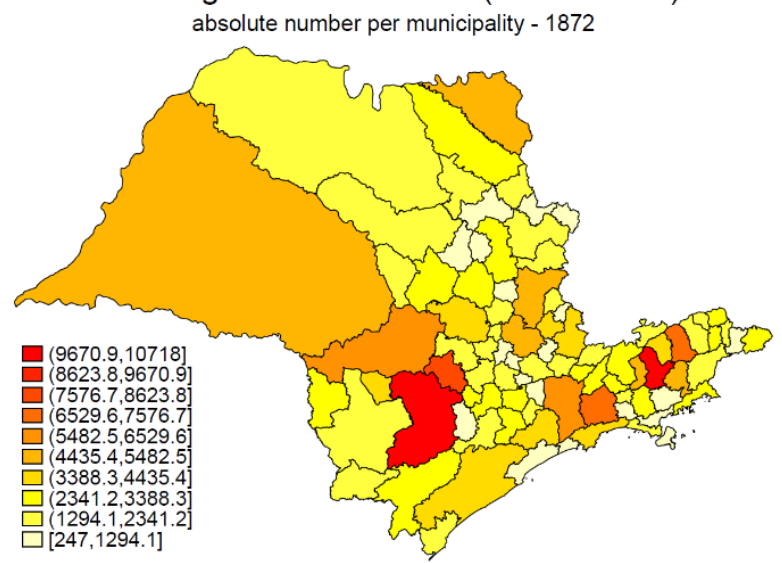


Figure 1.3 - Geographic distribution of the main immigrant nationalities (1872)
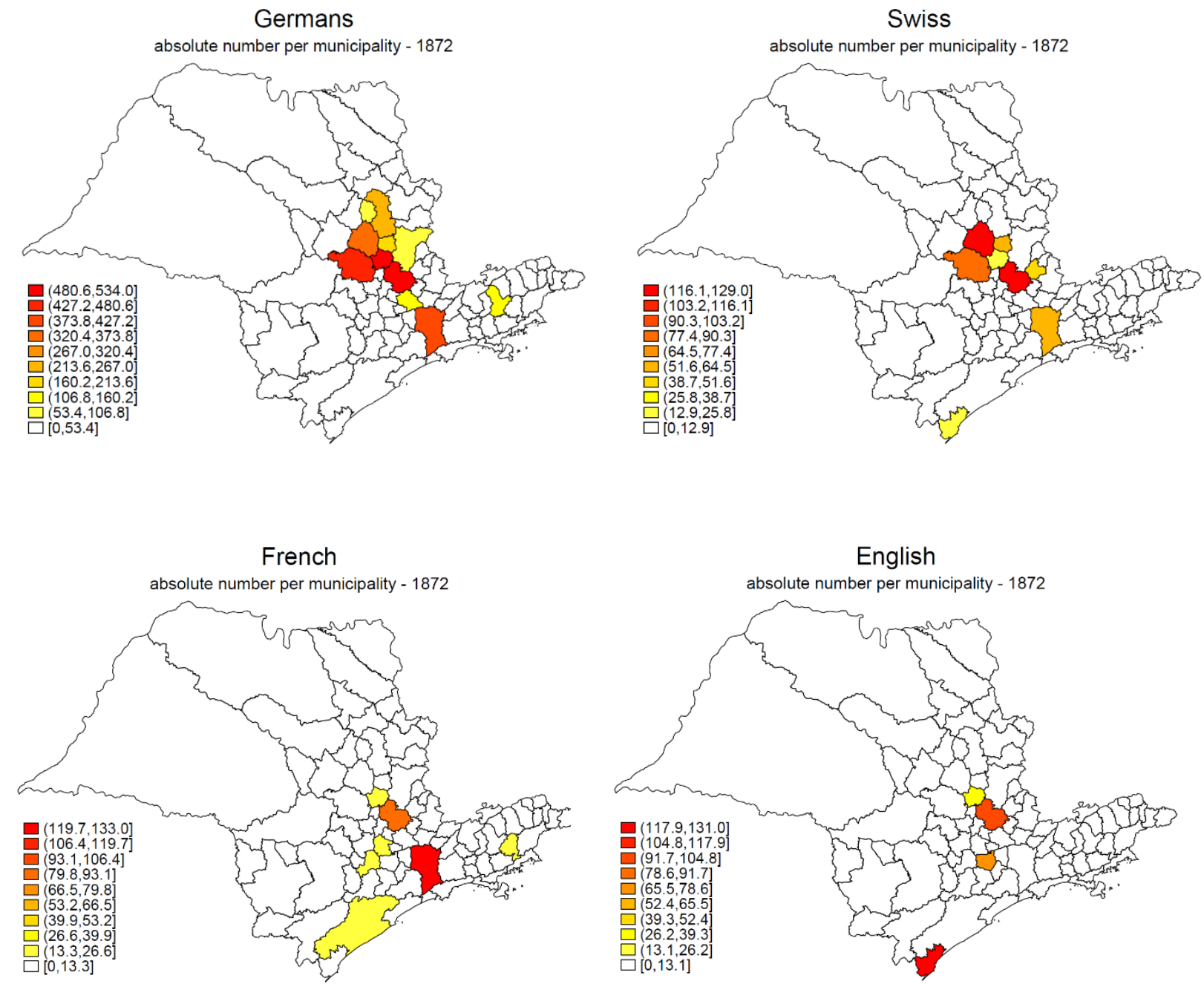
Figure 1.3 (Ctd.)
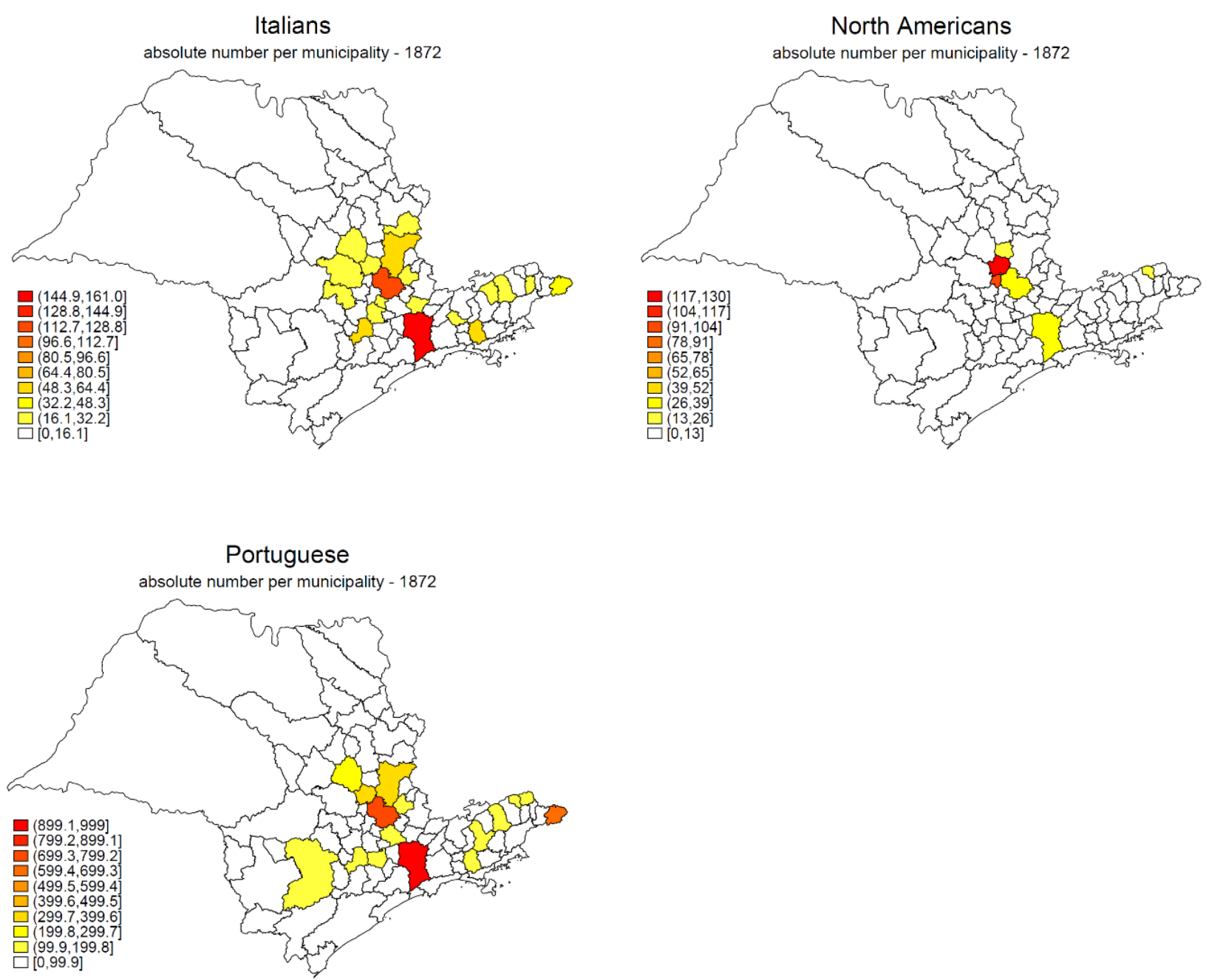



\title{
2. The rationale of sharecropping: immigrant bonded laborers and the transition from slavery in Brazil (1830-1890)
}

\begin{abstract}
Summary
This chapter studies the history of bonded labor in the plantations of São Paulo. Brazilian farmers proposed various contracts to bond immigrant households with a credit-labor interlinkage. The chapter discusses why different labor-rental arrangements were adopted. In particular, vis-à-vis the alternatives of fixed rents and wage systems, it asks why sharecropping contracts were offered to European laborers during the transition from slavery in Brazil. Building on some new historical evidence and a formal model, the chapter makes two propositions about the rationale of bonded labor and sharecropping. First, the credit dimension was more important to landowners than specific labor-rental regimes. The credit supplied by landowners allowed for the tying of immigrants via indebtedness. This mechanism guaranteed a secure and stable supply of labor to local agricultural elites and permitted the immigration of poor and credit-constrained Europeans. This prepared the insertion of Brazil into the global circuit of the Age of Mass Migration without promoting institutional reforms to attract non-bonded immigrants. Second, sharecropping became the most prevalent contract in the first phase of the transition from slavery not because of an economically rational decision taken by landowners, but more as an emulation of other historical and international experiences with this labor-rental arrangement
\end{abstract}





\section{Introduction}

Bonded labor and sharecropping have pervaded the entire history of agricultural production as mechanisms of factor allocation ${ }^{1}$. In particular, indentured servants, redemptioners, indebted peons, coolies and contract laborers played a major role in the settlement of the Americas since the seventeenth century ${ }^{2}$. Europeans and Asians thus immigrated bonded their labor force for a fixed period or until the repayment of the outstanding debts incurred in the process. In a period when high transportation costs and low average incomes in the source countries majorly constrained international migration, these arrangements allowed for the allocation of people to regions with a high land per labor ratio ${ }^{3}$. With the expansion of agricultural frontiers in the nineteenth century, especially in the U.S., sharecropping acquired the similar status of an institution to allocate labor to land. In that context, sharecropping started to be seen as an intermediate rung in the socioeconomic ladder that led from rural employment to landownership. Criticized for its empirical inadequacies and ideological ballast, this hypothesis remains nonetheless resilient to explain the settlement of agricultural frontiers. ${ }^{4}$ In line with such criticism, a different and much less favorable view about sharecropping focuses on the post-Civil War American South ${ }^{5}$. This literature aims at explaining the coexistence of various types of contracts, including sharecropping, in a post-slavery economy.

This chapter contributes to these branches of the literature by studying the combined history of bonded labor and sharecropping in the context of the transition from slavery in Brazil. Studying these questions in the context of the Brazilian transition from slavery also provides some new analytical features of interest ${ }^{6}$. First, the technology of production in coffee plantations differed from that of cotton, sugarcane and winery, which have been the crops mostly studied by the literature on historical sharecropping. Second, the trends in nationalities and immigration

\footnotetext{
${ }^{1}$ For the global history of sharecropping in the long run, see Byres (1983). For classical views on coercion - a stricter category than bonded labor -, see Domar (1970), Evans (1970), Lagerlöf (2009) and Acemoglu and Wolitztky (2011).

${ }^{2}$ Hatton and Williamson (2009, p. 22) and Ferrie and Hatton (2015, pp. 53-6). Eltis (1983) and Donoghue (2013) survey the history of indenture servitude in the Atlantic economy. For the U.S., see Galenson (1981, 1984, 1991), Heavner (1973), Menard (1973), Grubb (1985, 1994), Grubb and Stitt (1994) and Abramitzky and Braggion (2006). For the West Indies, see Roberts and Byrne (1966) and Engerman (1983).

${ }^{3}$ Hatton and Williamson (1994, p. 542; 2009, p. 18), Wegge (2002, p. 370) and Engerman and Margo (2010). Sánchez-Alonso (2007, pp. 408-10) and Engerman and Sokoloff (2011, p. 24) compare indentures in the U.S. to subsidized European immigration to Brazil.

${ }^{4}$ Spillman (1919), Tungeln (1927) and Wehrwein (1931). Cox (1944) first opposed the concept, which Lee and Kaufmann (1997) revisited for the American South; and Engerman and Sokoloff (2011, p. 31) discussed implicitly. ${ }^{5}$ Black and Allen (1937), Taylor (1943), Reid (1973, 1979), Higgs (1974), Alston and Higgs (1982) and Shlomowitz (1984). Alston (1981) and Alston and Ferrie (1985) explain tenure choices in the twentieth century.

${ }^{6}$ The Brazilian historiography on contract labor is very rich. Classical studies include Buarque de Holanda (1941), Witter (1974), Dean (1977), Stolcke and Hall (1983), Lamounier (1986) and Viotti da Costa (1998). The current chapter attempts to update some debates they raised in light of new theoretical and historiographic developments.
} 
policies prevailing in São Paulo tended to run counter those in the U.S. and in the Caribbean ${ }^{7}$. In a period when mass immigration of Europeans to the U.S. was becoming spontaneous, i.e. non-bonded, Europeans in São Paulo were mainly laborers tied to a debt obligation. Relatedly, while the re-emergence of indentures in the Caribbean and South America was mainly related to Asian immigrants, the hiring of Chinese coolies in São Paulo failed throughout the nineteenth century, before the consolidation of the Japanese immigration at the beginning of the twentieth century ${ }^{8}$.

From the 1830s, plantation owners in São Paulo started looking for labor arrangements to substitute the evermore-threatened institution of slavery. The Brazilian ban on the transatlantic slave traffic in 1850 prompted new contractual experiments that aimed at securing a stable and cheap supply of unskilled laborers to the plantations. One of the solutions was to propose different labor-rental contracts interlinked to a credit dimension to poor and credit-constrained European immigrants. Brazilian landowners supplied loans to cover the transportation and installment costs of foreigners, who then bonded the labor of their entire households to the repayment of these debts. In this form of immigrant bonded labor, sharecropping became the most prevalent labor-rental arrangement in the 1850s. Immigrants retained a share of the net profits from harvesting the cash crops - usually coffee - and of their foodstuff cultivation' From the late 1840 s to the early 1870 s, about 8,000 German-speakers were hired as contract laborers to the plantations of São Paulo under this regime ${ }^{10}$. Free Brazilians, Portuguese and other immigrant minorities complemented this non-captive labor force in the plantations ${ }^{11}$.

These experiments were limited in scale, especially if compared to the mass immigration of Italians to the plantations of São Paulo that started in the $1880 \mathrm{~s}^{12}$. Nevertheless, the period 1830-90 witnessed fundamental changes in Brazilian labor markets, inextricably related to the abolition of slavery. Bonded labor was the first non-captive labor arrangement considered acceptable in a plantation system that had been fueled by an elastic supply of African slaves for

\footnotetext{
${ }^{7}$ Eltis (1983), Engerman and Margo (2010) and Engerman and Sokoloff (2011).

${ }^{8}$ Engerman (1983), Hatton (2011, pp. 205-6) and Ferrie and Hatton (2015, pp. 62-4).

${ }^{9}$ I partially follow Premchander et al. (ILO 2014, p. iii) in defining bonded labor as labor tying associated with an outstanding debt. However, I do not follow the definition that bonded labor is a form of forced labor. Bonded labor here is similar to Engerman's (1983, p. 639) indentured labor, an arrangement that "entailed an exchange of transport costs for labor services". However, I differentiate between indentured and contract labor. I understand the former as the bonding of labor for a fixed period and the latter, for a variable period (e.g. via debt obligations). That is how Lamounier (1986, p. 20) differentiates between European contract laborers and Asian coolies in Brazil. ${ }^{10}$ The exact number of German-speakers is disputable (Witzel de Souza, 2012, p. 85). See Heinke (1905, p. 267), Scheler (1905, p. 171), Buarque de Holanda (1941, pp. 27-8), Sommer (1953, V) and Methner (1962, p. 49).

${ }^{11}$ Bassanezi (1998, pp. 395-409).

12 Viotti da Costa (1998, p. 169).
} 
three centuries ${ }^{13}$. Moreover, the experience with bonded labor paved the way to transform São Paulo into a major destination in the Americas during the Age of Mass Migration. The Brazilian expertise in hiring Europeans and the networks of immigrants influenced future migratory flows, especially of German-speakers. Most importantly, the credit-labor interlinkage first tried in this period long outlived the sharecropping contracts. The focus on poor and creditconstrained households became a core strategy of the Brazilian immigration policy. Finally, the clauses of the sharecropping contracts experimented with in this period influenced the formulation of subsequent contracts and those old labor-rental arrangements had long-standing consequences for the Brazilian rural markets deep into the twentieth century.

The Brazilian experience with sharecroppers bonded to a credit obligation raises two questions of interest to the literature. First, considering that sharecropping prevailed as the first noncaptive labor-rental arrangement during the transition from slavery, one is led to inquire about the economic rationale for its adoption at that particular moment. Was the employment of sharecropping a necessary condition for the success of credit the interlinkage or were other labor-rental arrangements also feasible? A branch of the Brazilian historiography has even considered sharecropping as the least efficient labor arrangement because it was applied in the first phases of the transition from slavery, in a period when, allegedly, more efficient arrangements would be unfeasible ${ }^{14}$. The question is thus whether sharecropping had any inherent feature that made it the most adequate labor-rental arrangement for the prevailing circumstances. Furthermore, by noticing that the credit dimension pervaded the entire history of immigration to Brazil in the nineteenth and early twentieth century, the second question deals with the economic and political rationale of the credit-labor interlinkage. To put it more explicitly, the question is whether Brazilian rural elites strategically tailored the country's immigration policy towards poor and credit-constrained European households.

In this context, a conceptual contribution of this chapter is to analyze the historical pervasiveness of the credit-labor interlinkage jointly (i.e. sharecropping bonded-labor), rather than the labor-rental regime separately (i.e. sharecropping only). To this end, I develop a model in which a landowner maximizes his/her rents subjected to the participation constraint of contract laborers. Landowner's rents comprehend two dimensions. The production dimension requires labor for a fixed amount of land and labor can be obtained under sharecropping, fixed

\footnotetext{
${ }^{13}$ Leff (1972, p. 492), Klein (1995, p. 208), Viotti da Costa (1998, pp. 73-4) and Oberacker Jr. (2004, p. 271). For the efficiency of the international allocation of slaves, see Engerman and Sokoloff (2011, pp. 20-1).

${ }^{14}$ Witter $(1973,1974,1982)$, Viotti da Costa (1998), Ianni (2004) and Petrone (2004). See Section 5 for a distinction between their arguments.
} 
rents, or wage systems. The credit dimension allows for the immigration of contract laborers and the resulting indebtedness provides landowners with a control mechanism that was familiar to a slaveholder.

The model shows that sharecropping, fixed rents and wage systems interlinked to a credit dimension can lead to the same per worker costs (PWC), as perceived by landowners in the absence of productivity differentials. This condition is important, as differences in productivity preclude the existence of perfectly competitive labor markets or of less efficient labor arrangements. The historical analysis, in turn, shows the obvious nonexistence of perfectly competitive labor markets and that landowners had no preoccupation with the efficiency of specific labor-rental arrangements in the first phases of the adoption of bonded labor. In complement to the model, the historical evidence thus indicates that landowners were indifferent to specific labor-rental arrangements in the first phases of the transition from slavery. The chapter hence proposes that sharecropping was not a theoretically necessary first step in this process. The consolidation of this labor-rental arrangement resulted mainly from the emulation of other historical and international experiences. Moreover, the credit dimension permitted the immigration of Europeans who otherwise would not have been able to cover the costs. This allowed Brazilian elites to obtain immigrants without promoting institutional reforms to make the country more attractive to non-bonded immigrants. The model shows the feasibility of this approach, as a linear credit-labor interlinkage can lead to the same optimality conditions independent of the labor arrangement chosen. The historical analysis, in turn, provides vast evidence that Brazilian politicians, diplomatic authorities and landowners were well aware of this strategy.

The chapter derives its historical conclusions from a systematic review of the Brazilian Digital Newspapers' Repository. This online platform of the Brazilian National Library Foundation digitized different kinds of periodicals and press material. The Repository currently comprises 6,449 titles from 1740 to 2018 and covers most Brazilian states and some international publications ${ }^{15}$. I created a sample with 20 newspapers of the capital and 20 of the countryside and coastal regions of São Paulo, from which I selected news that contained at least one of 31 terms related to the immigration of contract laborers or rural settlers ${ }^{16}$. In a first round of

\footnotetext{
${ }^{15}$ Available at http://bndigital.bn.gov.br/hemeroteca-digital, accessed last on October 122018.

${ }^{16}$ These 31 terms refer to the roots of the words. The research included adaptations to nineteenth century spelling as well. See Appendix III for a detailed description of these sources and methodology.
} 
selection, I identified $c a$. 11,000 entries related to these themes. I then selected about 2,000 entries, which constitute the primary sources for this chapter.

The historiography on the transition from slavery in Brazil has extensively used newspapers as primary sources; I attempted to indicate all references that used the same news as I did in the footnotes. What this chapter does differently is to benefit from the unification of sources in a single Repository that allows for automatized research, raising the potentials and challenges of big data analyses to the study of qualitative sources ${ }^{17}$. In this chapter, I do not explore the quantitative dimension of the research thus conducted - e.g. I do not quantify the incidence of terms to assess trends of topics per region or over time. However, the automatized search allowed me to group the news thematically, providing a broad overview of similar topics covered in different sources and periods. This approach led to the finding of a document of particular interest to the Brazilian historiography ${ }^{18}$. On January 23, 1836, the newspaper $O$ Paulista Official published a contract of a consortium signed in 1835 to hire German and Swiss immigrants. This contract was a mix between bonded labor and rural settlement, similar to the headright system and homesteading in the U.S. The firm that proposed the consortium was headed by Luiz Vergueiro, son of one of the most important promoters of bonded European immigration to Brazil. Although mentioned en passant by the literature, the current chapter is, to the best of my knowledge, the first to analyze the actual clauses of this contract, which might provide an important benchmark to the history of immigration to Brazil ${ }^{19}$.

The chapter is organized as follows. Section 2 provides a historical contextualization of the transition from slavery in Brazil. It focuses on the alternatives that landowners in São Paulo envisaged to substitute the slaves. Sections 3 and 4 present a chronological analysis of the rise and decline of sharecropping bonded labor in São Paulo. Based on this historical evidence, Section 5 discusses three theoretical propositions: (i) sharecropping was not a necessary first stage in the Brazilian transition from slavery; (ii) its expansion resulted from the path dependence created by the first hirers of immigrants; (iii) the credit interlinkage outlived the specific labor-rental regime of sharecropping. Section 6 concludes with some comparisons between the prevalence of sharecropping in São Paulo and recent research about the historical rationale of this labor-rental arrangement.

\footnotetext{
${ }^{17}$ See the illustrative research lines in Michel et al. (2011) and Shiller (2017). I thank Manuel Santos Silva for the references and debates on this theme.

${ }^{18}$ Marília Jordan obtained this source independently. I thank her readiness in sharing this important document.

${ }^{19}$ Calógeras ([1933] 1998, p. 353) and Castro (n.d., p. 28) mention the 1835 contract, but they do not explore its content, nor its consequences for the history of immigration to Brazil.
} 


\section{Bonded labor and the abolition of slavery in Brazilian coffee plantations}

Brazil is infamous for being the last country in the Americas to abolish slavery. The legal abolition in 1888 was the result of socioeconomic and political changes that matured over almost a century. A myriad of forces influenced this long-termed transition, including the increased resistance of slaves, manifested in mass escapes, conflicts and a daily opposition to captive work ${ }^{20}$; changes in the social perception about slavery bolstered by abolitionists ${ }^{21}$; international pressure in the context of the consolidation of industrial capitalism $^{22}$; and modifications in Brazilian institutions and local labor markets. The transition was gradual and deliberately sluggish, providing enough time for the rural elites, sometimes with diverging regional interests, to weave compromises that safeguarded their investments in captives and granted them alternative sources of labor ${ }^{23}$.

For the purposes of this chapter, it is useful to categorize the history of the transition into two phases $^{24}$. The first spanned until 1850 and aimed at banning the Brazilian transatlantic slave traffic. Economically, the period was characterized by the expansion of the coffee plantations towards the central-western plateau of São Paulo, departing from the older farms in the Paraíba Valley, i.e. the region bordering the province of Rio de Janeiro. The second phase witnessed the passing of laws that gradually led to the unconditional abolition of slavery. This period was marked by the political and economic consolidation of the coffee planters of the central westernplateau of the province ${ }^{25}$. The agricultural frontier, in turn, kept expanding to the west of the São Paulo, gradually reached by the new railway infrastructure, especially after the $1870 \mathrm{~s}^{26}$.

An increasing diplomatic and military pressure from Britain marked the abolition of the Portuguese and Brazilian slave traffic between 1807 - when the British banned slave trade under their own flag - and 1850 - when Brazil started enforcing laws in this direction. Clauses prescribing the ban of the traffic embedded the British recognition of the Brazilian independence in 1822 and were soon followed by similar laws in 1827 and 1831. However, their enforcement was so lax that the Brazilian expression "Law for the English to see" survives until today to describe a dead-letter legislation. As a result, the Aberdeen Act was passed in the UK in 1845. The Act gave the status of piracy to Brazilian ships trafficking slaves and allowed

\footnotetext{
${ }^{20}$ Dean (1977, pp. 90-4, 125-7, 138-46) and Viotti da Costa (1998, Part II, Chapter 3).

${ }^{21}$ Viotti da Costa (1998, Part III - Chapters 1 and 2).

${ }^{22}$ Beiguelman (1967) and Viotti da Costa (1998, pp. 17-9).

${ }^{23}$ See Leff (1972, p. 490) for different regional economic performances in nineteenth century Brazil.

${ }^{24}$ See Engerman and Margo (2010, pp. 298-9) for a similar periodization.

${ }^{25}$ This region corresponds roughly to the category Old-West in the empirical analysis of Chapter 3.

${ }^{26}$ Viotti da Costa (1998, pp. 219-20) and Lamounier (2000).
} 
the British Admiralty to trial the slave-traders. Foreseeing shortages in the supply of slaves, Brazilian landowners invested heavily in the traffic, paradoxically increasing the entries of slaves in this period ${ }^{27}$. The Brazilian public opinion rolled back against this imposition in 1851, when British warships entered Brazilian territorial waters in pursuit of slave-traders ${ }^{28}$.

Under this diplomatic pressure, the Brazilian government approved and started to enforce the ban on slave trade in 1850 . The price of captives rose significantly, even in the face of the increased interprovincial slave trade ${ }^{29}$. The expected shortage in the supply of slaves met an increased demand for labor caused by the expansion of coffee plantations towards the centralwestern plateau in the $1850 \mathrm{~s}^{30}$. Moreover, lacking natural endowments of direct interest to the mercantilist economy of the colonial period - e.g. in comparison to the gold mines of the province of Minas Gerais -, São Paulo had a relatively low stock of slaves in the first decades of the nineteenth century ${ }^{31}$. This relative shortage of captive laborers was especially acute in the central-western plateau by the $1840 \mathrm{~s}^{32}$.

Under these circumstances, landowners had three potential alternative sources of labor ${ }^{33}$.

The most obvious was to indurate slavery and to increase the stock of captives in the agriculturally expanding regions of São Paulo ${ }^{34}$. The economic expertise with this labor arrangement and the socio-political status of slaveholders explain the ferocious attempts of plantation owners in smuggling African slaves until the late 1850s; in promoting the interprovincial traffic of captives; and in fighting for the last remnants of slavery until $1888^{35}$. Nevertheless, the import of African slaves became too risky after 1850, contributing to an increased risk-premium in the price of captives $^{36}$. The interprovincial traffic took pace in the 1860 s, but its costs also grew prohibitively high vis-à-vis the increased demand and as new taxes attempted to restrain the outflow of slaves from Northern Brazil ${ }^{37}$.

\footnotetext{
${ }^{27}$ Ibid. (1998, p. 254).

${ }^{28}$ For a description of the legal and diplomatic consequences of this period, see Viotti da Costa (1998, pp. 74-86).

${ }^{29}$ Dean (1977, p. 66) shows that the prices of male slaves (15-29 years old) in the municipality of Rio Claro rose from 550 mil-réis in 1843 to a peak of 2,300 mil-réis in 1880. See also Viotti da Costa (1998, pp. 49-50, 97-8).

${ }^{30}$ See Witter (1974, pp. 395-9) for a case study of farm Ibicaba.

${ }^{31}$ Laborsaving physical capital was also scarce. For theoretical implications, see Leff (1972, pp. 492-3).

${ }^{32}$ Buarque de Holanda (1941, p. 16) and Viotti da Costa (1998, p. 69).

${ }^{33}$ Witter (1974, p. 398) and Viotti da Costa (1998, pp. 69-71). These alternatives are similar to Engerman and Margo's (2010, pp. 291-9) description of types of laborers employed in the settlement of the U.S.

${ }^{34}$ Viotti da Costa (1998, p. 70).

${ }^{35}$ Ibid. (1998, pp. 86-92). Engerman (1983, p. 644) argues that plantation owners preferred ex-slaves to immigrants due to higher productivity and lower transaction costs in hiring and employing them.

${ }^{36}$ Slaves were smuggled until 1856 (Viotti da Costa, 1998, pp. 85-6).

${ }^{37}$ Dean (1977, pp. 69-73) and Viotti da Costa (1998, pp. 155-7, 256-68).
} 
Consequently, proposals to substitute the slave workforce in the plantations gradually gained political prominence ${ }^{38}$.

A second alternative was to employ free Brazilians. Various forms of peonage and patron-client relations had always coexisted with slavery in the plantations. Free Brazilians tended to be employed in rural activities that involved a high risk of escapes or depreciation of the capital invested in slaves, such as in the cleansing of forestry for the formation of plantations ${ }^{39}$. However, the systematic employment of free Brazilians in ordinary tasks in the coffee plantations of São Paulo was limited by many reasons. The demographic density of São Paulo was low, estimated at about 0.7 inhabitants per square kilometer in the $1820 \mathrm{~s}-30 \mathrm{~s}$. The literature has shown, however, that the absolute supply of Brazilian labor was not low, but only unevenly distributed $^{40}$. Hence, the question remains as to why free Brazilians did not migrate to regions like the central-western plateau of São Paulo. First, because the high land per labor ratio prevailing in some regions did not translate into higher remuneration to labor, as technological barriers impaired gains in labor productivity. Second, the established rural elite imposed institutional constraints that limited access to land, impeding a potentially more efficient distribution of factors ${ }^{41}$. Third, patron-client relations between landowners and freemen living in their orbit of influence limited the mobility of free Brazilians ${ }^{42}$. Finally, in a slave-based economy, physical and rural works were considered socially degrading. The reluctance of locals to accept employment in the plantations reinforced prejudices about the laziness and vagrancy of the Brazilian population; combined with racist arguments, landowners tended to idealize European immigrants, at least until the outbursts of their labor riots ${ }^{43}$.

A third alternative was to increase the supply of labor with immigrants. As shown in Chapter 1, while the central government favored the foundation of rural colonies, plantation owners strived for the immigration of bonded laborers. The bonding of immigrant labor with debt mechanisms first essayed in the 1840s-50s provided a mainstay for the Brazilian immigration policy until the late 1920s. In the 1850s, the credit-labor interlinkage was associated mainly with sharecropping contracts. This labor-rental arrangement expanded significantly until the

\footnotetext{
${ }^{38}$ Leff (1972, p. 492) and Viotti da Costa (1998, pp. 143-5).

${ }^{39}$ Viotti da Costa (1998, pp. 73-4).

${ }^{40}$ Witter (1974, p. 401), Lamounier (1986) and Stolcke and Hall (1983, p. 170).

${ }^{41}$ Leff (1972, p. 495) and Stolcke and Hall (1983, p. 170).

${ }^{42}$ Ianni (2004, p. 360-1) and Viotti da Costa (2004, pp. 172-3).

${ }^{43}$ Lamounier (2000, p. 66), Oberacker Jr. (2004, pp. 263-5) and Viotti da Costa (2004, pp. 197-8).
} 
1860s, when it began to be substituted by fixed remunerations per piece rate, per time worked, or by fixed rents and wage systems.

The last two decades of slavery in Brazil were marked by the passing of palliative laws aiming to temper the increased pressure of slaves and abolitionists ${ }^{44}$. In 1871, a law declared free the newborn children of slaves, but established that the offspring should serve the slave master until the age of majority, i.e. 18 and 21 years old for females and males, respectively. In 1885, slaves older than 65 years were legally freed. By the same law, slaves between 60 and 65 years old, however, had to serve their masters for three years as a compensation ${ }^{45}$. The political fight for an unrestricted abolition continued until the final shattering of the old socio-political order in 1888 , when it was finally proclaimed. It took little more than one year for the centralist Brazilian monarchy to fall under a new federalist republican government.

Foreseeing the impossibility of holding back the abolitionist movement, new projects to obtain labor for the plantations in this period focused on the coercion of Brazilians, freed slaves and projected future freedmen ${ }^{46}$. The proposals aimed at bonding those individuals for fixed periods (between five and seven years); or involved penal labor for rebellious slaves and the tightening of vagrancy laws ${ }^{47}$. However, the most successful policy built on the experience accumulated with bonded immigrants. From the 1880s, the government of São Paulo started subsidizing the transport of immigrants to work in the coffee plantations. The credit-labor interlinkage became a cornerstone of the insertion of São Paulo into the global circulation of labor. Between 1885 and 1914, about 1.15 million people gross-immigrated to São Paulo. Combined with the position of Italy as a major sending country - supplying an impressive $82 \%$ of immigrants to São Paulo in $1885-9^{48}$-, this policy granted a stable supply of labor to the plantations, even if landowners kept complaining about the turnover and mobility of free laborers ${ }^{49}$.

\footnotetext{
44 Viotti da Costa (1998, p. 251).

${ }^{45}$ Dean $(1977$, pp. 126-34, 139) and Viotti da Costa (1998, p. 322).

${ }^{46}$ Stolcke and Hall (1983, pp. 180-3) and Lamounier (1986, e.g. pp. 81-90, 98-103). For similar proposals in the U.S., see Engerman and Sokoloff (2011, footnote 11).

${ }^{47}$ For the actual indenture of freed slaves at the eve of the abolition, see Dean (1977, pp. 134, 139-43, 146-8).

${ }^{48}$ Own calculations with data from Levy (1974, Appendix Table 8).

${ }^{49}$ Petrone (2004, pp. 342-3) and Martins (1989, p. 16).
} 


\section{The rise of European bonded labor under sharecropping (1835-60)}

\subsection{The rise and primacy of Vergueiro \& Co. (1835-47)}

In July 1847, a first successful experiment with European bonded labor, hired under sharecropping contracts, started in farm Ibicaba ${ }^{50}$. At the time located in the municipality of Limeira, in the central-western plateau of São Paulo, Ibicaba was proprietary to the firm Vergueiro \& Co., founded and administered by Senator Nicolau Pereira de Campos Vergueiro and sons ${ }^{51}$. Vergueiro $\&$ Co. became a leading firm in the international trade of Brazilian coffee and was deeply associated with the immigration policy. Nicolau Vergueiro participated actively in the elaboration of the immigration policies carried out in the province since 1827 . He strongly opposed immigration policies based on rural settlements, as carried out in São Paulo since 1828 with German-speakers ${ }^{52}$. By 1847, this leading political figure of the Brazilian empire seized the opportunity to essay his own immigration policy, i.e. the hiring of bonded labor to the plantations. Certainly not unintentionally, Senator Vergueiro labeled the experience carried out with immigrants in his farm in 1847 as 'Colony' Senador Vergueiro, implicitly suggesting a very different type of settlement than the actual bonding of immigrant labor being practiced ${ }^{53}$.

Colony Senador Vergueiro was inaugurated with 423 German-speakers hired in Rhenish Prussia and Holstein ${ }^{54}$; sixteen Portuguese remnants from an older experiment with bonded labor joined them. Other immigration waves in 1849 and 1851 expanded the number of these pioneers by 65 German-speakers and 50 Portuguese ${ }^{55}$. In less than eight years, the farm reached a peak of about 900 bonded laborers, a number that stabilized around 670 in $1855^{56}$.

These immigrants were bonded to loans supplied by Vergueiro \& Co., which covered migratory costs and the yearly advances in cash, foodstuff and other goods obtained in the farm's grocery store. To supply the loans, Vergueiro \& Co. obtained a funding of about 3.2 million mil-réis from the imperial budget in $1845-6^{57}$. The firm then subcontracted the hiring of the laborers in

\footnotetext{
${ }^{50}$ Buarque de Holanda (1941) and Witter (1974). Heflinger Jr. (2007, 2009) provides new archival research.

${ }^{51}$ Witter (1982, pp. 107-16).

52 See Chapter 1.

${ }^{53}$ For the ideological ballast of the word, confounding bonded labor in plantations with settlement colonies, see Buarque de Holanda (1941, pp. 7-8), Oberacker Jr. (2004, p. 271) and Petrone (2004, p. 325). Sharecroppers were also labelled colons in Loire-Inférieure (Garrido, 2017, p. 983). See also footnotes 185 and 193 of this chapter.

${ }^{54}$ Grubb (1994, p. 813, footnote 16) highlights the importance of Rhineland for immigration to the Americas.

${ }^{55}$ Report of the President of S. Paulo in Correio Paulistano (20/02/1855, p. 1). See also Dean (1977, p. 98).

${ }^{56}$ Idem (20/02/1855, p. 1). The numbers of the first immigrant wave vary between 423 and 426 .

${ }^{57}$ In 1855 , the provincial presidency required information from the treasury about a loan amounting to $32,271.755$ réis received by José Vergueiro \& Co. according to the budgetary law of September 181845 (Correio Paulistano, 27/04/1855, p. 4, my underline). See Bassanezi, Scott, Bacellar, Truzzi and Gouvea (2008, p. 15).
} 
Hamburg with Dr. Fr. Schmidt and Captain M. Valentin. Lacking their own vessels, these agents further subcontracted the transatlantic transport with other ship-owners.

Immigrants were hired under a sharecropping contract. The shares applied over a labor and a land-rental dimension. In terms of labor, immigrants received a fifty percent share of the net yearly profit obtained from the coffee they harvested and processed; Vergueiro \& Co., in turn, was responsible for transporting and marketing the produce. New contracts from 1852 onwards excluded immigrants from the processing of the coffee beans; as a compensation to the farmer, the laborers now had to pay a fixed amount for the coffee beans processed by the landowner at his own cost. In terms of land-rentals, immigrant households received a plot for own cultivation and paid a fifty percent share of produce they sold in the market, but not of goods they consumed themselves ${ }^{58}$. The land-rental shares were mostly abandoned in later periods, most likely because of high monitoring costs ${ }^{59}$.

The 1847 hiring was relatively successful; as discussed in Section 3.2, the contracts signed by the German-speakers in Ibicaba laid the foundations for an extensive adoption of sharecropping by other farmers in the 1850 s. However, this first case of relative success was preceded by two failed attempts of family Vergueiro to hire bonded laborers in 1835 and 1840. These experiences demonstrate a learning process that led to the consolidation of the contractual formulae of 1847 .

The first immigrants actually hired by Senator Vergueiro as bonded laborers were 80 Portuguese who arrived at farm Ibicaba in 1840. This experiment with non-captives was shortlived and most laborers abandoned the farm by $1842^{60}$. The senator attributed this failure to politically-motivated hostilities against him, caused by his participation in a political upheaval against the central government in 1842. However, other critical accounts explain the stampede of the Portuguese from Ibicaba as the consequence of contractual clauses that leaned towards excessive controls and of mismanagements in enforcing the contracts.

The 1840 contract included a credit-labor interlinkage. The credit dimension offered to the Portuguese was similar to that accepted by the German-speakers in 1847. However, while the tying of the German-speakers extended until the repayment of outstanding debts, it seems that

\footnotetext{
${ }^{58}$ Dean (1977, p. 172) and Stolcke and Hall (1983, p. 184).

${ }^{59}$ Lamounier (1986) and Witzel de Souza (2012).

${ }^{60}$ See Correio Paulistano (20/02/1855, p. 1) for a brief contemporaneous account of the 1840 hiring. Two Spanish were among these immigrants (Correio Paulistano, 20/02/1855, p. 1).
} 
the Portuguese were submitted to a fixed-term indenture ${ }^{61}$. The labor dimension, on the other hand, differed substantially. Some Portuguese worked under a regime of fixed monthly payments. Others received plots of land under fixed-rent contracts, but were obliged to work for the landowner as well ${ }^{62}$. There were two main complaints of the Portuguese about the enforcement of the labor dimension of the contracts. First, they were subjected to excessive monitoring. Second and relatedly, the labor arrangements were seen as too similar to the slaves' gang system ${ }^{63}$.

This failed but actual hiring was preceded by another attempt made by family Vergueiro to promote European immigration of bonded laborers. In 1835, a consortium named Luiz Vergueiro \& Co. proposed the hiring of Swiss or southern German laborers ${ }^{64}$. This proposal came out in a period of intense debates about the banning of the transatlantic slave trade, when the Brazilian government announced its intention to increase the inflow of immigrants to substitute the captives. Simultaneously, some interest groups started stressing the role of private firms in promoting the business of immigration, rather than relying on public efforts in this direction ${ }^{65}$. Proposals of private ventures to foster immigration received ample press coverage in the $1830 s^{66}$.

Luiz Vergueiro \& Co. planned a public-private joint venture financed by the provincial government and by a well-connected political and economic elite ${ }^{67}$. Luiz Vergueiro \& Co. supported the enterprise with an equity of 1.44 million mil-réis, corresponding to $90 \%$ of the value of the venture, which it obtained with stocks traded in Rio de Janeiro. This amount would back-up the credit dimension of the contracts offered to the immigrants. Each of the 240 "suitable" Swiss or southern Germans were entitled to a loan of 60 mil-réis ${ }^{68}$. The consortium commissioned another firm, H. Hiller \& Co., as its representative in the Brazilian capital, which, in turn, would subcontract the hiring of immigrants in Europe with the captain of a ship named Creole.

\footnotetext{
${ }^{61}$ According to my interpretation of Calógeras ([1933] 1998, p. 353).

${ }^{62}$ Dean (1977, p. 96).

${ }^{63}$ Calógeras ([1933] 1998, pp. 353-4), Buarque de Holanda (1941, p. 16), Dean (1971, pp. 612-3), Lamounier (1986, p. 24) and Heflinger Jr. (2007, pp. 26-34).

${ }^{64} \mathrm{He}$ was not a member of the societal composition of Vergueiro \& Co. as founded in 1846.

${ }^{65}$ Calógeras ([1933] 1998, pp. 337-8, 351).

${ }^{66}$ O Novo Farol Paulistano (08/08/1835; 29/08/1835 - p. 3; 08/10/1836, p. 1). Bassanezi et al. (2008, pp. 14-5).

${ }^{67}$ O Paulista Official (23/01/1836, pp. 3-4).

${ }^{68}$ The firm offered additional five pezos per person to cover extraordinary expenses. "Suitable" were males and females in the age ranges 8-45 and 10-35 years old, respectively; "suitable" is a free-translation to "de número".
} 
The 1835 consortium proposed a sui generis contract to the immigrants. Divided into three phases, the contract combined an indenture with a conditional promise of landownership. Upon arrival, an agent would match immigrants and private employers under an indenture of three years. The contract stipulated two labor regimes. Unskilled laborers would earn a fixed payment per day worked (jornal). Remunerations ranged from 0.1 to 0.24 mil-réis per day according to age-sex groups. Specific laborers, probably associated with higher skills - including carpenters, blacksmiths and different types of potters -, would earn according to their "capacity and merits" and to the conditions prevailing in the labor markets of São Paulo ${ }^{69}$. Upon the completion of three years of private employment, immigrants would receive plots demarcated in public lands, which they were expected to cultivate for six years. At a final stage, immigrants who settled in their plots for that period would then receive property titles over the land. Civil and religious liberty were also assured.

The propositions contained in the 1835 contract never materialized and no immigration wave consolidated upon $\mathrm{it}^{70}$. Nevertheless, this document is of great value for three reasons.

First, it adds an important benchmark to the history of immigration to Brazil. Changes between the contract proposed in 1835 and that enforced in 1847 demonstrate the learning process in designing the contracts and how their clauses related to the generally prevalent immigration policies in the country. As noticed, Nicolau Vergueiro severely opposed the foundation of rural colonies in the 1820s. Nevertheless, that immigration policy was so preponderant at the time that it permeated the proposal of the 1835 contract as well: rural settlement automatically followed the three-year indenture in it. In 1847, however, plots of land in the farm of the proprietor were leased-out under shares to the immigrants as a constituent part of the creditlabor interlinkage; the guarantee of settlement upon the completion of the contractual obligations had been dismissed altogether ${ }^{71}$.

Second, the document enlarges our perspectives on labor arrangements proposed in the 1830s40s. This supports the proposition that sharecropping was not an obvious solution in the first periods of the transition from slavery. The 1835 consortium had no clause based on shares;

\footnotetext{
${ }^{69}$ Unskilled males older than 45 years were also subjected to this remuneration system. The objective in this case was most likely to set an earning lower than the fixed daily payments.

${ }^{70}$ Viotti da Costa (1998, p. 111) reports the immigration of 27 families in 1836 to work in the roadways of Santos. They probably have no connection to Luiz Vergueiro \& Co. See also Calógeras ([1933] 1998, pp. 342-3).

${ }^{71}$ Buarque de Holanda (1941, p. 13) argues that José Vergueiro and his father-in-law, Mr. Gavião Peixoto, considered sharecropping an intermediate step between labor in the plantations and landownership in settlement colonies, somewhat similar to the agricultural ladder hypothesis. See also Lamounier (1986, p. 23).
} 
rather, it interlinked credit to a labor dimension that mixed fixed remunerations and varying salaries per occupation. Likewise, the 1840 contract treated the Portuguese as agricultural laborers earning fixed payments. To this, I would like to add a fact already extensively surveyed by the historiography, which has nonetheless received less attention in theoretical terms ${ }^{72}$. In 1847, it was not obvious that sharecropping would become the prevailing labor-rental arrangement in the 1850s. It seems that Vergueiro \& Co. even considered proposing two contracts to the German-speakers, namely sharecropping itself and a labor system based on fixed payments per time worked (locação de serviços). The latter was the only labor arrangement covered by the Brazilian legislation, incentivizing its adoption to diminish institutional uncertainties ${ }^{73}$. Finally, there is also evidence that Vergueiro \& Co. assisted subgroups of specific German-speakers - with whom the firm "was not pleased" -, to buy land close to the municipality of Campinas as early as $1851^{74}$. Related to this effervescent mix of contractual clauses and potential labor arrangements, by 1855, the ex-director of immigrants in farm Ibicaba - Ms. Carlos Kruger - bought a coffee farm in the municipality of Paraibuna for the selling of small installments; interestingly, a sharecropping contract was offered as a mean to amortize the debt incurred in the buying of such plots ${ }^{75}$.

Third, the structure of the 1835 contract shows how the Brazilian experience with bonded laborers emulated other historical and international experiences. The joint inclusion of clauses bonding labor and allowing for posterior settlement in a single contract was very similar to the American headright system, applied in the thirteen colonies since the seventeenth century. The headright system granted land to immigrants upon the completion of a three-year period of indentured servitude ${ }^{76}$. The homesteading system applied in the U.S. in the nineteenth century followed in the footsteps of that older arrangement ${ }^{77}$. It is hardly by chance that Luiz Vergueiro $\&$ Co. proposed a contract with exactly the same stipulations as those tried in the U.S. for about two hundred years.

\footnotetext{
${ }^{72}$ Stolcke and Hall (1983, p. 171, footnote 189) and Lamounier (1986, p. 25).

${ }^{73}$ Ibid. (1983, p. 194); ibid. (1986, pp. 15, 53, 62, 96).

${ }^{74}$ O Mercantil (04/10/1851, p. 2). See also Dean (1977, p. 98).

${ }^{75}$ Correio Paulistano (20/02/1855, p. 1).

${ }^{76}$ Engerman and Sokoloff (2011, p. 26).

${ }^{77}$ Ibid. (pp. 30-3). I thank Renato Colistete for suggesting this point.
} 


\subsection{The expansion of bonded labor under sharecropping contracts (1847-60)}

After the consolidation of sharecropping in farm Ibicaba between 1847 and 1851, the period from 1851 to 1856 was characterized by a substantial expansion in the employment of bonded laborers in other coffee plantations. An official estimate calculated that about 30 farms employed $c a$. 3,500 bonded laborers in $1856^{78}$. This official report remarked that a significantly larger number of bonded laborers worked in smaller farms not included in the estimates. In a previous work, I identified 109 farms in 24 municipalities that employed various forms of contract labor between 1847 and $1860^{79}$.

This augmented number of farmers employing immigrants implied a gradual increase in the competition for the still scarce supply of bonded laborers. Newspapers' advertisements reflect the novelty of this process. In the sample of news researched for this chapter, landowners demanded unskilled labor, while immigrants who advertised their skills were either craftsmen or demanded positions as farms' administrators ${ }^{80}$. The reaching of an equilibrium took long; as late as 1873, farm Morro Azul, neighboring farm Ibicaba, advertised vacancies for contract laborers in French, German and Portuguese ${ }^{81}$. These announcements stressed that immigrants should have no pending obligations with other landowners and that their tasks would involve not only the cultivation of coffee, but also of $\operatorname{cotton}^{82}$.

The first explanation for this initial expansion of sharecropping relates to the intense propagandistic effort carried out by Vergueiro \& Co. The firm gradually became an agent in the hiring of bonded laborers to other landowners, profiting from a fee charged per worker imported. The periodical $O$ Mercantil served as platform for the political positions of family Vergueiro $^{83}$. This periodical reproduced ad nauseam a pamphlet in which the Swiss ex-consul, Charles Perret-Gentil, advocated the advantages of sharecropping and described very positively

\footnotetext{
${ }^{78}$ Correio Paulistano (23/02/1856, p. 1).

${ }^{79}$ Witzel de Souza (2012, p. 85).

${ }^{80}$ For skilled German-speakers (including teachers and preceptors), see e.g. Correio Paulistano (12/01/1870, p. 3; 13/01/1870, p. 3; 14/01/1870, p. 4); Gazeta de Campinas (25/09/1873, p. 3; 28/09/1873, p. 4; 03/05/1874, p. 4; 07/05/1874, p. 4); Jornal da Tarde (14/06/1881, p. 4).

${ }^{81}$ The German version mentioned employment only in the coffee plantations. The Portuguese asserted that coffee trees were mature, but below the age of peak production. This information was not available in German.

${ }^{82}$ Correio Paulistano - Feb. 1869 (13, p. 3; 14, 16, 17-9, 21, 23-6 - p. 4); Diário de S. Paulo - March 1869 (6, 7, 9 - p. $3 ; 13$, p. $4 ; 16$, p. $3 ; 19-20$, p. $3 ; 31$, p. 3$)$; April 1869, p. $3(3,7,22,23,28,29)$; May 1869 (1-2 - p. 4; 4-5 - p. 3 ; 15, 20, 23, 26 - p. 3); June 1869, p. 3 (1-5, 12, 15, 16); October 1871 (11, p. 3; 12-3, 17, 21 - p. 4); May 1873, p. 4 (8-10, 16-7, 21, 30-1).

${ }^{83}$ Newspapers with critical views were also active; e.g. A Aurora Paulistana (22/09/1851, p. 1), which nonetheless published some of Vergueiro \& Co's announcements in 1852.
} 
the experience in Ibicaba ${ }^{84}$. Perret-Gentil had abandoned his diplomatic career to pursue businesses related to the European immigration to Brazil, including the foundation of a private settlement colony in the current state of Paraná ${ }^{85}$. He soon encountered family Vergueiro and, united to them by kinship, became a fiery defender of the labor arrangement designed by Vergueiro \& Co.

There is some suggestive evidence that Perret-Gentil's publication in 1851 could have been a reaction against some immigrants who accused Vergueiro \& Co. of breaching contractual clauses. In that year, a commission of four German-speakers intended to present their complaints to the president of the province, but were dissuaded by Senator Souza Queiroz ${ }^{86}$. This premature upheaval of bonded laborers was not powerful enough to discourage other landowners to hire immigrants. On the contrary: the propaganda bore the expected results. Between 1851 and 1852, Vergueiro \& Co. announced new arrivals of German-speakers and advertised the manifold possibilities of employing them as agricultural laborers ${ }^{87}$. The firm stressed its promptitude to fulfil the demands of interested farmers, tailored to their proposals ${ }^{88}$. In a procedure that became frequent in that decade, interested landowners were invited to check the results reached with bonded labor in farm Ibicaba ${ }^{89}$. Landowners seem to have responded positively to those calls. An example is described in 1854, when a farmer from the municipality of Taubaté went to Limeira not only to gain personal experience, but also to inform his fellow farmers at home about the new labor system of Ibicaba ${ }^{90}$.

Two major developments influenced the adoption of bonded labor as of 1852. Both show how political laces were becoming increasingly more intricate with the interests of plantation owners in elaborating and conducting the immigration policy of the province. First, Senator Souza Queiroz joined the efforts of his brother-in-law, Senator Vergueiro, in hiring laborers from

\footnotetext{
${ }^{84}$ O Mercantil - 1851 (02/04, p. 2; 23/04, p. 3; 24/05, p. 4; 02/06, pp. 3-4; 19/07, p. 4; 23/07, p. 1; 30/07, p. 4; 02/08, p. 4; 12/11, p. 4). Complete chapters published in - 1851 (23/04, pp. 1-2; 17/05, pp. 1-2; 28/05, p. 1; 04/06, pp. $1-2 ; 14 / 06$, pp. $1-2 ; 05 / 07$, pp. $1-2 ; 08 / 07$, pp. $1-2 ; 12 / 07$, p. $3 ; 16 / 07$, pp. $3-4 ; 23 / 07$, pp. $2-3$ ).

${ }^{85} \mathrm{https}: / /$ www.swiss-archives.ch/detail.aspx?ID=10364453 - document E2200.67-02\#1000/675\#121*, accessed on December 07 2018, and Arlettaz (1979, p. 162). I thank Marília Jordan for providing me with all references about Perret-Gentil.

${ }^{86}$ O Mercantil - 1851 (04/10, pp. 1-2); A Aurora Paulistana (21/11/1851, pp. 2-3).

${ }^{87}$ A Aurora Paulistana - 1852, p. 4 (14/08, 21/08, 29/08).

${ }^{88}$ O Mercantil (22/10/1851, p. 4).

${ }^{89}$ For the role of Ibicaba as a farm-model, see Diário de S. Paulo (16/01/1868, pp. 1-2); Gazeta de Campinas (17/10/1872, pp. 1-2). A praising about Vergueiro's initiative is in Correio Paulistano (28/06/1866, p. 2).

${ }^{90}$ Correio Paulistano (20/10/1854, p. 3). In 1856, only one farm employed contract laborers in Taubaté (idem, 23/02/1856, p. 3), although farmers had petitioned in favor of it (Viotti da Costa, 1998, p. 123).
} 
Europe. Second, Vergueiro \& Co. signed its first successful public contract to hire Germanspeakers and Portuguese to plantations and public works.

Without exaggerating the importance of individuals at the expense of macro determinants, the solutions found for the labor problem in São Paulo owe much to a closely networked elite, which shared economic interests, held highly-ranked political positions and influenced the course of the immigration policy of the province deep into the twentieth century ${ }^{91}$. To a large extent, the expansion of sharecropping in the 1850s resulted from the positional advantage of the first main hirers, whose proposed contracts were then adopted by other landowners.

Families Vergueiro and Souza Queiroz are the most distinguishable representatives of these interconnections. Most of their relations are well-illustrated by the laces we find already in 1835 in the private-public consortium proposed by Luiz Vergueiro \& Co. The signatories of that document were the core of an elite that was directly or indirectly related by familiar ties. Luiz Vergueiro \& Co. was the firm responsible for the business, whose liability was shared with João da Silva Machado, father-in-law of Luiz. Family Silva Prado was represented by Antonio and his half-brother Joaquim, son-in-law of Silva Machado ${ }^{92}$. Bernardo Gavião Peixoto was another signatory. His daughter Umbelina married José Vergueiro, the future head of Vergueiro \& Co. ${ }^{93}$ Finally, family Souza Queiroz was represented by Francisco, Vicente and Luis. Francisco and Vicente were sons of Brigadier Luiz A. de Souza Queiroz, the first business partner of Senator Vergueiro in Brazil; Luis, in turn, was a grandson of Senator Vergueiro ${ }^{94}$.

This elite carefully defended its economic interests in the course of the nineteenth century, especially in conducting the immigration policies. João da Silva Machado was one of the founders of the German colony of Rio Negro in the $1820 \mathrm{~s}^{95}$. The same imperial dispatch that ordered its creation also routed to São Paulo the German-speakers who settled in the colonies of Santo Amaro and Itapecerica - i.e. that immigration policy arduously opposed by Nicolau Vergueiro. Gavião Peixoto was president of the province in 1836 and vice-president in 1847, i.e. in periods crucially around the 1835 consortium and the consolidation of the 1847 hiring $^{96}$.

\footnotetext{
${ }^{91}$ Lagerlöf (2009) rationalizes the role of political elites as setters of property rights over land and labor. Engerman and Sokoloff (2011), however, notice that even elites were constrained by endowments, mainly by labor scarcity.

${ }^{92}$ Waldman (2009, pp. 23-9).

${ }^{93}$ Buarque de Holanda (1941, p. 13).

${ }^{94}$ Castro (n.d., pp. 22-33) provides a detailed account about the family ties between Souza Queiroz and Vergueiro.

${ }^{95}$ For the political interests of this Baron in consolidating large-scale estates, see Dean (1971, p. 610).

${ }^{96}$ Egas (1926, p. 805), Buarque de Holanda (1941, pp. 12, 19) and Viotti da Costa (1998, pp. 121-3, 328).
} 
Besides all other connections, Senator Souza Queiroz brokered the renewal of the contract to hire immigrants between Vergueiro \& Co. and the presidency of São Paulo in the $1850 \mathrm{~s}^{97}$.

As the pioneers in the hiring of European bonded laborers, families Vergueiro and Souza Queiroz set a strong foothold in the business and politics of immigration. The contracts they first proposed set the standards over which labor negotiations took place for a long time; although sharecropping declined in the 1870s, most rural labor arrangements adopted later on had their origins in the regimes designed in the $1840 \mathrm{~s}$ and $1850 \mathrm{~s}^{98}$.

To farmers not accustomed to non-captive labor in ordinary agricultural tasks, the contracts proposed by these hirers were a benchmark to be followed. As other landowners accumulated experience with new labor regimes, contractual modifications started varying more widely later on. However, the scope for changes in this early expansion period was limited by the readymade formulae written by the main hirers. The following excerpt provides a picturesque image of this phenomenon. It describes how Joaquim Bonifácio do Amaral negotiated his first hiring of immigrants with Senator Souza Queiroz in 1851. Bonifácio do Amaral became himself an innovative hirer in the 1870 s, with his own immigration projects. However, at the beginning of the 1850s, the propositions of Senator Souza Queiroz fully determined the labor regime to be adopted. Bonifácio do Amaral describes: "[Senator Souza Queiroz said]: 'You told me elsewhere that you want colonists. I know, however, that you have no single coffee tree. Tell me whether you nevertheless want them, because I have my quill in my hand, ready to place an order. 'I want them', replied [Bonifácio do Amaral]. The senator replicated: 'What type of contract would be considered more suitable for you?' 'The same that is suitable for your Excellency' [...]. And nine months later [...] the small colony was formed with about eighty German workers" "99. The new landowner employing non-captive laborers was indifferent to the type of contract because he knew no alternative. At the time, the choice was not about incentives, controls, or efficiency. On a related note, the influence of Vergueiro \& Co. on the hiring of bonded laborers was such that contracts interlinking sharecropping to a credit dimension became known as the Vergueiro system among planters and public authorities.

This advantageous economic position of the hirers was reinforced by the political connections that allowed them to design the immigration policy itself ${ }^{100}$. Vergueiro \& Co. reached the apex

\footnotetext{
${ }^{97}$ Siriani (2005, p. 97).

${ }^{98}$ Buarque de Holanda (1941, p. 34), Dean (1977, p. 164) and Stolcke and Hall (1983, p. 183).

${ }^{99}$ Gazeta de Campinas (27/01/1870, p. 2), reproduced in Correio Paulistano (08/02/1870, p. 1).

${ }^{100}$ Buarque de Holanda (1941, p. 17), Witter (1974, pp. 403-6) and Lamounier (1986, pp. 24, 39, 52). 
of the intermingling between politics and private interests in the business of immigration between 1852 and 1856. In this interval, the firm signed two contracts with the government of São Paulo to hire 4,500 European agricultural laborers ${ }^{101}$. To be eligible to the public budget that renewed the contract - a loan of 2.5 million mil-réis -, the firm had to increase the number of hired immigrants ${ }^{102}$. Vergueiro \& Co. signed other two contracts to hire Portuguese, Swiss and southern Germans as laborers to roadway construction and posterior settlement ${ }^{103}$.

The similitude between these two last contracts and that proposed by the 1835 consortium is worth noting ${ }^{104}$. Immigrants signed a labor arrangement by which $20 \%$ of their fixed daily salaries were withheld to amortize the loans received; contracts terminated upon three years of work $^{105}$. The strategy of hiring the poor prevailed here as well. Moreover, with the objective of promoting the Brazilian image in Europe, the presidency of São Paulo refused to lower wages in the hiring process. However, there were large gaps between remunerations proposed in Europe and the actual earnings of immigrants in Brazil, with a clear discrimination against the Portuguese ${ }^{106}$.

According to the budgetary laws, the public contracts with Vergueiro \& Co. prevailed until 1857. In 1856, the presidency signed new contracts with Theodor Wille \& Co. and with Captain Joaquim de Andrada to hire European contract laborers ${ }^{107}$. In 1858 , Theodor Wille \& Co. advanced loans to mere 49 emigrants departing to São Paulo from Antwerp, Bremen, Hamburg, Havre and Liverpool ${ }^{108}$. In the following year, however, the number of immigrants hired by this firm increased to $519^{109}$. Finally, in $1856 \mathrm{Mr}$. Achilles d'Estadens endorsed an interesting contract with the charterer Leroy \& Steinmann, in Antwerp, which formulated the conditions of a general sharecropping contract between a European laborer and a Brazilian landowner ${ }^{110}$. This contract offered more benefits to immigrants than those of Vergueiro \& Co., including a longer maturation of interest-free-debt and lower interest rates ${ }^{111}$.

\footnotetext{
${ }^{101}$ Correio Paulistano (26/08/1854, p. 1; 28/08/1854, p. 1; 17/02/1855, p. 2; 11/05/1855, p. 1; 18/05/1855, p.1).

102 Idem (12-13/09/1854, p. 1; 19/09/1854, p. 3; 17/02/1855, p. 2). Viotti da Costa (1998, p. 151) remarks that Vergueiro \& Co. made similar propositions to the provincial governments of Minas Gerais and Maranhão.

${ }^{103}$ A small group was transferred to private employers, who paid for their debts. Idem (23/02/1856, p. 3).

${ }^{104}$ Correio Paulistano (12/09/1854, p. 1; 27/12/1854, pp. 3-4; 03/01/1855, p. 1; 11/01/1855, p. 1).

105 The presidency allowed for contractual lengths between 2 and 3 years, varying according to the ease of obtaining laborers in Europe (Correio Paulistano, 03/01/1855, p. 1).

${ }^{106}$ In total, 204 German-speakers, 199 Portuguese and 96 family members (idem, 23/02/1856, p. 3 ).

${ }^{107}$ Idem (12/09/1856, p. 1; 25/07/1857, p. 1). See also Viotti da Costa (1998, p. 124) and Siriani (2005, p. 97).

${ }^{108}$ Brazil received 6,089 immigrants in 1859 , corresponding to only $4.5 \%$ of emigrants departing from those ports (Correio Paulistano, 21/12/1859, pp. 1-2).

${ }^{109}$ Lamounier (1986, p. 50).

${ }^{110}$ Correio Paulistano (03/06/1856, p. 4).

111 The case cited in Davatz ([1858] 1941, p. 218) most likely refers to a signatory of this contract.
} 


\section{The decline of sharecropping (1860-90)}

From the 1860s, labor regimes based on fixed payments per piece-rate or time worked, wage systems and contracts that mixed shares and fixed remunerations gained ground against sharecropping. This section discusses three reasons for this relative decline of sharecropping. First, riots by bonded laborers led to gradual modifications in the contracts. Second, labor markets and immigration policies adapted endogenously to the novelties introduced by sharecropping. Finally, an elastic supply of immigrants from the 1880s started substituting the more direct bonding of labor. However, this did not imply that the credit dimension was abandoned. On the contrary, it became a consolidated policy once the government started to subsidize the immigration of agricultural laborers.

\subsection{Labor riots and movements of social unrest}

Contrary to the idea that sharecropping harmonized the interests of laborers and landowners a concept vastly prevalent among contemporary observers ${ }^{112}-$, the expansion of this contract in the 1850s was characterized by conflicts from the start. The petition of the German-speakers that led to Perret-Gentil's pamphlet in 1851 is one example. German-speakers had led riots and movements of social unrest since the 1820 s, when the immigration policy was still focused on settlement colonies ${ }^{113}$. The disputes as of 1847 had new motivations, related to the economic interests of bonded laborers. De facto, landowners resisted following the letter of the contracts and preferred the enforcement of contracts based on patron-client and paternalistic relations ${ }^{114}$. Immigrants, in turn, had exaggerated expectations about working conditions in the coffee plantations, usually nourished by the pro-emigration propaganda in Europe ${ }^{115}$.

Quarrels about contracts were recurrent throughout the period, but reached a peak in 1856 with the so-called Sharecropper's Riot. Led by the Swiss schoolmaster Thomas Davatz, this riot broke out in farm Ibicaba. It is probably the best-known episode in the history of the Germanspeaking immigration to São Paulo, not only due to its long-termed and international repercussions, but also because its leader published a detailed account about the movement in

\footnotetext{
112 Tschudi ([1866] 1953, pp. 129-30) is a representative example.

${ }^{113}$ Appendix II surveys news referring to labor riots and movements of social unrest from the 1820s to the 1890 s.

114 Dean (1977, p. 124).

115 Siriani (2005, p. 95) and Witzel de Souza (2012, pp. 83, 104) for Brazil, and Grubb (1994, p. 810) for the U.S.
} 
$1858^{116}$. However, this was by no means an isolated episode. Two other riots preceded it in the same year. They occurred in different municipalities, conducted by different nationalities, who had been hired by different agents in Europe ${ }^{117}$. Nevertheless, the similarity in the structure of these riots reveals that conflicts were all related to the non-enforcement of contracts, to biased interpretations of clauses by landowners and laborers, to problems with labor monitoring and to the lack of transparency in the accountancy of immigrants' debts and yearly revenues.

In the aftermath of the Sharecroppers' Riot, the Swiss Confederation, Prussia and the Duchy of Saxe-Coburg-Gotha conducted intense diplomatic inquiries into their emigration policies to Brazil $^{118}$. In 1858, the Prussian government enacted a censure motion inviting the German States to oppose emigration to Brazil. This directive mentioned the precarious situation of Protestants in the officially Roman-Catholic Brazilian Empire and the working conditions that allegedly equated German-speakers to African slaves ${ }^{119}$. This thesis of a "white slavery" perpetuated in political circles of the German States ${ }^{120}$. The bonding of labor and malpractices related to patron-client relations led to the consolidation of this view as an academic thesis as well ${ }^{121}$. Similar to other international abuses practiced against bonded laborers, some Europeans were subjected to extreme rights violation in São Paulo. These cases included foreigners been whipped, in a procedure applied only to slaves and even the tying of a worker "for days" in a farmyard after a laborers' riot, ten years after the abolition of slavery ${ }^{122}$. Notwithstanding, there are enough reasons to reject the thesis of white slavery. Landowners never acquired property over laborers. Abuses were never generalized and the episodes described always rose public outcries and consular inspections. The legal status of the foreigners, their domestic and international safeguards and, most importantly, the voice they had were features not compatible with the definition of slavery ${ }^{123}$.

\footnotetext{
116 Davatz ([1858] 1941).

${ }^{117}$ Correio Paulistano (27/05/1856, pp. 2-3). See also Heflinger (2014 pp. 55-70).

${ }^{118}$ Dean (1977, p. 107) and Heflinger Jr. (2007, pp. 65-6; 2009, pp. 55, 71).

${ }^{119}$ Gazeta de Campinas - 1870, pp. 1-2 (14/04; 08/05). Switzerland passed a motion demanding a more humane treatment of immigrants by the Brazilian government; idem (05/05/1870, p. 1).

${ }^{120}$ Citing Molinari, even José Vergueiro argued that “[ . . . a ] foreigner who leaves the fatherland without possessing capital [...] subjects himself to a 'truly temporary slavery' in order to pay for his fare" (Gazeta de Campinas, $31 / 03 / 1870$, p. 1). See further debates on the theme in idem (10/04/1870, pp. 1-2).

${ }^{121}$ Particularly influential in the German-speaking academia (see Rossfeld and Ziegler, 2003). In the Portuguesespeaking world, a softened version is from Witter (1974, pp. 420-1). Dean (1977, pp. 97, 173) classifies bonded laborer as a type of serfdom, but rejects the idea of white slavery. Viotti da Costa (2004, p. 193) argues that contract laborers were in a condition of serfdom - a position she later abandons (Viotti da Costa, 1998).

${ }^{122}$ Correio Paulistano - 1874 (04/03, p. 3; 05/03, p. 2). Consular inspections likely related to these cases are reported in idem - 1874 (19/04, p. 2; 25/04, p. 2; 11/07, p. 3). For the latter case, see A Nação $(26 / 03 / 1898$, p. 2).

${ }^{123}$ Engerman (1983, pp. 645-6). See also a discussion of the legal status of slaves in Dean (1977, p. 77).
} 
In any case, abuses reported after the Sharecropper's Riot were strong enough to support the enactment of the Rescript von der Heydt by Prussia in 1859. This governmental regulation canceled hiring licenses of some agents and prohibited the pro-emigration propaganda, first to São Paulo and later to Brazil ${ }^{124}$. This implied that Brazilian landowners had to look for alternative hirers, majorly diminishing the inflow of German-speakers to São Paulo, even if the Rescript did not prohibit emigration by itself ${ }^{125}$.

Brazilian immigration policies remained a source of diplomatic discomfort with the German States and with the German Empire throughout the 1860s and 1870s ${ }^{126}$. Opinions about Brazil as a destination country oscillated substantially over time. Opposition to emigration to Brazil was active in the German-speaking press since the early 1850s and intensified in the 1870s, in some cases with public support, as alleged by a self-interested Brazilian press ${ }^{127}$. Brazilian political elites attempted to counteract with strong publicity ${ }^{128}$. In this, immigrants' letters remained the favorite supporting material, being considered the ultimate proof of immigrants' satisfaction and an important stimulus for chain migration ${ }^{129}$.

\subsection{Endogenous market responses: migratory costs and immigrants' networks}

In this relatively unfavorable diplomatic scenario, the landowner Joaquim Bonifácio do Amaral attempted to conduct the hiring of German laborers in person in $1871^{130}$. Even if also characterized by labor riots later on, his experiments with bonded labor included important contractual innovations, such as the possibility given to immigrants in his farm to finance the travel costs of their compatriots.

Bonifácio do Amaral first hired German-speaking laborers to Colony Sete Quedas in 1852, in the process intermediated by Senator Souza Queiroz, as described before. He became prominent

\footnotetext{
${ }^{124}$ See Heflinger Jr. (2009, pp. 55-63).

125 The misinterpretation that the Rescript prohibited emigration appears in current studies and primary sources. See e.g. Correio Paulistano (29/05/1879, p. 1) and Diário de S. Paulo (04/09/1872, p. 2). In the latter, the misinterpretation was politically motivated and the Rescript was considered "[...] the Aberdeen Act of a new type from the Prussian government".

${ }^{126}$ See Appendix II.

${ }^{127}$ A Aurora Paulistana (04/05/1852, pp. 1-2); Correio Paulistano (21/11/1854, pp. 1-2); Gazeta de Campinas (14/04/1870, pp. 1-2).

${ }^{128}$ Paraphrased from Correio Paulistano (12/10/1865, p. 1; 11/03/1866, pp. 3-4) in an attempt to increase the inflow of Europeans and Americans to Brazil. In line, Idem (19/09/1875, p. 2) reported an attempt to establish a newspaper to be circulated within Brazil and in foreign countries, especially in Portugal, to attract immigrants.

${ }^{129}$ Correio Paulistano (09/01/1859, p. 4; 15/01/1876, p. 2 - the latter about a colony in the province of Paraná).

${ }^{130}$ Buarque de Holanda (1941, p. 33) and Viotti da Costa (1998, p. 233).
} 
in the immigration debate for opposing José Vergueiro's view on the Brazilian immigration policy ${ }^{131}$. Bonifácio do Amaral urged at solving an agency problem: because European hirers received a commission per immigrant, he argued, the hirers had no incentives to screen for laborers with adequate skills and high morals ${ }^{132}$. Landowners had raised similar cries since the 1850s; although partially exaggerated, this point was not completely devoid of truth. In 1859 , Brazilian consular authorities were concerned that the most accredited charterers promoting the emigration from the German States to the U.S. refused to enter the Brazilian market due to the lack of adequate regulations in Brazil ${ }^{133}$. Bonifácio do Amaral expected to circumvent similar problems and to recover some confidence of the German States in the Brazilian immigration policy by conducting the hiring himself ${ }^{134}$. His focus on German-speakers was based on an idealized, laudatory view about the German States ${ }^{135}$.

The difficult circumstances of his mission worsened with the outbreak of the Franco-Prussian War when Bonifácio do Amaral had left for Europe. After some exploratory travels in the German States and neighboring countries, and in spite of his fierce critics against European agents, Bonifácio do Amaral finally contracted the services of a hirer based in Hamburg ${ }^{136}$. Notwithstanding these problems, Colony Sete Quedas received 207 bonded laborers in 1871.

New types of mixed contracts had evolved in the 1860s, partially combining fixed payments for the caring of the coffee trees during the lean season with shares of the yearly profits from the harvested product. The contracts signed by the new immigrants with Bonifácio do Amaral had a similar structure, but the landowner added a novelty to the land-rentals. Immigrants received the option of leasing-in plots of land for independent agricultural production, most likely of foodstuff easily marketable in the neighboring municipality of Campinas. Land was supplied by the landowner in a regime of fixed rents; however, the marginal rents increased with the area demanded by the immigrants ${ }^{137}$. Hence, the contractual mix provided a screening mechanism to the landowner and gave more agency to the immigrants. Foreign households less

\footnotetext{
${ }^{131}$ See debate in Gazeta de Campinas, as mentioned in this thesis and analyzed by Stolcke and Hall (1983, footnote 56). Manuel de Campos Sales, future Brazilian president, tended to agree with Amaral (idem, 05/05/1870, p. 1).

${ }^{132}$ Gazeta de Campinas (27/01/1870, pp. 1-2), reproduced in Correio Paulistano (08/02/1870, p. 1). For José Vergueiro's opposite view, see Gazeta de Campinas (27/03/1870, pp. 1-2).

${ }^{133}$ Correio Paulistano (21/12/1859, p. 2).

${ }^{134}$ Idem (01/07/1870, p. 1); Gazeta de Campinas (24/07/1870, p. 1). Relatedly, in the 1880s, Francisco de Queiroz Telles commissioned an ex-sharecropper to conduct the hiring in Switzerland to avoid exactly the same problem of agency. See Scheler (1905, p. 180) and Grininger (1991).

${ }^{135}$ Gazeta de Campinas - 1870 (24/07, p. 1;06/01, p. 2); Correio Paulistano (15/10/1871, p. 1). For a similar view of José Vergueiro about the German-speakers, see Gazeta de Campinas - 1870 (10/04, pp. 1-2; 21/04, p. 1).

${ }^{136}$ For a description of the travel in times of war, see Correio Paulistano (19/11/1870, pp. 2-3) and Gazeta de Campinas (24/11/1870, p. 1), which reproduce Amaral's letter first published in O Diário do Rio (07/11/1870).

${ }^{137}$ Correio Paulistano (15/10/1871, p. 1).
} 
efficient in harvesting the cash crop could lease-in more land, from which the proprietor derived a fixed remuneration. The increasing marginal rents for leasing-in land, however, implied that the average immigrant household would not completely specialize in the production of foodstuff at the expense of cultivating and harvesting coffee.

The experiment prospered and Bonifácio do Amaral repeatedly commented on the wellbeing of the laborers ${ }^{138}$. Consequently, the landowner planned the hiring of about 1,000 northern Germans to his farms in the municipalities of Campinas and Amparo. To this end, he obtained a declaration of 24 household heads asking for the hiring of friends and relatives. According to this document, immigrants working in Amaral's farms expressed their willingness to supply credit to their compatriots. The proposed scheme included the supply of loans amounting to 140 mil-réis to people older than 10 years and 70 mil-réis to the younger, as well as free inland transportation to the farms ${ }^{139}$.

As immigrants became potential suppliers of credit to friends and relatives, the old direct control of landowners over laborers' indebtedness diminished in importance. Immigration enhanced by networks abroad partially dismissed the indebtedness control designed by Vergueiro \& Co. This did not imply, however, that the credit dimension of the interlinkage faded out. In imperfect credit markets, as in rural Brazil in the nineteenth century, these laborers probably had their credit as a positive annual account with the farmer, rather than in cash or savings. Paraphrasing Dean (1976, p. 489), not only the debt but also the credit of laborers bonded them to the landowner. Moreover, the focus remained on poor and credit-constrained potential immigrants, who could not finance on their own the costs of the move. By using the funds of immigrants, the landowner avoided the risk of the credit operation and likewise obtained laborers. What Bonifácio do Amaral essayed privately here would consolidate as the state policy of fully subsidizing the immigration of contract laborers in the 1880 s.

\footnotetext{
${ }^{138}$ Gazeta de Campinas - 1874 (16/07, pp. 2-3; 30/07, p. 2; 02/08, p. 2; 06/08, pp. 1-2) and Correio Paulistano (17/07, p. 1) - for instance, report a laborers' get-together in Amaral's farm, under obvious patron-client relations, probably published as a propagandistic reaction against some personal and work-related conflicts.

${ }^{139} \operatorname{Idem}(06 / 08 / 1874$, p. 1).
} 


\subsection{New labor arrangements and subsidized mass immigration (1860-90)}

By the end of the 1880s, São Paulo became a major destination for immigrants in the Americas ${ }^{140}$. This was mainly a consequence of the landowners' response to the abolition of slavery in 1888; to accommodate the shock in the labor supply, the government of São Paulo started to publicly subsidize the migratory costs of foreign households who accepted employment as rural laborers. This section discusses how these economic and institutional conditions in the 1880s-90s maturated over the 1860s-70s and how these, in turn, had been influenced by the experiences with bonded labor in the 1840s-50s.

The intermediary period of the 1860s-70s was marked by an important dualism. On the one hand, the rural elite of São Paulo attempted to preserve immigration channels that had been established since the 1820s. The immigration policy remained focused on poor, creditconstrained and, initially, German-speaking immigrants. On the other hand, landowners experimented more intensely with alternative labor-rental arrangements, until the consolidation of the so-called colonato system - usually associated to the mass immigration of Italians as of the 1880 s.

In terms of labor-rental arrangements, the colonato system was the most important and enduring innovation of this period ${ }^{141}$. It consolidated a mixed contract that had two complementary remuneration systems. The first comprehended a variable remuneration based on the performance of the households in the annual harvesting. This was usually a share of the yearly profit from the harvest, constituting a remnant of sharecropping as applied in the $1840 \mathrm{~s}-50 \mathrm{~s}^{142}$. The second included fixed remunerations per piece-rate executed during the lean season for the maintenance of the coffee trees. This scheme commenced as a variation of sharecropping contracts that stipulated side payments for agricultural tasks not specified in the contracts ${ }^{143}$. These tasks tended to have high monitoring costs and outcomes that could not be assessed as clearly as the harvesting, e.g. the pruning and weeding of the coffee trees.

\footnotetext{
${ }^{140}$ Hatton and Williamson (2004, pp. 23-7) and Ferrie and Hatton (2015, p. 65) outline the position of Brazil in international labor markets in this period. Dean (1977, p. 162), Holloway (1978), Stolcke and Hall (1983, p. 182) and Lamounier (1986, pp. 20, 146, 154) discuss the establishment of a rural proletariat in São Paulo.

${ }^{141}$ For a contemporaneous description of labor arrangements in 1870 by José Vergueiro, see Correio Paulistano (11/10/1870, pp. 1-2). For a general review of the colonato system, see Bassanezi (1986).

${ }^{142}$ Stolcke and Hall (1983, p. 179), Martins (1989, pp. 8, 20-2) and Viotti da Costa (1998, p. 240) also interpret the colonato system as a continuation of the experiments carried out with sharecropping.

${ }^{143}$ Bardhan (1977), Lucas (1979), Alston and Ferrie (1985) and Kotwal (1985) discuss the application of side payments in sharecropping arrangements for tasks with high monitoring costs.
} 
Another novelty was the expansion of labor arrangements based on fixed payments per piecerate or time worked. These regimes had been applied for long to rural laborers who cleansed forestry for the formation of plantations ${ }^{144}$. However, in the 1860s, landowners started employing these labor arrangements systematically for ordinary rural tasks as well ${ }^{145}$. This paved the way to wage-based remunerations, including a first systematic experiment with a farm run only with free Portuguese laborers in the1860s ${ }^{146}$.

Finally, contracts started being diversified for the cultivation of different crops. This was the case with Bernardo Gavião, who offered alternative contracts to Portuguese laborers after a failed coffee harvest in 1870 . In his coffee plantations, the colonato system prevailed at the time. For planting sugarcane, laborers were offered a sharecropping contract with a $2 / 3$ share to be paid as land-rentals. Disillusioned with the outcomes, the immigrants abandoned the crop, but received a fixed payment for the completed tasks. A similar contract was applied to tobacco cultivation; the $2 / 3$ share was used to amortize the debt incurred by households during the planting of the trees ${ }^{147}$.

Despite these important innovations, sharecropping retained a prominent position in the 1870s.

Some of the leading hiring families of the 1850s kept their enthusiasm for this specific laborrental arrangement: Francisco de Souza Queiroz considered sharecropping as the usual employment system in São Paulo by the end of the 1860s; praising the accomplishments of the deceased Senator Vergueiro, Francisco kept hiring German-speaking sharecroppers ${ }^{148}$. Moreover, the accumulated expertise of landowners with this labor arrangement implied a greater acceptance of its clauses than those of alternative contracts, even if the latter proved to be successful, as it seems to have been the case with the first application of the wage system mentioned above. Furthermore, the defense of sharecropping became a Brazilian response against accusations raised in the German parliament in 1872 about the precairous working conditions of immigrants. To defend sharecropping as a non-exploitative labor relation meant

\footnotetext{
${ }^{144}$ Labeled as camaradas. For Italian immigrants in these positions, see Stolcke and Hall (1983, footnote 85).

${ }^{145}$ Martins (1989, p. 23) shows the simultaneous application of these various types of contracts in the plantations. 146 Witter (1974, pp. 409-10) and Lamounier (1986, pp. 45-7). There are innumerous contemporary references to this farm, named Nova Lousã. The reports in Diário de S. Paulo (11/03/1870, p. 2; 22/03/1872, p. 2) are particularly interesting in their analysis of the hiring method applied by the farmer. For the biography of its founder and the history of this institutionally advanced farm, see Freitas (2013).

${ }^{147}$ Correio Paulistano (01/11/1872, p. 2).

${ }^{148}$ For the arrivals of immigrants see idem (20/06/1869, p. 1; 10/08/1869, p. 2; 15/06/1870, p. 1).
} 
also defending the foundations of the immigration policy carried out in São Paulo since the $1840 \mathrm{~s}^{149}$.

On the other hand, the idea that the indebtedness of immigrants could be a source of economic inefficiency or of political distress gained attention, especially in light of the sharp and recurrent critics against the Brazilian immigration policy raised in the German States ${ }^{150}$. A simple solution would be the substitution of a perfectly elastic supply of immigrant labor for the control that farmers had over labor via indebtedness. As paradoxical as this may sound, José Vergueiro was one of the first proponents of this idea ${ }^{151}$; his suggestion was to promote a massive immigration from 10,000 to 20,000 settlers for public lands and from 100,000 to 200,000 agricultural laborers ${ }^{152}$. Similar views underpinned the projects for the full subsidization of immigration ${ }^{153}$. According to this policy, foreign households who accepted agricultural employment upon arrival in São Paulo would have their transportation costs covered by the provincial budget. This proposition required about one and a half decade to maturate. Nevertheless, publicly subsidized immigration attracted a substantial share of the $c a .1 .15$ million foreigners gross-immigrated to São Paulo from 1885 to $1914^{154}$.

Nevertheless, this radically new solution to the labor question kept the credit interlinkage fundamentally unaltered. Clearly, the political and economic elites of São Paulo insisted in the policy of attracting poor and credit-constrained foreign laborers. As argued in the next section, this was a deliberate strategy to obtain foreign labor without reforming domestic institutions to make Brazil more attractive to non-bonded immigrants. The credit interlinkage allowed for the consecution of this goal in the 1880s-90s as it had done since its proposal in 1835. Relatedly, the credit interlinkage permitted ex-slaveholders to constrain pure market-oriented labor relations. Planters kept attempting to restrain the competition for labor. Even forward-thinking landowners like Bonifácio do Amaral, Gavião Peixoto and José Vergueiro complained about the supply of incentives to lure laborers from other farmers ${ }^{155}$. In this context, credit obligations

\footnotetext{
${ }^{149}$ Idem - 1872 (04/08, p. 2; 04/09, p. 2; 05/09, p. 1). For the centrality of sharecropping contracts in the Bonifácio do Amaral - José Vergueiro debate, see Gazeta de Campinas (08/05/1870, p. 1).

${ }^{150}$ See Correio Paulistano (04/03/1874, p. 2) and the quote in Viotti da Costa (1998, p. 130).

${ }^{151}$ José Vergueiro maintained his prominence in the immigration policy, but had to deal with the economic crisis of Vergueiro \& Co. He defended the bailout of the firm in 1865 also to preserve " 60 years of intelligent and active work as well as the patriotic efforts of an entire family" (Diário de S. Paulo, 16/01/1868, pp. 1-2).

152 Correio Paulistano (11/10/1870, p. 2).

${ }^{153}$ Levy (1974, p. 55), Dean (1976, p. 488; 1977, p. 95), Holloway (1978, pp. 194-5, 204-6), Lamounier (1986, pp. 152, 154), Viotti da Costa (1998, p. 328) and Petrone (2004, pp. 327 ff.).

${ }^{154}$ Levy (1974, Appendix Table 8).

155 Correio Paulistano (11/10/1870, pp. 1-2; 01/11/1872, p. 2; 11/07/1874, pp. 1-2) and the case described in Gazeta de Campinas (06/08/1874, pp. 1-2). A similar opposition to competition for indentured labor was observed in the U.S. in the seventeenth and nineteenth centuries (Reid, 1973, pp. 109-10, 124; Alston and Higgs, 1982, pp. 338-
} 
partly restrained the high turnover and mobility that characterized labor markets in São Paulo after the beginning of mass immigration.

Finally, this period was marked by the founding of new organizations to promote immigration. They aimed at regaining credibility in Europe and functioning as joint ventures to increase the gross-immigration of laborers ${ }^{156}$. Having José Vergueiro as one of its proponents, Associação Auxiliadora da Colonisação e Imigração hired mainly German-speakers in a process resembling that established by Vergueiro \& Co ${ }^{157}$. As of 1886, the Sociedade Promotora da Imigração became a cornerstone for the mass immigration of Italians to São Paulo ${ }^{158}$. Founded as a consortium of coffee planters, this society integrated the processes of hiring, transporting, lodging and matching landowners and laborers. Given its importance, it ended up incorporated by the state of São Paulo in $1895^{159}$.

In conclusion, profound contractual and institutional innovations in immigrant labor markets took place between 1835 and 1890. Most of them were responses to the socioeconomic convulsions stemming from the long abolition of slavery, as well as a learning process triggered by labor riots and endogenous changes in immigration policies. Nevertheless, the history of labor-credit interlinkages in São Paulo is one of continuity. Sharecropping expanded as a contractual arrangement because of the emulation of its clauses by farmers following the first hirers, who enjoyed privileged and powerful economic and political positions. Clauses from contracts signed in the 1840s-50s continued to influence the design of other labor arrangements far after the heydays of sharecropping. The bonding of labor via credit, in turn, was a constant in the Brazilian immigration policy. Although the private-public relations in the provision of credit to immigrants changed substantially over time, bonding labor via an outstanding debt was the main response of Brazilian public authorities and of landowners demanding immigrant labor to the relatively low attractiveness of the coffee plantations in international labor markets. The next section attempts to explain the two principal phenomena discussed in this historical analysis. I first ask why sharecropping prevailed as the first labor-rental arrangement. In the

9; and Galenson, 1984, p. 5). Acemoglu and Wolitzky (2011) argue that producers tend not to compete with each other in coercive regimes.

${ }^{156}$ Correio Paulistano (21/05/1875, p. 1).

${ }^{157}$ Idem-1875 (10/03, p. 2; 02/04, p. 3;03/04, p. 4;04/04, p. 4;21/05, p. $1 ; 23 / 06$, p. $3 ; 24 / 06$, p. $3 ; 26 / 06$, p. 4; 02/07, p. 4; 03/07, p. 4; 11/08, p. 3; 07/09, p. 3;08/09, p. 3; 12/09, p. 3). For the history of the association, see Gazeta de Campinas (03/04/1870, p. 2), Viotti da Costa (1998, p. 234) and Petrone (2004, pp. 328-9).

158 Viotti da Costa (1998, p. 237) and Petrone (2004, pp. 330-1).

${ }^{159}$ Dean (1977, p. 152), Holloway (1978, pp. 193-7) and Siriani (2005, p. 99). 
sequence, the inquiry is on why the Brazilian immigration policy depended so extensively and for so long on the credit interlinkage.

\section{The rationale of sharecropping and bonded labor: a theoretical analysis}

The prevalence of sharecropping in different historical contexts and across regions with the most diverse geographic characteristics is a puzzle that has intrigued theorists and historians alike $^{160}$. The literature has attempted to explain this pervasiveness by either dismantling the argument that sharecropping is an inefficient labor-rental arrangement or by demonstrating other benefits that it entails. The prevalence of sharecropping in the transitional economy of São Paulo adds to this puzzle.

This section proposes some theoretical explanations as to why sharecropping consolidated as the first labor-rental arrangement applied to European bonded laborers in Brazilian coffee plantations. In particular, I am interested on why sharecropping predominated over the alternatives of fixed rents and wage systems as the labor-rental dimension of the first contracts successfully enforced with non-captives.

To this end, I develop a simple model in which landowners maximize their rents subjected to the participation constraint of potential immigrant bonded laborers; a linear credit-labor interlinkage allows landowners to derive rents from immigrants' labor supply and from loans advanced to them ${ }^{161}$. Although the model is derived primarily to explain the adoption of sharecropping in the initial phases of the transition from slavery - i.e. it has no dynamic component and is based on assumptions that characterize well, I argue, only that specific historical moment -, it nonetheless allows for some further inquiry into the relationship between sharecropping contracts and the bonding of labor. Considering that the latter outlived the specific clauses of sharecropping, the final question of this section is then about the economic and political rationale of the credit interlinkages.

The theoretical analysis implies that a rent-maximizing landowner looking for a stable supply of laborers had no particular reason to adopt sharecropping as the labor-rental dimension of an interlinked contract. In particular, the model shows that landowners faced potentially the same

\footnotetext{
${ }^{160}$ For a review, see Bardhan (1980), Byres (1983) and Caballero (1983). Moreover, see the research motivation in Bardhan and Srinivasan (1974), Quibria and Rashid (1984) and Garrido (2017).

${ }^{161}$ I discuss the model and its results in the main text, leaving its formal derivation to the appendix of this chapter.
} 
per worker costs if sharecropping, fixed rents, or wage systems constituted the labor-rental dimension of the contracts. I therefore argue that the first propositions to adopt this specific contract resulted from the emulation of similar arrangements applied internationally and in other historical periods. Relatedly, I argue that the expansion of sharecropping in the 1850s and the influence it exercised on other labor arrangements were a consequence of path dependence. The expertise accumulated with sharecropping by the mid-nineteenth century determined the perpetuation of some of its characteristics into other arrangements, such as the colonato system.

A similar argument about path dependence applies to the credit interlinkage. The continuity of this contractual component has important implications to the history of immigration to Brazil. The focus on poor and credit-constrained immigrants, with fewer or no alternative destinations, was constant in the Brazilian immigration policy. The theoretical model shows that the credit dimension was malleable enough to lead to the same optimality conditions, irrespective of the labor-rental dimension of the contract. This partially explains the survival of credit interlinkages long after the decline of sharecropping.

\subsection{The adoption of sharecropping: theoretical and historical explanations}

\subsubsection{A review of theoretical explanations}

Theoretical explanations for the prevalence of sharecropping during the first phase of the transition from slavery in Brazil oscillate between two traditions. On the one hand, more macrooriented explanations assume an evolutionary perspective about changes in labor relations in the economy at wide. On the other hand, more micro-oriented approaches emphasize the economic rationale of different labor arrangements applied at the level of the farms ${ }^{162}$.

Theories of stages of development usually support the macro approach, being particularly influential in classical historical analyses in Latin America ${ }^{163}$. Simply put, these theories posit an evolutionary process that starts with slavery and closes with modern labor markets. One strand of the Brazilian historiography used this benchmark to describe the transition from slavery as a process that led to the adoption of increasingly more efficient labor arrangements. Under this perspective, labor markets for non-captives would have departed away from the least

\footnotetext{
162 This is only a schematic view, as both are concerned with the adoption of contracts by farmers and the consequences for the total labor supply. Lagerlöf (2009, pp. 321) proposes a similar divide in surveying the literature on coercion.

${ }^{163}$ See the review in Otsuka et al. (1992, p. 1973, footnote 51) and Sadoulet (1992, pp. 1031-2).
} 
productive arrangement of sharecropping, as this was the first labor-rental arrangement that prevailed in the coffee plantations during the transition from slavery ${ }^{164}$. Another strand, broader in scope, characterized slavery as a backward stage of economic development ${ }^{165}$. Its gradual abolition was endogenously related to technological adoption and innovation, to the freeing up of capital previously invested in slaves, to the development of market institutions and to a rationality more tilted towards efficiency. In this all-encompassing sociological and economic interpretation, labor regimes employed in the final periods of the transition would necessarily overtake previous arrangements because of their earlier proximity to slavery ${ }^{166}$.

The observation that different labor regimes coexisted in relatively narrow areas led to the first implicit rejection of theories of a transition based on clearly identifiable phases ${ }^{167}$. Other criticisms of theories of stages of development gained strength with the advancement of a literature that attempted to rehabilitate the rationale of sharecropping against ingrained theoretical traditions that linked share contracts to allocative inefficiency ${ }^{168}$; disincentives towards investments ${ }^{169}$; and patron-client relations ${ }^{170}$. As Stiglitz $(1974$, p. 251) summarizes, "[i]t is not as if landlords and workers, anticipating the analysis of Marshall and other economists, discovered that [sharecropping] provided too little incentive to work and therefore they replaced an inefficient payments system with a more efficient one". These new theoretical developments stressed the role of sharecropping as a mechanism of risk-sharing ${ }^{171}$; of screening for land-renters of different risk and productivity types ${ }^{172}$; of lowering transaction costs in labor markets ${ }^{173}$; and of creating implicit markets for non-tradable services, such as managerial skills and labor monitoring ${ }^{174}$. Moreover, this literature has shown how missing or incomplete markets affect each other. If land, labor, or credit markets are interlinked and at least one is missing or incomplete, then sharecropping can lead to higher allocative efficiency ${ }^{175}$. Finally, recent empirical evidence has shown that the historical enforcement of sharecropping in

\footnotetext{
164 Witter $(1973,1974,1982)$. Petrone (2004, pp. 324-6) adopts a similar categorization of phases of development, but stresses the importance of the coexistence of various labor arrangements in the coffee plantations.

165 The view that slavery was economically backward has been continually challenged since the 1970s. For a review, see Eltis (1983, p. 266), Lagerlöf (2009, pp. 319, 335) and Acemoglu and Wolitzky (2011, pp. 557-60).

${ }^{166}$ Ianni (2004, pp. 363-4) and Viotti da Costa (1998).

${ }^{167}$ Stolcke and Hall (1983) and Lamounier (1986). Hints in this direction are also in Buarque de Holanda (1941).

${ }^{168}$ For a review of opposing theories on the efficiency of sharecropping, see Otsuka et al. (1992).

${ }^{169}$ Newbery (1977, p. 585) and Quibria and Rashid (1984, pp. 103) discuss the history of this negative perception.

${ }^{170}$ Higgs (1894, pp. 4-9), Camara (2006, pp. 215, 226) and Garrido (2017, pp. 989-90) discuss norms supporting sharecropping. For paternalism and indenture, see Bardhan (1980, pp. 94-6) and Lee and Kaufmann (1997, p. 467). ${ }^{171}$ Cheung (1969), Stiglitz (1974), Reid (1975) and Newbery (1977).

172 Allen (1982), Shetty (1988) and Basu (1992). Braverman and Guasch (1984) deal simultaneously with screening and credit-labor interlinkages.

${ }^{173}$ Cheung (1969), Reid (1975), Bell and Zusman (1976), Lucas (1979) and Alston, Datta and Nugent (1984).

${ }^{174}$ Eswaran and Kotwal (1985) and Braverman and Stiglitz (1986).

${ }^{175}$ Bardhan (1980) and Braverman and Stiglitz (1982).
} 
southern Europe was indeed allocative-inefficient; nevertheless, this land-rental arrangement had a clear economic rationale, as it allowed for long-term investments in the planting of crops, especially in viticulture ${ }^{176}$.

In this context, Stolcke and Hall (1983) pioneered the more micro-based explanations for the choice of labor arrangements in the plantations of São Paulo. They identified two main reasons for the adoption of sharecropping. The first recognized that sharecropping contracts had a labor and a land-rental dimension. This gave more agency to immigrant households in allocating their labor force; and because these households could produce subsistence goods, the sharecropping contract reduced the unitary costs faced by landowners in maintaining the laborers. Moreover, contrary to prevailing interpretations that sharecropping was inefficient, these authors defended that an income that varied with the annual harvest incentivized immigrants to increase their labor effort.

While the first explanation has the merit of recognizing the different dimensions imbued in a single contract, the second ignores the classical argument that sharecropping is inefficient precisely because it extracts a fixed share of produce independent of the level of effort. Furthermore, the direction of the effect is not as obvious as Stolcke and Hall (1983) propose. Because labor was interlinked to a credit dimension, the expectation of a poor harvest could indeed incentivize risk-averse households to put more effort into production. However, nothing impeded that the disillusionment with a bad harvest - implying an increasing indebtedness could lead bonded laborers to abandon the cash crops or to riot, as they frequently did ${ }^{177}$.

This motivates the current chapter to look for an alternative rationale of sharecropping. The historical analysis suggests three other explanations for its consolidation in Brazilian plantations.

First, by exploring the credit dimension of the interlinkage, landowners could have used the alleged allocative inefficiency of sharecropping to increase the length of the contracts. This proposition assumes that sharecropping induces laborers to put a sub-optimal level of effort into production, i.e. the classical Marshallian inefficiency of sharecropping. In this case, landowners could be trading effort for a secure supply of labor: with laborers bonded by debt, low effort

\footnotetext{
${ }^{176}$ Carmona and Simpson $(1999,2012)$ and Garrido (2017). Camara (2006) presents a similar argument without focusing on specific crops; Garrido and Calatayud (2011) adopt the same reasoning, but for fixed rents in Spain. 177 Stolcke and Hall's (1983) argument would be in line with Acemoglu and Wolitzky (2011, pp. 557, 567-8, 5712), whose model posits that coercion and effort are complementary.
} 
would imply a longer duration of the contract. The validity of this explanation depends on the adequacy of the Marshallian inefficiency of sharecropping to characterize that specific historical moment; its actual occurrence in the coffee plantations of São Paulo is an empirical question that has been so far scrutinized only under thin evidence, given the scarcity or spread of the required data. Moreover, it ignores that suboptimal efficiency cannot generate a longterm equilibrium and that risk-averse landowners would not accept contracts that increased excessively the risk of default of laborers.

Second, sharecropping could have been adopted because its risk-sharing feature increased the pool of potential immigrants also among the most risk-averse European laborers. However, fixed remunerations or wage systems would have been a simpler solution in this case, as landowners would bear the risk alone. This was, indeed, an important motivation to substitute sharecropping with fixed remunerations in the $1860 \mathrm{~s}^{178}$. Furthermore, in the sharecropping contracts designed by Vergueiro \& Co., the shares applied not only to the land-rentals, but also and most importantly to the labor dimension ${ }^{179}$. Under this setting, it is not clear whether sharecropping provides a risk-sharing mechanism to the laborer, because not only the landrental paid to the landowner is a share, but the labor-income of the immigrant also becomes a share of a varying output. Variations in the international price of coffee and the lack of immigrants' control over its marketing were important sources of risk to the bonded laborers ${ }^{180}$. Finally, this explanation ignores that landowners could be risk-averse as well. While this was not a problem for the potentates that first employed sharecropping, the risk-aversion of farmers gained importance with the expansion of sharecropping in the 1850s - even if Vergueiro \& Co. carefully increased contractual controls to give more security to landowners ${ }^{181}$.

Third, sharecropping can be designed to explore the comparative advantages of the contracting parties over labor and capital. In this case, sharecropping compensates for the nonexistence or incompleteness of markets. From a purely economic point of view, this explanation describes well the experience in the Brazilian coffee plantations ${ }^{182}$. In the rural economy of São Paulo, landowners provided the managerial skills in organizing production and marketing output;

\footnotetext{
178 Viotti da Costa (1998, pp. 148-9).

${ }^{179}$ Stolcke and Hall (1983) discuss this theoretical channel as well.

${ }^{180}$ Buarque de Holanda (1941, p. 31), Witter (1974, p. 434) and Viotti da Costa (1998, p. 149; 2004, pp. 193-5).

${ }^{181}$ Dean (1977, p. 101), Stolcke and Hall (1983, p. 177) and Viotti da Costa (1998, p. 131). Petrone (2004, p. 325) highlights the importance of transparency in the design of labor contracts. Lamounier (1986, pp. 39, 51, 70, 1167, 121-2), in turn, shows that the period was marked by intense legislative discussions on how to judicially protect landowners' investments in immigrants.

${ }^{182}$ Eswaran and Kotwal (1985). In particular, "[...] sharecropping would dominate when markets are either absent or underdeveloped and the class structure is polarized" (p. 361).
} 
immigrants, in turn, supplied an adequate level of effort in production by closely monitoring the labor of each household member. Sharecropping allowed immigrants to choose their level of effort and gave them operational freedom ${ }^{183}$. At the same time, a firm like Vergueiro \& Co. had a clear comparative advantage in the international marketing of the agricultural output ${ }^{184}$. However, this view has an implication to the political economy of labor relations that is fundamentally at odds with the historical analysis of the current chapter. By exploring the synergies between capital and labor, this theoretical explanation considers sharecropping as an arrangement that harmonizes the interests of the contracting parties. As Eswaran and Kotwal (1985, p. 353) put it, sharecropping is "a partnership arrangement in which both agents have incentives to self-monitor" ${ }^{\prime 185}$. This harmonious view fails to explain the intense labor disputes, violent riots and their long-termed consequences for immigration policies, which triggered deep contractual modifications over time ${ }^{186}$. On a related note, this explanation disregards potential inequality in assets between landowners and laborers. As Acemoglu and Wolitzky (2011, p. 569-72) show, inequality is central for the emergence of more stringent forms of labor coercion.

\subsubsection{Alternative explanations: credit-labor interlinkages and the historical dependence of sharecropping}

Notwithstanding the abundance of mechanisms suggested, none of the previous theoretical explanations provides a clear-cut reasoning for why sharecropping prevailed in Brazilian coffee plantations in the $1850 \mathrm{~s}$. A central argument of the current chapter is that sharecropping was not an unequivocal solution to the labor problem in the transition from slavery. The lack of an all-encompassing theoretical underpinning for its adoption suggests, in addition to the historical discussion, that other arrangements could have led to the same economic results.

Sharecropping, fixed rents and wage systems can indeed lead to the same per worker costs with a contract that interlinks these labor-rental dimensions to credit. From an economic point of view, it is possible to design an interlinkage that makes landowners indifferent among these three arrangements. That is what appendix to this chapter does by modelling a partial equilibrium, in which a landowner maximizes rents subjected to the participation constraint of

\footnotetext{
${ }^{183}$ Stolcke and Hall (1983, p. 174) and Lamounier (1986, p. 24) as well as quotes of Tschudi therein (footnote 9). ${ }^{184}$ Dean $(1971$, pp. 613-4, 617-9) and Levy (1974, p. 51). For a view on the capital needs to succeed in that export economy, see Leff (1972, p. 491).

185 They notice that "[...] in the Philippines the word for sharecropping also means partnership" (ibid., 1985, p. 353). Remarkably, the Portuguese term for sharecropping can be translated literally as partnership as well.

${ }^{186}$ See Appendix II.
} 
bonded laborers. Landowner's rents include two dimensions. The production dimension implies that labor is demanded under either sharecropping, or fixed rents, or wage systems. The credit dimension determines the participation constraint of the laborers, as I assume that laborers are foreigners that require credit to immigrate to a Brazilian plantation.

The model is derived under two scenarios.

The first assumes no productivity differentials among the three labor-rental regimes. Under this circumstance, the credit-labor interlinkage allows for the equalization of the per worker costs of sharecropping, fixed rents and wage systems. Consequently, landowners could have been indifferent among these alternative labor-rental arrangements once the credit dimension was added to the contract. This result describes well the situation faced by landowners in the early 1850 s, when the adoption of sharecropping still had a tentative nature and the parties involved were not preoccupied with the efficiency of the labor-rental arrangements.

The second scenario is based on the assumption that sharecropping was less efficient than fixed rents and wage systems, which are treated as equally efficient in the model. The first part of the assumption - i.e. the low efficiency of sharecropping - is based on the classical interpretation of the Marshallian inefficiency of sharecropping arrangements ${ }^{187}$. For the second part of the assumption to hold - i.e. the efficiency equalization of fixed rents and wage systems -, one needs further to assume that labor monitoring was costless to the landowner and perfectly enforceable. Under these circumstances, the model shows that there is no possibility of equating the per worker costs among the three labor-rental regimes. Results thus lead to the conclusion that the consolidation of a perfectly competitive wage system would either cancel productivity differentials among the labor arrangements or lead to the elimination of the least productive.

Ranking productivity differentials between sharecropping, wage systems and fixed rents is an empirical question that cannot be answered satisfactorily with data currently available.

Nevertheless, this chapter argues that the assumption of no-productivity differentials in the first scenario describes well the first phase of adoption of sharecropping in Brazilian coffee plantations. The historical analysis showed that, in the early expansion of sharecropping, farmers had little knowledge about contractual clauses and their mechanisms. Even wellinformed landowners, such as Bonifácio do Amaral, adopted sharecropping in the early 1850s

\footnotetext{
${ }^{187}$ See discussion in Stolcke and Hall (1983, p. 174): "It has long been maintained that sharecropping is less efficient than wage labour [...]", a proposition they justify with the Marshallian inefficiency of sharecropping.
} 
only because they were unaware of alternatives. Therefore, at least in the initial economic calculations of landowners, the first scenario does seem adequate. Moreover, from a theoretical point of view, interlinkages allow landowners to play with the credit dimension of the contract to lead to an efficient allocation in the labor dimension. Under this perspective, no-productivity differentials in the labor dimension could even be seen as an outcome of the interlinkage, not as an assumption ${ }^{188}$.

To be sure, this proposition that landowners were indifferent between these three labor-rental dimensions under a credit interlinkage provide a hypothesis to the literature, not a tested result. Nevertheless, this hypothesis is endorsed by theoretical reasoning and solid historical evidence.

On the other hand, the assumption of productivity equality between wage system and fixed rents in the second scenario might be questionable both historically and contemporaneously. Nevertheless, in our view, the fact that immigrants were hired as entire households supports this assumption. This format of immigration had the potential to increase the self-monitoring of family members, who were jointly responsible for the outstanding debt of the entire household. Nevertheless, if one agrees with this argument, it would be hard not to apply the same logic to sharecropping as well - and, in this case, we would be back to the previous scenario of non-productivity differentials.

Finally, Section 3.2 showed that excessive monitoring was one of the leading causes for the debacle of the experience with Portuguese contract laborers in 1840-42. This remarkable case was not an isolated one: a plethora of labor complaints during riots included questions on monitoring. This observation obviously weakens the assumption that monitoring costs were non-relevant. If this is true, then the relationship between sharecropping and wage systems would be significantly more complex than the strict lower efficiency of sharecropping proposed in the second scenario. The Marshallian inefficiency of sharecropping would stand against the costly labor enforcement of a wage system. Sharecropping could then be legitimately assumed as more, less, or equally efficient as the wage system. From a theoretical point of view, this would alter the relationship between the per worker costs of sharecropping and of the wage systems. Nevertheless, this modification would not alter the qualitative conclusions of the model in the second scenario, which is derived by comparing the PWCs of sharecropping to that of fixed rents.

${ }^{188}$ I thank Stephan Klasen for discussions about this theoretical argument. 
In short, if the first scenario is indeed the historically most adequate setting to describe the first phase of adoption of contract labor in São Paulo, then the theoretical analysis of the labor-credit interlinkage leads us to the conclusion that landowners were indifferent between sharecropping and alternative labor-rental regimes. Consequently, the theoretical reasoning of why the former prevailed in São Paulo in the 1850s requires a complementary historical explanation. This approach is in line with the literature that considers sharecropping as an institution in itself, over and above a simple contract externally enforced ${ }^{189}$. As such, this labor-rental arrangement can be understood comprehensively only if complemented by considerations of political, sociological and historical nature ${ }^{190}$.

This chapter therefore proposes that sharecropping was adopted in the coffee plantations of São Paulo as the result of a long learning process that involved emulations of other historical and international experiences. Important precedents that influenced Brazilian politicians were the well-known and long-lived French mètayage and its "share correspondent" in the U.S., as discussed by Marshall ${ }^{191}$. During the first two decades of the nineteenth century, these mechanisms of land rental and labor allocation fomented political discussions about the organization of rural production in the newly founded Brazilian Empire. Other political references in this period mentioned sharecropping as applied in the Madeira Archipelago ${ }^{192}$; experiences with sharecropping in the Iberian Peninsula were likely influential among Brazilian elites. Having studied Law at the University of Coimbra, Senator Vergueiro was probably acquainted with the so-called contractos de meia and contractos de colonia ${ }^{193}$. The former was a share contract, usually on a fifty percent basis ${ }^{194}$. The latter constituted a type of perennial tenancy ${ }^{195}$. Both prevailed in the Madeira Island since the 1750s. Moreover, potential immigrants were probably not taken aback by this labor arrangement either, as forms of bonded sharecropping were common in the German-speaking world by the nineteenth century ${ }^{196}$. Luiz

\footnotetext{
${ }^{189}$ Bardhan and Srinivasan (1974, p. 48), Bardhan (1980, pp. 87-90) and Quibria and Rashid (1984, pp. 108-9). Koo $(1973$, p. 579) argues that even the fundamental parameter of rentals "[...] will depend on the historical accident, custom or institutional factors".

${ }^{190}$ For its links to history, see Koo (1973, pp. 579-80), Stiglitz (1974, pp. 251-2), Bell and Zusman (1976, pp. 5789), Bardhan (1977, p. 105; 1980, pp. 82-7), Mitra (1982, p. 167) and Otsuka et al. (1992, pp. 1976-7, 2003-4).

${ }^{191}$ Marshall ([1894] 2013, p. 535). See also Higgs (1894) and Hoffman (1984).

192 Buarque de Holanda (1941, p. 19) and Dean (1977, p. 194, footnote 5).

${ }^{193}$ Camara (2006). It is tempting to trace a parallel between the title of this contract and the term "sharecropping colony [colonia de parceria]” as adopted by Senator Vergueiro. See also footnote 53.

${ }^{194}$ Meia can be literally translated as "half".

195 Garrido and Calatayud (2011) discuss how ownership over investments - similar to the Madeira Island's contracto de meia - actually led to land-rental contracts based on fixed rents, rather than sharecropping.

${ }^{196}$ Anderson (2001, pp. 11-3, footnote 8) discusses forms of tied and free sharecropping in eastern Westphalia. Furthermore, part of the report of J. J. von Tschudi reproduced in Gazeta de Campinas (07/04/1870, p. 1) mentions the widespread use of sharecropping contracts in large German estates and in Peruvian mines.
} 
Vergueiro, the head of the 1835 consortium, was most likely acquainted with this juncture in the German States after having studied Law at the University of Göttingen ${ }^{197}$.

The same argument about historical and international emulations applies to the bonding of labor ${ }^{198}$. Arrangements to bond labor played a central role in the settling of the U.S., where the market for redemptioners was abundantly supplied by laborers from the German States since the early seventeenth century ${ }^{199}$. Like in Brazil later on, credit interlinkages - independent of the labor-rental dimension of the contracts - allowed for the emigration of the poor. Some of these arrangements persisted in the U.S. until the $1820 \mathrm{~s}^{200}$. However, it was in the Caribbean and South America that indentures and other forms of labor tying regained most ground in the nineteenth century, especially with Asian immigrants ${ }^{201}$. Brazilian politicians and public commentators that favored the hiring of bonded Chinese coolies highlighted these other Latin American experiences in tying the labor of Asians ${ }^{202}$. The specific immigration of Chinese coolies did not take off in Brazil, but it reflected an extreme version of the tying of labor - a strategy that indeed pervaded the entire history of immigration to São Paulo ${ }^{203}$.

\subsection{The bonding of labor and the pervasiveness of the credit dimension}

\subsubsection{The political rationale of the credit-labor interlinkage}

If one single feature characterizes the Brazilian immigration policy in the period 1820-1920 it is its strategic focus on poor and credit-constrained households. The consecution of this strategy was independent of labor-rental arrangements, as the credit dimension of the interlinkage was malleable enough to adapt to any of the labor regimes considered in this study.

This pervasiveness of the credit-labor interlinkage resulted from the intersecting interests of the elite of coffee planters and the elaborators of the Brazilian immigration policy, in a symbiosis that grew tighter over time. It also met some objectives of sending countries, in particular of

\footnotetext{
${ }^{197}$ Castro (n.d., p. 25). I thank Leonardo Gardenal for this information, which deserves further historical scrutiny. José Vergueiro had also studied in the German States, according to Tschudi ([1866] 1953, p. 134).

198 Buarque de Holanda (1941), Witter (1974) and, to a lesser extent, Dean (1977) explain the adoption of sharecropping in São Paulo as a mimicking of indentures. However, the distinction between sharecropping and bonded labor is not always clear. This is different from Leff (1972, p. 491), who sees landowners' avoidance of free land tenures as an explicit mechanism to tie labor.

${ }^{199}$ Galenson (1984, footnotes 33, 43, 52) and Grubb (1994, p. 797). See also the summaries of Eltis (1983) and Donoghue (2013). For its diminished importance in the nineteenth century, see Wegge (2002, p. 386).

${ }^{200}$ Engerman and Margo (2010, p. 303). They notice that bonded labor was prohibited in the U.S. only in 1885.

${ }^{201}$ Buarque de Holanda (1941, p. 18), Galenson (1981) and Engerman (1983).

${ }^{202}$ Leff (1972, p. 492), Conrad (1975), Lamounier (1986, pp. 131, 135) and Viotti da Costa (1998, p. 187).

${ }^{203}$ For abuses against Asian indentures and the views of Brazilian politicians, see Yang (1977).
} 
the German States and Switzerland. In spite of the opposition that grew stronger in the second half of the nineteenth century, emigration by the mid-nineteenth century was seen as a measure of poverty relief. In the 1850 s, Vergueiro \& Co. 's hiring in Switzerland involved the councils of emigrants' municipalities, which advanced loans to those wishing to emigrate ${ }^{204}$.

The credit interlinkage fulfilled the farmers' objective of obtaining a stable and secure supply of laborers during the transition from slavery. This contractual instrument also complied with the political objective of attracting immigrants to Brazil. By focusing on households with fewer or no alternative destinations because of their poverty constraints, this policy allowed for an increased number of immigrants to Brazil without promoting reforms to make the country more attractive to non-bonded immigrants. The period considered in this chapter was particularly critical in terms of the international competition for labor: between 1847 and 1854, the U.S. received the highest contingency of immigrants as a share of its population ${ }^{205}$. Analysts at the time showed great awareness that the credit-labor interlinkage was the most effective policy to attract immigrants to Brazil under the institutions prevailing in the country. As summarized by a contemporaneous commentator, increasing non-bonded immigration to Brazil would demand reforms to "[...] facilitate land acquisition by the immigrant; allow for religious liberty, civil marriage, easy naturalization; equalize [the rights of] foreigners and Brazilians etc. etc."206

Bonding labor with a credit instrument was an undoubtedly costly policy. In a first moment, it involved the provision of public loans to private hirers and, posteriorly, the public subsidization of immigration. Between 1847 and 1878, about 30 million mil-réis were disbursed directly through immigration and settlement policies ${ }^{207}$. However, these policies delivered the expected results, especially in terms of labor supply. Despite high absolute disbursements, the costbenefit of these immigration policies was low vis-à-vis the increase in coffee exports that it permitted and the resulting public revenues ${ }^{208}$. Moreover, the institutional reforms mentioned above had an extremely high political and social cost for the Brazilian elites, in general, and for the ruling monarchy, in particular. Contemporaneous political analysts filled records with debates on how to increase the influx of immigrants by allowing for freedom of religion; easing

\footnotetext{
${ }^{204}$ Davatz ([1858] 1941, pp. 142-3 and contract in pp. 233-7). See also Correio Paulistano (12/02/1857, pp. 1-2).

${ }^{205}$ Engerman and Margo (2010, p. 303) and Engerman and Sokoloff (2011, pp. 19, 28). Interestingly, in 1865 the Brazilian central government sent a dispatch to its consulates in Prussia and Saxony informing that the costs differentials between immigrating to Brazil against the U.S. would be covered by the Brazilian government (Correio Paulistano, 14.09.1865, p. 2).

${ }^{206}$ Gazeta de Campinas (24/04/1870, p. 2).

207 Viotti da Costa (1998, pp. 183, 248). Dean (1977, p. 152) estimates 42 million mil-réis until 1904.

${ }^{208}$ Paraphrased from the argument by Petrone (2004, p. 346).
} 
access to landownership; and abolishing slavery itself ${ }^{209}$. The matter of fact, however, is that the Brazilian Empire fell in 1889 right in the aftermath of the abolition of slavery in 1888. Moreover, disputes with the Catholic Church - the state religion of the Brazilian Empire weakened the monarchists since the 1870s. Finally, landownership remained one of the most delicate issues in Brazilian politics and a restrictive law on access to land was passed in 1850, at the time of immigration of bonded laborers ${ }^{210}$.

Therefore, it was politically rational for the Brazilian elites to incur the costs of immigration associated with the credit interlinkage rather than to promote those institutional reforms. The consideration was much more of political economy than of public finance. While some forms of subsidized immigration took place in the U.S., American political elites had recognized that civil liberties and access to land precluded the need to subsidize immigration ${ }^{211}$. Brazilian policy-makers mirrored this strategy, taking exactly the opposite direction.

Various high-ranked authorities explicitly recognized this strategy ${ }^{212}$. The president of the province of São Paulo and a Brazilian consul in Geneva shared the opinion that only bonded labor was feasible as an immigration policy while the country did not promote institutional reforms; twenty years separated their analyses ${ }^{213}$. Relatedly, the Brazilian General Consul in Hamburg argued in 1858 that Brazil could expect only the immigration of subsidized households, given that only the poor considered the country as an alternative ${ }^{214}$. Similarly, the Brazilian Consul in the Hanseatic Cities had defended in 1856 that the government of São Paulo should guarantee a collateral security to immigrants, a proposition welcomed by the Swiss Consul in Hamburg as well ${ }^{215}$. Interestingly, the latter suggested that farmers in São Paulo could experiment with various labor-rental arrangements; these included sharecropping as proposed by Vergueiro \& Co., fixed remunerations per day worked and a complex arrangement that mixed fixed payments with shares in smallholdings for land acquisition and contract labor ${ }^{216}$. Finally, a future president of the Brazilian Republic, Manuel de Campos Sales, argued in 1870 that policy-makers were failing not only to modernize institutions to attract immigrants, but

\footnotetext{
${ }^{209}$ Viotti da Costa (1998, p. 186). See Abrantes (1846) for reforms related to landownership and Dean (1971, p. $617)$ and Witzel de Souza (2012, p. 89) for an evaluation of this source.

${ }^{210}$ Dean (1971), Leff (1972, p. 491), Engerman and Sokoloff (2011, p. 32) and Engerman and Margo (2010, pp. 293, 296-8).

${ }^{211}$ Engerman and Margo (2010, pp. 297-8, 302).

${ }^{212}$ Leff (1972, p. 493) and Sánchez-Alonso (2007, p. 399).

${ }^{213}$ Correio Paulistano (20/02/1855, p. 1) and Diário de S. Paulo (04/12/1875, pp. 1-2).

${ }^{214}$ Correio Paulistano (21/12/1859, pp. 1-2).

${ }^{215}$ Idem (12/02/1857, pp. 1-2). Notice the irony of the date of this suggestion: December 26 1856, i.e. two days after the Sharecroppers' Riot, certainly still not known by the European consular authority.

${ }^{216}$ This proposition is similar to the indenture contract of the Virginia Co. in 1620 (Galenson, 1984, p. 4).
} 
were also risking the immigration of bonded laborers due to the international lack of confidence on the Brazilian judiciary to guarantee an impartial enforcement of labor contracts ${ }^{217}$.

\subsubsection{The economic rationale of the credit-labor interlinkage}

The main economic concern of landowners during the transition from slavery was to obtain a supply of labor that was secure - substituting the increasingly riskier international slave markets - and stable - thus restricting fluctuations caused by labor turnover and mobility in non-captive markets ${ }^{218}$. These were crucial preoccupations of landowners accustomed with a perfect continuity in the elastic supply of slaves until that moment ${ }^{219}$. By interlinking labor to credit, the contracts transformed the flow of secure and stable labor into the main control variable of landowners, as long as they had credit instruments at their disposal.

Immigrants' initial debt corresponded to the costs of overseas and in-land transportation. These costs were determined by the size of the households and their age-sex composition, which allowed landowners to calculate roughly the average productive capacity of the immigrant households thus obtained. To this initial indebtedness, a varying annual parcel was added, comprised by advancements made to immigrants during their stay in the farms.

The time required by an average immigrant household to amortize the debt in the 1850 s is still susceptible to doubts. Estimates tend to be based on samples with limited coverage and vary between three and nine years, depending on the priors of the researcher about the productivity of sharecroppers ${ }^{220}$. Notwithstanding the imprecision of the estimates, it is safe to assume that the payback period of an average immigrant household was shorter than the average productive life of a slave, estimated to be around fifteen years ${ }^{221}$. Assuming an expected payback period of five years, landowners hiring bonded laborers had to incur in transaction (recruiting) costs

${ }^{217}$ Gazeta de Campinas (07/04/1870, p. 1). See Acemoglu and Wolitzky (2011, footnote 3, pp. 561, 569-70, 5878) for a discussion about the judiciary and general institutions as sources of labor coercion.

218 Other elites undergoing deep institutional modifications raised similar pleas, including in the post-bellum American South (Reid, 1973, 1975; Kotwal, 1985) and post-abolition West Indies (Engerman, 1983).

${ }^{219}$ See Otsuka et al. (1992, pp. 1973) for the Latin American problem of transitioning bonded labor into a flux of "modern agribusiness plantations based on free wage labor". Bardhan (1980, pp. 88-9, 92-4) discusses interlinkage as a form of labor tying.

${ }^{220}$ Viotti da Costa (1998) and Stolcke and Hall (1983, footnote 32). Dean (1977) notices that three years is a lowbound for an average estimate of five years.

${ }^{221}$ Viotti da Costa (2004, pp. 178-9). Dean (1977, pp. 84-5) reviews estimates on the productive life of slaves in agricultural tasks; estimates varied between 7 and 13 years, depending on the demographics of the slave force. 
three times more frequently than with the buying of a slave - a strong motivation to bond labor, especially if seasonality is important, as it is in coffee harvesting ${ }^{222}$.

The credit dimension had also the advantage of being very malleable. An additive credit-labor interlinkage as designed in the model of the appendix always leads to the same optimality condition for the credit dimension, irrespective of the labor-rental regimes. This implies that the credit dimension did not restrict landowners in the choice of the labor-rental arrangements. Conversely, changes in the labor-rental dimension of the contracts did not preclude the possibility of a credit interlinkage.

This result is in line with the interpretation that the bonding of labor via credit was a core characteristic of the Brazilian immigration policy between 1820 and 1920.

The Brazilian historiography has paid surprisingly little attention to the theoretical implications of this continuity in the credit-labor interlinkage. This is partially due to a lack of consensus about the objective functions of the plantation owners. One strand of the literature opposes the thesis that rural labor in the 1850s in São Paulo was a type of debt peonage. According to this view, the "[s]tability of labor on the plantation was a welcome by-product" of the credit interlinkage, not its main goal ${ }^{223}$. Relatedly, landowners in the 1850 s would allegedly have developed an economic rationale that went far beyond controls used in a slave-based society ${ }^{224}$. Consequently, landowners aimed at maximizing rents; the obtainment of a stable labor supply was only a means towards that end, not an objective per se. The other strand of the literature argues that the control over labor was more important than considerations about productivity or specific labor-rental arrangements ${ }^{225}$. According to this view, bonding labor was an objective on its own to guarantee a stable workforce. The prominence of this goal would be observable not only in the plantations, but also in the institutions that determined labor regulations in the country.

This dissent reflects different conceptualizations about the economic rationality of Brazilian rural elites in the nineteenth century. However, these interpretations are contradictory only at face value. They can actually be synthesized by a model in which landowners maximize rents, but have labor and credit as the choice variables, as accomplished in this chapter ${ }^{226}$. In this case,

\footnotetext{
${ }^{222}$ Bardhan (1980, pp. 92-3), Alston (1981, p. 213) and Mukherjee and Ray (1994, pp. 209-10).

${ }^{223}$ Stolcke and Hall (1983, p. 170, footnote 40).

${ }^{224}$ Ibid. (1983, p. 188).

${ }^{225}$ Dean (1977) and Viotti da Costa (1998, pp. 137-47). Stolcke and Hall (1983, footnote 115) explicitly criticize Dean's views.

${ }^{226}$ In line with Lamounier (1986).
} 
the result that the credit dimension subsists with different labor-rental arrangements holds irrespective of how we justify the motivations of the rent maximizers.

\section{Concluding remarks}

This chapter outlined a history of bonded labor in the plantations of São Paulo by the midnineteenth century. Building on some new historical evidence and a theoretical model, the chapter evaluated the choice of labor contracts applied to non-captives during the Brazilian transition from slavery.

The chapter showed how the 1850s were characterized by an increasing number of farmers employing bonded laborers, especially under sharecropping contracts. This period was preceded by intense debates about alternative sources of labor vis-à-vis the imminent risk of the Brazilian ban on the transatlantic slave trade. The 1860s-70s, in turn, witnessed the substitution of sharecropping by other labor-rental arrangements, including fixed rents and remuneration systems closer to market-based salaries. Nevertheless, the new contracts retained the credit dimension of the interlinkage and their clauses continued to be influenced by those of sharecropping. Finally, the credit interlinkage consolidated as a state policy in the 1880 s, when the government of São Paulo started subsidizing the migratory costs of households that accepted employment in the plantations.

The long-lasting influence of the sharecropping contracts and the continuity of the immigration policy based on the credit-labor interlinkage support the two propositions of this chapter.

The first proposition is that sharecropping did not prevail during the first phase of the Brazilian transition from slavery because of a rational economic decision taken by landowners. From the 1830 s to the 1850 s, alternative projects included a vast array of contractual arrangements, such as indentures, a type of headright system, land-rentals under fixed rents, fixed payments per piece-rate or time worked etc. Theoretical results and historical evidence suggest that it was neither necessary nor sufficient that sharecropping would prevail as the first labor-rental dimension of non-captive labor in Brazil. It did so mainly because of path dependence and emulations of other international and historical experiences.

The second proposition is that the credit-labor interlinkage was more important to landowners than specific labor-rental arrangements, creating a thread for the Brazilian immigration policy 
that endured from the 1820 s to the $1920 \mathrm{~s}^{227}$. Bonding immigrant labor with a credit interlinkage was an arrangement not completely alien to slave-based economies ${ }^{228}$. Moreover, the interlinkage had a clear political rationale, as it allowed for the immigration of poor and creditconstrained Europeans. This inserted Brazil into the circuit of the Age of Mass Migration without the promotion of institutional reforms that represented a serious political risk to the ruling elites.

These propositions add to the renewed interest in the rationale and historical pervasiveness of sharecropping and bonded labor. The literature on the historical adoption of different laborrental arrangements has recently thrived in showing that the rationality of various contractual arrangements is a function of a number of other considerations, much beyond pure concerns about allocative efficiency ${ }^{229}$. Other motives include the regulation of property rights over investments undertaken by tenants; risk considerations about the depletion of soil and crops; seasonality; and monitoring. The study of sharecropping contracts with bonded Europeans in the coffee economy of São Paulo contributes with a case in which credit-labor interlinkages provide yet another motive, with a clear political underpinning.

The study of bonded labor and sharecropping in Brazilian plantations is far from exhausted and three research lines seem particularly fruitful. First, there is an urge for collecting quantitative data on labor, credit, production and types of contract prevailing in different Brazilian regions. Both micro and macro evidence are required to test for differences in labor productivity under various contracts, as hypothesized in this chapter. Second, it is necessary to find more contracts to evaluate their clauses. Only comparative microeconomic analyses of contractual mechanisms will allow us to grasp fully the path dependence in the adoption of sharecropping contracts and their influence on posterior labor arrangements. Finally, this chapter provides only the tip of the iceberg in terms of newly available digitized sources. New online archives with automatized search engines shelter an immense quantity of factual evidence for the history of immigration and bonded labor in Brazil and its global context. A systematic review of other newspapers, official reports, travelers' compendia and international press bears an enormous potential.

\footnotetext{
${ }^{227}$ Sánchez-Alonso (2007, pp. 406-7, 410-1) and Ferrie and Hatton (2015, pp. 64-6).

${ }^{228}$ As classically studied by Reid (1975) and motivated by Kotwal (1985).

${ }^{229}$ Carmona and Simpson (1999, 2012), Camara (2006), Garrido and Calatayud (2011) and Garrido (2017).
} 


\section{Appendix: Per worker costs of sharecropping, fixed rents and wage systems}

\subsection{Motivation and setting}

In this appendix, I formalize the proposition that landowners in São Paulo could have been indifferent among various labor-rental arrangements. I am particularly interested in the first period of employment of bonded labor in the plantations. In this context, the underlying question is whether landowners had any special, theoretically founded economic motivation to adopt sharecropping contracts in the early 1850s, when alternative labor-rental regimes seem to have been feasible in historical terms.

The model builds on variations of a partial equilibrium, in which a single landowner maximizes his/her rents. The landowner chooses among different labor-rental regimes interlinked to a credit dimension to form a specific contract. Laborers, in turn, are immigrants who require a loan to cover immigration costs and demand other credit advances during their stay in the farms. The participation constraint of the laborers subsumes to the acceptance or not of a specific type of contract that includes a labor-rental and a credit dimension. The objective function of the landowner and the participation constraint of laborers vary according to each labor-rental regime, but the problem always subsumes to a linear credit-labor interlinkage ${ }^{230}$.

The model presents the conditions for the equality of the per worker costs (PWC) of employing sharecroppers, wage laborers, or renters who paid fixed land-rentals to the landowner. Conditional on obtaining laborers - i.e. that the loans allow for the immigration of laborers -, the landowner will prefer the labor-rental arrangement with the lowest PWC, i.e. the cheapest source of labor conditional on the participation constraint of foreigners. In this partial equilibrium analysis, I assume that the demand of any single landowner does not affect the unitary cost of labor in any of the labor-rental regimes considered, an adequate assumption in the context of a large international pool of poor and credit-constrained potential immigrants.

I compare the PWCs of sharecropping, fixed rents and wage systems in two scenarios. In the first, I assume no productivity differentials among the three labor-rental regimes. The historical evidence presented in the chapter showed that landowners in the late 1840s and 1850s were tentatively experimenting with different labor-rental regimes. In this context, concerns about productivity differentials among contracts were minimal, if existent at all. Therefore, I consider

${ }^{230}$ In line with the basic model presented in Basu (2003, Chapter 14, especially pp. 286-291). 
this assumption adequate to illustrate this first phase of adoption of bonded labor in the plantations of São Paulo ${ }^{231}$. In the second scenario, I assume that sharecropping leads to lower labor productivity vis-à-vis fixed rents and wage systems. As discussed in the chapter, this assumption is based on the idea that the Marshallian inefficiency of sharecropping prevailed in the coffee plantations and that the self-monitoring of household members would have precluded monitoring costs under wage systems.

The first scenario allows for the possibility of equalizing the PWCs of sharecropping, fixed rents and wage systems. This supports the claim that the adoption of sharecropping in the 1850s was not the result of a pure economic decision of landowners. Other feasible labor-rental arrangements could have led to the same economic outcomes in terms of the supply of labor and its costs. The second scenario shows that the equalization of the PWCs among the three labor-rental arrangements preclude either differences in labor productivity among them or the existence of perfectly competitive wage systems.

Moreover, the model shows that the credit dimension of the interlinkage did not depend on any specific labor-rental arrangement. With an additive credit-labor interlinkage, the same optimality condition is obtained for the credit dimension, irrespective of labor-rentals. This malleability helps to explain the pervasiveness of the credit interlinkage in the Brazilian immigration policy throughout the nineteenth century.

\subsection{The model}

Define agricultural production, $Y=Y\left(N^{i}, \bar{H}\right)$, as a function of units of labor $N$ under laborrental regime $i$ and a fixed amount of land $\bar{H}$, following standard properties for an internal solution. The set of labor-rental regimes include sharecropping $(s h)$, fixed rents $(f)$ and wage system (ws). For simplicity, I assume that the labor-rental dimension is always in pure form i.e. I exclude mixed contracts and the coexistence of different labor-rental regimes.

The rents perceived by the landowner are an additively separable function of a labor-rental and a credit dimension:

$$
R^{i}=f(Y)+g(L)=f\left(Y\left(N^{i}, \bar{H}\right)\right)+g(L)^{232}
$$

\footnotetext{
${ }^{231}$ As pointed out in the chapter, one can read the non-differentials in productivity as the outcome of an interlinked contract in which landowners adjust either the credit or the labor dimension to lead to an efficient outcome.

${ }^{232}$ I set the price of output as the numeraire throughout.
} 
The landowner maximizes rents, $R^{i}$, and has as choice variables the units of labor to be hired in a specific labor-rental regime, $N^{i}$, and the amount of loans to be supplied, L. Output shares and interest rates are exogenous parameters determined by custom and the market ${ }^{233}$.

The labor-rental dimension varies according to the labor-rental regime considered.

In pure form, $f(Y)=\alpha Y+F$, where $\alpha$ stands for output share and $\mathrm{F}$ for fixed amounts paid to workers (wages) or received as rents. In short:

$$
f(Y)=\alpha Y+F:\left\{\begin{array}{l}
0<\alpha<1 \text { and } F=0, \text { if } i=s h \\
\alpha=0 \text { and } F \lessgtr 0, \text { if } i=(w s, f)
\end{array}\right.
$$

Landowner's maximization of rents is subject to the participation constraint of laborers. By assuming $N^{i}$ to be perfectly enforceable at no cost to the landowner, this setting gives agency to laborers only in terms of their participation constraint. This implies a binary decision to accept a certain contract and reflects laborers' decision to immigrate based exclusively on the prospects of that specific contract, which combines a labor-rental and a credit dimension.

The assumption that laborers have agency only in terms of their participation constraints ignores a number of labor riots discussed in the thesis. However, these riots and other expressions of dissatisfaction of immigrants with their living and working conditions were the result of the experience accumulated over time with the enforcement of different contracts. At the first phase of the adoption of bonded labor, this assumption does seem to reflect the perceptions of landowners and the choices available to laborers ${ }^{234}$.

Adapting Basu (2003, p. 289), I define laborers as having utility $u=u(w, L)$, where $w$ reflects the opportunity costs of labor (including in the countries of origin) and $L$ captures the utility of emigrating - which, according to the historical discussion, was not possible without the credit dimension, reflected by $L$ in the formal setting. I assume $u$ to be an increasing and concave function in both arguments and rewrite it in terms of the reservation frontier of the laborers ${ }^{235}$ :

$$
w=\phi(L, u)
$$

\footnotetext{
${ }^{233}$ Interest rates in 1847 were based on legal interests; output shares were set at the customary $1 / 2$. On the exogeneity of similar parameters, determined by historical custom, see Koo (1973, p. 579).

${ }^{234}$ I thank Samuel Garrido for discussing this point.

$235[\partial \phi(L, u) / \partial \mathrm{L}]>0$ holds for the actual immigrants, which corresponds more strictly to $[\partial \phi(L, \tilde{u}) / \partial \mathrm{L}]>0$, according to the notation used below. The idea is that laborers who actually immigrate are willing to do so (explaining the positive partial derivative), but cannot until the poverty constraints are removed by the loans $L$ supplied by the landowner.
} 
Finally, I assume that all agents have perfect information and are risk-neutral. In the model, there is no uncertainty in production nor default on loans ${ }^{236}$.

In the sequence, I compare the three labor-rental regimes to each other and to a benchmark in which slavery prevails and the market for captives is perfectly competitive. In such comparisons, I impose no functional form to $Y\left(N^{i}, \bar{H}\right)$ nor to $\phi(L, u)$. Rather, comparisons are made in terms of per worker costs of the different labor-rental regimes.

\subsection{Partial-equilibria: landowner's rents with different labor-rental regimes}

\subsubsection{Slave labor}

As a benchmark, consider a perfectly competitive market for captive labor. Landowner's rents include only the labor dimension and the problem pinpoints to a usual maximization:

$$
\max _{N^{s l}} \mathrm{R}^{s l}=Y\left(N^{s l}, \bar{H}\right)-c N^{s l}
$$

where $c$ reflects the unitary cost of a slave ${ }^{237}$. Given that the model is instantaneous, this parameter incorporates the lifelong costs of the captive from the viewpoint of the landowner.

In this simple case, the unitary cost of a slave equals his/her marginal productivity.

$$
\partial \mathrm{R}^{s l} / \partial N^{s l}=0 \Rightarrow c=\partial Y / \partial N^{s l}(E q .1)
$$

\subsubsection{Perfectly competitive wage system}

Similarly, in a perfectly competitive free labor market, a rent-maximizing landowner who interlinks labor and credit in a contract solves the following problem:

$$
\max _{N^{w s}, L} \mathrm{R}^{w s}=Y\left(N^{w s}, \bar{H}\right)-\phi(L, \tilde{u}) N^{w s}+(i-r) L N^{w s}
$$

The labor dimension reflects the cost per unit of labor, conditional on the participation constraint ${ }^{238}$. The credit dimension, in turn, reflects the amount of loans, $L$, and its corresponding opportunity cost, i.e. the difference between the actual interest rate $i$ and the

\footnotetext{
${ }^{236}$ The same argument about laborers' agency applies here to justify these assumptions.

${ }^{237}$ For historical differentiation, I use the term $c$ to reflect the price of a slave. It corresponds to a disbursement $F$ in the general labor dimension $f(Y)$.

${ }^{238} \tilde{u}$ indicates that the specific laborer decided to immigrate (differing from $u$, as above). The conditions for the prevalence of $\tilde{u}$ are binding, i.e. they limit the discretionary power of landowners in setting $N^{i}$ and $L$.
} 
return on alternative investments, $r$. Please notice that I assume that the landowner has enough sources of credit to supply any amount $L$ of loans to the laborers. Part of these loans are used by the laborers to cover the immigration costs and are, therefore, fixed - as the migratory costs are exogenous to any landowner. Nevertheless, laborers demand further loans while in the farm $-e . g$. to cover their consumption of foodstuff bought in the farm's grocery store. That is the reason for considering $L$ a choice variable of the landowner ${ }^{239}$.

The PWC in perfectly competitive markets can be directly defined with the previous expression:

$$
R^{w s}=Y\left(N^{w s}, \bar{H}\right)-N^{w s}[\phi(L, \tilde{u})-(i-r) L]=Y\left(N^{w s}, \bar{H}\right)-N^{w s} P W C
$$

From the FOCs:

$$
\begin{gathered}
\partial \mathrm{R}^{w s} / \partial N^{w s}=0 \Rightarrow \partial \mathrm{Y} / \partial N^{w s}=\phi(L, \tilde{u})+(i-r) L=C^{w s}(E q .2) \\
\partial \mathrm{R}^{w s} / \partial \mathrm{L}=0 \Rightarrow \partial \phi / \partial \mathrm{L}=(i-r)(E q .3)
\end{gathered}
$$

In a standard result for competitive markets, equation (2) shows that the marginal productivity of labor equals its marginal cost. This corresponds also, by definition, to the PWC of a wage system in a perfectly competitive market. Assuming no productivity differentials with respect to slavery, i.e. $\left(\partial \mathrm{Y} / \partial N^{s l}=\partial \mathrm{Y} / \partial N^{w s}\right)$, a necessary condition to employ wage laborers is that $C^{w s}=c$. This result is immediate from the setting, in which captive and free labor markets are perfectly competitive. Although theoretically uninteresting per se, it shows that systems that belong to historically different categories can lead to identical outcomes. As Eltis (1983, p. 266) argues: "The conviction of the superiority of free labor on the part of the economically advanced nations was not shaken by the fact that sugar, coffee and cotton could all be produced more cheaply by unfree labor" ${ }^{240}$.

Equation (3) shows that the marginal effect of loans on the reservation frontier of laborers must equal the opportunity cost of landowner's capital in a perfectly competitive market. Despite standard, this result provides a benchmark for comparisons with other labor-rental regimes.

\footnotetext{
${ }^{239} \mathrm{~L}$ can be modeled as a function of a fixed parcel used to cover immigration costs and a varying parcel, reflecting the demand of credit by laborers in the farm. For ease of exposition, I considered only the supply side by the landowner, making $L$ a single choice variable. I thank Holger Strulik for pointing this out.

${ }^{240}$ This argument refers only to the partial equilibrium from the point of view of a rent-maximizing landowner. It does not take into account the deleterious effects of slavery for socio-economic development, nor its abhorrent nature in terms of human rights. Dean (1977, p. 184) and Acemoglu and Wolitzky (2011) highlight that slavery can lead to higher productivity and profits, but always generates socially inefficient outcomes.
} 


\subsubsection{Sharecropping}

Under sharecropping, the landowner makes no disbursement in the labor dimension and receives a fraction $\alpha$ of the produce. The problem is now:

$$
\begin{aligned}
& \max _{N^{s h}, L} R^{s h}=\alpha Y\left(N^{s h}, \bar{H}\right)+(i-r) L N^{s h} \\
& \text { s.t. }(1-\alpha) Y\left(N^{s h}, \bar{H}\right)=\phi(L, \tilde{u}) N^{s h}
\end{aligned}
$$

Setting the Lagrangean Z, we obtain the following FOCs:

$$
\begin{gathered}
\partial \mathrm{Z} / \partial N^{s h}=0 \Rightarrow \alpha \partial \mathrm{Y} / \partial N^{s h}+(i-r) L+\lambda\left[(1-\alpha) \partial \mathrm{Y} / \partial N^{s h}-\phi\right]=0(E q .4) \\
\partial \mathrm{Z} / \partial \mathrm{L}=0 \Rightarrow(i-r)-\lambda^{\partial \phi} / \partial \mathrm{L}=0(E q .5)
\end{gathered}
$$

To compare different labor-rental regimes without specific functional forms for the production function or the reservation frontier, I use the PWC of each labor-rental regime and set it against the standard result obtained from the wage system in perfectly competitive markets ${ }^{241}$. By doing so, I obtain the following PWC of sharecropping:

$$
P W C^{s h}=\partial \mathrm{Y} / \partial N^{s h}\left[\alpha+\frac{(i-r)(1-\alpha)}{\partial \phi / \partial \mathrm{L}}\right]+\phi\left[1-\frac{(i-r)}{\partial \phi / \partial \mathrm{L}}\right](E q .6 a)
$$

The expression shows that the PWC of sharecropping is a function of two additive components. The first reflects the labor dimension. Here, the marginal productivity of labor in this laborrental regime is weighted by the output share, by the opportunity cost of the loans and by the

${ }^{241}$ For this, solve for the Lagrangean multipliers from the FOCs:

$$
\frac{\phi(i-r)}{\partial \phi / \partial \mathrm{L}}-(i-r) L=\alpha \partial \mathrm{Y} / \partial N^{s h}+\left[\frac{(i-r)(1-\alpha) \partial \mathrm{Y} / \partial N^{s h}}{\partial \phi / \partial \mathrm{L}}\right](E q .6 b)
$$

Since $P W C$ is given by definition, we can determine the difference between the $P W C$ in perfectly competitive wage systems and the expression above, i.e. call the left-hand side of the previous expression $X$; then we have:

$P W C-X=(.) \Leftrightarrow P W C=()+$.

$P W C-X=\phi-(i-r) L-\frac{\phi(i-r)}{\partial \phi / \partial \mathrm{L}}+(i-r) L \Rightarrow()=.\phi\left[1-\frac{(i-r)}{\partial \phi / \partial \mathrm{L}}\right]$

By inserting (.) back into Eq. 6b, we obtain the PWC under sharecropping (i.e. Eq. 6a). 
impact that the loans have on the reservation frontier. The second reflects the credit dimension, with laborer's reservation frontier weighted by the opportunity cost of the loan.

\subsubsection{Fixed rents}

To set the problem analogously to sharecropping, I assume that fixed rents $(F)$ are not a choice variable of the landowner, but a parameter determined in the market or by custom ${ }^{242}$.

The maximization problem is now:

$$
\begin{gathered}
\max _{N^{f}, L} \mathrm{R}^{f}=F N^{f}+(i-r) L N^{f} \\
\text { s.t. } Y\left(N^{f}, \bar{H}\right)-F N^{f}=\phi(L, \tilde{u}) N^{f}
\end{gathered}
$$

Setting the Lagrangean Z, we obtain the following FOCs:

$$
\begin{gathered}
\partial \mathrm{Z} / \partial N^{f}=0 \Rightarrow F+(i-r) L+\lambda\left[\partial \mathrm{F} / \partial N^{f}-F-\phi\right]=0(E q .7) \\
\partial \mathrm{Z} / \partial \mathrm{L}=0 \Rightarrow(i-r)-\lambda^{\partial \phi} / \partial \mathrm{L}=0(E q .8)
\end{gathered}
$$

With the same procedure as for sharecropping, we obtain the following PWC of fixed rents:

$$
P W C^{f}=\partial \mathrm{Y} / \partial N^{f}\left[\frac{(i-r)}{\partial \phi / \partial \mathrm{L}}\right]+(F+\phi)\left[1-\frac{(i-r)}{\partial \phi / \partial \mathrm{L}}\right](E q .9)
$$

Equations (5) and (8) show that the optimality conditions stemming from the credit dimension of the interlinkage are identical for sharecropping and fixed rents. This result depends on the assumption that rents are a linear additive function of the labor-rental and the credit dimensions. Nevertheless, this equality shows that it was possible to design a contract in which the optimality condition of the credit dimension did not depend on specific labor-rental arrangements. Notice, however, that the credit dimension still has different influences on the PWCs of sharecropping and fixed rents. Thus, the argument is not that the labor-rental and the credit dimensions are totally independent of each other, but that the latter could be adapted to the specificities of each labor-rental regime.

${ }^{242}$ We can also model fixed rents as a function of units of labor. With a word of caution, this is similar to Bonifácio do Amaral's contract in the 1870 s. In this case, $F=F\left(N^{f}, \bar{H}\right)$ leads to:

$$
P W C^{f^{\prime}}=\partial \mathrm{Y} / \partial N^{f}\left[\frac{(i-r)}{\partial \phi / \partial \mathrm{L}}\right]+\left(\partial \mathrm{F} / \partial N^{f}+\phi\right)\left[1-\frac{(i-r)}{\partial \phi / \partial \mathrm{L}}\right]
$$




\subsection{Comparing PWCs of different labor-rental regimes}

Equations (2), (6) and (9) allow us to determine the conditions under which

$$
C^{w s}=P W C^{s h}=P W C^{f}
$$

i.e. the conditions that lead to the same PWC of the three labor-rental regimes as perceived by the landowner. For this exercise, I will consider two scenarios. The first assumes that there are no differentials in productivity for the three labor-rental regimes. The second assumes the Marshallian inefficiency of sharecropping vis-à-vis fixed rents and wage systems, which are considered equally efficient.

\subsubsection{No productivity differentials}

Under the assumption of no differentials in productivity, i.e. $\left(\partial \mathrm{Y} / \partial N^{i}=\partial \mathrm{Y} / \partial \mathrm{N}\right)$, the equilibrium conditions derived from the PWC of each labor-rental regime lead to the following pairwise comparison between them:

$$
\begin{gathered}
P W C^{s h}=P W C^{f} \Leftrightarrow \partial \mathrm{Y} / \partial N=\frac{F}{\alpha} 243 \\
P W C^{s h}=C^{w s} \Leftrightarrow \partial \mathrm{Y} / \partial N=\frac{\phi}{(1-\alpha)} \\
P W C^{f}=C^{w s} \Leftrightarrow \partial \mathrm{Y} / \partial N=F+\phi
\end{gathered}
$$

From these, it is straightforward to show that the condition $\left[\phi=\frac{(1-\alpha) F}{\alpha}\right]$ satisfies the equality $C^{w s}=P W C^{s h}=P W C^{f}$.

If there are no productivity differentials among the three labor-rental regimes - factually so or as perceived by the landowner -, it is possible to design a credit-labor interlinkage that equates the per worker costs of sharecropping, fixed rents and wage systems. From a theoretical point of view, sharecropping was neither a necessarily superior nor necessarily inferior contract to a landowner who maximized rents in the first period of the transition from slavery in São Paulo.

${ }^{243}$ For the extension in which $F=F\left(N^{f}, \bar{H}\right), P W C^{f^{\prime}}=P W C^{s h} \Leftrightarrow \partial \mathrm{Y} / \partial N=\frac{\partial \mathrm{F} / \partial N}{\alpha}$ 


\subsubsection{PWCs under the Marshallian inefficiency of sharecropping}

Under the assumption that sharecropping suffers from allocative inefficiencies vis-à-vis the other two labor regimes, i.e. $\left(\partial \mathrm{Y} / \partial N_{s h}<\partial \mathrm{Y} / \partial N^{f}=\partial \mathrm{Y} / \partial N^{w s}\right)$, we get the following conditions for the equalization of the PWCs between sharecropping and fixed rents:

$$
\begin{gathered}
P W C^{s h}=P W C^{f} \\
\Rightarrow\left[\alpha \partial \mathrm{Y} / \partial N_{s h}-F\right]\left[\frac{\partial \phi / \partial \mathrm{L}}{(i-r)}-1\right]=\left[\partial \mathrm{Y} / \partial N^{f}-\partial \mathrm{Y} / \partial N^{s h}\right]>0
\end{gathered}
$$

For this expression to hold, we need:

i. $\quad\left[\alpha \partial \mathrm{Y} / \partial N^{s h}-F\right]>0 \Rightarrow \partial \mathrm{Y} / \partial N^{s h}>\frac{F}{\alpha}$

and

ii. $\left[\frac{\partial \phi / \partial \mathrm{L}}{(i-r)}-1\right]>0 \Rightarrow \partial \phi / \partial \mathrm{L}>(i-r)$

or

iii. Equivalently, strictly negative inequalities for both expressions.

This means that the equality of the PWCs of sharecropping and fixed rents under productivity differentials precludes the existence of a perfectly functioning wage system, for in that case $\partial \phi / \partial \mathrm{L}=(i-r)$ to fulfill optimality condition (3). In other words, we cannot have simultaneously a perfectly functioning wage system, lower productivity in sharecropping and equal PWCs of sharecropping and fixed rents. Analogous results hold for $\left(P W C^{s h}=C^{w s}\right)$ and $\left(P W C^{f}=C^{w s}\right)$.

In conclusion, a landowner who does not foresee (or if there is no) productivity differentials among the three labor-rental regimes can design contractual arrangements that equalize the PWCs of sharecropping, fixed rents and wage system (scenario 1). Conversely, the existence of perfectly competitive wage systems precludes either the equality of the PWCs or differentials in productivity among these three labor-rental regime. (scenario 2 ). 



\title{
3. Immigration and the path dependence of education: the case of German-speakers in São Paulo (1820-2010)*
}

\begin{abstract}
Summary
This chapter studies the path dependence of human capital accumulation. It focuses on the impacts that German-speaking immigrants had on education through three channels: their share of the population in the nineteenth century, their on-the-job skills and the schools they founded. By combining data of almanacs from 1873 and 1888, these effects are evaluated for the nineteenth, early twentieth and early twenty-first centuries. Results show that the institutionalized demand for education of these immigrants, reflected by the establishment of schools, was their main contribution to the accumulation of human capital. The effect of German schools on educational levels required a period to mature and dissipated over time. Nevertheless, their influence was substantial at the beginning of the twentieth century, affecting enrolment levels in private and in state schools, a result that suggests the existence of spillover and contagion effects. Moreover, current indicators of stocks and flows of human capital in São Paulo are strongly associated with their historical levels. At the same time, path dependence is conditional on the type of school: while a positive persistence is found for the private system throughout the twentieth century, a reversal of performance occurred in state schools.
\end{abstract}

\footnotetext{
* A shortened version of this chapter was published as: Witzel de Souza, B. G. (2018). "Immigration and the path dependence of education: the case of German-speakers in São Paulo, Brazil (1840-1920)". The Economic History Review, Vol. 71 (2) - https://onlinelibrary.wiley.com/doi/full/10.1111/ehr.12575, accessed on December 03 2018. I thank the editor Jaime Reis and three anonymous referees for the discussions. This chapter is an independent work and I am solely responsible for its content. An updated argument about the relationship between German schools and settlement colonies was included in the appendix to this chapter.
} 



\section{Introduction}

In the past two decades, the literature on the deep determinants of economic development has raised many new research questions by using historical events to explain current economic performance. One cornerstone of this approach is to explain the historical dynamics of institutions by their colonial origins ${ }^{1}$. A more recent strand of this literature shows that the relationship between current outcomes and historical determinants can vary substantially according to the period and region covered ${ }^{2}$. By moving away from cross-country studies towards regional analyses, this strand has suggested that external shocks can - at least partially - divert outcomes from a path set early on by institutions in colonial times. Those changes in path dependence seem to be particularly important for the accumulation of human capital. A recent literature focused on Brazil has emphasized how international migration can be seen as a shock that influences educational path dependence in a positive manner ${ }^{3}$.

In an attempt to contribute to this literature, this chapter explores whether German-speaking immigrants impacted the accumulation of human capital in the province of São Paulo in the short and long run. The underlying hypothesis is that these immigrants had a positive influence on the path dependence of education in the province/state because of their relatively high levels of human capital, compared to the Brazilian average, in terms of schooling and on-the-job skills. It is argued that the influence of these immigrants can be seen as an exogenous shock to the accumulation of human capital in the nineteenth century - one that reverberated down into the twentieth century, indirectly influencing current educational outcomes at the municipal level.

The chapter shows that the presence of German-speaking immigrants per se had no impact on the historical accumulation of human capital. However, a positive influence emerges where these immigrants were able to institutionalize their higher levels of education through founding schools. This historical impact of German schools required a maturation period and dissipated over time, having its strongest influence at the beginning of the twentieth century. German schools robustly influenced enrolment both in private and in state schools in the 1910s. This result suggests the existence of spillovers and contagion effects in the supply and demand for education, respectively.

\footnotetext{
${ }^{1}$ Among the plethora of works in this direction, see the seminal contributions for the Americas by Mariscal and Sokoloff (2000), Sokoloff and Engerman (2000) and Acemoglu, Johnson and Robinson (2001, 2002).

${ }^{2}$ Glaeser, La Porta, López-de-Silanes and Shleifer (2004), Przeworski (2004), Pande and Udry (2005), Nunn (2009), Summerhill (2010) and Nunn, Qian and Sequeira (2017).

${ }^{3}$ Carvalho Filho and Colistete (2010), Carvalho Filho and Monasterio (2012), Stolz, Baten and Botelho (2013), Musacchio, Fritscher and Viarengo (2014) and Rocha Ferraz and Soares (2017).
} 
The chapter also demonstrates that indicators for current stocks and flows of human capital are strongly associated with their historical counterparts. The path dependence of current enrolment is additionally shown to be conditional on the type of school. On the one hand, a positive persistence was found for the private schools, showing that municipalities that had more of this type of school at the beginning of the twentieth century retained an advantage in this modality of education almost a century later. On the other hand, a negative relation was found between current and historical enrolment in state schools; this favors the hypothesis that the Brazilian public educational system had a reversal in its capacity to accumulate human capital over the twentieth century.

The analysis presented here focuses on a historically-specific process and a geographicallydelimited area, which gives this approach two empirical advantages. First, São Paulo is culturally and institutionally more homogenous than larger units of aggregation, which reduces concerns about unobserved heterogeneity ${ }^{4}$. Second, the immigration of German-speakers is seen as an exogenous shock to the demand for education in the state. Conditional on further controls, the initial allocation of these immigrants, mostly bonded laborers on plantations or settlers in rural colonies, is argued to be exogenous to the contemporary educational levels of the municipalities where these plantations or rural colonies were located. As seen in Chapter 1, German-speakers did not sort to municipalities according to prevailing literacy or enrolment rates by 1872 . In addition, incentives to accumulate human capital among these immigrants were also associated with cultural traits, such as religion, being therefore more exogenous to prevailing economic conditions than current decisions to invest in education ${ }^{5}$.

The choice of the state of São Paulo as the unit of analysis has important implications for the emerging strand of literature focused on the historical accumulation of human capital, especially for that branch using the Brazilian case. Although São Paulo currently has the highest absolute level of income of any Brazilian state, it was considered a region of marginal importance during most of the colonial era (1500-1822). Changes in the state's relative economic position began mainly during the second half of the nineteenth century, around the time that São Paulo became the most attractive destination for immigrants in Brazil ${ }^{6}$. This reversal in economic importance was simultaneous to a sustained increase in educational performance, leading the literature to

\footnotetext{
${ }^{4}$ Pande and Udry (2005) and Gennaioli, La Porta, López-de-Silanes and Shleifer (2013).

${ }^{5}$ For the relation between educational attainment and religion, see Becker and Woessmann (2009, 2010).

${ }^{6}$ Summerhill (2010, p. 13).
} 
hypothesize that the inflow of immigrants caused this modification in the path of human capital accumulation ${ }^{7}$.

The immigration of German-speakers in particular presented different features in São Paulo compared to other regions in the country. While immigrant communities in southern Brazil were more isolated and ethnically homogenous, in São Paulo the socioeconomic and cultural integration into the native population was faster and smoother ${ }^{8}$. This increased the likelihood of spillover and contagion effects among immigrants and Brazilian-born individuals, a result that is actually found in this chapter's empirical analysis.

Region-specific characteristics can clarify to some extent the diverse mechanisms described in the literature to explain how immigration impacted educational performance across Brazilian states in the long run. Carvalho Filho and Colistete (2010) and Rocha, Ferraz and Soares (2017) find a positive and significant impact of European immigrants on the accumulation of human capital in São Paulo during the first decades of the twentieth century. These results are similar to those of Stolz, Baten and Botelho (2013), who use numeracy and assess the impact on the country as a whole. The last two studies also explore on-the-job skills as a further transmission channel. Carvalho Filho and Monasterio (2012), in turn, argue that lower inequality associated with German immigrants in the southernmost state of Rio Grande do Sul had a larger impact on development than transfers of human capital. Although these studies differ in the specific transmission channels assessed, they all point to a positive and significant relationship between immigration and educational development in the long run. In contrast, Musacchio, Fritscher and Viarengo (2014) argue that the political economy of financing education was the main factor behind the reversal of educational performance across Brazilian states, not immigration. They even find a negative correlation between immigration and expenditures on education of the Brazilian government. This result is explained by the fact that Portuguese, Italian and Spanish - the main nationalities immigrated to Brazil - had a relatively low level of human capital in their countries or origin: there simply was not much human capital to be gained from them ${ }^{9}$.

\footnotetext{
${ }^{7}$ See the review of this argument in Musacchio, Fritscher and Viarengo (2014, pp. 731-3).

${ }^{8}$ Buarque de Holanda (1941, pp. 23-4) and Tschudi ([1866] 1953, e.g. pp. 163, 168). Naturally, this does not imply that integration was without conflicts. For problems associated with German schools, see Witzel de Souza (2014, pp. 24-7).

${ }^{9}$ Musacchio, Fritscher and Viarengo (2014, p. 747). For a criticism on the perspective that southern Europeans in Latin America were overall worse selected in terms of human capital, see Sánchez-Alonso (2007).
} 
The chapter is organized as follows. Section 2 provides an overview of the history of Germanspeaking immigration to São Paulo. The historical experience is used to derive the working hypotheses about the relationship between immigration and human capital accumulation. Section 3 presents the methodology for the empirical analysis. In particular, I describe the homogenization of the datasets that allows for the study of human capital accumulation in the long run. Section 4 presents the results, which are subjected to two main robustness checks in Section 5. Section 6 contains some concluding remarks.

\section{German-speakers and human capital: historical overview and hypotheses}

Perhaps no other ethno-linguistic group illustrates better the divide of Brazilian immigration policies discussed in Chapters 1 and 2 than the migratory waves of German-speakers to São Paulo. The inflow of Germans and Swiss to the countryside of that province/state can be clearly separated according to the two main immigration policies discussed ${ }^{10}$. From 1847 to the early 1870 s the main modality was the immigration of bonded laborers to coffee plantations. Problems with the applicability of labor contracts in a slave-based society undermined this type of privately-led immigration. Renewed migratory waves of German-speakers became particularly numerous in the first decades of the twentieth century with immigration to rural colonies that were either officially established by the government or set up by private land sellers ${ }^{11}$.

To recapitulate, the hiring of bonded laborers was related to the abolition of the transatlantic slave trade, culminating with its prohibition by the Brazilian government in 1850. In 1847, looking for new secure sources of labor supply, the firm Vergueiro \& Co. contracted the first immigrants from Holstein and Rhineland for its farm, named Ibicaba. This initiated a hiring process that grew considerably in the $1850 \mathrm{~s}^{12}$. The farmers' method of attracting poor and credit-constrained immigrants was to supply loans for the transatlantic travel and for the maintenance of the immigrant families, who were meant to pay back the debt with yearly outcomes of coffee harvesting under sharecropping contracts. This constituted the first larger-scale use of non-slave labor in Brazilian plantations. The turning point of this phase was the outbreak of the Sharecroppers' Riot in 1856, led by the Swiss Thomas Davatz, who triggered it by sending to

\footnotetext{
${ }^{10}$ Austrians constituted a relatively different group. Therefore, I focus more on German and Swiss immigrants.

${ }^{11}$ Chapter 1 showed the overrepresentation of German-speakers - in this case including Austrians - in the settlement colonies for the period 1897-1920. In addition, see Heinke (1905) and Sommer (1953).

${ }^{12}$ Perret-Gentil (1851) and Heflinger (2007).
} 
Europe a report in which he demanded an official inspection of the living and working conditions on the plantations ${ }^{13}$. In the aftermath of the riot, especially in the 1860s, sharecropping gradually declined and was replaced by other labor-rental arrangements.

This riot had major diplomatic consequences and led to a sharp decline in the number of Germanspeaking immigrants to Brazil. Those who continued to arrive in the province did so mostly under a modality of immigration involving official rural settlements, as it had been the case with Germanspeakers in the 1820s. Among the new rural colonies, German-speakers had a major presence in the settlements of Campos Salles (in the municipality of Cosmópolis) and Nova Europa (in Ibitinga) ${ }^{14}$. In the Republican period (starting in 1889), colonies populated mostly by Germanspeakers were established in the western areas of the state, reached by the agricultural frontier and railroad infrastructure during the early decades of the twentieth century. These included colonies in the municipalities of Presidente Venceslau, Assis and Araçatuba ${ }^{15}$.

Although bonded laborers (who arrived mostly during the period 1840-70) and official settlers (who arrived mostly during the period 1870-1920) had potentially different cultural, social and economic backgrounds, their mechanisms of socio-cultural assimilation in São Paulo seem to have been rather similar. There is vast historical evidence that these immigrants had a major impact on formal schooling in the regions where they settled. German-speaking immigrants were, on average, better educated than Brazilians, an advantage they kept in spite of the frequently precarious educational conditions prevailing in rural areas and the high opportunity costs faced by children in the plantations. German-speakers had the highest literacy rates of all immigrants in the period 1908-32 and founded the largest number of foreign schools in the country by the early decades of the twentieth century ${ }^{16}$. In the countryside of São Paulo, the current study identified 44 schools established by German-speaking communities, 14 of them before $1900^{17}$.

The most direct impact of a German school on the educational level of a municipality was to increase the number of pupils enrolled in them. Because I defined all German school as private institutions, the creation of those foreign schools obviously augmented the number of students enrolled in private schools. The question remains on whether this impact was large enough to be

\footnotetext{
${ }^{13}$ Davatz ([1858] 1941).

${ }^{14}$ Keller (1919) and Sommer (1953).

${ }^{15}$ Bezerra (2007) and Silva (2010).

${ }^{16}$ Kreutz (2005, pp. 92-3).

17 The historiography dealing partly or entirely with German schools in São Paulo includes Grininger (1991), Karastojanov (1998), Nobre (2004), Kreutz (2005), Ribeiro (2005), Bezerra (2007), Silva (2010), Gouvêa (2011) and Varussa (2017).
} 
statistically significant and economically relevant ${ }^{18}$. Furthermore, other less direct effects might be observed as well. First, teachers trained in those schools may have gone on to teach in the Brazilian public educational system. Second, spillovers might have fostered the enrolment of native Brazilians in German schools. Finally, contagion effects could have led to an increase in the demand for education from Brazilians, prompted by their perceptions of the German-speaking community. The relatively smoother integration and more frequent interactions between Germanspeakers and the Brazilian-born population in São Paulo imply that spillover and contagion effects were more likely to be observed there than in the southern provinces.

The existence of these diverse effects can be tested by examining the impact that German schools had on enrolment in different types of educational institutions. The dataset used in this chapter allows this disaggregation for enrolment in municipal, state and private schools. Given that German schools are classified as private, their impact on the public educational system can be interpreted as evidence of the above-mentioned spillovers and contagion effects. As will be discussed, this is indeed what is found in the analysis for the beginning of the twentieth century.

Moreover, we have seen in Chapter 1 that German-speakers did not sort as agricultural laborers, nor as landowners in 1872. In line with this conclusion, the disaggregated data based on the almanacs show that German-speakers were overrepresented in urban activities ${ }^{19}$. After leaving the rural economy, one of the main channels for the economic integration of those immigrants was to specialize in craftsmanship in economically dynamic urban centers, usually around the place of first residence or with a consolidated network of immigrants. Despite being an ethno-linguistic minority, disaggregated data from the almanacs show a quasi-monopoly of German-speakers in some specialized jobs. In 1873, 80 percent of brewers, 71 percent of cart manufacturers, 67 percent of tanners, 60 percent of gun-makers and sellers and 47 percent of machinists and watchmakers had surnames that could be traced back to German-speaking immigrants. In 1888, these shares diminished substantially as a result of new immigration waves from other countries, especially the beginning of the mass immigration of Italians. Nevertheless, German surnames still appeared

\footnotetext{
${ }^{18}$ More precisely, German schools could be either private or associative. The former implied the payment of fees per pupil. The latter had funds raised by the community of immigrants as an association. For a study of the structure of the German schools, see Bezerra (2007). Witzel de Souza (2014, pp. 24-7) discusses the financial structure of some of those schools.

${ }^{19}$ See also evidence on the descriptive statistics of this chapter (Table 3.2).
} 
frequently in cart production (67 percent), mechanized manufactures (38 percent), breweries (34 percent), tanning (33 percent) and watch-making (26 percent $)^{20}$.

This more anecdotal evidence motivates the hypothesis that German-speaking immigrants might have also contributed to formal schooling via their on-the-job skills. Although mainly related to applied knowledge, the specialized crafts they exercised could have required a minimum level of literacy and numeracy, increasing their overall demand for schooling - both in private and public institutions. An empirical novelty of the current chapter is to identify the surnames of individuals in two almanacs of 1873 and 1888, whose data were harmonized. This new dataset allows us to determine the share of German-speaking surnames per profession, which can be aggregated by sector or by the total number of professions in a municipality. These variables are then used to test empirically the impact that on-the-job skills of German-speaking immigrants had on different educational institutions over time.

In short, this chapter hypothesizes that the relative advantage in human capital of German-speaking immigrants constituted an initial shock in the period 1840-1920 whose effects persisted over time. An exploratory approach with difference-in-means tests supports this idea. Table 3.1 (below) shows that municipalities that had proportionally more German-speaking immigrants than the sample mean had a higher number of literate people in 1872 and total enrolment in the 1910s. Interestingly, a higher proportion of German-speakers was not associated with a higher mean enrolment in 1872, suggesting that immigrants influenced the stock of human capital (reflected in literacy), but failed to increase enrolment, at least in 1872. If the number of German schools is used as the identifier, we see a significantly higher mean for all indicators considered. The differences-in-means are large, but few municipalities had a German school, raising the question on whether these schools nonetheless had a statistically significant impact on the historical accumulation of human capital.

\footnotetext{
${ }^{20}$ As argued in Chapter 1, the fact that German-speakers attained almost a monopoly in some specialized crafts does not invalidate the average effect that they sorted in manufacturing only in regions where settlement colonies prevailed. Results in Chapter 1 refer to ceteris paribus effects of the economic structure on the sorting of foreigners. The historical evidence discussed above refers to the presence of those immigrants in specific occupations.
} 
Table 3.1 - Difference-in-means tests (by share of German-speakers and their schools)

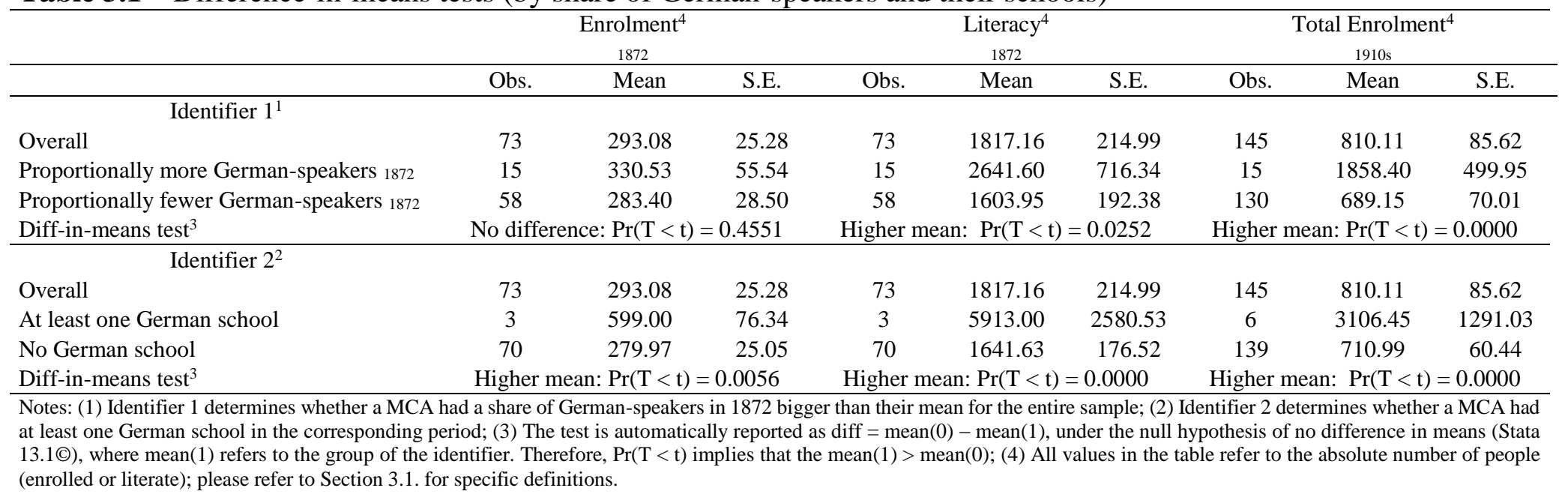




\section{Empirical analysis: methodology}

\subsection{Specification}

The empirical analysis aims at identifying the influence that German-speaking immigrants, their on-the-job skills and their schools had on the educational levels of municipalities in 1872, at the beginning of the twentieth century and for the period 1999-2011. For 1872, this study investigates whether the immigrants had a contemporaneous impact on the educational performance of the recipient society. For the long-term analyses - that is, the 1910s and the years 1999-2011 -, the effects are evaluated for enrolment in different types of educational institutions: private, municipal and state schools. Additionally, in order to assess the current determinants of education, the study looks at whether measures of stocks and flows of human capital in 1999-2011 were influenced by their historical counterparts. Combined with the categorization by type of schools, this approach shows that the path dependence of education is conditional on whether the educational system is private or public.

For 1872 and the 2000s, baseline results are obtained by an ordinary least squares estimator (OLS). For the 1910s, an instrumental variable provides the baseline estimation ${ }^{22}$. All estimators are obtained with the following functional form:

$$
\begin{aligned}
\text { Educ }_{n}=\alpha+ & (\text { German speaking presence })^{\prime} \beta+\left(W_{n}\right)^{\prime} \gamma+\left(R_{n}\right)^{\prime} \delta+\left(\alpha_{n}\right)^{\prime} \theta \\
+ & 1^{2000 s}\left(\text { Educ }_{n}^{1910 s}\right)^{\prime}+\varepsilon_{n}
\end{aligned}
$$

Different measures are used as the dependent variable in order to evaluate the impact of Germanspeaking immigrants on diverse facets of education, $\left(E d u c_{n}\right)$. For 1872 , literacy and absolute enrolment are used as dependent variables, measuring human capital stocks and flows, respectively. For the 1910s and for 1999-2011, total enrolment is considered first ${ }^{23}$. This is subsequently separated into enrolment in each specific type of school (state, municipal and private). An indicator for the total number of children who completed the basic cycle in state schools complements those previous measures of flows ${ }^{24}$. This implies that the baseline models are always estimated for five dependent variables for the 1910s. In addition to the same measures

\footnotetext{
22 The published version discusses also the OLS estimates for the 1910s.

${ }^{23}$ This is the only variable created as the sum of enrolment in all types of schools. The subcategories had no interpolated data or imputed zeros. See Section 5.2 for a discussion on missing values and robustness checks.

${ }^{24}$ Absolute levels were preferred to the rates provided by the original source because the latter was based on fixed estimates of the total number of school-age children. In contrast to Chapter 1, the shares of German-speakers in each occupation was used because the denominators were defined from the same source.
} 
of flows, the analyses for the period 1999-2011 also include indicators for the stocks of human capital. They are measured by average years of schooling, illiteracy and an index from the educational component of the Municipal Human Development Index (MHDI) ${ }^{25}$.

The set (German speaking presence ${ }_{n}$ ) includes the main variables of interest: the share of German-speakers in the population in 1872, (German speakers (share) ${ }_{n}^{1872}$ ); the number of schools established in a municipality by those immigrants, (German schools ${ }_{n}^{t}$ ), in which $t$ refers to the period considered in each cross-sectional analysis ${ }^{26}$; and the measures of the on-the-job skill components of the German-speakers. The latter is defined either as the share of those immigrants in all professions in a municipality, or categorized per sector.

These three groups of variables are included jointly in the baseline models to assess the partial effect of the presence of immigrants per se, the institutionalized demand for education (creation of schools) and the on-the-job skill components of human capital.

Controls for demographic and economic characteristics of the municipalities are included in the set $W_{n}$. Although it was not always possible to perfectly match those variables over time due to constraints imposed by different sources of data, controls for the economic structure, fiscal situation and population are included in all specifications ${ }^{27}$. Except for 1872, variables accounting for economic conditions were constructed with data lagged by at least one year with respect to the dependent variable to rule out direct simultaneity between educational conditions and economic performance. In the historical analyses, variables for the economic structure of the municipalities are derived from the 1873 and 1888 almanacs. These variables are presented either as an aggregate measure of employment or categorized by sector. For the 1910s, the sector composition is based on the almanac from 1888, under the assumption that this structure was persistent over time. Finally, for the current period, the economic structure is based on the share of value added by agriculture, industry, services and public administration ${ }^{28}$.

\footnotetext{
${ }^{25}$ The municipal HDI adapts the calculation of global HDI to the level of Brazilian municipalities. The educational component is the geometric average of (i) the share of population older than 18 with complete basic schooling (weight 1) and (ii) the flows of enrolment in primary and secondary schools categorized by age groups (weight 2). Source: http://www.atlasbrasil.org.br/2013/pt/o_atlas/idhm/, accessed on November 262018.

${ }^{26}$ For the current period, I used the number of German schools founded until the 1930s, when the Brazilian government started the nationalization of foreign schools.

${ }^{27}$ The fiscal situation is measured in 1872 by the total municipal budget in that year, in the 1910s by the average total municipal expenditure and in the 2000s by the average municipal expenditure on education.

${ }^{28}$ Further economic controls include the share of land dedicated to coffee production in the 1910s, for that period, and average municipal income for the 1999-2011 analysis.
} 
The set $R_{n}$ includes characteristics that are specific of each period analyzed. For 1872, municipal dependence on slavery is taken into account, measured by the recorded number of captives. Considering the relevance of international migration during this entire period, the share of nonGerman-speaking immigrants in 1872 and the proportion of foreign rural workers in the 1910s were controlled for in the respective specifications. Furthermore, for 1872 the share of foreigners of any nationality in the public administration is used to assess the degree of local institutional openness and the civic participation of foreigners. For the 1910s, this variable is substituted by the share of farms owned by foreigners in 1905. Finally, the number of state schools is also added to the latter specification to control for the supply of public education.

$\alpha_{n}$ comprises a set of geographic characteristics, including altitude, latitude, area and average straight-line distance to the capital of the province/state, for all periods ${ }^{29}$. For the 1999-2011 analysis, annual average rainfall and temperature are also included.

Finally, to assess the path dependence of current levels of education, I added a historical indicator to the last period. The indicator $1^{2000 s}\left(E d u c_{n}^{1910 s}\right)$ implies that, for the $2000 \mathrm{~s}$, the correspondent historical educational component in the 1910s is included as a covariate. This aims at testing whether there was historical dependence between the levels of education. Each dependent variable is matched here to its specific historical correspondent - that is, current enrolment in each type of school is regressed on that specific type of school in the 1910s (the same for completion). However, this procedure has a problematic ceteris paribus interpretation: by holding population constant in the regressions, an increase in the number of pupils implies an increase in enrolment rates, which have already converged to 100 percent in primary schooling for most municipalities ${ }^{30}$. This is yet another reason to evaluate the impact of historical schooling on current average years of education, illiteracy rates and the educational component of the MHDI.

\subsection{Estimation strategies and historical identification}

The current section discusses different estimation strategies based on the historical setting outlined in Section 2. I argue that the estimation with OLS is sufficient to identify the impact of the variables

\footnotetext{
${ }^{29}$ By the definition of MCAs, area and distance to the capital from a specific point are constant over time, although they varied at the municipal level once the agricultural frontier expanded and new administrative units were created.

${ }^{30}$ This ratio is above 1 in some cases because it is a 5-year average which does not penalize for repetition.
} 
in the set (German speaking presence ${ }_{n}$ ) both for 1872 and 1999-2011, while an instrument is proposed for the variable (German schools ${ }_{n}$ ) in the 1910s.

For the last period, it is not reasonable to expect that immigrants in the nineteenth century would have self-selected to specific municipalities based on the development of the educational systems in the municipalities more than a century later. Simultaneity is ruled out by the definition of the variables considered. Nevertheless, one could still argue that path dependence in economic performance creates a link between immigration in the nineteenth century and current educational performance in a manner which is non-orthogonal to the error term. In particular, some omitted variables correlated with institutions and cultural traits could have attracted immigrants or have been influenced by their presence in the nineteenth century and also be correlated with the economic and educational performance of municipalities nowadays. Another problem would be the self-selection of immigrants based on the economic performance or wealth of the municipalities. These are expected to be directly correlated with the educational performance of a municipality later on. In order to accommodate these concerns at least partially, all regressions include controls for the financial situation of the municipalities, indicators for economic prosperity and economic structure.

For 1872, in turn, the immigration of German-speakers to São Paulo was at the inflexion point from bonded laborers to official settlers. Although old bonded laborers had had time to migrate internally in the province since 1847 and to self-select into municipalities with better education, the last sharecroppers and the new settlers were being allocated in a manner which was not systematically related to the educational conditions of the municipalities ${ }^{31}$. Furthermore, older immigrants (1847-72) clustered around municipalities to which they had been initially allocated as sharecroppers. If we accept that the allocation of bonded laborers to farms was independent of the educational conditions in the municipalities where those farms were located and that this period set a path for the future spatial distributions of immigrants, then there is less reason to expect simultaneity between educational conditions and the presence of German-speakers in a municipality, at least in 1872 .

The claim that German-speaking sharecroppers did not know which farms they would be allocated to is supported by historical evidence. The so-called "transference clause" in sharecropping contracts allowed a farmer who originally hired a family of immigrants in Europe to transfer its

\footnotetext{
${ }^{31}$ A similar argument is made for official settlement colonies by Rocha, Ferraz and Soares (2017).
} 
contracts to another farmer. This implied that the immigrants could not know a priori whether the family would indeed be allocated to the farmer with whom they had signed the contract $^{32}$. Moreover, the Swiss municipalities displayed a remarkable ignorance about the living conditions in São Paulo: Thomas Davatz, the schoolmaster who led the Sharecroppers' Riot, received a questionnaire from his municipal council in Switzerland which included a section on religion and education. The questions were as basic as "Are there means of instruction? If so, what are they?" 33 If even the administrative boards of Swiss cantons that subsidized emigration had no information on this topic, it is unlikely that immigrants would have had enough information to be able to select their initial allocation according to the educational conditions that prevailed in the Brazilian municipalities. This argument disregards the fact that some immigrants had been invited to immigrate by their kinsmen and acquaintances, who could have provided better information on living standards. Indeed, Chapter 1 has shown how networks influenced the allocation of the Germans across municipalities and Chapter 2 has argued that these networks gradually diminished the control mechanism that landowners originally had in bonding labor. However, this concern is mitigated for the current empirical analysis by the fact that many of the letters sent to Europe were censored to give a better impression of the conditions on the farms ${ }^{34}$.

By the 1910s, however, most of the bonded laborers and official settlers had had enough time to adapt to local educational conditions and to set up their own schools accordingly. The simultaneity of the variable (German schools ${ }_{n}$ ) is therefore critical for the 1910s. For this reason, this covariate is instrumented with the variable (\# Farms bonded $d_{n}^{1850 s-60 s}$ ), which measures the number of farms employing contract labor in the $1850 \mathrm{~s}-60 \mathrm{~s}$. I call the attention of the reader to the fact that this variable was constructed with the same source as for the policy indicator (ID bonded) of Chapter $1^{35}$. While (ID bonded) is a binary indicator on whether a municipality had a farm with bonded laborers in the 1850s-60s, (\# Farms bonded ${ }_{n}^{1850 s-60 s}$ ) is a count variable for the same data. I opted for the latter in the current estimations for statistical reasons: while (ID bonded) rendered weak instruments, (\# Farm bonded $d^{1850 s-60 s}$ ) proved to be highly correlated with the potentially endogenous (German schools $\left.{ }_{n}\right)^{36}$. This shows that later migratory

\footnotetext{
${ }^{32}$ Dean (1977, p. 122), Lamounier (1986, pp. 28-9) and Witzel de Souza (2012, p. 87).

${ }^{33}$ Davatz ([1858] 1941 - Appendix 2, pp. 238-241).

${ }^{34}$ See Heflinger (2009, pp. 50-5). For letters potentially used as propaganda, see Ibid. (2007, pp. 39-46).

${ }^{35}$ Witzel de Souza (2011).

${ }^{36}$ The unconditional correlation between (\# Farm bonded ${ }_{n}^{1850 s-60 s}$ ) and (German schools ${ }_{n}$ ) is the highest for the 1910 s, reaching 0.82 against 0.72 and 0.47 for 1872 and the 1930 s, respectively.
} 
waves tended to cluster around regions that employed bonded laborers in the nineteenth century besides the network effects assessed in Chapter 1.

The existence of a farm that employed bonded laborers in the 1850 s is unlikely to have a direct influence on that municipality's educational performance sixty years later. However, the presence of this type of farm might have impacted institutional and economic conditions related to education. For this reason, all instrumental variable (IV) estimates control for the full set of covariates, including the indicators of economic performance and structure. Conditional on these, the existence of a farm employing bonded laborers in the nineteenth century fulfils the exclusion restriction, properly instrumenting (German schools ${ }_{n}$ ) in the $1910 \mathrm{~s}^{37}$.

\subsection{Sources of data}

The dataset for the current chapter was constructed with information for three periods: 1872, 19031914 and 1999-2011. For each, three sets of variables were compiled: educational performance, economic conditions and regional characteristics. Although different sources were used, covariates and of geographic units of analysis were standardized to allow for assessments in the long run and comparisons over different specifications.

The almanacs edited by Luné and Fonseca (1873) and Seckler (1888) are the sources for most of the economic variables for the first period. An empirical innovation of the current study was to transform the nominal lists in these two almanacs into quantitative indicators for the sector composition of municipalities and for the share of German-speakers in them. The main difficulty refers to the fact that the sources for 1873 and 1888 are not directly comparable, since editors had different classifications for the economic activities and frequently registered different types of professions. Extending the methodology used in Chapter 1 to construct the sector composition of municipalities in 1872, the objective now is to create variables which are consistent over time. Therefore, I classified all different economic activities into the following categories: (i) rentier activities $\left(\right.$ Rent $\left._{\cdot n}\right)$; (ii) manufacturing $\left(\operatorname{Manuf}_{\cdot n}\right)$; (iii) services (Serv.n $)$; (iv) public

\footnotetext{
${ }^{37}$ The distance of municipality $_{n}$ to the MCA Grande Limeira was also proposed as an instrument, because the corresponding MCA includes Cordeirópolis, the municipality where farm Ibicaba is located in current municipal borders. This instrument proved to be extremely weak and its addition always led to the non-rejection of the underidentification hypothesis. I would like to thank two anonymous referees for suggestions on this approach.
} 


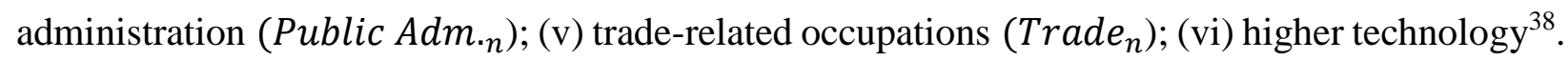
I then aggregated these into a single indicator representing the total number of professions existing in a municipality in 1872 and $1888^{39}$. To avoid the problem of source comparability faced in Chapter 1, I did not use census data for the agricultural sector; rather, I counted only the landowners mentioned in the almanacs. I aggregated these landowners to the moneylenders and other individuals classified in the sources as capitalists, leading to the sector I labelled above as "rentier activities".

To summarize, the variables for sector composition measure the share of professionals per category with respect to the total number of professionals in a municipality. In contrast to Chapter 1, I now use shares instead of absolute numbers because the estimates include only professions mentioned in the almanacs ${ }^{40}$. Although this creates a bias towards urban activities, this choice eliminates the problems of comparability between the almanacs and census data. Furthermore, it is important to stress that my variables for sector composition reflect only the share of people working in each activity, not of assets or capital employed in them.

The almanacs also permit the compilation of variables for the share of German-speakers in each sector, reflecting their on-the-job skills. The absence of a complete list of immigrants for the period is a limitation, since I cannot differentiated between descendants and immigrants. This is a minor concern for this study, however: the almanacs are from 1873 and 1888, a period when Brazilianborn descendants of German-speaking immigrants were, at most, second generation Brazilians hence still likely sharing common cultural traits, such as language and religion.

The other variables for education and municipal characteristics for the nineteenth century were compiled from the 1872 Brazilian Census.

For the beginning of the twentieth century, data for education come from the Annuarios de Ensino do Estado de São Paulo. These are official publications from the State Education Inspectorate and contain information about enrolment in different types of schools. Averages of these indicators were calculated for the years 1908-14, except for 1912. Variables for economic performance were based on the official statistical yearbooks of the state, the Annuarios Estatísticos de São Paulo

\footnotetext{
${ }^{38}$ This category included steam machinery and mechanized tools in agriculture and manufacturing. I did not use it in the econometric analysis to avoid double-counting and due to the somewhat vague definition for these items.

${ }^{39}$ For ease of exposition, I present the results with aggregate measures in the main text, leaving the estimates with categories to the appendix of this chapter.

${ }^{40}$ To clearly differentiate when using shares instead of levels - as in Chapter 1 -, I always indicate whether a share is being employed in the analysis.
} 
(1904-1907) and on the Estatística Agrícola e Zootécnica do Estado de São Paulo (1904-1905), an agricultural census which includes classification of properties by nationality. Complementary information about economic performance was obtained from the Erstes Jahrbuch für die deutschsprechende Kolonie im Staate São Paulo (1905), an almanac published by the Germanspeaking community ${ }^{41}$.

Finally, for the current period, information for economic and educational performance are from the dataset on municipal characteristics (Informações dos Municípios Paulistas - IMP) compiled by the Fundação Sistema Estadual de Análise de Dados (SEADE), the independent agency for data compilation of the state of São Paulo.

Given the expansion of the agricultural frontier since 1872, the political borders of the municipalities underwent continuous changes in the period studied. To unify the data over time, I use minimum comparable areas (MCAs) from Carvalho Filho and Colistete (2010), with two major modifications ${ }^{42}$. First, Grande Limeira was created as an independent MCA and its municipalities were subtracted from Grande Campinas ${ }^{43}$. The reason is that the axis formed by the municipalities Campinas, Limeira and Rio Claro concentrated most of the German-speakers immigrated as bonded laborers and a significant part of the rural settlers. To include Limeira in the MCA of Campinas, which already had a dynamic economy in the nineteenth century, would inflate the impact of these immigrants. Second, I excluded the MCA Grande São Paulo from the sample, since the capital of the state is an outlier in terms of the number of German schools ${ }^{44}$. However, I kept the MCAs Santana do Parnaíba, Santo Amaro and Itapecerica da Serra, which are nowadays districts or part of the metropolitan area of the capital. The motivation to keep them in the sample is that Santana do Parnaíba could be clearly identified as an independent municipality in the past and that Santo Amaro and Itapecerica da Serra were the regions where the first German-speakers settled in rural colonies in the $1820 \mathrm{~s}$, as presented in Chapter $1^{45}$.

\footnotetext{
${ }^{41}$ Referenced in this thesis by the editor Uhle, A. (1905).

${ }^{42}$ Other minor modifications include (i) classifying Itápolis, S. J. do Rio Preto and S. Rita do Passa Quatro as independent MCAs; (ii) separating between S. Rita d'Oeste and S. Rita do Passa Quatro, while including the first in the MCA Western Frontier; (iii) matching districts from almanacs into MCAs.

${ }^{43}$ The MCA Grande Limeira includes the municipalities of Limeira, Cordeirópolis and Iracemápolis. The MCA Grande Campinas comprises the municipalities of Campinas, Americana, Artur Nogueira, Conchal, Cosmópolis, Engenheiro Coelho, Holambra, Hortolândia, Jaguariúna, Mogi Mirim, Nova Odessa, Paulínia, Santo Antônio da Posse, Sumaré and Valinhos.

44 Witzel de Souza (2014, p. 39).

${ }^{45}$ See also Sommer (1953) and Siriani (2003).
} 
Current geographical units were matched to their correspondents in 1905, leading to the definition of 145 MCAs out of 645 current municipalities. There are two concerns here. First, the MCA Western Frontier, the agricultural frontier at the beginning of the twentieth century, is disproportionally large and comprises 269 current municipalities. I tested the sensitivity of the results by excluding this observation and found that they remained fundamentally unaltered.

Second, the paucity of information from the nineteenth century constituted a limitation because I classified municipalities which had not been officially created until 1905 as missing values. In order not to bias the results towards the average of the MCA in which the nonexistent municipality would be inserted, I decided to not impute zeros nor to interpolate data from neighboring regions. This led to a sample with unbalanced missing values and a varying number of observations, a problem discussed in the robustness checks.

Based mainly on the almanacs, some descriptive statistics are provided in Table 3.2 (below). The relative stability in the sector composition of the workforce between 1873 and 1888 suggests that the standardization of the different sources can be trusted. In line with Section 2, the statistics show that German-speaking immigrants were prominent in manufacturing and services comparatively to trade-related occupations. In line with the historiography and results of Chapter 1 , it is noticeable that the share of German-speaking in "rentier activities" was minor in 1873, given the potential financial constraint of the ex-bonded laborers and the difficult access to landownership.

In turn, the variables for education reflect the poor educational conditions prevailing historically in São Paulo ${ }^{46}$. In complement to the data on enrolment and literacy discussed in Chapter 1, the current analysis shows that the MCAs Grande Botucatu and Grande Campinas had the highest levels of enrolment and literacy in 1872, respectively. Nevertheless, even the attainment of these best performers was minimal: among free individuals, less than a fifth of the inhabitants of Grande Botucatu were literate. The situation improved over time, but not dramatically, and in the 1910s, Grande Campinas assumed the leadership in total enrolment as well. Finally, we notice an increase in the number of (German schools ${ }_{n}$ ) over time, as new immigration waves arrived and older ones settled and established their schools. While in 1872 only three MCAs had a German school, by the 1930 s the 44 schools established by the German-speakers spread over 14 MCAs.

\footnotetext{
${ }^{46}$ See Carvalho Filho and Colistete (2010, pp. 9-10) and Musacchio, Fritscher and Viarengo, (2014, pp. 733-5) for comparative figures on educational performance.
} 
Table 3.2 - Descriptive statistics (selected variables)

\begin{tabular}{|c|c|c|c|c|c|}
\hline & Obs. & Mean & S.D. & Min. & Max. \\
\hline \multicolumn{6}{|c|}{ Sector composition } \\
\hline Rent. 1872 (share) & 72 & 0.2745 & 0.2004 & 0 & 0.9388 \\
\hline Rent. 1888 (share) & 70 & 0.2567 & 0.1493 & 0 & 0.5952 \\
\hline Manuf. 1872 (share) & 72 & 0.1431 & 0.1000 & 0 & 0.4461 \\
\hline Manuf. 1888 (share) & 70 & 0.1610 & 0.0857 & 0 & 0.5112 \\
\hline Serv. 1872 (share) & 72 & 0.0749 & 0.1149 & 0 & 0.6553 \\
\hline Serv. 1888 (share) & 70 & 0.0995 & 0.0656 & 0 & 0.3000 \\
\hline Public Adm. 1872 (share) & 72 & 0.2081 & 0.1967 & 0.0141 & 0.8571 \\
\hline Public Adm. 1888 (share) & 70 & 0.2025 & 0.1403 & 0.0251 & 0.9412 \\
\hline Trade 1872 (share) & 72 & 0.1625 & 0.1095 & 0 & 0.6619 \\
\hline Trade 1888 (share) & 70 & 0.1756 & 0.0881 & 0 & 0.5215 \\
\hline \multicolumn{6}{|c|}{ Education: historical and current $^{1}$} \\
\hline Enrolment 1872 & 73 & 293.08 & 215.99 & 15 & 1,082 \\
\hline Literacy 1872 & 73 & $1,817.16$ & $1,836.89$ & 132 & 11,049 \\
\hline Total enrolment 1910s & 145 & 810.11 & $1,031.03$ & 50.60 & 7,775 \\
\hline Enrolment state $1910 \mathrm{~s}$ & 145 & 571.56 & 625.94 & 50.60 & $4,624.40$ \\
\hline Enrolment munic. 1910s & 96 & 155.48 & 172.69 & 12 & $1,015.40$ \\
\hline Enrolment private $1910 \mathrm{~s}$ & 102 & 192.78 & 411.10 & 8 & $3,087.20$ \\
\hline Completion state $1910 \mathrm{~s}$ & 102 & 202.72 & 88.58 & 47.33 & 548.50 \\
\hline Total enrolment 2000s & 139 & $29,189.94$ & $71,727.41$ & 639.40 & 610,175 \\
\hline Enrolment state $2000 \mathrm{~s}$ & 130 & $14,612.15$ & $39,009.31$ & 32.20 & 287,220 \\
\hline Enrolment munic. 2000s & 117 & $4,455.81$ & $10,821.24$ & 4.20 & $81,745.20$ \\
\hline Enrolment private $2000 \mathrm{~s}$ & 138 & $11,858.62$ & $25,563.96$ & 357.60 & 241,210 \\
\hline Completion state $2000 \mathrm{~s}$ & 130 & $2,172.32$ & $5,697.53$ & 25.80 & $47,621.00$ \\
\hline Avg. years educ. 2000s & 139 & 6.43 & 0.7008 & 4.23 & 8.42 \\
\hline Educ. MHDI 2000s & 139 & 0.6664 & 0.0445 & 0.5530 & 0.7640 \\
\hline Illiteracy rate 2000 s & 139 & 6.91 & 2.16 & 2.96 & 14.80 \\
\hline \multicolumn{6}{|c|}{ German-speaking immigrants } \\
\hline German-speakers 1872 (share) & 73 & 0.0042 & 0.0097 & 0 & 0.0439 \\
\hline German schools 1872 & 145 & 0.0345 & 0.2476 & 0 & 2 \\
\hline German schools 1910s & 145 & 0.1103 & 0.6023 & 0 & 5 \\
\hline German schools 1930s & 145 & 0.3448 & 1.46 & 0 & 14 \\
\hline German workers 1872 (share) & 72 & 0.0210 & 0.0392 & 0 & 0.1705 \\
\hline German workers 1888 (share) & 74 & 0.0284 & 0.0543 & 0 & 0.3100 \\
\hline German rent. 1872 (share) & 72 & 0.0070 & 0.0302 & 0 & 0.2414 \\
\hline German rent. 1888 (share) & 69 & 0.0354 & 0.1203 & 0 & 0.7692 \\
\hline German manuf. 1872 (share) & 72 & 0.0406 & 0.0740 & 0 & 0.3929 \\
\hline German manuf. 1888 (share) & 70 & 0.0538 & 0.0920 & 0 & 0.5000 \\
\hline German serv. 1872 (share) & 72 & 0.0304 & 0.0666 & 0 & 0.3235 \\
\hline German serv. 1888 (share) & 69 & 0.0309 & 0.0502 & 0 & 0.2500 \\
\hline German trade 1872 (share) & 72 & 0.0219 & 0.0461 & 0 & 0.2500 \\
\hline German trade 1888 (share) & 73 & 0.0185 & 0.0422 & 0 & 0.2169 \\
\hline \# Farms bonded $1850 \mathrm{~s}-60 \mathrm{~s}$ & 145 & 0.7104 & 3.40 & 0 & 33 \\
\hline
\end{tabular}




\section{Empirical analysis: results}

\subsection{The effect of German-speakers on educational performance - 1872}

The analyses of the results are divided into the three periods considered in this chapter. Results for the nineteenth century are reported in Table 3.3, below. None of the variables in the set (German speaking presence ${ }_{n}$ ) has a significant effect, either on the measures of stocks or flows of human capital. In the baselines for enrolment and literacy in 1872 the share of German-speakers, their schools and on-the-job skills proved to be statistically non-significant.

The statistical non-significance of the German schools could be expected for historical reasons. Only three MCAs had German schools in 1872: Grande Campinas, Rio Claro and Santos. Moreover, these schools had been established very recently at the time. The two oldest - the Reading-and-School-Association of Campinas $^{47}$ and Collegio Florence - had been founded in 1863. This implied that the lifespan of these educational organizations was not long enough to influence the flows of human capital and certainly not long enough to impact on its stocks.

Although non-significant, estimates for the share of German-speakers have positive signs for literacy, but negative for enrolment. This pattern reinforces the hypothesis that immigrants had an advantage in terms of literacy, but that their children faced high opportunity costs as potential laborers in the plantations ${ }^{48}$. I tested for this frequently repeated historical argument in a short excursion that adds the number of farms employing bonded laborers in the $1850 \mathrm{~s}-60 \mathrm{~s}$, i.e. (\# Farms bonded ${ }_{n}^{1850 s-60 s}$ ), to the 1872 specification. (\#Farms bonded ${ }_{n}^{1850 s-60 s}$ ) is statistically non-significant for the literacy levels of municipalities in 1872. However, it has a negative effect on enrolment: one additional farm employing bonded laborers in the 1850s-60s was correlated with $c a$. 15 less students enrolled in $1872^{49}$. This indicates that plantations employing bonded laborers indeed had a negative ceteris paribus effect on education, even if they had the collateral effect of allowing for the immigration of nationalities that later contributed to the educational performance of municipalities where they settled - as will be seen in the next $\operatorname{section}^{50}$.

\footnotetext{
${ }^{47}$ Author's free translation from the original in German: Lese- und-Schulverein Campinas.

${ }^{48}$ The vice-consul of Switzerland, for instance, reported that, in the 1840s, workers in coffee harvesting included fiveyear-old children of German-speaking immigrants (Perret-Gentil, 1851, p. 53).

${ }^{49}$ Significant at the 10 percent level.

${ }^{50}$ Not reported to save space. Available upon request.
} 
Table 3.3 - OLS: German-speakers and education (1872)

\begin{tabular}{|c|c|c|c|c|}
\hline & $\begin{array}{c}\text { Enrolment } \\
1872 \\
\end{array}$ & $\begin{array}{c}\text { Enrolment } \\
1872 \\
\end{array}$ & $\begin{array}{c}\text { Literacy } \\
1872 \\
\end{array}$ & $\begin{array}{c}\text { Literacy } \\
1872 \\
\end{array}$ \\
\hline \multicolumn{5}{|c|}{ German-speaking presence } \\
\hline German schools 1872 & $\begin{array}{l}119.15 \\
(90.14)\end{array}$ & $\begin{array}{c}149.4 \\
(178.2)\end{array}$ & $\begin{array}{c}486.77 \\
(671.23)\end{array}$ & $\begin{array}{c}690.2 \\
(1,354)\end{array}$ \\
\hline German-speakers 1872 (share) & $\begin{array}{l}-2,028.59 \\
(3,742.77)\end{array}$ & $\begin{array}{l}-1,737 \\
(5,566)\end{array}$ & $\begin{array}{c}23,104.08 \\
(27,871.04)\end{array}$ & $\begin{array}{c}12,896 \\
(42,309)\end{array}$ \\
\hline German workers 1872 (share) & $\begin{array}{c}369.36 \\
(982.94)\end{array}$ & & $\begin{array}{l}-8,641.25 \\
(7,320.58)\end{array}$ & \\
\hline German manuf. 1872 (share) & & $\begin{array}{l}-19.96 \\
(583.5)\end{array}$ & & $\begin{array}{l}-1,652 \\
(4,435)\end{array}$ \\
\hline German serv. 1872 (share) & & $\begin{array}{c}754.6 \\
(720.9)\end{array}$ & & $\begin{array}{c}5,047 \\
(5,479)\end{array}$ \\
\hline German trade 1872 (share) & & $\begin{array}{l}-720.0 \\
(747.5)\end{array}$ & & $\begin{array}{l}-1,180 \\
(5,681)\end{array}$ \\
\hline German rent. 1872 (share) & & $\begin{array}{l}-2,572 \\
(4,379)\end{array}$ & & $\begin{array}{l}-36,747 \\
(33,287)\end{array}$ \\
\hline \multicolumn{5}{|c|}{ Other variables of interest } \\
\hline Other immigrants 1872 (share) & $\begin{array}{c}3,262.49 * * \\
(1,458.99)\end{array}$ & $\begin{array}{c}3,768 * * \\
(1,639)\end{array}$ & $\begin{array}{c}9,351.60 \\
(10,864.56)\end{array}$ & $\begin{array}{c}11,190 \\
(12,461)\end{array}$ \\
\hline \# Slaves 1872 & $\begin{array}{c}-0.0838 * * * \\
(0.0276)\end{array}$ & $\begin{array}{c}-0.0944 * * * \\
(0.0321)\end{array}$ & $\begin{array}{l}-0.2983 \\
(0.2055)\end{array}$ & $\begin{array}{l}-0.329 \\
(0.244)\end{array}$ \\
\hline Population 1872 & $\begin{array}{c}0.0296 * * * \\
(0.0075)\end{array}$ & $\begin{array}{c}0.0313 * * * \\
(0.00799)\end{array}$ & $\begin{array}{c}0.1804 * * * \\
(0.0559)\end{array}$ & $\begin{array}{r}0.188^{* * * *} \\
(0.0607)\end{array}$ \\
\hline Municipal budget 1872 & $\begin{array}{c}0.0047 \\
(0.0044)\end{array}$ & $\begin{array}{c}0.00634 \\
(0.00510)\end{array}$ & $\begin{array}{l}0.0833 * * \\
(0.0331)\end{array}$ & $\begin{array}{r}0.0860^{* *} \\
(0.0388)\end{array}$ \\
\hline $\begin{array}{l}\text { Foreign Public Adm } 1872 \\
\text { (share) }\end{array}$ & $\begin{array}{c}299.12 \\
(712.78)\end{array}$ & $\begin{array}{c}167.1 \\
(772.0)\end{array}$ & $\begin{array}{c}13,652.60 * * \\
(5,307.84)\end{array}$ & $\begin{array}{l}11,101 * \\
(5,867)\end{array}$ \\
\hline Municipal characteristics $1872^{1}$ & Yes & Yes & Yes & Yes \\
\hline Economic structure $1872^{2}$ & Yes & Yes & Yes & Yes \\
\hline Observations & 40 & 40 & 40 & 40 \\
\hline Adj. $R^{2}$ & 0.673 & 0.649 & 0.798 & 0.774 \\
\hline
\end{tabular}

Notes: (1) Municipal characteristics 1872 include: average straight-line distance to the state capital, area, latitude and altitude; (2) Economic structure 1872 include: share of employment in rentier activities, manufacturing, services, public administration and trade-related occupations in 1872. The term 'German' always refers to 'German-speakers'; the abbreviation is used only to facilitate the reading of the table. Robust standard errors in parenthesis if the hypothesis of homoscedasticity was rejected at the 10 percent level. *, ** and $* * *$ indicate $\mathrm{p}<0.10, \mathrm{p}<0.05$ and $\mathrm{p}<0.01$, respectively.

Other independent variables behave as expected. First, there is a clear difference between enrolment and literacy when it comes to the impact of the share of non-German-speaking immigrants and slaves: enrolment is always significantly influenced by the two variables (in a positive and negative way, respectively), while literacy is not. Moreover, the sizeable impact of (Foreign Public Adm (share $\left.)_{n}\right)$ - i.e. the share of foreigners in public administration - on literacy deserves attention, as this is a variable that proxies for the degree of political openness of the municipalities and the civic participation of foreigners. Evaluated at the mean, a one- 
percentage-point increase in this variable implies, ceteris paribus, 225.27 more literate people, equivalent to 12.40 percent of the mean literacy in the municipalities ${ }^{51}$. Combined with the nonsignificance of the share of German-speakers and other immigrants, this result helps to qualify some of the findings of the literature focused on immigration in general. The relative advantage of immigrants in terms of human capital can be seen as a necessary, but not sufficient, condition for enhancing local educational performance. In the case of São Paulo, the potentially higher demand for education of the immigrants seems to have required other institutional and economic conditions for it to develop. This conclusion is similar to that of Chapter 1, which shows the importance of prevailing immigration policies for the occupational sorting of foreigners. The results of this chapter now show that political participation mattered for the contribution of immigrants to the educational level of the receiving societies.

\subsection{The effect of German-speakers on educational performance - 1910s}

Turning to the second period, Tables 3.4-3.8 (below) present the IV estimates for enrolment in each type of school and completion in state schools. The coefficient of the instrument is presented in panel B of each table. Besides highly significant, the instrument performs well by rejecting the under-identification hypothesis at the 1 percent level in all specifications and presenting a Wald F-statistic which is always above Stock and Yogo's (2002) 10 percent critical value. The first stage is robust and precise: (\# Farms bonded ${ }_{n}^{1850 s-60 s}$ ) is significant in all specifications and presents a point estimate varying between 0.14 and 0.16 .

The estimates provide strong evidence that the share of German-speakers in the nineteenth century was non-influential for the educational performance in the 1910s in terms of enrolment. If anything, we notice two large negative effects on completion in state schools in specifications that control for the on-the-job skills in 1872. Conditional on their schools and skills, a higher share of German-speakers in a municipality had per se no positive effect on its educational performance.

By contrast, German schools had a strong impact on educational conditions at the beginning of the twentieth century, which, in turn, set the path for human capital accumulation in the long run. In

\footnotetext{
51 (Mean proportion of foreigners in public administration)*(Coefficient)/(Mean Total Enrolment $\left.{ }_{1872}\right)$.
} 
the 1910s, 16 German schools had been founded across six MCAs and had diverse timespans to influence local educational conditions.

When enrolment is categorized by type of school, a fundamental result is that the variable (German schools ${ }_{n}^{1910 s}$ ) has a systematic positive impact on enrolment not only in private schools - as would be expected -, but also in state schools at the beginning of the twentieth century. As a consequence, this variable has a positive effect on total enrolment as well. It has no effect, however, on enrolment in municipal schools and completion in state schools ${ }^{52}$.

Importantly, it should be noted that the significance of (German schools ${ }_{n}^{1910 s}$ ) is conditional on the controls for the on-the-job skills of the immigrants. The level of significance is weakened if I control for the measures from 1888; and it usually vanishes if the share of German-speakers is categorized into sectors in 1888. However, results are very robust if the 1872 measures are used instead.

Were it not for its magnitude, the impact of German schools on enrolment in private schools would be tautological, given that these institutions have always been classified as private in the dataset. However, the magnitudes of the significant point estimates vary between 79.03 and 84.16; these coefficients are larger than the mean enrolment in German schools, calculated with data currently available to be $c a$. 56 students $^{53}$. Although the estimates of enrolment in German schools must be considered with caution, it is implausible that the scale of these educational institutions would fully accommodate an increase in enrolment in private schools as large as their coefficients imply. It is likely that contagion effects in the demand for education and spillovers in the supply were at play here. A similar argument can be made about the impact of the German schools on enrolment in state schools, which is significant and positive for the three first specifications. This is a strong result, given that the supply of state schools is also controlled for in the regressions for the 1910s. The conclusion that German schools positively influenced other educational institutions contrasts with Musacchio, Fritscher and Viarengo (2014, p. 739), who discuss the historical substitutability between state, municipal and private schools in Brazil. On the other hand, it seems to confirm Stolz, Baten and Botelho's (2013, p. 115) argument that educated immigrants could supply teachers and schools also for Brazilian-born individuals.

\footnotetext{
52 The 10 percent significant case for enrolment in municipal schools, however, is less robust than the other results.

${ }^{53}$ Calculated with all available data points, which are nevertheless scattered over time and across MCAs.
} 
Table 3.4 - IV: German-speakers and education (1910s) - total enrolment

\begin{tabular}{|c|c|c|c|c|}
\hline \multicolumn{5}{|c|}{ Panel A: Second stage estimates } \\
\hline & $\begin{array}{c}\text { Total } \\
\text { Enrolment } \\
1910 \text { s } \\
\end{array}$ & $\begin{array}{c}\text { Total } \\
\text { Enrolment } \\
1910 \mathrm{~s} \\
\end{array}$ & $\begin{array}{c}\text { Total } \\
\text { Enrolment } \\
1910 \text { s } \\
\end{array}$ & $\begin{array}{c}\text { Total } \\
\text { Enrolment } \\
1910 \mathrm{~s} \\
\end{array}$ \\
\hline \multicolumn{5}{|c|}{ German-speaking presence } \\
\hline German schools 1910 s & $\begin{array}{c}152.06^{* *} \\
(74.35)\end{array}$ & $\begin{array}{l}136.12 \\
(82.79)\end{array}$ & $\begin{array}{l}113.85^{*} \\
(65.29)\end{array}$ & $\begin{array}{l}112.42 \\
(79.49)\end{array}$ \\
\hline German-speakers 1872 (share) & $\begin{array}{c}1,198.61 \\
(3,692.69)\end{array}$ & $\begin{array}{l}-2,185.95 \\
(6,283.36)\end{array}$ & $\begin{array}{c}1,385.33 \\
(3,087.16)\end{array}$ & $\begin{array}{c}3,818.08 \\
(7,385.61)\end{array}$ \\
\hline German workers 1872 (share) & $\begin{array}{c}-2,202.66 * * * \\
(686.29)\end{array}$ & & & \\
\hline German workers 1888 (share) & & $\begin{array}{c}-64.60 \\
(2,337.44)\end{array}$ & & \\
\hline German manuf. 1872 (share) & & & $\begin{array}{c}1,204.33^{*} \\
(713.29)\end{array}$ & \\
\hline German serv.1872 (share) & & & $\begin{array}{c}-1,031.83 * \\
(577.27)\end{array}$ & \\
\hline German trade 1872 (share) & & & $\begin{array}{c}-2,654.02 * * * \\
(973.32)\end{array}$ & \\
\hline German rent. 1872 (share) & & & $\begin{array}{c}3,328.98 \\
(3,872.28)\end{array}$ & \\
\hline German manuf. 1888 (share) & & & & $\begin{array}{l}-751.87 \\
(920.26)\end{array}$ \\
\hline German serv.1888 (share) & & & & $\begin{array}{l}-1,599.99 \\
(1,990.74)\end{array}$ \\
\hline German trade 1888 (share) & & & & $\begin{array}{c}734.70 \\
(1,494.10)\end{array}$ \\
\hline German rent. 1888 (share) & & & & $\begin{array}{c}120.21 \\
(605.53)\end{array}$ \\
\hline \multicolumn{5}{|c|}{ Other variables of interest } \\
\hline Population 1910s & $\begin{array}{c}0.0048 \\
(0.0046)\end{array}$ & $\begin{array}{c}0.0058 \\
(0.0045)\end{array}$ & $\begin{array}{c}0.0061 \\
(0.0038)\end{array}$ & $\begin{array}{c}0.0031 \\
(0.0058)\end{array}$ \\
\hline$\%$ foreign rural workers $1910 \mathrm{~s}$ & $\begin{array}{c}252.71 \\
(159.80)\end{array}$ & $\begin{array}{c}243.54 \\
(159.41)\end{array}$ & $\begin{array}{c}175.23 \\
(156.19)\end{array}$ & $\begin{array}{c}403.20 * * \\
(172.22)\end{array}$ \\
\hline$\%$ foreign landown. $1910 \mathrm{~s}$ & $\begin{array}{c}63.30 \\
(509.73)\end{array}$ & $\begin{array}{c}36.84 \\
(522.80)\end{array}$ & $\begin{array}{l}-231.34 \\
(385.89)\end{array}$ & $\begin{array}{c}161.79 \\
(660.31)\end{array}$ \\
\hline Area coffee 1910s (share) & $\begin{array}{l}-273.35 \\
(203.23)\end{array}$ & $\begin{array}{l}-195.50 \\
(222.88)\end{array}$ & $\begin{array}{l}-143.86 \\
(212.35)\end{array}$ & $\begin{array}{l}-114.05 \\
(213.06)\end{array}$ \\
\hline Munic. Expend. 1910s & $\begin{array}{c}0.0016^{* * * *} \\
(0.0003)\end{array}$ & $\begin{array}{c}0.0016 * * * \\
(0.0004)\end{array}$ & $\begin{array}{c}0.0018 * * * \\
(0.0004)\end{array}$ & $\begin{array}{c}0.0017 * * * \\
(0.0003)\end{array}$ \\
\hline State schools 1910 s & $\begin{array}{c}42.74 * * * \\
(5.88)\end{array}$ & $\begin{array}{c}40.77 * * * \\
(5.77)\end{array}$ & $\begin{array}{c}39.15 * * * \\
(5.79)\end{array}$ & $\begin{array}{c}42.85^{* * * *} \\
(6.44)\end{array}$ \\
\hline Municipal characteristics $1910 \mathrm{~s}^{1}$ & Yes & Yes & Yes & Yes \\
\hline Economic structure $1888^{2}$ & Yes & Yes & Yes & Yes \\
\hline Observations & 47 & 48 & 47 & 42 \\
\hline \multicolumn{5}{|c|}{ Panel B: First stage estimates: German schools $1910 \mathrm{~s}^{3}$} \\
\hline \# Farms bonded $1850 \mathrm{~s}-60 \mathrm{~s}$ & $\begin{array}{c}0.1405 * * * \\
(0.0266)\end{array}$ & $\begin{array}{c}0.1446^{* * *} \\
(0.0309)\end{array}$ & $\begin{array}{c}0.1384 * * * \\
(0.0195)\end{array}$ & $\begin{array}{c}0.1571 * * * \\
(0.0208)\end{array}$ \\
\hline $\begin{array}{l}\text { Notes: (1) Municipal characteristic } \\
\text { latitude and altitude. (2) Econom } \\
\text { manufacturing, services, public ad } \\
\text { instrument German schools } 1910 \text { s } \\
\text { rejected at the } 1 \text { percent level and } \\
(2002) 10 \text { percent critical value. Ro } \\
\text { p }<0.05 \text { and p }<0.01 \text {, respectively. }\end{array}$ & $\begin{array}{l}\text { 10, include: ave } \\
\text { structure } 1888 \text { in } \\
\text { nistration and } \\
\text { th (\# Farms b } \\
\text { e F-Statistic of } \\
\text { ust standard err }\end{array}$ & $\begin{array}{l}\text { ge straight-line } \\
\text { ude: share of } \\
\text { ade-related occ } \\
\text { zded } d_{n}^{150 s-60 s} \text { ) } \\
\text { e instrument is } \\
\text { in parenthese }\end{array}$ & $\begin{array}{l}\text { stance to the st } \\
\text { ployment in re } \\
\text { ations in } 1888 . \\
\text { Under-identific } \\
\text { ways above St } \\
, * * \text { and } * * * \text { in }\end{array}$ & $\begin{array}{l}\text { capital, area, } \\
\text { tier activities, } \\
\text { 3) All models } \\
\text { on is always } \\
\mathrm{k} \text { and Yogo's } \\
\text { cate p }<0.10 \text {, }\end{array}$ \\
\hline
\end{tabular}


Table 3.5 - IV: German-speakers and education (1910s) - enrolment state schools

\begin{tabular}{|c|c|c|c|c|}
\hline \multicolumn{5}{|c|}{ Panel A: Second stage estimates } \\
\hline & $\begin{array}{l}\text { Enrolment } \\
\text { state }\end{array}$ & $\begin{array}{l}\text { Enrolment } \\
\text { state }\end{array}$ & $\begin{array}{l}\text { Enrolment } \\
\text { state }\end{array}$ & $\begin{array}{l}\text { Enrolment } \\
\text { state }\end{array}$ \\
\hline & $1910 \mathrm{~s}$ & $1910 \mathrm{~s}$ & $1910 \mathrm{~s}$ & $1910 \mathrm{~s}$ \\
\hline German schools 1910s & $40.95^{* *}$ & $36.39^{*}$ & $39.33 * *$ & 32.94 \\
\hline & $(17.23)$ & $(19.55)$ & $(18.50)$ & $(20.05)$ \\
\hline German-speakers 1872 (share) & $1,056.14$ & 312.38 & 746.69 & -432.52 \\
\hline & $(988.35)$ & $(1,915.66)$ & $(948.38)$ & $(2,035.01)$ \\
\hline German workers 1872 (share) & $\begin{array}{c}-517.21 * * \\
(261.86)\end{array}$ & & & \\
\hline German workers 1888 (share) & & $\begin{array}{c}56.86 \\
(752.72)\end{array}$ & & \\
\hline German manuf. 1872 (share) & & & $\begin{array}{c}142.63 \\
(181.21)\end{array}$ & \\
\hline German serv.1872 (share) & & & $\begin{array}{c}-67.73 \\
(168.23)\end{array}$ & \\
\hline German trade 1872 (share) & & & $\begin{array}{l}-460.15 \\
(353.95)\end{array}$ & \\
\hline German rent. 1872 (share) & & & $\begin{array}{c}270.92 \\
(1,057.59)\end{array}$ & \\
\hline German manuf. 1888 (share) & & & & $\begin{array}{c}-53.92 \\
(277.69)\end{array}$ \\
\hline German serv.1888 (share) & & & & $\begin{array}{l}-427.34 \\
(500.43)\end{array}$ \\
\hline German trade 1888 (share) & & & & $\begin{array}{c}675.44 \\
(508.23)\end{array}$ \\
\hline German rent. 1888 (share) & & & & $\begin{array}{c}48.87 \\
(128.91)\end{array}$ \\
\hline Population 1910s & $\begin{array}{c}0.0018 \\
(0.0013)\end{array}$ & $\begin{array}{c}0.0024 * * \\
(0.0011)\end{array}$ & $\begin{array}{l}0.0023 * \\
(0.0012)\end{array}$ & $\begin{array}{c}0.0024 * * \\
(0.0011)\end{array}$ \\
\hline$\%$ foreign rural workers $1910 \mathrm{~s}$ & $\begin{array}{l}76.25 * \\
(40.39)\end{array}$ & $\begin{array}{l}70.43^{*} \\
(40.93)\end{array}$ & $\begin{array}{l}72.09 * \\
(37.23)\end{array}$ & $\begin{array}{l}79.50 * \\
(45.84)\end{array}$ \\
\hline$\%$ foreign landown. 1910s & $\begin{array}{c}75.86 \\
(100.87)\end{array}$ & $\begin{array}{c}43.75 \\
(109.10)\end{array}$ & $\begin{array}{c}15.30 \\
(79.05)\end{array}$ & $\begin{array}{c}35.25 \\
(127.07)\end{array}$ \\
\hline Area coffee 1910 s (share) & $\begin{array}{l}-70.10 \\
(54.78)\end{array}$ & $\begin{array}{l}-57.53 \\
(61.78)\end{array}$ & $\begin{array}{l}-49.14 \\
(60.16)\end{array}$ & $\begin{array}{l}-34.09 \\
(62.50)\end{array}$ \\
\hline Municipal expenditures 1910 s & $\begin{array}{l}0.0002 * * * \\
(7.67 \mathrm{e}-05)\end{array}$ & $\begin{array}{c}0.0002 * * \\
(9.12 \mathrm{e}-05)\end{array}$ & $\begin{array}{c}0.0002 * * \\
(0.0001)\end{array}$ & $\begin{array}{c}0.0002 * * \\
(9.52 \mathrm{e}-05)\end{array}$ \\
\hline State schools 1910s & $\begin{array}{c}38.65 * * * \\
(1.58)\end{array}$ & $\begin{array}{c}38.09 * * * \\
\quad(1.50)\end{array}$ & $\begin{array}{c}38.05 * * * \\
(1.76)\end{array}$ & $\begin{array}{c}37.77 * * * \\
(1.53)\end{array}$ \\
\hline Municipal characteristics 1910 s & Yes & Yes & Yes & Yes \\
\hline Economic structure 1888 & Yes & Yes & Yes & Yes \\
\hline Observations & 47 & 48 & 47 & 42 \\
\hline Panel B: F & st stage estim: & es: German sc & Dols 1910s & \\
\hline \# Farms bonded $1850 \mathrm{~s}-60 \mathrm{~s}$ & $\begin{array}{c}0.1405 * * * \\
(0.0266)\end{array}$ & $\begin{array}{c}0.1446 * * * \\
(0.0309)\end{array}$ & $\begin{array}{c}0.1384 * * * \\
(0.0195)\end{array}$ & $\begin{array}{c}0.1571 * * * \\
(0.0208)\end{array}$ \\
\hline
\end{tabular}


Table 3.6 - IV: German-speakers and education (1910s) - enrolment private schools

\begin{tabular}{|c|c|c|c|c|}
\hline \multicolumn{5}{|c|}{ Panel A: Second stage estimates } \\
\hline & $\begin{array}{c}\text { Enrolment } \\
\text { private } \\
1910 \mathrm{~s}\end{array}$ & $\begin{array}{c}\text { Enrolment } \\
\text { private } \\
1910 \mathrm{~s}\end{array}$ & $\begin{array}{c}\text { Enrolment } \\
\text { private } \\
1910 \mathrm{~s}\end{array}$ & $\begin{array}{c}\text { Enrolment } \\
\text { private } \\
1910 \mathrm{~s}\end{array}$ \\
\hline German schools 1910s & $\begin{array}{l}84.16^{* *} \\
(40.65)\end{array}$ & $\begin{array}{l}79.03^{*} \\
(45.26)\end{array}$ & $\begin{array}{l}75.75^{* *} \\
(33.37)\end{array}$ & $\begin{array}{c}29.34 \\
(41.53)\end{array}$ \\
\hline German-speakers 1872 (share) & $\begin{array}{l}-1,072.81 \\
(1,964.59)\end{array}$ & $\begin{array}{c}-894.12 \\
(4,508.38)\end{array}$ & $\begin{array}{l}-1,753.11 \\
(1,280.95)\end{array}$ & $\begin{array}{l}-4,162.34 \\
(3,521.59)\end{array}$ \\
\hline German workers 1872 (share) & $\begin{array}{c}-1,637.38 * * * \\
(366.06)\end{array}$ & & & \\
\hline German workers 1888 (share) & & $\begin{array}{l}-1,181.08 \\
(1,607.57)\end{array}$ & & \\
\hline German manuf. 1872 (share) & & & $\begin{array}{c}972.88 * * * \\
(356.48)\end{array}$ & \\
\hline German serv.1872 (share) & & & $\begin{array}{l}-601.76^{*} \\
(317.42)\end{array}$ & \\
\hline German trade 1872 (share) & & & $\begin{array}{c}-2,429.31 * * * \\
(636.51)\end{array}$ & \\
\hline German rent. 1872 (share) & & & $\begin{array}{c}1,576.91 \\
(2,251.28)\end{array}$ & \\
\hline German manuf. 1888 (share) & & & & $\begin{array}{l}-345.88 \\
(491.10)\end{array}$ \\
\hline German serv.1888 (share) & & & & $\begin{array}{c}-1,185.12 \\
(867.31)\end{array}$ \\
\hline German trade 1888 (share) & & & & $\begin{array}{l}1,239.20 \\
(779.44)\end{array}$ \\
\hline German rent. 1888 (share) & & & & $\begin{array}{c}-1,086.94 * * * \\
(420.15)\end{array}$ \\
\hline Population 1910s & $\begin{array}{l}-0.0032 \\
(0.0028)\end{array}$ & $\begin{array}{l}-0.0027 \\
(0.0030)\end{array}$ & $\begin{array}{l}-0.0023 \\
(0.0025)\end{array}$ & $\begin{array}{l}-0.0038 \\
(0.0027)\end{array}$ \\
\hline$\%$ foreign rural workers $1910 \mathrm{~s}$ & $\begin{array}{c}155.05 \\
(133.80)\end{array}$ & $\begin{array}{c}195.78 \\
(127.43)\end{array}$ & $\begin{array}{c}91.61 \\
(139.20)\end{array}$ & $\begin{array}{c}308.52 * * * \\
(111.94)\end{array}$ \\
\hline$\%$ foreign landown. 1910s & $\begin{array}{c}140.49 \\
(334.47)\end{array}$ & $\begin{array}{c}134.39 \\
(331.93)\end{array}$ & $\begin{array}{c}-8.44 \\
(256.00)\end{array}$ & $\begin{array}{c}696.40 \\
(497.19)\end{array}$ \\
\hline Area coffee 1910 s (share) & $\begin{array}{l}-143.98 \\
(121.95)\end{array}$ & $\begin{array}{c}-85.94 \\
(140.23)\end{array}$ & $\begin{array}{c}-10.28 \\
(113.23)\end{array}$ & $\begin{array}{c}-36.29 \\
(135.73)\end{array}$ \\
\hline Municipal expenditures 1910s & $\begin{array}{c}0.0011 * * * \\
(0.0001)\end{array}$ & $\begin{array}{c}0.0011 * * * \\
(0.0002)\end{array}$ & $\begin{array}{c}0.0012 * * * \\
(0.0002)\end{array}$ & $\begin{array}{c}0.0013 * * * \\
(0.0002)\end{array}$ \\
\hline State schools 1910 s & $\begin{array}{l}7.24 * * \\
(3.42)\end{array}$ & $\begin{array}{l}6.24 * \\
(3.43)\end{array}$ & $\begin{array}{c}4.80 \\
(3.14)\end{array}$ & $\begin{array}{l}6.59 * * \\
(2.90)\end{array}$ \\
\hline Municipal characteristics 1910s & Yes & Yes & Yes & Yes \\
\hline Economic structure 1888 & Yes & Yes & Yes & Yes \\
\hline Observations & 38 & 39 & 38 & 36 \\
\hline Panel B: & irst stage esti & es: German s & hools 1910s & \\
\hline \# Farms bonded $1850 \mathrm{~s}-60 \mathrm{~s}$ & $\begin{array}{c}0.1392 * * * \\
(0.0271)\end{array}$ & $\begin{array}{c}0.1459 * * * \\
(0.0309)\end{array}$ & $\begin{array}{c}0.1413 * * * \\
(0.0197)\end{array}$ & $\begin{array}{c}0.1496 * * * \\
(0.0207)\end{array}$ \\
\hline
\end{tabular}


Table 3.7 - IV: German-speakers and education (1910s) - enrolment municipal schools

\begin{tabular}{|c|c|c|c|c|}
\hline \multicolumn{5}{|c|}{ Panel A: Second stage estimates } \\
\hline & $\begin{array}{c}\text { Enrolment } \\
\text { munic. } \\
1910 \text { s }\end{array}$ & $\begin{array}{c}\text { Enrolment } \\
\text { munic. } \\
1910 \text { s }\end{array}$ & $\begin{array}{c}\text { Enrolment } \\
\text { munic. } \\
1910 \text { s }\end{array}$ & $\begin{array}{c}\text { Enrolment } \\
\text { munic. } \\
\text { 1910s }\end{array}$ \\
\hline German schools 1910 s & $\begin{array}{c}31.97 \\
(19.51)\end{array}$ & $\begin{array}{l}33.93 * \\
(19.82)\end{array}$ & $\begin{array}{c}12.09 \\
(21.84)\end{array}$ & $\begin{array}{c}20.76 \\
(21.80)\end{array}$ \\
\hline German-speakers 1872 (share) & $\begin{array}{l}-1,490.29 \\
(1,022.02)\end{array}$ & $\begin{array}{l}-1,182.00 \\
(2,464.48)\end{array}$ & $\begin{array}{c}-1,402.74 \\
(967.00)\end{array}$ & $\begin{array}{c}-232.23 \\
(3,731.88)\end{array}$ \\
\hline German workers 1872 (share) & $\begin{array}{l}-348.22 \\
(241.80)\end{array}$ & & & \\
\hline German workers 1888 (share) & & $\begin{array}{l}-461.76 \\
(803.23)\end{array}$ & & \\
\hline German manuf. 1872 (share) & & & $\begin{array}{c}436.91 * * \\
(212.57)\end{array}$ & \\
\hline German serv.1872 (share) & & & $\begin{array}{l}-446.10 \\
(274.57)\end{array}$ & \\
\hline German trade 1872 (share) & & & $\begin{array}{l}-642.16^{*} \\
(342.81)\end{array}$ & \\
\hline German rent. 1872 (share) & & & $\begin{array}{c}1,823.02 \\
(1,418.72)\end{array}$ & \\
\hline German manuf. 1888 (share) & & & & $\begin{array}{l}-325.63 \\
(251.10)\end{array}$ \\
\hline German serv.1888 (share) & & & & $\begin{array}{l}-149.89 \\
(753.27)\end{array}$ \\
\hline German trade 1888 (share) & & & & $\begin{array}{c}162.55 \\
(676.14)\end{array}$ \\
\hline German rent. 1888 (share) & & & & $\begin{array}{c}141.31 \\
(265.31)\end{array}$ \\
\hline Population 1910 s & $\begin{array}{c}0.0063 * * * \\
(0.0015)\end{array}$ & $\begin{array}{c}0.0060 * * * \\
(0.0018)\end{array}$ & $\begin{array}{c}0.0061 * * * \\
(0.0017)\end{array}$ & $\begin{array}{c}0.0059 * * \\
(0.0023)\end{array}$ \\
\hline$\%$ foreign rural workers $1910 \mathrm{~s}$ & $\begin{array}{c}49.44 \\
(87.42)\end{array}$ & $\begin{array}{c}68.37 \\
(78.82)\end{array}$ & $\begin{array}{c}-11.33 \\
(101.59)\end{array}$ & $\begin{array}{c}94.41 \\
(85.57)\end{array}$ \\
\hline$\%$ foreign landown. 1910s & $\begin{array}{c}517.81 * * * \\
(159.47)\end{array}$ & $\begin{array}{c}514.13 * * * \\
(169.21)\end{array}$ & $\begin{array}{c}504.10 * * * \\
(158.87)\end{array}$ & $\begin{array}{c}492.93 * * \\
(244.75)\end{array}$ \\
\hline Area coffee 1910s (share) & $\begin{array}{l}-36.34 \\
(62.97)\end{array}$ & $\begin{array}{l}-18.11 \\
(68.93)\end{array}$ & $\begin{array}{c}10.48 \\
(59.16)\end{array}$ & $\begin{array}{c}4.74 \\
(79.23)\end{array}$ \\
\hline Municipal expenditures 1910s & $\begin{array}{c}0.0002 \\
(9.77 \mathrm{e}-05)\end{array}$ & $\begin{array}{c}0.0001 \\
(9.54 \mathrm{e}-05)\end{array}$ & $\begin{array}{c}0.0003 * * \\
(0.0001)\end{array}$ & $\begin{array}{c}0.0002 \\
(0.0001)\end{array}$ \\
\hline State schools $1910 \mathrm{~s}$ & $\begin{array}{l}-2.11 \\
(1.73)\end{array}$ & $\begin{array}{l}-2.16 \\
(1.87)\end{array}$ & $\begin{array}{l}-3.11 * \\
(1.77)\end{array}$ & $\begin{array}{l}-1.80 \\
(2.04)\end{array}$ \\
\hline Municipal characteristics 1910 s & Yes & Yes & Yes & Yes \\
\hline Economic structure 1888 & Yes & Yes & Yes & Yes \\
\hline Observations & 38 & 39 & 38 & 35 \\
\hline Panel B: $\mathrm{F}$ & st stage estir & es: German s & ools 1910s & \\
\hline \# Farms bonded 1850s-60s & $\begin{array}{c}0.1463 * * * \\
(0.0319)\end{array}$ & $\begin{array}{c}0.1511 \text { *** } \\
(0.0320)\end{array}$ & $\begin{array}{c}0.1489 * * * \\
(0.0196)\end{array}$ & $\begin{array}{c}0.1540 * * * \\
(0.0207)\end{array}$ \\
\hline
\end{tabular}


Table 3.8 - IV: German-speakers and education (1910s) - completion state schools

\begin{tabular}{|c|c|c|c|c|}
\hline \multicolumn{5}{|c|}{ Panel A: Second stage estimates } \\
\hline & $\begin{array}{l}\text { Completion } \\
\text { state }\end{array}$ & $\begin{array}{l}\text { Completion } \\
\text { state }\end{array}$ & $\begin{array}{l}\text { Completion } \\
\text { state }\end{array}$ & $\begin{array}{l}\text { Completion } \\
\text { state }\end{array}$ \\
\hline & $1910 \mathrm{~s}$ & 1910s & $1910 \mathrm{~s}$ & 1910s \\
\hline German schools 1910 s & $\begin{array}{c}24.80 \\
(25.73)\end{array}$ & $\begin{array}{c}18.56 \\
(25.91)\end{array}$ & $\begin{array}{c}26.14 \\
(32.77)\end{array}$ & $\begin{array}{l}33.40^{*} \\
(19.09)\end{array}$ \\
\hline German-speakers 1872 (share) & $\begin{array}{c}-2,774.29 * * \\
(1,321.14)\end{array}$ & $\begin{array}{c}-2,889.09 \\
(1,861.66)\end{array}$ & $\begin{array}{c}-3,888.81^{* *} \\
(1,528.10)\end{array}$ & $\begin{array}{c}-139.70 \\
(2,378.31)\end{array}$ \\
\hline German workers 1872 (share) & $\begin{array}{c}27.15 \\
(461.44)\end{array}$ & & & \\
\hline German workers 1888 (share) & & $\begin{array}{c}395.49 \\
(888.32)\end{array}$ & & \\
\hline German manuf. 1872 (share) & & & $\begin{array}{c}405.06 * * \\
(182.83)\end{array}$ & \\
\hline German serv.1872 (share) & & & $\begin{array}{c}-34.86 \\
(247.20)\end{array}$ & \\
\hline German trade 1872 (share) & & & $\begin{array}{c}421.86 \\
(380.72)\end{array}$ & \\
\hline German rent. 1872 (share) & & & $\begin{array}{c}-2,935-17^{*} \\
(1,57112)\end{array}$ & \\
\hline German manuf. 1888 (share) & & & & $\begin{array}{l}-437.12 \\
(292.40)\end{array}$ \\
\hline German serv.1888 (share) & & & & $\begin{array}{c}1,578.48 * \\
(849.37)\end{array}$ \\
\hline German trade 1888 (share) & & & & $\begin{array}{l}-100.61 \\
(449.36)\end{array}$ \\
\hline German rent. 1888 (share) & & & & $\begin{array}{c}782.91 * * * \\
(199.53)\end{array}$ \\
\hline Population 1910s & $\begin{array}{l}-0.0002 \\
(0.0019)\end{array}$ & $\begin{array}{c}0.0003 \\
(0.0020)\end{array}$ & $\begin{array}{c}0.0010 \\
(0.0023)\end{array}$ & $\begin{array}{c}0.0020 \\
(0.0022)\end{array}$ \\
\hline$\%$ foreign rural workers $1910 \mathrm{~s}$ & $\begin{array}{c}68.29 \\
(79.56)\end{array}$ & $\begin{array}{c}30.13 \\
(74.43)\end{array}$ & $\begin{array}{c}68.65 \\
(94.57)\end{array}$ & $\begin{array}{c}-172.13^{* * *} \\
(74.93)\end{array}$ \\
\hline$\%$ foreign landown. $1910 \mathrm{~s}$ & $\begin{array}{c}311.06 \\
(222.93)\end{array}$ & $\begin{array}{c}264.70 \\
(216.15)\end{array}$ & $\begin{array}{c}130.32 \\
(233.09)\end{array}$ & $\begin{array}{c}-62.83 \\
(187.09)\end{array}$ \\
\hline Area coffee 1910 s (share) & $\begin{array}{l}-41.39 \\
(71.19)\end{array}$ & $\begin{array}{l}-43.81 \\
(63.16)\end{array}$ & $\begin{array}{c}23.06 \\
(59.38)\end{array}$ & $\begin{array}{l}-104.08 \\
(72.21)\end{array}$ \\
\hline Municipal expenditures 1910s & $\begin{array}{c}-7.45 \mathrm{e}-05 \\
(0.0001)\end{array}$ & $\begin{array}{c}-5.74 \mathrm{e}-05 \\
(0.0001)\end{array}$ & $\begin{array}{c}-8.94 \mathrm{e}-05 \\
(0.0002)\end{array}$ & $\begin{array}{c}-0.0002 \\
(0.0002)\end{array}$ \\
\hline State schools $1910 \mathrm{~s}$ & $\begin{array}{c}1.09 \\
(1.70)\end{array}$ & $\begin{array}{c}1.07 \\
(1.90)\end{array}$ & $\begin{array}{c}-0.3488 \\
(1.79)\end{array}$ & $\begin{array}{c}-0.0245 \\
(1.52)\end{array}$ \\
\hline Municipal characteristics 1910 s & Yes & Yes & Yes & Yes \\
\hline Economic structure 1888 & Yes & Yes & Yes & Yes \\
\hline Observations & 40 & 41 & 40 & 36 \\
\hline Panel B: & t stage estims & es: German scl & ools 1910s & \\
\hline \# Farms bonded $1850 \mathrm{~s}-60 \mathrm{~s}$ & $\begin{array}{c}0.1398 * * * \\
(0.0265)\end{array}$ & $\begin{array}{c}0.1459 * * * \\
(0.0314)\end{array}$ & $\begin{array}{c}0.1403 * * * \\
(0.0232)\end{array}$ & $\begin{array}{c}0.1540 * * * \\
(0.0218)\end{array}$ \\
\hline
\end{tabular}

Notes: See Table 3.4. 
In terms of the supply of educational services, the foundation of a new German school implied that, at least in principle, native Brazilians could also enroll in it. In 1873, for instance, the School Germania was founded by some discontent members of the old Reading-and-School-Association of Campinas. The Association had strict rules of membership according to nationality, a condition that was eliminated by the founders of School Germania ${ }^{54}$. Indirect effects could also be at work. Teachers trained in German schools had the potential to join the Brazilian public educational system at a later stage. A relevant historical case in line with this explanation can be found in the municipality of Rio Claro, where one of the founders of the first public school was João von Atzingen, a first-generation descendant of Swiss and German immigrants ${ }^{55}$. In parallel, in 1873 five out of six teachers in the German School of Santos had Portuguese-Brazilian surnames: it is likely that they could apply the skills acquired in the German schools, in which they were trained, to the public educational system ${ }^{56}$. To a lesser extent, other material conditions of the German schools, including textbooks, could also bear positive externalities for the Brazilian public system. A report about the German educational system in Brazil in the late 1920s, for instance, recommended the use of books produced in Brazil, especially in the southern states, rather than importing them from Europe ${ }^{57}$.

As discussed in Section 2, explanations based on the demand for education must take into account that German-speaking immigrants had a comparatively smoother integration in São Paulo than in southern Brazil - with more intense and frequent contact with the native population ${ }^{58}$. Indeed, nominal lists in the almanacs show that German-speaking immigrants, their descendants and native Brazilians jointly established a series of cultural associations in the countryside of São Paulo, including schools and reading clubs ${ }^{59}$. It is important to notice that this symbiosis was two-sided, with some German-speaking communities benefiting from the support of native Brazilians as well. In the 1920s, for example, the School of Kirchdorf, in the municipality of Leme, received financial support from the local municipal chamber ${ }^{60}$. In this scenario of intense interactions, contagion in the demand for education was likely to occur. Natives could have demanded more education (privately or publicly) if influenced by the cultural traits of the immigrants or by their social perception about the German-speakers who attended schools. In this direction, in a report written

\footnotetext{
${ }^{54}$ Karastojanov (1998, pp. 109-11).

${ }^{55}$ Penteado (1983, p. 30). I am indebted to Leonardo Gardenal for this important illustration.

${ }^{56}$ Compilation based on Luné and Fonseca (1873).

${ }^{57}$ Keller and Linhart (1926, p. 11) and Bezerra (2007, p. 192). For a discussion on the courseware and its relation to the Brazilian educational system, see Nobre (2004, p. 49).

${ }^{58}$ Buarque de Holanda (1941) and Carvalho Filho and Colistete (2010).

${ }^{59}$ Compilation based on Luné and Fonseca (1873). See comments about the associations in Kreutz (2005).

${ }^{60}$ Information based on Instituto Martius Staden, Document: II. Einnahme, Kirchdorf, 1929/30.
} 
in 1874, José Vergueiro argued that one of the advantages of immigration was to increase the level of education of the Brazilians, given that the local population tended to emulate the foreigners, not wishing to "lag behind" them ${ }^{61}$.

Finally, the on-the-job skills of the German-speakers had more complex effects on educational attainment than hypothesized. The share of German-speakers in the total workforce in 1888 did not influence any educational indicator in the 1910s. This result also holds if the share of Germanspeakers per sector in 1888 is used instead ${ }^{62}$. However, the situation changes if we consider the on-the-job skills of the German-speakers in 1872. In all significant cases, their share in the total workforce in 1872 has a negative partial effect. This result goes against the hypothesis that the specialized skills brought by these immigrants were complementary to schooling. Nevertheless, some patterns appear if the sector categories in 1872 are controlled for. The share of Germanspeakers in trade-related occupations has a sizeable negative effect on total enrolment, on enrolment in private and municipal schools and on completion in state schools. Evaluated at mean of the sample, the coefficient for the share of German-speakers in trade-related occupations in 1872 would correspond to a reduction of total enrolment at about $9.91 \%$ of the sample mean ${ }^{63}$. An effect in the same direction is observed for their shares in services, but with smaller absolute magnitudes and led only by enrolment in private schools. These effects are partially compensated by the large and positive impact of manufacturing, this time in line with the hypothesis that immigrants' crafts were related to formal schooling. Evaluated at the mean of the sample, the coefficient for the share of German-speakers in manufacturing in 1872 would correspond to an increase of total enrolment at about $6.03 \%$ of the sample mean ${ }^{64}$.

In conclusion, the on-the-job skills of German-speaking immigrants in 1872 played a more important role than their correspondents in 1888 for the educational attainment of municipalities in the 1910s. This probably reflects the fact that the shares of German-speaking immigrants diminished sensitively in the 1880s, with the beginning of the mass immigration of Italians - and, therefore, of their overall participation in the labor force. Results for 1872, however, are not as straightforward as hypothesized. There is evidence of a positive association between the share of German-speakers in manufacturing and the levels of education, but this effect is more than compensated by the negative influence of their shares in trade-related occupations. The

\footnotetext{
${ }^{61}$ Vergueiro (1874, p. 9). Free translation from the original in Portuguese.

${ }^{62}$ With one exception for enrolment in private schools and another for completion in state schools.

63 (Mean share German-speakers in trade 1872 )*(Coefficient)/(Mean Total Enrolment ${ }_{1910 \mathrm{~s}}$ ).

${ }^{64}$ (Mean share German-speakers in manuf. 1872)*(Coefficient)/(Mean Total Enrolment ${ }_{1910 \mathrm{~s}) .}$
} 
transmission channels at work here deserve further empirical analysis. In principle, they remind us of the results of Chapter 1, which argued that occupational sorting in trade-related occupations was probably an easier and less capital-intensive form of economic integration. This could have led to a negative self-selection into that occupation, with deleterious effects for education.

Before proceeding to the next period, Table 3.8 shows that the determinants of completion of the basic cycle in primary schooling differed substantially from the determinants of enrolment. Although there is some erratic patterns for variables in the set (German speaking presence ${ }_{n}$ ), none of the other variables in the table is statistically significant and the highest adjusted R-squared is close to zero. The determinants for enrolment and completion were very different in the 1910s; for this dependent variable, the covariates were not even jointly significant.

\subsection{The path dependence of education - current estimates}

Turning to the last period, I first investigate the path dependence of current flows and stocks of human capital. For the flows, I check whether current enrolment per type of school depended on their historical counterparts at the beginning of the twentieth century. Results are in Table 3.9, below. For the stocks, I test whether illiteracy rates, average years of education and the educational component of the municipal HDI depended on enrolment in different types of school at the beginning of the twentieth century. Table 3.10 presents the results that control for enrolment in state schools in the 1910s, which provided significant cases of long-term dependence. The other regressions are in Tables A3.1-A3.3 (in the appendix to this chapter); their results are different for educational path dependence, but not for the variables in the set (German speaking presence ${ }_{n}$ ).

For the educational flows, Table 3.9 is conclusive in showing that enrolment and completion in state schools had a reversal in their performance over the twentieth century. This is reflected in the always significant and negative effect of enrolment and completion in this type of school in the 1910s. This implies that, on average, municipalities that started off with higher enrolment and completion in state schools did not keep this advantage in levels over time; conversely, those municipalities that started worse off did improve their enrolment and completion levels in state schools over the twentieth century. 
Table 3.9 - OLS: Path dependence and flows of human capital (2000s)

\begin{tabular}{|c|c|c|c|c|c|c|c|c|c|c|}
\hline & $\begin{array}{c}\text { Total } \\
\text { enrolment } \\
\text { 2000s }\end{array}$ & $\begin{array}{c}\text { Total } \\
\text { enrolment } \\
2000 \mathrm{~s}\end{array}$ & $\begin{array}{c}\text { Enrolment } \\
\text { state } \\
2000 \text { s }\end{array}$ & $\begin{array}{c}\text { Enrolment } \\
\text { state } \\
2000 \text { s }\end{array}$ & $\begin{array}{c}\text { Enrolment } \\
\text { private } \\
\text { 2000s }\end{array}$ & $\begin{array}{c}\text { Enrolment } \\
\text { private } \\
2000 \mathrm{~s}\end{array}$ & $\begin{array}{c}\text { Enrolment } \\
\text { munic. } \\
2000 \text { s }\end{array}$ & $\begin{array}{c}\text { Enrolment } \\
\text { munic. } \\
2000 \text { s }\end{array}$ & $\begin{array}{c}\text { Completion } \\
\text { state } \\
2000 \text { s } \\
\end{array}$ & $\begin{array}{l}\text { Completion } \\
\text { state } \\
2000 \mathrm{~s} \\
\end{array}$ \\
\hline \multicolumn{11}{|c|}{ Path dependence in education } \\
\hline Total enrolment 1910s & $\begin{array}{c}-2.975^{* * * *} \\
(0.899)\end{array}$ & $\begin{array}{c}-3.376 * * * \\
(0.708)\end{array}$ & & & & & & & & \\
\hline Enrolment state $1910 \mathrm{~s}$ & & & $\begin{array}{c}-6.574 * * * \\
(2.376)\end{array}$ & $\begin{array}{c}-6.552 * * * \\
(2.255)\end{array}$ & & & & & & \\
\hline Enrolment private $1910 \mathrm{~s}$ & & & & & $\begin{array}{l}3.085^{* *} \\
(1.332)\end{array}$ & $\begin{array}{l}3.814 * * \\
(1.440)\end{array}$ & & & & \\
\hline Enrolment munic. 1910s & & & & & & & $\begin{array}{l}-5.908 \\
(5.512)\end{array}$ & $\begin{array}{l}-5.996 \\
(6.261)\end{array}$ & & \\
\hline Completions state 1910 s & & & & & & & & & $\begin{array}{l}-2.942 * \\
(1.562)\end{array}$ & $\begin{array}{l}-2.674^{*} \\
(1.494)\end{array}$ \\
\hline \multicolumn{11}{|c|}{ German-speaking presence } \\
\hline German schools 1930 s & $\begin{array}{l}-996.2^{*} \\
(550.7)\end{array}$ & $\begin{array}{l}-874.7 \\
(663.4)\end{array}$ & $\begin{array}{l}-2,275^{*} \\
(1,251)\end{array}$ & $\begin{array}{c}-2,347^{*} \\
(1,186)\end{array}$ & $\begin{array}{c}240.7 \\
(195.4)\end{array}$ & $\begin{array}{l}-98.76 \\
(219.0)\end{array}$ & $\begin{array}{c}753.9 \\
(935.6)\end{array}$ & $\begin{array}{c}1,330 \\
(1,014)\end{array}$ & $\begin{array}{l}-237.3 \\
(185.6)\end{array}$ & $\begin{array}{l}-229.1 \\
(168.9)\end{array}$ \\
\hline German-speakers 1872 (share) & $\begin{array}{l}-15,400 \\
(29,950)\end{array}$ & $\begin{array}{c}87,461 \\
(91,067)\end{array}$ & $\begin{array}{c}74,755 \\
(82,237)\end{array}$ & $\begin{array}{c}228,402 \\
(231,763)\end{array}$ & $\begin{array}{c}-8,066 \\
(15,615)\end{array}$ & $\begin{array}{c}17,809 \\
(28,723)\end{array}$ & $\begin{array}{l}-42,308 \\
(71,292)\end{array}$ & $\begin{array}{c}-98,569 \\
(148,182)\end{array}$ & $\begin{array}{c}14,419 \\
(14,368)\end{array}$ & $\begin{array}{l}58,656^{*} \\
(31,792)\end{array}$ \\
\hline German workers 1872 (share) & $\begin{array}{c}-1,697 \\
(15,834)\end{array}$ & & $\begin{array}{l}-16,216 \\
(36,919)\end{array}$ & & $\begin{array}{c}-10,636^{*} \\
(5,245)\end{array}$ & & $\begin{array}{c}22,761 \\
(28,590)\end{array}$ & & $\begin{array}{l}-1,897 \\
(4,391)\end{array}$ & \\
\hline German workers 1888 (share) & & $\begin{array}{l}-36,284 \\
(27,542)\end{array}$ & & $\begin{array}{c}-64,596 \\
(72,998)\end{array}$ & & $\begin{array}{l}-8,248 \\
(9,600)\end{array}$ & & $\begin{array}{c}23,397 \\
(46,982)\end{array}$ & & $\begin{array}{l}-15,723 \\
(9,917)\end{array}$ \\
\hline \multicolumn{11}{|c|}{ Other variables of interest } \\
\hline Population 1999-2004 & $\begin{array}{c}0.205^{* * *} \\
(0.0128)\end{array}$ & $\begin{array}{c}0.209 * * * \\
(0.0105)\end{array}$ & $\begin{array}{c}0.150 * * * \\
(0.0189)\end{array}$ & $\begin{array}{c}0.152 * * * \\
(0.0172)\end{array}$ & $\begin{array}{c}0.0138 * * * \\
(0.00229)\end{array}$ & $\begin{array}{c}0.0124 * * * \\
(0.00213)\end{array}$ & $\begin{array}{c}0.0451 * * * \\
(0.0119)\end{array}$ & $\begin{array}{c}0.0475 * * * \\
(0.00793)\end{array}$ & $\begin{array}{c}0.0215^{* * * *} \\
(0.00293)\end{array}$ & $\begin{array}{l}0.0215 * * * \\
(0.00250)\end{array}$ \\
\hline Income 1999-2004 & $\begin{array}{c}-1.644 * * * \\
(0.591)\end{array}$ & $\begin{array}{c}-1.827 * * * \\
(0.498)\end{array}$ & $\begin{array}{c}0.648 \\
(1.101)\end{array}$ & $\begin{array}{c}0.393 \\
(1.054)\end{array}$ & $\begin{array}{c}0.380^{* *} \\
(0.159)\end{array}$ & $\begin{array}{c}0.482 * * * \\
(0.160)\end{array}$ & $\begin{array}{c}-2.453^{* * *} \\
(0.834)\end{array}$ & $\begin{array}{c}-2.706 * * * \\
(0.714)\end{array}$ & $\begin{array}{l}-0.183 \\
(0.153)\end{array}$ & $\begin{array}{l}-0.203 \\
(0.145)\end{array}$ \\
\hline Munic. expend. educ. 2002-2003 & $\begin{array}{l}-3.22 \mathrm{e}-05 \\
(5.13 \mathrm{e}-05)\end{array}$ & $\begin{array}{l}-3.59 \mathrm{e}-05 \\
(4.10 \mathrm{e}-05)\end{array}$ & $\begin{array}{c}-0.000312 * * * \\
(7.69 \mathrm{e}-05)\end{array}$ & $\begin{array}{c}-0.000298 * * * \\
(6.76 \mathrm{e}-05)\end{array}$ & $\begin{array}{c}7.54 \mathrm{e}-06 \\
(1.27 \mathrm{e}-05)\end{array}$ & $\begin{array}{c}7.92 \mathrm{e}-06 \\
(1.07 \mathrm{e}-05)\end{array}$ & $\begin{array}{c}0.000241 * * * \\
(5.20 \mathrm{e}-05)\end{array}$ & $\begin{array}{c}0.000243 * * * \\
(5.50 \mathrm{e}-05)\end{array}$ & $\begin{array}{c}-3.71 \mathrm{e}-05^{* * *} \\
(1.10 \mathrm{e}-05)\end{array}$ & $\begin{array}{c}-3.52 \mathrm{e}-05^{* * * *} \\
(9.61 \mathrm{e}-06)\end{array}$ \\
\hline Municipal characteristics $2000 \mathrm{~s}^{1}$ & Yes & Yes & Yes & Yes & Yes & Yes & Yes & Yes & Yes & Yes \\
\hline Economic structure $2000 \mathrm{~s}^{2}$ & Yes & Yes & Yes & Yes & Yes & Yes & Yes & Yes & Yes & Yes \\
\hline Observations & 68 & 59 & 63 & 54 & 51 & 46 & 50 & 46 & 52 & 46 \\
\hline Adj. $R^{2}$ & 0.996 & 0.997 & 0.967 & 0.970 & 0.976 & 0.977 & 0.951 & 0.954 & 0.950 & 0.957 \\
\hline
\end{tabular}


The correspondent effects for municipal schools have suggestive negative signs - as for the state schools. Nevertheless, these coefficients are not statistically significant.

By contrast, enrolment in private schools proved to be very persistent. In this case, positive and significant coefficients are found in all specifications. This implies that municipalities which started relying more on private schools in the 1910s still have an advantage in this modality of education nowadays: ceteris paribus, approximately three more students are enrolled currently in private schools per additional student enrolled in them back in the 1910s.

A concern with the results for the state schools is that enrolment rates in primary education converged to 100 percent by the end of the 1990 s in Brazil ${ }^{65}$. Considering that population is held constant in the regressions, the significant negative signs could be a statistical artefact for a variable reaching an upper ceiling in this period. To avoid this problem, Table 3.10 reports the effects of historical enrolment in state schools on three measures for the stocks of human capital. The long-term effect remains for average years of education and illiteracy rates, but no effect is found for the educational component of the municipal HDI. It should be highlighted that, in contrast to current enrolment, the stocks of human capital are only influenced by enrolment in state schools in the 1910s. Other results in the appendix show that enrolment in private and municipal schools, total enrolment and completion in state schools had no effect on current stocks of human capital ${ }^{66}$. It is likely that only enrolment in state schools had the necessary scale to impact the stocks of human capital over a century.

The magnitudes of the coefficients of historical enrolment deserve some attention. For average years of education, the smallest coefficient implies a current increase of 0.00024 years per child enrolled in a state school in the 1910s. Evaluated at the mean of the sample, this coefficient corresponds to about 2.3 percent of current average years of schooling ${ }^{67}$. Although not large, this effect still shows how certain variables have a direct and persistent effect for development, even one hundred years after its occurrence. For the region with the highest number of children enrolled in state schools in the 1910s - the MCA Grande Campinas - the coefficient implies a sizeable effect: ceteris paribus, the effect of enrolment in state schools in the 1910s corresponds to about 16 percent of current average years of education in that locality ${ }^{68}$. A similar argument

\footnotetext{
${ }^{65}$ See a summary in Kang (2017, pp. 35, 38-9).

${ }^{66}$ Completion in state schools in the 1910s is also related to an increase in average years of education in one baseline model. Because this result does not appear for the other indicators, I considered it rather weak.

67 (Mean Total Enrolment ${ }_{1910 \mathrm{~s}}$ )*(Coefficient)/(Mean Years of Education $2000 \mathrm{~s}$ ).

${ }^{68}$ It should be highlighted that Grande Campinas was the only MCA to have enough children enrolled in state schools in the 1910s to imply an increase of one entire year of education with the corresponding coefficient.
} 
applies for illiteracy. The smallest coefficient in absolute terms implies that illiteracy rates would be lowered by 0.0006 percentage points per child enrolled in state schools in the 1910s. Evaluated at the mean of the sample, this is equivalent to $c a$. 5 percent of current illiteracy rates. Again, the coefficient is large enough to show the importance of historical determinants for current educational outcomes.

Table 3.10 - OLS: Path dependence and stocks of human capital (2000s) - with historical enrolment in state schools

\begin{tabular}{|c|c|c|c|c|c|c|}
\hline & $\begin{array}{l}\text { Avg. Years } \\
\text { Educ. } \\
\text { 2000s }\end{array}$ & $\begin{array}{l}\text { Avg. Years } \\
\text { Educ. } \\
\text { 2000s }\end{array}$ & $\begin{array}{l}\text { Illiteracy } \\
\text { rate } \\
2000 \text { s }\end{array}$ & $\begin{array}{l}\text { Illiteracy } \\
\text { rate } \\
2000 \mathrm{~s}\end{array}$ & $\begin{array}{l}\text { Educ. } \\
\text { MHDI } \\
\text { 2000s }\end{array}$ & $\begin{array}{l}\text { Educ. } \\
\text { MHDI } \\
\text { 2000s }\end{array}$ \\
\hline \multicolumn{7}{|c|}{$\underline{\text { Path dependence in education }}$} \\
\hline Enrolment state 1910 s & $\begin{array}{l}0.000252 * \\
(0.000135)\end{array}$ & $\begin{array}{l}0.000240 * \\
(0.000132)\end{array}$ & $\begin{array}{c}-0.000604 * * \\
(0.000285)\end{array}$ & $\begin{array}{c}-0.000772 * * \\
(0.000320)\end{array}$ & $\begin{array}{c}6.70 \mathrm{e}-06 \\
(8.22 \mathrm{e}-06)\end{array}$ & $\begin{array}{c}1.09 \mathrm{e}-05 \\
(8.16 \mathrm{e}-06)\end{array}$ \\
\hline \multicolumn{7}{|c|}{ German-speaking presence } \\
\hline German schools 1930 s & $\begin{array}{c}-0.108 \\
(0.0944)\end{array}$ & $\begin{array}{l}-0.237 * * \\
(0.0887)\end{array}$ & $\begin{array}{c}0.131 \\
(0.224)\end{array}$ & $\begin{array}{c}0.300 \\
(0.201)\end{array}$ & $\begin{array}{l}-0.00617 \\
(0.00573)\end{array}$ & $\begin{array}{c}-0.0137 * * \\
(0.00550)\end{array}$ \\
\hline German-speakers 1872 (share) & $\begin{array}{c}2.869 \\
(7.941)\end{array}$ & $\begin{array}{l}-21.03 \\
(13.30)\end{array}$ & $\begin{array}{c}7.554 \\
(11.96)\end{array}$ & $\begin{array}{l}56.33 * * \\
(21.55)\end{array}$ & $\begin{array}{c}0.395 \\
(0.482)\end{array}$ & $\begin{array}{l}-0.399 \\
(0.824)\end{array}$ \\
\hline German workers 1872 (share) & $\begin{array}{c}0.781 \\
(2.490)\end{array}$ & & $\begin{array}{l}-7.856 \\
(4.713)\end{array}$ & & $\begin{array}{l}0.0593 \\
(0.151)\end{array}$ & \\
\hline German workers 1888 (share) & & $\begin{array}{c}11.03 * * \\
(4.159)\end{array}$ & & $\begin{array}{c}-24.82 * * * \\
(6.991)\end{array}$ & & $\begin{array}{l}0.458^{*} \\
(0.258)\end{array}$ \\
\hline \multicolumn{7}{|c|}{ Other variables of interest } \\
\hline Population 1999-2004 & $\begin{array}{l}-8.26 \mathrm{e}-07 \\
(8.03 \mathrm{e}-07)\end{array}$ & $\begin{array}{c}-1.07 \mathrm{e}-06 \\
(7.25 \mathrm{e}-07)\end{array}$ & $\begin{array}{c}3.57 \mathrm{e}-07 \\
(1.74 \mathrm{e}-06)\end{array}$ & $\begin{array}{c}9.16 \mathrm{e}-07 \\
(1.63 \mathrm{e}-06)\end{array}$ & $\begin{array}{c}2.92 \mathrm{e}-08 \\
(4.88 \mathrm{e}-08)\end{array}$ & $\begin{array}{c}1.09 \mathrm{e}-08 \\
(4.49 \mathrm{e}-08)\end{array}$ \\
\hline Income $1999-2004$ & $\begin{array}{l}-2.93 e-06 \\
(6.65 e-05)\end{array}$ & $\begin{array}{c}9.34 \mathrm{e}-05 \\
(6.45 \mathrm{e}-05)\end{array}$ & $\begin{array}{c}0.000241 \\
(0.000191)\end{array}$ & $\begin{array}{c}4.55 \mathrm{e}-05 \\
(0.000200)\end{array}$ & $\begin{array}{c}8.12 \mathrm{e}-07 \\
(4.04 \mathrm{e}-06)\end{array}$ & $\begin{array}{c}5.71 \mathrm{e}-06 \\
(4.00 \mathrm{e}-06)\end{array}$ \\
\hline Munic. expend. educ. 2002-2003 & $\begin{array}{c}5.62 \mathrm{e}-09 \\
(5.07 \mathrm{e}-09)\end{array}$ & $\begin{array}{c}1.98 \mathrm{e}-10 \\
(4.79 \mathrm{e}-09)\end{array}$ & $\begin{array}{l}-2.04 \mathrm{e}-08 \\
(1.25 \mathrm{e}-08)\end{array}$ & $\begin{array}{l}-6.85 e-09 \\
(1.32 e-08)\end{array}$ & $\begin{array}{l}-8.50 \mathrm{e}-11 \\
(3.08 \mathrm{e}-10)\end{array}$ & $\begin{array}{l}-3.30 \mathrm{e}-10 \\
(2.97 \mathrm{e}-10)\end{array}$ \\
\hline Municipal characteristics & Yes & Yes & Yes & Yes & Yes & Yes \\
\hline Economic structure $2000 \mathrm{~s}$ & Yes & Yes & Yes & Yes & Yes & Yes \\
\hline Observations & 68 & 59 & 68 & 59 & 68 & 59 \\
\hline Adj. $\mathrm{R}^{2}$ & 0.585 & 0.671 & 0.682 & 0.708 & 0.596 & 0.642 \\
\hline
\end{tabular}

As a final evaluation, I now turn to the variables in the set (German speaking presence ${ }_{n}$ ).

Whenever significant, German schools established until the 1930s have a negative effect for current educational attainment. For the stocks of human capital, this negative association is systematic if we control for the on-the-job skills in 1888. This robust pattern leads to the rejection of the hypothesis that German schools created until the 1930s had a direct positive influence on current educational performance. However, this does not imply a rejection of the hypothesis of the historical importance of the German schools in setting a positive path dependence for the accumulation of human capital in the long run. It should be borne in mind that for the 1910s German schools robustly influenced enrolment in state and private schools. 
For the current period, we observed how persistent enrolment in private schools was and how enrolment in state schools reverted over time. Once historical conditions are controlled for, the negative impact of German schools is just another facet of that change in performance of state schools across different municipalities.

For the current flows of human capital, the shares of German-speakers in the population in the nineteenth century have no significant effect in any estimate, in line with results of previous periods. The share of German-speakers in total professions in 1872 and 1888 had no systematic significant effect on current flows either ${ }^{69}$. In terms of capacity to accumulate human capital, the effects of the German-speakers dissipated over the twentieth century.

However, some different patterns emerge for the stocks of human capital. Overall, the share of German-speakers in the total workforce in 1888 is systematically correlated with higher average years of education and lower illiteracy rates nowadays ${ }^{70}$. The share of German-speakers in the total workforce in 1872 is also systematically related to lower illiteracy rates nowadays. Moreover, in specifications that control for the on-the-job skills in 1888, the share of Germanspeakers in the population in the nineteenth century becomes statistically related to higher illiteracy rates. This further suggests that a positive influence of immigrants on the receiving societies depends on adequate economic integration.

These results for the on-the-job skills are less congruous with previous periods. They indicate a positive and long-term impact of the skills of German-speakers on the stocks of human capital in São Paulo. The effects required time to maturate: the same variables had been either innocuous or double-edged for education in the 1910s, but have a positive effect in the long run. This indicates that other transmission channels could be at work. For instance, historical on-the-job skills could have influenced the pace of technological adoption, changes in the sector composition of municipalities and modifications in the skills demanded from the workforce. In the current analysis, I only controlled for the levels of the sector composition of the municipalities. A promising line of research is now to study the impact of immigrants on changes in the sector composition and the influence this might have exerted on education.

\footnotetext{
${ }^{69}$ With the exception of a coefficient significant at the 10 percent level for enrolment in private schools.

${ }^{70}$ This is the only variable in the set (German speaking presence ${ }_{n}$ ) to be statistically significant also for the educational component of the municipal HDI, although at the 10 percent level and in specifications that control either for total historical enrolment or historical enrolment in state schools.
} 


\section{Robustness checks}

This section conducts two groups of robustness checks. The first tests for the sensitivity of results to subsample analyses that account for specific regions in the province/state. The aim is to determine whether results are robust to changes in MCAs whose historical experience could be leading the conclusions. The second discusses the effects of bootstrapping standard errors to deal with the varying number of observations across specifications ${ }^{71}$. Although estimated, I argue that the structure of the data invalidates this approach.

\subsection{Sensitivity to MCAs: Western Frontier, Old-West and Holloway's Regions}

Three analyses are performed to test for the sensitivity of results to specific regions of São Paulo. A summary of results is presented in Tables A3.4-A3.7 (in the appendix to this (chapter $)^{72}$.

Although all baseline specifications control for a set of geographic variables, two concerns remain. First, regions with similar geographic characteristics could have experienced the advancement of the agricultural frontier in different periods. In this case, time-invariant characteristics could be correlated with time-varying omitted variables, including the year of settlement of a new region or the expansion of the transport infrastructure (mainly railways). Second, municipalities settled earlier on could have developed institutions and cultural idiosyncrasies not controlled for in the baselines.

To accommodate the first concern, I exclude the MCA Western Frontier. Located at the agricultural frontier in the 1910s, this MCA comprises 269 current municipalities. Dropping this MCA has no consequence either for results in 1872 or for those in the 1910s, given that the region was sparsely occupied by then. For the current period, minor modifications in the magnitudes of the coefficients do not alter the conclusions from the baselines with the full sample.

The second concern is mainly related to the MCAs Grande Campinas, Grande Limeira and Rio Claro, a region that I label jointly as the Old-West. This was the first region in the central plateau

\footnotetext{
${ }^{71}$ These checks resulted from discussions with three anonymous referees, to whom I express my gratitude.

${ }^{72}$ Robust standard errors were used throughout. Considering the number of specifications, the tables in the appendix to this chapter report only a summary of findings. The full set of covariates is available upon request.
} 
of São Paulo to experience the expansion of coffee plantations by the mid-nineteenth century. Consequently, the Old-West concentrated most farms employing bonded laborers in the 1850s$60 \mathrm{~s}$ and a large parcel of settlement colonies established in the 1890s-1910s. Descriptive statistics in Table A3.8 (in the appendix to this chapter) show that these MCAs had a higher share of immigrants in general; of German-speakers in particular; of settlement colonies; and of German schools than the average for the entire province/state for all periods considered.

To test for the sensitivity of results to these MCAs, the simplest strategy is to exclude them from the sample, as performed with the Western Frontier. However, this approach leads to the omission of the variable (German schools ${ }_{n}^{1910 s}$ ) and to the impossibility of obtaining the IV estimates, given that those three MCAs concentrated $62.14 \%$ of all farms employing bonded laborers in the $1850 \mathrm{~s}-60 \mathrm{~s}$ and $68.75 \%$ of German schools in the 1910s. To circumvent this limitation and still deal with regional idiosyncrasies, the other robustness checks add a control for regions in the province/state to the full sample ${ }^{73}$. Estimates from the baseline are robust to this new control.

In conclusion, the Old-West is indeed responsible for the lion's share of the results. Nevertheless, the significance of the coefficients is not modified by adding an important geographic variable that accounts for specific regional characteristics of the municipalities of São Paulo, including those in the Old-West.

\subsection{Number of observations and bootstrapping techniques: a discussion}

The number of observations in the regressions varies not only over time, but also across specifications. The variation across specifications occurs mainly because the Annuarios de Ensino report enrolment in state schools for $145 \mathrm{MCAs}$; in private schools for $102 \mathrm{MCAs}$; and in municipal schools for 96 MCAs. Combined with missing variables of other periods and sources, this leads to the varying number of observations for the analyses in the 1910s and in the current period. The variation over time, in turn, is caused by the data generating process, as I deliberately decided not to extrapolate data from neighbouring MCAs or to impute zeros to municipalities that did not exist as an official politico-administrative unit in a certain year ${ }^{74}$.

\footnotetext{
${ }^{73}$ Holloway's regions based on Carvalho Filho and Colistete (2010), as controlled for in Chapter 1.

${ }^{74}$ This implies that I use historical borders as the reference, instead of imputing historical values to current municipal borders.
} 
This varying number of observations lead to limited degrees of freedom in some specifications, raising concerns about the asymptotic properties of the estimators. A suggestion to accommodate this problem is to bootstrap the standard errors. Although conducted, this method proved to be rather problematic precisely because of the structure of the data.

To replicate the sample, bootstrapping techniques require the imputation of data for the missing values either a priori or a posteriori - that is, before or after each replication. These imputations are made under the assumption that values are "missing at random"75.

The estimations for a sample which imputed zeros to municipalities that did not exist in a certain year and which was then bootstrapped with 1,000-repetitions are presented in Tables A3.9A3.12 (in the appendix to this chapter).

These estimates would lead to the conclusion that only the share of German-speakers in 1872 had an influence on the educational performance of São Paulo, both historically and currently. The effects of the German schools and of their on-the-job skills disappear altogether ${ }^{76}$. These results imply either that all previous inferences were fundamentally wrong, or that there are problems with the bootstrapping. I consider that there are substantial reasons to defend the second proposition. The assumption that values are missing at random has no historical support, as the foundation of municipalities did not occur randomly, but followed the expansion of the agricultural frontier. Moreover, the zero-imputed dataset artificially inflated the adjusted Rsquared of the regressions, in some cases substantially (e.g. for the 1872 analysis in Table A3.9). Because we know that the models are unaltered with respect to the baseline, this augmented goodness-of-fit is only a statistical artefact caused by a higher variation imposed by the inclusion of zero-inflated observations.

\section{Concluding remarks}

This chapter studied the accumulation of human capital in the state of São Paulo, focusing on the long-term influences of German-speaking immigrants arrived mainly between 1840 and 1920. It has examined whether these immigrants represented a positive shock for historical and

\footnotetext{
${ }^{75}$ Davidson and Hinkley (1997, pp. 88-102).

${ }^{76} \mathrm{I}$ also conducted bootstrapping with missing values, implying a posteriori imputations. Results were unaltered in showing an almost overall non-significance for variables in the set (German speaking presence ${ }_{n}$ ). These are not reported to save space, but are available at https://onlinelibrary.wiley.com/doi/full/10.1111/ehr.12575, accessed on November 262018.
} 
current measures of human capital through different channels, namely their share in the population in the nineteenth century, the schools they founded and their on-the-job skills.

The findings have shown that the share of German-speakers in a municipality in the nineteenth century had per se no systematic impact on human capital formation, either historically or currently. However, the institutionalization of the higher levels of education of the Germanspeakers, through the creation of schools, proved to be a major contribution to an increase in the levels of enrolment at the beginning of the twentieth century. For human capital accumulation, the conclusions reached in this chapter favor institutional hypotheses over explanations that stress a direct influence of immigration via cultural traits ${ }^{77}$. A step ahead is now to explain the origins of those educational institutions, which depended on the cultural background of immigrants and the socio-economic conditions of receiving societies.

In analyzing this institutional explanation for the accumulation of human capital in São Paulo, the importance of differentiating between specific types of school was highlighted. The path dependence of enrolment in private, state and municipal schools differed substantially. A strong positive persistence was found for current enrolment in private schools with respect to enrolment levels in the 1910s. On the other hand, state schools showed a strong process of reversal in terms of enrolment at the beginning of the twentieth century.

With respect to the main variable of interest, German schools influenced enrolment levels both in private and in state schools in the 1910s. This finding seems to provide evidence of spillover and contagion effects among immigrants and native Brazilians, thus supporting a classical hypothesis of the Brazilian historiography, namely that German-speakers experienced a smoother integration process in São Paulo than in the southern provinces of the country.

The impact of the German schools, however, dissipated over time and the schools have no direct positive influence on current measures of human capital. At the same time, these educational institutions have an indirect effect on current educational performance via their influence on enrolment in private and state schools in the 1910s. In particular, it is noteworthy that historical enrolment in state schools is associated with current higher average years of education and lower levels of illiteracy.

\footnotetext{
${ }^{77}$ See in particular the debate between Glaeser et al. (2004), Gennaioli et al. (2013) and Acemoglu, Gallego and Robinson (2014) as well as the complement by Pande and Udry (2005).
} 
Unlike the literature focused on Brazil, which favors the hypothesis of a direct long-term impact of immigrants on human capital formation, the results of this study point towards dissipation effects that survive only indirectly in the long run ${ }^{78}$. From a broader perspective, the results also diverge from studies that assess the direct impact of immigrants on developmental outcomes in the long run ${ }^{79}$. A potential explanation for these diverging results is that this study has focused on an ethno-linguistic minority which represented less than one percent of the average population of the province in 1872 - and only 4.39 percent in the MCA with the maximum share of German-speakers. Repeating this analysis for a nationality numerically more substantial in São Paulo or for regions where German-speakers constituted a higher share of the population (in Brazil or globally) would allow us to determine whether the dissipation occurred because these immigrants were a minority or for other, institutional, reasons.

Finally, the analysis of the on-the-job skills of the German-speakers provided some puzzling results. While no robust effect was found for historical schooling, some direct impacts were systematically identified for current enrolment and measures of human capital stocks. This suggests that this component of human capital brought by the immigrants might have transmission channels other than a direct impact on formal education, as assessed in this chapter. Other potential explanations include the effect that these skills had on technological adoption and changes in the sector composition of the municipalities - and how these, in turn, affected education -, raising questions that merit further investigation.

\footnotetext{
${ }^{78}$ My argument is more in line with Carvalho Filho and Colistete (2010), who study the relationship between current educational performance and historical public investments, with the latter influenced by immigrants.

${ }^{79}$ See a critical review on this approach especially in Nunn, Qian and Sequeira (2017, p. 10) for the U.S.
} 


\section{Appendix: Complementary tables \& robustness checks for settlement colonies}

Table A3.1 - OLS: Path dependence and stocks of human capital (2000s) - average years of education

\begin{tabular}{|c|c|c|c|c|c|c|c|c|}
\hline & $\begin{array}{c}\text { Avg. Years Educ. } \\
2000 \mathrm{~s}\end{array}$ & $\begin{array}{c}\text { Avg. Years Educ. } \\
2000 \text { s } \\
\end{array}$ & $\begin{array}{c}\text { Avg. Years Educ. } \\
2000 \mathrm{~s}\end{array}$ & $\begin{array}{c}\text { Avg. Years Educ. } \\
2000 \mathrm{~s}\end{array}$ & $\begin{array}{c}\text { Avg. Years Educ. } \\
2000 \mathrm{~s}\end{array}$ & $\begin{array}{c}\text { Avg. Years Educ. } \\
2000 \text { s } \\
\end{array}$ & $\begin{array}{c}\text { Avg. Years Educ. } \\
2000 \mathrm{~s}\end{array}$ & $\begin{array}{c}\text { Avg. Years Educ. } \\
2000 \mathrm{~s}\end{array}$ \\
\hline Total enrolment $1910 \mathrm{~s}$ & $\begin{array}{c}0.000144 \\
(9.04 \mathrm{e}-05)\end{array}$ & $\begin{array}{c}0.000126 \\
(9.15 \mathrm{e}-05)\end{array}$ & & & & & & \\
\hline Enrolment private 1910 s & & & $\begin{array}{c}0.000122 \\
(0.000310)\end{array}$ & $\begin{array}{c}0.000159 \\
(0.000336)\end{array}$ & & & & \\
\hline Enrolment munic. 1910s & & & & & $\begin{array}{l}-0.000203 \\
(0.000619)\end{array}$ & $\begin{array}{l}-0.000161 \\
(0.000635)\end{array}$ & & \\
\hline Completion state 1910 s & & & & & & & $\begin{array}{c}0.00128 * \\
(0.000746)\end{array}$ & $\begin{array}{c}0.000889 \\
(0.000761)\end{array}$ \\
\hline German schools 1930s & $\begin{array}{c}-0.128 \\
(0.0945)\end{array}$ & $\begin{array}{c}-0.251 * * * \\
(0.0901)\end{array}$ & $\begin{array}{l}-0.161 \\
(0.103)\end{array}$ & $\begin{array}{c}-0.236^{* *} \\
(0.102)\end{array}$ & $\begin{array}{l}-0.136 \\
(0.100)\end{array}$ & $\begin{array}{l}-0.204 * \\
(0.103)\end{array}$ & $\begin{array}{l}-0.0777 \\
(0.0957)\end{array}$ & $\begin{array}{l}-0.191 * \\
(0.0961)\end{array}$ \\
\hline German-speakers 1872 (share) & $\begin{array}{c}3.447 \\
(7.993)\end{array}$ & $\begin{array}{l}-20.10 \\
(13.72)\end{array}$ & $\begin{array}{c}0.584 \\
(8.765)\end{array}$ & $\begin{array}{l}-13.50 \\
(16.32)\end{array}$ & $\begin{array}{l}-2.122 \\
(8.484)\end{array}$ & $\begin{array}{l}-18.42 \\
(15.03)\end{array}$ & $\begin{array}{c}2.096 \\
(7.969)\end{array}$ & $\begin{array}{l}-14.79 \\
(14.38)\end{array}$ \\
\hline German workers 1872 (share) & $\begin{array}{l}0.970 \\
(2.505)\end{array}$ & & $\begin{array}{c}2.333 \\
(2.832)\end{array}$ & & $\begin{array}{l}2.556 \\
(2.662)\end{array}$ & & $\begin{array}{l}-0.152 \\
(2.561)\end{array}$ & \\
\hline German workers 1888 (share) & & $\begin{array}{l}10.99 * * \\
(4.300)\end{array}$ & & $\begin{array}{c}8.220 \\
(5.220)\end{array}$ & & $\begin{array}{l}9.082 * \\
(4.765)\end{array}$ & & $\begin{array}{c}7.899 \\
(4.665)\end{array}$ \\
\hline Population 1999-2004 & $\begin{array}{l}-7.76 \mathrm{e}-07 \\
(8.09 \mathrm{e}-07)\end{array}$ & $\begin{array}{l}-9.83 e-07 \\
(7.35 e-07)\end{array}$ & $\begin{array}{l}-9.51 e-07 \\
(9.06 e-07)\end{array}$ & $\begin{array}{l}-7.98 \mathrm{e}-07 \\
(8.23 \mathrm{e}-07)\end{array}$ & $\begin{array}{l}-8.32 \mathrm{e}-07 \\
(8.74 \mathrm{e}-07)\end{array}$ & $\begin{array}{l}-6.31 \mathrm{e}-07 \\
(8.04 \mathrm{e}-07)\end{array}$ & $\begin{array}{l}-8.19 \mathrm{e}-07 \\
(8.04 \mathrm{e}-07)\end{array}$ & $\begin{array}{l}-8.19 \mathrm{e}-07 \\
(7.47 \mathrm{e}-07)\end{array}$ \\
\hline Income $1999-2004$ & $\begin{array}{l}-6.72 \mathrm{e}-07 \\
(6.71 \mathrm{e}-05)\end{array}$ & $\begin{array}{c}9.23 \mathrm{e}-05 \\
(6.60 \mathrm{e}-05)\end{array}$ & $\begin{array}{c}6.02 \mathrm{e}-05 \\
(8.24 \mathrm{e}-05)\end{array}$ & $\begin{array}{c}0.000126 \\
(8.48 \mathrm{e}-05)\end{array}$ & $\begin{array}{c}5.37 \mathrm{e}-05 \\
(7.13 \mathrm{e}-05)\end{array}$ & $\begin{array}{c}0.000104 \\
(7.24 \mathrm{e}-05)\end{array}$ & $\begin{array}{c}1.21 \mathrm{e}-05 \\
(6.60 \mathrm{e}-05)\end{array}$ & $\begin{array}{c}8.07 \mathrm{e}-05 \\
(6.79 \mathrm{e}-05)\end{array}$ \\
\hline Mun. expend. educ. 2002-2003 & $\begin{array}{c}5.50 \mathrm{e}-09 \\
(5.11 \mathrm{e}-09)\end{array}$ & $\begin{array}{c}2.81 \mathrm{e}-10 \\
(4.89 \mathrm{e}-09)\end{array}$ & $\begin{array}{c}2.94 \mathrm{e}-09 \\
(6.67 \mathrm{e}-09)\end{array}$ & $\begin{array}{l}-2.67 e-09 \\
(6.53 e-09)\end{array}$ & $\begin{array}{c}2.85 \mathrm{e}-09 \\
(5.82 \mathrm{e}-09)\end{array}$ & $\begin{array}{l}-1.55 \mathrm{e}-09 \\
(5.58 \mathrm{e}-09)\end{array}$ & $\begin{array}{c}5.25 \mathrm{e}-09 \\
(5.20 \mathrm{e}-09)\end{array}$ & $\begin{array}{c}9.52 \mathrm{e}-10 \\
(5.12 \mathrm{e}-09)\end{array}$ \\
\hline Municipal characteristics 2000s & Yes & Yes & Yes & Yes & Yes & Yes & Yes & Yes \\
\hline Economic structure 2000 s & Yes & Yes & Yes & Yes & Yes & Yes & Yes & Yes \\
\hline $\begin{array}{l}\text { Observations } \\
\text { Adj. } R^{2}\end{array}$ & $\begin{array}{c}68 \\
0.577 \\
\end{array}$ & $\begin{array}{c}59 \\
0.660\end{array}$ & $\begin{array}{c}51 \\
0.535 \\
\end{array}$ & $\begin{array}{c}46 \\
0.576\end{array}$ & $\begin{array}{c}50 \\
0.576 \\
\end{array}$ & $\begin{array}{c}46 \\
0.624\end{array}$ & $\begin{array}{c}56 \\
0.562 \\
\end{array}$ & $\begin{array}{c}50 \\
0.632 \\
\end{array}$ \\
\hline
\end{tabular}


Table A3.2 - OLS: Path dependence and stocks of human capital (2000s) - illiteracy rate

\begin{tabular}{|c|c|c|c|c|c|c|c|c|}
\hline & $\begin{array}{c}\text { Illiteracy rate } \\
2000 \mathrm{~s}\end{array}$ & $\begin{array}{c}\text { Illiteracy rate } \\
2000 \mathrm{~s}\end{array}$ & $\begin{array}{c}\text { Illiteracy rate } \\
2000 \mathrm{~s}\end{array}$ & $\begin{array}{c}\text { Illiteracy rate } \\
2000 \mathrm{~s}\end{array}$ & $\begin{array}{c}\text { Illiteracy rate } \\
2000 \mathrm{~s}\end{array}$ & $\begin{array}{c}\text { Illiteracy rate } \\
2000 \mathrm{~s}\end{array}$ & $\begin{array}{c}\text { Illiteracy rate } \\
2000 \mathrm{~s} \\
\end{array}$ & $\begin{array}{c}\text { Illiteracy rate } \\
2000 \text { s }\end{array}$ \\
\hline Total enrolment 1910 s & $\begin{array}{l}-0.000249 \\
(0.000208)\end{array}$ & $\begin{array}{l}-0.000311 \\
(0.000255)\end{array}$ & & & & & & \\
\hline Enrolment private $1910 \mathrm{~s}$ & & & $\begin{array}{c}0.000327 \\
(0.000558)\end{array}$ & $\begin{array}{c}0.000309 \\
(0.000635)\end{array}$ & & & & \\
\hline Enrolment munic. $1910 \mathrm{~s}$ & & & & & $\begin{array}{l}0.000959 \\
(0.00150)\end{array}$ & $\begin{array}{l}0.000818 \\
(0.00159)\end{array}$ & & \\
\hline Completion state $1910 \mathrm{~s}$ & & & & & & & $\begin{array}{l}-0.00240 \\
(0.00186)\end{array}$ & $\begin{array}{l}-0.00276 \\
(0.00211)\end{array}$ \\
\hline German schools 1930 s & $\begin{array}{c}0.179 \\
(0.224)\end{array}$ & $\begin{array}{c}0.339 \\
(0.216)\end{array}$ & $\begin{array}{c}0.166 \\
(0.209)\end{array}$ & $\begin{array}{c}0.215 \\
(0.275)\end{array}$ & $\begin{array}{c}0.221 \\
(0.234)\end{array}$ & $\begin{array}{c}0.250 \\
(0.298)\end{array}$ & $\begin{array}{l}0.0949 \\
(0.208)\end{array}$ & $\begin{array}{c}0.198 \\
(0.244)\end{array}$ \\
\hline German-speakers 1872 (share) & $\begin{array}{c}5.679 \\
(12.48)\end{array}$ & $\begin{array}{c}56.34 * * \\
(24.69)\end{array}$ & $\begin{array}{l}10.50 \\
(18.75)\end{array}$ & $\begin{array}{l}43.25 \\
(29.53)\end{array}$ & $\begin{array}{c}17.24 \\
(17.82)\end{array}$ & $\begin{array}{l}49.68^{*} \\
(27.58)\end{array}$ & $\begin{array}{c}6.155 \\
(14.82)\end{array}$ & $\begin{array}{c}29.96 \\
(22.78)\end{array}$ \\
\hline German workers 1872 (share) & $\begin{array}{l}-8.751^{*} \\
(4.685)\end{array}$ & & $\begin{array}{l}-9.854^{*} \\
(5.454)\end{array}$ & & $\begin{array}{l}-11.98^{*} \\
(6.221)\end{array}$ & & $\begin{array}{l}-4.893 \\
(4.819)\end{array}$ & \\
\hline German workers 1888 (share) & & $\begin{array}{c}-25.90 * * * \\
(8.193)\end{array}$ & & $\begin{array}{l}-19.24 * \\
(10.59)\end{array}$ & & $\begin{array}{l}-20.17 * \\
(9.972)\end{array}$ & & $\begin{array}{l}-13.67 \\
(8.321)\end{array}$ \\
\hline Population 1999-2004 & $\begin{array}{c}7.52 \mathrm{e}-08 \\
(1.57 \mathrm{e}-06)\end{array}$ & $\begin{array}{c}4.31 \mathrm{e}-07 \\
(1.43 \mathrm{e}-06)\end{array}$ & $\begin{array}{c}1.20 \mathrm{e}-06 \\
(1.19 \mathrm{e}-06)\end{array}$ & $\begin{array}{c}3.46 \mathrm{e}-07 \\
(1.12 \mathrm{e}-06)\end{array}$ & $\begin{array}{c}6.85 \mathrm{e}-07 \\
(1.37 \mathrm{e}-06)\end{array}$ & $\begin{array}{l}-2.04 \mathrm{e}-07 \\
(1.22 \mathrm{e}-06)\end{array}$ & $\begin{array}{c}5.21 \mathrm{e}-07 \\
(1.45 \mathrm{e}-06)\end{array}$ & $\begin{array}{c}4.79 \mathrm{e}-07 \\
(1.15 \mathrm{e}-06)\end{array}$ \\
\hline Income $1999-2004$ & $\begin{array}{c}0.000224 \\
(0.000187)\end{array}$ & $\begin{array}{c}3.86 \mathrm{e}-05 \\
(0.000194)\end{array}$ & $\begin{array}{c}0.000156 \\
(0.000205)\end{array}$ & $\begin{array}{c}3.29 \mathrm{e}-05 \\
(0.000221)\end{array}$ & $\begin{array}{c}4.47 \mathrm{e}-05 \\
(0.000145)\end{array}$ & $\begin{array}{l}-4.13 \mathrm{e}-05 \\
(0.000172)\end{array}$ & $\begin{array}{c}0.000226 \\
(0.000179)\end{array}$ & $\begin{array}{c}8.07 \mathrm{e}-05 \\
(0.000195)\end{array}$ \\
\hline Mun. expend. educ. 2002-2003 & $\begin{array}{l}-1.98 \mathrm{e}-08 \\
(1.23 \mathrm{e}-08)\end{array}$ & $\begin{array}{l}-6.52 \mathrm{e}-09 \\
(1.29 \mathrm{e}-08)\end{array}$ & $\begin{array}{l}-2.53 e-08 \\
(1.76 e-08)\end{array}$ & $\begin{array}{l}-1.00 \mathrm{e}-08 \\
(1.61 \mathrm{e}-08)\end{array}$ & $\begin{array}{l}-1.22 \mathrm{e}-08 \\
(1.15 \mathrm{e}-08)\end{array}$ & $\begin{array}{l}-6.30 \mathrm{e}-11 \\
(1.08 \mathrm{e}-08)\end{array}$ & $\begin{array}{l}-2.41 \mathrm{e}-08^{*} \\
(1.30 \mathrm{e}-08)\end{array}$ & $\begin{array}{l}-1.23 \mathrm{e}-08 \\
(1.33 \mathrm{e}-08)\end{array}$ \\
\hline Municipal characteristics 2000s & Yes & Yes & Yes & Yes & Yes & Yes & Yes & Yes \\
\hline Economic structure $2000 \mathrm{~s}$ & Yes & Yes & Yes & Yes & Yes & Yes & Yes & Yes \\
\hline $\begin{array}{l}\text { Observations } \\
\text { Adj. } \mathrm{R}^{2}\end{array}$ & $\begin{array}{c}68 \\
0.671\end{array}$ & $\begin{array}{c}59 \\
0.690\end{array}$ & $\begin{array}{c}51 \\
0.633\end{array}$ & $\begin{array}{c}46 \\
0.624\end{array}$ & $\begin{array}{c}50 \\
0.672\end{array}$ & $\begin{array}{c}46 \\
0.672\end{array}$ & $\begin{array}{c}56 \\
0.687\end{array}$ & $\begin{array}{c}50 \\
0.698\end{array}$ \\
\hline
\end{tabular}


Table A3.3 - OLS: Path dependence and stocks of human capital (2000s) - education MHDI

\begin{tabular}{|c|c|c|c|c|c|c|c|c|}
\hline & $\begin{array}{c}\text { Educ. MHDI } \\
2000 \mathrm{~s}\end{array}$ & $\begin{array}{c}\text { Educ. MHDI } \\
2000 \mathrm{~s}\end{array}$ & $\begin{array}{c}\text { Educ. MHDI } \\
2000 \text { s }\end{array}$ & $\begin{array}{c}\text { Educ. MHDI } \\
2000 \text { s }\end{array}$ & $\begin{array}{c}\text { Educ. MHDI } \\
2000 \text { s }\end{array}$ & $\begin{array}{c}\text { Educ. MHDI } \\
2000 \mathrm{~s}\end{array}$ & $\begin{array}{c}\text { Educ. MHDI } \\
\text { 2000s }\end{array}$ & $\begin{array}{c}\text { Educ. MHDI } \\
\text { 2000s }\end{array}$ \\
\hline Total enrolment 1910s & $\begin{array}{c}1.77 \mathrm{e}-06 \\
(5.47 \mathrm{e}-06)\end{array}$ & $\begin{array}{c}4.90 \mathrm{e}-06 \\
(5.65 \mathrm{e}-06)\end{array}$ & & & & & & \\
\hline Enrolment private $1910 \mathrm{~s}$ & & & $\begin{array}{l}-1.09 e-05 \\
(1.73 e-05)\end{array}$ & $\begin{array}{l}-1.09 \mathrm{e}-06 \\
(1.91 \mathrm{e}-05)\end{array}$ & & & & \\
\hline Enrolment munic. 1910s & & & & & $\begin{array}{l}-1.73 e-05 \\
(3.76 e-05)\end{array}$ & $\begin{array}{c}5.27 \mathrm{e}-06 \\
(3.83 \mathrm{e}-05)\end{array}$ & & \\
\hline Completion state 1910 s & & & & & & & $\begin{array}{c}6.97 \mathrm{e}-05 \\
(4.22 \mathrm{e}-05)\end{array}$ & $\begin{array}{c}7.02 \mathrm{e}-05 \\
(4.35 \mathrm{e}-05)\end{array}$ \\
\hline German schools 1930 s & $\begin{array}{l}-0.00672 \\
(0.00572)\end{array}$ & $\begin{array}{r}-0.0143 * * \\
(0.00556)\end{array}$ & $\begin{array}{l}-0.00699 \\
(0.00578)\end{array}$ & $\begin{array}{l}-0.0123 * * \\
(0.00583)\end{array}$ & $\begin{array}{l}-0.00779 \\
(0.00609)\end{array}$ & $\begin{array}{l}-0.0139 * * \\
(0.00621)\end{array}$ & $\begin{array}{l}-0.00526 \\
(0.00542)\end{array}$ & $\begin{array}{l}-0.0115^{* *} \\
(0.00549)\end{array}$ \\
\hline German-speakers 1872 (share) & $\begin{array}{c}0.421 \\
(0.484)\end{array}$ & $\begin{array}{l}-0.383 \\
(0.847)\end{array}$ & $\begin{array}{c}0.272 \\
(0.490)\end{array}$ & $\begin{array}{l}0.0588 \\
(0.930)\end{array}$ & $\begin{array}{c}0.184 \\
(0.514)\end{array}$ & $\begin{array}{l}-0.122 \\
(0.907)\end{array}$ & $\begin{array}{l}0.306 \\
(0.451)\end{array}$ & $\begin{array}{c}0.175 \\
(0.821)\end{array}$ \\
\hline German workers 1872 (share) & $\begin{array}{l}0.0738 \\
(0.152)\end{array}$ & & $\begin{array}{l}0.0998 \\
(0.158)\end{array}$ & & $\begin{array}{c}0.131 \\
(0.161)\end{array}$ & & $\begin{array}{c}-0.00220 \\
(0.145)\end{array}$ & \\
\hline German workers 1888 (share) & & $\begin{array}{l}0.467 * \\
(0.265)\end{array}$ & & $\begin{array}{c}0.272 \\
(0.297)\end{array}$ & & $\begin{array}{c}0.344 \\
(0.288)\end{array}$ & & $\begin{array}{c}0.198 \\
(0.266)\end{array}$ \\
\hline Population 1999-2004 & $\begin{array}{c}3.40 \mathrm{e}-08 \\
(4.90 \mathrm{e}-08)\end{array}$ & $\begin{array}{c}1.67 \mathrm{e}-08 \\
(4.54 \mathrm{e}-08)\end{array}$ & $\begin{array}{c}9.50 \mathrm{e}-09 \\
(5.07 \mathrm{e}-08)\end{array}$ & $\begin{array}{c}2.14 \mathrm{e}-08 \\
(4.69 \mathrm{e}-08)\end{array}$ & $\begin{array}{c}1.44 \mathrm{e}-08 \\
(5.30 \mathrm{e}-08)\end{array}$ & $\begin{array}{c}2.92 \mathrm{e}-08 \\
(4.85 \mathrm{e}-08)\end{array}$ & $\begin{array}{c}1.09 \mathrm{e}-08 \\
(4.55 \mathrm{e}-08)\end{array}$ & $\begin{array}{c}1.13 \mathrm{e}-08 \\
(4.26 \mathrm{e}-08)\end{array}$ \\
\hline Income 1999-2004 & $\begin{array}{c}1.14 \mathrm{e}-06 \\
(4.06 \mathrm{e}-06)\end{array}$ & $\begin{array}{c}5.75 \mathrm{e}-06 \\
(4.07 \mathrm{e}-06)\end{array}$ & $\begin{array}{c}2.81 \mathrm{e}-06 \\
(4.61 \mathrm{e}-06)\end{array}$ & $\begin{array}{c}5.70 \mathrm{e}-06 \\
(4.83 \mathrm{e}-06)\end{array}$ & $\begin{array}{c}3.90 \mathrm{e}-06 \\
(4.32 \mathrm{e}-06)\end{array}$ & $\begin{array}{c}6.63 \mathrm{e}-06 \\
(4.37 \mathrm{e}-06)\end{array}$ & $\begin{array}{c}1.08 \mathrm{e}-06 \\
(3.74 \mathrm{e}-06)\end{array}$ & $\begin{array}{c}4.88 \mathrm{e}-06 \\
(3.88 \mathrm{e}-06)\end{array}$ \\
\hline Mun. expend. educ. 2002-2003 & $\begin{array}{l}-9.54 \mathrm{e}-11 \\
(3.09 \mathrm{e}-10)\end{array}$ & $\begin{array}{l}-3.31 \mathrm{e}-10 \\
(3.02 \mathrm{e}-10)\end{array}$ & $\begin{array}{c}-0 \\
(3.73 \mathrm{e}-10)\end{array}$ & $\begin{array}{l}-3.02 \mathrm{e}-10 \\
(3.72 \mathrm{e}-10)\end{array}$ & $\begin{array}{l}-1.93 e-10 \\
(3.53 e-10)\end{array}$ & $\begin{array}{l}-4.15 \mathrm{e}-10 \\
(3.37 \mathrm{e}-10)\end{array}$ & $\begin{array}{c}-0 \\
(2.94 \mathrm{e}-10)\end{array}$ & $\begin{array}{l}-2.23 \mathrm{e}-10 \\
(2.93 \mathrm{e}-10)\end{array}$ \\
\hline Municipal characteristics 2000s & Yes & Yes & Yes & Yes & Yes & Yes & Yes & Yes \\
\hline Economic structure 2000s & Yes & Yes & Yes & Yes & Yes & Yes & Yes & Yes \\
\hline $\begin{array}{l}\text { Observations } \\
\text { Adj. } \text { R }^{2}\end{array}$ & $\begin{array}{c}68 \\
0.591\end{array}$ & $\begin{array}{c}59 \\
0.633\end{array}$ & $\begin{array}{c}51 \\
0.568\end{array}$ & $\begin{array}{c}46 \\
0.569\end{array}$ & $\begin{array}{c}50 \\
0.571\end{array}$ & $\begin{array}{c}46 \\
0.600\end{array}$ & $\begin{array}{c}56 \\
0.641\end{array}$ & $\begin{array}{c}50 \\
0.665\end{array}$ \\
\hline
\end{tabular}




\section{Tables A3.4-A3.7 - Explanatory notes}

The following tables summarize the robustness checks conducted for the different regions of São Paulo. Considering the large number of coefficients in the set (German speaking presence ${ }_{n}$ ), the tables report only the number of models in which the variables were significant at least at the 10 percent level (entries labeled as "Signif.") and the range of significant coefficients (the smallest and the largest). Individual specifications are available upon request.

The column "Full Sample" provides the benchmark estimates; "No Western Frontier" refers to a sample that excludes the MCAs of the corresponding region and analogously so for "No OldWest". Because the latter limited the estimations in some cases (see the main text), I accommodate for specific regional characteristics by controlling for Holloway's regions (from Carvalho Filho and Colistete, 2010) in specifications once again with the full sample - this corresponds to the column "Control region".

For the IV estimates in the 1910s, the first and second stages are shown in separate pages (Table A3.5).

For the OLS estimates of the flows of human capital in the 2000s, I present the variables of the set (German speaking presence $_{n}$ ) in Table A3.6.

Finally, considering the more limited number of variables measuring the stocks of human capital in the 2000s, all estimates are presented in Table A3.7. 
Table A3.4 - OLS: Summary of subsample analyses (1872)

\begin{tabular}{|c|c|c|c|c|c|c|c|c|c|}
\hline & & \multicolumn{4}{|c|}{$\begin{array}{c}\text { Enrolment } \\
1872\end{array}$} & \multicolumn{4}{|c|}{$\begin{array}{c}\text { Literacy } \\
1872 \\
\end{array}$} \\
\hline & & $\begin{array}{c}\text { Full } \\
\text { sample }\end{array}$ & $\begin{array}{l}\text { Control } \\
\text { region }\end{array}$ & $\begin{array}{c}\text { No } \\
\text { Western } \\
\text { Frontier }\end{array}$ & $\begin{array}{l}\text { No Old- } \\
\text { West }\end{array}$ & $\begin{array}{c}\text { Full } \\
\text { sample }\end{array}$ & $\begin{array}{l}\text { Control } \\
\text { region }\end{array}$ & $\begin{array}{c}\text { No } \\
\text { Western } \\
\text { Frontier }\end{array}$ & $\begin{array}{c}\text { No Old- } \\
\text { West }\end{array}$ \\
\hline \multirow[t]{3}{*}{ German schools 1872} & Signif. & 0 & 0 & 0 & 0 & 0 & 0 & 0 & 0 \\
\hline & Min. & - & - & - & - & - & - & - & - \\
\hline & Max. & - & - & - & - & - & - & - & - \\
\hline \multirow[t]{3}{*}{ German-speakers 1872 (share) } & Signif. & 0 & 0 & 0 & 0 & 0 & 0 & 0 & 1 \\
\hline & Min. & - & - & - & - & - & - & - & $73,463.5$ \\
\hline & Max. & - & - & - & - & - & - & - & $73,463.5$ \\
\hline \multirow[t]{3}{*}{ German workers 1872} & Signif. & 0 & 0 & 0 & 0 & 0 & 0 & 0 & 0 \\
\hline & Min. & - & - & - & - & - & - & - & - \\
\hline & Max. & - & - & - & - & - & - & - & - \\
\hline \multirow[t]{3}{*}{ German manuf. 1872} & Signif. & 0 & 0 & 0 & 0 & 0 & 0 & 0 & 0 \\
\hline & Min. & - & - & - & - & - & - & - & - \\
\hline & Max. & - & - & - & - & - & - & - & - \\
\hline \multirow[t]{3}{*}{ German serv. 1872} & Signif. & 0 & 0 & 0 & 0 & 0 & 0 & 0 & 0 \\
\hline & Min. & - & - & - & - & - & - & - & - \\
\hline & Max. & - & - & - & - & - & - & - & - \\
\hline \multirow[t]{3}{*}{ German trade 1872} & Signif. & 0 & 0 & 0 & 0 & 0 & 0 & 0 & 0 \\
\hline & Min. & - & - & - & - & - & - & - & - \\
\hline & Max. & - & - & - & - & - & - & - & - \\
\hline \multirow[t]{3}{*}{ German rent 1872} & Signif. & 0 & 0 & 0 & 0 & 0 & 0 & 0 & 0 \\
\hline & Min. & - & - & - & - & - & - & - & - \\
\hline & Max. & - & - & - & - & - & - & - & - \\
\hline
\end{tabular}


Table A3.5 - IV: Summary of subsample analyses (1910s) - second-stage estimates

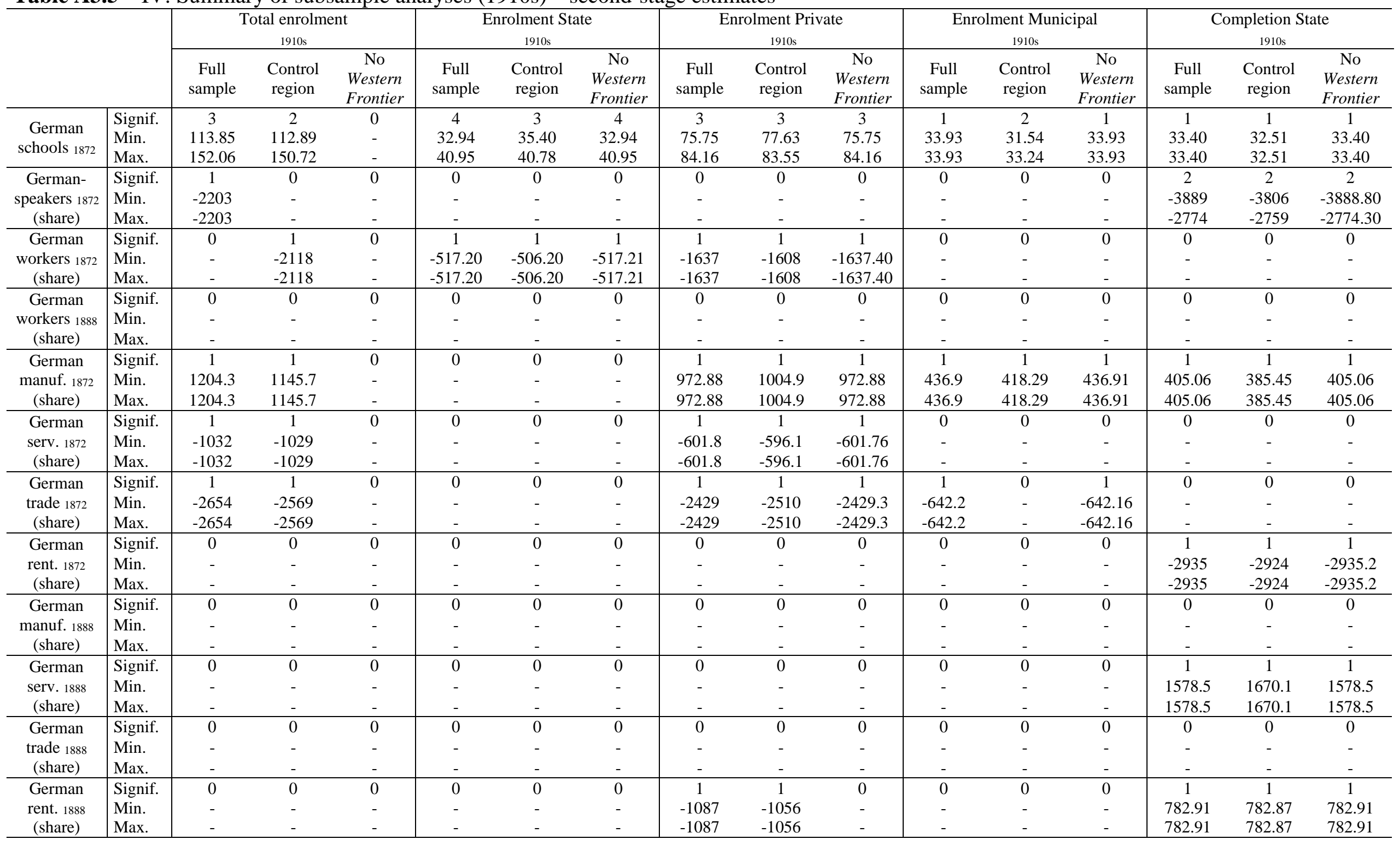


Table A3.5 (Ctd.) - IV: Summary of subsample analyses (1910s) - first-stage estimates

\begin{tabular}{|c|c|c|c|c|c|c|c|c|c|}
\hline & \multicolumn{3}{|c|}{ Full Sample } & \multicolumn{3}{|c|}{ Control region } & \multicolumn{3}{|c|}{ No Western Frontier } \\
\hline & Signif. & Min. & Max. & Signif. & Min. & Max. & Signif. & Min. & Max. \\
\hline \multicolumn{10}{|c|}{ Total enrolment 1910 s } \\
\hline \# Farms bonded 1850s-60s & $100 \%$ & 0.138 & 0.157 & $100 \%$ & 0.138 & 0.158 & $0 \%$ & - & - \\
\hline Reject underident. & $100 \%$ & & & $100 \%$ & & & - & & \\
\hline Reject weak instrum. & $100 \%$ & & & $100 \%$ & & & - & & \\
\hline \multicolumn{10}{|c|}{ Enrolment state $1910 \mathrm{~s}$} \\
\hline \# Farms bonded $1850 \mathrm{~s}-60 \mathrm{~s}$ & $100 \%$ & 0.138 & 0.157 & $100 \%$ & 0.138 & 0.158 & $100 \%$ & 0.138 & 0.157 \\
\hline Reject underident. & $100 \%$ & & & $100 \%$ & & & $100 \%$ & & \\
\hline Reject weak instrum. & $100 \%$ & & & $100 \%$ & & & $100 \%$ & & \\
\hline \multicolumn{10}{|c|}{ Enrolment private $1910 \mathrm{~s}$} \\
\hline \# Farms bonded $1850 \mathrm{~s}-60 \mathrm{~s}$ & $75 \%$ & 0.139 & 0.146 & $100 \%$ & 0.139 & 0.151 & $75 \%$ & 0.139 & 0.146 \\
\hline Reject underident. & $100 \%$ & & & $100 \%$ & & & $100 \%$ & & \\
\hline Reject weak instrum. & $100 \%$ & & & $100 \%$ & & & $100 \%$ & & \\
\hline \multicolumn{10}{|c|}{ Enrolment munic. $1910 \mathrm{~s}$} \\
\hline \# Farms bonded 1850s-60s & $100 \%$ & 0.146 & 0.154 & $100 \%$ & 0.146 & 0.154 & $100 \%$ & 0.146 & 0.154 \\
\hline Reject underident. & $100 \%$ & & & $100 \%$ & & & $100 \%$ & & \\
\hline Reject weak instrum. & $75 \%$ & & & $75 \%$ & & & $75 \%$ & & \\
\hline \multicolumn{10}{|c|}{ Completion state $1910 \mathrm{~s}$} \\
\hline \# Farms bonded $1850 \mathrm{~s}-60 \mathrm{~s}$ & $100 \%$ & 0.140 & 0.154 & $100 \%$ & 0.140 & 0.154 & $75 \%$ & 0.140 & 0.146 \\
\hline Reject underident. & $100 \%$ & & & $100 \%$ & & & $100 \%$ & & \\
\hline Reject weak instrum. & $100 \%$ & & & $100 \%$ & & & $100 \%$ & & \\
\hline
\end{tabular}


Table A3.6 - OLS: Summary of subsample analyses: flows (2000s)

\begin{tabular}{|c|c|c|c|c|c|c|c|c|c|c|c|c|c|}
\hline & \multicolumn{4}{|c|}{$\begin{array}{c}\text { Total enrolment } \\
2000 \text { s } \\
\end{array}$} & \multicolumn{4}{|c|}{$\begin{array}{c}\text { Enrolment state } \\
2000 \text { s }\end{array}$} & \multicolumn{4}{|c|}{$\begin{array}{c}\text { Enrolment private } \\
2000 \mathrm{~s}\end{array}$} \\
\hline & & $\begin{array}{c}\text { Full } \\
\text { sample }\end{array}$ & $\begin{array}{l}\text { Control } \\
\text { region }\end{array}$ & $\begin{array}{c}\text { No } \\
\text { Western } \\
\text { Frontier }\end{array}$ & $\begin{array}{l}\text { No } \\
\text { Old- } \\
\text { West }\end{array}$ & $\begin{array}{c}\text { Full } \\
\text { sample }\end{array}$ & $\begin{array}{l}\text { Control } \\
\text { region }\end{array}$ & $\begin{array}{c}\text { No } \\
\text { Western } \\
\text { Frontier }\end{array}$ & $\begin{array}{c}\text { No } \\
\text { Old-West }\end{array}$ & $\begin{array}{c}\text { Full } \\
\text { sampl } \\
\mathrm{e} \\
\end{array}$ & $\begin{array}{l}\text { Control } \\
\text { region }\end{array}$ & $\begin{array}{c}\text { No } \\
\text { Western } \\
\text { Frontier }\end{array}$ & $\begin{array}{l}\text { No } \\
\text { Old- } \\
\text { West }\end{array}$ \\
\hline \multirow{3}{*}{$\begin{array}{c}\text { German } \\
\text { schools } 1872\end{array}$} & Signif. & 1 & 2 & 2 & 1 & 4 & 4 & 4 & 3 & 0 & 0 & 0 & 3 \\
\hline & Min. & -996.2 & -1236 & -1755.4 & -4803 & -2678 & -2676 & -3109.2 & -11191 & - & - & - & 897.4 \\
\hline & Max. & -996.2 & -1006 & -1436.7 & -4803 & -1408 & -1417 & -1660.2 & -5940.8 & - & - & - & 897.4 \\
\hline \multirow{3}{*}{$\begin{array}{c}\text { German- } \\
\text { speakers } 1872 \\
\text { (share) }\end{array}$} & Signif. & 0 & 0 & 0 & 0 & 0 & 0 & 0 & 1 & 0 & 0 & 0 & 0 \\
\hline & Min. & - & - & - & - & - & - & - & 237071 & - & - & - & - \\
\hline & Max. & - & - & - & - & - & - & - & 237071 & - & - & - & - \\
\hline \multirow{3}{*}{$\begin{array}{c}\text { German } \\
\text { workers } 1872 \\
\text { (share) }\end{array}$} & Signif. & 0 & 0 & 0 & 0 & 0 & 0 & 0 & 0 & 0 & 1 & 0 & 1 \\
\hline & Min. & - & - & - & - & - & - & - & - & - & -12620 & - & -15074 \\
\hline & Max. & - & - & - & - & - & - & - & - & - & -12620 & - & -15074 \\
\hline \multirow{3}{*}{$\begin{array}{l}\text { German } \\
\text { workers } 1888 \\
\text { (share) }\end{array}$} & Signif. & 0 & 0 & 0 & 1 & 0 & 0 & 0 & 1 & 0 & 0 & 0 & 0 \\
\hline & Min. & - & - & - & -55031 & - & - & - & -103563 & - & - & - & - \\
\hline & Max. & - & - & - & -55031 & - & - & - & -103563 & - & - & - & - \\
\hline \multirow{3}{*}{$\begin{array}{c}\text { German } \\
\text { manuf. } 1872 \\
\text { (share) }\end{array}$} & Signif. & 0 & 0 & 0 & 0 & 0 & 0 & 0 & 0 & 0 & 0 & 0 & 0 \\
\hline & Min. & - & - & - & - & - & - & - & - & - & - & - & - \\
\hline & Max. & - & - & - & - & - & - & - & - & - & - & - & - \\
\hline \multirow{3}{*}{$\begin{array}{l}\text { German } \\
\text { serv. } 1872 \\
\text { (share) }\end{array}$} & Signif. & 0 & 0 & 0 & 0 & 0 & 0 & 0 & 0 & 0 & 0 & 0 & 0 \\
\hline & Min. & - & - & - & - & - & - & - & - & - & - & - & - \\
\hline & Max. & - & - & - & - & - & - & - & - & - & - & - & - \\
\hline \multirow{3}{*}{$\begin{array}{l}\text { German } \\
\text { trade } 1872 \\
\text { (share) }\end{array}$} & Signif. & 0 & 0 & 0 & 0 & 0 & 0 & 0 & 1 & 0 & 0 & 0 & 0 \\
\hline & Min. & - & - & - & - & - & - & - & -52482 & - & - & - & - \\
\hline & Max. & - & - & - & - & - & - & - & -52482 & - & - & - & - \\
\hline \multirow{3}{*}{$\begin{array}{l}\text { German } \\
\text { rent. } 1872 \\
\text { (share) }\end{array}$} & Signif. & 0 & 0 & 0 & 0 & 0 & 1 & 0 & 0 & 0 & 0 & 0 & 0 \\
\hline & Min. & - & - & - & - & - & 124915 & - & - & - & - & - & - \\
\hline & Max. & - & - & - & - & - & 124915 & - & - & - & - & - & - \\
\hline \multirow{3}{*}{$\begin{array}{l}\text { German } \\
\text { manuf. } 1888 \\
\text { (share) }\end{array}$} & Signif. & 0 & 0 & 0 & 0 & 0 & 0 & 0 & 0 & 0 & 0 & 0 & 0 \\
\hline & Min. & - & - & - & - & - & - & - & - & - & - & - & - \\
\hline & Max. & - & - & - & - & - & - & - & - & - & - & - & - \\
\hline \multirow{3}{*}{$\begin{array}{l}\text { German } \\
\text { serv. } 1888 \\
\text { (share) }\end{array}$} & Signif. & 0 & 0 & 0 & 0 & 0 & 0 & 0 & 1 & 0 & 0 & 0 & 0 \\
\hline & Min. & - & - & - & - & - & - & - & -46484 & - & - & - & - \\
\hline & Max. & - & - & - & - & - & - & - & -46484 & - & - & - & - \\
\hline \multirow{3}{*}{$\begin{array}{l}\text { German } \\
\text { trade } 1888 \\
\text { (share) }\end{array}$} & Signif. & 0 & 0 & 0 & 0 & 1 & 1 & 1 & 0 & 0 & 0 & 0 & 0 \\
\hline & Min. & - & - & - & - & 49329 & 50506 & 45734 & - & - & - & - & - \\
\hline & Max. & - & - & - & - & 49329 & 50506 & 45734 & - & - & - & - & - \\
\hline \multirow{3}{*}{$\begin{array}{l}\text { German } \\
\text { rent. } 1888 \\
\text { (share) }\end{array}$} & Signif. & 1 & 1 & 1 & 0 & 1 & 1 & 1 & 1 & 0 & 0 & 0 & 0 \\
\hline & Min. & -31359 & -31823 & -37548 & - & -91197 & -91041 & -95839 & -77182 & - & - & - & - \\
\hline & Max. & -31359 & -31823 & -37548 & - & -91197 & -91041 & -95839 & -77182 & - & - & - & - \\
\hline
\end{tabular}


Table A3.6 (Ctd.)

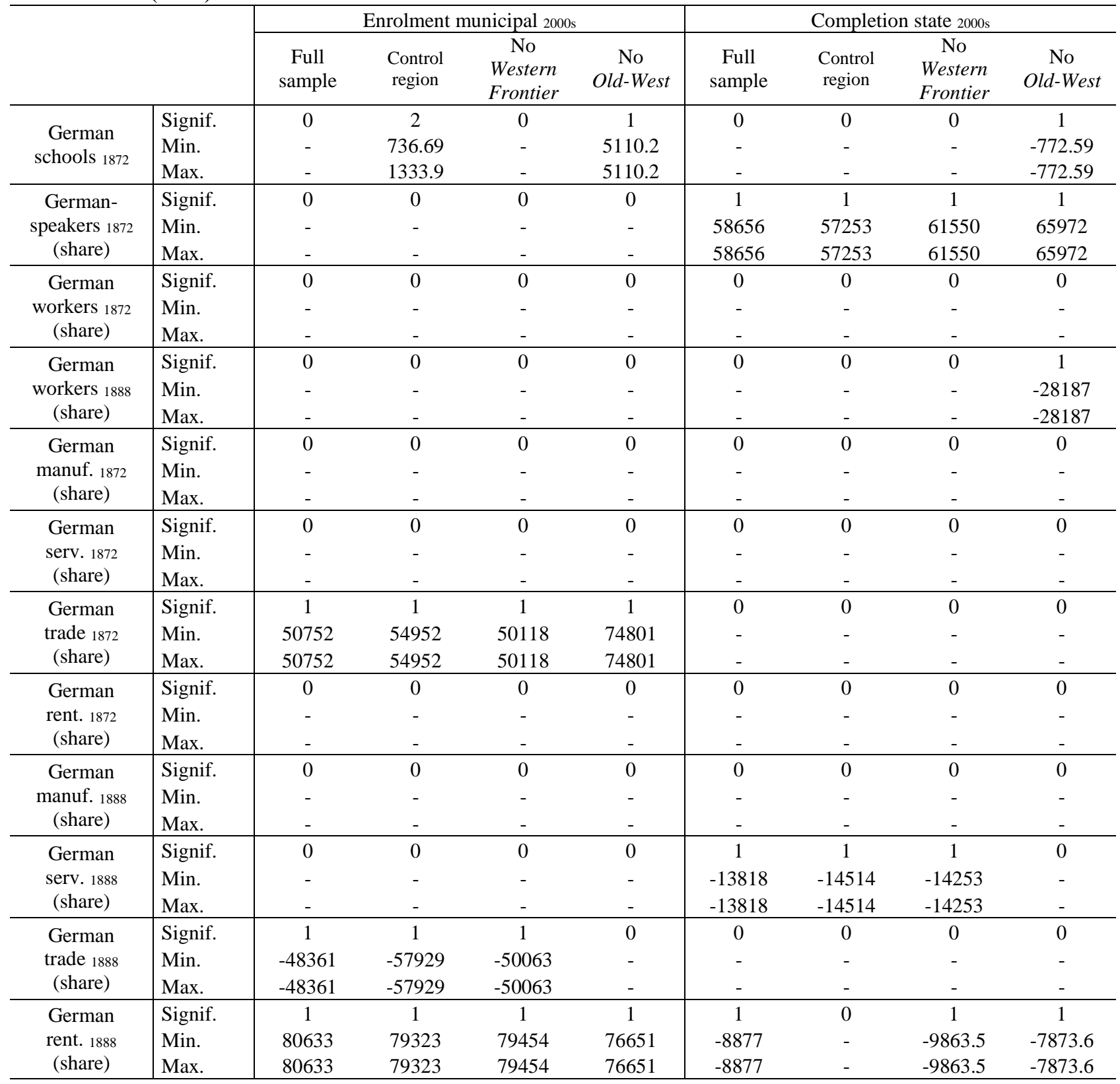


Table A3.6 (Ctd.)

\begin{tabular}{|c|c|c|c|c|c|c|c|c|c|c|c|c|c|c|c|c|c|c|c|c|c|}
\hline & \multicolumn{4}{|c|}{$\begin{array}{c}\text { Total enrolment } \\
\text { 2000s }\end{array}$} & \multicolumn{4}{|c|}{$\begin{array}{c}\text { Enrolment state } \\
2000 \mathrm{~s}\end{array}$} & \multicolumn{4}{|c|}{$\begin{array}{c}\text { Enrolment private } \\
\text { 2000s }\end{array}$} & \multicolumn{4}{|c|}{$\begin{array}{c}\text { Enrolment munic. } \\
2000 \mathrm{~s}\end{array}$} & \multicolumn{4}{|c|}{$\begin{array}{c}\text { Completion state } \\
\text { 2000s }\end{array}$} \\
\hline & & $\begin{array}{c}\text { Full } \\
\text { sample }\end{array}$ & $\begin{array}{l}\text { Region. } \\
\text { control }\end{array}$ & $\begin{array}{c}\text { No } \\
\text { Western } \\
\text { Frontier }\end{array}$ & $\begin{array}{c}\text { No } \\
\text { Old- } \\
\text { West }\end{array}$ & $\begin{array}{c}\text { Full } \\
\text { sample }\end{array}$ & $\begin{array}{l}\text { Region. } \\
\text { control }\end{array}$ & $\begin{array}{c}\text { No } \\
\text { Western } \\
\text { Frontier }\end{array}$ & $\begin{array}{l}\text { No } \\
\text { Old- } \\
\text { West }\end{array}$ & $\begin{array}{c}\text { Full } \\
\text { sample }\end{array}$ & $\begin{array}{l}\text { Region. } \\
\text { control }\end{array}$ & $\begin{array}{c}\text { No } \\
\text { Western } \\
\text { Frontier }\end{array}$ & $\begin{array}{l}\text { No } \\
\text { Old- } \\
\text { West }\end{array}$ & $\begin{array}{c}\text { Full } \\
\text { sample }\end{array}$ & $\begin{array}{l}\text { Region. } \\
\text { control }\end{array}$ & $\begin{array}{c}\text { No } \\
\text { Western } \\
\text { Frontier }\end{array}$ & $\begin{array}{l}\text { No } \\
\text { Old- } \\
\text { West }\end{array}$ & $\begin{array}{c}\text { Full } \\
\text { sample }\end{array}$ & $\begin{array}{l}\text { Region. } \\
\text { control }\end{array}$ & $\begin{array}{c}\text { No } \\
\text { Western } \\
\text { Frontier }\end{array}$ & $\begin{array}{c}\text { No } \\
\text { Old- } \\
\text { West }\end{array}$ \\
\hline $\begin{array}{l}\text { Total } \\
\text { enrolment }{ }_{1910 \mathrm{~s}}\end{array}$ & $\begin{array}{l}\text { Signif } \\
\text { Min. } \\
\text { Max. }\end{array}$ & $\begin{array}{c}4 \\
-3.38 \\
-2.71 \\
\end{array}$ & $\begin{array}{c}4 \\
-3.38 \\
-2.69 \\
\end{array}$ & $\begin{array}{c}4 \\
-3.38 \\
-3.38 \\
\end{array}$ & $\begin{array}{c}4 \\
-3.78 \\
-3.22 \\
\end{array}$ & & & & & & & & & & & & & & & & \\
\hline $\begin{array}{l}\text { Enrolment } \\
\text { state }_{1910 \mathrm{~s}}\end{array}$ & $\begin{array}{l}\text { Signif } \\
\text { Min. } \\
\text { Max. } \\
\end{array}$ & & & & & $\begin{array}{c}4 \\
-7.71 \\
-4.52 \\
\end{array}$ & $\begin{array}{c}4 \\
-7.77 \\
-4.50 \\
\end{array}$ & $\begin{array}{c}4 \\
-8.13 \\
-4.75 \\
\end{array}$ & $\begin{array}{c}4 \\
-7.95 \\
-5.59 \\
\end{array}$ & & & & & & & & & & & & \\
\hline $\begin{array}{l}\text { Enrolment } \\
\text { private }{ }_{1910 \mathrm{~s}}\end{array}$ & $\begin{array}{l}\text { Signif } \\
\text { Min. } \\
\text { Max. }\end{array}$ & & & & & & & & & \begin{tabular}{c|}
4 \\
3.08 \\
3.81
\end{tabular} & $\begin{array}{c}2 \\
3.13 \\
3.99 \\
\end{array}$ & $\begin{array}{c}4 \\
3.01 \\
3.73 \\
\end{array}$ & $\begin{array}{c}4 \\
3.62 \\
4.72\end{array}$ & & & & & & & & \\
\hline $\begin{array}{l}\text { Enrolment } \\
\text { munic. 1910s }\end{array}$ & $\begin{array}{l}\text { Signif } \\
\text { Min. } \\
\text { Max. }\end{array}$ & & & & & & & & & & & & & $\begin{array}{l}0 \\
- \\
- \\
\end{array}$ & $\begin{array}{c}1 \\
-7.21 \\
-7.21 \\
\end{array}$ & $\begin{array}{l}0 \\
- \\
- \\
\end{array}$ & $\begin{array}{l}0 \\
- \\
- \\
\end{array}$ & & & & \\
\hline $\begin{array}{l}\text { Completion } \\
\text { state }{ }_{1910 \text { s }}\end{array}$ & $\begin{array}{l}\text { Signif } \\
\text { Min. } \\
\text { Max. } \\
\end{array}$ & & & & & & & & & & & & & & & & & $\begin{array}{c}2 \\
-3.11 \\
-2.94 \\
\end{array}$ & $\begin{array}{l}0 \\
- \\
-\end{array}$ & $\begin{array}{c}1 \\
-3.09 \\
-3.09 \\
\end{array}$ & $\begin{array}{c}3 \\
-4.22 \\
-4.08 \\
\end{array}$ \\
\hline
\end{tabular}


Table A3.7 - OLS: Summary of subsample analyses: stocks (2000s)

\begin{tabular}{|c|c|c|c|c|c|c|c|c|c|c|c|c|c|}
\hline & \multicolumn{4}{|c|}{$\begin{array}{c}\text { Avg. Years Educ. } \\
\text { 2000s }\end{array}$} & \multicolumn{4}{|c|}{$\begin{array}{c}\text { Illiteracy rate } \\
2000 \mathrm{~s}\end{array}$} & \multicolumn{4}{|c|}{$\begin{array}{c}\text { Educ. MHDI } \\
\text { 2000s }\end{array}$} \\
\hline & & $\begin{array}{c}\text { Full } \\
\text { sample }\end{array}$ & $\begin{array}{l}\text { Control } \\
\text { Region }\end{array}$ & $\begin{array}{c}\text { No } \\
\text { Western } \\
\text { Frontier }\end{array}$ & $\begin{array}{c}\text { No Old- } \\
\text { West }\end{array}$ & $\begin{array}{c}\text { Full } \\
\text { sample }\end{array}$ & $\begin{array}{l}\text { Control } \\
\text { Region }\end{array}$ & $\begin{array}{c}\text { No } \\
\text { Western } \\
\text { Frontier }\end{array}$ & $\begin{array}{l}\text { No Old- } \\
\text { West }\end{array}$ & $\begin{array}{c}\text { Full } \\
\text { sample }\end{array}$ & $\begin{array}{l}\text { Control } \\
\text { Region }\end{array}$ & $\begin{array}{c}\text { No } \\
\text { Western } \\
\text { Frontier } \\
\end{array}$ & $\begin{array}{l}\text { No Old- } \\
\text { West }\end{array}$ \\
\hline \multirow{3}{*}{$\begin{array}{c}\text { German } \\
\text { schools } 1872\end{array}$} & Signif. & 12 & 4 & 12 & 8 & 0 & 0 & 0 & 0 & 13 & 4 & 13 & 7 \\
\hline & Min. & -0.251 & -0.2219 & -0.2478 & -0.7928 & - & - & - & - & -0.015 & -0.013 & -0.0147 & -0.047 \\
\hline & Max. & -0.191 & -0.2061 & -0.1891 & -0.3899 & - & - & - & - & -0.01 & -0.012 & -0.0104 & -0.0242 \\
\hline \multirow{3}{*}{$\begin{array}{c}\text { German- } \\
\text { speakers } \\
1872 \text { (share) }\end{array}$} & Signif. & 0 & 0 & 0 & 0 & 5 & 0 & 5 & 4 & 0 & 3 & 0 & 0 \\
\hline & Min. & - & - & - & - & 29.17 & - & 29.289 & 55.316 & - & 0.755 & - & - \\
\hline & Max. & - & - & - & - & 66.09 & - & 66.119 & 84.563 & - & 1.6285 & - & - \\
\hline \multirow{3}{*}{$\begin{array}{c}\text { German } \\
\text { workers } \\
1872 \text { (share) }\end{array}$} & Signif. & 0 & 0 & 0 & 0 & 3 & 2 & 4 & 0 & 0 & 0 & 0 & 0 \\
\hline & Min. & - & - & - & - & -11.98 & -6.261 & -11.965 & - & - & - & - & - \\
\hline & Max. & - & - & - & - & -8.751 & -5.767 & -7.8558 & - & - & - & - & - \\
\hline \multirow{3}{*}{$\begin{array}{c}\text { German } \\
\text { workers } \\
1888 \text { (share) }\end{array}$} & Signif. & 4 & 1 & 4 & 2 & 4 & 0 & 4 & 3 & 2 & 0 & 2 & 0 \\
\hline & Min. & 7.8992 & 8.12468 & 7.8978 & 10.407 & -25.9 & - & -25.794 & -26.503 & 0.4579 & - & 0.4549 & - \\
\hline & Max. & 11.034 & 8.12468 & 11.018 & 10.632 & -19.24 & - & -19.208 & -19.355 & 0.4666 & - & 0.4641 & - \\
\hline \multirow{3}{*}{$\begin{array}{l}\text { German } \\
\text { manuf. } 1872 \\
\text { (share) }\end{array}$} & Signif. & 0 & 0 & 0 & 0 & 0 & 0 & 0 & 1 & 1 & 3 & 1 & 1 \\
\hline & Min. & - & - & - & - & - & - & - & -4.856 & -0.135 & -0.152 & -0.1353 & -0.128 \\
\hline & Max. & - & - & - & - & - & - & - & -4.856 & -0.135 & -0.111 & -0.1353 & -0.128 \\
\hline \multirow{3}{*}{$\begin{array}{c}\text { German } \\
\text { serv. } 1872 \\
\text { (share) }\end{array}$} & Signif. & 4 & 5 & 4 & 1 & 2 & 0 & 2 & 1 & 5 & 2 & 5 & 2 \\
\hline & Min. & 2.318 & 2.7424 & 2.3182 & 2.3182 & -6.388 & - & -6.4102 & -6.1542 & 0.1436 & 0.1903 & 0.1436 & 0.16 \\
\hline & Max. & 2.9171 & 3.15723 & 2.9089 & 2.3182 & -6.086 & - & -6.1047 & -6.1542 & 0.175 & 0.193 & 0.1753 & 0.1682 \\
\hline \multirow{3}{*}{$\begin{array}{l}\text { German } \\
\text { trade } 1872 \\
\text { (share) }\end{array}$} & Signif. & 0 & 2 & 0 & 0 & 0 & 1 & 0 & 0 & 0 & 0 & 0 & 0 \\
\hline & Min. & - & -4.1171 & - & - & - & 9.6581 & - & - & - & - & - & - \\
\hline & Max. & - & -3.7225 & - & - & - & 9.6581 & - & - & - & - & - & - \\
\hline \multirow{3}{*}{$\begin{array}{c}\text { German } \\
\text { rent. } 1872 \\
\text { (share) }\end{array}$} & Signif. & 0 & 1 & 0 & 0 & 0 & 0 & 0 & 0 & 0 & 0 & 0 & 0 \\
\hline & Min. & - & 9.3292 & - & - & - & - & - & - & - & - & - & - \\
\hline & Max. & - & 9.3292 & - & - & - & - & - & - & - & - & - & - \\
\hline \multirow{3}{*}{$\begin{array}{l}\text { German } \\
\text { manuf. } 1888 \\
\text { (share) }\end{array}$} & Signif. & 0 & 0 & 0 & 0 & 2 & 0 & 2 & 0 & 0 & 0 & 0 & 0 \\
\hline & Min. & - & - & - & - & -7.72 & - & -7.743 & - & - & - & - & - \\
\hline & Max. & - & - & - & - & -7.681 & - & -7.7075 & - & - & - & - & - \\
\hline \multirow{3}{*}{$\begin{array}{c}\text { German } \\
\text { serv. } 1888 \\
\text { (share) }\end{array}$} & Signif. & 0 & 5 & 0 & 0 & 0 & 0 & 0 & 0 & 0 & 4 & 0 & 0 \\
\hline & Min. & - & 3.8955 & - & - & - & - & - & - & - & 0.2031 & - & - \\
\hline & Max. & - & 5.5856 & - & - & - & - & - & - & - & 0.354 & - & - \\
\hline \multirow{3}{*}{$\begin{array}{c}\text { German } \\
\text { trade } 1888 \\
\text { (share) }\end{array}$} & Signif. & 0 & 2 & 0 & 0 & 0 & 0 & 0 & 0 & 0 & 3 & 0 & 0 \\
\hline & Min. & - & -5.6718 & - & - & - & - & - & - & - & -0.461 & - & - \\
\hline & Max. & - & -5.119 & - & - & - & - & - & - & - & -0.372 & - & - \\
\hline \multirow{3}{*}{$\begin{array}{l}\text { German } \\
\text { rent. } 1888 \\
\text { (share) }\end{array}$} & Signif. & 0 & 0 & 0 & 1 & 0 & 0 & 0 & 0 & 0 & 0 & 0 & 2 \\
\hline & Min. & - & - & - & 3.4106 & - & - & - & - & - & - & - & 0.1859 \\
\hline & Max. & - & - & - & 3.4106 & - & - & - & - & - & - & - & 0.1967 \\
\hline & Signif. & 0 & 2 & 0 & 2 & 0 & 0 & 0 & 0 & 0 & 0 & 0 & 0 \\
\hline enrolment & Min. & - & 0.0001 & - & 0.0002 & - & - & - & - & - & - & - & - \\
\hline & Max. & - & 0.0001 & - & 0.0002 & - & - & - & - & - & - & - & - \\
\hline Enrolment & Signif. & 3 & 0 & 3 & 2 & 4 & 2 & 4 & 4 & 0 & 0 & 0 & 0 \\
\hline state & Min. & 0.0002 & - & 0.0002 & 0.0003 & $-8 \mathrm{E}-04$ & $-5 \mathrm{E}-04$ & -0.0008 & -0.0008 & - & - & - & - \\
\hline $1910 \mathrm{~s}$ & Max. & 0.0003 & - & 0.0003 & 0.0003 & $-6 \mathrm{E}-04$ & $-4 \mathrm{E}-04$ & -0.0006 & -0.0006 & - & - & - & - \\
\hline Enrolment & Signif. & 0 & 0 & 0 & 0 & 0 & 1 & 0 & 0 & 0 & 0 & 0 & 0 \\
\hline private & Min. & - & - & - & - & - & 0.0011 & - & - & - & - & - & - \\
\hline $1910 \mathrm{~s}$ & Max. & - & - & - & - & - & 0.0011 & - & - & - & - & - & - \\
\hline Enrolment & Signif. & 0 & 0 & 0 & 0 & 0 & 0 & 0 & 0 & 0 & 0 & 0 & 0 \\
\hline munic. & Min. & - & - & - & - & - & - & - & - & - & - & - & - \\
\hline $1910 \mathrm{~s}$ & Max. & - & - & - & - & - & - & - & - & - & - & - & - \\
\hline Complet. & Signif. & 2 & 1 & 2 & 2 & 0 & 1 & 0 & 0 & 1 & 3 & 1 & 3 \\
\hline state & Min. & 0.0013 & 0.0011 & 0.0013 & 0.0014 & - & -0.003 & - & - & $9 \mathrm{E}-05$ & $6 \mathrm{E}-05$ & 9E-05 & 7E-05 \\
\hline 1910s & Max. & 0.0015 & 0.0011 & 0.0015 & 0.0014 & - & -0.003 & - & - & 9E-05 & 9E-05 & 9E-05 & 9E-05 \\
\hline
\end{tabular}


Table A3.8 - German-speakers in the MCAs of the Old-West

\begin{tabular}{lccccc}
\hline & \multirow{2}{*}{ Limeira } & \multirow{2}{*}{ Rio Claro } & \multirow{2}{*}{ Campinas } & \multicolumn{2}{c}{ Province/State } \\
\cline { 5 - 6 } & & & & Mean & S.D. \\
\hline German-speakers 1872 (share) & 0.0387 & 0.0327 & 0.0116 & 0.0042 & 0.0097 \\
Other immigrants 1872 (share) & 0.0630 & 0.0668 & 0.0673 & 0.0245 & 0.0248 \\
\# Farms bonded 1850s-60s & 19 & 12 & 33 & 0.7103 & 3.3992 \\
German schools 1872 & 0 & 2 & 2 & 0.0345 & 0.2476 \\
German schools 1910s & 2 & 4 & 5 & 0.1103 & 0.6023 \\
German schools 1930s & 2 & 5 & 8 & 0.3448 & 1.4643 \\
\hline
\end{tabular}


Table A3.9 - OLS: German-speakers and education (1872) bootstrapped: zero-imputed data

\begin{tabular}{lcc}
\hline & Enrolment & Literacy \\
& 1872 & 1872 \\
\hline German schools 1872 & 34.26 & 233.7 \\
German-speakers 1872 (share) & $(220.8)$ & $(1,188)$ \\
& $-2,551$ & 5,555 \\
German workers 1872 (share) & $(2,387)$ & $(11,349)$ \\
& $1,493 *$ & 865.5 \\
Other immigrants 1872 (share) & $(857.0)$ & $(5,584)$ \\
& 1,235 & $-1,514$ \\
\# Slaves 1872 & $(1,217)$ & $(5,725)$ \\
& -0.0437 & 0.0364 \\
Population 1872 & $(0.0314)$ & $(0.134)$ \\
& $0.0272 * * *$ & $0.121 * * *$ \\
Municipal budget 1872 & $(0.00575)$ & $(0.0319)$ \\
& -0.00248 & 0.0308 \\
Foreign Public Adm. (share) & $(0.00597)$ & $(0.0320)$ \\
& 255.3 & 11,125 \\
Municipal characteristics 1872 & $(797.1)$ & $(8,187)$ \\
Economic structure 1872 & & Yes \\
Observations & Yes & Yes \\
Adj. R & Yes & 145 \\
Complete replications & & 0.864 \\
Incomplete replications & 145 & 946 \\
\hline
\end{tabular}


Table A3.10 - IV: German-speakers and education (1910s) - bootstrapped: zero-imputed data

\begin{tabular}{|c|c|c|c|c|c|c|c|c|c|c|}
\hline & $\begin{array}{c}\text { Total } \\
\text { enrolment } \\
1910 \mathrm{~s}\end{array}$ & $\begin{array}{c}\text { Total } \\
\text { enrolment } \\
1910 \mathrm{~s}\end{array}$ & $\begin{array}{c}\text { Enrolment } \\
\text { state } \\
1910 \text { s }\end{array}$ & $\begin{array}{c}\text { Enrolment } \\
\text { state } \\
1910 \text { s }\end{array}$ & $\begin{array}{c}\text { Enrolment } \\
\text { private } \\
1910 \text { s }\end{array}$ & $\begin{array}{c}\text { Enrolment } \\
\text { private } \\
1910 \mathrm{~s}\end{array}$ & $\begin{array}{c}\text { Enrolment } \\
\text { munic. } \\
1910 \text { s }\end{array}$ & $\begin{array}{c}\text { Enrolment } \\
\text { munic. } \\
1910 \text { s }\end{array}$ & $\begin{array}{c}\text { Completion. } \\
\text { state } \\
1910 \text { s }\end{array}$ & $\begin{array}{c}\text { Completion } \\
\text { state } \\
1910 \mathrm{~s}\end{array}$ \\
\hline \multicolumn{11}{|c|}{ Panel A: Second-stage Estimates } \\
\hline German schools 1910s & $\begin{array}{c}207.6 \\
(4,201)\end{array}$ & $\begin{array}{c}202.5 \\
(40,529)\end{array}$ & $\begin{array}{c}63.63 \\
(966.2)\end{array}$ & $\begin{array}{c}62.31 \\
(8,691)\end{array}$ & $\begin{array}{c}114.2 \\
(3,014)\end{array}$ & $\begin{array}{c}110.6 \\
(31,871)\end{array}$ & $\begin{array}{c}29.85 \\
(2,390)\end{array}$ & $\begin{array}{c}29.62 \\
(3,577)\end{array}$ & $\begin{array}{l}-29.49 \\
(3,356)\end{array}$ & $\begin{array}{c}-27.83 \\
(36,999)\end{array}$ \\
\hline German-speakers 1872 (share) & $\begin{array}{c}1,805 \\
(140,828)\end{array}$ & $\begin{array}{c}-1,116 \\
(39,160)\end{array}$ & $\begin{array}{c}1,723 \\
(8,570)\end{array}$ & $\begin{array}{c}1,526 \\
(8,062)\end{array}$ & $\begin{array}{c}207.7 \\
(120,692)\end{array}$ & $\begin{array}{c}-2,020 \\
(32,180)\end{array}$ & $\begin{array}{c}-125.8 \\
(12,681)\end{array}$ & $\begin{array}{l}-621.2 \\
(5,362)\end{array}$ & $\begin{array}{c}-1,538 \\
(67,284)\end{array}$ & $\begin{array}{c}-760.8 \\
(38,550)\end{array}$ \\
\hline German workers 1872 (share) & $\begin{array}{l}-1,990 \\
(6,878)\end{array}$ & & $\begin{array}{l}-729.9 \\
(1,506)\end{array}$ & & $\begin{array}{l}-1,319 \\
(5,831)\end{array}$ & & $\begin{array}{c}58.69 \\
(972.9)\end{array}$ & & $\begin{array}{c}703.4 \\
(4,275)\end{array}$ & \\
\hline German workers 1888 (share) & & $\begin{array}{c}-12.58 \\
(10,913)\end{array}$ & & $\begin{array}{l}-327.8 \\
(2,131)\end{array}$ & & $\begin{array}{c}99.81 \\
(8,810)\end{array}$ & & $\begin{array}{c}215.4 \\
(557.2)\end{array}$ & & $\begin{array}{c}98.58 \\
(9,778)\end{array}$ \\
\hline$\%$ foreign rural workers $1910 \mathrm{~s}$ & $\begin{array}{l}9.415 \\
(358)\end{array}$ & $\begin{array}{c}11.64 \\
(773.3)\end{array}$ & $\begin{array}{c}17.65 \\
(91.13)\end{array}$ & $\begin{array}{c}21.29 \\
(159.5)\end{array}$ & $\begin{array}{c}-4.579 \\
(346)\end{array}$ & $\begin{array}{l}-4.054 \\
(652.7)\end{array}$ & $\begin{array}{l}-3.654 \\
(117.5)\end{array}$ & $\begin{array}{l}-5.604 \\
(147.9)\end{array}$ & $\begin{array}{c}123.9 \\
(287.8)\end{array}$ & $\begin{array}{c}122.3 \\
(765.1)\end{array}$ \\
\hline$\%$ foreign landown. $1910 \mathrm{~s}$ & $\begin{array}{l}-0.267 \\
(1,437)\end{array}$ & $\begin{array}{c}-7.664 \\
(962)\end{array}$ & $\begin{array}{c}30.7 \\
(308.2)\end{array}$ & $\begin{array}{c}21.91 \\
(240.1)\end{array}$ & $\begin{array}{l}-208.3 \\
(1,369)\end{array}$ & $\begin{array}{l}-211.2 \\
(1,007)\end{array}$ & $\begin{array}{c}177.4 \\
(413.1)\end{array}$ & $\begin{array}{c}181.6 \\
(441.2)\end{array}$ & $\begin{array}{c}213 \\
(1,042)\end{array}$ & $\begin{array}{c}217.4 \\
(1,391)\end{array}$ \\
\hline Population 1910 s & $\begin{array}{l}0.00738 \\
(0.0136)\end{array}$ & $\begin{array}{l}0.00879 \\
(0.0741)\end{array}$ & $\begin{array}{l}0.00129 \\
(0.0026)\end{array}$ & $\begin{array}{c}0.0017 \\
(0.0156)\end{array}$ & $\begin{array}{l}0.000298 \\
(0.00911)\end{array}$ & $\begin{array}{l}0.00127 \\
(0.0588)\end{array}$ & $\begin{array}{c}0.00579 \\
(0.00749)\end{array}$ & $\begin{array}{c}0.00582 \\
(0.00627)\end{array}$ & $\begin{array}{l}0.000388 \\
(0.00987)\end{array}$ & $\begin{array}{c}-7.62 \mathrm{E}-05 \\
(0.0673)\end{array}$ \\
\hline Area coffee 1910s (share) & $\begin{array}{l}-61.13 \\
(351.5)\end{array}$ & $\begin{array}{l}-49.77 \\
(792.5)\end{array}$ & $\begin{array}{l}-38.88 \\
(56.76)\end{array}$ & $\begin{array}{l}-35.15 \\
(163.1)\end{array}$ & $\begin{array}{l}-43.57 \\
(340.6)\end{array}$ & $\begin{array}{c}-35.9 \\
(636.8)\end{array}$ & $\begin{array}{c}21.33 \\
(78.52)\end{array}$ & $\begin{array}{l}21.28 \\
(86.1)\end{array}$ & $\begin{array}{l}-58.36 \\
(243.8)\end{array}$ & $\begin{array}{l}-62.25 \\
(726.2)\end{array}$ \\
\hline Munic. expend. 1910s & $\begin{array}{l}0.000914 \\
(0.00197)\end{array}$ & $\begin{array}{c}0.000841 \\
(0.0202)\end{array}$ & $\begin{array}{c}\text { 7.99E-05 } \\
(0.000451)\end{array}$ & $\begin{array}{l}6.00 \mathrm{E}-05 \\
(0.00433)\end{array}$ & $\begin{array}{c}0.000675 \\
(0.00118)\end{array}$ & $\begin{array}{c}0.000624 \\
(0.0159)\end{array}$ & $\begin{array}{l}0.000159 \\
(0.00119)\end{array}$ & $\begin{array}{l}0.000157 \\
(0.00175)\end{array}$ & $\begin{array}{r}-5.02 \mathrm{E}-06 \\
(0.00158)\end{array}$ & $\begin{array}{l}1.88 \mathrm{E}-05 \\
(0.0183)\end{array}$ \\
\hline State schools $1910 \mathrm{~s}$ & $\begin{array}{c}44.25 \\
(36.91)\end{array}$ & $\begin{array}{c}42.55 * * * \\
(10.49)\end{array}$ & $\begin{array}{c}39.94 * * * \\
(2.93)\end{array}$ & $\begin{array}{c}39.35 * * * \\
(2.654)\end{array}$ & $\begin{array}{c}6.327 \\
(31.39)\end{array}$ & $\begin{array}{c}5.185 \\
(8.103)\end{array}$ & $\begin{array}{l}-2.016 \\
(4.544)\end{array}$ & $\begin{array}{l}-1.987 \\
(2.516)\end{array}$ & $\begin{array}{c}3.462 \\
(17.77)\end{array}$ & $\begin{array}{c}4.056 \\
(10.69)\end{array}$ \\
\hline Municipal characteristics 1910s & Yes & Yes & Yes & Yes & Yes & Yes & Yes & Yes & Yes & Yes \\
\hline Economic structure 1888 & Yes & Yes & Yes & Yes & Yes & Yes & Yes & Yes & Yes & Yes \\
\hline Observations & 145 & 145 & 145 & 145 & 145 & 145 & 145 & 145 & 145 & 145 \\
\hline Complete replications & 996 & 998 & 996 & 998 & 996 & 998 & 996 & 998 & 996 & 998 \\
\hline Incomplete replications & 4 & 2 & 4 & 2 & 4 & 2 & 4 & 2 & 4 & 2 \\
\hline
\end{tabular}


Table A3.11 - OLS: Path dependence and flows of human capital (2000s) - bootstrapped: zero-imputed data

\begin{tabular}{|c|c|c|c|c|c|c|c|c|c|c|}
\hline & $\begin{array}{c}\text { Total } \\
\text { enrolment } \\
2000 \mathrm{~s}\end{array}$ & $\begin{array}{c}\text { Total } \\
\text { enrolment } \\
2000 \mathrm{~s}\end{array}$ & $\begin{array}{l}\text { Enrolment } \\
\text { state } \\
2000 \text { s }\end{array}$ & $\begin{array}{l}\text { Enrolment } \\
\text { state } \\
2000 \text { s }\end{array}$ & $\begin{array}{c}\text { Enrolment } \\
\text { private } \\
2000 \mathrm{~s}\end{array}$ & $\begin{array}{c}\text { Enrolment } \\
\text { private } \\
2000 \mathrm{~s}\end{array}$ & $\begin{array}{c}\text { Enrolment } \\
\text { munic. } \\
2000 \text { s }\end{array}$ & $\begin{array}{c}\text { Enrolment } \\
\text { munic. } \\
2000 \text { s }\end{array}$ & $\begin{array}{c}\text { Completion } \\
\text { state } \\
2000 \mathrm{~s}\end{array}$ & $\begin{array}{c}\text { Completion } \\
\text { state } \\
2000 \mathrm{~s}\end{array}$ \\
\hline Total enrolment 1910s & $\begin{array}{l}-2.043^{*} \\
(1.076)\end{array}$ & $\begin{array}{c}-2.073 * * \\
(1.016)\end{array}$ & & & & & & & & \\
\hline Enrolment State $1910 \mathrm{~s}$ & & & $\begin{array}{c}-4.412 * * \\
(2.173)\end{array}$ & $\begin{array}{c}-4.689 * * \\
(2.003)\end{array}$ & & & & & & \\
\hline Enrolment Private 1910 s & & & & & $\begin{array}{c}2.171^{* *} \\
(0.925)\end{array}$ & $\begin{array}{c}2.003 * * \\
(0.837)\end{array}$ & & & & \\
\hline Enrolment Municipal 1910s & & & & & & & $\begin{array}{l}-3.238 \\
(3.599)\end{array}$ & $\begin{array}{l}-2.267 \\
(3.344)\end{array}$ & & \\
\hline Completion State $1910 \mathrm{~s}$ & & & & & & & & & $\begin{array}{c}-1.743 * * \\
(0.707)\end{array}$ & $\begin{array}{c}-1.994 * * * \\
(0.66)\end{array}$ \\
\hline German schools $1930 \mathrm{~s}$ & $\begin{array}{l}-1,284 \\
(1065)\end{array}$ & $\begin{array}{l}-1,299 \\
(1012)\end{array}$ & $\begin{array}{l}-1,565 \\
(1373)\end{array}$ & $\begin{array}{l}-1,763 \\
(1,346)\end{array}$ & $\begin{array}{c}7.63 \\
(251.81)\end{array}$ & $\begin{array}{c}-45.86 \\
(228.45)\end{array}$ & $\begin{array}{c}170.75 \\
(874.98)\end{array}$ & $\begin{array}{c}377.77 \\
(799.26)\end{array}$ & $\begin{array}{c}-154.27 \\
(190.41)\end{array}$ & $\begin{array}{l}-203.02 \\
(180.86)\end{array}$ \\
\hline German-speakers 1872 (share) & $\begin{array}{c}-4,025 \\
(52761)\end{array}$ & $\begin{array}{l}-17,463 \\
(86,981)\end{array}$ & $\begin{array}{c}28,104 \\
(77,547)\end{array}$ & $\begin{array}{c}9,960 \\
(113,232)\end{array}$ & $\begin{array}{c}10,226 \\
(16,282)\end{array}$ & $\begin{array}{c}11,032 \\
(19,420)\end{array}$ & $\begin{array}{l}-19,939 \\
(85,751)\end{array}$ & $\begin{array}{l}-10,468 \\
(86,554)\end{array}$ & $\begin{array}{c}10,862 \\
(13,548)\end{array}$ & $\begin{array}{c}8,524 \\
(19,127)\end{array}$ \\
\hline German workers 1872 (share) & $\begin{array}{l}-239.05 \\
(19955)\end{array}$ & & $\begin{array}{l}-17,656 \\
(29,551)\end{array}$ & & $\begin{array}{l}-6,358 \\
(5,846)\end{array}$ & & $\begin{array}{c}21,047 \\
(22,847)\end{array}$ & & $\begin{array}{l}-3,861 \\
(4,239)\end{array}$ & \\
\hline German workers 1888 (share) & & $\begin{array}{c}4,641 \\
(23132)\end{array}$ & & $\begin{array}{c}-1,634 \\
(29,998)\end{array}$ & & $\begin{array}{c}-3,338 \\
(4,874)\end{array}$ & & $\begin{array}{c}7,296 \\
(16,209)\end{array}$ & & $\begin{array}{l}-984.11 \\
(5,590)\end{array}$ \\
\hline Municipal characteristics 2000s & Yes & Yes & Yes & Yes & Yes & Yes & Yes & Yes & Yes & Yes \\
\hline Economic structure $2000 \mathrm{~s}$ & Yes & Yes & Yes & Yes & Yes & Yes & Yes & Yes & Yes & Yes \\
\hline Observations & 145 & 145 & 145 & 145 & 145 & 145 & 145 & 145 & 145 & 145 \\
\hline Adj. $R^{2}$ & 0.997 & 0.997 & 0.983 & 0.982 & 0.992 & 0.992 & 0.985 & 0.984 & 0.985 & 0.984 \\
\hline Complete replications & 1000 & 1000 & 1000 & 1000 & 1000 & 1000 & 1000 & 1000 & 1000 & 1000 \\
\hline Incomplete replications & 0 & 0 & 0 & 0 & 0 & 0 & 0 & 0 & 0 & 0 \\
\hline
\end{tabular}




\section{Table A3.12 - Explanatory notes}

In line with Table 3.10 (in the main text), the next table reports estimates only for the regressions that control for enrolment in state schools in the 1910s. Results controlling for other historical variables lead to the same conclusions, except for the following cases:

1. For (Avg.Years Educ.2000s), the share of German-speakers in the population in the nineteenth century is always significant and positive if we control for the on-the-job skills in 1872 .

2. For (Illiteracy rates ${ }_{n}^{2000 s}$ ), the only potentially significant variable in terms of path dependence is that reported in the table; none of the others was statistically significant. 
Table A3.12 - OLS: Path dependence and stocks of human capital (2000s) - bootstrapped: zero-imputed data with historical enrolment in state schools

\begin{tabular}{|c|c|c|c|c|c|c|}
\hline & $\begin{array}{c}\text { Avg. Years } \\
\text { Educ. } \\
2000 \text { s }\end{array}$ & $\begin{array}{c}\text { Avg. Years } \\
\text { Educ. } \\
2000 \text { s }\end{array}$ & $\begin{array}{c}\text { Illiteracy } \\
\text { rate } \\
2000 \text { s } \\
\end{array}$ & $\begin{array}{c}\text { Illiteracy } \\
\text { rate } \\
2000 \mathrm{~s} \\
\end{array}$ & $\begin{array}{c}\text { Educ. } \\
\text { MHDI } \\
2000 s \\
\end{array}$ & $\begin{array}{c}\text { Educ. } \\
\text { MHDI } \\
2000 \mathrm{~s}\end{array}$ \\
\hline Enrolment state $1910 \mathrm{~s}$ & $\begin{array}{c}0.000167 \\
(0.000148)\end{array}$ & $\begin{array}{c}0.000150 \\
(0.000139)\end{array}$ & $\begin{array}{c}-0.000522 \\
(0.000318)\end{array}$ & $\begin{array}{c}-0.000574 * \\
(0.000315)\end{array}$ & $\begin{array}{c}3.56 \mathrm{e}-06 \\
(8.72 \mathrm{e}-06)\end{array}$ & $\begin{array}{c}2.92 \mathrm{e}-06 \\
(8.20 \mathrm{e}-06)\end{array}$ \\
\hline German schools 1930 s & $\begin{array}{r}-0.0837 \\
(0.130)\end{array}$ & $\begin{array}{l}-0.0954 \\
(0.114)\end{array}$ & $\begin{array}{l}0.0731 \\
(0.277)\end{array}$ & $\begin{array}{l}0.0371 \\
(0.268)\end{array}$ & $\begin{array}{l}-0.00223 \\
(0.00752)\end{array}$ & $\begin{array}{c}-0.00267 \\
(0.00663)\end{array}$ \\
\hline German-speakers 1872 (share) & $\begin{array}{c}11.57 \\
(7.297)\end{array}$ & $\begin{array}{c}10.64 \\
(8.348)\end{array}$ & $\begin{array}{l}-11.54 \\
(16.43)\end{array}$ & $\begin{array}{l}-22.58 \\
(19.01)\end{array}$ & $\begin{array}{l}0.686^{*} \\
(0.374)\end{array}$ & $\begin{array}{c}0.507 \\
(0.500)\end{array}$ \\
\hline German workers 1872 (share) & $\begin{array}{l}-1.061 \\
(2.073)\end{array}$ & & $\begin{array}{l}-2.252 \\
(4.995)\end{array}$ & & $\begin{array}{l}-0.0220 \\
(0.125)\end{array}$ & \\
\hline German workers 1888 (share) & & $\begin{array}{l}-0.156 \\
(1.700)\end{array}$ & & $\begin{array}{l}2.834 \\
(4.17)\end{array}$ & & $\begin{array}{l}0.0525 \\
(0.101)\end{array}$ \\
\hline Population 1999-2004 & $\begin{array}{c}1.16 \mathrm{e}-07 \\
(1.32 \mathrm{e}-06)\end{array}$ & $\begin{array}{c}8.20 \mathrm{e}-08 \\
(1.25 \mathrm{e}-06)\end{array}$ & $\begin{array}{l}-2.69 \mathrm{e}-06 \\
(3.12 \mathrm{e}-06)\end{array}$ & $\begin{array}{c}-2.91 \mathrm{e}-06 \\
(3.18 \mathrm{e}-06)\end{array}$ & $\begin{array}{c}6.88 \mathrm{e}-08 \\
(7.70 \mathrm{e}-08)\end{array}$ & $\begin{array}{c}6.56 \mathrm{e}-08 \\
(7.71 \mathrm{e}-08)\end{array}$ \\
\hline Income $1999-2004$ & $\begin{array}{c}2.92 \mathrm{e}-05 \\
(8.13 \mathrm{e}-05)\end{array}$ & $\begin{array}{c}3.27 \mathrm{e}-05 \\
(7.80 \mathrm{e}-05)\end{array}$ & $\begin{array}{c}0.000145 \\
(0.000209)\end{array}$ & $\begin{array}{c}0.000171 \\
(0.000211)\end{array}$ & $\begin{array}{c}-1.22 \mathrm{e}-06 \\
(4.73 \mathrm{e}-06)\end{array}$ & $\begin{array}{c}-8.26 \mathrm{e}-07 \\
(4.80 \mathrm{e}-06)\end{array}$ \\
\hline Munic expend. educ. 2002-2003 & $\begin{array}{c}-1.56 \mathrm{e}-09 \\
(4.38 \mathrm{e}-09)\end{array}$ & $\begin{array}{c}-1.47 \mathrm{e}-09 \\
(3.97 \mathrm{e}-09)\end{array}$ & $\begin{array}{c}1.10 \mathrm{e}-09 \\
(1.14 \mathrm{e}-08)\end{array}$ & $\begin{array}{c}3.65 \mathrm{e}-10 \\
(1.15 \mathrm{e}-08)\end{array}$ & $\begin{array}{l}-1.89 \mathrm{e}-10 \\
(2.91 \mathrm{e}-10)\end{array}$ & $\begin{array}{l}-2.04 \mathrm{e}-10 \\
(2.81 \mathrm{e}-10)\end{array}$ \\
\hline Municipal characteristics 2000s & Yes & Yes & Yes & Yes & Yes & Yes \\
\hline Economic structure 2000 s & Yes & Yes & Yes & Yes & Yes & Yes \\
\hline Observations & 145 & 145 & 145 & 145 & 145 & 145 \\
\hline Adj. $R^{2}$ & 0.895 & 0.895 & 0.714 & 0.715 & 0.949 & 0.949 \\
\hline Complete replications & 1000 & 1000 & 1000 & 1000 & 1000 & 1000 \\
\hline Incomplete replications & 0 & 0 & 0 & 0 & 0 & 0 \\
\hline
\end{tabular}




\section{Settlement colonies and German schools (1910s)}

This appendix elaborates on a concern related to the geographic distribution of immigrants that was not fully addressed by the subsample analyses. The problem refers to the impact that settlement colonies could have had on the educational performance of the municipalities. Rocha, Ferraz and Soares (2017) show that regions with settlement colonies had better educational performance in the 1920s. More strongly than the arguments of the current chapter, they argue that the positive effects of settlement colonies on education persisted until the 2000s.

Hence, the question addressed here is whether the omission of settlement colonies in the baselines for the 1910s could have biased the estimates for (German schools ${ }_{n}^{1910 s}$ ). This is relevant because Chapter 1 showed that German-speakers were overrepresented in settlement colonies in the period 1897-1920 vis-à-vis their overall shares in the immigration flows to Brazil. Moreover, Table A3.13 shows the strong correlation between the number of German schools and some variables related to the existence of settlement colonies in the municipalities ${ }^{80}$.

Table A3.13 - Correlation matrix: German schools and settlement colonies

\begin{tabular}{|c|c|c|c|c|c|c|}
\hline & $\begin{array}{c}\text { German } \\
\text { schools } \\
1872 \\
\end{array}$ & $\begin{array}{c}\text { German } \\
\text { schools } \\
1910 \mathrm{~s}\end{array}$ & $\begin{array}{c}\text { German } \\
\text { schools } \\
\text { 1930s } \\
\end{array}$ & $\begin{array}{c}\text { \# sett. } \\
\text { colonies } \\
1910 \mathrm{~s}\end{array}$ & $\begin{array}{c}\# \text { schools } \\
\text { colonies } \\
1910 \mathrm{~s} \\
\end{array}$ & $\begin{array}{c}\text { Pop/schools } \\
\text { colonies } \\
\text { 1910s } \\
\end{array}$ \\
\hline German schools 1872 & 1 & & & & & \\
\hline German schools 1910s & 0.9126 & 1 & & & & \\
\hline German schools 1930 s & 0.8723 & 0.9227 & 1 & & & \\
\hline \# settl. colonies 1910 s & 0.7749 & 0.7399 & 0.8361 & 1 & & \\
\hline \# schools colonies 1910 s & 0.7765 & 0.722 & 0.7441 & 0.9072 & 1 & \\
\hline pop/schools colonies $1910 \mathrm{~s}$ & 0.182 & 0.164 & 0.3452 & 0.6153 & 0.3861 & 1 \\
\hline
\end{tabular}

Notes: "German schools," refers to the number of German schools created in a MCA until the period considered. The other variables are defined in this appendix.

To test for potential biases, I constructed three indicators to capture the effect of settlement colonies on the educational performance of municipalities in the 1910s. As in Chapter 1, the source for this dataset is the Statistical Yearbook of the State of São Paulo. Considering that the dependent variables are averaged for the period 1908-14 (except for 1912), the new independent variables were also constructed as averages for the period 1911-4 ${ }^{81}$. Moreover, because a MCA

\footnotetext{
${ }^{80}$ I would like to remark, however, that the approach pursued in this appendix has only a tentative nature, as the relationship between settlement colonies and German schools is not the main research question of Chapter 3 and would require the compilation of data that go beyond the scope of this thesis.

${ }^{81}$ The Statistical Yearbooks have no data for settlement colonies before 1911 (except for 1898-1900).
} 
could have more than a single settlement colony, all variables for the colonies are averaged per MCA, including the count variables.

The first indicator, (\# sett.colonies ${ }_{n}$ ), is a count variable for the number of settlement

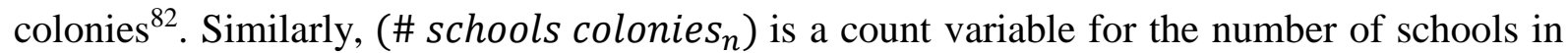
these colonies. The first robustness checks are conducted with these variables. A summary of results is presented in Table A3.14 (below).

The number of schools in the colonies robustly and positively influences enrolment in private schools, as well as enrolment in state schools if the on-the-job skills of German-speakers are categorized by sector. Most importantly, the number of settlement colonies is always significant and positive for total enrolment, a result that is driven by their effect on enrolment in private or state schools, depending on the specification.

Most importantly for the conclusions of the current chapter, the inclusion of these controls does make (German schools ${ }_{n}^{1910 s}$ ) non-significant.

However, these are poor approaches to the problem at hand. First, nearly every region where German schools were founded in the 1910s had a settlement colony as well, leading to a high collinearity among the variables of interest, as shown above. Second, this approach penalizes the variable (German schools ${ }_{n}^{1910 s}$ ) much more than it does for the corresponding variables for the settlements. Because (\# sett. colonies ${ }_{n}$ ) and (\# schools colonies ${ }_{n}$ ) attribute a single data point to the entire MCA where the colony (or colonies) was located, these indicators ignore variations in the scale and in the educational performance between and within settlement colonies in a single MCA. To accommodate for these limitations, the other robustness checks

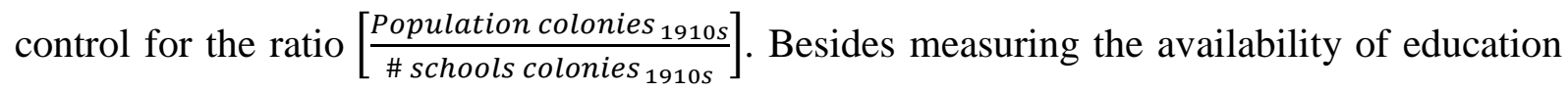
per capita in a colony, this variable takes into account variations in the size of the settlements. With this control, the effects of (German schools ${ }_{n}^{1910 s}$ ) on enrolment in private and state schools remain significant as in the baselines. It is noticeable, however, that its significance for total enrolment vanishes ${ }^{83}$.

\footnotetext{
${ }^{82}$ I coded only colonies reported in the Statistical Yearbooks. An alternative is to consider the secondary data in Rocha, Ferraz and Soares (2017). My objective in using the former was to harmonize the datasets as much as possible to reduce measurement error.

${ }^{83}$ In this appendix, I report only the IV estimates for considering them the most adequate. OLS estimates are available online at https://onlinelibrary.wiley.com/doi/full/10.1111/ehr.12575, accessed on November 262018.
} 
Overall, these robustness checks show a non-negligible correlation among the share of Germanspeaking immigrants, the number of their schools and the existence of settlement colonies. The results obtained in the baselines for (German schools ${ }_{n}^{1910 s}$ ) are indeed affected by the inclusion of variables related to settlement colonies. Nevertheless, in specifications that consider the scale of the settlements - therefore partially accounting for differences between them -, the positive effect of having a German school remains. This shows that the influence of German schools are not completely confounded with those of the settlement colonies.

Nonetheless, the changes in significance point to the complex relationship between the foundation of German schools and the existence of settlement colonies in a certain region. Empirically, a better assessment of this relationship requires more refined information on the educational performance of the settlements. Further analyses should control for the ratio $\left[\frac{\text { Children in school age in colonies } 1910 \mathrm{~s}}{\# \text { schools colonies } 1910 \mathrm{~s}}\right]$ and for literacy rates or total literacy in the colonies. These approaches are feasible but they are still only preliminary with data currently available ${ }^{84}$. New datasets need to be compiled with original sources beyond the Statistical Yearbooks, in which five settlement colonies have missing data on those variables for the period considered ${ }^{85}$. Moreover, as in Chapter 1, the increasing number of specifications raises concerns about multiple hypothesis testing.

Historically, we still need to establish more clearly the links between education in settlement colonies and the foundation of German schools. A great deal of information has already been analyzed about the foundation of German schools in private colonies and in other rural regions of São Paulo ${ }^{86}$. Nevertheless, the interconnections among settlement colonies, schools established in them and foreign schools developed around them deserve further research.

\footnotetext{
${ }^{84}$ Some of these analyses have been conducted in the abovementioned online appendix. I did not report them here for considering the approaches still as statistically unsettled.

${ }^{85}$ Namely, Bom Sucesso (municipality of Largo de Sorocaba), Piaguhy (Guaratinguetá), Martinho Prado Jr. (Mogi Guaçú), Sabaúna (Mogi das Cruzes) and S. Bernardo (homonymous municipality).

${ }^{86}$ See, among others, the case studies by Grininger (1991), Bezerra (2001), Silva (2010), Gouvêa (2011) and Varussa (2017), as well as the summary works by Kreutz (2005) and Bezerra (2007).
} 
Table A3.14 - IV: Partial effects of German Schools and settlement colonies (1910s)

\begin{tabular}{|c|c|c|c|c|c|c|c|c|c|c|c|c|}
\hline & $(1)$ & (2) & (3) & (4) & (1) & (2) & (3) & (4) & (1) & $(2)$ & (3) & (4) \\
\hline \multicolumn{13}{|c|}{ Total enrolment $1910 \mathrm{~s}$} \\
\hline \multirow[t]{2}{*}{ German schools 1910s } & 64.27 & 41.25 & -16.21 & -84.84 & 101.8 & 97.17 & 38.78 & 1.659 & $146.3 *$ & 131.1 & $112.2^{*}$ & 104.5 \\
\hline & -99.5 & -114.4 & -82.46 & -129.8 & -92.01 & -106.2 & -79.77 & -106.9 & -75.99 & -83.81 & -65.06 & -80.45 \\
\hline \multirow[t]{2}{*}{ \# settlement colonies 1910s } & $155.2 * *$ & $175.9^{*}$ & $258.5^{* *}$ & $360.5 * *$ & & & & & & & & \\
\hline & -71.74 & -101.8 & -104.5 & -152.8 & & & & & & & & \\
\hline \multirow[t]{2}{*}{ \# schools colonies $1910 \mathrm{~s}$} & & & & & 61.13 & 48.29 & $101.3 *$ & $132.7 * *$ & & & & \\
\hline & & & & & -37.26 & -47.71 & -59.05 & -66.05 & & & & \\
\hline \multirow[t]{2}{*}{ (Pop.)/(Schools) colonies $1910 \mathrm{~s}$} & & & & & & & & & 0.0835 & 0.0919 & 0.0603 & 0.134 \\
\hline & & & & & & & & & -0.0945 & -0.102 & -0.07 & -0.11 \\
\hline \multicolumn{13}{|c|}{ Enrolment in state schools $1910 \mathrm{~s}$} \\
\hline \multirow[t]{2}{*}{ German schools 1910s } & 30.33 & 24.89 & 25.71 & -25.82 & 35.48 & 33.73 & 33.64 & -1.058 & $42.32 * *$ & $37.57 *$ & $39.98 * *$ & 32.93 \\
\hline & -25.38 & -30.88 & -24.26 & -39.41 & -22.89 & -27.45 & -22.62 & -29.74 & -18.14 & -20.29 & -18.62 & -20.86 \\
\hline \multirow[t]{2}{*}{ \# settlement colonies 1910s } & 18.77 & 21.33 & 27.09 & $107.4^{* *}$ & & & & & & & & \\
\hline & -22.03 & -31.69 & -22.96 & -52.76 & & & & & & & & \\
\hline \multirow[t]{2}{*}{ \# schools colonies 1910s } & & & & & 6.66 & 3.299 & 7.678 & $40.74 *$ & & & & \\
\hline & & & & & -10.49 & -13.98 & -10.43 & -20.79 & & & & \\
\hline \multirow[t]{2}{*}{ (Pop.)/(Schools) colonies $1910 \mathrm{~s}$} & & & & & & & & & -0.02 & -0.0218 & -0.0242 & 0.000197 \\
\hline & & & & & & & & & -0.0276 & -0.0286 & -0.0233 & -0.0249 \\
\hline \multicolumn{13}{|c|}{ Enrolment in private schools $1910 \mathrm{~s}$} \\
\hline \multirow[t]{2}{*}{ German schools 1910s } & 11.83 & 11.99 & -68.87 & -76.84 & 26.37 & 52.38 & $-135.9 *$ & -94.34 & $80.46^{*}$ & $76.19 *$ & $73.95 * *$ & 29.55 \\
\hline & -62.02 & -83.38 & -67.87 & -79.46 & -64.24 & -88.18 & -76.17 & -79.26 & -41.35 & -46.3 & -33.6 & -41.56 \\
\hline \multirow[t]{2}{*}{ \# settlement colonies $1910 \mathrm{~s}$} & $134.9 * *$ & 124.8 & $266.8 * *$ & $202.6^{*}$ & & & & & & & & \\
\hline & -56.92 & -97.3 & -108.6 & -107.3 & & & & & & & & \\
\hline \multirow[t]{2}{*}{ \# schools colonies 1910s } & & & & & $76.86^{*}$ & 33.87 & $264.2 * * *$ & $152.8 * *$ & & & & \\
\hline & & & & & -43.03 & -71.37 & -77.45 & -69.54 & & & & \\
\hline \multirow[t]{2}{*}{ (Pop.)/(Schools) colonies $1910 \mathrm{~s}$} & & & & & & & & & 0.0681 & 0.0519 & 0.0396 & -0.0059 \\
\hline & & & & & & & & & -0.0628 & -0.0633 & -0.0586 & -0.0697 \\
\hline
\end{tabular}




\section{Table A 3.14 (Ctd.)}

\begin{tabular}{|c|c|c|c|c|c|c|c|c|c|c|c|c|}
\hline & (1) & (2) & (3) & (4) & (1) & (2) & (3) & (4) & (1) & (2) & (3) & (4) \\
\hline \multicolumn{13}{|c|}{ Enrolment in municipal schools $1910 \mathrm{~s}$} \\
\hline \multirow[t]{2}{*}{ German schools 1910 s } & 45.18 & 54.76 & 13.8 & -16.98 & 49.15 & 55.86 & 18.64 & -2.652 & 31.65 & 33.77 & 12.21 & 15.79 \\
\hline & -34.04 & -39.98 & -31.99 & -39 & -37.14 & -38.35 & -38.27 & -46.85 & -20.36 & -20.57 & -22.73 & -22.63 \\
\hline \multirow[t]{2}{*}{ \# settlement colonies $1910 \mathrm{~s}$} & -24.75 & -38.93 & -3.353 & 71.37 & & & & & & & & \\
\hline & -34.12 & -47.5 & -37.1 & -48.01 & & & & & & & & \\
\hline \multirow{2}{*}{ \# schools colonies 1910s } & & & & & -23.76 & -29.33 & -9.091 & 30.47 & & & & \\
\hline & & & & & -26.85 & -27.6 & -36.18 & -41.37 & & & & \\
\hline \multirow[t]{2}{*}{ (Pop.)/(Schools) colonies $1910 \mathrm{~s}$} & & & & & & & & & 0.0053 & 0.0028 & -0.0028 & 0.075 \\
\hline & & & & & & & & & -0.0507 & -0.0566 & -0.043 & -0.0572 \\
\hline \multicolumn{13}{|c|}{ Completion in state schools $1910 \mathrm{~s}$} \\
\hline \multirow[t]{2}{*}{ German schools 1910 s } & 53.14 & 46.96 & 11.65 & 25.27 & 24.91 & 18.12 & -6.359 & 20.96 & 22.26 & 16.84 & 25.88 & 26.69 \\
\hline & -55.96 & -60.61 & -57.38 & -51.48 & -49.02 & -49.88 & -44.68 & -39.65 & -27.05 & -26.47 & -32.45 & -18.29 \\
\hline \multirow[t]{2}{*}{ \# settlement colonies $1910 \mathrm{~s}$} & -50.35 & -53.31 & 27.82 & 14.61 & & & & & & & & \\
\hline & -80.36 & -88.39 & -66.81 & -71.86 & & & & & & & & \\
\hline \multirow{2}{*}{ \# schools colonies $1910 \mathrm{~s}$} & & & & & -0.14 & 0.537 & $40.64 *$ & 14.21 & & & & \\
\hline & & & & & -41 & -42.13 & -24.41 & -31.91 & & & & \\
\hline \multirow[t]{2}{*}{ (Pop.)/(Schools) colonies 1910s } & & & & & & & & & 0.0556 & 0.0582 & 0.0814 & $0.130^{* * *}$ \\
\hline & & & & & & & & & -0.0627 & -0.0596 & -0.0574 & -0.0374 \\
\hline
\end{tabular}

Note: Each group of four specifications follows the structure of the baselines: (1) controls for the Share of German workers in 1872; (2) controls for the Share of German workers in 1888;

(3) controls for the share of German-speakers per sector in 1872; and (4) controls for the shres of German-speakers per sector in 1888 . All regressions control for the full set of covariates as in the baseline. Unde as in the baseline. Under-identification is always rejected at the 1 percent level and the F-Statistic of the instrument is always above Stock and Yogo's (2002) 10 percent critical value. Robus 


\section{Appendix I: Indicators for insalubrious regions (1850-74)}

\section{Motivation and summary of compiled controls}

Mainly since Acemoglu, Johnson and Robinson (2001), economists have paid increasingly more attention to historical data on settlers' mortality to explain the decisions of Europeans to settle in certain regions, with long-termed consequences for the institutions therein installed. In line with this conceptual proposition, omitting this type of variable could bias the estimates on the immigration policies studied in Chapter 1. Indeed, there is historical evidence that public authorities in the nineteenth century were vigilant about epidemics and considered the degree of salubrity of certain regions an important determinant for the location of settlement colonies. Furthermore, it seems that foreigners in São Paulo were aware of local diseases and epidemics, even if frequently deceived by the pro-immigration propaganda on other aspects ${ }^{1}$.

However, datasets on mortality disaggregated at subnational levels are still scarce ${ }^{2}$. The problem at hand is not exactly lack of data. Indicators of mortality per municipality exist for São Paulo in 1854 and the state's government started to compile them systematically since 1893. To the best of my knowledge, however, these statistics are not available at a disaggregated level for the 1870s. Using information only from 1854 would be an unreliable approach, as foreigners could have adapted to the salubrity prevailing across regions and changed their place of residency accordingly.

To circumvent this limitation, I constructed four proxies for the degree of salubrity of municipalities based on qualitative information from the Annual Reports of the Presidency of São Paulo, covering the period 1850-74³ . To recapitulate, the baseline estimates of Chapter 1 controls for two of these proxies: (i) an indicator for regions considered insalubrious because of their geographic location and (ii) an indicator on whether a municipality registered widespread diseases or epidemics in that period. The robustness checks substitute these proxies by: (iii) a categorical variable for regions in (i); and (iv) a counting variable for the number of widespread diseases and epidemics registered in (ii).

\footnotetext{
${ }^{1}$ See, for instance, Davatz ([1858] 1941, pp. 62-3, 107-8, 250).

${ }^{2}$ Similar to what was discussed for the returns to skill in Chapter 1.

${ }^{3}$ I consider two years after the 1872 Census to capture widespread diseases and epidemics that could have been brewing for some period before they actually broke out.
} 


\section{Source of data and variables on epidemics and widespread diseases}

From the Annual Reports, I collected information from the headings Introduction and Public Health, which reported cases of widespread diseases and epidemics of the municipalities. Naturally, only the cases of higher intensity were worth reporting. This implies that the indicators are a lower bound estimate of the diseases actually prevailing in the municipalities.

The construction of the indicator on whether a municipality had a widespread disease or epidemics in a certain year followed straightforwardly from the qualitative source. Aggregating the information for a municipality $n$ over $t$ years, this indicator reports whether a municipality ever had cases of widespread diseases or epidemics registered in the Annual Reports.

The counting variable, in turn, was constructed by adding all diseases registered in the period considered.

Figure AI.1 plots the counting variable, while Table AI.1 provides details about the registered diseases and their distribution over time and across municipalities. Besides few other specific diseases, one notices the emphatic reporting of cholera morbus, yellow fever and - to a substantially higher degree - smallpox.

Table AI.1 - Diseases registered in the Annual Reports (1850-74)

\begin{tabular}{|c|c|c|c|}
\hline Disease & \# Entries $^{1}$ & Years & Municipalities \\
\hline Smallpox $^{2}$ & 78 & $\begin{array}{c}1852,1854, \\
1857-60, \\
1862-3,1865- \\
6,1868,1871- \\
2,1874\end{array}$ & $\begin{array}{l}\text { Bananal, Caçapava, Campinas, Cananéia, Capivari, Conceição do } \\
\text { Itanhaém, Constituição, Cubatão, Franca, Guaratinguetá, Iguape, } \\
\text { Iporanga, Itapeva da Faxina, Itu, Jacareí, Jundiaí, Lençóis, } \\
\text { Limeira, Lorena, Mogi das Cruzes, Mogi Mirim, Nazareth, } \\
\text { Paraibuna, Parnaíba, Pindamonhangaba, Porto Feliz, Queluz, Rio } \\
\text { Claro, S. Bento do Sapucaí, S. Bernardo, S. João da Boa Vista, } \\
\text { S. José do Paraitinga, S. Luiz, S. Pedro (Constituição), S. Roque, } \\
\text { S. Simão, Santos, S. Paulo, Sorocaba, Tatuí, Taubaté, Jacareí, } \\
\text { Sorocaba }\end{array}$ \\
\hline Cholera morbus & 15 & 1856 & $\begin{array}{l}\text { Areas, Bananal, Cananéia, Caraguatatuba, Iguape, Queluz, S. } \\
\text { Bento do Sapucaí, S. Sebastião, Santos, S. Paulo, Silveiras, } \\
\text { Ubatuba }\end{array}$ \\
\hline Yellow fever & 10 & $\begin{array}{c}1850-1,1853- \\
4,1859,1870 \\
1873\end{array}$ & Iguape, Santos, Ubatuba, S. Paulo \\
\hline Fever & 4 & 1852 & Araraquara, Campinas, Casa Branca, Mogi Mirim \\
\hline Bilious Colic ${ }^{3}$ & 1 & 1852 & Cananéia \\
\hline Dysentery & 1 & 1852 & Santos \\
\hline "Local diseases"4 & 1 & 1850 & S. Sebastião \\
\hline Measles & 1 & 1862 & S. Paulo \\
\hline Pertussis & 1 & 1858 & Iguape \\
\hline $\begin{array}{l}\text { Stillbirth \& maternal post- } \\
\text { birth mortality }\end{array}$ & 1 & 1852 & Sorocaba \\
\hline Typhoid fever & 1 & 1852 & Itapetininga \\
\hline
\end{tabular}




\section{Classification of "insalubrious regions"}

Regions located along specific rivers tended to be associated with the outbreak of epidemics, especially those surrounding rivers Atibaia, Camanducaia, Jaguari, Mogi Guaçú and Pardo. Other regions considered particularly problematic were located on the coast of the province. The Annual Reports mentioned, in particular, widespread diseases and epidemics that broke out in the regions of the Ribeira Valley and in the northern coast of the province.

To construct the indicator for the geographically insalubrious regions, I considered all coastal municipalities as more susceptible to epidemics. For regions along the rivers, my coding followed the dataset Unidade de Gerenciamento de Recursos Hídricos (UGRHI) - 2000, provided by Fundação SEADE. This dataset determines whether a municipality is related to the hydrographic basin of a certain river. All municipalities bathed by the abovementioned rivers were coded as geographically insalubrious. Figure AI.2 plots this indicator. The categorical variable used in the robustness checks codes the municipalities according to the rivers that bathe them or to their location on the coast of São Paulo. The values of the categories are uninformative per se, but they differentiate among specific regions.

\section{Complementary information}

The Annual Reports also provide quantitative information for further assessments about the health conditions in São Paulo by the mid-nineteenth century. Very rich for certain localities, especially for those that had a public hospital or a so-called "vaccination institute", these data unfortunately do not cover the entire province and, therefore, were not used in the previous compilations. It is worth noticing, however, that the vaccination institutes registered the number of people vaccinated, categorized by gender, social status (whether free or slave) and by result of vaccination (immunized, ineffective vaccination, or with no follow-up). The hospitals, in turn, registered the annual balance of entries, exits, casualties and discharges ${ }^{4}$.

\footnotetext{
${ }^{4}$ Both datasets are compiled and available upon request.
} 
Figure AI.1 - Absolute number of widespread diseases and epidemics municipalities (1850-74)

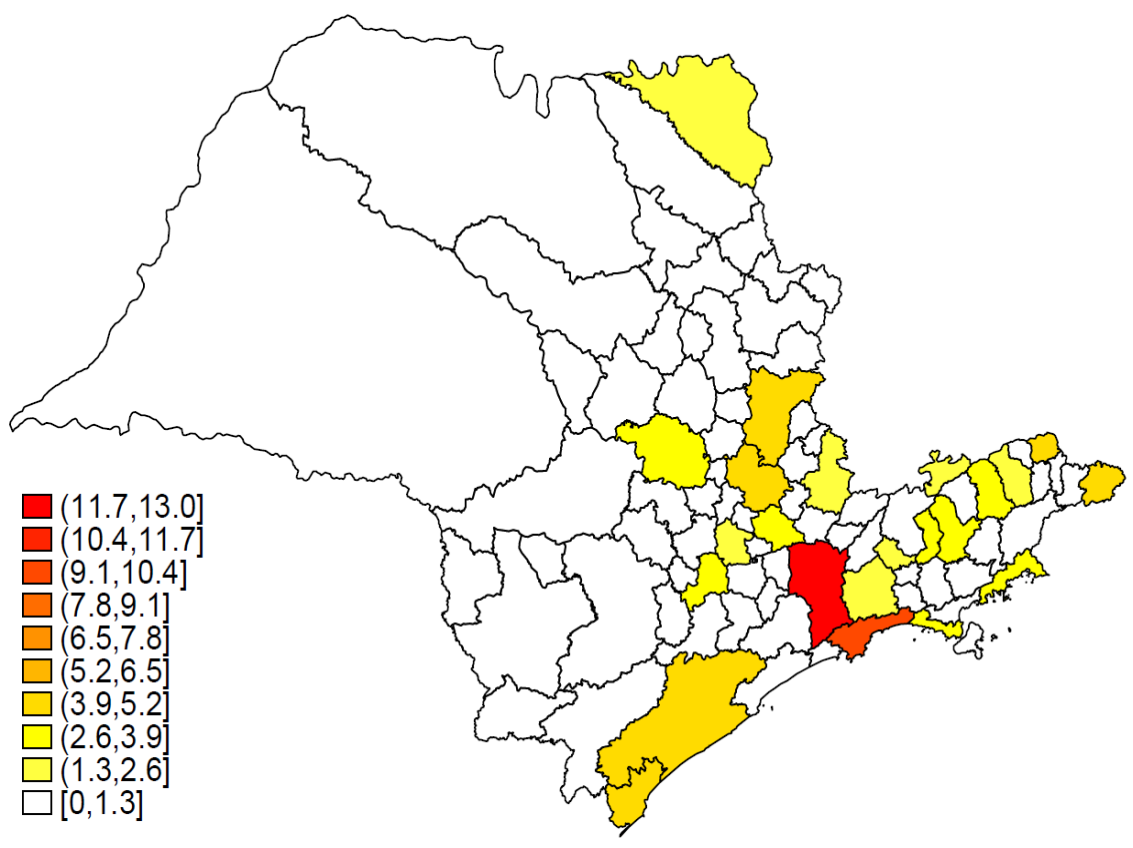

Figure AI.2 - Insalubrious regions according to geographic location

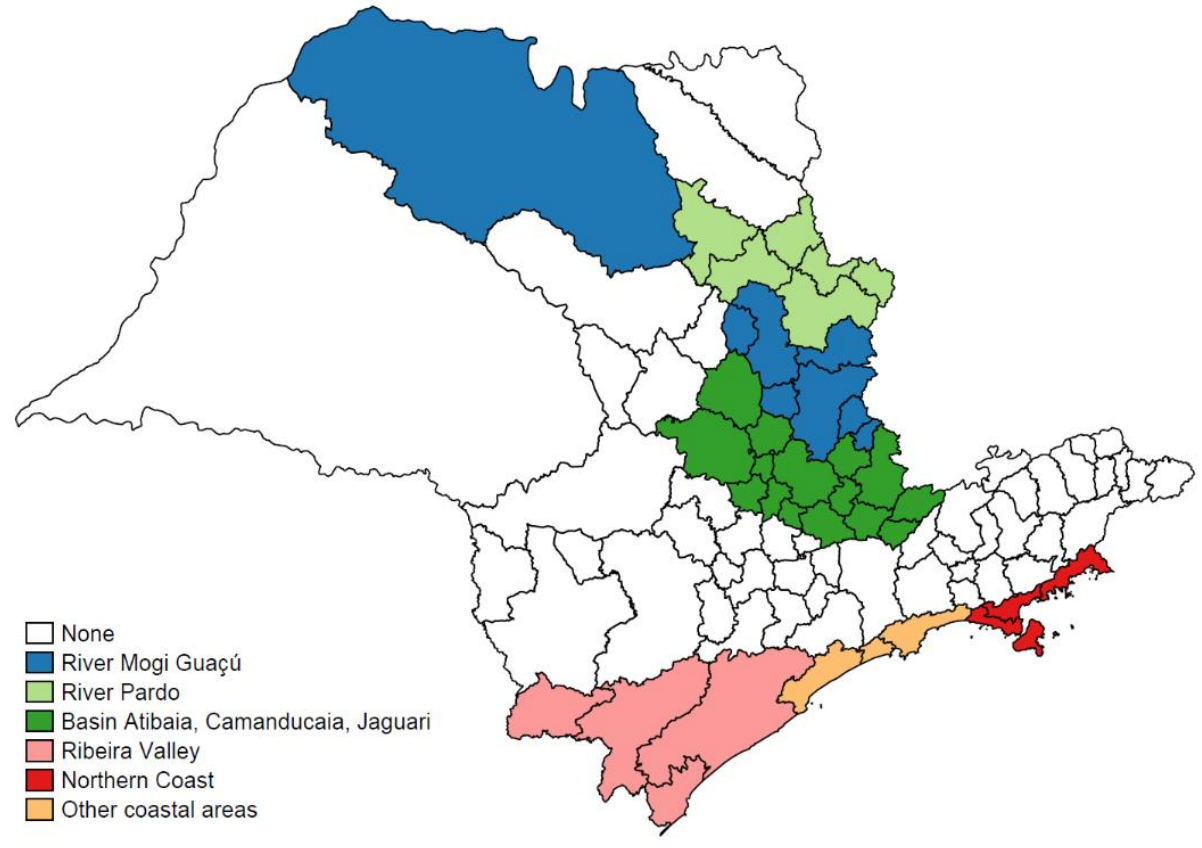




\section{Appendix II: Labor riots and movements of social unrest among immigrants}

\section{Motivation}

The research conducted with the Brazilian Digital Newspapers' Repository revealed a number of labor riots and movements of social unrest involving immigrants. The historiography has long recognized the importance of rural strikes and immigrants' mobs in molding immigration policies in Brazil; in changing international perceptions about the country; and in influencing the transition from slavery ${ }^{5}$. To the best of my knowledge, however, an all-encompassing register of riots led by foreigners is still missing. In an initial effort to fill this research gap, the current appendix provides a list of sources that reported labor riots and movements of social unrest among immigrants, especially German-speakers. The list is far from exhaustive and still lacks historical and conceptual dilapidation. It nevertheless outlines some interconnections between labor riots over time as well as across municipalities and provinces.

A general survey of riots would allow us to compare not only the similitude of the complaints of immigrants, but also to assess the direct connections among some rioters. Moreover, it would contribute to the history of labor and international relations, as the Brazilian immigration policy remained at the center of important diplomatic tensions until the early twentieth century. Finally, the strikes have important consequences for economic analyses as well. First, the riots show that there was no automatism in the adoption of different labor regimes. An intense bargaining process, frequently confrontational, determined whether and how contracts were enforced and modified. Second, quantitative inquiries about riots and movements of social unrest in the rural economy of nineteenth century Brazil remain untapped. A quantitative survey of these events - including measures of frequency and intensity - would allow us to answer some old questions. In particular, we would be interested on how influential immigrants' mobs were for the transition from slavery. Did the strikes lower the inflow of foreigners to the regions where they were more intense? Did immigrants influence the discipline of slaves and viceversa? Did the riots affect remuneration levels? Were they influential enough to lead to institutional reforms?

\footnotetext{
${ }^{5}$ Witter (1974, footnote 127) and Stolcke and Hall (1983, pp. 185-6). Surveys of rural riots can be found in Lamounier (1986, pp. 35-49) and Viotti da Costa (1998, pp. 126-30). For a detailed account of riots in late nineteenth century, especially in the central-western plateau of São Paulo, see Dean (1977, pp. 170-5).
} 


\section{Precedents: riots of settlers and laborers in public works (1820-40)}

The first movements of social unrest led by immigrants in São Paulo occurred with Germanspeakers settled in rural colonies. The mobs were mostly related to an inadequate supply of infrastructure and to the non-enforcement of property rights. The first surveyed riot took place in Santo Amaro in $1829^{6}$.

- For the motives of the riot: O Farol Paulistano (08/04/1829, pp. 2-3).

- For the escalation of the movement: Idem - (27/05/1829, p. 2); the mob even included a rally against the headquarters of the director of the colony (Idem-06/06/1829, p. 2).

- For its de-escalation and a strengthened monitoring by the Brazilian authorities: Idem $1830(27 / 05 / 1830$, p. 1).

Another riot took place in the colony of Rio Negro, located in the current state of Paraná. This settlement was founded by the same imperial dispatch that had ordered the distribution of German-speakers to São Paulo in 1827.

- For a reference to the riot: O Paulista Official (02/03/1836, p. 2).

Upheavals of German-speaking laborers hired for public works in the 1830s were more similar to the riots of bonded laborers in the plantations in the $1850 \mathrm{~s}$.

- For a riot in the public Iron Fabric of Ipanema: A Phenix (06/02/1839, pp. 5-6).

Riots and strikes of immigrants hired to work in the roadways of Cubatão tended to be more systematic. The complaints raised by workers about their living and working conditions spread from the 1830 s to the 1860 s.

- For the burst of a mob after the imprisonment of three German-speakers who evaded work and the context of the hiring: A Phenix - 1839 (30/01, p. 2; 06/02, pp. 3, 5-6; 21/08/, pp. 1-2).

- The entire hiring episode is critically discussed in Idem (02/01/1839, pp. 1-4).

- For the complaints of a German inspector about his remuneration during hospitalization: Correio Paulistano - 1859 (22/06, pp. 2-3; 23/06, p. 2).

- For two rallies motivated by payment cutbacks that involved even cases of assassination: Idem (08/06/1864, p. 1).

- For an attack of Portuguese laborers against a German and an Italian family: Diário de S. Paulo (16/09/1865, p. 1).

\footnotetext{
${ }^{6}$ Besides these sources, Siriani (2003) analyzes this episode in detail.
} 
Immigrants' labor riots caused social alarm and frequently triggered xenophobic reactions.

- For the alleged fear of the citizens of São Paulo after the mob of the German-speakers in Santo Amaro and its view under the light of a rebellion of German and Irish mercenaries in Rio de Janeiro: O Farol Paulistano - 1828 (12/07, pp. 3-4; 20/08, pp. 13; 03/09, pp. 2-3).

- For a description of the rebellion in Rio de Janeiro: Gazeta de Campinas (21/07/1872, p. 1).

- For the oscillating societal perception about the benefits of immigration, see examples in: Diário de S. Paulo (01/08/1872, p. 1); Santos Commercial (21/05/1895, p. 1) besides the debate between José Vergueiro and Bonifácio do Amaral in Gazeta de Campinas, discussed in Chapter 2.

\section{Riots of bonded laborers (1850-70)}

From the 1850s, the riots were motivated by complaints of rural laborers about the design and enforcement of contracts. The first movement of this type took place in farm Ibicaba in 1851:

- For Senator Vergueiro's view on the dispute: O Mercantil (19/07/1851, p. 4).

- For a heated discussion in the press about the incidence: Idem - 1851 (02/06, pp. 3-4; 19/07, p. 4). Vergueiro \& Co. published an open letter of support signed by 40 German household heads in Idem (4/10, pp.1-2); the voluntariness of this document steered yet another debate: A Aurora Paulistana (21/11/1851, pp. 2-3).

Besides previous references to the Sharecropper's Riot in 1856, see the following complementary documents about this important strike:

- For a judicious evaluation of the riot's juncture by the presidency of the province: Correio Paulistano (13/05/1857, p. 1).

- For the inspection of Dr. Heusser in farms Ibicaba and Angélica in the aftermath of the Sharecropper's Riot: Idem (24/03/1857, p. 4). This source includes Dr. Heusser's contradictory positive views about these farms.

In 1870, a German sharecropper accused farmer Luiz A. de Souza Barros of contractual breaches. Inspections in his farm took place in 1872 but reports appeared only in $1874^{7}$ :

\footnotetext{
${ }^{7}$ Lamounier (1986, pp. 41-2) cites this episode as evidence that landowners' problems were not about specific labor regimes: Souza Barros was successful with sharecropping but not with contracts based on fixed payments. For the hiring of immigrants to his farms, see Correio Paulistano (02/07/1867, p. 2; 03/07/1867, p. 2; 20/06/1869, p. 1) and Diário de S. Paulo (08/05/1872, p. 2).
} 
- For the nomination of an investigation commission and the landowner's appalled reaction to the inspection: Correio Paulistano - 1872, p. 2 (16/04; 18/05; 25/07); Diário de S. Paulo - 1872, p. 2 (18/04; 08/05; 24/07).

- For critics, the inspection and data about immigrants' economic statuses, as elaborated by the farmer: Correio Paulistano (10/06/1874, p. 2).

- For the relatively good financial situation of the laborers: Idem (08/05/1872, p. 2).

In 1874, Joaquim Bonifácio do Amaral faced accusations in the press after ordering the imprisonment of an immigrant who left the farm without permission, in order to get married:

- For the landowner's views on the episode: Gazeta de Campinas (06/08/1874, pp. 1-2).

- For the propaganda carried out by Bonifácio do Amaral to preserve the image of his farm: Idem (16/07/1874, pp. 2-3; 30/07, p. 2); Correio Paulistano - 1874 (17/07, p. 1).

Two other riots led by German-speakers and Tiroleans burst in Bonifácio do Amaral's farms. These incidences had diplomatic consequences: Correio Paulistano - p. 2 (06/07/1878; $11 / 07 / 1878 ; 13 / 11 / 1878$, p. $2 ; 15 / 11 / 1878$, p. $1 ; 30 / 11 / 1878$, p. $1 ; 04 / 04 / 1879$, p. 2).

Similar problems occurred in farm Salto Grande, whose news brings an evaluation of the immigration waves conducted by Bonifácio do Amaral: Jornal da Tarde (19/11/1878, pp. 1-2).

Finally, the following sample collects immigrants' complaints and cases of physical violence:

- For complaints received by the German consul about weights and measures used by a landowner in assessing immigrants' production in the municipality of Araras: Diário de S. Paulo (14/01/1875, p. 1).

- For a complaint sent to the German consul regarding the use of police force against a German-speaker in the same municipality of Araras: Idem (30/08/1877, p. 1).

- For a riot of Germans in farm S. Manoel do Paraiso, municipality of Limeira, with a summarized list of complaints: Idem - 1878 (17/02, p. 1; 21/02, p. 1; 13/03, p. 2; 05/04, p. 2).

- For a riot in farm Sant'Anna, municipality of Botucatu: A Nação (06/10/1897, p. 1).

- For a riot in municipality of Rio das Pedras, with a casualty: Idem (16/10/1897, p. 2).

- For conflicts with laborers in two farms in the municipality of Ribeirão Preto involving corporal punishment: Idem (26/03/1898, p. 2). 


\section{Riots in settlement colonies (1860-90)}

With the reemergence of settlement colonies in the 1870 s, immigrants' complaints about property rights and inadequate infrastructure reappeared, as in the 1820s:

- For a strike in the military colony of Avanhandava and the strict punishment of the rioters in 1866: Correio Paulistano (28/10/1866, p. 1; 13/10/1868, p. 2).

- For a riot in the settlement of Cananéia: $\operatorname{Idem}(01 / 02 / 1867$, p. 1).

- For a commission of settlers in São Bernardo, who demanded an audience due to lack of payment, see: Idem $(01 / 05 / 1878$, p. 2).

Similar mobs took place in other Brazilian provinces/states as well. The following sample collects the information as reported in the press of São Paulo:

- For a mob of German-speakers in colony Teresópolis (province of Santa Catarina): Diário de S. Paulo (14/12/1869, p. 2). Similar events took place one decade later: Correio Paulistano (18/04/1878, p. 2; 06/03/1879, p. 2).

- For inspections carried out by a German mission and a Brazilian counsellor in colony Santa Leopoldina (province of Espírito Santo): Idem (23/07/1873, p. 1).

- For another problem with immigrants in colony Santo Angelo (province of Rio Grande do Sul): Idem (23/07/1873, p. 1).

- For a riot in colony Comandatuba (province of Bahia): Diário de S. Paulo (21/08/1873, p. 2); Correio Paulistano (27/07/1873, p. 2). Idem $(05 / 02 / 1874$, p. 1) probably refers to the same event).

- For a violent conflict between Germans and the Brazilian authority establishing the rural plots in colony Barão do Triumpho (province of Rio Grande do Sul): O Mercantil (11/01/1891, p. 2).

- For mention of complaints of German-speakers in the province of Santa Catarina and about diplomatic actions: A Nação (23/10/1898, p. 2).

\section{Brazilian immigration policy and diplomatic tensions (1850-80)}

Beyond the well-studied consequences of the Sharecropper's Riot and of the Rescript von der Heydt, German-Brazilian relations revolved around immigration policies throughout the nineteenth century:

- For the exclusion of Brazil from the emigration legislation of Prussia, Baden and the Northern German Confederation: Correio Paulistano - p. 2 (08/10/1868); Diário de S. Paulo - p. 2 (15/10/1867, p. 2). Idem (04/09/1872, p. 2) provides an extensive analysis 
linking the German discussions about emigration to Brazil to the Rescript von der Heydt.

- For political tensions caused by migration-related topics in 1871: Diário de S. Paulo (23/07/1871, p. 3). The hiring process in Germany was conducted by "two [commercial] houses from London".

- For the German opposition to emigration to Brazil, its relation to the Franco-Prussian War and outmigration from Alsace-Loraine: Diário de S. Paulo (05/09/1872, p. 1); Correio Paulistano (08/08/1871, p. 1; 22/10/1872, p. 2).

A diplomatic crisis started in 1872, when the imprisonment of German officers in Rio de Janeiro allegedly triggered military threats from Germany ${ }^{8}$. This crisis was fueled more by rumors in the press than by actual international politics. Nevertheless, Brazilian periodicals reported such a dramatic escalation that even the Brazilian emperor had to intervene. Besides specific political circumstances, the episode involved political discussions about German immigration to Brazil: Diário de S. Paulo - 1872 (18/01, p. 2; 24/01, p. 1; 28/01, p. 1; 30/01, p. 2; 04/02, pp. 1-2; 20/02, p. $3 ; 24 / 02$, p. 3); an almost identical media coverage is in Correio Paulistano - 1872 (24/01, p. $2 ; 28 / 01$, p. $3 ; 31 / 01$, p. $1 ; 01 / 02$, pp. $1-2 ; 02 / 02$, p. $1 ; 04 / 02$, p. 1$)^{9}$.

- For the Brazilian perception that the German government orchestrated the incidence to avoid a rebound of emigration to Brazil: Gazeta de Campinas (01/02/1872, p. 1).

Discussions in the German Parliament in 1872 renewed the diplomatic distress. The debate was motivated by a petition in which German immigrants praised the living conditions in the southern province of Rio Grande do Sul: Diário de S. Paulo - 1872 (01/08, pp. 1-2).

Finally, see the following sample for other documents related to the diplomatic consequences of immigration to Brazil:

- For a motion of the Swiss Council against the treatment received by immigrants in Brazil and an internal circular to the cantonal governments: Diário de S. Paulo $(01 / 08 / 1872$, p. 2). The enforcement of the Brazilian law that allowed for the imprisonment of contract laborers motivated the dispatch; interestingly, the law was applied also to female laborers hired for domestic services ${ }^{10}$.

\footnotetext{
${ }^{8}$ Senra (2006, section “As sete faces de Manoel Francisco Correia [...]") reviews this diplomatic distress. The episode is studied by Correia, M. F. "Prisão de Oficiais da Coverta 'Nymphe', em 1871". Revista do Instituto Histórico e Geográfico Brasileiro, Vol. 64 (2), to which I unfortunately had no access.

${ }^{9}$ A more violent episode occurred in 1877 , but had no diplomatic consequences. It involved a shooting between German marines and the police of Santos: Correio Paulistano (15/08/1877). The crew of that ship had been accused of indiscipline in 1872, when it awaited the flotilla allegedly sent from Germany (Idem, 30/01/1872, pp. 1-2).

${ }^{10}$ For contemporaneous comments about this legislation, including advertisements for the capture of contract laborers who evaded the farms, see: Correio Paulistano (05/09/1856, p. 4; 28/07/1866, p. 1; 29/09/1866, p. 1; $18 / 06 / 1875$, p. $2 ; 28 / 07 / 1876$, p. 2); Diário de S. Paulo (06/02/1870, p. $3 ; 23 / 10 / 1877$, p. 1$)$.
} 
- For the reference to a dispatch of the German government opposing emigration to Brazil: Idem (10/12/1874, p. 3). Idem (04/12/1875, pp. 1-2) brings a detailed evaluation of countries with potentially high outmigration, especially Germany and Switzerland. The restrictive measures against emigration was observed by Brazilians as the result of labor scarcity for rural employment in the German States (Idem, 08/12/1874, p. 2).

- For an open letter defending immigration to Brazil written by Dr. Theodore Reichert, an influential German medical doctor and banker in São Paulo: Correio Paulistano (03/06/1874, p. 1); Diário de S. Paulo (10/06/1874, p. 3). This document is similar to another open letter he published in 1856: Correio Paulistano $(05 / 11 / 1856, \text { p. } 3)^{11}$.

- For an interesting analysis of the two main complaints raised by the German government against emigration to Brazil, namely the lack of religious freedom and the legislation regulating labor relations in Brazil: Idem (04/03/1874, p. 2).

- For another petition of German-speakers in southern Brazil: Idem (06/07/1879, p. 2); Jornal da Tarde (05/07/1879, p. 3); Relatedly, Idem - 1879 (29/05/1879, p. 1) discusses the foundation of the "Central Association of Commercial Geography and Representation of Foreign German Interests", which counted members who supported emigration to Brazil. However, the fact that German-speakers participated in riots in the farms Saltinho, Salto Grande and S. Manoel do Paraíso in the late 1870s certainly did not improve the international perception about Brazil (Diário de S. Paulo - 1878 (17/02, p. $1 ; 13 / 03$, p. 2; 05/04, p. 2).

${ }^{11}$ Siriani $(2005$, p. 98$)$ refers to another open letter by Dr. Reichert. He also summoned publicly the Germanspeakers of São Paulo to join their compatriots from other Brazilian provinces and the Brazilians as volunteers in the Paraguay War (Correio Paulistano, 31/08/1865, p. 2). 


\section{Appendix III: Brazilian Digital Newspaper's Repository}

\section{Sources and Methodology}

The Brazilian Digital Newspapers 'Repository is part of the Digital National Library, a project of the Brazilian National Library Foundation ${ }^{12}$. It aims at digitizing periodical publications, including newspapers, yearbooks and magazines. Although the literature on the transition from slavery in Brazil has already made extensive use of similar sources, their digitalization, unification in a single platform and the possibility of automatized research has brought the challenges and potentialities of big data analysis to qualitative studies.

For this thesis, I conducted a systematic review of periodicals published in São Paulo to create a sample of news that dealt with the themes of immigration, bonded labor, labor riots and settlement colonies. From an initial selection of $c a$. 11,000 entries obtained with the automatized search for the themes of the thesis, I selected a sample of about 5,000, of which a sub-sample of about 2,000 were analyzed ${ }^{13}$. This appendix discusses the methodology applied in selecting the sources and their thematic, geographic and timely coverage.

\subsection{Methodology}

In the Repository, I opted for a geographic-based research for São Paulo in the period 18201920. Alternatives in the archival platform include research by periodicals or period. I preferred the geographic approach to avoid biases towards publications I knew a priori.

With this specification, I selected eighteen newspapers whose municipality of publication could be identified from the title. The objective was to obtain a balanced sample of newspapers from the countryside and coastal regions of the province/state. Two other newspapers were added; their place of publication could not be determined a priori, but it was recognizable that they were not published in the capital ${ }^{14}$.

\footnotetext{
${ }^{12}$ Free translated from the original in Portuguese: Hemeroteca Digital Brasileira; Biblioteca Nacional Digital; and Fundação Biblioteca Nacional, respectively.

${ }^{13}$ These numbers correspond to the entries researched, not to the number of news, as a single news can contain and it usually did - more than one single term researched.

${ }^{14}$ Correio do Sertão and A Aurora.
} 
Table AIII.1 - Newspapers researched in the Brazilian Digital Newspapers' Repository

\begin{tabular}{|c|c|c|c|c|c|c|}
\hline \multirow[b]{2}{*}{ Newspaper } & \multicolumn{6}{|c|}{ Availability in the Repository } \\
\hline & Ye: & & Eds. & Pages & Municipality & Owner/Editor ${ }^{2}$ \\
\hline A Aurora Paulista & 1851 & 1852 & 59 & 241 & Capital & Antonio L. Antunes \\
\hline A Nação & 1898 & 1898 & 199 & 812 & Capital & Partido Rep. Federal (Felix Bocayuva) \\
\hline A Phenix & 1838 & 1841 & 361 & 1450 & Capital & Typ. Costa Silveira \\
\hline A Tarde & 1895 & 1895 & 1 & 4 & Capital & - \\
\hline A Tarde Illustrada & 1896 & 1896 & 2 & 12 & Capital & Typ. Industrial de S. Paulo \\
\hline Correio Paulistano & 1850 & 1880 & 6196 & 24806 & Capital & Marques \& Irmão \\
\hline Diário de S. Paulo & 1865 & 1878 & 3635 & 14554 & Capital & Alvim, Cintra \& Schroeder (Typ. Alemã) \\
\hline Ensaios Litterarios & 1847 & 1850 & 11 & 348 & Capital & Ass. Academicos (Typ. do Governo) \\
\hline Jornal da Tarde & 1878 & 1881 & 974 & 3901 & Capital & Antonio Elias da Silva \\
\hline Lavoura e Commercio & 1898 & 1900 & 196 & 789 & Capital & J. A. Leite Penteado \\
\hline O Farol Paulistano & 1827 & 1831 & 489 & 2092 & Capital & Roa E.C \\
\hline O Novo Farol Paulistano & 1831 & 1837 & 338 & 1450 & Capital & Typ. Farol Paulistano \\
\hline O Paulista Official & 1835 & 1838 & 225 & 971 & Capital & Typ. do Governo \\
\hline O Piratininga & 1849 & 1850 & 43 & 172 & Capital & Typ. Viúva Sobral \\
\hline O Trabalho & 1876 & 1877 & 41 & 164 & Capital & Escritório Typ. Allemã \\
\hline O Commercio de São Paulo & 1893 & 1909 & 5274 & 24271 & Capital & Couto de Magalhães; F. Neves Jr. \\
\hline O Commercial [S. Paulo] & 1851 & 1851 & 4 & 16 & Capital & Typ. arrendada Antonio L. Antunes \\
\hline O Amparense & 1896 & 1896 & 1 & 4 & Amparo & José Ferreira Louzada \\
\hline Tribuna Amparense & 1877 & 1877 & 1 & 4 & Amparo & J. Rebello de Amorim \\
\hline O Bragantino & 1876 & 1880 & 5 & 20 & Bragança & José C. Furquim de Campos \\
\hline Gazeta de Brotas & 1895 & 1895 & 1 & 4 & Brotas & Manoel de Souza Leite \\
\hline Gazeta de Campinas & 1865 & 1888 & 605 & 2462 & Campinas & F. Quirino dos Santos \& Carlos Ferreira \\
\hline O Piracicabano & 1877 & 1884 & 4 & 16 & Constituição & J. Moreira Coelho \\
\hline O Cunhense & 1877 & 1878 & 2 & 8 & Cunha & Antonio Xavier Freire \\
\hline Limeirense & 1877 & 1877 & 1 & 4 & Limeira & João Ludovice; Getulio M. de Andrade \\
\hline Pindamonhagabense & 1874 & 1877 & 43 & 182 & Pindamonh. & J. Silveira da Costa \\
\hline Echo de Pirassununga & 1877 & 1877 & 1 & 4 & Pirassununga & F. S. Bastos \\
\hline O Pirassununga & 1877 & 1877 & 1 & 4 & Pirassununga & F. S. Bastos \\
\hline Jornal de Queluz & 1877 & 1880 & 3 & 12 & Queluz & Typ. do Jornal de Queluz \\
\hline O Mercantil & 1850 & 1891 & 354 & 1437 & Santos & Typ. Imparcial \\
\hline Revista Commercial & 1872 & 1872 & 53 & 216 & Santos & Behn \& Irmão \\
\hline O Commercial [Santos] & 1860 & 1860 & 2 & 8 & Santos & Typ. Marques \& Irmão \\
\hline Correio dos Santos & 1878 & 1878 & 1 & 8 & Santos & - \\
\hline Santos Commercial & 1895 & 1895 & 156 & 634 & Santos & Saldanha \& M. Lapetina \\
\hline Correio do Sertão & 1902 & 1903 & 94 & 375 & S.C. Rio Pardo & Antonio Galvão \\
\hline O Barreirense & 1876 & 1877 & 3 & 12 & S. J. Barreiro & Cruz Moraes \& Cia. \\
\hline O Echo de Bocaina & 1877 & 1877 & 1 & 4 & S. J. Barreiro & João Pedro Baptista \\
\hline Tribuna de São Carlos & 1877 & 1879 & 2 & 8 & S. Carlos & Ernesto Luiz Gonçalves \\
\hline A Aurora & 1876 & 1877 & 2 & 8 & Silveiras & Vicente Felix \& Ernesto Castro \\
\hline Monitor de Taubaté & 1877 & 1877 & 2 & 8 & Taubaté & José Vicente d'Aquila A. Aymbere \\
\hline
\end{tabular}

Notes: (1) The years refer to entries digitized in the Repository, not to the complete period of publication; (2) Owner/Editor refers to names of individuals and/or firms that could be identified in the newspapers as responsible for their content publication and/or typographical work. 
Excluding these in a second round of selection of periodicals, I re-evaluated the titles to look for newspapers with a statewide coverage. These were mostly published in the capital of the province/state and sometimes in the seaport city of Santos. This led to a sample of further twenty periodicals. Table AIII.1 lists the newspapers and some of their characteristics.

In the next step, I stablished the terms to be researched within those newspapers. I based this approach on the two main themes covered by the historiography on immigration to São Paulo, i.e. bonded labor immigrants and settlers in rural colonies. Moreover, I focused on Germanspeaking immigrants because of their prominent position as bonded laborers. I also identified names of personalities, events and localities frequently cited in relation to these two themes. In complement, I added variations adapted to nineteenth century spelling and to changes that the OCR technology was likely to recognize. Table AIII.2 presents the terms researched.

A main shortcoming of this methodology refers to the multiple meaning of most words. To cite two examples, country-related terms referred not only to the immigration of certain nationalities, but most frequently to international geopolitics; the term "parceria", in turn, meant not only sharecropping, but any type of partnership. To tailor the entries only those meanings relevant to my research questions, I cursory read all entries found automatically by the search machine of the Repository and selected those related to the topics of interest. Another problem is that all terms listed in Table AIII.2 were researched independently of the time coverage of the newspapers. This methodology generated some spurious results: the automatic search returned some positive entries for events that had not taken place within the period of publication of certain periodicals. For instance, 18 entries were reported for Colony Riograndense before its foundation in 1922. Therefore, those terms must have existed independently of the events I was looking for and were being used in different contexts. Combining the automatic research with the personal scanning of entries, I excluded these spurious associations.

Notwithstanding the effort to create a geographically and timely representative sample of news, I highlight the impossibility of conducting a completely exhaustive survey of themes. I could have extended the list of researched terms to include, for instance, regions of origin of immigrants, embarking and arrival ports, names of different colonies, politicians involved in the immigration policy, prominent immigrants, translations into other languages etc. Finally, the same methodology could be extended to a larger sample of periodicals in the Repository and to other sources now available in digital form. I am confident that this line of research will bear significant fruits in terms of historiographical novelties. 
Table AIII.2 - List of terms researched

\begin{tabular}{|c|c|c|}
\hline Term & Spelling variations & \# Entries ${ }^{1}$ \\
\hline Alemanha & $\begin{array}{l}\text { Allemanha; Alimanha; Allimanha; Allema; Alemao; Allemao; Allima; Alima; } \\
\text { Allimao; Alimao }\end{array}$ & 10,333 \\
\hline Suica & Suissa; Suico; Suisso & 2,315 \\
\hline Austria & Austriaca; Austriaco & 3,550 \\
\hline Vergueiro & - & 3,860 \\
\hline Ibicaba & Ibbicaba; Ybicaba & 142 \\
\hline Fazenda Angelica & Fazenda Angellica & 61 \\
\hline Parceria & Parceira; Parceiro & 507 \\
\hline Lousa & Louza & 442 \\
\hline Revolta & - & 1,327 \\
\hline Saltinho & - & 23 \\
\hline Davatz & Davat; Davats; Dawatz & 2 \\
\hline Heusser & Heußer; Heuser & 9 \\
\hline Tschudi & - & 4 \\
\hline Perret [Gentil] & Perret Gentil; Perret-Gentil & 103 \\
\hline Krug & - & 477 \\
\hline Heydt & Heidt & 6 \\
\hline Oswald & Osvald; Oschwald; Oschvald; Ochwald; Ochvald & 591 \\
\hline Colonia & $\begin{array}{l}\text { Colona; Colono; Colonisar; Colonisacao; Colonizar; Colonizacao; Collona; } \\
\text { Collono; Collonisar; Collonisacao; Collonizar; Collonizacao }\end{array}$ & 7,571 \\
\hline Nucleo Colonial & $\begin{array}{l}\text { Nucleo Collonial; Nucleos Coloniaes; Nucleos Coloniais; Nucleos Colloniaes; } \\
\text { Nucleos Colloniais }\end{array}$ & 515 \\
\hline Cananeia & Cananea; Cannanea; Canannea & 2,230 \\
\hline Itambure & Ytambure & 0 \\
\hline Pariquera-Assu & Pariquerassu; Pariquera Assu; Pariquera & 68 \\
\hline Superagui & Superaguy; Super agui; Super aguy & 4 \\
\hline Colonia Campos Salles & $\begin{array}{l}\text { Colonia Campos Sales; Collonia Campos Salles; Collonia Campos Sales; } \\
\text { Nucleo Colonial Campos Salles; Nucleo Colonial Campos Sales; Nucleo } \\
\text { Collonial Campos Sales }\end{array}$ & 103 \\
\hline Nova Europa & - & 29 \\
\hline Quellentau & Quellent; Quelentau & 0 \\
\hline Tannenberg & Tanenberg & 2 \\
\hline Aimore & Aymore & 189 \\
\hline Colonia riograndense & $\begin{array}{l}\text { Colonia rio grandense; Colonia rio-grandense; Collonia riograndense; Collonia } \\
\text { rio grandense; Collonia rio-grandense; Nucleo Colonial riograndense; Nucleo } \\
\text { Colonial rio grandense; Nucleo Colonial rio-grandense; Nucleo Collonial } \\
\text { riograndense; Nucleo Collonial rio grandense; Nucleo Collonial rio-grandense }\end{array}$ & 18 \\
\hline Colonia Paulista & Colonia Paullista; Collonia Paulista; Collonia Paullista & 1 \\
\hline Colonia Costa Machado & Collonia Costa Machado & 0 \\
\hline
\end{tabular}

Notes: (1) "\# Entries" refers to the number of news identified with the corresponding term and variations; (2) None of the researched terms included accents; (3) Personal names Vergueiro, Davatz, Heusser, Tschudi, Perret-Gentil, Krug and Oswald might refer to other individuals than those related to bonded labor; (4) Parceria might refer to any type of partnership; (5) Cananeia, Itambure, Pariquera-Assu and Superagui might refer to these localities in general and not only to colonies in them; (6) The same applies to official and private colonies Saltinho, Nova Europa, Quellentau, Tannenberg, Riograndense, Paulista and Costa Machado; (7) Lousa, without accent, might refer to blackboard or tombstone; (8) Revolta might refer to any social upheaval; (9) Colonia and Nucleo Colonial (to a lesser extent) might refer to any cluster of immigrants or expats. 


\section{Sample of sources: geographic and temporal analyses}

In this section, I check for the geographic and temporal distribution of the entries that compose my historical sources ${ }^{15}$. Besides evaluating the sources themselves, this analysis also shows some trending topics in the Brazilian press for the themes researched, separated by regions and periods. Although this research can be refined by programming the context in which a certain term is used, this first approach already shows some results of interest.

\subsection{Distribution per region}

Table AIII.1 reveals a strong imbalance in the distribution of pages available per region. Given that newspapers of the capital tended to be daily and to be published for longer periods, they provided significantly more entries than sources of any other region. Figure AIII.1 formalizes this observation by plotting the number of available pages by region in São Paulo ${ }^{16}$.

Figure AIII.1 - Number of pages of newspapers by region of publication

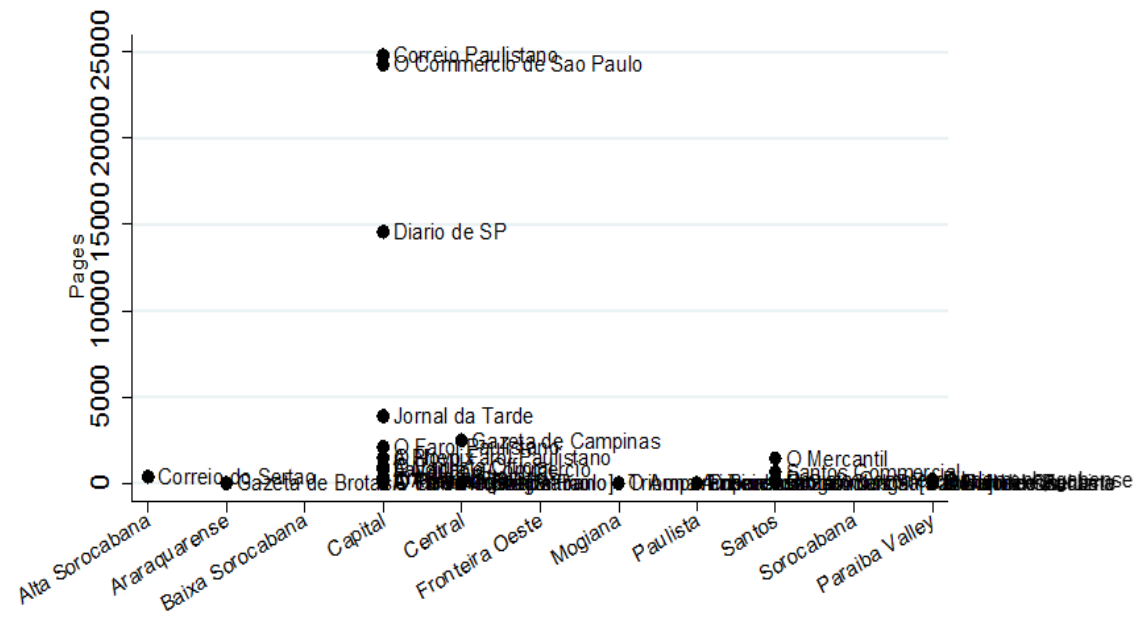

Given their scale, these daily newspapers of the capital probably had a higher absolute number of entries for any theme considered in this thesis. To avoid this problem of scale in analyzing the distribution of themes per region, I created an index for the intensity of a theme as reported per region. The index divides the number of entries for a specific theme by the number of pages

\footnotetext{
${ }^{15}$ Referring to the online version available on June 202018.

16 The regions follow Holloway's classification used by Carvalho Filho and Colistete (2010).
} 
available in a certain newspaper; I then collapse the means of the index over time and across the various newspapers published in a certain region. Figure AIII.2 shows the distribution of some selected themes and Table AIII.3 complements it with descriptive statistics.

Figure AIII.2 - Index of themes distributed by region of publication

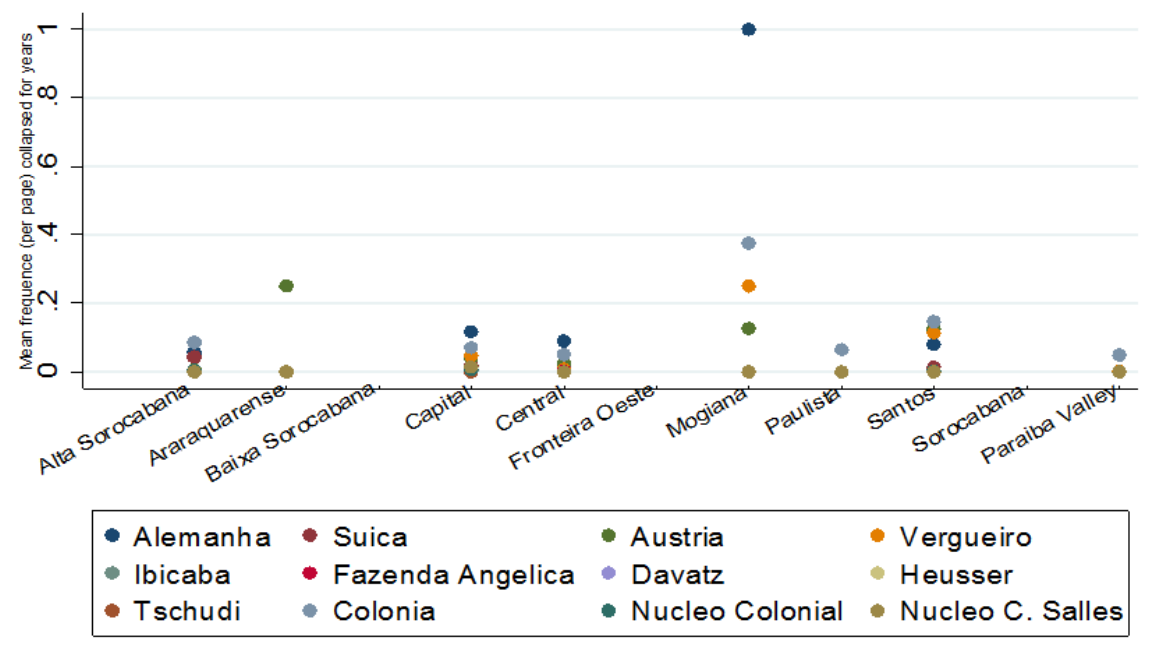

As Figure AIII.2 shows, the high absolute number of pages in the capital's newspapers did not influence the distribution of themes' frequencies. Across different regions, the highest frequencies referred to country-related news, as they probably reflected international events being reported in the Brazilian press. Table AIII.3 shows that news related to Germany dominated the frequency in the capital and in the countryside. Those related to Austria dominated in Santos, probably due to commercial relations. Finally, information related to Switzerland had a prominence in the countryside vis-à-vis other regions. The term "colonia" was the second most frequent. In the capital and Santos, it frequently referred to a cluster or network of foreigners. In the countryside, where the frequency is the second highest, it meant primarily farms employing bonded labor or settlement colonies. Also common were the terms "revolta" and Vergueiro. I do not emphasize the first because it could refer to any social upheaval, not necessarily related to immigrants. The latter is more interesting, especially because it prevailed in Santos, where the headquarters of Vergueiro \& Co. were located. 
Table AIII.3 - Descriptive statistics: Index of themes by specific regions

\begin{tabular}{|c|c|c|c|c|c|c|c|c|c|c|c|c|c|c|c|}
\hline & \multicolumn{3}{|c|}{ Overall } & \multicolumn{3}{|c|}{ Capital } & \multicolumn{3}{|c|}{ Santos } & \multicolumn{3}{|c|}{ Paraíba Valley } & \multicolumn{3}{|c|}{ Countryside $^{1}$} \\
\hline & Mean & S.D. & Max. & Mean & S.D. & Max. & Mean & S.D. & Max. & Mean & S.D. & Max. & Mean & S.D. & Max. \\
\hline Alemanha & 0.1258 & 0.3274 & 2 & 0.1164 & 0.1541 & 0.5135 & 0.0790 & 0.1237 & 0.2824 & 0.0476 & 0.0945 & 0.2500 & 0.2113 & 0.5959 & 2 \\
\hline Suica & 0.0299 & 0.1188 & 0.7500 & 0.0177 & 0.0287 & 0.1034 & 0.0121 & 0.0173 & 0.0370 & 0 & 0 & 0 & 0.0759 & 0.2242 & 0.7500 \\
\hline Austria & 0.0470 & 0.0824 & 0.2500 & 0.0401 & 0.0640 & 0.2488 & 0.1241 & 0.1174 & 0.2500 & 0 & 0 & 0 & 0.0526 & 0.0988 & 0.2500 \\
\hline Vergueiro & 0.0470 & 0.1016 & 0.5000 & 0.0463 & 0.0533 & 0.1738 & 0.1131 & 0.1542 & 0.3750 & 0.0008 & 0.0021 & 0.0055 & 0.0475 & 0.1502 & 0.5000 \\
\hline Ibicaba & 0.0004 & 0.0011 & 0.0049 & 0.0004 & 0.0010 & 0.0032 & 0.0010 & 0.0022 & 0.0049 & 0 & 0 & 0 & 0.0003 & 0.0011 & 0.0037 \\
\hline Faz. Angelica & 0.0065 & 0.0395 & 0.2500 & 0.0002 & 0.0006 & 0.0023 & 0.0001 & 0.0003 & 0.0007 & 0 & 0 & 0 & 0.0233 & 0.0752 & 0.2500 \\
\hline Parceria & 0.0153 & 0.0790 & 0.5000 & 0.0022 & 0.0034 & 0.0102 & 0.0006 & 0.0012 & 0.0028 & 0 & 0 & 0 & 0.0521 & 0.1493 & 0.5000 \\
\hline Lousa & 0.0198 & 0.0873 & 0.5000 & 0.0016 & 0.0025 & 0.0074 & 0.0003 & 0.0006 & 0.0014 & 0 & 0 & 0 & 0.0695 & 0.1611 & 0.5000 \\
\hline Revolta & 0.0414 & 0.1263 & 0.7500 & 0.0405 & 0.0712 & 0.2500 & 0.0289 & 0.0544 & 0.1250 & 0 & 0 & 0 & 0.0747 & 0.2245 & 0.7500 \\
\hline Saltinho & 0.0004 & 0.0017 & 0.0107 & 0.0001 & 0.0003 & 0.0013 & 0.0001 & 0.0003 & 0.0007 & 0 & 0 & 0 & 0.0011 & 0.0032 & 0.0107 \\
\hline Davatz & 0.0000 & 0.0000 & 0.0000 & 0.0000 & 0.0000 & 0.0000 & 0 & 0 & 0 & 0 & 0 & 0 & 0 & 0 & 0 \\
\hline Heusser & 0.0000 & 0.0000 & 0.0003 & 0.0000 & 0.0001 & 0.0003 & 0 & 0 & 0 & 0 & 0 & 0 & 0 & 0 & 0 \\
\hline Tschudi & 0.0000 & 0.0001 & 0.0008 & 0.0000 & 0.0000 & 0.0001 & 0 & 0 & 0 & 0 & 0 & 0 & 0.0001 & 0.0002 & 0.0008 \\
\hline Perret & 0.0006 & 0.0017 & 0.0073 & 0.0006 & 0.0011 & 0.0041 & 0.0014 & 0.0031 & 0.0070 & 0 & 0 & 0 & 0.0007 & 0.0022 & 0.0073 \\
\hline Krug & 0.0025 & 0.0134 & 0.0849 & 0.0008 & 0.0016 & 0.0054 & 0 & 0 & 0 & 0 & 0 & 0 & 0.0080 & 0.0255 & 0.0849 \\
\hline Heydt & 0.0000 & 0.0002 & 0.0012 & 0.0001 & 0.0003 & 0.0012 & 0 & 0 & 0 & 0 & 0 & 0 & 0 & 0 & 0 \\
\hline Oswald & 0.0046 & 0.0181 & 0.0913 & 0.0107 & 0.0270 & 0.0913 & 0.0003 & 0.0006 & 0.0014 & 0 & 0 & 0 & 0 & 0 & 0 \\
\hline Colonia & 0.0871 & 0.1341 & 0.5000 & 0.0694 & 0.1144 & 0.4286 & 0.1467 & 0.2080 & 0.5000 & 0.0476 & 0.0610 & 0.1250 & 0.1124 & 0.1600 & 0.5000 \\
\hline N. Colonial & 0.0035 & 0.0118 & 0.0532 & 0.0076 & 0.0174 & 0.0532 & 0.0014 & 0.0031 & 0.0070 & 0 & 0 & 0 & 0.0003 & 0.0008 & 0.0027 \\
\hline Cananeia & 0.0076 & 0.0145 & 0.0581 & 0.0170 & 0.0184 & 0.0581 & 0.0022 & 0.0050 & 0.0111 & 0 & 0 & 0 & 0.0003 & 0.0010 & 0.0032 \\
\hline Pariquer. & $1.4 \mathrm{E}-04$ & 4.7E-04 & 0.0025 & 0.0003 & 0.0007 & 0.0025 & 0 & 0 & 0 & 0 & 0 & 0 & 0 & 0 & 0 \\
\hline N. C. Salles & 5.0E-03 & $2.2 \mathrm{E}-02$ & 0.1153 & 0.0118 & 0.0334 & 0.1153 & 0 & 0 & 0 & 0 & 0 & 0 & 0 & 0 & 0 \\
\hline Superagui & 2.1E-04 & $1.3 \mathrm{E}-03$ & 0.0083 & 0.0005 & 0.0020 & 0.0083 & 0 & 0 & 0 & 0 & 0 & 0 & 0 & 0 & 0 \\
\hline N. Europa & $3.0 \mathrm{E}-05$ & $1.9 \mathrm{E}-04$ & 0.0012 & 0.0001 & 0.0003 & 0.0012 & 0 & 0 & 0 & 0 & 0 & 0 & 0 & 0 & 0 \\
\hline Tannenberg & $2.0 \mathrm{E}-06$ & $1.3 \mathrm{E}-05$ & 0.0001 & 0.0000 & 0.0000 & 0.0001 & 0 & 0 & 0 & 0 & 0 & 0 & 0 & 0 & 0 \\
\hline Aimore & $9.1 \mathrm{E}-04$ & $4.6 \mathrm{E}-03$ & 0.0283 & 0.0021 & 0.0069 & 0.0283 & 0.0003 & 0.0006 & 0.0014 & 0 & 0 & 0 & 0 & 0 & 0.0000 \\
\hline Riograndense & $6.3 \mathrm{E}-04$ & $2.3 \mathrm{E}-03$ & 0.0133 & 0.0006 & 0.0016 & 0.0055 & 0.0001 & 0.0003 & 0.0007 & 0 & 0 & 0 & 0.0012 & 0.0040 & 0.0133 \\
\hline C. Paulista & $1.0 \mathrm{E}-06$ & $6.5 \mathrm{E}-06$ & 0.0000 & 0.0000 & 0.0000 & 0.0000 & 0 & 0 & 0 & 0 & 0 & 0 & 0 & 0 & 0 \\
\hline
\end{tabular}

for Austria in Santos Commercial, all other minima equal zero; (4) The sample is composed by 17 newspapers from the capital, 5 from Santos, 7 from Paraíba Valley and 11 from the countryside. 


\subsection{Distribution over time}

Applying the same methodology as before, but now ordering the index over time (instead of doing so across regions), Figure AIII. 3 presents the distribution of some selected themes ${ }^{17}$.

Figure AIII.3 - Index of themes distributed by year of publication

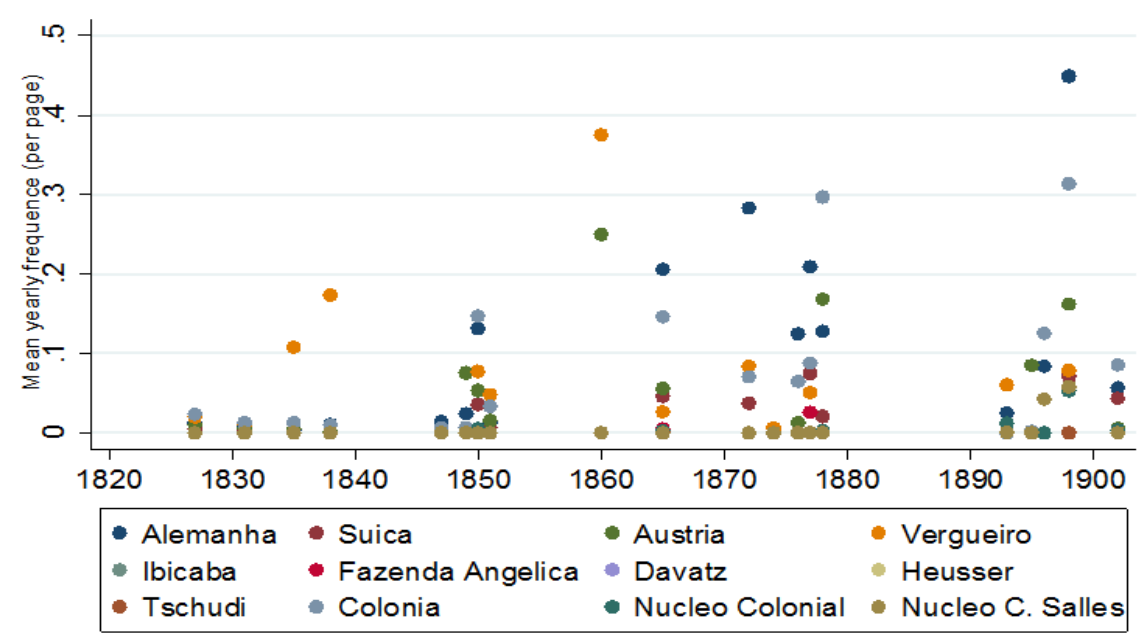

The figure suggests that three outstanding themes had been reported by the press of São Paulo, whose evolution over time I explore below.

First, Figure AIII.4 shows how country-related news reflected the geopolitics of the nineteenth century. The peaks in news about Germany and Austria in the 1860s-70s are the result of the German Unification and related wars.

Figure AIII.4 - Trend in news (index): German-speaking countries

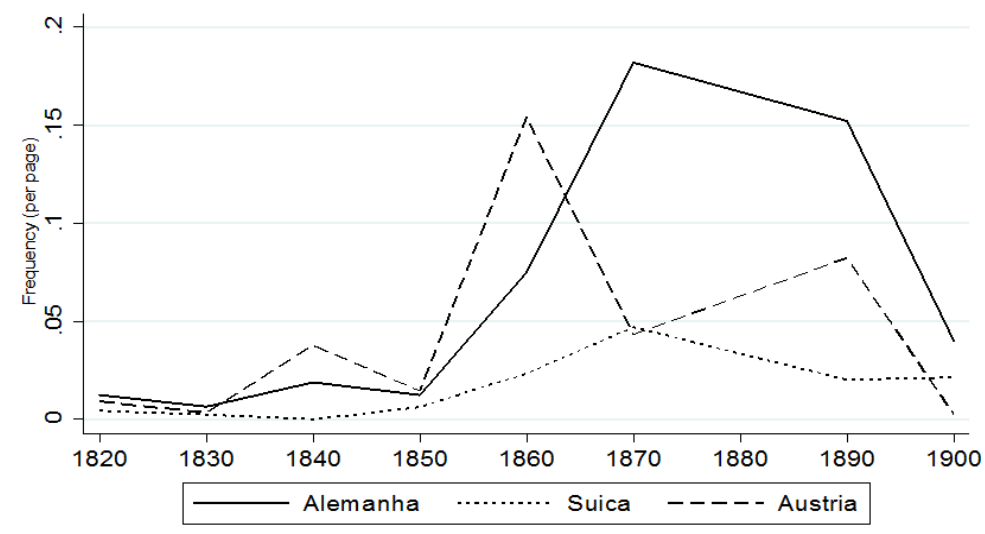

${ }^{17}$ The overall picture is not modified if I average the number of pages by the first or last year of publication. 
Second, news related to the name Vergueiro have two peaks in Figure AIII.5. The one in the 1830s is associated with the prominence of Nicolau Vergueiro in the political debates about immigration policies; the second shows the importance of Vergueiro \& Co. in the consolidation of bonded labor in the $1850 \mathrm{~s}$.

Figure AIII.5 - Trend in news (index): Vergueiro \& Cia.

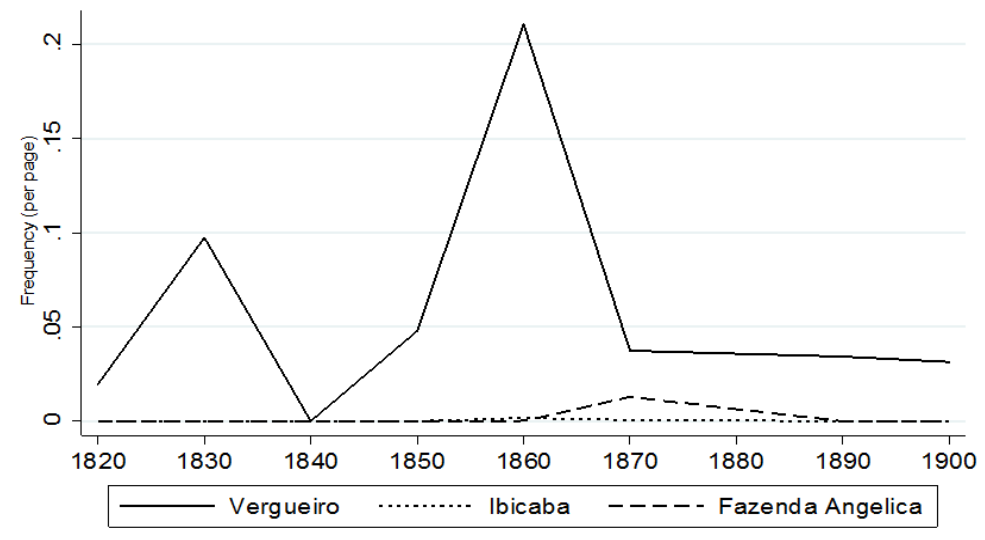

Finally, a related trend can be observed for immigration policies pursued in the province. A first peak of the term "colonia" occurred in the 1820s, but it declined until the 1840s, probably reflecting the initial prominence of settlement colonies in Santo Amaro and Itapecerica. The same figure shows a tentative reversal of trends for the terms "parceria" and "nucleo colonial". The term "parceria" declines steadily from the 1870 s, when the term "nucleo colonial" takes pace exactly at the moment of the revival of this immigration policy in the São Paulo ${ }^{18}$.

Figure AIII.6 - Trend in news (index): Immigration policies

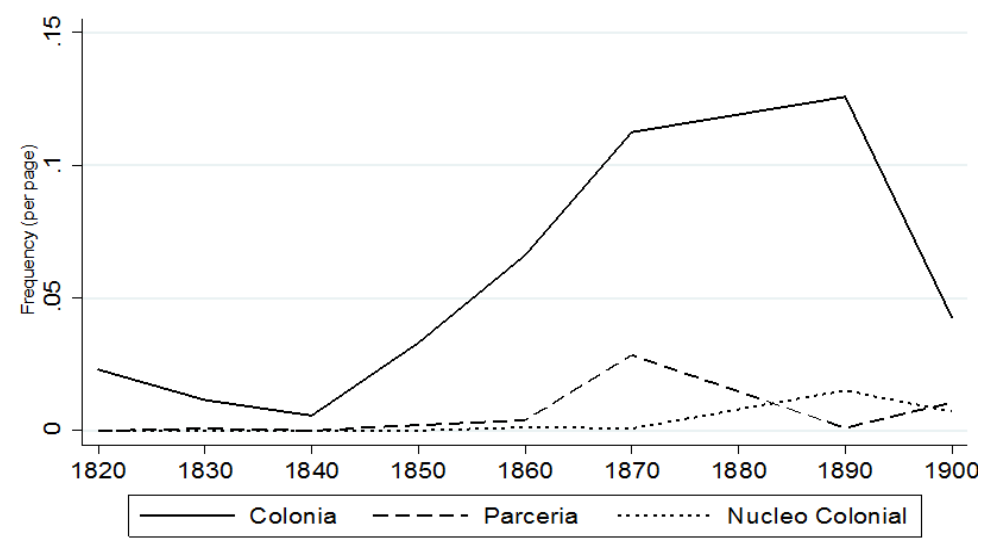

\footnotetext{
${ }^{18}$ I stress the tentative nature of assessing these trends because of the multiple meanings of the term "parceria".
} 


\section{Appendix IV: Maps - main localities referred to in the thesis}

Figure AIV.1 - Selected (current) Brazilian states ploted againts historical borders (1872)

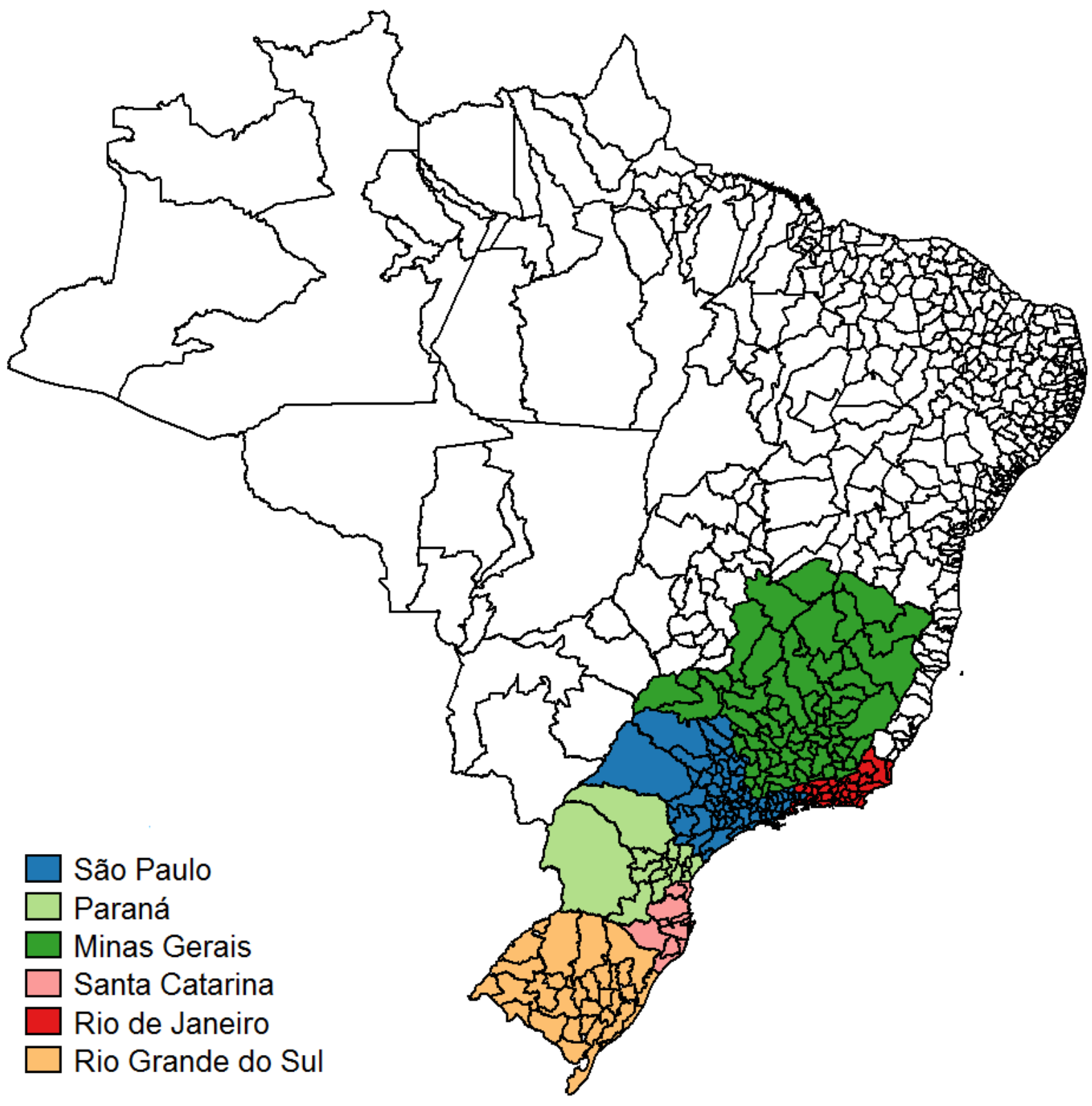

Political borders in the map correspond to those in 1872. For the indicated provinces, this configuration did not change substantially in later periods, except for the distribution of areas between Paraná and Santa Catarina. 
Figure AIV.2 - Selected municipalities in São Paulo (1872)

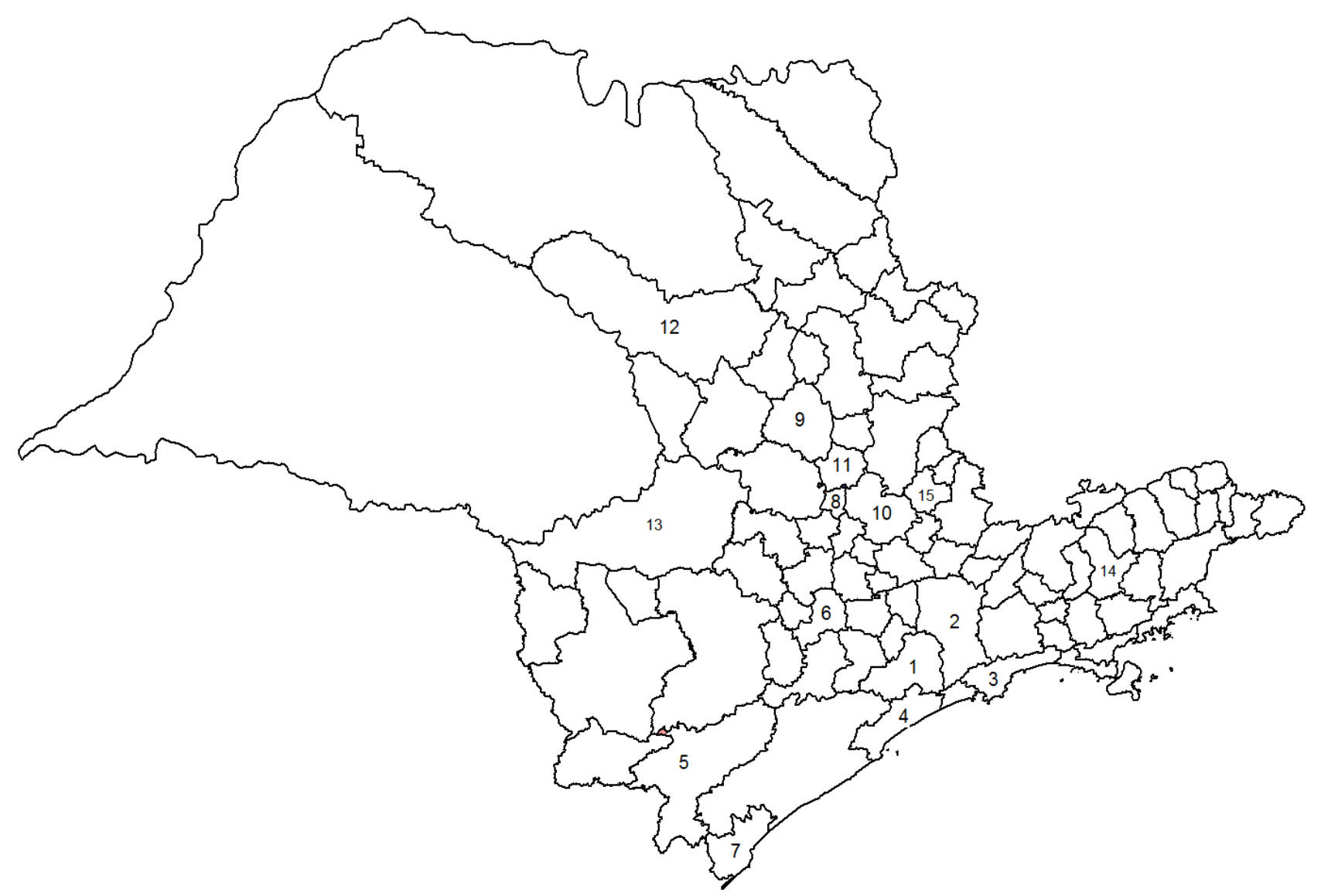

\begin{tabular}{|c|c|c|c|}
\hline 1 & Santo Amaro & 6 Sorocaba & 11 Limeira (including Leme) \\
\hline 2 & São Paulo (including Itapecerica) & 7 Cananéia & 12 Araraquara (including Ibitinga) \\
\hline 3 & Santos (including Cubatão) & 8 Santa Bárbara & 13 Botucatú \\
\hline 4 & Itanhaém & 9 Rio Claro & 14 Taubaté \\
\hline 5 & Xiririca & 10 Campinas (including Cosmópolis) & 15 Amparo \\
\hline
\end{tabular}




\section{Variable's definitions: a summary}

Variables used in the empirical exercises of the thesis are defined summarily in the following tables. See Chapters 1 and 3 and the Appendix for specific compilations.

\begin{tabular}{|c|c|c|c|}
\hline Variable & Source(s) & Sample(s) & Definition \\
\hline \multicolumn{4}{|c|}{ Demography } \\
\hline Population 1872 & 1872 Census & Municipalities 1872 & Total population of municipalities \\
\hline Population 1910 s & Erstes Jahrbuch / Anuários Ensino & Municipalities 1910 s & Total population of municipalities averaged for the period considered \\
\hline Population $1897-1920$ & Anuários Estatísticos & Colonies $1897-1920$ & Total population of settlement colonies \\
\hline Population 1999-2004 & SEADE/IMP & Municipalities 2000s & Total population of municipalities averaged for the period considered \\
\hline$<6$ years old (share) & 1872 Census & Municipalities 1872 & Share of population younger than 6 years old \\
\hline $6-15$ years old (share) & 1872 Census & Municipalities 1872 & Share of population in the age range 6-15 years old \\
\hline $16-20$ years old (share) & 1872 Census & Municipalities 1872 & Idem for $16-20$ years old \\
\hline 21-30 years old (share) & 1872 Census & Municipalities 1872 & Idem for 21-30 years old \\
\hline $31-60$ years old (share) & 1872 Census & Municipalities 1872 & Idem for 31-60 years old \\
\hline$>60$ years old $($ share $)$ & 1872 Census & Municipalities 1872 & Share of population older than 60 years old \\
\hline$<7$ years old (share) & Anuários Estatísticos & Colonies $1897-1920$ & Share of population younger than 7 years old \\
\hline $7-14$ years old (share) & Anuários Estatísticos & Colonies $1897-1920$ & Share of population in the age range $7-14$ years old \\
\hline 14-21 years old (share) & Anuários Estatísticos & Colonies $1897-1920$ & Idem for $14-21$ years old \\
\hline$\%$ Infants & 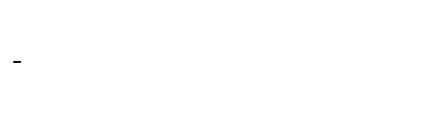 & 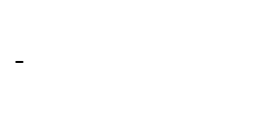 & $\begin{array}{l}\text { Summary groups for the year categories }<6 \text { years old (for the municipalities } 1872 \text { ) and }<7 \text { years old (for } \\
\text { settlement colonies 1897-1920). Used for ease of exposition in descriptive statistics, but not in empirical } \\
\text { exercises }\end{array}$ \\
\hline$\%$ Children & - & - & Summary category harmonizing the year categories 6-15 years old and 7-14 years old. Idem. \\
\hline$\%$ Young adults & - & - & Summary category harmonizing the year categories $16-20$ years old and $14-21$ years old. Idem. \\
\hline Singles (share) 1872 & 1872 Census & Municipalities 1872 & Share of single individuals among the free population \\
\hline Singles (share) checks 1872 & 1872 Census & Municipalities 1872 & Share of single individuals in the total population, including slaves \\
\hline Singles (share) $1897-1920$ & Anuários Estatísticos & Colonies 1897-1920 & Share of single individuals in the total population \\
\hline Widows (share) 1872 & 1872 Census & Municipalities 1872 & Share of widows among the free population \\
\hline $\begin{array}{l}\text { Widows (share) checks } \\
1872\end{array}$ & 1872 Census & Municipalities 1872 & Share of widows in the total population, including slaves \\
\hline Widows (share) $1897-1920$ & Anuários Estatísticos & Colonies $1897-1920$ & Share of widows in the total population \\
\hline Total mortality $1897-1920$ & Anuários Estatísticos & Colonies 1897-1920 & Mortality registered among the total population \\
\hline Mortality foreign. 1897-1920 & Anuários Estatísticos & Colonies $1897-1920$ & Mortality registered only among foreigners, without differentiation by nationality \\
\hline
\end{tabular}




\begin{tabular}{|c|c|c|c|}
\hline Variable & Source(s) & Sample(s) & Definition \\
\hline \multicolumn{4}{|c|}{ Educational performance } \\
\hline Literacy 1872 & 1872 Census & Municipalities 1872 & Total number of literate people in the municipalities \\
\hline Literacy rate 1872 & 1872 Census & Municipalities 1872 & Share of literate people among the free population of the municipalities \\
\hline Literacy rate $1897-1920$ & Anuários Estatísticos & Colonies $1897-1920$ & Total number of literate people in the settlement colonies \\
\hline Literacy rate $1897-1920$ & Anuários Estatísticos & Colonies $1897-1920$ & Share of literate people in the total population of the settlement colonies \\
\hline Enrolment 1872 & Census 1872 & Municipalities 1872 & Total number of children who "were receiving education", according to the source \\
\hline Enrolment rate 1872 & Census 1872 & Municipalities 1872 & Enrolment rate based on the previous definition \\
\hline \# Schools $1897-1920$ & Anuários Estatísticos & Colonies $1897-1920$ & Number of schools registered in settlement colonies \\
\hline Pop/school colonies 1910s & Anuários Estatísticos & Municipalities 1910s & $\begin{array}{l}\text { Proxy for the educational level of settlement colonies (measured by the number of schools available in the } \\
\text { colonies, averaged for the period considered) and their scale (measured by the population, averaged for } \\
\text { the period considered). See the Appendix of Chapter } 3 \text { for details on compilation }\end{array}$ \\
\hline State schools 1910 s & Anuário de Ensino & Municipalities 1910 s & Number of state schools, averaged for the period considered \\
\hline Total enrolment $1910 \mathrm{~s}$ & Anuários de Ensino & Municipalities 1910s & $\begin{array}{l}\text { Total number of children enrolled in schools, averaged for the period considered; variable compiled as the } \\
\text { sum of the following subcategories in the } 1910 \mathrm{~s}\end{array}$ \\
\hline Enrolment state 1910 s & Anuários de Ensino & Municipalities 1910s & Total number of children enrolled in state schools, averaged for the period considered \\
\hline Enrolment munic. 1910s & Anuários de Ensino & Municipalities 1910s & Idem for municipal schools \\
\hline Enrolment private 1910 s & Anuários de Ensino & Municipalities 1910s & Idem for private schools \\
\hline Completion state 1910 s & Anuários de Ensino & Municipalities 1910s & $\begin{array}{l}\text { Total number of children who completed the basic cycle of four years of education in state schools, } \\
\text { averaged for the period considered }\end{array}$ \\
\hline Total enrolment 2000s & SEADE/IMP & Municipalities 2000s & $\begin{array}{l}\text { Total number of children enrolled in schools, averaged for the period considered; variable compiled as the } \\
\text { sum of the following subcategories in the } 2000 \mathrm{~s}\end{array}$ \\
\hline Enrolment state 2000 s & SEADE/IMP & Municipalities 2000s & Total number of children enrolled in state schools, averaged for the period considered \\
\hline Enrolment munic. 2000s & SEADE/IMP & Municipalities 2000s & Idem for municipal schools \\
\hline Enrolment private 2000 s & SEADE/IMP & Municipalities 2000s & Idem for private schools \\
\hline Completion state 2000 s & SEADE/IMP & Municipalities 2000s & $\begin{array}{l}\text { Total number of children who completed the basic cycle of eight years in state schools (Ensino } \\
\text { Fundamental), averaged for the period considered }\end{array}$ \\
\hline Avg. years educ. 2000s & SEADE/IMP & Municipalities 2000s & Average years of education of population between 15 and 64 years old, averaged for the period considered \\
\hline Educ. MHDI 2000s & SEADE/IMP & Municipalities 2000s & $\begin{array}{l}\text { Educational component of the Human Development Index applied to Brazilian municipalities (see Chapter } \\
3 \text { for its the methodology), averaged for the period considered }\end{array}$ \\
\hline Illiteracy rate 2000s & SEADE/IMP & Municipalities 2000s & Illiteracy rate of population older than 15 years old, averaged for the period considered \\
\hline
\end{tabular}




\begin{tabular}{|c|c|c|c|}
\hline Variable & Source(s) & Sample(s) & Definition \\
\hline & & & Culture \\
\hline Non-Catholics (share) 1872 & Census 1872 & Municipalities 1872 & Share of non-Catholics in the total population \\
\hline Non-Catholics (share) 1897-1920 & Anuários Estatísticos & Colonies $1897-1920$ & Idem \\
\hline \# Religious buildings $1897-1920$ & Anuários Estatísticos & Colonies 1897-1920 & Number of religious buildings of any type in settlement colonies \\
\hline Stock immigrants 1854 & Bassanezi (1998) & Municipalities 1872 & Total stock of immigrants of any nationality in the municipalities in 1854 \\
\hline ID quality 1854 & - & Municipalities 1872 & $\begin{array}{l}\text { (Identifier }=1 \text { ) if data for the stocks of immigrants in } 1854 \text { had a statistical remark in the original source } \\
\text { or in Bassanezi (1998). This ID controls for the quality of the available data on the stocks of immigrants }\end{array}$ \\
\hline \multicolumn{4}{|c|}{ Geography } \\
\hline Avg. distance capital & - & Municipalities (overall) & $\begin{array}{l}\text { Average distance in straight line from the administrative center of a municipality to the administrative } \\
\text { center of the municipality of São Paulo. Considering that usually more than a single municipality is } \\
\text { encompassed by a MCA, the average of distances was considered }\end{array}$ \\
\hline Latitude & SEADE/IMP & Municipalities (overall) & Average of the latitudes of the municipalities encompassed by a MCA \\
\hline Altitude & SEADE/IMP & Municipalities (overall) & Idem for altitude \\
\hline Area & SEADE/IMP & Municipalities (overall) & $\begin{array}{l}\text { Idem for area at each period considered. Please notice that municipal areas changed as the politico- } \\
\text { administrative borders were altered, but not the fixed area of a MCA }\end{array}$ \\
\hline Avg. yearly pluviometry 2000s & SEADE/IMP & Municipalities 2000s & $\begin{array}{l}\text { Average rainfall for the municipalities encompassed by a MCA, averaged over summer, winter, spring, } \\
\text { and fall }\end{array}$ \\
\hline Avg. yearly temperature $2000 \mathrm{~s}$ & SEADE/IMP & Municipalities 2000s & Idem for temperature \\
\hline ID insalubrious region & See Appendix I & Municipalities 1872 & $($ Identifier $=1)$ if municipalities were located in regions considered geographically insalubrious \\
\hline Categories insalubrious & See Appendix I & Municipalities 1872 & Categorical identification of the previous variable according to Holloway's regions (see Chapter 3) \\
\hline ID diseases & See Appendix I & Municipalities 1872 & $\begin{array}{l}\text { (Identifier }=1 \text { ) if municipalities had at least one case of widespread diseases or epidemics registered in } \\
\text { the Presidential Reports of São Paulo for the period 1850-74 }\end{array}$ \\
\hline \# diseases & See Appendix I & Municipalities 1872 & Count variable of the previous indicator \\
\hline Holloway's categories overall & Carvalho Filho and Colistete (2010) & Municipalities overall & Categorical variable for regions in São Paulo sharing geographic and socioeconomic characteristics \\
\hline \multicolumn{4}{|c|}{ Economic variables } \\
\hline \# Slaves 1872 & Census 1872 & Municipalities 1872 & Total number of slaves registered in the municipalities \\
\hline Municipal budget 1872 & Erstes Jahrbuch & Municipalities 1872 & Nominal value of annual municipal budget \\
\hline \# Free non-whites 1872 & Census 1872 & Municipalities 1872 & Total number of free people in any other category than "white" in the 1872 Census \\
\hline Labor productivity (nominal) & Anuários Estatísticos & Colonies 1897-1920 & $\begin{array}{l}\text { Ratio between the nominal value of total annual production in settlement colonies and the number of } \\
\text { people older than } 7 \text { years old in them }\end{array}$ \\
\hline Cultivated area (share) $1897-1920$ & Anuários Estatísticos & Colonies 1897-1920 & Share of area being cultivated in a settlement colony wrt its total area \\
\hline Munic. Expend. 1910s & Anuários Estatísticos & Municipalities $1910 \mathrm{~s}$ & Total annual municipal expenditures of any type, averaged for the period considered \\
\hline Munic. expend. educ. 2002-2003 & SEADE/IMP & Municipalities 2000s & Municipal expenditures with education, averaged for the period considered \\
\hline Income 1999-2004 & SEADE/IMP & Municipalities 2000s & Total annual income of municipalities, averaged for the period considered \\
\hline
\end{tabular}


Manuf. 1872

Manuf. (share) 1872

Manuf. 1888

Manuf. (share) 1888

Manuf. 1897-1920

Manuf. (share) 1897-1920

Serv. 1872

Serv. (share) 1872

Serv. 1888

Serv. (share) 1888

Trade 1872

Trade (share) 1872

Trade 1888

Trade (share) 1888

Trade 1897-1920

Trade (share) 1897-1920

Public Adm. 1872

Public Adm. (share) 1872

Public Adm. 1888

Public Adm. (share) 188

Public Adm. 1897-1920

Public Adm. (share) 1897-1920

Rent. 1872

Rent. (share) 1872

Rent. 1888

Rent. (share) 1888

Other professions 1897-1920

Other professions (share) 1897-1920

Total urban professions 1872

Total urban professions 1888

Total professions 1897-1920

Foreign Public Adm (share)

VA agriculture (share) 2000s

VA industry (share) 2000

VA services (share) 2000s

VA public adm. (share) 2000s

Agr L 1872

Landowners 1872

Foreign land 1872

$\%$ foreign rural workers 1910

$\%$ foreign landown. 1910 s
Luné \& Fonseca (1873)

Luné \& Fonseca (1873)

Seckler (1888)

Seckler (1888)

Anuários Estatísticos

Anuários Estatísticos

Luné \& Fonseca (1873)

Luné \& Fonseca (1873)

Seckler (1888)

Seckler (1888)

Luné \& Fonseca (1873)

Luné \& Fonseca (1873)

Seckler (1888)

Seckler (1888)

Anuários Estatísticos

Anuários Estatísticos

Luné \& Fonseca (1873)

Seckler (1888)

Seckler (1888)

Luné \& Fonseca (1873)

Anuários Estatísticos

Anuários Estatísticos

Luné \& Fonseca (1873)

Luné \& Fonseca (1873)

Seckler (1888)

Seckler (1888)

Anuários Estatísticos

Anuários Estatísticos

Luné \& Fonseca (1873)

Seckler (1888)

Anuários Estatísticos

Luné \& Fonseca (1873)

SEADE/IMP

SEADE/IMP

SEADE/IMP

SEADE/IMP

1872 Census

Luné \& Fonseca (1873)

Luné \& Fonseca (1873)

Estatística Zootec. 1905

Estatística Zootec. 1905
Municipalities 1872

Municipalities 1872

Municipalities 1910

Municipalities 1910

Colonies 1897-1920

Colonies 1897-1920

Municipalities 1872

Municipalities 1872

Municipalities 1910

Municipalities 1910

Municipalities 1872

Municipalities 1872

Municipalities 1910

Municipalities 1910

Colonies 1897-1920

Colonies 1897-1920

Municipalities 1872

Municipalities 1910

Municipalities 1910

Municipalities 1872

Colonies 1897-1920

Colonies 1897-1920

Municipalities 1910

Municipalities 1872

Colonies 1897-1920

Colonies 1897-1920

Colonies 1897-1920

Colonies 1897-1920

Municipalities 1872

Municipalities 1910

Colonies 1897-1920

Municipalities 1872

Municipalities 2000

Municipalities 2000

Municipalities 2000

Municipalities 2000

Municipalities 1872

Municipalities 1872

Municipalities 1872

Municipalities 1910

Municipalities 1910

\section{Sector composition}

Number of individuals registered in occupations categorized in the methodology as manufacturing Share of the previous category wrt total number of professions in a municipality (from the same source)

Idem for the 1888 source

Idem for the 1888 source

Number of individuals registered in the original source as manufacturers and industrialists

Share of the previous category wrt total number of professions registered in the original source

Number of individuals registered in occupations categorized in the methodology as services

Share of the previous category wrt total number of professions in a municipality (from the same source)

Idem for the 1888 source

Idem for the 1888 source

Number of individuals registered in occupations categorized in the methodology as trade-related

Share of the previous category wrt total number of professions in a municipality (from the same source)

Idem for the 1888 source

Idem for the 1888 source

Number of individuals registered in the original source as traders/retailers

Share of previous category wrt total number of professions registered in the original source

Number of individuals registered in occupations categorized in the methodology as public administrators

Share of the previous category wrt total number of professions in a municipality (from the same source)

Idem for the 1888 source

Idem for the 1888 source

Number of individuals registered in the original source as public administrators

Share of previous category wrt total number of professions registered in the original source

Number of individuals registered as rural proprietors and capitalists. Aggregate used in Chapter 3

Share of previous category wrt total number of professions registered in the original source

Idem for the 1888 source

Idem for the 1888 source

Number of individuals registered in the original source as other professions

Share of previous category wrt total number of professions registered in the original source

Total number of individuals of all previous categories for this year and source

Idem for the 1888 source

Total number of individuals of all previous categories for this year and source

Foreign individuals, identified with non-Iberian surnames, working in public administration

Share of total value added by agriculture, averaged for the period considered

Idem for industry

Idem for services

Idem for public administration

Free individuals working in agriculture, explicitly excluding slaves. See methodology in Chapter 3

Total number of landowners listed in the corresponding source. Idem

Number of farms owned by foreigners. Idem

Percentage of foreign agricultural laborers

Percentage of land owned by non-Brazilians 


\begin{tabular}{|c|c|c|c|}
\hline Variable & Source(s) & Sample(s) & Definition \\
\hline \multicolumn{4}{|c|}{ Immigration policies } \\
\hline ID bonded & Witzel de Souza (2011) & Municipalities 1872 & (Identifier $=1$ ) if municipalities had at least one farm employing bonded laborers in the $1850 \mathrm{~s}-1860 \mathrm{~s}$ \\
\hline \# Farms bonded 1850s & Witzel de Souza (2011) & Municipalities 1872 & Count variable for the previous indicator \\
\hline ID settl & Rocha et al. (2017) & Colonies $1897-1920$ & $\begin{array}{l}\text { (Identifier }=1 \text { ) if municipalities had at least one settlement colony founded until } 1872 \\
\text { Number of settlement colonies registered in the original source, averaged for the period considered. See }\end{array}$ \\
\hline \# settl. colonies 1910 s & Anuários Estatísticos & Municipalities 1910s & $\begin{array}{l}\text { Appendix to Chapter } 3 \text { for clarifications on why this variable is compiled with a different source than that } \\
\text { of (ID settl) }\end{array}$ \\
\hline ID colony & Anuários Estatísticos & Colonies 1897-1920 & $\begin{array}{l}\text { Categorical variable identifying the idiosyncratic characteristics of settlement colonies in POLS estimates } \\
\text { (dropped in the FE estimations) }\end{array}$ \\
\hline Foreigners-i & 1872 Census & Municipalities 1872 & Total number of other expatriates than the nationality considered as the dependent variable \\
\hline Foreigners-i & Anuários Estatísticos & Colonies $1897-1920$ & Idem for settlement colonies \\
\hline Other immigrants 1872 (share) & 1872 Census & Municipalities 1872 & Share of non-German-speaking immigrants in the total population \\
\hline Year & Anuários Estatísticos & Colonies $1897-1920$ & Time trend for the panel of settlement colonies \\
\hline \multicolumn{4}{|c|}{$\underline{\text { German-speaking immigrants }}$} \\
\hline German-speakers 1872 (share) & 1872 Census & Municipalities 1872 & Share of German-speakers in the total population of the municipalities \\
\hline German schools 1872 & Witzel de Souza (2014) & Municipalities 1872 & Number of German schools created in the municipalities until 1872 \\
\hline German schools 1910s & Witzel de Souza (2014) & Municipalities $1910 \mathrm{~s}$ & Idem until 1914 \\
\hline German schools 1930s & Witzel de Souza (2014) & Municipalities 2000s & Idem until 1939 \\
\hline German workers 1872 (share) & Luné and Fonseca (1873) & Municipalities 1872 & Share of German-speakers, identified by surnames, in the total workforce of municipalities \\
\hline German workers 1888 (share) & Seckler (1888) & Municipalities $1910 \mathrm{~s}$ & Idem for the 1888 source \\
\hline German rent. 1872 (share) & Luné and Fonseca (1873) & Municipalities 1872 & Share of German-speakers, identified by surnames, in rental activities \\
\hline Germans rent. 1888 (share) & Seckler (1888) & Municipalities $1910 \mathrm{~s}$ & Idem for the 1888 source \\
\hline Germans manuf. 1872 (share) & Luné and Fonseca (1873) & Municipalities 1872 & Share of German-speakers, identified by surnames, in manufacturing \\
\hline Germans manuf. 1888 (share) & Seckler (1888) & Municipalities $1910 \mathrm{~s}$ & Idem for the 1888 source \\
\hline Germans serv. 1872 (share) & Luné and Fonseca (1873) & Municipalities 1872 & Share of German-speakers, identified by surnames, in services \\
\hline Germans serv. 1888 (share) & Seckler (1888) & Municipalities $1910 \mathrm{~s}$ & Idem for the 1888 source \\
\hline Germans trade 1872 (share) & Luné and Fonseca (1873) & Municipalities 1872 & Share of German-speakers, identified by surnames, in trade-related activities \\
\hline Germans trade 1888 (share) & Seckler (1888) & Municipalities $1910 \mathrm{~s}$ & Idem for the 1888 source \\
\hline
\end{tabular}




\section{Bibliography}

Abramitzky, R. and Braggion, F. (2006). "Migration and Human Capital: Self-Selection of Indentured Servants to the Americas". The Journal of Economic History, Vol. 66 No. 4.

Abramitzky, R., Boustan, L. P., and Eriksson, K. (2012). "Europe's Tired, Poor, Huddled Masses: Self-Selection and Economic Outcomes in the Age of Mass Migration". The American Economic Review, Vol. 102 - No. 5.

Abramitzky, R., Boustan, L. P., and Eriksson, K. (2014). "A Nation of Immigrants: Assimilation and Economic Outcomes in the Age of Mass Migration". Journal of Political Economy, Vol. 122 - No. 3.

Abramitzky, R. and Boustan, L. P. (2017). "Immigration in American Economic History". Journal of Economic Literature, Vol. 55 - No. 4.

Abrantes, V. (1846). Memoria sobre Meios de Promover a Colonisação. Berlin: Typographia de Unger Irmãos.

Acemoglu, D. (2009). Introduction to Modern Economic Growth. Princeton and Oxford: Princeton University Press.

Acemoglu, D., Gallego, F., and Robinson, J. A. (2014). "Institutions, Human Capital and Development". NBER Working Paper No. 19933.

Acemoglu, D., Johnson, S., and Robinson, J. A. (2001). "The Colonial Origins of Comparative Development: An Empirical Investigation". The American Economic Review, Vol. 91 - No. 5.

(2002). "Reversal of Fortune: Geography and Institutions in the Making of the Modern World Income Distribution”. The Quarterly Journal of Economics, Vol. 117 - No 4.

Acemoglu, D. and Wolitzky, A. (2011). "The Economics of Labor Coercion”. Econometrica, Vol. 79 - No. 2.

Allen, F. (1982). “On Share Contracts and Screening”. The Bell Journal of Economics, Vol. 13 - No. 2.

Almeida Prado, J. F. (2007). "Capítulo II: O Regime das Capitanias”. In Buarque de Holanda, S. (ed.) História Geral da Civilização Brasileira, Tomo 1, Vol. 1 - "Do descobrimento à expansão territorial", Book 3. Rio de Janeiro: Bertrand Brasil $\left(15^{\text {th }}\right.$ ed.)

Alston, L. J. (1981). “Tenure Choice in the Southern Agriculture, 1930-1960”. Explorations in Economic History, Vol. 18 - No. 3.

Alston, L. J., Datta, S. K., and Nuggent, J. B. (1984). "Tenancy Choice in a Competitive Framework with Transaction Costs". Journal of Political Economy, Vol. 92 - No. 6.

Alston, L. J. and Ferrie, J. P. (1985). "Labor Costs, Paternalism, and Loyalty in Southern Agriculture: A Constraint on the Growth of the Welfare State". The Journal of Economic History, Vol. XLV - No. 1.

Alston, L. J. and Higgs, R. (1982). "Contractual Mix in Southern Agriculture Since the Civil War: Facts, Hypotheses, and Tests”. The Journal of Economic History, Vol. XLII No. 2. 
Anderson, T. (2001). "Proto-Industrialization, Sharecropping and Outmigration in NineteenthCentury Rural Westphalia”. The Journal of Peasant Studies, Vol. 29 - No. 1.

Argollo Ferrão, A. M. (1999). "Colonos na Fazenda Ibicaba, Empresários em Piracicaba: a Evolução Sócio-econômica de um Grupo de Alemães (1850-1880)". Proceedings of the $3^{\text {rd }}$ Brazilian Congress of Economic History and $4^{\text {th }}$ International Conference on Business History.

Arlettaz, G. (1979). Emigration et Colonization Suisses en Amérique (1815-1918). Bern: Archives Fédérales Suisses - Etudes et Sources, Vol. 5.

Ashley, W. J. (1895). "The Historical School, a Retrospect". Publications of the American Economic Association - Supplement, Vol. 10 - No. 3.

Balderas, J. U. and Greenwood, M. J. (2010). "From Europe to the Americas: a Comparative Panel-Data Analysis of Migration to Argentina, Brazil, and the United States, 18701910”. Journal of Population Economics, Vol. 23 - No. 4.

Bardhan, P. K. and Srinivasan, T. N. (1974). "Cropsharing Tenancy in Agriculture: Rejoinder". The American Economic Review, Vol. 64 - No. 6.

Bardhan, P. K. (1977). "Variations in Forms of Tenancy in a Peasant Economy". Journal of Development Economics, Vol. 4 - No. 2.

(1980). "Interlocking Factor Markets and Agrarian Development: A Review of Issues". Oxford Economic Papers, New Series, Vol. 32 - No. 1.

Bassanezi, M. S. C. B. (1986). "Família e Força de Trabalho no Colonato. Subsídios para a Compreensão da Dinâmica Demográfica no Período Cafeeiro". Textos NEPO/UNICAMP, No. 8.

(1998). São Paulo do Passado. Dados Demográficos 1836 (Vol. I). Campinas: Universidade de Campinas - Núcleos de Estudos de População (NEPO). (Available at www.nepo.unicamp.br/publicacoes/censos.php, accessed on October 5 2018).

Bassanezi, M. S. C. B., Scott, A. S. V., Bacellar, C. A. P., Truzzi, O. M. S., and Gouvea, M. (2008). Repertório de Legislação Brasileira e Paulista Referente à Imigração. São Paulo: Editora UNESP.

Basu, K. (1992). "Limited Liability and the Existence of Share Tenancy". Journal of Development Economics, Vol. 38 - No. 1.

(2003). Analytical Development Economics. The Less Developed Economy Revisited. Cambridge/ London: The MIT Press.

Becker, S. O. and Woessmann, L. (2009). "Was Weber Wrong? A Human Capital Theory of Protestant Economic History”. The Quarterly Journal of Economics, Vol. 124 - No. 2.

(2010). "The Effect of Protestantism on Education before the Industrialization: Evidence from 1816 Prussia”. Economic Letters, Vol. 107 - No. 2.

Begliomini, H. (n.d.) "Cadeira N. 43. Patrono. Justiniano de Melo Franco, 1774-1839": Biography Paper. (Available at https://www.academiamedicinasaopaulo.org.br/, accessed on October 05 2018).

Beiguelman, P. (1967). “A Destruição do Escravismo Capitalista”. Revista de História, Vol. 34 - No. 69.

Bell, C. and Zusman, P. (1976). "A Bargaining Theoretic Approach to Cropsharing Contracts". The American Economic Review, Vol. 66 - No. 4. 
Benigsen, E. (1954). "Bibliografia russa sôbre o barão Jorge Henrique Langsdorf”. Revista de História, Vol. 8 - No. 17.

Bezerra, M. C. S. (2001). Imigração, Educação e Religião: um Estudo Histórico-sociológico do Bairro dos Pires de Limeira, uma Comunidade Rural de Maioria Teuto-Brasileira. Campinas: Universidade Estadual de Campinas (Master's thesis).

(2007). Educação Étnica: a Pluralidade das Propostas Educacionais de Origem Germânica no Estado de São Paulo. Campinas: Universidade Estadual de Campinas ( $\mathrm{PhD}$ thesis).

Black, J. D. and Allen, R. H. (1937). "The Growth of Farm Tenancy in the United States". The Quarterly Journal of Economics, Vol. 51 - No. 3.

Borger, S. C. (2010). "Self-selection and Liquidity Constraints in Different Migration Cost Regimes". Working Paper. (Available at https://www.frbatlanta.org//media/documents/news/conferences/2010/ac-remittances/borger.pdf, accessed on October 05 2018).

Borjas, G. J. (1987). "Self-selection and the Earnings of Immigrants". NBER Working Paper No. 2248.

(1989). "Economic Theory and International Migration". International Migration Review, Vol. 23 - No. 3 (Special Silver Anniversary).

(1994). "The Economics of Immigration". Journal of Economic Literature, Vol. XXXII.

Borjas, G. J., Bronars, S. G., and Trejo, S. J. (1992). "Self-selection and Internal Migration in the United States". Journal of Urban Economics, Vol. 32.

Braverman, A. and Guasch, J. L. (1984). "Capital Requirements, Screening and Interlinked Sharecropping and Credit Contracts". Journal of Development Economics, Vol. 14 No. 3.

Braverman, A. and Stiglitz, J. E. (1982). "Sharecropping and the Interlinking of Agrarian Markets". The American Economic Review, Vol. 72 - No. 4.

(1986). "Landlords, Tenants and Technological Innovations". Journal of Development Economics, Vol. 23 - No. 2.

Buarque de Holanda, S. (1941). "Prefácio do Tradutor". In Davatz, T. Memórias de um Colono no Brasil (1850). São Paulo: Martins Fontes.

(2007a). "Capítulo I: As primeiras expedições". In Buarque de Holanda, S. (ed.) História Geral da Civilização Brasileira, Tomo 1, Vol. 1 - "Do descobrimento à expansão territorial”, Book 3. Rio de Janeiro: Bertrand Brasil (15 ${ }^{\text {th }}$ ed.)

Brasil, Directoria Geral de Estatística (1872). Recenseamento Geral do Brazil de 1872. Rio de Janeiro.

(1939-1940). Anuário Estatístico do Brasil. Ano V - 1939/1940. Rio de Janeiro: Instituto Brasileiro de Geografia e Estatística, Conselho Nacional de Estatística.

Byres, T. J. (1983). "Historical Perspectives on Sharecropping". The Journal of Peasant Studies. In Byres, T. J. (ed.) Special Issue on Sharecropping and Sharecroppers, Vol. $10-$ Nos. 2 and 3.

Caballero, J. M. (1983). "Sharecropping as an Efficient System: Further Answers to an Old Puzzle". The Journal of Peasant Studies. In Byres, T. J. (ed.) Special Issue on Sharecropping and Sharecroppers, Vol. 10 - Nos. 2 and 3. 
Calógeras, J. P. ([1933] 1998). A Política Exterior do Império. Vol. III: Da Regência à Queda de Rosas. Brasília: Senado Federal - Coleção Biblioteca Básica Brasileira (fac-similar edition).

Camara, B. (2006). "The Portuguese Civil Code and the Colonia Tenancy Contract in Madeira (1867-1967)". Continuity and Change, Vol. 21 - No. 2.

Campos Araújo, J. R., Cruz Paiva, O., and Rodriguez, C. L. (2006). "Immigrants and Entrepreneurs in São Paulo, Brazil: Economic Development in the Brazilian 'Melting Pot"”. Development Entrepreneurship: Adversity, Risk, and Isolation, Vol. 5.

Carmona, J. and Simpson, J. (1999). “The 'Rabassa Morta' in Catalan Viticulture: The Rise and Decline of a Long-Term Sharecropping Contract, 1670s-1920s". The Journal of Economic History, Vol. 59 - No. 2.

(2012). "Explaining Contract Choice: Vertical Coordination, Sharecropping, and Wine in Europe, 1850-1950". The Economic History Review, Vol. 65 - No. 3.

Carvalho Filho, I. and Colistete, R. P. (2010). "Education Performance: Was It All Determined 100 Year Ago? Evidence from São Paulo, Brazil”. MPRA Working Paper No. 24494.

Carvalho Filho, I., and Monasterio, L. M. (2012). "Immigration and the Origins of Regional Inequality: Government-sponsored European Migration to Southern Brazil before World War I". Regional Science and Urban Economics, Vol. 42 - No. 5.

Carrington, W. J., Detragiache, E., and Vishwanath, T. (1996). "Migration with Endogenous Moving Costs". The American Economic Review, Vol. 86 - No. 4.

Castro, M. C. B. P. (n.d.). Álbum de Família. Souza Queiroz. São Paulo: Instituto Ana-Rosa. (Available at http://anarosa.org.br/livros-e-periodicos, accessed on January 18 2018).

Cheung, S. N. S. (1969). "Transaction Costs, Risk Aversion, and the Choice of Contractual Arrangements". The Journal of Law \& Economics, Vol. 12 - No. 1.

Chiswick, B. R. (1999). “Are Immigrants Favorably Self-selected?” The American Economic Review, Papers and Proceedings, Vol. 89 - No. 2.

Colistete, R. P. and Lamounier, M. L. (2014). "Land Inequality in a Coffee Economy: São Paulo during the Early Twentieth Century". Working Paper Series of the Department of Economics FEA/USP No. 2014-1.

Cohn, R. L. (1995). "Occupational Evidence on the Causes of Immigration to the United States, 1836-1853”. Explorations in Economic History, Vol. 32 - No. 3.

Conrad, R. (1975). "The Planter Class and the Debate over Chinese Immigration to Brazil, 1850-1893”. International Migration Review, Vol. 9 - No. 1.

Covarrubias, M., Lafortune, J., and Tessada, J. (2015). "Who Comes and Why? Determinants of Immigrants Skill Level in the Early $\mathrm{XX}^{\text {th }}$ Century U.S." Journal of Demographic Economics, Vol. 81 - No. 1.

Cox, L. F. (1944). "Tenancy in the United States, 1865-1900: A Consideration of the Validity of the Agricultural Ladder Hypothesis". Agricultural History, Vol. 18 - No. 3.

Davatz, T. ([1858] 1841). Memórias de um Colono no Brasil (1850). São Paulo: Ed. Martins Fontes.

Davidson, A. C. and Hinkley, D. V. (1997). Bootstrap Methods and their Application. Cambridge Series in Statistical and Probabilistic Mathematics. Cambridge University Press. 
Dean, W. (1971). "Latifundia and Land Policy in Nineteenth-Century Brazil". The Hispanic American Historical Review, Vol. 51 - No. 4.

(1976). "A Pequena Propriedade Dentro do Complexo Cafeeiro: Sitiantes no Município de Rio Claro, 1870-1920". Revista de História, No. 106, $2^{\circ}$ trimestre.

(1977). Rio Claro: Um Sistema Brasileiro de Grande Lavoura, 1820-1920. Rio de Janeiro: Ed. Paz e Terra.

Diamond, J. and Robinson, J. A. (2010, eds.). Natural Experiments of History. Cambridge/London: The Belknap Press of the Harvard University Press.

Docquier, F., Perim, G., and Ruyssen, I. (2014). "The Cross-country Determinants of Potential and Actual Migration". International Migration Review, Vol. 48 - No. S1.

Domar, E. D. (1970). "The Causes of Slavery or Serfdom: A Hypothesis". The Journal of Economic History, Vol. 30 - No. 1.

Donoghue, J. (2013). "Indentured Servitude in the $17^{\text {th }}$ Century English Atlantic: A Brief Summary of the Literature". Historical Compass, Volume 11 - No. 10.

Dorfman, J. (1955). "The Role of the German Historical School in American Economic Thought”. The American Economic Review, Papers and Proceedings, Vol. 45 - No. 2.

Egas, E. (1926). Galeria dos Presidentes de São Paulo. Período Monarchico 1822-1889. São Paulo: Secção de Obras d'O estado de S. Paulo.

Eltis, D. (1983). "Free and Coerced Transatlantic Migrations: Some Comparisons". The American Historical Review, Vol. 88 - No. 2.

Engerman, S. L. (1983). "Contract Labor, Sugar, and Technology in the Nineteenth Century". The Journal of Economic History, Vol. XLIII - No. 3.

Engerman, S. L. and Margo, R. A. (2010). "Free Labor and Slave Labor". In Irwin, D. and Sylla, R. (eds.): Founding Choices: American Economic Policy in the 1790s. Chicago: University of Chicago Press.

Engerman, S. L. and Sokoloff, K. L. (2011). "Once Upon a Time in the Americas: Land and Immigration Policies in the New World". In Costa, D. L. and Lamoreaux, N. R. (eds.): Understanding Long-Run Economic Growth: Geography, Institutions, and the Knowledge Economy. Chicago: Chicago University Press.

Eswaran, M. and Kotwal, A. (1985). "A Theory of Contractual Structure in Agriculture”. The American Economic Review, Vol. 75 - No. 3.

Evans Jr., R. (1970). "Some Notes on Coerced Labor". The Journal of Economic History. Vol. 30 - No. 4.

Farnam, H. W. (1912). "The Economic Utilization of History: Annual Address of the President". The American Economic Review, Papers and Proceedings - Supplement, Vol. 2 - No. 1.

Ferrie, J. F. (1997a). "The Entry into the U.S. Labor Market of Antebellum European Immigrants, 1840-1860". Explorations in Economic History, Vol. 34 - No. 3.

(1997b). "Migration to the Frontier in Mid-Nineteenth Century America: A ReExamination of Turner's 'Safety Valve"'. Working Paper. (Available at http://faculty.wcas.northwestern.edu/ fe2r/papers/munich.pdf, accessed on October 05 2018). 
Ferrie, J. P. and Hatton, T. J. (2015). "Chapter 2: Two Centuries of International Migration". In Chiswick, B. and Miller, P. (eds.) Handbook of the Economics of International Migration, Vol. 1A. Amsterdam: Elsevier.

Freeman, R. B. (2006). "People Flows in Globalization". Journal of Economic Perspectives, Vol. 20 - No. 2.

Freitas, S. M. (2013). Vida e Obra do Comendador Montenegro. Um lousanense visionário no Brasil. São Paulo: Ed. Polo Printer.

Galenson, D. W. (1981). "White Servitude and the Growth of Black Slavery in Colonial America". The Journal of Economic History, Vol. XLI - No. 1.

(1984). "The Rise and Fall of Indentured Servitude in the Americas: An Economic Analysis". The Journal of Economic History, Vol. XLIV - No. 1.

(1991). "Economic Opportunity on the Urban Frontier: Nativity, Work, and Wealth in Early Chicago". The Journal of Economic History, Vol. 51 - No. 3.

Garrido, S. (2017). "Sharecropping Was Sometimes Efficient: Sharecropping with Compensation for Improvements in European Viticulture". The Economic History Review, Vol. 70 - No. 3.

Garrido, S., and Calatayud, S. (2011). "The Price of Improvements: Agrarian Contracts and Agrarian Development in Nineteenth-Century Eastern Spain". The Economic History Review, Vol. 64 - No. 2.

Gennaioli, N., La Porta, R., López-de-Silanes, F., and Shleifer, A. (2013). "Human Capital and Regional Development". The Quarterly Journal of Economics, Vol. 128 - No. 1.

Glaeser, E. L., La Porta, R., López-de-Silanes, F., and Shleifer, A. (2004). "Do Institutions Cause Growth?" Journal of Economic Growth, Vol. 9 - No. 3.

Goldman, F. (1957). "Uma Tentativa de Colonização no Litoral Sul de São Paulo por Imigrantes Oriundos do Sul dos Estados Unidos Após a Guerra Civil”. Revista de História, Vol. XIV - No. 29.

(2004). “Aspectos das migrações norte-americanas após a Guerra Civil”. In Buarque de Holanda, S. and Campos, P. M. (ed.) História Geral da Civilização Brasileira. Tomo II, Vol. 5: "O Brasil Monárquico: Reações e transações". Rio de Janeiro: Betrand Brasil ( $8^{\text {th }}$ edition).

Gouvêa, F. M. (2011). Os Imigrantes Alemães em Rio Claro: Estratégias de Sobrevivência e Redes de Sociabilidades nos Séculos XIX e XX. Franca: Universidade Estadual Paulista (Master's thesis).

Gras, N. S. B. (1920). "The Present Condition of Economic History". The Quarterly Journal of Economics, Vol. 34 - No. 2.

(1927). "The Rise and Development of Economic History". The Economic History Review, Vol. 1 - No. 1.

Grininger, V. (1991). Imigração Suíça em São Paulo: A História da Colônia Helvetia. Campinas: Universidade Estadual de Campinas (Master's thesis).

Grogger, J. and Hanson, G. H. (2011). "Income Maximization and the Selection and Sorting of International Migrants". Journal of Development Economics, Vol. 95 - No. 1.

Grubb, F. (1985). "The Market for Indentured Immigrants: Evidence on the Efficiency of Forward-Labor Contracting in Philadelphia, 1745-1773”. The Journal of Economic History, Vol. XLV - No. 4. 
(1994). "The Auction of Redemptioner Servants, Philadelphia, 1771-1804: An Economic Analysis". The Journal of Economic History, Vol. XLVIII - No. 3.

Grubb, F. and Stitt, T. (1994). "The Liverpool Emigrant Servant Trade and the Transition to Slave Labor in the Chesapeake, 1697-1707: Market Adjustments to War". Explorations in Economic History, Vol. 31 - No. 3.

Haas, H. (2010). "Migration Transitions. A Theoretical and Empirical Enquiry into the Developmental Drivers of International Migration". International Migration Institute: DEMIG Project Paper 1.

(2011). "The Determinants of International Migration. Conceptualising Policy, Origin, and Destination Effects". International Migration Institute: DEMIG Project Paper 2.

(2014). "Migration Theory. Quo Vadis?" International Migration Institute: DEMIG Project Paper 24.

Hatton, T. J. (2011). "Chapter 6: The Cliometrics of International Migration: A Survey". In Greasley, D. and Oxley, L. (eds.) Economics and History. Surveys in Cliometrics. Sussex: Wiley-Blackwell.

(2014). "The Economics of International Migration: A Short History of the Debate". Labour Economics, Vol. 30.

Hatton, T. J. and Williamson, J. G. (1992). "International Migration and World Development: A Historical Perspective”. NBER Historical Paper No. 41.

(1994). "What Drove the Mass Migrations from Europe in the Late Nineteenth Century?" Population and Development Review, Vol. 20 - No. 3.

(2002). "What Fundamentals Drive World Migration?" NBER Working Paper No. 9159.

(2004). "International Migration in the Long-run: Positive Selection, Negative Selection and Policy". NBER Working Paper No. 10529.

(2009). "Emigration in the Long-run: Evidence from Two Global Centuries". Asian Pacific Economic Literature, Vol. 23 - No. 2.

Heavner, R. (1973). "Indentured Servitude: The Philadelphia Market, 1771-1773". The Journal of Econmic History, Vol. XXXVIII - No. 3

Heflinger Jr., J. E. (2007). Ibicaba: O Berço da Imigração Européia de Cunho Particular. (Ibicaba: Die Wiege der privat Organisierten Europäischen Einwanderung). Limeira: Unigráfica, Portuguese/German.

(2009). A Revolta dos Parceiros na Ibicaba (The Rebellion of the Sharecroppers in Ibicaba). Limeira: Editora Unigráfica, Portuguese/English.

(2014). O Sistema de Parceria e a Imigração Europeia. (The sharecropping system and the European immigration). Limeira: Editora Unigráfica, Portuguese/English.

Herscovici, S. (1998). "Migration and Economic Mobility: Wealth Accumulation and Occupational Change among Antebellum Migrants and Persisters". The Journal of Economic History, Vol. 58 - No. 4.

Heinke, E. (1905). "Lose Blätter aus der Geschichte der deutschen Kolonie von São Paulo (1800-1900)“. In Uhle A. (ed.) Erstes Jahrbuch für die deutschsprechende Kolonie im Staate S. Paulo. São Paulo: Druck und Verlag von Adolph Uhle.

Higgs, H. (1894). “'Metayage’ in Western France”. The Economic Journal, Vol. 4 - No. 13. 
Higgs, R. (1974). "Patterns of Farm Rental in the Georgia Cotton Belt, 1880-1900". The Journal of Economic History. Vol. 34 - No. 2.

Hodgson, G. M. (2001). How Economics Forgot History. The Problem of Historical Specificity in Social Science. London and New York: Routledge.

Hoffman, P. T. (1984). “The Economic Theory of Sharecropping in Early Modern France". The Journal of Economic History, Vol. XLIV - No. 2.

Holloway, T. H. (1978). "Creating the Reserve Army? The Immigration Program of São Paulo, 1886-1930". International Migration Review, Vol. 12 - No. 2.

Humphries, J. and Leunig, T. (2009). "Was Dick Whittington Taller Than Those He Left Behind? Anthropometric Measures, Migration and the Quality of Life in Early Nineteenth Century London?" Explorations in Economic History, Vol. 46 - No. 1.

Ianni, O. (2004). "O Progresso Econômico e o Trabalhador Livre”. In Buarque de Holanda, S. and Campos, P. M. (ed.) História Geral da Civilização Brasileira. Tomo II, Vol. 5: "O Brasil Monárquico: Reações e transações". Rio de Janeiro: Betrand Brasil ( $8^{\text {th }}$ edition).

International Migration Report (2017). Highlights. New York: United Nations. (Available at http://www.un.org/en/development/desa/population/migration/publications/migrationr eport/docs/MigrationReport2017_Highlights.pdf, accessed on October 05 2018).

James, P. E. (1932). "The Coffee Lands of Southeastern Brazil”. Geographic Review, Vol. 22 - No. 2.

(1940). “The Expanding Settlements of Southern Brazil”. Geographic Review, Vol. 30 - No. 4.

Johnson, A. (1937). "The Economist in a World in Transition: Annual Address of the President", The American Economic Review, Vol. XXVII - No. 1.

Kang, T. (2017). "Educação para as elites, financiamento e ensino primário no Brasil, 19301964". Latin American Research Review, Vol. 52 - No. 1.

Karastojanov, A. M. S. (1998). Vir, Viver e Talvez Morrer em Campinas: Um Estudo sobre a Comunidade Alemã Residente na Zona Urbana Durante o II Império. Campinas: Universidade Estadual de Campinas (Master's thesis).

Keller, J. (1919). "Bericht über die gegenwärtige Lage der Landschulen im Innern des Staates São Paulo. Vortrag gehalten am 6. Mai 1919 an der Lehrervereins Versammlung im Klubhaus der 'Germania', von J. Keller, Direktor der Deutschen Schule Villa Marianna”. São Paulo: Typographia Hennies Irmãos \& Cia.

Keller, J. and Linhart, H. (1926). Entwurf für den Lehrplan für deutsche Kolonieschulen. São Paulo: Typographia Hennies Irmãos \& Cia.

Klein, H. S. (1995). "European and Asian Migration to Brazil". In Cohen, R. (ed.) The Cambridge Survey of World Migration. Cambridge: Cambridge University Press.

Koo, A. Y. C. (1973). “Towards a More General Model of Land Tenancy and Reform”. The Quarterly Journal of Economics, Vol. 87 - No. 4.

Kotwal, A. (1985). "The Role of Consumption Credit in Agricultural Tenancy". Journal of Development Economics, Vol. 18 - Nos. 2-3.

Kosack, E. and Ward, Z. (2014). "Who Crossed the Border? Self-selection of Mexican Migrants in the Early Twentieth Century". The Journal of Economic History, Vol. 74 - No. 4. 
Kreutz, L. (2005). “Escolas Étnicas dos Imigrantes Alemães no Brasil”. Martius-StadenJahrbuch, Vol. 52.

Kuhlman, A. (1905). "Der Staat São Paulo". In Uhle A. (ed.) Erstes Jahrbuch für die deutschsprechende Kolonie im Staate São Paulo 1905. São Paulo: Druck und Verlag von Adolph Uhle.

Kupfer, E. E., Kutschat, R. S. G., Rothfuss, D., and Fouquet, B. (2016 eds.). Martius-StadenJahrbuch, Vol. 61.

Lagerlöf, N. P. (2009). "Slavery and Other Property Rights". The Review of Economic Studies, Vol. 76 - No. 1.

Lamounier, M. L. (1986). Formas de Transição da Escravidão ao Trabalho Livre: a Lei de Locação de Serviços de 1879. Campinas: Universidade Estadual de Campinas (Master's thesis). (2000). "Ferrovias, Agricultura de Exportação e Mão-de-obra no Brasil no Século XIX”. História Econômica e História de Empresas, Vol. 21 - No. 1.

Lee, J. A. and Kaufmann, K. D. (1997). "Agricultural Chutes and Ladders: New Estimates of Sharecroppers and 'True Tenants' in the South, 1900-1920". The Journal of Economic History, Vol. 57 - No. 2.

Leff, N. H. (1972). "Economic Retardation in Nineteenth-Century Brazil". The Economic History Review, Vol. 25 - No. 3.

Levy, M. S. F. (1974). "O Papel da Imigração Internacional na Evolução da População Brasileira (1872 a 1972)". Revista de Saúde Pública, Vol. 8 - Suplemento.

Loos, I. A. (1918). "Historical Approach to Economics". The American Economic Review, Vol. 8 - No. 3.

Lucas, R. E. B. (1979). "Sharing, Monitoring, and Incentives: Marshallian Misallocation Reassessed", Journal of Political Economy, Vol. 97 - No. 3.

Luné, A. J. B. and Fonseca, P. D. ([1873] 1973). Almanak da Província de São Paulo para 1873. São Paulo: Imprensa Oficial do Estado/Arquivo do Estado (fac-similar edition).

Mariscal, E. and Sokoloff, K. L. (2000). "Schooling, Suffrage, and the Persistence of Inequality in the Americas, 1800-1945". In Haber, S. (ed.) Political Institutions and Economic Growth in Latin America. Essays in Policy, History, and Political Economy. Hoover Institution Press Publication, No. 458.

Marshall, A. ([1894] 2013). Principles of Economics. Hampshire and New York: Palgrave Macmillan - Palgrave Classics in Economics ( $8^{\text {th }}$ ed.)

Martins, J. S. (1989). “A Imigração Espanhola para o Brasil e a Formação da Força-detrabalho na Economia Cafeeira: 1880-1930". Revista de História, No. 121, $2^{\circ}$ semestre.

Massey, D. S., Arango, J., Hugo, G., Kouaouci, A., Pellegrino, A., and Taylor, J. E. (1993). "Theories of International Migration: A Review and Appraisal". Population and Development Review, Vol. 19 - No. 3.

McIver, R. M. (1943). "History and Social Causation". The Journal of Economic History, Vol. 3 - Supplement.

McKenzie, D. and Rapoport, H. (2010). "Self-selection Patterns in Mexico-U.S. Migration: The Role of Migration Networks". The Review of Economics and Statistics, Vol. 92 No. 4. 
McKenzie, D., Stillman, S., and Gibson, J. (2010). "How Important is Selection? Experimental vs. Non-experimental Measures of the Income Gains from Migration". Journal of the European Economic Association, Vol. 8 - No. 4.

Menard, R. R. (1973). "From Servant to Freeholder: Status Mobility and Property Accumulation in Seventeenth-Century Maryland". The William and Mary Quarterly, Vol. 30 - No. 1.

Methner, P. H. (1962) “A Comunidade Evangélica Luterana de Campinas”. In Grobel, H. (ed.) Comemoração do 50. Aniversário do Sínodo Evangélico do Brasil Central (Jubiläums-Festschrift). São Paulo.

Michel, J. B., Shen, Y. K., Aiden, A. P., Veres, A., Gray, M. K., The Google Books Team, Pickett, J. P., Hoiberg, D., Clancy, D., Norvig, P., Orwant, J., Pinker, S., Nowak, M. A., Aiden, E. L. (2011). "Quantitative Analysis of Culture Using Millions of Digitized Books". Science, Vol. 331 - Issue 6014.

Mills, F. C. (1941). "Economics in a Time of Change". The American Economic Review, Vol. $31-$ No. 1 .

Mitra, P. K. (1982). "A Theory of Interlinked Rural Transactions". Journal of Public Economics, Vol. 20 - No. 2.

Monasterio, L. and Reis, E. (2008). "Mudanças na Concentração Espacial das Ocupações Manufatureiras no Brasil - 1872-1920”. IPEA Discussion Paper No. 1361.

Monasterio, L. and Lopes, D. (2018). "Brasil Sem Imigrantes: Estimativas de Longo Prazo Baseadas em Microdados". MPRA Working Paper No. 88170.

Mueller, D. P. ([1838] 1978). Ensaio d'Um Quadro Estatístico da Província de São Paulo. Ordenado Pelas Leis Provinciais de 11 de Abril de 1836 e 10 de Março de 1837. São Paulo: Governo do Estado de São Paulo (fac-similar edition).

Mukherjee, A. and Ray, D. (1994). "Labor Tying”. Journal of Development Economics, Vol. 47 - No. 2.

Musacchio, A., Fritscher, A. M., and Viarengo, M. (2014). "Colonial Institutions, Trade Shocks, and the Diffusion of Elementary Education in Brazil, 1889-1930". The Journal of Economic History, Vol. 74, Issue (3).

Naritomi, J., Soares, R. R., and Assunção, J. J. (2012). "Institutional Development and Colonial Heritage within Brazil". The Journal of Economic History, Vol. 72 - Issue 2.

Nef, J. U. (1941). “The Responsibility of Economic Historians". The Journal of Economic History, Vol. 1 - No. S1 - Supplement.

(1944). "What is Economic History?" The Journal of Economic History, Vol. 4 - No. S1 - Supplement.

Newbery, D. M. G. (1977). "Risk Sharing, Sharecropping and Uncertain Labor Markets". The Review of Economic Studies, Vol. 44 - No. 3.

Nobre, S. A. S. (2004). Associação dos Professores Teuto-brasileiros do Estado de São Paulo: uma Reconstrução Histórica da Trajetória de um Órgão Associativo Voltado à Educação Étnica no Período de 1916 a 1938. Campinas: Universidade Estadual de Campinas (Master's thesis).

Nunn, N. (2009). “The Importance of History for Economic Development”. Annual Review of Economics, Vol. 1. 
Nunn, N., Qian, N., and Sequeira, S. (2017). "Migrants and the Making of America: the Short- and Long-run Effects of Immigration during the Age of Mass Migration". NBER Working Paper No. 23289.

Oberacker Jr., C. H. (1967). "Vestígios Suíços na História do Brasil". Revista de História, Vol. 35 - No. 72.

(2004). "A Colonização Baseada no Regime da Pequena Propriedade Agrícola". In Buarque de Holanda, S. and Campos, P. M. (ed.) História Geral da Civilização Brasileira. Tomo II, Vol. 5: "O Brasil Monárquico: Reações e transações". Rio de Janeiro: Betrand Brasil ( $8^{\text {th }}$ edition).

Orrenius, P. M. and Zavodny, M. (2005). "Self-selection among Undocumented Immigrants from Mexico". Journal of Development Economics, Vol. 78 - No. 1.

Otsuka, K., Chuma, H. and Hayami, Y. (1992). "Land and Labor Contracts in Agrarian Economies: Theories and Facts”. Journal of Economic Literature, Vol. 30 - No. 4.

Paiva, C., Godoy, M. M., Rodarte, M. M. S., and Santos, D. (2012). "Publicação Crítica do Recenseamento Geral do Império do Brasil de 1872”. Provisional Report of the Núcleo de Pesquisa em História Econômica e Demográfia (NPHED - CEDEPLAR): Universidade Federal de Minas Gerais.

Pande, R. and Udry, C. (2005). "Institutions and Development: a View from Below". Economic Growth Center Working Paper No. 928 - Yale University.

Pasckes, M. L. N. A. (1991). "Notas sobre os Imigrantes Portugueses no Brasil (Sécs. XIX e XX)”. Revista de História, No. 123-4.

Penteado, O. A. (1983). Efemérides Rio-Clarenses. Rio Claro: Arquivo Público e Histórico IMESP/SA.

Pérez, S. (2017). "The (South) American Dream: Mobility and Economic Outcomes of Firstand Second-Generation Immigrants in Nineteenth-Century Argentina". The Journal of Economic History, Vol. 77 - No. 4.

Perret-Gentil, C. (1851). A Colônia Senador Vergueiro. Santos: Typographia Imparcial.

Petrone, T. S. (2004). "Imigração Assalariada". In Buarque de Holanda, S. and Campos, P. M. (ed.) História Geral da Civilização Brasileira. Tomo II, Vol. 5: "O Brasil Monárquico: Reações e transações". Rio de Janeiro: Betrand Brasil ( $8^{\text {th }}$ edition).

Platt, R. S. (1935). "Coffee Plantations of Brazil: A Comparison of Occupance Patterns in Established and Frontier Areas". Geographical Review, Vol. 25 - No. 2.

Premchander, S., Prameela, V., and Chidambaranathan, (2014). Prevention and Elimination of Bonded Labour: The Potential and Limits of Microfinance-led Approaches. Employment Sector. Geneva: ILO.

Przeworski, A. (2004). "The Last Instance: Are Institutions the Primary Cause of Economic Development?" Working Paper New York University / CEBRAP Conference 2003 on "Institutions, Behavior, and Outcomes".

Quibria, M. G. and Rashid, S. (1984). "The Puzzle of Sharecropping: A Survey of Theories”. World Development, Vol. 12 - No. 2.

Reid, J. D. (1973). "Sharecropping as an Understandable Market Response: The Post-Bellum South". The Journal of Economic History, Vol. 33 - No. 1. (1975). "Sharecropping in History and Theory". Agricultural History, Vol. 49 - No. 2. 
(1979). "White Land, Black Labor, and Agricultural Stagnation. The Causes and Effects of Sharecropping in the Postbellum South". Explorations in Economic History, Vol. 16 - No. 1.

Ribeiro, M. J. F. A. (2005). Memória, Imigração e Educação: Fábrica de Tecidos Carioba, uma Vila Industrial Paulista no Início do Século XX. Campinas: Universidade Estadual de Campinas (PhD thesis).

Roberts, G. W. and Byrne, J. (1966). "Summary Statistics on Indenture and Associated Migration Affecting the West Indies, 1834-1918”. Population Studies, Vol. 20 - No. 1.

Rocha, R., Ferraz, C., and Soares, R. (2017). "Human Capital Persistence and Development". American Economic Journal: Applied Economics, Vol. 9 - No. 4.

Rossfeld, R. and Ziegler, B. (2003 eds.). Der Traum vom Glück. Schweizer Auswanderung auf brasilianische Kaffeeplantagen, 1852-1888. Verlag Hier und Jetzt.

Roy, A. D. (1951). "Some Thoughts on the Distribution of Earnings". Oxford Economic Papers, New Series, Vol. 3 - No. 2.

Sadoulet, E. (1992). "Labor-Service Tenancy Contracts in a Latin American Context". The American Economic Review, Vol. 82 - No. 4.

Salisbury, L. (2014). "Selective Migration, Wages, and Occupational Mobility in Nineteenth Century America”. Explorations in Economic History, Vol. 53 (C).

Sánchez-Alonso, B. S. (2007). "The Other Europeans: Immigration into Latin America and the International Labour Market (1870-1930)". Revista de História Económica, Journal of Iberian and Latin American Economic History, Vol. 25 - No. 3.

São Paulo. Repartição de Estatística e do Archivo de São Paulo. Annuario Estatítico do Estado de São Paulo. São Paulo: Typographia do Diário Official. Editions: 18981900, 1911-1916, 1918-1920.

São Paulo. Annual Reports of the Presidency and Vice-Presidency. Editions: 1850-1875. (Available at http://www-apps.crl.edu/brazil/provincial/s\%C3\%A3o_paulo, accessed on October 05 2018).

São Paulo. Secretaria dos Negócios da Agricultura, Commércio e Obras Públicas. Estatística Agrícola e Zootécnica do Estado de São Paulo, 1904-5.

São Paulo. Fundação Sistema Estadual de Análise de Dados. IMP: Informações dos Municípios Paulistas. (Available at http://www.imp.seade.gov.br, accessed on October 05 2018).

Schnaiderman, B. (1966). "Documentos russos sôbre o Brasil”. Revista de História, Vol. 33 No. 67.

Scheler, C. F. (1905). "Beiträge zur Kenntnis des Staates São Paulo und seiner deutschen Niederlassungen". In Uhle A. (ed.) Erstes Jahrbuch für die deutschsprechende Kolonie im Staate S. Paulo. São Paulo: Druck und Verlag von Adolph Uhle.

Schumpeter, J. A. (1947). "The Creative Response in Economic History". The Journal of Economic History, Vol. VII - No. 2.

(1949). "Science and Ideology". The American Economic Review, Vol. 39 - No. 2.

Seckler, J. (1888). Almanach da Província de São Paulo para 1888. Administrativo, Commercial e Industrial. São Paulo: Jorge Seckler \& Comp. 
Senra, N. (2006). História das Estatísticas Brasileiras. Vol. 1: Estatísticas Desejadas (1822c.1889). Rio de Janeiro: Instituto Brasileiro de Geografia e Estatística.

Shetty, S. (1988). "Limited Liability, Wealth Differences and Tenancy Contracts in Agrarian Economies". Journal of Development Economics, Vol. 29 - No. 1.

Shiller, R. J. (2017). "Narrative Economics”. American Economic Review, Vol. 107 - No. 4.

Shlomowitz, R. (1984). “'Bound' or 'Free'? Black Labor in Cotton and Sugarcane Farming, 1865-1880". The Journal of Southern History, Vol. 50 - No. 4.

Silva, F. R. (2010). A Educação Alemã na Colônia Riograndense: 1922-1938 (Maracaí/Cruzália - SP). Presidente Prudente: Universidade Estadual Paulista (Master's thesis).

Siriani, S. C. L. (2003). Uma São Paulo Alemã: Vida Quotidiana dos Imigrantes Germânicos na Região da Capital (1827-1889). São Paulo: Arquivo do Estado (Coleção Teses e Monografias, Vol. 6). (2005). “Os Descaminhos da Imigração Alemã para São Paulo no Século XIX Aspectos Políticos”. Almanack Braziliense, No. 2.

Sjaastad, L. A. (1962). "The Costs and Return of Human Migration”. The Journal of Political Economy, Vol. 70 - No. 5, Part 2.

Sokoloff, K. L. and Engerman, S. L. (2000). "History Lessons: Institutions, Factor Endowments, and Paths of Development in the New World". Journal of Economic Perspectives, Vol. 14 - No. 3.

Spiethoff, A. (1952). "The 'Historical' Character of Economic Theories". The Journal of Economic History, Vol. 12 - No. 2.

Solow, R. M. (1985). "Economic History and Economics". The American Economic Review, Papers and Proceedings, Vol. 75 - No. 2.

Sombart, W. (1929). "Economic Theory and Economic History". The Economic History Review, Vol. 2 - No. 1.

Sommer, F. (1950). Major Joh. Bloem und die deutsche Einwanderung in die Provinz São Paulo von 1838. I \& II. In Deutsche Zeitung, January 281950 \& February 041950 Archives of Instituto Martius-Staden - Reference "Pasta Sommer, No. 268".

(1953). São Paulo und die Deutschen - Archives of Instituto Martius-Staden: Artigos Deutsche Zeitung, São Paulo (Artigos I-X).

Spillman, W. J. (1919). "The Agricultural Ladder". The American Economic Review, Papers and Proceedings - Supplement, Vol. 9 - No. 1.

Stewart, J. I. (2006). "Migration to the Agricultural Frontier and Wealth Accumulation, 18601870”. Explorations in Economic History, Vol. 43 - No. 4.

Stiglitz, J. E. (1974). "Incentives and Risk Sharing in Sharecropping". The Review of Economic Studies, Vol. 41 - No. 2.

Stock, J. H. and Yogo, M., (2002). "Testing for weak instruments in linear IV regression", NBER Technical Working Paper No. 284.

Stolcke, V., and Hall, M. M. (1983). "The Introduction of Free Labour on São Paulo Coffee Plantations". The Journal of Peasant Studies, Vol. 10 - No. 1. 
Stolz, Y., Baten, J., and Botelho, T. (2013). "Growth Effects of $19^{\text {th }}$ Century Mass Migrations: 'Fome Zero' for Brazil?" European Review of Economic History, Vol. 17 - No. 1

Summerhill, W. R. (2010). "Colonial Institutions, Slavery, Inequality, and Development: Evidence from São Paulo, Brazil”. MPRA Working Paper No. 22162.

Taylor, R. H. (1943). "Post-Bellum Southern Rental Contracts". Agricultural History, Vol. 17 - No. 2.

Tschudi, J. J. ([1866] 1953). Viagem às Províncias do Rio de Janeiro e S. Paulo. São Paulo: Livraria Martins Editora. Coleção Biblioteca Histórica Paulista.

Tungeln, G. H. von (1927). "Some Observations on the So-Called Agricultural Ladder". Journal of Farm Economics, Vol. 9 - No. 1.

Uhle, A. (1905, ed.) Erstes Jahrbuch für die deutschsprechende Kolonie im Staate S. Paulo. São Paulo: Druck und Verlag von Adolph Uhle.

Varussa, E. R. (2017). Os Imigrantes Alemães no Bairro Rural de Ferraz: Terra, Identidade, Memórias e Patrimônio Cultural. Rio Claro: Universidade Estadual Paulista (Master's thesis).

Vergueiro, J. (1874). Memorial Acerca da Colonisação e Cultivo de Café. Apresentado a S. Exc. O Sr. Ministro e Secretário d'Estado dos Negócios da Agricultura. Campinas: Typographia Constitucional.

Viotti da Costa, E. (1998). Da Senzala à Colônia. São Paulo: Fundação Editora da UNESP ( $4^{\text {th }}$ ed.)

(2004). "O Escravo na Grande Lavoura". In Buarque de Holanda, S. and Campos, P. M. (ed.) História Geral da Civilização Brasileira. Tomo II, Vol. 5: "O Brasil Monárquico: Reações e transações". Rio de Janeiro: Betrand Brasil ( $8^{\text {th }}$ edition).

Waibel, L. (1950). "European Colonization in Southern Brazil”. Geographic Review, Vol. 40 - No. 4.

Waldman, T. C. (2009). Moderno Bandeirante: Paulo Prado entre espaços e tradições. São Paulo: Universidade de São Paulo (Master's thesis).

Walker, T. R. (2000). "Economic Opportunity on the Urban Frontier: Wealth and Nativity in Early San Francisco”. Explorations in Economic History, Vol. 37 - No. 3.

Wegge, S. A. (1999). "To Part or Not to Part: Emigration and Inheritance Institutions in Mid$19^{\text {th }}$ Century Germany". Explorations in Economic History, Vol. 36 - No. 1.

(2002). "Occupational Self-selection of European Emigrants: Evidence from Nineteenth-Century Hesse-Cassel”. European Review of Economic History, Vol. 6 No. 3.

Wehrwein, C. F. (1931). “The 'Agricultural Ladder' in a High Tenancy Region”. The Journal of Land \& Public Utility Economics, Vol. 7 - No. 1.

Wey, L. K. (2005). "Landownership as a Determinant of International and Internal Migration in Mexico and Internal Migration in Thailand". International Migration Review, Vol. $39-$ No. 1.

Williamson, J. G. (2015). "World Migration in Historical Perspective: Four Big Issues". In Chiswick, B. R. and Miller, P. W. (eds.) The Handbook of the Economics of International Migration, Vol. 1A. Amsterdam: Elsevier. 
Witter, J. S. (1973). A Contribuição da Fazenda Ibicaba para a Introdução do Braço Livre na Lavoura Nrasileira. In Paula, E. S. (ed.) Trabalho Livre e Trabalho Escravo, Vol. I Anais do VI Simpósio Nacional dos Professores Universitários de História.

(1974). "Um Estabelecimento Agrícola do Estado de São Paulo nos Meados do século XIX”. Revista de História, Vol. 48 - No. 98.

(1982). Ibicaba, Uma Experiência Pioneira. São Paulo: Arquivo do Estado (2 $2^{\text {nd }}$ ed.)

Witzel de Souza, B. G. (2011). Liberdade ou Grilhões? Um Estudo dos Contratos de Parceria à Luz da Imigração Germânica em São Paulo, 1840-1870. São Paulo: Universidade de São Paulo (Bachelor's thesis).

(2012). "Imigração Alemã e Mercado de Trabalho na Cafeicultura Paulista - um Estudo Quantitativo dos Contratos de Parceria". História Econômica \& História de Empresas, Vol. 15 - No. 2.

(2014). The Combined Effect of Institutions and Human Capital for Economic Development: A case Study of German Immigration to São Paulo, Brazil (1840-1920). Göttingen: University of Goettingen (Master's thesis).

Woolcock, M., Szreter, S., and Rao, V. (2011). "How and Why Does History Matter for Development Policy?” The Journal of Development Studies, Vol. 47 - No. 1.

Yang, A. C. Y. (1977). “O Comércio dos 'Coolie' (1819-1920)”. Revista de História, No. $112,4^{\mathrm{o}}$ trimestre. 